
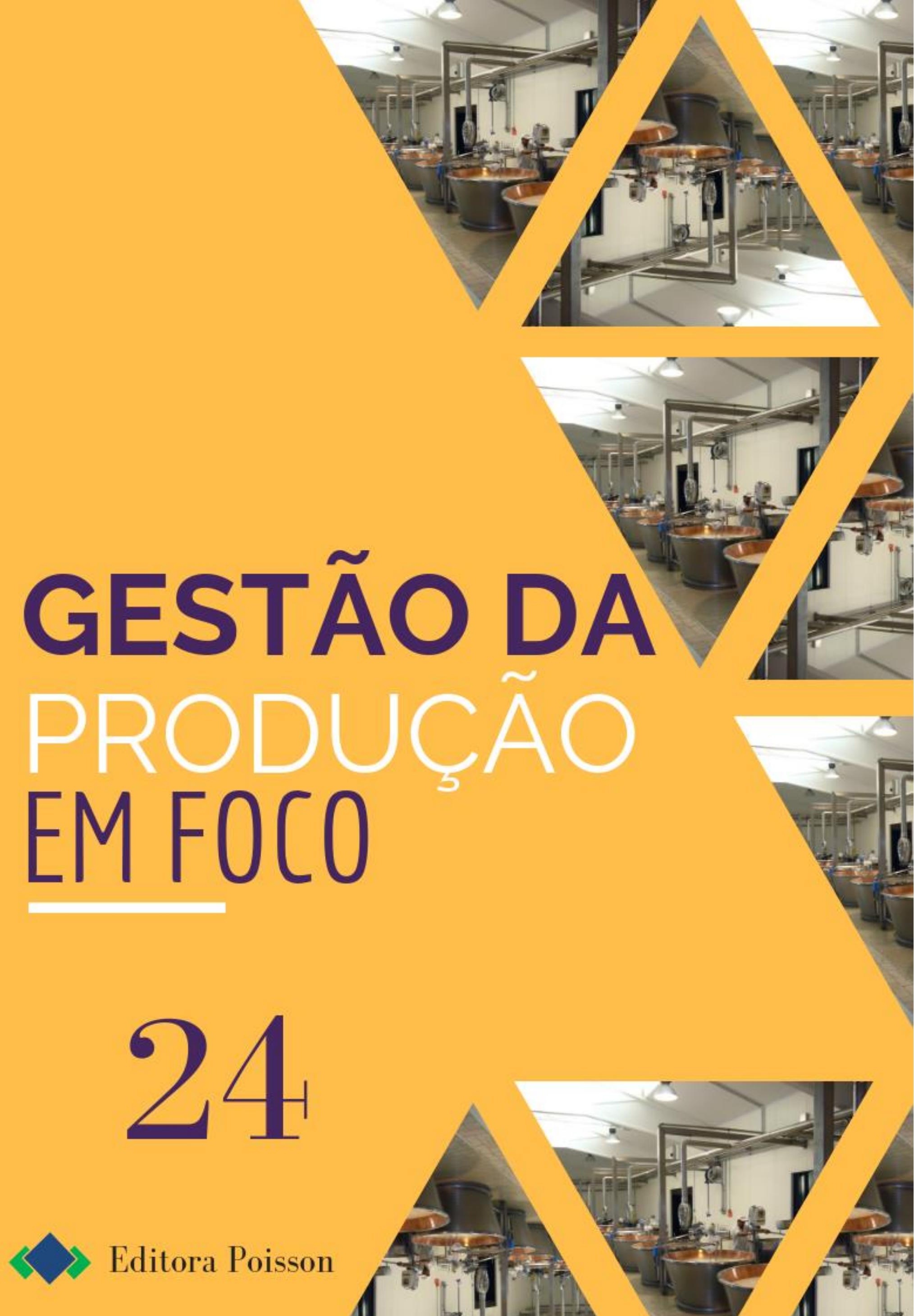
Editora Poisson

\title{
Gestão da Produção em Foco Volume 24
}

\author{
1a Edição
}

Belo Horizonte

Poisson

2018 
Editor Chefe: Dr. Darly Fernando Andrade

Conselho Editorial

Dr. Antônio Artur de Souza - Universidade Federal de Minas Gerais

Dr. José Eduardo Ferreira Lopes - Universidade Federal de Uberlândia

Dr. Otaviano Francisco Neves - Pontifícia Universidade Católica de Minas Gerais

Dr. Luiz Cláudio de Lima - Universidade FUMEC

Dr. Nelson Ferreira Filho - Faculdades Kennedy

Ms. Valdiney Alves de Oliveira - Universidade Federal de Uberlândia

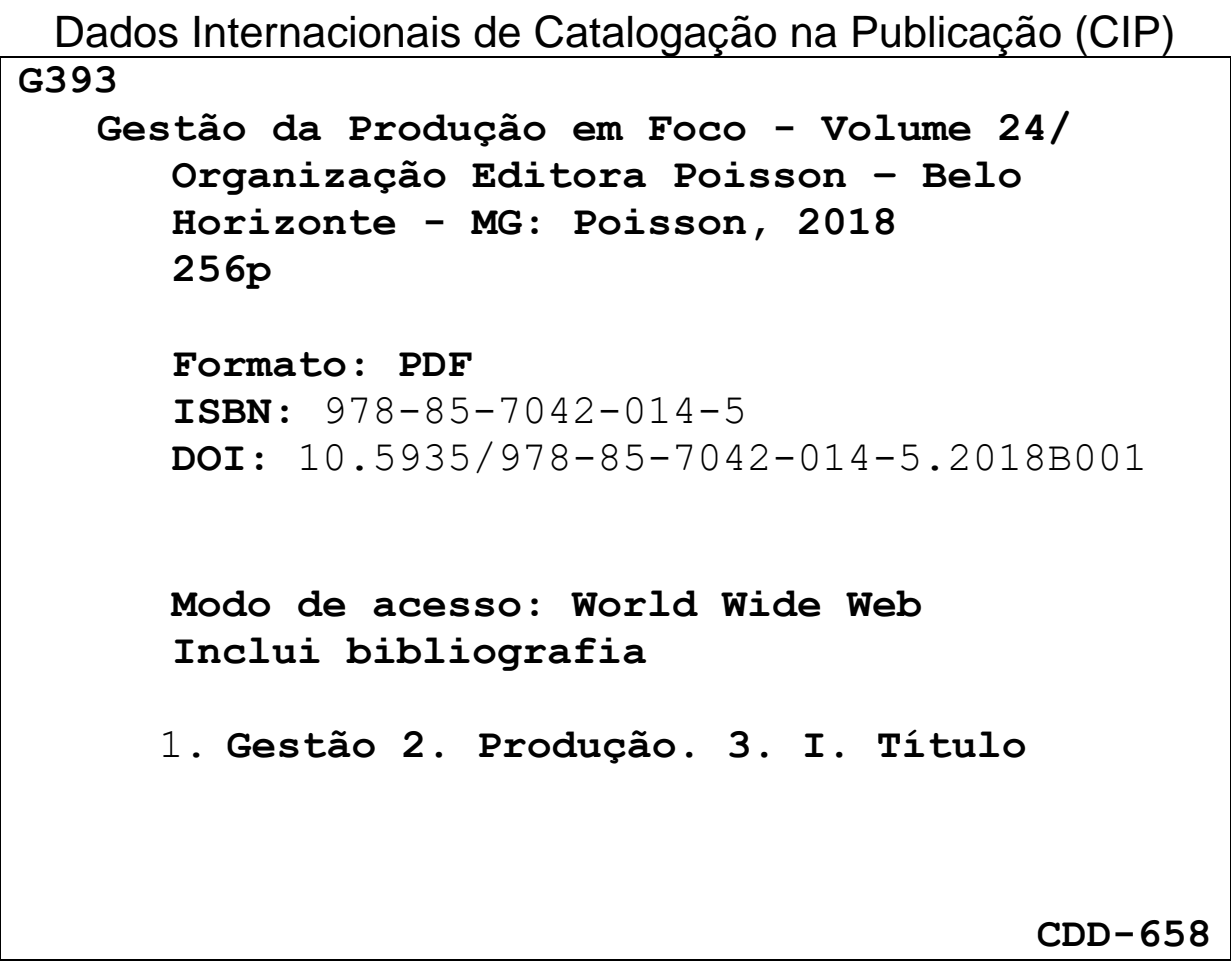

O conteúdo dos artigos e seus dados em sua forma, correção e confiabilidade são de responsabilidade exclusiva dos seus respectivos autores.

$\underline{\text { www.poisson.com.br }}$

contato@poisson.com.br 


\section{Sumário}

Capítulo 1: Aplicação do framework baseado nos conceitos de Workload Control para identificação de problemas relacionados à confiabilidade de entrega em uma oficina do setor de manutenção aeronáutica.

Tatiana Kimura Kodama, Fernando José Gómez Paredes, Moacir Godinho Filho

Capítulo 2: Aplicação do design for assembly and manufacturing (DFMA) no projeto conceitual de um comedouro automático para cães

Adriana Ribeiro de Souza, Kêmyle Moreira Silva, Everton Costa Santos, Anne Beatriz de Camargo Gomes, Rosana Brito Santos

Capítulo 3: Evolução do agente pedagógico emocional dóris em um ambiente virtual de ensino-aprendizagem

Danielli Cossul, Rejane Frozza, Brunno José Fagundes, Guilherme Ferreira, Liane Mahlmann Kipper, Marcus Vinicius Castro Witczak

Capítulo 4: Gestão de estoques - estudo de caso em uma metalúrgica usando o sistema ERP

Wesley Barbosa de Oliveira, Cesar Augusto Della Piazza, Luis Fernando Quintino, Wagner Costa Botelho

Capítulo 5: Energia Elétrica: Uso de fontes renováveis a favor do meio ambiente Marlon Figueiredo Coura de Oliveira, Elizabeth Ferreira de Pádua Campos

Capítulo 6: Instalações como fator-chave na cadeia de suprimentos, para o equilíbrio entre responsividade e eficiência: um estudo de caso Jessika Kauanny de Souza Eurico, Luiza Albuquerque Santos, Priscila Pereira Suzart de Carvalho

Capítulo 7: Análise do processo de implantação de um sistema de gestão da qualidade numa indústria de confecções do estado do Ceará: Sandro Ítalo de Oliveira, lasmin Alexandrino de Miranda

Capítulo 8: Gerenciamento da incerteza aplicado a uma Startup

Capítulo 9: Aspectos da gestão da qualidade no beneficiamento do café: estudo de caso sobre a aplicação da Gestão da Qualidade Total..............................................79 Dayane Menezes Bessa, Paulo Renato Pakes, Guilherme Mendes de Souza, Aline Okumoto Gomes, Brena Bezerra Silva, Vivian Karina Bianchini

Capítulo 10: Aplicação da filosofia Lean Manufacturing para melhoria da produtividade na indústria do setor automobilístico.

Euclides Fernandes dos Reis, Marcio do Carmo Boareto, Luciana Vieira de Melo, Vagner Rosalem, Sara da Costa Fernandes 


\section{Sumário}

Capítulo 11: Aplicação do algoritmo do caminho mínimo em uma empresa processadora de miúdos no sudeste goiano.

Pedro Henrique Borges Xavier, Laura Teixiera Hohl, Anderson Clayton Lima Alencar, Thainara

Danielle Barbosa Marçal, Naiara Faiad Sebba Calife Garcia

Capítulo 12: Discussões iniciais sobre sustentabilidade da bioenergia e das biomassas brasileiras e suas rotas de conversão energética 103 Herbert Carneiro Rangel, Luiz Lúcio de Aragão Pedroso, Igor Cassiano Rangel, Milton Erthal Júnior, Claudio Luiz Melo de Souza

Capítulo 13: Estratégias de inovação e modos de gestão da pesquisa empresarial ...111 Omar Ouro-Salim, Karine de Jesus Santana, José Eduardo Machado Barroso, Marcela Cabral Mendes Barroso, Fausto Teodoro Neves, Elcimara Rabelo de Oliveira

Capítulo 14: Green it: Uma análise de cocitação em múltiplas perspectivas 119 Carulina Marques, Nelson Dias da Costa Júnior, Dalton Matsuo Tavares, Stella Jacyszyn Bachega

Capítulo 15: Indústria 4.0 e seus pressupostos: estudo de caso de aderência ao conteúdo programático do curso de engenharia de mecatrônica de um instituto federal do nordeste brasileiro

Hector Leonardo Mota Moreira, Matheus Araújo dos Santos, Isadora Costa Vasconcelos Vieira, Daniel Xavier Sousa, Cícero Roberto de Oliveira Moura, Karine Bessa Porto Pinheiro Vasques

Capítulo 16: O governo eletrônico: aspectos gerais sobre a modernização administrativa da gestão publica brasileira.

Fernando Cerutti Aguiar, Fabricio Freitas da Silva, Julio Cezar Negri Ramos, Claudio Luiz Melo de

Souza, Milton Erthal Junior

Capítulo 17: Otimização das atividades diárias através da implantação do grd no setor de manutenção de uma universidade pública.

Higor Coimbra Lucindo, Ana Flavia da Fonseca Barroso, André Luiz Francisco Ferreira

Capítulo 18: Potencial de economia de energia elétrica na iluminação e refrigeração da Universo/JF

Brehme Rezende de Oliveira, Ana Flavia da Fonseca Barroso, Élcio Barreira da Silva Castro, Robert Alexandre de Ávila

Capítulo 19: Utilização de resíduos de concreteira para a fabricação de pavers 166 Roberto Fernandes dos Reis Filho, Ed Carlo Rosa Paiva, José Waldo Martínez Espinosa 


\section{Sumário}

Capítulo 20: Projeto de terceirização do gerenciamento de manutenção de uma planta de lubrificantes do segmento de óleo \& gás.

Fábio Esperança, João Luiz Cesarino Ferreira, Nélio Domingues Pizzolato

Capítulo 21: Previsão de Demanda: Aplicação da técnica de ajustamento exponencial com tendência em uma empresa de montagem de equipamentos para beleza

João Lucas Ferreira dos Santos, Afonso José Lemos, Jessycka Brandão Santana Rony Peterson da Rocha

Capítulo 22: Utilização de ferramentas da qualidade no processo produtivo da Casa das Fraldas de Campo Mourão/PR para a identificação de possíveis melhorias. Francisco Costa Machado Neto, Igor de Prince, Matheus Felipe Pires, Gustavo Henrique Marques, Rubya Vieira de Mello Campos

Capítulo 23: Inovação do processo produtivo da cerveja artesanal: algumas reflexões

Fernanda Batista Hagge, Antonio Oscar Santos Goes

Capítulo 24: Análise da matriz curricular do curso de engenharia de produção agroindustrial - estudo de caso

Guilherme Fernando Ribeiro, Andréa Machado Groff

Capítulo 25: Adequação do manejo pré-abate de frangos ao programa nacional de abate humanitário - Steps - estudo de caso em uma indústria frigorífica.

Gabriel Andrian Gentilin, Andréa Machado Groff 


\section{Capítulo 1}

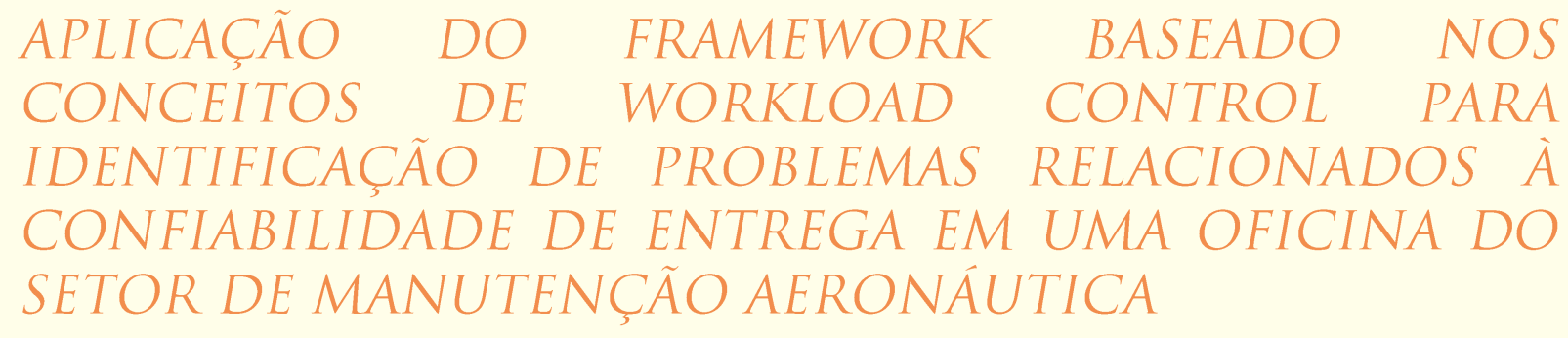

Tatiana Kimura Kodama,

Fernando José Gómez Paredes

Moacir Godinho Filho

Resumo: Esta pesquisa investiga como um framework de diagnóstico pode ser usado para identificar como a confiabilidade de entrega é influenciada pelas decisões de Planejamento e Controle da Produção (PCP). Para o desenvolvimento desta pesquisa, realizou-se um estudo de caso, em uma oficina de computadores de uma empresa do setor de manutenção aeronáutica. Os resultados apontam que, na oficina estudada, o desempenho da confiabilidade de entrega é influenciado pela determinação errônea das datas de entrega (foco em DP-Date Promissing), pois as capacidades são superestimadas. A principal contribuição da aplicação framework apresentado é uma análise agregada do comportamento dos atrasos em um determinado período de tempo. As pesquisas futuras devem desenvolver critérios para a criação de subsets e estudar mais profundamente o framework com o intuito de aprimorá-lo.

Palavras chave: Framework; Workload Control, Empresas MTO, Confiabilidade de Entrega. 


\section{INTRODUÇÃO}

Em empresas Make-to-Order (MTO), os preços e os prazos de entrega são determinados para cada trabalho e considerados fatores cruciais para ganhar 0 pedido (KINGSMAN; HENDRY, 2002; STEVENSON; HENDRY; KINGSMAN, 2005). De acordo com Thürer e Godinho Filho (2012), uma das competências operacionais importantes para empresas MTO é atingir um lead time reduzido e previsível com o objetivo de manter a promessa ao cliente, enquanto reduzir os prazos de entrega pode ser um critério determinante para ganhar o pedido. Portanto, as decisões de Planejamento e Controle da Produção (PCP) devem estar alinhadas para o alcance desse objetivo.

Segundo Kingsman e Hendry (2002), as decisões de PCP que influenciam a confiabilidade de entrega estão alicerçadas nos controles de entradas e de saídas. Conforme Soepenberg et al. (2008), o desempenho da confiabilidade de entrega precisa ser rastreado até as decisões da PCP. Segundo Soepenberg (2010), para melhorar esse desempenho, é preciso reconhecer as causas dos atrasos, se as mesmas são originadas no processo da determinação do prazo de entrega (DP-Delivery Time Promissing) ou no processo de realização do pedido (RP - Realisation Process).

Entre as abordagens propostas na literatura, o Workload Control (WLC) é considerado como uma das principais soluções de PCP para empresas MTO (KINGSMAN; HENDRY, 2002; STEVENSON; HENDRY; KINGSMAN, 2005). Como benefícios, essa metodologia permite que os custos de produção e inventário sejam reduzidos, o que resulta em preços competitivos e prazos de entrega confiáveis (KINGSMAN; HENDRY, 2002). Soepenberg, Land e Gaalman (2012a), com base nos conceitos de WLC, propuseram um framework com objetivo de diagnosticar as causas de atrasos de entrega influenciadas pelas decisões de PCP. No entanto, segundo os autores, o framework precisa ser refinado para a sua aplicação prática. Este estudo tem exatamente o objetivo de aplicar o framework proposto por Soepenberg et al. (2012a) em um estudo de caso em uma empresa MTO do setor de manutenção aeronáutica.

Este artigo está estruturado da seguinte forma: na seção 2 é apresentado um referencial teórico que aborda os conceitos e detalhes do framework estudado, bem como as ferramentas de diagnóstico (Throughput Diagram e Order Progress Diagram). A seção 3 apresenta o método de pesquisa e os resultados. A seção 4 apresenta as conclusões do estudo de caso e o direcionamento para pesquisas futuras.

\section{REFERENCIAL TEÓRICO}

\subsection{AS FERRAMENTAS UTILIZADAS NO FRAMEWORK}

\subsubsection{THROUGHPUT DIAGRAM (TD)}

O TD auxilia no diagnóstico da confiabilidade de entrega e tem como finalidade descrever graficamente o comportamento dos inputs e outputs cumulativamente de um dado centro de trabalho ao longo do tempo (WIENDAHL, 1995). O TD pode ajudar a analisar os efeitos da aplicação do mecanismo de controle do WLC com a adoção do balanceamento de carga central, que objetiva atingir pequenos e constantes buffers no chão de fábrica (SOEPENBERG; LAND; GAALMAN, 2012b). Para o TD apresentado na Figura 1, o eixo horizontal representa o tempo (datas) e o eixo vertical mostra a quantidade de trabalho. A diferença entre as curvas identifica a entrada e saída de trabalho em relação a um fluxo do processo de ordens cumulativas. 
Figura 1 - Princípios do Throughput Diagram de um centro de trabalho

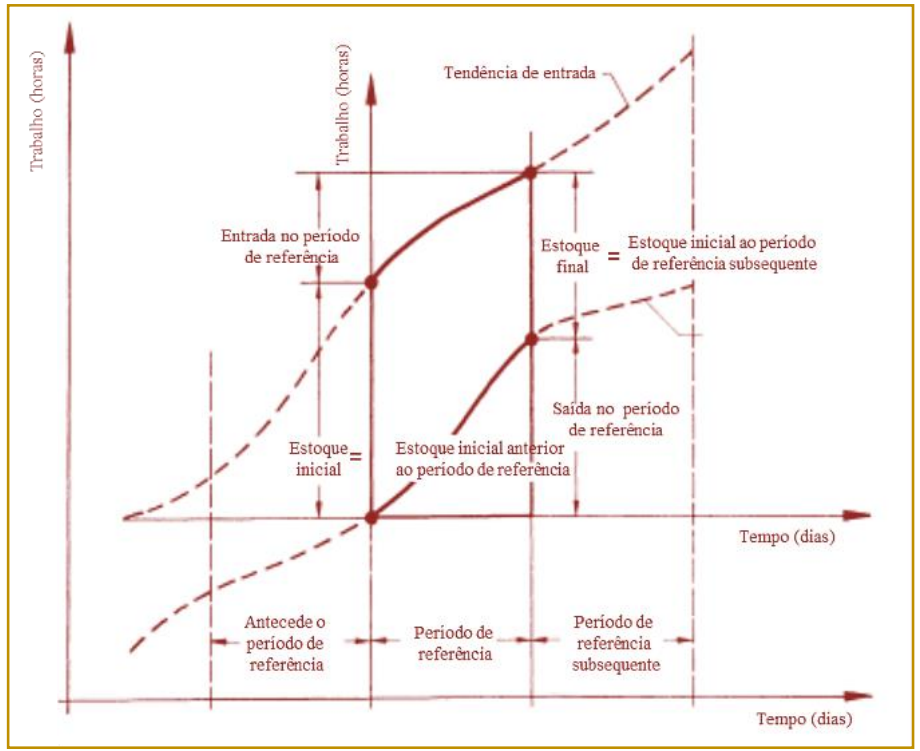

Fonte: Adaptado de Wiendahl (1995)

\subsubsection{ORDER PROGRESS DIAGRAM (OPD)}

O OPD é uma ferramenta desenvolvida com o objetivo de auxiliar na explicação da variação de atraso, pois relaciona o atraso dos pedidos individualmente e o progresso do pedido através de um controle de decisões de entrada e saída de determinado processo do centro de trabalho (SOEPENBERG; LAND; GAALMAN, 2008). Dessa forma, é possível analisar as ordens que estão atrasadas e as que estão adiantadas em cada fase do pedido. Para cada etapa, o OPD mostra a diferença entre tempos de processamento individuais realizados e os tempos médios de processamento. Os atrasos positivos ocorrem quando as datas de realização ultrapassam os dias planejados (valores positivos) e os atrasos negativos ocorrem quando as datas de realização são concluídas antes do planejado (valores negativos). Para ilustrar o funcionamento do OPD, apresenta-se a Figura 2.

Figura 2- Order progress diagram de um processo de produção

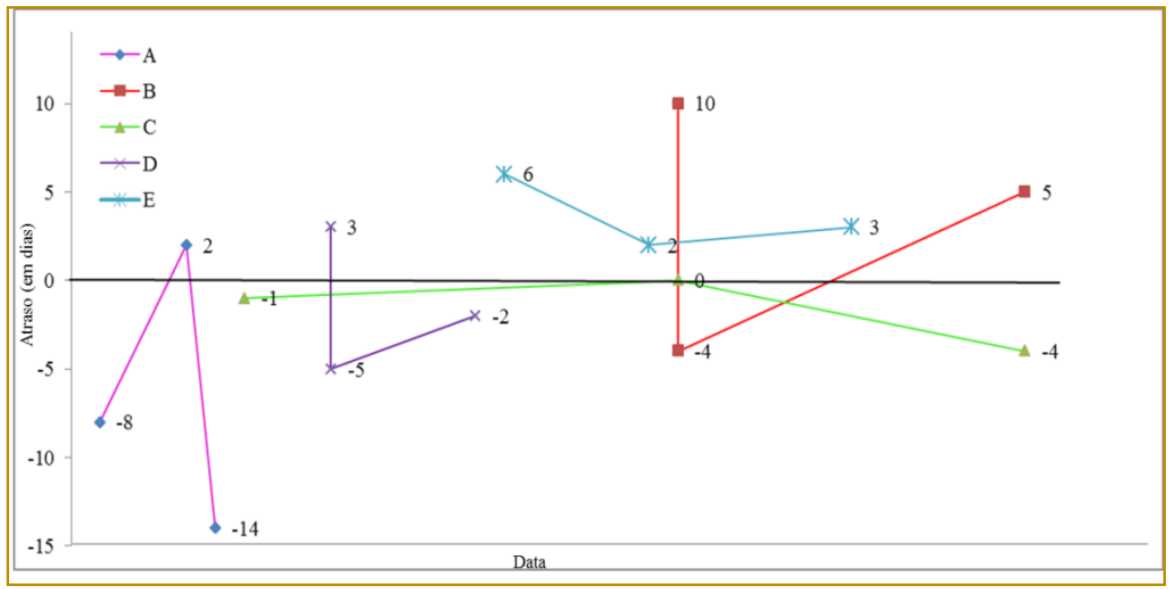

Fonte: Elaborado pelos autores 
Na Figura 2, o eixo horizontal representa as datas das fases do pedido. Já o eixo vertical mostra o atraso de uma ordem, seja que ultrapassa o prazo pré-estabelecido (valores positivos) ou que são concluídas antes da data planejada (valores negativos) (SOEPENBERG; LAND; GAALMAN, 2008).

\subsection{FRAMEWORK DESENVOLVIDO POR SOEPENBERG ET AL. (2012A)}

Esta seção apresenta o framework que apoia o diagnóstico do desempenho da confiabilidade de entrega. O diagnóstico fornecido pelo framework implica em orientar os atrasos pela média ou pela variância. A seguir, apresenta-se o detalhe da sequência de passos do framework e na Figura 3, a visão completa do modelo.

\section{Passo 1: Analisar a distribuição de atraso}

O diagnóstico inicia-se com a determinação da porcentagem de pedidos entregues atrasados em um determinado período. Continua-se com a criação da distribuição de atraso, com base em todas as ordens. Segundo a característica da distribuição do atraso, a análise continua orientado pela média ou pela variância (Figura 3).

Passo 2: Analisar as diferenças entre subconjuntos de ordem

Ao analisar o atraso médio, deve-se verificar se um número limitado de subconjuntos de ordem é responsável pela média alta. Se a distribuição de atraso é orientada pela variância, duas situações podem surgir:

a) Alguns subconjuntos de ordem têm uma alta variância interna de atraso, o que resultaria na continuação da análise da variância dentro desses subconjuntos;

b) A variação interna desses subconjuntos é limitada e a variância de atraso é principalmente o resultado de variância entre os subgrupos. Neste último caso, a análise deve proceder, focando esse subconjunto onde o atraso médio é alto.

\section{Passo 3: Analisar as diferenças ao longo do tempo}

Para obter insights sobre a dependência do tempo, o diagnóstico continua analisando mudanças do atraso ao longo do tempo. A análise do atraso médio pode revelar que períodos específicos de tempo apresentam valores de atrasos relativamente elevados em comparação a outros, sugerindo foco específico sobre esses períodos. Em termos de variância, duas situações podem tornar-se evidentes:

a) Primeiro, se variância de atraso é dependente do tempo no processo de diagnóstico, pode-se alternar análise da variância de atraso para análise direcionado pelo atraso médio;

b) Posteriormente, se a variância de atraso é independente do tempo, o diagnóstico continua ao longo dos ramos relacionados com a variação de atraso.

\section{Passo 4: Analisar DP e RP}

O quarto passo do diagnóstico visa determinar se o diagnóstico deve focar-se na DP ou na RP. A Figura 3 apresenta o framework desenvolvido por Soepenberg et al. (2012a), com a relação dos quatro passos recém descritos. 
Figura 3 - Framework para diagnosticar o atraso

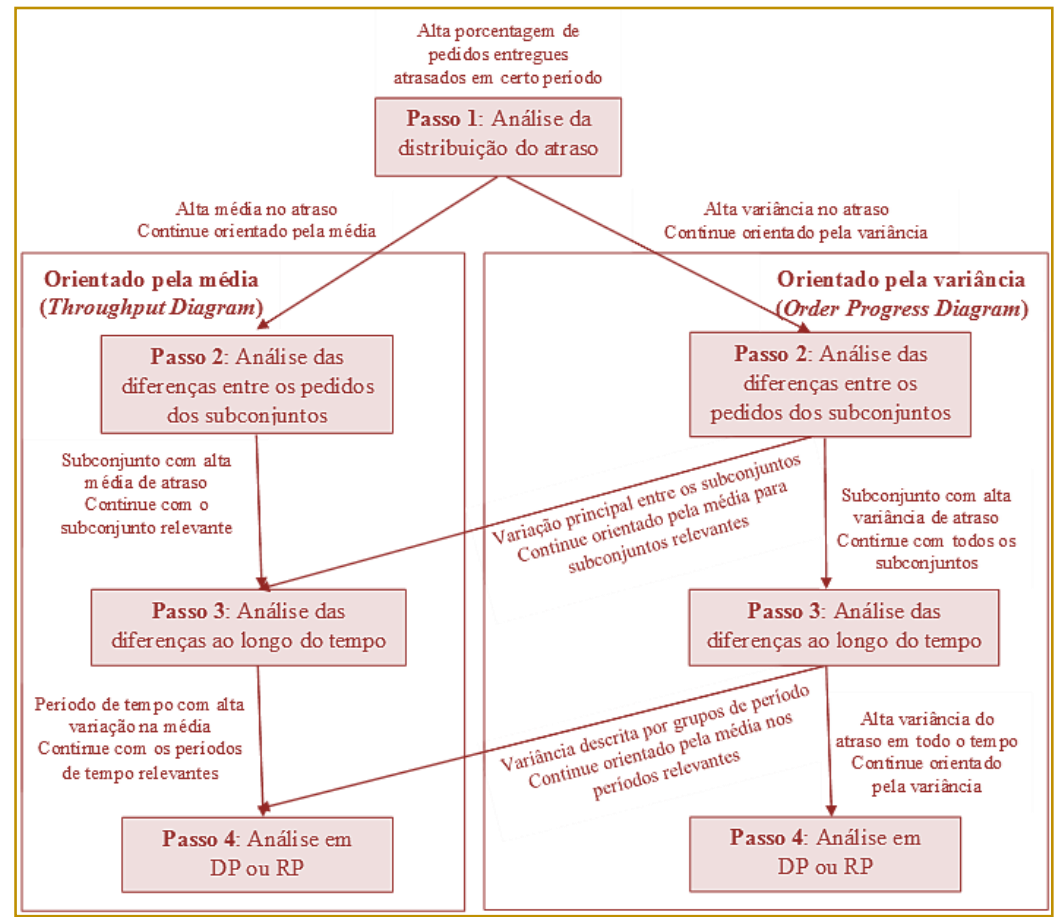

Fonte: Adaptado de Soepenberg et al. (2012b)

Sendo o último passo determinar se 0 diagnóstico deve focar-se no DP ou no RP, usam-se as ferramentas TD e OPD. A Figura 4 ilustra como essas duas ferramentas como suportam o foco determinado no passo 4 e como continuar as análises.

Figura 4 - Diagramas-chave para o processo de diagnóstico
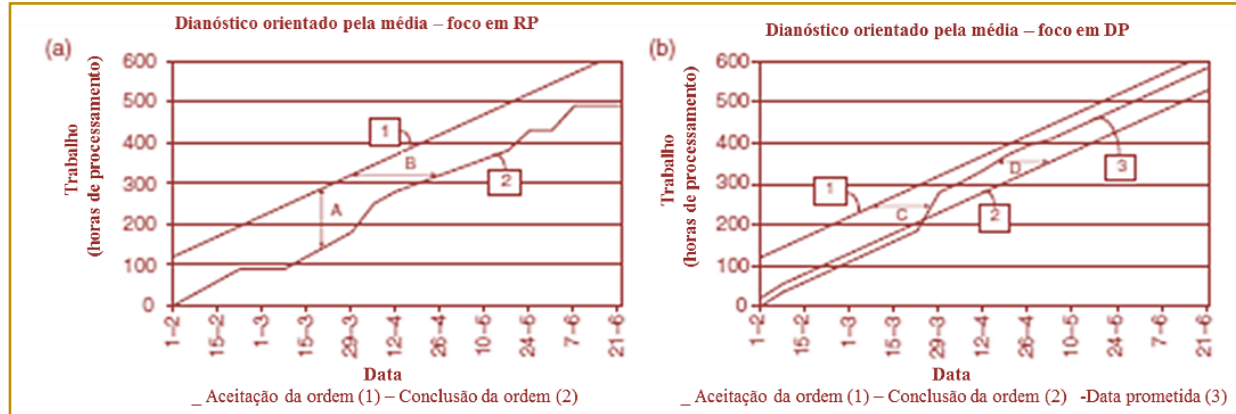

(c) Dianóstico orientado pela variância - foco em

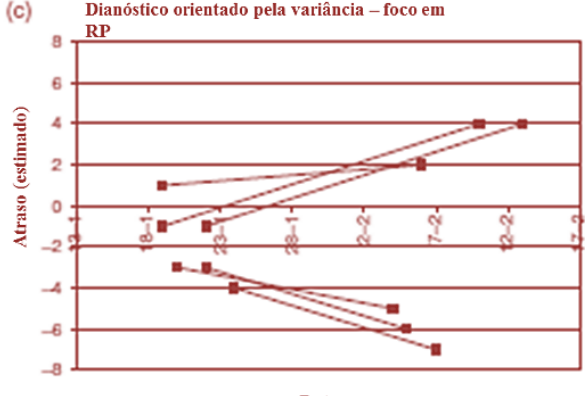

(d) Dianóstico orientado pela variância - foco em

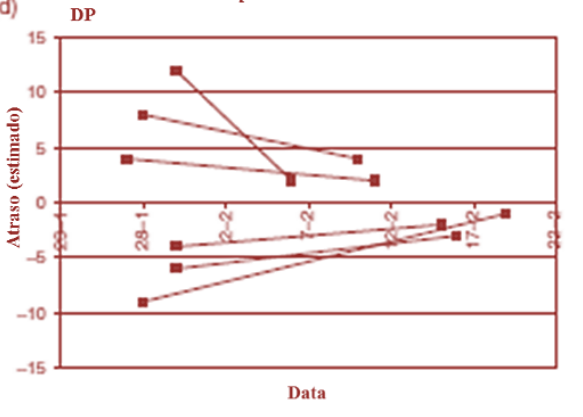

Fonte: Adaptado de Soepenberg et al. (2012c) 


\subsubsection{DIAGNÓSTICO ORIENTADO PELA} MÉDIA: DP OU RP?

O TD representado pelas Figuras 4 (a) e (b) é particularmente útil para busca de insights quando a tomada de decisão sobre o atraso médio deve concentrar-se na DP ou na RP. Nesta fase do diagnóstico, busca-se um resumo agregado com apenas duas ou três curvas. A curva de entrada (1) na Figura 4 (a) e (b) refere-se à ordem de aceitação. A curva de produção cumulativa (2) refere-se à conclusão real da ordem. Estas curvas aumentam, respectivamente, em valor, as necessidades de capacidade da ordem no momento da sua aceitação ou a sua conclusão. Além disso, a Figura 4 (b) mostra uma curva de data de entrega planejada ou estimada (3), que aumenta em valor cada vez que um pedido é prometido para ser entregue a um cliente. A distância vertical entre a curva de aceitação da ordem e a curva de execução (A) mostra o estoque em processo (WIP) da empresa, e a distância horizontal (B) refere-se aos tempos médios de atravessamento da RP. Analogamente, (C) reflete a média dos prazos de entrega prometidos e (D) o atraso médio.

De acordo com Soepenberg et al. (2012a), um atraso médio que justifique uma investigação mais aprofundada seria indicado no diagrama por uma curva de conclusão real (2), que se situa próximo ou mesmo abaixo da curva de conclusão planejada (3), durante um período considerável de tempo (Figura 4-b). Muitas vezes, é difícil excluir totalmente a RP ou a $\mathrm{DP}$, que, respectivamente, influenciam a curva final da conclusão e a curva de data de chegada do diagnóstico. No entanto, algumas orientações podem ser utilizadas para decidir em quais desses processos devem se concentrar.

Um DP descontrolado é muitas vezes indicado por irregularidades ao longo do tempo na curva da data de conclusão planejada (3). Isto é mostrado na Figura 4 (b), onde existe uma mudança súbita em um determinado período de tempo, resultando em uma média elevada do atraso (positivo) a partir desse momento. A RP descontrolada pode muitas vezes ser indicado por irregularidades na conclusão da ordem curva (como na curva 2 na Figura 4-a), a menos que estas flutuações sigam a curva de data de entrega prometida.

Deve notar-se que, embora um nível estável na conclusão da ordem pode sugerir um controle adequado da RP, mas os tempos médios de taxa de atravessamento podem ser percebidos como demasiadamente longos. Para o estágio do pre-shop pool, este poderia ser o resultado dos prazos médios de entrega de materiais relativamente longos, enquanto que no chão de fábrica poderia resultar de espera desnecessária muitas vezes causada por excesso de proteção da capacidade.

\subsubsection{DIAGNÓSTICO ORIENTADO PELA VARIÂNCIA: DP OU RP?}

A Figura 4 (c) e 4 (d) mostram o progresso de seis ordens de sua aceitação até a sua conclusão. Para decidir-se entre o DP ou RP, uma comparação da variação do atraso estimado em na aceitação da ordem e da variância de atraso no fechamento do pedido é realizado e ilustrado usando a Figura 4 (c) e (d). A Figura 4 (d) mostra uma situação em que a variância de atraso estimado já é elevada no momento da aceitação. Nesta situação, a RP, embora acelerando os pedidos mais urgentes, não podem compensar suficientemente para a variabilidade nos prazos de entrega prometidos. Esta conclusão iria dirigir uma investigação mais aprofundada para a DP.

Já a Figura 4 (c) mostra uma situação em que a variância estimada de atraso no tempo de aceitação é relativamente baixa. No entanto, as encomendas urgentes abrandaram no RP, enquanto as encomendas menos urgentes são aceleradas. Como resultado, a variância (estimativa) e aumento dos atrasos durante o $\mathrm{RP}$, resultando em atrasos na entrega de algumas ordens. Este fato sugere uma investigação com foco mais aprofundada sobre a RP.

\section{ESTUDO DE CASO}

\subsection{MÉTODO DE PESQUISA}

Tendo em vista a aplicação do framework de Soepenberg et al. (2012a), utilizou-se o método de estudo de caso, pois aliam-se as justificativas de Meredith (1998) e Yin (2009) que apontam que o estudo de caso é um excelente veículo para o desenvolvimento da compreensão quando o assunto é complexo exercendo um papel fundamental nesse campo. A Figura 5 apresenta os estágios utilizados do processo de condução de pesquisa de Stuart et al. (2002). 
Figura 5 - Estágios para o desenvolvimento da presente pesquisa

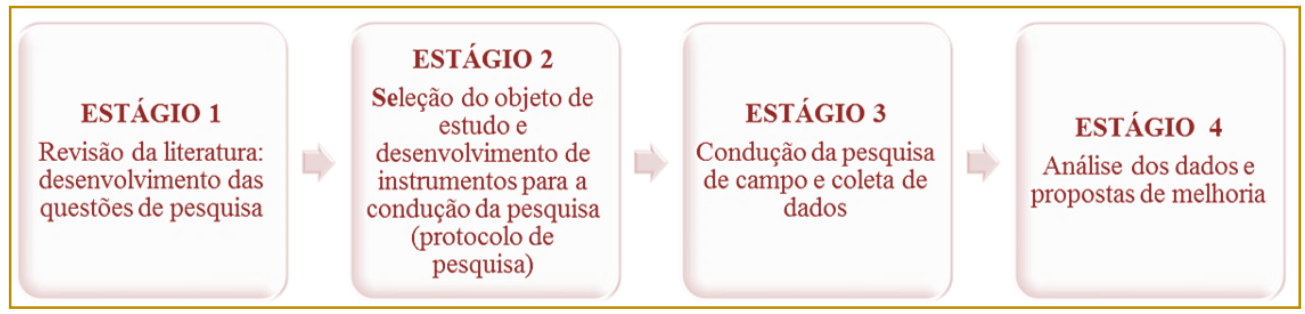

Fonte: Adaptado de Stuart et al. (2002).

A questão de pesquisa foi definida após a revisão da literatura, como aconselhado por alguns autores (EISENHARDT, 1989; SCHMENNER; SWINK, 1998; STUART et al., 2002) e, a partir disso, definiu-se a questão de pesquisa: "Como o framework de diagnóstico do rendimento da confiabilidade de entrega contribui para identificar os problemas de confiabilidade de entrega associados ao Planejamento e Controle da Produção?"
A oficina de manutenção de aeronaves foi escolhida por: a) comportar-se como MTO (STEVENSON; HENDRY; KINGSMAN, 2005), b) o prazo de entrega sofre uma grande pressão de clientes internos, e c) pela disponibilidade de dados sobre as datas de planejamento e realização das ordens. A figura 6 apresenta as sete etapas utilizadas nesta pesquisa para uma efetiva condução da coleta de dados e sua respectiva validação, seguindo as recomendações de Yin (2009)

Figura 6 - Síntese das etapas para a efetiva condução da coleta de dados do estudo de caso

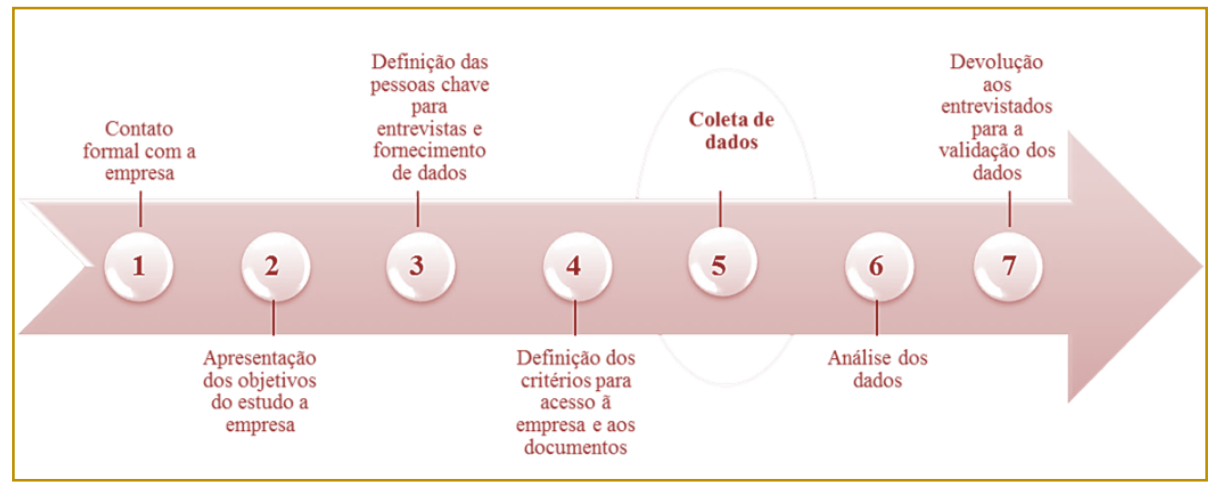

Fonte: Elaborado pelos autores

Com relação às fontes de dados, esta pesquisa utilizou, conforme indicado por Barrat et al (2011): entrevistas semiestruturadas; observação com visitas técnicas e participação em reuniões; documentos do organograma, registros do atraso dos pedidos, e relatórios. As fontes de dados foram trianguladas, a fim de aumentar a confiabilidade e deixar mais robustas as fundamentações e as construções das preposições (EISENHARDT, 1989; LEONARDBARTON, 1990; VOSS; TSIKRIKTSIS; FROHLICH, 2002). Os dados obtidos correspondem ao período entre janeiro de 2013 e maio de 2014. Todos os dados foram tabulados e analisados através de planilhas eletrônicas.

\subsection{CARACTERIZAÇÃO DA UNIDADE DE ANÁLISE: A OFICINA DE COMPUTADORES}

A unidade de negócio estudada encontra-se instalada no interior do Estado de São Paulo e possui cerca de 1.200 funcionários. As instalações contam com hangares que têm a capacidade para atender, simultaneamente, sete aeronaves possibilitando atender mais de 120 aeronaves por ano. Dentre as atividades executadas pela unidade estudada destacam-se: manutenção de aeronaves; manutenção de componentes; treinamento, 
manutenção de linha e fornecimento de equipamentos de apoio no solo. A oficina de computadores é responsável pela manutenção de 228 part numbers e opera em três turnos, devida à restrição de equipamento para a realização de um teste específico.

\subsection{APLICAÇÃO DO FRAMEWORK NA OFICINA DE COMPUTADORES}

A seguir, apresentam-se os resultados da aplicação do framework de Soepenberg et al. (2012a) na unidade de análise.

\section{Passo 1: Análise da distribuição do atraso}

Como resultado do passo 1 , verificou-se que o valor da média dos atrasos das 2.496 ordens é de 0,25 dias e o desvio padrão é de 29,83 dias, sendo um atraso máximo de 345 dias. Aproximadamente $89 \%$ das ordens são concluídas antes do prazo pré-estabelecido. Dessa forma, conclui-se que os atrasos das ordens são orientados pela variância, pelo valor do coeficiente de variação de 119,32.

Passo2: Análise das diferenças entre as ordens do subconjunto

No passo 2, chegou-se ao resultado que os grandes atrasos eram ocasionados por falta de peças. Como esse tempo depende de fornecedores externos à empresa, a estimação não está dentro do escopo do presente estudo. Retirando-se as ordens atrasadas por falta de peças, o total de ordens restante é de 2.284 ordens. A estatística descritiva para as ordens encontrase na Tabela 1. Ainda assim, o valor do módulo da média é inferior ao valor do desvio padrão e as análises continuam sendo orientadas pela variância do atraso.

Tabela 1 - Análise considerando o lead time estabelecido pela oficina de computadores

\begin{tabular}{|cc|}
\hline Análise Estatistica Descritiva dos atrasos \\
\hline Média (dias) & $-7,20$ \\
Desvio Padrăo (dias) & 10,12 \\
Variância da amostra (dias) & 102,41 \\
Mínimo (dias) & -14 \\
Máximo (dias) & 14 \\
Quantidade de ordens & 2.284 \\
\hline
\end{tabular}

Fonte: Elaborado pelos autores

Passo 3: Análise da diferença no tempo

Como apresentado na figura 7 , não se observa uma diferença pontual ao longo do tempo em relação aos atrasos. Também não foi encontrado um período de tempo com comportamento particular e a análise continua orientada pela variância. 
Figura 7 - Throughput diagram dos atrasos da oficina de computadores

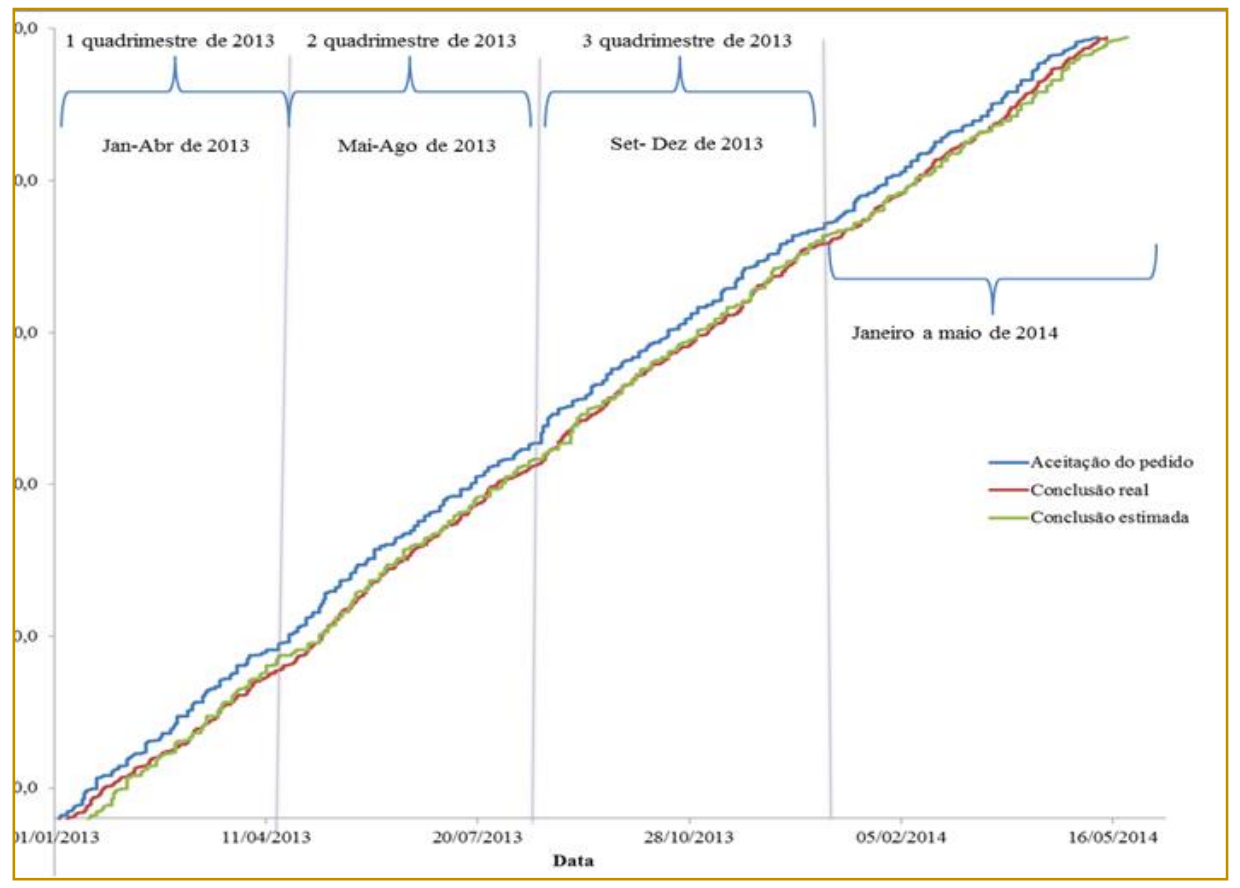

Fonte: Elaborado pelos autores

Passo 4: Análise do DP e do RP

Conforme visto no passo anterior, o diagnóstico será orientado pela variância. Nesses casos, OPD é a ferramenta ideal para auxiliar a empresa a decidir sobre o foco em DP ou RP. A Figura 8 mostra o máximo e o mínimo das possibilidades dos atrasos, tanto na chegada do pedido quanto da conclusão da ordem.

Figura 8 - Order progress diagram da oficina de computadores simplificado

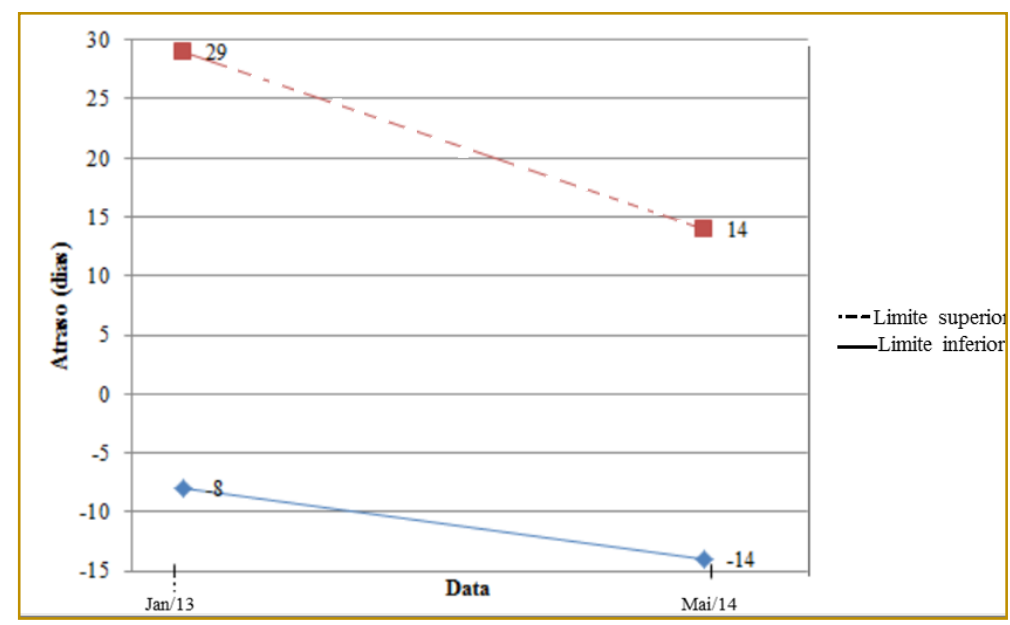

Fonte: Elaborado pelos autores

Observando a Figura 8, vê-se que a variação de atraso na chegada do pedido (reta vermelha) é de 37 dias e a conclusão da ordem (reta azul) é de 28 dias. Dessa forma, a variação da chegada do pedido é maior que a variação na conclusão da ordem, destacando que o planejamento da chegada real das ordens na produção não é condizente com as estimadas pela oficina. Dessa forma, a Figura 8 mostra uma situação em que a variância de atraso estimado já é elevada no momento da aceitação. Nesta situação, os processos de realização da ordem não podem compensar a variabilidade nos prazos de entrega 
prometidos. Esta conclusão faz com que a investigação seja com o foco orientado pela DP (Figura 4-d).

Devido à dominância da variância do atraso com foco em DP, analisou-se o fato de aproximadamente $89 \%$ das ordens serem concluídas antes do prazo pré-estabelecido. Para isso, foi realizada uma análise da capacidade estimada e utilizada de acordo com as 2.496 ordens (todas as ordens do período analisado). Como apresentado na Tabela 2, a capacidade engloba horas de mão de obra e capacidade do equipamento.

Tabela 2 - Análise da capacidade estimada e utilizada da oficina de computadores

\begin{tabular}{|cc|}
\hline \multicolumn{2}{|c|}{ Análise da capacidade } \\
\hline Capacidade Utilizada em 2013 (horas) & 16.279 \\
Capacidade Utilizada em 2014 (horas) & 7.555 \\
Capacidade Estimada2013 (horas) & 25.116 \\
Capacidade Estimada 2014 (horas) & 9.716 \\
Diferença entre Capacidade Estimada - Utilizada 2013 & 8.837 \\
(horas) & 879 \\
Diferença entre Capacidade Estimada - Utilizada 2014 & $64,81 \%$ \\
Percentual de capacidade estimada 2013 & $90,96 \%$ \\
Percentual de capacidade estimada 2014 & $35,19 \%$ \\
Percentual de Capacidade Ociosa 2013 & $9,04 \%$ \\
Percentual de Capacidade Ociosa 2014 & \\
\hline
\end{tabular}

Fonte: Elaborado pelos autores

De acordo com a diferença da capacidade estimada versus capacidade utilizada (Tabela 2), encontra-se uma sobre estimação da capacidade, pois 265.124 horas não são utilizadas no período analisado. A mensuração reflete em um desperdício mensal de 17.674 horas de capacidade.

Portanto, a revisão dos métodos de PCP utilizados pela empresa através de uma análise mais profícua do histórico para uma determinação mais precisa das datas de chegada faz-se necessário, tendo em vista a mensuração do desperdício de recursos e como consequência um elevado custo pela falta de gerenciamento.

\subsection{ANÁLISE E DISCUSSÃO DO CASO}

Os problemas identificados na oficina de computadores através da aplicação do framework de Soepenberg et al. (2012a) são: falta de acurácia para determinação do DP e falta de peças. Embora, os atrasos da oficina de computadores sejam orientados pela variância, o diagnóstico do atraso tem foco em DP. Esse fato justifica-se devido à oficina não estimar corretamente as datas de chegada e não possuírem um roteiro de manutenção para cada part number. Dessa forma, a oficina estima um lead time de manutenção fixo (14 dias) sem levar em consideração as diferentes peças.

Um efeito dos problemas encontrados é que os cálculos para o dimensionamento da capacidade de carga de trabalho nas oficinas não são exatos devido à falta de informações, criando um terceiro problema. O sistema de informação utilizado não possui uma estrutura para dar suporte à atividade de análise e liberação de ordens, segundo critérios de prioridades.

A falta de peças para realização dos serviços impacta em atraso nas entregas de componentes por parte da produção, pois a maioria das peças é importada. Os atrasos decorrentes da falta de peças são justificados pelos atrasos das entregas por parte dos fornecedores, ocasionando a paralisação das ordens de serviço. A estratégia da oficina para compensar esse atraso é utilizar a capacidade inflacionada, embora seja estimada uma data de entrega não realista. 
Portanto, dos dois problemas detectados pelo framework, grande parte das soluções encontra-se na melhoria da gestão de informação dos departamentos responsáveis pelo planejamento e controle das atividades dessa oficina. A partir do momento que as informações são organizadas em um banco de dados, é possível realizar uma análise precisa do histórico, a fim de estimar um lead time mais realista. Esse gerenciamento de informações resolveria o terceiro problema aferido: erro de cálculo na determinação da capacidade utilizada. O framework de Soepenberg et al. (2012a) apresentou-se com uma importante ferramenta prática para a detecção de problemas relacionados com a confiabilidade de entrega.

\section{CONCLUSÕES}

A presente pesquisa teve como objetivo principal analisar como o framework proposto por Soepenberg et al. (2012a) auxilia no diagnóstico no desempenho da confiabilidade de entrega influenciado pelas decisões de PCP. Tal objetivo foi alcançado, o qual identificou a falta de materiais, a determinação errônea da data de entrega (DP) como as principais causas dos atrasos. Com os resultados, encontrou-se que a resposta da oficina está baseada na sobre capacidade.

Soepenberg et al. (2012a) desenvolveu o framework para pequenas e médias empresas caracterizadas por serem MTO. No entanto,

\section{REFERÊNCIAS}

[1] Barratt, M.; Choi, T. Y.; LI, M. Qualitative case studies in operations management: Trends, research outcomes, and future research implications. Journal of Operations Management, v. 29, n. 4, p. 329-342, 2011.

[2] Eisenhardt, K. M. Building Theories from Case Study Research.Academy of Management Review, 1989

[3] Kingsman, B. G.; Hendry, L. C. The relative contributions of input and output control on the performance of a workload control system in Make-to-Order companies. Production Planning \& Control, v. 13, n. 7, p. 579-590, 2002.

[4] Leonard-Barton, D. A dual methodology for case studies: Synergistic use of a longitudinal single site with replicated multiple sites. Organization Science, v. 1, n. 3, p. 248-266, 1990.

[5] Meredith, J. Building operations management theory through case and field esta pesquisa verificou que existe aplicabilidade em uma grande empresa com características MTO. Partindo desta constatação, o framework pode trazer importantes contribuições na detecção de problemas na confiabilidade de entrega em empresas MTO em geral

A principal vantagem do framework apresentado é uma análise agregada do comportamento dos atrasos em um determinado período de tempo. Essa agregação permite uma análise global e facilita a identificação de ações de melhoria. Pois, como exposto neste trabalho, o framework identifica duas causas que são responsáveis pelo atraso das ordens: problemas na realização dos processos produtivos (RP) ou falta de precisão para a determinação da data de conclusão (DP).

A desvantagem encontrada baseia-se no passo 2 do framework, onde a criação de subsets não é bem definida. Dependendo das características do sistema produtivo estudado, as variáveis para a realização do agrupamento não seriam possíveis. Neste ponto, sugere-se que sejam desenvolvidos critérios para a criação de subsets e que possam ser considerados no framework utilizado nesta pesquisa.

A pesquisa limitou-se por ser um caso único e apenas um tipo de sistema produtivo foi analisado através do framework. Além disso, a falta de disponibilidade de dados das liberações das ordens ocasionou em uma limitante da pesquisa.

research. Journal of Operations Management, $v$. 16, n. 4, p. 441-454, jul. 1998

[6] Schmenner, R. W.; Swink, M. L. On theory in operations management. Journal of Operations Management, v. 17, n. 1, p. 97-113, 1998.

[7] Soepenberg, G. D. Workload Control under diagnosis. Groningen: Universidade de Gröningen, 2010.

[8] Soepenberg, G. D.; land, M.; Gaalman, G. The order progress diagram: A supportive tool for diagnosing delivery reliability performance in maketo-order companies. International Journal of Production Economics, v. 112, n. 1, p. 495-503, 2008.

[9] Soepenberg, G. D.; Land, M. J.; Gaalman, G. J. C. A framework for diagnosing the delivery reliability performance of make-to-order companies. International Journal of Production Research, v. 50, n. 19, p. 5491-5507, 2012a. 
[10] Soepenberg, G. D.; Land, M. J.; Gaalman, G. J. C. Adapting workload control for job shops with high routing complexity. International Journal of Production Economics, v. 140, n. 2, p. 681-690, $2012 b$.

[11] Soepenberg, G. D.; Land, M. J.; Gaalman, G. J. C. A framework for diagnosing the delivery reliability performance of make-to-order companies. International Journal of Production Research, v. 50, n. 19, p. 5491-5507, 2012c.

[12] Stevenson, M.; Hendry, L. C.; Kingsman, B. G. A review of production planning and control: the applicability of key concepts to the make-toorder industry. International Journal of Production Research, v. 43, n. 5, p. 869-898, 2005.

[13] Stuart, I. et al. Effective case research in operations management: A process perspective. Journal of Operations Management, v. 20, n. 5, p. 419-433, set. 2002.
[14] Thürer, M.; Godinho Filho, M. Redução do lead time e entregas no prazo em pequenas $\mathrm{e}$ médias empresas que fabricam sob encomenda: $A$ abordagem Worload Control (WLC) para O Planejamento e Controle da Produção (PCP). Gestão \& Produção, v. 19, n. 1, p. 43-58, 2012.

[15] Voss, C.; Tsikriktsis, N.; Frohlich, M. Case research in operations management. International Journal of Operations \& Production Management, v. 22, n. 2, p. 195-219, 2002.

[16] Wiendahl, H.-P. Load-Oriented Manufacturing Control. New York: Springer-Verlag Berlin Heidelberg, 1995.

[17] YIN, R. K. Case Study Research: Design and Methods. 4. ed. Thousand Oaks, California: SAGE Publications, Inc, 2009. 


\section{Eapítulo 2}

\section{APLICACÃO DO DESIGN FOR ASSEMBLY AND MANUFACTURING (DFMA) NO PROJETO CONCEITUAL DE UM COMEDOURO AUTOMÁTICO PARA CÃES}

\section{Adriana Ribeiro de Souza}

\section{Kêmyle Moreira Silva}

Everton Costa Santos

Anne Beatriz de Camargo Gomes

\section{Rosana Brito Santos}

Resumo: Este trabalho propõe a aplicação da metodologia DFMA (Design for Manufacturing and Assembly) em um comedouro automático, produto que se encontra em fase de desenvolvimento com foco em simplicidade e eficiência, propondo ainda um sistema inovador para a liberação e bloqueio da ração para o pet. A necessidade de alimentar o animal na ausência do dono foi o ponto de partida para o desenvolvimento deste produto. Desta forma brainstormings foram realizados com a equipe, onde várias sugestões de sistemas e subsistemas foram levantadas até se chegar à solução atual. Após definir o modelo básico da estrutura partiu-se para o seu detalhamento utilizando tecnologias CAD/CAE (Computer Aided Design/Engineering), em específico, o software SolidWorks. Com o intuito de criar um produto que atendesse às especificações básicas e ao mesmo tempo apresentasse simplicidade na manufatura e montagem, o projeto conceitual foi aplicado seguindo a metodologia DFMA, onde chegou-se à solução apresentada neste trabalho, que apresenta características intermediárias aos disponíveis no mercado, ou seja, libera a ração automaticamente em uma porção limitada, conservando-a internamente no comedouro, e não possui sistemas lógicos, com botões, placas digitais, o que consequentemente aumentaria drasticamente o custo do produto.

Palavras-Chave: Comedouro Automático, Tecnologias CAD/CAE, DFMA. 


\section{INTRODUÇÃO}

O mercado de produtos para animais domésticos continua crescendo apesar do cenário econômico brasileiro. Segundo a Associação Brasileira de Produtos para Animais de Estimação (Abinpet) o setor teve uma alta de mais ou menos 7,4\% entre $2014 \mathrm{e}$ 2015. Na contramão de muitos setores, esse mercado voltado para animais de estimação tem conseguindo manter o ritmo de expansão, o Brasil ficou em terceiro lugar no ranking de faturamento global do setor pet, perdendo apenas para os Estados Unidos da América e Reino Unido.

Muitos produtos vêm sendo desenvolvidos neste ramo, principalmente as inovações nos serviços oferecidos. Neste trabalho o foco foi definir um produto tangível, um comedouro automático, com o intuito de facilitar a administração da alimentação do animal em caso de ausência do(s) dono(s) e para isso recorreu-se a literatura para resgatar conceitos de desenvolvimento de produtos. A importância de um bom planejamento durante a fase de desenvolvimento de um determinado produto tem sido, na atualidade, o ponto diferencial das empresas para permanecerem competitivas no mercado. Para auxiliar nesta tarefa, existem metodologias capazes de analisar criteriosamente todas as fases do processo, destacando problemas até então não percebidos pela equipe multifuncional.

O processo de desenvolvimento de produtos engloba técnicas de gestão, métodos de criatividade, bem como ferramentas que podem ser aplicadas com o objetivo de promover uma melhoria no produto que o projeto irá entregar e dentre os mais eficazes métodos, destaca-se o método DFMA ( Design for Manufacturing and Assembly).

O Design for Manufacturing and Assembly, é uma filosofia aplicada à produtos que utiliza diversos conceitos, técnicas, ferramentas e métodos para aperfeiçoar a fabricação dos componentes relacionados ou simplificar a montagem de produtos, utilizando para tal desde a análise de valores de tolerâncias, a complexidade do produto, número mínimo de componentes necessários, layout do produto, dentre outros. Refere-se, basicamente, à compreensão das interações nos sistemas de manufatura e montagem, e uso destes conhecimentos para otimizá-los, visando à eficiência na qualidade, custos e tempo reduzido de manufatura e montagem (Bralla, 1986).

Fagade e Kazmer (1998) afirmam em seu trabalho que os benefícios mais significativos da adoção do Design for Manufacturing and Assembly estão na redução de custos causada pelo menor número de partes a serem montadas (ou fabricadas) e o encorajamento do trabalho em equipe entre o projeto e a manufatura, melhorando a confiabilidade do produto devido à redução da probabilidade de falha de um sistema componente ou peça.

Este trabalho busca apresentar um projeto conceitual de um comedouro automático para cães de forma que o alimento seja liberado em uma porção limitada a partir do acionamento pelo próprio animal. O produto deve possuir geometria simples com um menor número possível e peças e para o atendimento desses requisitos foi recorrido à metodologia supracitada.

\section{REFERENCIAL TEÓRICO}

Esta sessão busca contextualizar a aplicação do DFMA bem como fundamentar outros conceitos que apoiaram a criação do produto em questão.

\subsection{PLANEJAMENTO PARA A CRIAÇÃO DE UM NOVO PRODUTO}

De acordo com Rozenfeld et al. (2006), o desenvolvimento de produtos é um processo de negócio cada vez mais crítico devido a internacionalização dos mercados, o aumento da diversidade de produtos e a redução do seus ciclos de vida, sendo assim novos produtos buscam atender segmentos específicos de mercado, incorporando novas tecnologias e se adequando a novos padrões e restrições legais.

O Processo de Desenvolvimento de Produto (PDP) tem sido muito pesquisado devido à grande importância que o mercado econômico têm dado ao mesmo, por ser uma das formas de tornar-se competitiva no mercado atual, onde a concorrência é cada vez maior. Conforme Brown \& Esisenhardt (apud MUNDIM, 1995) num ambiente de grande competitividade, internacionalização das operações e rápidas mudanças tecnológicas, exige-se das empresas agilidade, produtividade e alta qualidade, que 
dependem necessariamente da eficiência $e$ eficácia do processo de desenvolvimento do produto. Um desempenho superior deste processo torna-se, então, condição essencial para garantir linhas de produtos atualizadas tecnologicamente e com características de desempenho, custo e distribuição condizentes com o atual nível de exigência dos consumidores.

O PDP é considerado complexo devido à sua multidisciplinaridade e necessidade de um bom planejamento. Silva (2002) afirma que as abordagens que estudam o desenvolvimento do produto provêm de diferentes áreas, interrelacionadas, porém com focos específicos. Pode-se destacar entre as disciplinas necessárias para a adequada gestão do PDP, a gestão de projetos, ergonomia, estilo de produto, qualidade, dentre outras e ainda tecnologias que agilizam o processo de desenvolvimento como as tecnologias CAD (Computer Aided Design), utilizada neste projeto.

\subsection{QUALIDADE E DESENVOLVIMENTO DE PRODUTO}

O foco da gestão da qualidade era a padronização dos processos de trabalho e sua análise criteriosa, visando à melhoria contínua dos mesmos. Dessa forma, as mudanças se concentravam em atividades mais operacionais, com menor impacto na gestão do negócio, mas que geravam mudanças rápidas no dia-a-dia de algumas áreas.

A segunda onda da gestão de processos ocorreu em meados da década de 1990, com os conceitos de reengenharia dos processos, disseminados principalmente por Tom Davemport e por Michael Hammer. Sua base estava no redesenho dos processos, a partir da análise das melhores práticas de mercado, já buscando uma visão multifuncional desses processos, isto é, o processo que passa por diversas áreas da empresa. As mudanças proporcionadas pela reengenharia tinham grande impacto no negócio e, consequentemente, exigiam um tempo maior de implantação com riscos também maiores. Por estas razões, muitos projetos falharam, levando ao descrédito muitos trabalhos de processos em andamento.

Para Falconi (1992) o verdadeiro critério para boa qualidade é a preferência do consumidor em relação ao concorrente, uma vez que isso garantirá a sobrevivência da empresa. A preferência se dá através da adequação do produto ou serviço as necessidades, expectativas e ambições do consumidor como uma forma de agregar valor ao que será produzido por menor custo. Estes aspectos foram considerados em todos os brainstormings para a criação deste produto bem como detalhes referentes à simplicidade e eficiência do produto.

\subsection{DFMA (DESIGN FOR ASSEMBLY)}

Ao longo do desenvolvimento do comedouro proposto neste artigo, pensou-se a todo o momento em definir um produto que atendesse as especificações básicas (armazenar internamente a ração e liberá-la automaticamente com o acionamento do animal uma porção limitada), porém este mesmo produto deveria ter a geometria simples, buscando facilitar a manufatura, bem como deveria apresentar facilidade de montagem utilizando o menor número possível de peças. Com isto em mente recorreu-se à metodologia DFMA (Design for Assembly and Manufacturing), onde foram identificadas características básicas para o desenvolvimento enxuto de um produto bem como elementos de fixação simples e eficientes úteis para este fim.

A área militar é marcada por dar grandes contribuições à engenharia, diga-se de passagem, pode-se citar o desenvolvimento da pesquisa operacional que busca a otimizar, através da resolução de equações matemáticas, a utilização dos recursos disponíveis e o DFMA passou por um contexto similar. (BARBOSA, 2007) explica em seu trabalho que os conceitos desta metodologia começaram a serem desenvolvidos quando Eli Whitney, que trabalhava para o governo norte-americano, precisava desenvolver um sistema de manufatura para armas. Ele criou uma produção com peças intercambiáveis que substitui a fabricação manual, onde nenhuma arma era igual à outra e as peças não podiam ser trocadas. Whitney reprojetou cada peças com uma tolerância limitada e dimensões específicas e padronizadas. Décadas mais tarde Henry Ford, desenvolveu o chamado automóvel "Model $T$ " com um revolucionário sistema de montagem, promovendo produtos com qualidade, confiabilidade e custos reduzidos. 
O pensamento DFMA vem desde a década de 1968 e atualmente foi expandido para outras áreas, ficando conhecida genericamente por Design for Excellence (DFX), que engloba o Design for Assembly, Design for Manufacturing, Design for Higher Quality, Design for Cost, Design for Enviroment, Design for Logistics, dentre outros.

O Design for Assembly (DFA) e Design for Manufacturing (DFM) compõem o DFMA. (BARBOSA, 2007) diz que o objetivo do DFM é desenvolver um produto que atendo a todos os requisitos funcionais e que também seja de fácil manufatura, o que diminuirá os custos de produção. Esta técnica é composta por vários princípios, conceitos, regras e recomendações que guiam aquele que está projetando a definir a melhor geometria do ponto de vista da fabricação. O DFA tem por objetivo racionalizar a etapa de montagem por meio da redução do número de peças e da facilidade de montagem, analisando separadamente a função, forma, material e montagem de cada peça e assim desenvolver um produto simples e funcional.

O comedouro proposto neste artigo se encontra em fase de projeto conceitual, o momento ideal para se pensar nesta metodologia. Segundo Boothroyd; Dewhurst; Knight (1994), o DFMA deve ser utilizado em maior ênfase no início da fase conceitual do projeto, pois nesta etapa os custos de modificação são mais baixos e o tempo de duração do projeto pode ser reduzido, disponibilizando o produto mais rapidamente ao mercado e com um preço significativamente melhor. Abaixo estão listadas as regras para aplicação do DFMA em produtos definidas pelo mesmo autor supracitado.

- Reduzir o número de partes de um produto e facilitar a manipulação e montagem das partes restantes;

- Simplificar a estrutura do produto para reduzir custos de montagem;

- Projetar para um número mínimo de partes;

- Desenvolver projetos modulares;

- Enfatizar a padronização;

- Projetar componentes multifuncionais;

- Projetar componentes de fácil fabricação;

- Evitar componentes de fixação (parafusos e outros);

- Eliminar ajustes desnecessários;

- Fazer um uso racional dos materiais.

Para que o produto atenda as especificações obedecendo a princípios do DFMA foi utilizado elementos de fixação do tipo SnapFit. Os elementos de junção apresentam uma grande diversidade e aparecem em diversos produtos, alguns são extremamente baratos e por isso são muito utilizados.

Os snap-fits surgiram com o objetivo de substituir sistemas mecânicos como parafusos e porcas, resolvendo o problema de junção de peças de forma simples e econômica. Segundo Klohn, 2007 é um mecanismo de fechamento embutido ou integrado com a função de encaixar uma parte na outra. É geralmente associado a partes plásticas, mas também pode ser união metal-metal e metal-plástico, o que determina o tipo de material a ser utilizado é a performance do encaixe. A figura 1 apresenta um dos diversos tipos de snap-fits disponíveis.

Figura 1: Snap-fit móvel

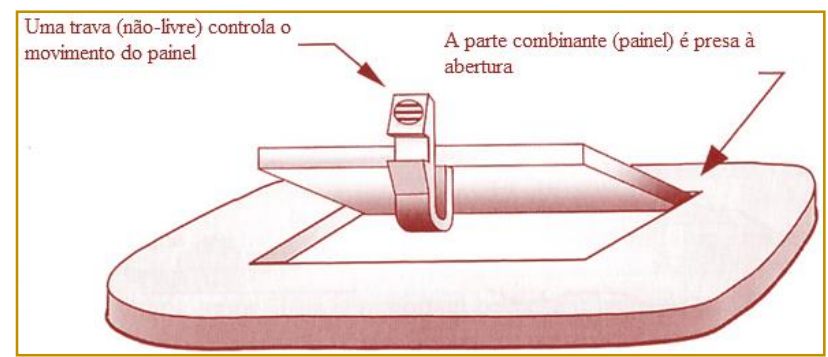

Fonte: (Klohn 2007) apud (Bonenberger 2005)

O produto proposto neste artigo foi concebido buscando reduzir o número de peças com um foco na montagem entre as mesmas e para facilitar esta montagem os snap-fits foram utilizados e estão ilustrados na seção 4 deste trabalho. 


\section{METODOLOGIA}

Este trabalho tem natureza prática onde se objetiva gerar conhecimentos a serem aplicados, dirigidas à solução de problemas específicos. Neste caso, partindo da problemática de criar um comedouro simples e eficiente, buscou-se uma solução criativa e que atendesse aos requisitos. Sobre os procedimentos técnicos, foi realizada uma pesquisa bibliográfica para a verificação dos conceitos sobre metodologias de montagens de sistemas e de desenvolvimento de produtos. Enquanto a abordagem, o trabalho apresenta característica qualitativa, onde não são utilizados procedimentos matemáticos ou estatísticos para a realização das analises relacionadas. A solução proposta foi baseada em técnicas de criatividade alimentada por motivação e fontes externas a partir da realização de benchmarkings para promover a melhor solução para o produto, como a redução de custo e facilidade de manuseio tanto para o fabricante quanto para 0 consumidor.

Quanto aos objetivos, trata-se de uma pesquisa descritiva, caracterizada observações sistemáticas visando também descrever a aplicação do método DFMA em um comedouro automático para cães e, por consequência, conhecer suas implicações no produto final. Segundo Solomon (2004), a pesquisa descritiva é aquela que visa definir melhor o problema, proporcionar as chamadas intuições de solução, descrever comportamentos e fenômenos, definir, classificar fatos e variáveis, podendo assim prever possiveis falhas.

Toda a estrutura do comedouro foi montada utilizando a tecnologia CAD/CAE, ferramenta esta chamada SolidWorks. Um software cujo o foco está no desenho técnico do produto e na documentação da fase de projeto. Durante o processo de engenharia, essa tecnologia facilita o processo de manufatura, transferindo diagramas detalhados dos materiais utilizados nos produtos, processos, tolerâncias e dimensionamentos e ao longo de todos os Brainstormings realizados 0 pensamento DFMA foi predominante e aplicado diretamente ao comedouro a partir do uso desta tecnologia, com o intuito de promover a melhor solução que busque atender aos requisitos técnicos básicos.

\section{APRESENTAÇÃO DO PRODUTO PRINCÍPIO DE FUNCIONAMENTO}

Como dito anteriormente, o sistema proposto busca oferecer praticidade na administração da alimentação de animais domésticos como cães e gatos. Sobre os já existentes, no mercado se encontra dois tipos básicos de comedouros automáticos. Por um lado existem aqueles de baixo custo e relativamente simples, neste, a medida que o animal se alimenta o sistema é reabastecido devido a ação da gravidade, porém para este tipo de comedouro o alimento é exposto a todo tempo, sendo assim propriedades nutritivas podem ser perdidas e outro problema está na proliferação de insetos ao redor do sistema. Por outro lado existe um comedouro onde a ração é armazenada internamente no comedouro e o usuário programa a saída da mesma. Este último é bastante sofisticado, apresentando painel digital, placa lógica, dentre outros subsistemas e consequentemente o custo deste produto se torna bastante expressivo, chegando a ser aproximadamente 30 vezes mais caro que o primeiro apresentado.

Diante deste cenário propõe-se então um comedouro com características intermediárias (figura 2) com foco no baixo custo, que armazene o alimento internamente, e libere uma quantidade limitada para o animal a partir do acionamento do mesmo. 
Figura 2: Comedouro Automático

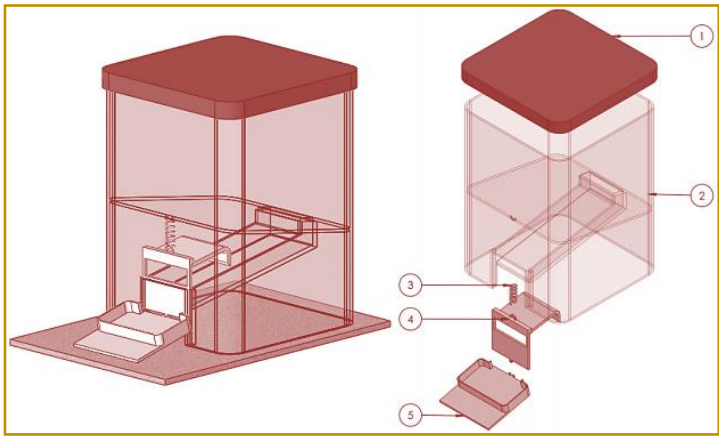

Fonte: Autoria própria

A figura 2 mostra a geometria do comedouro (vista recolhida e explodida, respectivamente) bem como uma inovação na forma pela qual a ração é liberada para que o animal possa se alimentar. $\mathrm{O}$ apêndice 1 apresenta os detalhes das dimensões do comedouro.

Nos brainstormings realizados para a criação deste produto, procurou-se levantar a ideia de um sistema que armazenasse a ração internamente ao sistema e que a saída da mesma acontecesse a partir do acionamento pelo próprio animal e em uma quantidade limitada. Nesta mesma etapa houve um foco na eficiência e simplicidade do produto sendo definido um total de 5 peças necessárias para a montagem completa. A partir deste mesmo raciocínio foi definido o funcionamento do sistema que é caracterizado por dois momentos distintos: animal fora da plataforma (peça 5) e animal em cima da plataforma. No momento em que o animal desejar se alimentar o mesmo precisa pisar nesta peça (detalhe na figura 3) e assim uma porção limitada de ração será liberada e acondicionada na região indicada.

A porção de ração que sai é controlada devido ao próprio projeto da peça 4.

Figura 3: Detalhes da peça 4

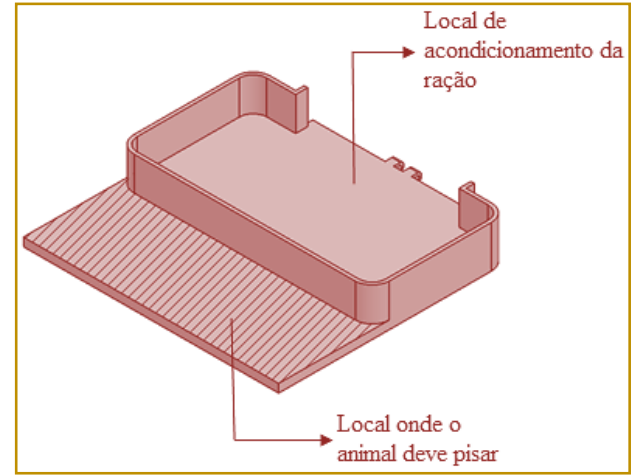

Fonte: Autoria própria

O ciclo de funcionamento do comedouro automático segue a sequência mostrada na figura 4, que mostra 2 estados: $\mathrm{Na}$ ausência do animal (estado 1) e na presença do animal, pisando na placa (estado 2). 
Figura 4: Ciclo de funcionamento do comedouro

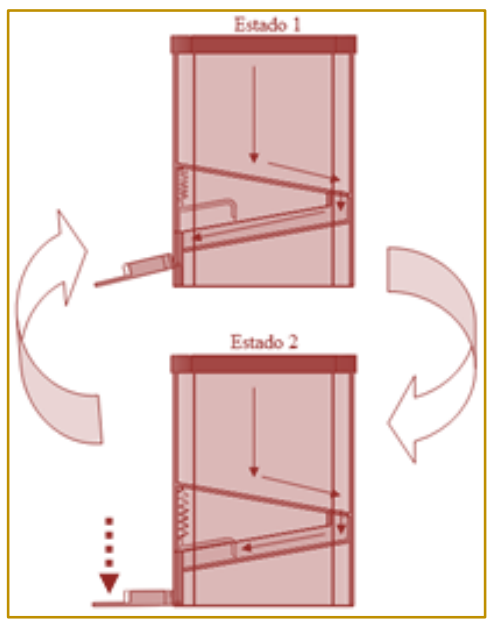

Fonte: Autoria própria

As setas contínuas na figura 4 indicam os locais que serão preenchidos pelo volume de ração, bem como o sentido da trajetória dos grãos. No estado 1 percebe-se que a peça 4 se encontra suspensa e a mola (peça 3), em contato com a mesma, no estado de equilíbrio. Neste momento a ração se encontra em contato com a peça 4, porém sua saída é bloqueada devido ao próprio projeto deste componente, que não permite a liberação de ração neste estado.

O estado 2 é marcado pela pisada no cão, no local indicado pela seta tracejada (figura 4), no momento em que o mesmo deseja se alimentar. Desta forma a peça 4 desce a seu nível mais baixo, a mola é estendida e devido a abertura projetada a ração é liberada instantaneamente em uma porção limitada e acondicionada no local indicado na figura 3. Quando o pet termina de se alimentar e deixa o comedouro, o sistema volta ao estado 1, bloqueando a saída de ração.

A figura 5 mostra o detalhe de como as peças 3,4 e 5 estão relacionadas, destacando a relação com a mola bem como a forma pela qual o volume é controlado.

Figura 5: Detalhe do sistema de amortecimento e limitação da saída da ração

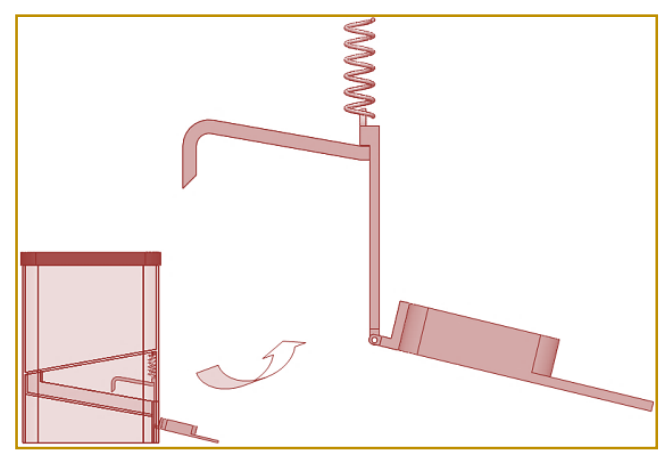

Fonte: Autoria própria

Dentro dos conceitos de DFMA, neste projeto optou-se por reduzir a quantidade de componentes a partir da utilização de elementos de fixação do tipo snap-fit. A montagem realizada entre as peças 4 e 5 para o controle da quantidade de ração liberada está representada na figura 6. 
Figura 6: Corte da montagem entre as peças 4 e 5

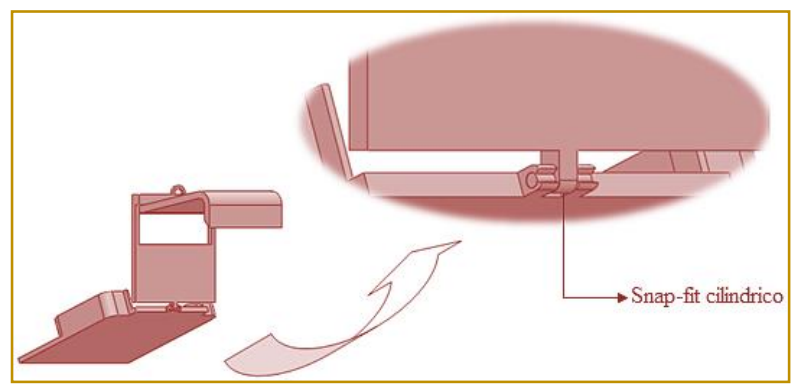

Fonte: Autoria própria

Como mostrado na figura 6 optou-se em utilizar elementos de fixação do tipo snap-fit para auxílio no controle da quantidade de ração que será liberada para o animal.

\section{CONSIDERAÇÕES FINAIS}

Para manter qualquer produto competitivo no mercado, garantindo que sejam bem aceitos pelos consumidores/clientes, uma organização deve sempre assegurar a qualidade dos mesmos. Um sistema de gestão da qualidade sólido preocupado com a atualização de sua metodologia é fundamental para que a empresa permaneça em vantagem frente aos seus concorrentes e esta foi uma das variáveis importantes consideradas neste trabalho.

\section{REFERÊNCIAS}

[1] Barbosa, G.F. Aplicação da Metologia DFMA - Design for Manufacturing and Assembly no projeto e fabricação de aeronaves. Dissertação de Mestrado, SP, 2007

[2] Boothroyd, G; Dewhurst, P; Knight, W. Product Design for Manufacturing and Assembly. New York: Marcel Dekker Inc, 1994

[3] Bralla, James G. Handbook. Of Product Design for Manufacturing. 1를 Ed, New York: Editor In Chief, 1986.

[4] Fagade, Adekunle A. ; Kazmer, David O. Early CostEstimation for Injection Molded Components. New York: University Of Massachusetrs, 1988.

[5] Falconi, Vicente. Controle de qualidade total no estilo japonês. Belo Horizonte; Fundacao Cristiano ottoni, 1992. 220 p.

[6] Klohn, S. C. Ecodesign: Desenvolvimento de pictogramas para o auxilio da desmontagem de produtos, RS, 2009.
A partir da orientação obtida na metodologia DFMA o conceito do comedouro proposto atende aos requisitos principais de operação do produto no que diz repeito à simplicidade e eficiência. Juntamente com o DFMA, tecnologias CAD foram fundamentais para a criação deste comedouro. Foi pesquisado no INPI sobre produtos similares e não existe patente com a inovação proposta na liberação e bloqueio de ração para os pets, mostrando o potencial de proteção da tecnologia.

Serão realizados trabalhos futuros no sentido de analisar o ciclo de vida e estudos de fadiga na mola presente no sistema a fim de contribuir com o adequado dimensionamento da mesma.

[7] Mundim, A.P.F.; Rozenfeld, H.; Amaral, D.C.; Silva, S.L.; Guerrero, V.; Horta, L.C.Aplicando o cenário de desenvolvimento de produtos em um caso prático de capacitação profissional. Núcleo de Manufatura Avançada, Escola de Engenharia de São Carlos, 2002. Disponível em: http://www.scielo.php?pid=s0104-

530 $2002000100002 \&$ script=sciarttexting=pt. Acesso em: 18 setembro 2016.

[8] Rozenfeld, H. et al. Gestão de Desenvolvimento de Produtos - uma referência para a melhoria do processo. São Paulo: Saraiva, 2006.

[9] Silva, S.L. Proposição de um modelo para caracterização das conversões do conhecimento no processo de desenvolvimento de produtos. Dissertação de Mestrado em Engenharia Mecânica - Universidade de São Paulo, São José dos Campos, 2002.

[10] Solomon, M. R. O comportamento do Consumidor: Comprando, Possuindo e Sendo. 5 ed., Porto Alegre: Bookman, 2004. 
APÊNDICE

Dimensionamento do Comedouro Automático

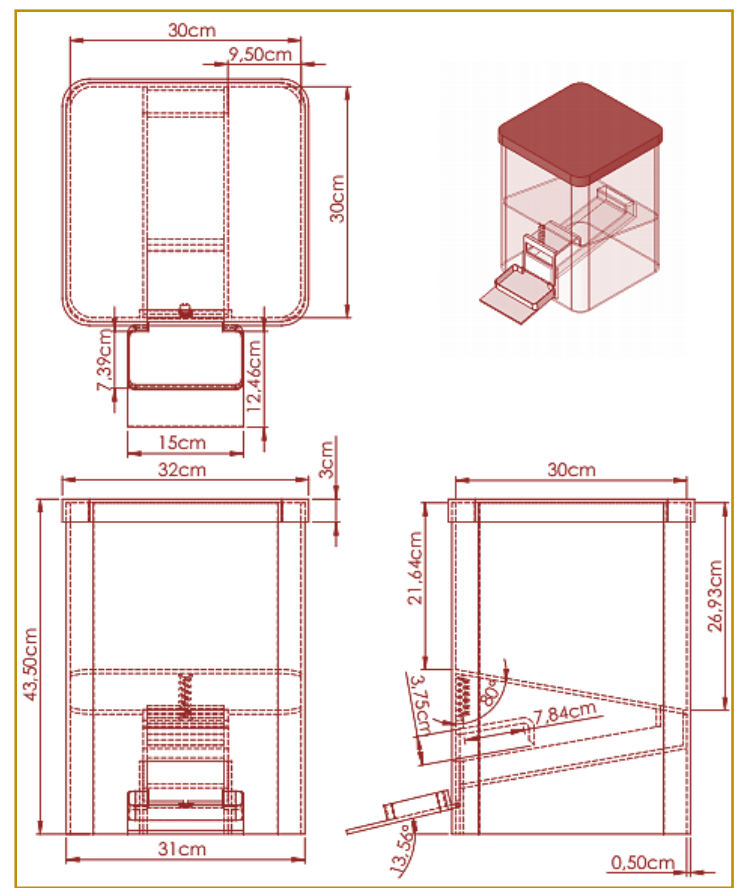




\title{
Capítulo 3
}

\section{EVOLUÇÃO DO AGENTE PEDAGÓGICO EMOCIONAL DÓRIS EM UM AMBIENTE VIRTUAL DE ENSINO- APRENDIZAGEM}

\author{
Danielli Cossul \\ Rejane Frozza \\ Brunno José Fagundes \\ Guilherme Ferreira \\ Liane Mahlmann Kipper \\ Marcus Vinicius Castro Witczak
}

Resumo: A educação necessita de novas formas de ensinar e aprender. Um ambiente virtual de aprendizagem com agentes pedagógicos inteligentes pode ser um caminho para o desenvolvimento de uma aprendizagem mais efetiva. Agentes Pedagógicos Inteligentes, quando inseridos em um Ambiente Virtual de Aprendizagem (AVA), têm como principal funcionalidade o acompanhamento, orientação e captação de informações provenientes da relação entre o estudante e a máquina. Desta forma, foi desenvolvido um AVA, no qual está inserido o agente Dóris, um agente pedagógico emocional, que atua como um tutor auxiliando os estudantes na interação com o conteúdo. O objetivo é avaliar o desenvolvimento da Dóris e sua interação com os estudantes no AVA, observando sua evolução desde 2000, ano em que foi projetada sua primeira versão. A metodologia de pesquisa foi realizada com a revisão bibliográfica dos artigos publicados pelo grupo de pesquisa, no período de 2001 a 2017, que abordam as funcionalidades da Dóris no ambiente, suas implementações e validações. Como resultado, uma síntese das publicações do grupo de pesquisa dividida em três períodos cronológicos revelou que atualmente a Dóris potencializa as habilidades intelectuais dos estudantes, com o auxílio das estratégias e táticas de ensino associadas aos Estilos Cognitivos de Aprendizagem. Ressalta-se a necessidade dos agentes pedagógicos terem as suas capacidades de interação em constante aperfeiçoamento e evolução, a fim de buscar sempre uma interação mais adequada e eficaz com o usuário.

Palavras-chave: Agentes Pedagógicos, Ambientes Virtuais de Aprendizagem, Evolução do Agente Pedagógico Dóris 


\section{INTRODUÇÃO}

A sociedade contemporânea está marcada por inúmeras mudanças no que diz respeito às formas de ser e estar no mercado de trabalho. Tais transformações são impulsionadas especialmente pela revolução tecnológica, responsável por arquitetar uma nova realidade, caracterizada pelo fluxo intenso e instantâneo de informações.

Esta nova realidade desloca-se paralelamente ao interesse intrínseco das organizações em manter seus padrões de lucro, de competitividade e de riqueza, exigindo 0 aperfeiçoamento do conhecimento de seus colaboradores. Neste contexto, a tecnologia é compreendida como um elemento que conduz ao engrandecimento intelectual nos níveis individual e coletivo, permitindo registrar e visibilizar 0 processo de aprendizagem, mapeando progressos, apontando dificuldades e traçando caminhos adaptativos diante de problemas (Morám, 2015).

Durante o processo de aprendizagem, a modalidade de ensino a distância (EAD) torna-se um produto da tecnologia que possibilita a autoaprendizagem (Meirelles et al., 2017). Atualmente, esta categoria vem crescendo cada vez mais, atendendo a diversas demandas tais como, sociais, econômicas, trabalhistas e educacionais. Além disso, este novo recurso educacional pode ser interpretado como um fenômeno pedagógico enfatizado pela superação da separação geográfica através do uso de Ambientes Virtuais de Aprendizagem (AVAs), utilizando materiais didáticos e tecnologias da informação e comunicação disponíveis para mediação entre tutor e estudante (Mülbert et al., 2011e Tenório et al., 2015).

Considera-se, portanto, que uma das caraterísticas predominantes no contexto educacional atual, em especial na educação profissional e tecnológica, é a perspectiva de mudança. Os estudantes mudaram e as escolas vivem em um contexto social, econômico e ambiental que impõem expectativas de alto desempenho. Para que isto ocorra, novas formas de ensinar e aprender são necessárias. Diferentes metodologias de aprendizagem tornam-se caminhos para a construção desta nova escola. Nesta perspectiva de mudança, o desenvolvimento de ambientes virtuais com agentes pedagógicos inteligentes, que promovam ações de ensino e aprendizagem centradas no estudante, também se faz necessário. Ambiente Virtual de Aprendizagem (AVA) e Agente Pedagógico Inteligente estão intrinsicamente interligados. As relações afetivas, cognitivas, simbólicas, entre outras, somadas a uma estrutura tecnológica, definem um AVA (Behar et al., 2007). Com essa definição é possível interpretar que um AVA, além de ser utilizado para estudos a distância, pode ser utilizado como objeto de aprendizagem presencial. É um espaço que possibilita a criação de uma esfera educacional, relacionando-se ao gerenciamento de conteúdos e ao monitoramento de estudantes (Behar et al., 2013). Os agentes inteligentes estão inseridos em um ambiente no qual recebem estímulos e realizam ações baseadas em seu conhecimento, sendo possível atuarem em conjunto por meio de processos de interação. São considerados agentes pedagógicos quando utilizados para fins educacionais, representando estudantes, auxiliares ou tutores virtuais, tendo como objetivo auxiliar os estudantes no processo de ensinoaprendizagem (Giraffa, 1999). Também acompanham a interação entre usuários e AVA, a fim de auxiliar nos processos de construção do conhecimento.

Estas aplicabilidades permitem a personalização do espaço educativo-virtual, neste caso, o AVA que atende aos estilos de aprendizagem de seus usuários. Professores e estudantes do Departamento de Computação e do Programa de PósGraduação em Sistemas e Processos Industriais (PPGSPI) da Universidade de Santa Cruz do Sul (UNISC), e do grupo de pesquisa Sistemas Computacionais de Apoio à Educação, desenvolveram um Ambiente Virtual de Aprendizagem (AVA) capacitado para promover conteúdos e metodologias facilitadoras para o processo instrutivo, a partir da atuação da Agente Pedagógica Dóris (Frozza et al., 2011).

Neste capítulo, será abordada a evolução da Dóris - desde 2000, ano em que foi projetada a sua primeira versão, fundamentalmente por ser um agente pedagógico animado, capacitado a demonstrar emoções através de expressões faciais e corporais, que são disparadas durante a interação do estudante com o AVA. Esse tipo de agente auxilia no processo motivacional, por estabelecer um vínculo afetivo com os usuários (Lester et al., 2007). 


\section{AGENTE PEDAGÓGICO DÓRIS}

A educação a distância vai além da disciplina e da determinação do estudante. Ela ultrapassa a simples postagem de materiais didáticos em plataformas educativas. O sujeito que busca este tipo de aprendizado precisa se sentir contemplado e estimulado para que não desista diante de suas dificuldades. Logo, as atividades a distância necessitam de tecnologias complementares para mediar a separação espacial entre estudante e professor, proporcionando o acompanhamento e incentivo ao usuário.

$\mathrm{Na}$ área educacional, especialmente em elearning, modalidade de ensino a distância baseada na autoaprendizagem e na mediação de um tutor virtual inserido em um AVA, o interesse em agentes conversacionais é grande e tem como justificativa as características desses agentes com uma interface mais natural e prática. São capazes de oferecer um suporte pessoal, de reconhecer pontos fortes, interesses e habilidades individuais dos estudantes (Morais et al., 2016). Com isso, é possível destacar maior independência e engajamento dos usuários durante o estudo.

Neste contexto apresenta-se o desenvolvimento da Dóris, uma agente caracterizada como pedagógico virtual, do tipo conversacional, que expressa emoções de tristeza, alegria, surpresa, indignação, expectativa, atenção e neutra, com o objetivo de tornar a interação dos usuários com o ambiente virtual mais natural e agradável. Sua função na interface sujeito-máquina auxiliar as relações estabelecidas com o conteúdo apresentado e durante a exploração da plataforma educativa.

Dóris foi desenvolvida para receber e interpretar informações via texto e áudio e também responder com texto, áudio e orientar a ação do usuário para redigir-se às páginas de conteúdo do AVA. Para executar todas essas habilidades, a sua arquitetura é composta por três módulos: perceptivo, cognitivo e reativo. Este processo intencionado inicia pelo módulo perceptivo que é responsável por receber a interação do usuário via texto ou áudio, convertendo o áudio em texto antes de enviar a informação para o módulo cognitivo. O módulo cognitivo é responsável pelas decisões ou reflexões sobre as suas futuras ações que se concretizarão no módulo reativo, que fornece sua resposta via texto e áudio em relação à ação definida no módulo cognitivo. Também neste módulo é definida a expressão de emoção da Dóris a partir das ações dos estudantes. A figura 1 apresenta os módulos da arquitetura da Dóris em sua versão mais recente.

Figura 1: Módulos da Agente Dóris

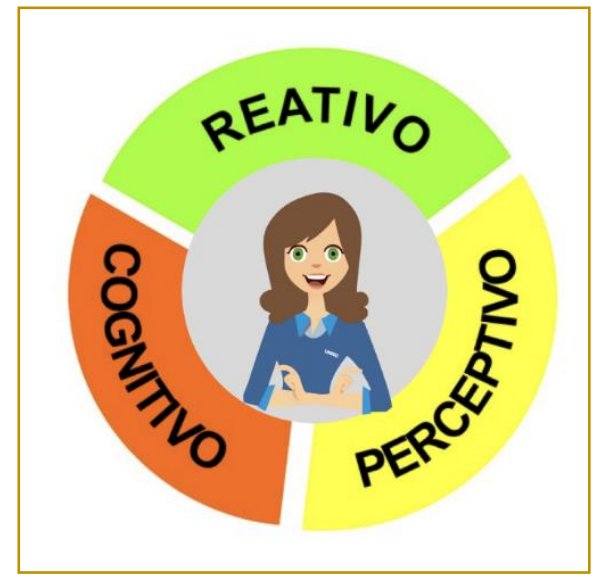

Além disso, outros elementos importantes constituem um agente virtual, são elas: age de forma autônoma em relação às outras entidades do sistema, tendo recursos para perceber e interpretar o que está a sua volta; é racional para atuar seguindo objetivos de acordo com o conhecimento que possui acerca do seu ambiente e das suas ações; possui um modelo limitado do mundo, experienciando somente o modelo de mundo necessário para efetivar 0 seu bom desempenho durante as tarefas.

Nessa nova versão da Dóris, o AVA utiliza todas as sete expressões definidas em 
Figura 2: Expressões da Agente Dóris

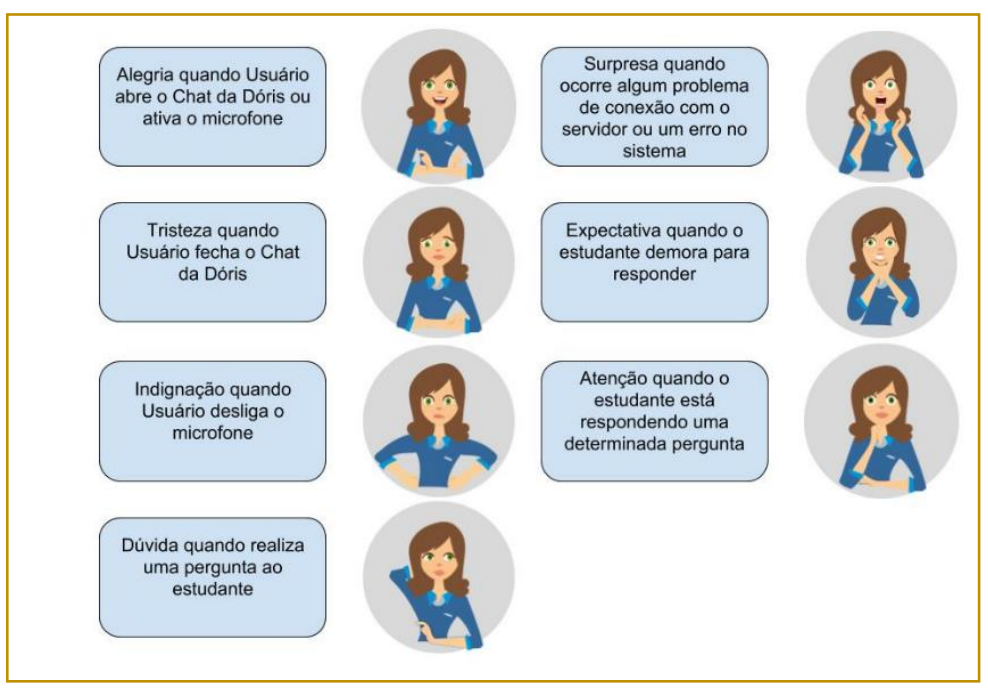

\section{METODOLOGIA}

A metodologia adotada foi Revisão Bibliográfica da Literatura (Santos e Candeloro, 2006). Realizada a partir do levantamento de referências publicadas exclusivamente pelo grupo de pesquisa de Sistemas Computacionais de Apoio à Educação, no período de 2001 a 2016. O objetivo é explicar as contribuições científicas dos trabalhos desenvolvidos sobre o domínio da pesquisa. Os dados coletados foram analisados individualmente e as informações foram tabeladas de forma cronológica, a fim de facilitar a compreensão do desenvolvimento evolutivo do Agente Pedagógico Dóris.

\section{RESULTADOS}

Esta seção contempla os resultados desta pesquisa. Como resultado principal, apresenta-se a organização cronológica (Quadro 1) das publicações do grupo de pesquisa Sistemas Computacionais de Apoio à Educação, no período de 2001 a 2016.

Quadro 1 - Síntese Cronológica das produções científicas do Projeto "O uso de Estilos Cognitivos e de Agentes Pedagógicos no processo de Ensino-aprendizagem em Sistemas Tutores Inteligentes"

\begin{tabular}{|c|c|c|}
\hline Artigo & Foco & Publicado Em \\
\hline $\begin{array}{l}\text { Dóris - Um Agente de } \\
\text { Acompanhamento } \\
\text { Pedagógico em Sistemas } \\
\text { Tutores Inteligentes } \\
\text { (Santos, Dahmer, Frozza e } \\
\text { Gaspary, 2001) }\end{array}$ & $\begin{array}{c}\text { Apresenta o cenário de desenvolvimento do } \\
\text { agente pedagógico Dóris, atuando como } \\
\text { auxiliar no processo de ensino-aprendizagem. } \\
\text { Este agente possui como função observar o } \\
\text { comportamento do estudante durante sua } \\
\text { interação com o conteúdo apresentado. O } \\
\text { artigo detalha características, funcionalidades } \\
\text { do agente desenvolvido e a arquitetura do } \\
\text { ambiente educacional. }\end{array}$ & $\begin{array}{l}\text { SBIE - Simpósio Brasileiro } \\
\text { de Informática na } \\
\text { Educação. Vitória, } 2001 .\end{array}$ \\
\hline $\begin{array}{l}\text { Dóris - Pedagogical Agent } \\
\text { in Intelligent Tutoring } \\
\text { Systems. (Santos, } \\
\text { Dahmer, Frozza e } \\
\text { Gaspary, 2002) }\end{array}$ & $\begin{array}{c}\text { Apresenta a primeira versão desenvolvida do } \\
\text { agente pedagógico Dóris e suas } \\
\text { funcionalidades de auxílio ao estudante. }\end{array}$ & $\begin{array}{l}\text { Intelligent Tutoring } \\
\text { Systems Conference. } \\
\text { Biarritz, } 2002\end{array}$ \\
\hline
\end{tabular}


(continuação ...)

Gestão do Conhecimento e Inovação - Volume 6

\begin{tabular}{|c|c|c|}
\hline Artigo & Foco & Publicado Em \\
\hline $\begin{array}{l}\text { Educational System based } \\
\text { on Cognitive styles and/or } \\
\text { Learning styles? (Mainieri } \\
\text { et al., 2005) }\end{array}$ & $\begin{array}{l}\text { Apresenta a investigação sobre as estratégias } \\
\text { de aprendizagem de estudantes dos cursos } \\
\text { de Psicologia e Ciência da Computação, com } \\
\text { o uso do Teste Cognitivo de Ross e com a } \\
\text { intenção que encontrar possíveis variáveis a } \\
\text { serem consideradas em um Sistema Tutor } \\
\text { Inteligente. }\end{array}$ & $\begin{array}{l}\text { Annual Meeting of the } \\
\text { Cognitive Science Society } \\
\text { Stresa: Cognitive Science } \\
\text { Society, } 2005 .\end{array}$ \\
\hline $\begin{array}{l}\text { Ambiente Educacional } \\
\text { Aplicado ao Domínio da } \\
\text { Geografia. (Frozza et al., } \\
\text { 2007) }\end{array}$ & $\begin{array}{l}\text { Apresenta o protótipo de um ambiente } \\
\text { educacional inteligente que possui uma base } \\
\text { de conteúdo instrucional direcionado à área } \\
\text { de Geografia, tendo como objetivo contribuir } \\
\text { no processo de ensino aprendizagem, com o } \\
\text { uso de táticas de ensino que se adaptam às } \\
\text { características individuais do estudante. }\end{array}$ & $\begin{array}{l}\text { Simpósio Brasileiro de } \\
\text { Informática na Educação } \\
\text { (SBIE). São Paulo: } \\
\text { Sociedade Brasileira de } \\
\text { Computação (SBC), } 2007 .\end{array}$ \\
\hline $\begin{array}{l}\text { O Método Clínico de } \\
\text { Piaget como forma de } \\
\text { Avaliação da } \\
\text { Aprendizagem em um } \\
\text { Sistema Tutor Inteligente } \\
\text { com Agente Pedagógico. } \\
\text { (Silva et al., 2010) }\end{array}$ & $\begin{array}{l}\text { Apresenta uma forma de identificar as } \\
\text { características de raciocínio de estudantes, } \\
\text { para definir seus estilos cognitivos, e analisar } \\
\text { as estratégias de aprendizagem aplicadas em } \\
\text { um Ambiente Virtual de Aprendizagem. }\end{array}$ & $\begin{array}{l}\text { Simpósio Brasileiro de } \\
\text { Informática a Educação } \\
\text { (SBIE). João Pessoa, } \\
2010 .\end{array}$ \\
\hline $\begin{array}{l}\text { Como Projetar Agentes } \\
\text { Pedagógicos Animados: } \\
\text { um Estudo de Caso com o } \\
\text { Agente Dóris (Moraes, } \\
\text { Selbach e Frozza, 2010) }\end{array}$ & $\begin{array}{l}\text { Tendo em vista que Agentes Pedagógicos } \\
\text { buscam a afetividade durante a interação com } \\
\text { o usuário de um Ambiente Virtual, para facilitar } \\
\text { o processo de ensino-aprendizagem, o artigo } \\
\text { buscou analisar a aplicabilidade de diretrizes, } \\
\text { considerando o comportamento e } \\
\text { características reativas do agente Dóris. }\end{array}$ & $\begin{array}{l}\text { Simpósio Brasileiro de } \\
\text { Informática na Educação } \\
\text { (SBIE). João Pessoa, } \\
2010 .\end{array}$ \\
\hline $\begin{array}{l}\text { Um Ambiente de EAD } \\
\text { como Catalisador da } \\
\text { Competitividade } \\
\text { Empresarial. (Schreiber et } \\
\text { al., 2010) }\end{array}$ & $\begin{array}{l}\text { Apresenta uma proposta de capacitação } \\
\text { corporativa utilizando um ambiente virtual de } \\
\text { aprendizagem, que tem como diferencial a } \\
\text { identificação do estilo cognitivo do usuário. }\end{array}$ & $\begin{array}{l}\text { Encontro Nacional de } \\
\text { Engenharia de Produção } \\
\text { (ENEGEP) - Maturidade e } \\
\text { desafios da Engenharia } \\
\text { de Produção: } \\
\text { competitividade das } \\
\text { empresas, condições de } \\
\text { trabalho, meio ambiente, } \\
2010 \text {. }\end{array}$ \\
\hline $\begin{array}{l}\text { Dimi 3D - Agente } \\
\text { companheiro para um } \\
\text { ambiente virtual de } \\
\text { aprendizagem. (Kunzel et } \\
\text { al., 2011) }\end{array}$ & $\begin{array}{l}\text { O Agente Companheiro Dimi atua na } \\
\text { motivação do estudante durante a interação e } \\
\text { realização das tarefas no Ambiente Virtual de } \\
\text { Aprendizagem. Este agente foi desenvolvido } \\
\text { expressando duas emoções, alegria e tristeza, } \\
\text { na interação com o estudante. }\end{array}$ & $\begin{array}{l}\text { Workshop-Escola de } \\
\text { Sistemas de Agentes, } \\
\text { seus ambientes e } \\
\text { aplicações (WESAAC). } \\
\text { Curitiba: Universidade } \\
\text { Tecnológica Federal do } \\
\text { Paraná (UTFPR), } 2011\end{array}$ \\
\hline $\begin{array}{l}\text { Development of a } \\
\text { companion agent for a } \\
\text { virtual learning } \\
\text { environment. (Kinzel et al., } \\
\text { 2011) }\end{array}$ & $\begin{array}{l}\text { Desenvolvimento de um agente pedagógico } \\
\text { atuando como companheiro do estudante no } \\
\text { ambiente virtual de aprendizagem (estudante } \\
\text { virtual). }\end{array}$ & $\begin{array}{l}\text { IADIS - International } \\
\text { Conference e-Learning. } \\
\text { Roma, } 2011\end{array}$ \\
\hline
\end{tabular}


(continuação ...)

\begin{tabular}{|c|c|c|}
\hline Artigo & Foco & Publicado Em \\
\hline $\begin{array}{l}\text { Jogo Computacional } \\
\text { como Tática de Ensino em } \\
\text { um Ambiente Educacional } \\
\text { Virtual. (Lux et al., 2011) }\end{array}$ & $\begin{array}{l}\text { Apresenta uma pesquisa em relação aos } \\
\text { indivíduos com dificuldades motoras, porém } \\
\text { com plenas capacidades cognitivas. Foi } \\
\text { utilizada a ferramenta Blender para } \\
\text { modelagem e construção do Jogo } \\
\text { Computacional, a fim de contribuir, com a } \\
\text { ludicidade e motivação, no processo de } \\
\text { ensino-aprendizagem, permitindo um melhor } \\
\text { desenvolvimento de habilidades motoras } \\
\text { adaptativas e cognitivas. }\end{array}$ & $\begin{array}{l}\text { Nuevas Ideas en } \\
\text { Informática Educativa: } \\
\text { Memorias del Congreso } \\
\text { Internacional de } \\
\text { Informática Educativa } \\
\text { (TISE). Santiago de Chile, } \\
2011 .\end{array}$ \\
\hline $\begin{array}{l}\text { Jogo Computacional para } \\
\text { Apoio a Pessoas com } \\
\text { Paralisia Cerebral. } \\
\text { (Baierle, Frozza e Lux, } \\
\text { 2012) }\end{array}$ & $\begin{array}{l}\text { Apresenta o jogo computacional desenvolvido } \\
\text { como uma nova tática de ensino em um } \\
\text { ambiente virtual de aprendizagem para } \\
\text { pessoas com deficiência. O objetivo do jogo } \\
\text { foi desenvolver o raciocínio lógico do usuário. }\end{array}$ & $\begin{array}{l}\text { Revista Jovens } \\
\text { Pesquisadores da } \\
\text { Universidade de Santa } \\
\text { Cruz do Sul (UNISC). } \\
\text { Santa Cruz do Sul, } 2012 .\end{array}$ \\
\hline $\begin{array}{l}\text { ChatterDóris - Um } \\
\text { Chatterbot que expressa } \\
\text { emoções. (Kuhleis et al., } \\
\text { 2012) }\end{array}$ & $\begin{array}{l}\text { O termo Chatterbot foi criado para descrever } \\
\text { os programas de computadores que simulam } \\
\text { a conversação humana. Assim, o artigo } \\
\text { propôs o ChatterDóris que oferece uma } \\
\text { interação via linguagem natural com o } \\
\text { estudante. }\end{array}$ & $\begin{array}{l}\text { Computer on the Beach. } \\
\text { Florianópolis: UNIVALI, } \\
2012 .\end{array}$ \\
\hline $\begin{array}{l}\text { Virtual Learning } \\
\text { Environments with } \\
\text { Emotional Pedagogical } \\
\text { Agents for Training in } \\
\text { Organizations. (Borin et } \\
\text { al., 2012) }\end{array}$ & $\begin{array}{l}\text { Apresenta as etapas de desenvolvimento do } \\
\text { Agente Dóris em 3D, expressando alegria, } \\
\text { tristeza, dúvida, indignação, surpresa, } \\
\text { expectativa e neutra. }\end{array}$ & $\begin{array}{l}\text { International Conference } \\
\text { on Industrial Engineering } \\
\text { and Operations } \\
\text { Management (ICIEOM). } \\
\text { Guimarães, Portugal, } 2012\end{array}$ \\
\hline $\begin{array}{l}\text { The use of Emotions in } \\
\text { Student Assessment in a } \\
\text { Virtual Learning } \\
\text { Environment. (Homrich, } \\
\text { Frozza e Schreiber, 2013) }\end{array}$ & $\begin{array}{l}\text { Apresenta uma proposta de relação entre } \\
\text { emoção e aprendizado. Foram analisadas as } \\
\text { emoções expressas pelos estudantes durante } \\
\text { a sua interação com o ambiente virtual de } \\
\text { aprendizagem, juntamente com as } \\
\text { características do seu estilo cognitivo, a fim de } \\
\text { avaliar a influência na aprendizagem. }\end{array}$ & $\begin{array}{l}\text { International Conference } \\
\text { on Industrial Engineering } \\
\text { and Operations } \\
\text { Management, (ICIEOM). } \\
\text { Rio de Janeiro: ABEPRO, } \\
2013 .\end{array}$ \\
\hline $\begin{array}{l}\text { Análise Comparativa de } \\
\text { Métodos/Técnicas } \\
\text { /Protocolos de } \\
\text { Comunicação para } \\
\text { Sistemas Multiagentes. } \\
\text { (Griesang et al., 2013) }\end{array}$ & $\begin{array}{l}\text { Apresenta o estudo de } \\
\text { métodos/técnicas/protocolos de comunicação } \\
\text { em sistemas multiagentes, a fim de propor um } \\
\text { mecanismo de comunicação entre os agentes } \\
\text { Dóris e Dimi para evitar conflitos de interação } \\
\text { com os estudantes em um ambiente virtual de } \\
\text { aprendizagem. }\end{array}$ & $\begin{array}{l}\text { Encontro Nacional de } \\
\text { Engenharia de Produção } \\
\text { (ENEGEP). Salvador, } 2013 .\end{array}$ \\
\hline $\begin{array}{l}\text { Development of a } \\
\text { communication } \\
\text { mechanism between } \\
\text { Pedagogical Agents in a } \\
\text { Virtual Learning } \\
\text { Environment. (Griesang et } \\
\text { al., 2013) }\end{array}$ & $\begin{array}{l}\text { Apresenta o mecanismo de interação } \\
\text { desenvolvido entre os agentes Dóris e Dimi } \\
\text { (tutor e companheiro). }\end{array}$ & $\begin{array}{l}\text { Workshop-Escola de } \\
\text { Sistemas de Agentes, } \\
\text { Ambientes e Aplicações } \\
\text { (WESAAC). São Paulo, } \\
2013 .\end{array}$ \\
\hline $\begin{array}{l}\text { Desenvolvimento de um } \\
\text { Mecanismo de } \\
\text { Comunicação entre os } \\
\text { Agentes Pedagógicos } \\
\text { Dóris e Dimi. (Lehmen e } \\
\text { Frozza, 2013) }\end{array}$ & $\begin{array}{l}\text { Apresenta a proposta de desenvolvimento de } \\
\text { um protocolo de comunicação entre os } \\
\text { agentes Dóris e Dimi, a fim de coordenar as } \\
\text { ações de interação dos agentes com os } \\
\text { estudantes. }\end{array}$ & $\begin{array}{l}\text { Seminário de Iniciação } \\
\text { Científica da Universidade } \\
\text { de Santa Cruz do Sul } \\
\text { (UNISC). Santa Cruz do } \\
\text { Sul: EDUNISC, } 2013\end{array}$ \\
\hline
\end{tabular}


(continuação ...)

\begin{tabular}{|c|c|c|}
\hline Artigo & Foco & Publicado Em \\
\hline $\begin{array}{l}\text { Uso de Rede Neural } \\
\text { Artificial para determinar o } \\
\text { Estilo Cognitivo do } \\
\text { Aprendizagem. (Flores et } \\
\text { al., 2013) }\end{array}$ & $\begin{array}{l}\text { Aborda o uso da técnica de inteligência } \\
\text { artificial, denominada Redes Neurais Artificiais, } \\
\text { para identificar os Estilos Cognitivos de } \\
\text { Aprendizagem de usuários que interagem no } \\
\text { Ambiente Virtual de Aprendizagem. }\end{array}$ & $\begin{array}{l}\text { Simpósio Brasileiro de } \\
\text { Informática na Educação } \\
\text { (SBIE), } 2013 .\end{array}$ \\
\hline $\begin{array}{l}\text { Desenvolvimento de } \\
\text { Táticas de Ensino a partir } \\
\text { da Identificação do Estilo } \\
\text { Cognitivo de Aprendizes. } \\
\text { (Barros, Homrich e Frozza, } \\
\text { 2013) }\end{array}$ & $\begin{array}{l}\text { Apresenta o desenvolvimento do conteúdo } \\
\text { Novo Acordo Ortográfico, a partir de táticas de } \\
\text { ensino que refletem as características dos } \\
\text { estilos cognitivos dos usuários, que são } \\
\text { apresentadas durante a sua interação com o } \\
\text { Ambiente Virtual de Aprendizagem. }\end{array}$ & $\begin{array}{l}\text { Seminário de Iniciação } \\
\text { Científica da Universidade } \\
\text { de Santa Cruz do Sul } \\
\text { (UNISC). Santa Cruz do } \\
\text { Sul: EDUNISC, } 2013 .\end{array}$ \\
\hline $\begin{array}{l}\text { Usabilidade em Ambientes } \\
\text { Virtuais de Aprendizagem } \\
\text { (Reis e Frozza, 2015) }\end{array}$ & $\begin{array}{l}\text { Apresenta a avaliação de usabilidade do } \\
\text { Ambiente Virtual de Aprendizagem, com a } \\
\text { utilização de testes de usabilidade com } \\
\text { usuários. A proposta foi desenvolver melhorias } \\
\text { na interface do ambiente. }\end{array}$ & $\begin{array}{l}\text { Salão de Ensino e de } \\
\text { Extensão da Universidade } \\
\text { de Santa Cruz do Sul } \\
\text { (UNISC). Santa Cruz do } \\
\text { Sul, 2015. }\end{array}$ \\
\hline $\begin{array}{l}\text { Avaliação do processo de } \\
\text { Ensino-aprendizagem de } \\
\text { estudantes na interação } \\
\text { com um Ambiente Virtual } \\
\text { de Aprendizagem } \\
\text { Baseado em Estilos } \\
\text { Cognitivos. (Rutsatz e } \\
\text { Frozza, 2015) }\end{array}$ & $\begin{array}{l}\text { Apresenta o estudo realizado sobre como os } \\
\text { estilos cognitivos de aprendizagem e a } \\
\text { afetividade influenciam no desenvolvimento } \\
\text { dos conteúdos abordados em Ambientes } \\
\text { Virtuais de Aprendizagem. }\end{array}$ & $\begin{array}{l}\text { Seminário de Iniciação } \\
\text { científica da Universidade } \\
\text { de Santa Cruz do Sul } \\
\text { (UNISC). Santa Cruz do } \\
\text { Sul, 2015. }\end{array}$ \\
\hline $\begin{array}{l}\text { Proposta de Tática de } \\
\text { ensino baseada em } \\
\text { animações para melhorar } \\
\text { o processo de } \\
\text { aprendizagem em } \\
\text { ambientes virtuais de } \\
\text { aprendizagem. (Silveira, } \\
\text { Schaefer e Frozza, 2015) }\end{array}$ & $\begin{array}{l}\text { Direção defensiva é uma técnica de } \\
\text { aperfeiçoamento para condutores referente à } \\
\text { forma adequada de dirigir um veículo no } \\
\text { trânsito. Assim, o artigo aborda o } \\
\text { desenvolvimento do conteúdo de direção } \\
\text { defensiva com o uso de tática de ensino } \\
\text { baseada em animações para o Ambiente } \\
\text { Virtual de Aprendizagem. }\end{array}$ & $\begin{array}{l}\text { Seminário delniciação } \\
\text { científica, da Universidade } \\
\text { de Santa Cruz do Sul } \\
\text { (UNISC). Santa Cruz do } \\
\text { Sul, 2015. }\end{array}$ \\
\hline $\begin{array}{l}\text { Estudo Comparativo entre } \\
\text { as Escolas da } \\
\text { Administração de } \\
\text { Recursos Humanos e as } \\
\text { Principais Teorias da } \\
\text { Aprendizagem do Século } \\
\text { XX. (Cossul et al., 2015) }\end{array}$ & $\begin{array}{l}\text { Aborda a pesquisa sobre o campo conceitual } \\
\text { da aprendizagem organizacional voltada para } \\
\text { inovação de sistemas, através da usabilidade } \\
\text { em Ambientes Virtuais de Aprendizagem. Além } \\
\text { disso, buscou-se por metodologias de } \\
\text { avaliação desta usabilidade associada a } \\
\text { processos de melhoria contínua (kaizen). }\end{array}$ & $\begin{array}{l}\text { Seminário de Iniciação } \\
\text { científica da Universidade } \\
\text { de Santa Cruz do Sul } \\
\text { (UNISC). Santa Cruz do } \\
\text { Sul, 2015. }\end{array}$ \\
\hline $\begin{array}{l}\text { Estudo Bibliométrico } \\
\text { Quantitativo abordando } \\
\text { Usabilidade, Ambientes } \\
\text { Virtuais de Aprendizagem } \\
\text { e Pessoas com } \\
\text { Deficiência. (Cabral, } \\
\text { Fagundes e Frozza, 2015) }\end{array}$ & $\begin{array}{l}\text { Apresenta os índices de produções científicas } \\
\text { sobre o conhecimento desenvolvido e } \\
\text { disseminado na utilização de Ambientes } \\
\text { Virtuais de Aprendizagem, usabilidade e } \\
\text { pessoas com deficiência. }\end{array}$ & $\begin{array}{l}\text { Seminário delniciação } \\
\text { científica da Universidade } \\
\text { de Santa Cruz do Sul } \\
\text { (UNISC). Santa Cruz do } \\
\text { Sul, 2015. }\end{array}$ \\
\hline
\end{tabular}


(continuação ...)

\begin{tabular}{|c|c|c|}
\hline 0 & כ & Publicado Em \\
\hline $\begin{array}{l}\text { Treinamentos E-Le } \\
\text { com estratégia de } \\
\text { baseada em anime } \\
\text { (Shaefer et al., } 2\end{array}$ & $\begin{array}{c}\text { Apresenta a estratégia de ensino baseada em } \\
\text { animações desenvolvida e utilizada para } \\
\text { treinamentos e-learning. }\end{array}$ & $\begin{array}{l}\text { Congreso Internacional de } \\
\text { Informática Eduactiva } \\
\text { (TISE). Santiago: } \\
\text { Universidad de Chile, } \\
2015 .\end{array}$ \\
\hline $\begin{array}{c}\text { Técnica de Clusterização } \\
\text { para Determinar o Estilo } \\
\text { Cognitivo de Usuários em } \\
\text { um Ambiente Virtual de } \\
\text { Aprendizagem. (Wegner et } \\
\text { al., 2015) }\end{array}$ & $\begin{array}{c}\text { Apresenta a utilização da técnica de } \\
\text { Clusterização, com o algoritmo k-means, para } \\
\text { identificar os Estilos Cognitivos de } \\
\text { Aprendizagem de usuários que interagem no } \\
\text { Ambiente Virtual de Aprendizagem. Os } \\
\text { resultados desta pesquisa foram comparados } \\
\text { aos resultados do trabalho que utilizou a } \\
\text { técnica de Redes Neurais Artificiais. }\end{array}$ & $\begin{array}{l}\text { Congresso Internacional } \\
\text { de Informática Educativa } \\
\text { (TISE). Santiago: } \\
\text { Universidad de Chile, } \\
\text { 2015. }\end{array}$ \\
\hline $\begin{array}{l}\text { Métodos e Técnicas de } \\
\text { Processamento de } \\
\text { Linguagem Natural para } \\
\text { chatterbots: análise de } \\
\text { trabalhos relacionados. } \\
\text { (Cortês, Bagatini e Frozza, } \\
\text { 2016) }\end{array}$ & $\begin{array}{l}\text { Apresenta os trabalhos relacionados } \\
\text { temas de Processamento de Lingua } \\
\text { Natural e chatterbots. Além disso, apre } \\
\text { um quadro comparativo e consideraç }\end{array}$ & $\begin{array}{l}\text { Simpósio de Engenharia } \\
\text { de Produção (SIMPEP). } \\
\text { Bauru, 2016. }\end{array}$ \\
\hline $\begin{array}{l}\text { Táticas de Ensino em } \\
\text { Ambientes Virtuais de } \\
\text { Aprendizagem: } \\
\text { perspectivas em } \\
\text { habilidades cognitivas. } \\
\text { (Frozza et al., 2016) }\end{array}$ & $\begin{array}{c}\text { Apresenta a proposta de elaboração de táticas } \\
\text { de ensino para desenvolver conteúdo em } \\
\text { diferentes estilos cognitivos de aprendizagem. }\end{array}$ & $\begin{array}{c}\text { CNEG - Congresso } \\
\text { Nacional de Excelência em } \\
\text { Gestão \& III INOVARSE - } \\
\text { Responsabilidade Social } \\
\text { Aplicada. Rio de Janeiro, } \\
2016 . \\
\end{array}$ \\
\hline $\begin{array}{l}\text { Análise Bibliométrica dos } \\
\text { Temas Usabilidade, } \\
\text { Ambientes Virtuais de } \\
\text { Aprendizagem e Pessoas } \\
\text { com Deficiência (Cabral et } \\
\text { al., 2016) }\end{array}$ & $\begin{array}{c}\text { O foco está na usabilidade em ambientes } \\
\text { virtuais de aprendizagem para pessoas com } \\
\text { deficiência. As buscas ocorreram nas bases } \\
\text { de dados da Revista Brasileira de Informática } \\
\text { na Educação (RBIE), no Simpósio Brasileiro de } \\
\text { Informática na Educação (SBIE), na } \\
\text { Conferência Internacional sobre Informática na } \\
\text { Educação (TISE), no portal de periódicos } \\
\text { CAPES e na base Web of Science. }\end{array}$ & $\begin{array}{c}\text { Revista Jovens } \\
\text { Pesquisadores da } \\
\text { Universidade de Santa } \\
\text { Cruz do Sul (UNISC). } \\
\text { Santa Cruz do Sul, } 2016 .\end{array}$ \\
\hline $\begin{array}{c}\text { Desenvolvimento de } \\
\text { Modelos de Apresentação } \\
\text { de Conteúdo baseados em } \\
\text { Estilos Cognitivos de } \\
\text { Aprendizagem (Fagundes } \\
\text { e Frozza, 2017) }\end{array}$ & $\begin{array}{c}\text { Apresenta uma proposta de metodologia para } \\
\text { o desenvolvimento de modelos para a } \\
\text { construção do conhecimento de usuários de } \\
\text { um AVA, considerando os estilos cognitivos de } \\
\text { aprendizagem para apresentação dos } \\
\text { conteúdos. }\end{array}$ & $\begin{array}{l}\text { Encontro Nacional de } \\
\text { Engenharia de Produção } \\
\text { (ENEGEP). Joinville, } 2017\end{array}$ \\
\hline
\end{tabular}

Com base na síntese cronológica das publicações, é possível constatar que foram encontrados 30 artigos que abordam as funcionalidades da Dóris no AVA, suas implementações e validações, além de atualizações que buscavam o aperfeiçoamento das suas atividades; dentre estes, dois artigos que relatam sobre o agente Dimi, companheiro da Dóris no Ambiente Virtual.

Inicialmente, as principais funções da Dóris contemplavam a observação do comportamento do estudante durante a sua interação com o conteúdo apresentado no AVA e demonstrava tristeza, felicidade e companheirismo através de sua imagem em 2D (duas dimensões). No período de 2005 a 2010, o AVA passou a utilizar testes cognitivos, na busca pela personalização dos conteúdos apresentados em diferentes estilos cognitivos de aprendizagem (ECA). Assim, foram propostas pela primeira vez, táticas de ensino adaptadas e personalizadas às características individuais de aprendizagem dos estudantes. Também foi abordado o método clínico de Piaget e a proposta de utilizar o ambiente em capacitações corporativas, tendo como diferencial a identificação dos estilos de aprendizagem dos usuários. Ainda nesta etapa a agente Dóris passa a ser apresentada em um formato 
3D, demonstrando alegria, tristeza, expectativa, indignação, surpresa, atenção e dúvida.

No período 2011 a 2016 destaca-se a utilização do ChatterDóris que expressa emoções através da simulação de conversação humana entre o usuário e a Dóris; a proposta de relação existente entre a emoção e o aprendizado, com análise paralela sobre os estilos de aprendizagens; a avaliação da usabilidade do AVA para realizar melhorias no ambiente; táticas de ensino baseadas em animações e sua aplicação em treinamentos e-learning; a mensuração de publicações sobre AVAS, usabilidade e pessoas com deficiências, para identificar produções científicas e lacunas de pesquisas; e por fim, a utilização da técnica de Clusterização, com o algoritmo k-means, para identificar os ECAs durante a interação com o AVA e sua comparação com os resultados da técnica que utilizou identificação por Redes Neurais Artificiais. Em 2017, começaram as atualizações no AVA e na aparência e funcionalidades da Dóris com interação em linguagem natural.

Durante as pesquisas e testes mais recentes realizados pelo grupo de pesquisa, a agente Dóris atendeu aos requisitos de usabilidade durante o processo de interação com os usuários quando submetida a testes de usabilidade.

Após estas avaliações e melhorias identificadas e aplicadas ao projeto, a agente Dóris passou a atender as necessidades de auxílio pedagógico quando solicitadas pelos estudantes, tanto por interação via texto como por fala, reproduzindo seus novos recursos implementados, referentes à interação em linguagem natural, nova aparência, auxílio ao usuário na realização de atividades e interpretação de conteúdos específicos.

\section{REFERÊNCIAS}

[1] Baierle, Jorlei Luis; Frozza, Rejane; Lux, Beatriz. Jogo Computacional para Apoio a Pessoas com Paralisia Cerebral. Revista Jovens Pesquisadores, n.1. Santa Cruz do Sul: EDUNISC, 2012

[2] Barros, J. F.; Homrich, N. C.; Frozza, R. Desenvolvimento de Táticas de Ensino a partir da Identificação do Estilo Cognitivo de Aprendizes. XIX Seminário de Iniciação Científica da Unisc. Santa Cruz do Sul: ADUNISC, 2013.
Além disso, observou-se a possibilidade de agente Dóris ser um facilitador no processo de acessibilidade aos usuários, visto que em sua última versão a agente é capaz de realizar a leitura do conteúdo ou a descrição de ilustrações aos usuários, totalmente via comando de voz.

\section{CONSIDERAÇÕES}

Os Ambientes Virtuais de Aprendizagem que utilizam agentes pedagógicos auxiliam em processos mais eficazes de ensinoaprendizagem de seus usuários. As pesquisas apresentadas sobre a evolução da Dóris mostram a importância do uso destes agentes em ambientes nos quais estudantes interagem individualmente com os conteúdos didáticos apresentados, guiando seu próprio processo de ensino-aprendizagem.

Personagens dotados de características e ações inteligentes, tais como expressões faciais, corporais e emoções, que interagem por linguagem natural, isto é, que se assemelhe à interação entre humanos, e que consideram os diferentes estilos de aprendizagem dos usuários, potencializam o processo educacional e demonstram pertinência e eficácia de tal personalização do AVA.

Dessa forma, a Dóris potencializa as habilidades intelectuais dos estudantes, com o auxílio das estratégias e táticas de ensino associadas aos estilos cognitivos. Neste aspecto faz-se uma ressalva à necessidade de que os agentes pedagógicos devem ter suas capacidades de interação em constante aperfeiçoamento e evolução, a fim de buscar sempre uma interação mais adequada e eficaz com o usuário.

[3] Behar, P. A; Meirelles L., S; Mazzocato, S. B; Souza, L. B; Siqueira, L. G. Avaliação de Ambientes Virtuais de Aprendizagem: O Caso do Rooda na UFRGS. Revista Avances en Sistemas e Informática. Vol. 4, No. 1. p.87-99. 2007.

[4] Behar. P. A.; Ribeiro, A. C. R.; Schneider, D.; SILVA, K.; Machado, L. R.; Longhi, M. T. Educação a distância e competências: uma articulação necessária. Competências em Educação a Distância. Porto Alegre: Penso. 2013. 
[5] Borin, Mirceia; frozza, rejane; kipper, liane m.; schreiber, jacques n.C. . Virtual Learning Environments with Emotional Pedagogical Agents for Training in Organizations. In: XVIII International Conference on Industrial Engineering and Operations Management (ICIEOM). Guimarães, Portugal. 2012. v. único. p. 1-10.

[6] Cabral, J. L.; Fagundes, T. dos S.; Frozza, R. Estudo Bibliométrico Quantitativo Abordando Usabilidade, Ambientes Virtuais de Aprendizagem e Pessoas com Deficiência. XXI Seminário de Iniciação científica, Santa Cruz do Sul, 2015.

[7] Cabral, J. L.; Fagundes, T. dos S.; Frozza, R; Lux, B. Análise bibliométrica dos temas usabilidade, ambientes virtuais de aprendizagem e pessoas com deficiência. Revista Jovens Pesquisadores, v.6, n.1. Santa Cruz do Sul: EDUNISC, 2016.

[8] Cortes, E. G.; Bagatini, Daniela Duarte Da Silva; Frozza, Rejane. Métodos e Técnicas de Processamento de Linguagem Natural para Chatterbots: Análise De Trabalhos Relacionados. In: XXIII Simpósio de Engenharia de Produção (SIMPEP). Bauru: Unesp, 2016. p. 1-12.

[9] Cossul, D.; Bastos, M. de; Witczak, M. V. de; Frozza, R.; Kipper, L. M. Estudo Comparativo entre as Escolas da Administração de Recursos Humanos e as Principais Teorias da Aprendizagem do Século XX. XXI Seminário de Iniciação científica, Santa Cruz do Sul, 2015.

[10] Fagundes, Brunno José; Frozza, Rejane. Desenvolvimento de Modelos de Apresentação de Conteúdo baseados em Estilos Cognitivos de Aprendizagem. In: XXXVII Encontro Nacional de Engenharia de Produção (ENEGEP). Joinville: Abepro, 2017, p. 1-16.

[11] Flores, M. dos S.; Frozza, R.; Bagatini, D. S.; Cruz, M. E. J. K. da. Uso de Rede Neural Artificial para determinar o Estilo Cognitivo do Aprendiz. XXIV Simpósio Brasileiro de Informática na Educação, 2013.

[12] Frozza, R.; Kipper, L. M.; Fagundes, T. S.; Witczak, M. V. C. Táticas de Ensino em Ambientes Virtuais De Aprendizagem: perspectivas em Habilidades Cognitivas. In: XII Congresso Nacional de Excelência em Gestão \& III INOVARSE Responsabilidade Social Aplicada, 2016. Rio de Janeiro. p. 1-11.

[13] Frozza, R.; Silva, A. A. K.; Scheiber, J. N. C.; Lux, B.; Molz, K. W.; Kipper L.M.; Borin, M. P.; Baierle, J. L.; Sampaio, L.; Agentes Pedagógicos Emocionais atuando em um Ambiente Virtual de Aprendizagem. Renote - Revista Novas Tecnologias na Educação, v. 9, n. 1, 2011.

[14] Frozza, R.; Silva, A. K. da; Wagner, A. L.; Molz, K.; Schreiber, J.; Lux, B.; Cruz, M. K. da; Kiehl, E. Ambiente Educacional Aplicado ao Domínio da Geografia. XVIII Simpósio Brasileiro de
Informática na Educação (SBIE). São Paulo: Sociedade Brasileira de Computação - SBC, 2007.

[15] Giraffa, L. M. M. Uma arquitetura de tutor utilizando estados mentais. Tese (Doutorado em Ciência da Computação) - Programa de PósGraduação em Ciência da Computação, UFRGS. 1999. 177p.

[16] Griesang, G.; Frozza, R.; Molz, R. F.; Dessbessell G.; Peiter, R. Development of a communication mechanism between Pedagogical Agents in a Virtual Learning Environment. VII Workshop-Escola de Sistemas de Agentes, seus Ambientes e Aplicações - WESAAC. São Paulo, 2013.

[17] Griesang, G.; Frozza, R.; Molz, R. F.; Peiter, R.; Junior, G. Dessbesell. Análise Comparativa de Métodos/Técnicas/Protocolos de Comunicação para Sistemas Multiagentes. Anais do XXXIII Encontro Nacional de Engenharia de Produção (ENEGEP). Rio de Janeiro: Abepro, 2013.

[18] Homrich, N. C.; Frozza, R.; Schreiber, J. N. C. The use of Emotions in Student Assessment in a Virtual Learning Environment. XIX International Conference on Industrial Engineering and Operations Management, Icieom 2013. Rio de Janeiro: Abepro, 2013.

[19] Kuhleis, R.; Schreiber, J. N. C.; Konzen, A.; Frozza, R.; Molz, K. W. ChatterDóris - Um Chatterbot que expressa emoções. Computer on the Beach - 2012. Florianópolis: UNIVALI, 2012.

[20] Kunzel, M. F. Silva, A. K. da; Frozza, R.; Bagatini, D. Lux. B. Dimi 3D - Companion Agente in a Learning Virtual Environment. V WorkshopEscola de Sistemas de Agentes, seus ambientes e aplicações (WESAAC 2011). Curitiba: Universidade Tecnológica Federal do Paraná (UTFPR), 2011.

[21] Kunzel, M. F.; Silva, A. K. da. Frozza, R.; Schreiber, J.; Lux, B. Development of a companion agent for a virtual learning environment. International Conference e-Learning. Roma: 2011. v. 2. p. 151-155.

[22] Lehmen, Cristian Robert; Frozza, Rejane. Desenvolvimento de um Mecanismo de Comunicação entre os Agentes Pedagógicos Dóris e Dimi. Anais do XIX Seminário de Iniciação Científica da Unisc. Santa Cruz do Sul: Edunisc, 2013.

[23] Lester, J.; Voerman, J. L.; Towns, S. G.; Callaway, C. B. Cosmo: A life-like animated pedagogical agent with deictic believability. In: IJCAI97 Workshop on Animated Interface Agents: Making them Intelligent. Proceedings. Nagoya, 2007.

[24] Lux, B.; Frozza, R.; Konzen, A.; Molz, K. W.; Schreiber, J.; Pittol, A, M.; Benetti, J. C.; GRIESANG, G. Jogo Computacional como Tática de Ensino em um Ambiente Educacional Virtual. Nuevas Ideas en Informática Educativa: Memorias 
del XVI Congresso Internacional de Informática Educativa, TISE. Santiago de Chile, 2011.

[25] Mainieri, A. G.; Frozza, R.; Schreiber, J. Molz, K. Educational System based on Cognitive styles and/or Learning styles? XXVII Anual Meeting of the Cognitive Science Society. Stresa: Cognitive Science Society, 2005.

[26] Meirelles, D. S.; Aguero, F. H.; Leon, D.; Santos, L. A. P. dos; Francisco, R. N. D. Tecnologia e Competências Tecnológicas em Educação a Distância: um estudo exploratório. Future Studies Research Journal, SP, V.9, 2017. Moraes, M. C.; Silveira, M. S.; Frozza, R. Como projetar agentes pedagógicos animados: um estudo de caso com o agente Dóris. In: Simpósio Brasileiro de Informática na Educação (SBIE). João Pessoa. 2010. v. único. p. 1-10.

[27] Morais, S., Santos, A., Redecker, M. Prototipação de Chatterbots como Método de Aprendizagem em Cursos de Computação: uma experiência em sala de aula. V Congresso Brasileiro de Informática na Educação (CBIE). Anais do XXII Workshop de Informática na Escola (WIE), 2016.

[28] Morám, José. Mudando a Educação com Mídias Ativas. Coleção Mídias Contemporâneas. Convergências Midiáticas, Educação e Cidadania: aproximações jovens. Vol. II. Proex/UEPG, 2015

[29] Mülbert, A. L.; Girondi. A.; Pereira, A. T. C.; Nakayama, M. K. A interação em ambientes virtuais de aprendizagem: motivações e interesses dos alunos. Revista Renote - Novas Tecnologias na Educação, v. 9, n. 1, 2011.

[30] Reis, K. M. dos. Frozza, R. Usabilidade em Ambientes Virtuais de Aprendizagem. VI Salão de Ensino e de Extensão, Santa Cruz do Sul: UNISC, 2015.

[31] Rutsatz, R. F.; Frozza, R. Avaliação do processo de Ensino-aprendizagem de estudantes na interação com um Ambiente Virtual de Aprendizagem Baseado em Estilos Cognitivos. XXI Seminário de Iniciação científica, Santa Cruz do Sul: UNISC, 2015.

[32] Santos, C. T. dos; Dahmer, A.; Frozza, R.; Gaspary, L. P. Dóris - Um Agente de Acompanhamento Pedagógico em Sistemas
Tutores Inteligentes. SBIE - Simpósio Brasileiro de Informática na Educação, 2001, Vitória, 2001.

[33] Santos, C. T.; Dahmer, A.; Frozza, R.; Gaspary, L. P. Dóris - Pedagogical Agent in Intelligent Tutoring Systems. Intelligent Tutoring Systems Conference, 2002, Biarritz. p. 91-104.

[34] Santos, V. D.; Candeloro, R. J. Trabalhos Acadêmicos: Uma orientação para a pesquisa e normas técnicas. Porto Alegre: AGE Ltda, 2006. $149 \mathrm{p}$.

[35] Schreiber, J. N. C.; Frozza, R.; Silva, A. A. K. da. Molz, K. W.; Lux, B. Um Ambiente de EAD como Catalisador da Competitividade Empresarial. In: Encontro Nacional de Engenharia de Produção (ENEGEP). 2010

[36] Shaefer, M.; Frozza, R.; Silveira, R. A. da. Rutsatz, R. F. Treinamentos E-Learning com estratégia de ensino baseada em animações. XX Congreso Internacional de Informática Educativa TISE. Santiago: Universidad de Chile, 2015.

[37] Silva, A. K. da; Frozza, R.; Borin, M. P.; MOLZ, K.; Schreiber. J.; LuX, B.; Brum. A. O Método Clínico de Piaget como forma de Avaliação da Aprendizagem em um Sistema Tutor Inteligente com Agente Pedagógico. Anais do XXI Simpósio Brasileiro de Informática a Educação, João Pessoa, 2010.

[38] Silveira, R. A. da. Shaefer, M.; Frozza, R. Proposta de Tática de ensino baseada em animações para melhorar o processo de aprendizagem em ambientes virtuais de aprendizagem. XXI Seminário de iniciação científica, Santa Cruz do Sul: UNISC, 2015.

[39] Tenório, T.; Laudelino, M. A.; Tenório, A. A Importância do Ambiente Virtual de Aprendizagem em um Curso de Graduação com Base nas Percepções de Alunos a Distância. Revista Científica em Educação a Distância, v. 5, n. 3, 2015.

[40] Wegner, W; Frozza, R.; Bagatini, D. D. S.; Cruz, M. E. J. K. da. Técnica de Clusterização para Determinar o Estilo Cognitivo de Usuários em um Ambiente Virtual de Aprendizagem. Congresso Internacional de Informática Educativa - TISE. Santiago: Universidad de Chile, 2015 


\section{Capítulo 4}

\section{GESTÃO DE ESTOQUES - ESTUDO DE CASO EM UMA METALÚRGICA USANDO O SISTEMA ERP}

\section{Wesley Barbosa de Oliveira \\ Cesar Augusto Della Piazza}

Luis Fernando Quintino

Wagner Costa Botelho

Resumo: Este trabalho visa analisar a gestão de estoques em uma metalúrgica, com o intuito de diagnosticar as atuais condições de gestão de estoque de matériaprima. Na metalúrgica em questão, foi analisada a gestão de estoques enfocando o estoque da matéria prima, apresentando alguns pontos positivos e negativo diagnosticado no referido estudo. A gestão de estoques é utilizada pelas empresas para controlar os custos e melhorar a qualidade dos produtos. Feita de forma eficiente, ela permite obter menores custos de manutenção e pedido de insumos, bem como minimiza as chances de falta de produtos para seus clientes. Onde planejar é essencial para a sobrevivência de qualquer empresa, principalmente devido ao caráter inconstante e competitivo que o mercado apresenta.

Palavras Chave: Gestão de Estoques, Sistema ERP, Custos de Implementação 


\section{INTRODUÇÃO}

No atual cenário empresarial mundial, as empresas buscam cada vez mais aumentar a sua competitividade, seja pela redução de custos, pela melhoria do produto, agregando mais valor ao produto e se diferenciando da concorrência ou se especializando em algum segmento ou nicho de mercado. Desta forma, as empresas buscam cada vez mais técnicas e ferramentas que a auxiliem no processo de gerenciamento de suas operações, como por exemplo, a gestão de estoques (PIMENTEL, 2004)

É importante que para que se haja uma gestão de estoques eficiente, as organizações desenvolvam estratégias que contribuam com a harmonia e trabalho em conjunto dos colaboradores, além de meios nos quais evitem conflitos entre quatro áreas internas sendo elas: compras, produção, vendas e finanças (CHASE, 2006; FRANCISCHINI; GURGEL, 2004).

Para Chase (2006), a média do custo dos estoques nas empresas gira em torno de $30 \%$ a 35\% de seu valor. Em consonância, Heizer e Render (2001) afirmam que este valor opera em torno de $40 \%$ do capital das empresas. Se por um lado, estoque disponível em excesso reduz a rentabilidade, por outro, uma quantidade de estoque disponível muito pequena diminui a confiança do cliente. Sendo assim, analisar e escolher a melhor política de estoques para uma empresa é de vital importância para manter-se competitiva no mercado (GAITHER; FRAZIER, 2002).

Apresentando custos com aquisição de materiais em torno de $49 \%$ do faturamento mensal, bem como sua gestão ser uma das áreas do planejamento e controle da produção mais negligenciada em pequenas e médias empresas devido a sua falta de estrutura organizacional (CHASE, 2006; FRANCISCHINI; GURGEL, 2004; HEIZER; RENDER, 2001).

Este artigo procurou detectar alguns pontos críticos referentes à gestão de estoques de

matérias-primas em uma metalúrgica. Neste sentido foram ressaltados alguns aspectos positivos e negativo, bem como, foram apresentadas algumas soluções alternativas. Neste sentido, o presente artigo objetiva analisar e selecionar uma política de controle de estoques, utilizando à medida que estas apresentam inegáveis contribuições para o bom desempenho da empresa, dentre estas destaca a Gestão de Estoques.
A programação dos estoques é imprescindível em termos financeiros, Lucena \& Filho (2002) enfatizam que "existe um custo dos estoques que aumenta os custos operacionais e diminui os lucros, razão por que a boa administração dos mesmos é essencial". Neste contexto, pretende-se analisar como a metalúrgica em foco, trabalha com as questões referentes ao planejamento e a gestão de estoques de matérias-primas, para operar de forma eficiente.

\section{METODOLOGIA DO TRABALHO}

O presente artigo utiliza pesquisa embasada em um estudo de caso, onde este se caracteriza como um estudo de um ou de poucos objetos, de maneira a permitir o seu conhecimento amplo e detalhado. Em se tratando da pesquisa, ela é baseada nos mesmos princípios da pesquisa bibliográfica e é desenvolvida com base em material já elaborado, constituindo-se principalmente de livros e artigos, bem como relatórios e registros gerais de empresas e organizações (GIL, 2007; ALVES, 2007).

Os dados aplicados na pesquisa são coletados dos registros das áreas de compras, almoxarifado e produção da empresa. E estes são analisados sob um ponto de vista quantitativo, que considera que tudo pode ser quantificado, significando assim a tradução de opiniões e informações (SILVA e MENEZES, 2001).

Em se tratando de desenvolvimento de artigo, inicialmente busca-se levantar e identificar os insumos da empresa, bem como suas respectivas demandas e unidades, aplicando - Sistema ERP para a solução dos problemas que a empresa enfrenta.

\section{GESTÃO DE ESTOQUES}

A meta principal de uma empresa é, sem dúvida, maximizar o lucro sobre o capital investido (DIAS, 1993). Os estoques são um bom exemplo de capital investido pelas organizações, os quais, segundo Moreira (2009), podem ser considerados como quaisquer quantidades de bens físicos que sejam conservados, de forma improdutiva, por algum intervalo de tempo; constituindo tantos produtos, como matérias-primas e componentes que aguardam utilização na produção. 
No entanto, Dias (1993) afirma que sem estoques é improvável uma empresa trabalhar, pois funcionam como amortecedor entre os vários estágios da produção até a venda final do produto. São indispensáveis, ao tempo que proporcionam vantagens competitivas.

No intuito de se justificar a existência de estoques, Heizer e Render (2001) afirmam que os estoques podem proteger a empresa da incerteza, dar suporte a um plano estratégico, obter vantagem de economia de escala e aproveitar descontos por quantidades.

As empresas estão buscando cada vez mais garantir uma determinada disponibilidade de produto com o menor nível de estoque possível. Por outro lado, algumas transformações têm influenciado a gestão de estoques através do aumento da eficiência nas operações de produção e de distribuição. Este aumento de eficiência significa muitas vezes reduzir os tempos de resposta e "variabilizar" os custos fixos, permitindo operar com tamanhos de lotes menores sem afetar a disponibilidade de produto ou incorrer em aumentos nos custos totais.

\subsection{CUSTOS DE ESTOQUES}

Segundo Gonçalves (2007), em estudos realizados em diversas empresas industriais, tanto no Brasil como no exterior, os custos de materiais representam um grande impacto nos custos globais. Assim, deve-se dar uma atenção especial aos materiais armazenados, dentre estes, podem ser citados os de pedido, manuseio e manutenção, material e falta ou escassez.

Estabelecer os níveis de estoque e sua localização segundo Hong (2006) é apenas uma parte do problema do controle de estoque. Considerando esse objetivo mais amplo, uma questão crítica e balancear os custos de manter e de pedir estoque, porque esses custos têm comportamentos conflitantes. Quanto maiores as quantidades estocadas, maiores serão os custos de manutenção.

Quanto maior for a quantidade do pedido, maior será o estoque médio e mais alto será o custo de mantê-lo. No entanto, se maiores quantidades forem solicitadas, menos pedidos serão feitos e, por consequência, menores custos de pedir serão incorridos. Deve-se obter o maior equilíbrio possível entre a produção e o custo de estoque, de um lado, e o nível de serviço prestado aos clientes, de outro lado.

Os custos de pedidos são custos relacionados à colocação de um novo pedido ou o preparo de um pedido de compra para um fornecedor ou uma ordem de produção para a oficina (RITZMAN; KRAJEWISK, 2004). Ele é a soma de todos os custos incorridos desde o momento em que o pedido é feito até o momento em que a mercadoria é estocada (MOREIRA, 2009).

Custos de manutenção e manuseio são os gastos pertinentes ao armazenamento de uma unidade de um produto por um determinado período de tempo. O custo de material, também chamado de custo ou preço unitário; é o custo de comprar ou fabricar internamente uma unidade do item (MOREIRA, 2009).

\section{SISTEMA ERP}

A sigla ERP - Enterprise Resource Planning traduzida literalmente, significa "Planejamento dos Recursos da Empresa", o que pode não refletir a realidade de seus objetivos. Koch, Slater e Baatz (1999) citam: "...esqueça a parte do planejamento - ele não o faz, e esqueça os recursos, é apenas um termo de ligação. Mas lembre-se da parte da empresa. Esta é a real ambição dos sistemas ERP". Na figura 1, temos a estrutura conceitual dos sistemas ERPs. 
Figura 1: Estrutura conceitual dos sistemas ERP e sua evolução desde o MRP.

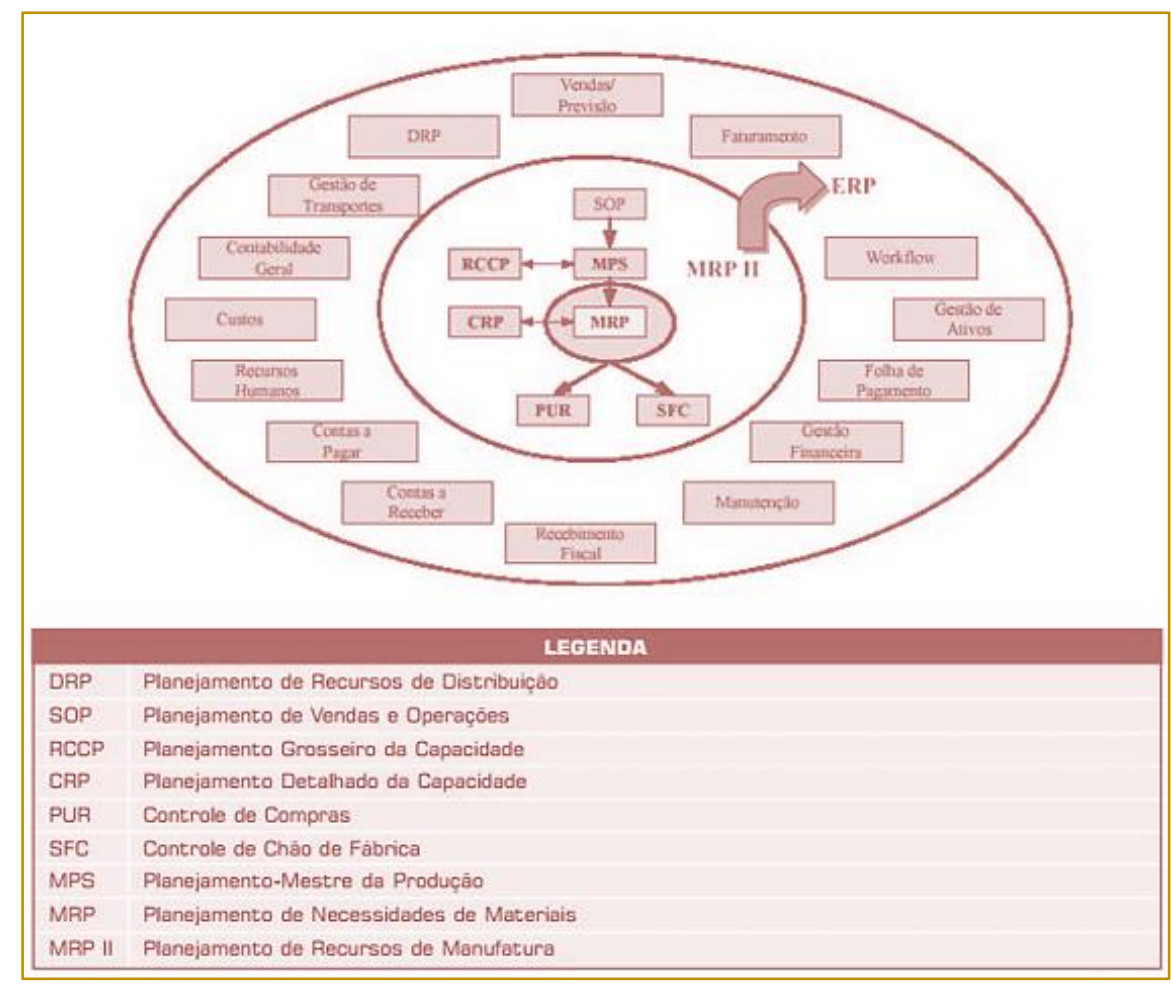

Fonte: Padilha; Marins (2005)

Os sistemas ERP fornecem rastreamento e visibilidade global da informação de qualquer parte da empresa e de sua cadeia de suprimento, o que possibilita decisões inteligentes (CHOPRA e MEINDL, 2003).

Estes Sistemas, também chamados no Brasil de Sistemas Integrados de Gestão Empresarial, controlam e fornecem suporte a todos os processos operacionais, produtivos, administrativos e comerciais da empresa. Todas as transações realizadas pela empresa devem ser registradas para que as consultas extraídas do sistema possam refletir o máximo possível a realidade.

Pode-se dizer que o ERP é um sistema integrado, que possibilita um fluxo de informações único, contínuo e consistente por toda a empresa, sob uma única base de dados. É um instrumento para a melhoria de processos de negócios, como a produção, compras ou distribuição, com informações online e em tempo real. Em suma, o sistema permite visualizar por completo as transações efetuadas pela empresa, desenhando um amplo cenário de seus negócios (CHOPRA e MEINDL, 2003).

Os sistemas de informação estão em evolução contínua desde que os processos produtivos e a cadeia produtiva começaram a despertar o interesse da alta administração. Em pouco tempo, houve uma evolução que consistiu no surgimento do MRP - Material Requirements Planning, passando pelo MRPII - Manufacturing Resources Planning e chegando ao Enterprise Resource Planning ERP (STAIR, 1999).

A introdução de um ERP em uma empresa tem um impacto enorme em todas as operações que são realizadas diariamente em suas instalações. Os sistemas ERP são atraentes porque unificam a informação, pois surgiram com a promessa de resolver problemas de integração, disponibilidade e confiabilidade de informações ao incorporar em um único sistema as funcionalidades que suportam diversos processos de negócios em uma empresa (OLIVEIRA \& RAMOS, 2002).

Muitas empresas estão adotando Sistemas ERP devido a várias razões, tais como: decepção com sistemas incompatíveis, incapacidade do Departamento de Tecnologia de Informação em realizar a integração entre os sistemas existentes atualmente na empresa e outros motivos que influenciam diretamente a competitividade da empresa. 


\subsection{FATORES IMPORTANTES PARA A IMPLANTAÇÃO}

- Alguns fatores podem garantir o sucesso da implementação. Nah et al. (2001) apresentam e discutem uma lista de 11 fatores que eles consideram críticos para 0 sucesso de uma implementação de ERP:

- Obter a participação ativa da alta gerência (Commitment);

- Implementar o gerenciamento de mudanças buscando reduzir o "medo" dos usuários pouco informados;

- Identificar os Usuários-chave, que são indispensáveis em seus respectivos departamentos;

- Escolher com segurança para Gerente do Projeto (Gerente-Usuário) um profissional experiente e respeitado, de modo a descaracterizar o ERP como um sistema da área de informática, e sim como um redesenho do modelo de gestão;

- Planejar e realizar treinamentos;

- Definir claramente os diversos papéis na implementação do sistema, através da união de conhecimentos e esforços para o alcance do sucesso;

- Adaptar o sistema à empresa e viceversa, refletindo sobre a realidade atual da empresa ou a utilização das melhores práticas (best-practices);

Escolher a consultoria adequada (know-how);

- Garantir a qualidade (Quality Assurance);

- Simplificar em todos os sentidos: na definição de modelos, no desenho da solução e na própria implementação do sistema.

Pode-se verificar que alguns dos fatores aqui propostos coincidem com alguns daqueles 11 elencados por Nah et al. (2001) e também por Akkermans e van Helden (2002). A ideia é que as estas listas se complementem, servindo como uma referência para aqueles que estejam se preparando para implementar uma solução de ERP.

Em um processo de implementação, o primeiro passo é determinar o escopo do projeto e a nova arquitetura de processo. Atualmente, durante esta definição, é comum

utilizar-se o enfoque da reengenharia de Hammer e Champy (1994), ou seja, parte-se de uma folha em branco e tenta-se adaptar o sistema ao processo da empresa.

\subsection{CUSTOS DO ERP}

Wagle (1998) recomenda que a decisão de implantar o ERP só deve ser tomada com base em um fluxo de caixa positivo, pois tratam-se de projetos nos quais o período de retorno do investimento (payback) é muito longo e o investimento muito grande.

Para calcularmos o custo total de um ERP, devemos levar em consideração fatores como licenças, personalizações, manutenções do software e treinamentos com os colaboradores. Nele, também são abordados os gastos com sistemas de backup, servidores e refrigeração, que serão instalados num espaço físico na empresa.

Como exemplo podemos citar a empresa Totvs que cobra o custo das licenças por $R \$ 100.000,00$, o serviço de implementação e treinamento $R \$ 375.000,00$, as atualizações por 12 meses $R \$ 36.000,00$ e o fornecimento de suporte técnico em por 12 meses $\mathrm{R} \$$ 102.000,00. O contrato estabelece um prazo mínimo de atendimento de 48 horas.

\section{RESULTADOS}

A empresa analisada é uma metalúrgica com de cerca de 100 colaboradores, instalada na cidade de São Paulo - SP. A mesma possui seu estoque dividido em matéria-prima, material de embalagem, produtos químicos, materiais secundários, combustíveis e lubrificantes onde cada um destes itens possuem um local de armazenamento específico.

A estrutura organizacional da empresa compreende nas áreas de produção, comercial, financeira, técnica- engenharia, recursos humanos, administrativos e marketing. Atualmente a produção é absorvida pelo mercado nacional.

\subsection{DESCRIÇÃO DA GESTÃO DE ESTOQUES NA METALÚRGICA}

A empresa analisada possui setor exclusivo para estoques, o qual se encontra estruturado da seguinte forma:

a) Conta com um almoxarifado que contém: matéria-prima, material de embalagem, 
produtos químicos, materiais secundários, combustíveis e lubrificantes, e cada um desses itens possuem um local de armazenamento específico:

b) O mesmo conta ainda com um setor de Expedição, onde ficam acomodados os produtos acabados, advindos do setor produtivo, até serem destinados aos clientes.

O controle de estoques é realizado através de um sistema de informações denominado Focco 3i, que faz inventários sobre determinadas famílias de itens. As informações sobre os estoques são coletadas diariamente pelo almoxarifado, informando o PCP sobre a atualização dos estoques do almoxarifado e expedição.

\subsection{LEVANTAMENTO DOS PONTOS POSITIVOS E CRÍTICO}

Verificou-se que a empresa em questão apresenta pontos positivos e negativos no que se refere à gestão de estoques. Para analisar o processo de gestão e controle de estoques, foram observados os seguintes aspectos:

\subsubsection{POSITIVOS}

- Os itens possuem um local de armazenamento específico;

- Planejamento da Produção é feito mensalmente envolvendo: Supervisor da Produção, Almoxarifado, PCP e Compras;

- Possui espaço satisfatório para armazenamento, e ainda detém espaço para ampliação;

- Apresenta boas condições de carregamento, trabalham com prateleiras, empilhadeiras e pontes rolantes.

\subsubsection{NEGATIVOS}

- A quantidade de estoques praticados pela empresa depende da variação da produção;

- - Verificou-se que ocorrem frequentemente paradas na produção, ocasionado por atrasos no planejamento de compra e entrega dos materiais.

\section{CONCLUSÃO}

As empresas buscam cada vez mais conhecer seus pontos fortes e fracos. Muitas definem um bom gerenciamento dos estoques de produtos acabados como sendo um ponto forte, chegando a utiliza-lo como estratégia de negócio. É através do controle dos estoques de segurança, estoques mínimos, ponto dos pedidos, estoques máximos, custos, etc., que define o sucesso ou até mesmo o fracasso das empresas.

Este artigo procurou detectar alguns pontos críticos referentes à gestão de estoques de materiais em uma metalúrgica. Neste sentido foram ressaltados alguns aspectos positivos e negativos como relatados anteriormente.

Todas as soluções sugeridas têm como objetivo investir em uma melhoria incremental nos processos, em conjunto com o gerenciamento rotina dia-a-dia. Como a empresa não possui nenhuma política de controle de estoque e seu sistema de controle de estoques, é realizado através de um sistema de informações denominado Focco $3 \mathrm{i}$ e não está sendo eficaz em resultados, sugerimos implantar o Sistema de ERP pela empresa Totvs, onde será possível uma consultoria eficaz que irá implantar as licenças, personalizações, manutenções do software e treinamentos com os colaboradores.

Uma gestão de estoques adequada à política empregada pela empresa pode trazer resultados muito interessantes para 0 processo de controle de materiais como um todo, principalmente nas áreas diretamente relacionadas à administração de materiais, como: PCP, Compras, Almoxarifado, Recebimento, Controle de Qualidade e o próprio Controle dos Estoques. Por fim, o presente artigo buscou outras soluções além das apresentadas como:

Realizar as reuniões de planejamento não mensalmente e sim semanalmente, pois no ramo de metalúrgica o cenário muda constantemente;

Serão indicadas algumas mudanças, tais como a adoção de um dimensionamento nos níveis de estoque, para equacionar a problemática apresentada no sistema, para evitar atrasos na movimentação de estoque.

Deixa-se como sugestão futura a continuação do estudo de mobilidade do almoxarifado para evitar atrasos, e de desenvolvimento e 
atualização do Sistema ERP, pois dessa maneira pode-se validar as ferramentas com relação à sua eficiência na elaboração de metas e desdobramento de problemas, bem como verificar o alcance dos objetivos do processo de produção.

\section{REFERÊNCIAS}

[1] Ching, Hong Yuh. Gestão de estoque na cadeia de logísticas integrada. - Supply Chain. São Paulo: Atlas, 2006

[2] Wanke, Peter. Gestão de estoque na cadeia de suprimentos. - Decisões e modelos quantitativos. São Paulo: Atlas, 2008.

[3] Moreira, Daniel Augusto. Administração da produção e operações - 2. ed.rev.e ampl. - São Paulo: Cengage Learning, 2013.

[4] Silva, Irani Xavier. Controle e gerenciamento de estoque das empresas comerciais de artigos de vestuários de Tangará da Serra do Mato Grosso. Disponível em: <http://www.convibra.com.br/2007/congresso/artig os/279.pdf> Acesso em: 20 março 2016.

[5] Rocha, Alex. Gerenciamento dos estoques de produto acabado em uma metalúrgica. Disponível
Espera-se que a empresa, baseada no estudo realizado, possa avaliar a possibilidade de implementação e obter sucesso no gerenciamento dos estoques de matériasprimas, matérias de consumos e produtos acabados.

<https://www.univates.br/bdu/bitstream/10737/564/ 1/2007AlexRocha.pdf> Acesso em: 20 março 2016.

[6] Padilha, Thais Cássia Cabral e Marins, Fernando Augusto Silva. Sistemas ERP: características, custos e tendências. Prod. [online]. 2005, vol.15, n.1, pp.102-113. ISSN 1980-5411.

[7] Possamai, Osmar, Muniz, Emerson Cleister Lima, Palomino, Reynaldo Chile. Análise e seleção de uma política de controle de estoques com base em ferramentas e métodos da gestão de estoques. Disponível em: <http://www.abepro.org.br/biblioteca/enegep2013 TN_STP_177_014_22262.pdf> Acesso em: 29 março 2016.

[8] Pimentel, Elthon Wanderley, Melo, Janaina Ferreira Marques, Oliveira, Jucelândia Nascimento. Planejamento e Controle da Produção e a Gestão de Estoques - um Estudo de Caso em uma Metalúrgica Paraibana. Disponível em: < http://revista.uepb.edu.br/index.php/qualitas/article/ viewFile/43/35> Acesso em: 29 março 2016. 


\section{Bapítulo 5}

\section{ENERGIA ELÉTRICA: USO DE FONTES RENOVÁVEIS A FAVOR DO MEIO AMBIENTE}

\section{Marlon Figueiredo Coura de Oliveira}

\section{Elizabeth Ferreira de Pádua Campos}

Resumo: A busca por fontes renováveis para geração de energia elétrica é intensa e diversos estudos são realizados para melhor aproveitar tais fontes, não agredindo o meio ambiente. Devido ao grande potencial hídrico existente em nosso país, a geração de energia elétrica ocorre em maior parte por hidrelétricas. Sendo assim, o presente trabalho busca analisar fontes de energia renováveis destacando suas vantagens e desvantagens. Este trabalho consiste em uma pesquisa bibliográfica documental, descritiva; foi realizada entre dezembro de 2015 a março de 2016. A pesquisa foi feita através da análise dos documentos das empresas energéticas brasileiras e de documentos em meio eletronico que tratavam do tema. A partir dos documentos analisados foi identificado que a água é uma fonte renovável possuindo vantagens e desvantagens. O sol é uma fonte altamente renovável e inesgotável de energia sendo que o Brasil se destaca no que se refere em recebimento de potencial solar, mas ainda sim aproveitamos pouco deste benfício para a geração de energia elétrica. A Agência Nacional de Energia Elétrica (ANEEL), tem incentivado o uso da energia solar para geração de energia elétrica, procurando desta forma amenizar as agressões sofridas pela natureza atendendo o consumidor em todas as suas necessidades.

Palavras-chave: Geração; Energia elétrica; Meio ambiente 


\section{INTRODUÇÃO}

A todo momento é necessário inovar, criar ou buscar no mercado algo de forma a economizar sem perder a qualidade e confiabilidade no processo. As empresas procurarm formas de continuarem produzindo de maneira eficiente, reduzindo custos com maneiras sustentáveis garantindo o seu futuro no ramo em que atua.

Para Inventta (2003), inovação é a exploração com sucesso de novas idéias, sendo que sucesso para as empresas significa aumento do faturamento, ganhar novos mercados, aumento do lucro, dentre outros. A também inovações que se referem a produtos ou processos que são consideradas inovações tecnológicas, e inovações que são relacionadas a novos mercados, novos modelos de negócios, métodos organizacionais ou até mesmo a novas fontes de suprimentos.

No mundo da eletricidade, estudos e investimentos tem sido realizados a fim de gerar energia elétrica suficiente para atender a toda população sem falhas de maneira sustentável utilizando recursos renováveis buscando não impactar no meio ambiente.

Como sabemos, a energia elétrica, embora podemos dispensá-la sendo contrário da água, é um recurso utilizado para satisfazer toda a humanidade e o seu uso é de grande importância para os empreendimentos, estudos dentre outros.

Esteves (2014), diz que estamos em um momento de transformação, pois, antigamente inovação para as empresas era algo voltado para fora, para criação de novos produtos ou serviços e que, atualmente é parte integrante das organizações ganhando um novo significado. Inovar é um modo de operar, de pensar e de estar no mundo.

Lavoisier disse que, "Na natureza nada se cria nada se perde, tudo se transforma". Diversas são as formas de aproveitar as energias contidas na natureza de nosso o planeta, sendo fontes totalmente renováveis dependendo somente da capacidade do homem de saber usufluir destas energias sem agredir o meio ambiente.

No Brasil, a maior fonte de geração de energia elétrica é através da rede fluvial. As hidrelétricas aproveitam as quedas d'água para movimentar as turbinas que irá girar 0 gerador obtendo como resultado a energia elétrica. A água é uma fonte totalmente renovável e limpa, mas apesar disso a construção de hidrelétricas com barragens possuem os seus impactos.

De acordo com Mendonça (2012), o setor elétrico ganhou um estímulo com a criação da lei $n^{\circ} 9.991 / 2000$ que estipula que as concessionárias e permissionárias de serviços publicos de distribuição de energia elétrica, ficam obrigadas a aplicar, anualmente, o montante de no mínimo, 0,75\% de sua receita operacional líquida em pesquisa e desenvolvimento do setor elétrico e, no mínimo $0,25 \%$ em programas de eficiência energética no uso final.

Devido aos impactos que as hidrelétricas podem criar, mesmo a água sendo uma fonte renovável, o setor elétrico estuda continuamente outras formas de geração também com fontes renováveis procurando agredir da menor maneira possível o meio ambiente.

Uma fonte altamente renovável existente em nosso planeta é a energia solar, já utilizada a vários anos para secar roupas, secar sal, aquecer água, dentre outros, tem sido amplamente estudada para a geração de energia elétrica, pois o sol é uma fonte inesgotável de energia e cabe ao homem saber aproveitar desta fonte.

Branco (2009), diz que a energia esta sempre presente na natureza terrestre, principalmente na forma de luz e calor cedidos pelo sol, e que, de toda energia irradiada pelo sol apenas uma pequena parcela atinge nossa terra. Mas essa pequena parcela representa quase 30 mil vezes a quantidade total de energia produzida e consumida pelos engenhos domésticos, industriais ou agrícolas no mundo todo.

Neste artigo iremos abordar a geração de energia elétrica solar no Brasil, relatando os impactos que poderá causar bem como suas vantagens, para o meio ambiente e consumidor.

\section{GERAÇÃO DE ENERGIA ELÉTRICA}

Conforme Branco (2009), a energia elétrica foi utilizada pela primeira vez em 1830 como meio de comunicação pelos fios de telégrafos, vindo a ser empregada na produção de luz somente em 1878, mas, as primeiras grandes usinas geradoras de energia elétrica foram construídas em Londres 
e Nova lorque por volta de 1880

Branco ainda diz que o Brasil foi um dos primeiros países do mundo a utilizar gerador de energia elétrica tendo sua primeira usina térmica instalada em 1883 e a primeira hidrelétrica em Juiz de Fora, Minas Gerais em 1889.

A contribuição da energia hidráulica na matriz de energia elétrica, segundo o Balanço Energético Nacional de 2015 é de, aproximadamente 63\%, tornando-se então uma excelente alternativa para aproveitamento de recursos energéticos da natureza. (ITAIPU).

O Brasil possui uma imensa rede fluvial e devido a isto grande parte das usinas são hidrelétricas, mas existem momentos em que a vazão da água pode ser maior, com a chegada das chuvas ou menor, para se ter um controle desta vazão são contruídas as barragens.

Algumas hidrelétricas são constiuídas de barragens que tem por objetivo interromper 0 curso normal do rio e permitir a formação do reservatório. Além de "estocar" a água, esses reservatórios têm outras funções: permitem a formação do desnível necessário para a configuração da energia hidráulica, a captação da água em volume adequado e a regularização da vazão dos rios em períodos de chuva ou estiagem. (ANEEL).

$\mathrm{Na}$ figura um, tem-se um exemplo de uma hidrelétrica em que, o reservatório ou barragem possuio acumulo de água e ao abrir a comporta a água passa por um duto girando a turbia acionando o gerador tendo como resultado a energia elétrica, após percorrido este caminho a água retorna para o rio.

Figura 1 - Exemplo de Usina Hidrelétrica

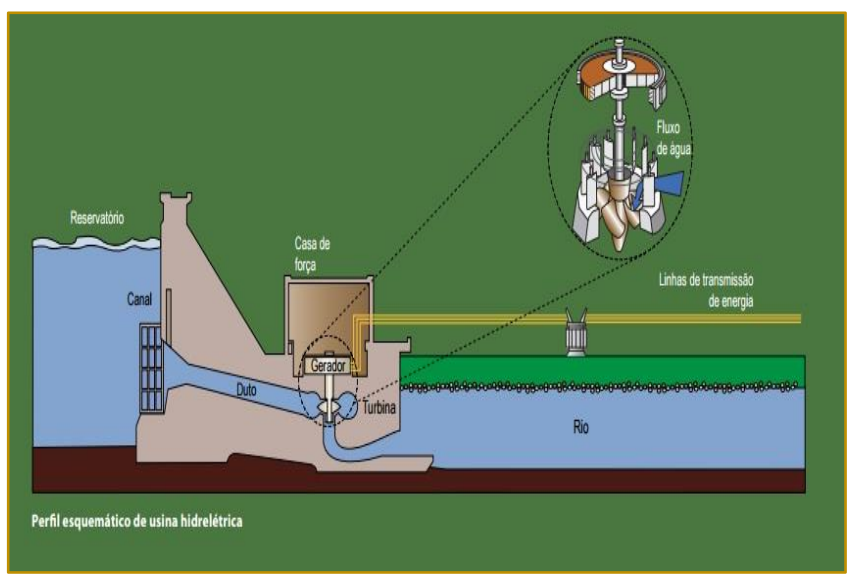

Fonte: ANEEL (2013)

A utilização da água para geração de eletricidade possui algumas vantagens como por exemplo, é um recurso renovável além de ser uma fonte limpa, e o seu uso nao polui o meio ambiente, o custo de produção para as hidrelétricas é baixo e a construção de barragens permite ser uma forma de abastecimento local para regadios.(PORTAL E ENERGIA, 2010).

Mas as hidrelétricas também trazem desvantagens. Pode-se infligir danos para a fauna e flora de uma região com a consrução de barragens causando algumas vezes ainda a alteração de ecossistemas inteiros, não contabilizando ainda a necessidade de muitas vezes deslocar populações inteiras.(JUNIOR et al, 2013).
Outra desvantagem no uso da fonte hídrica são os períodos de seca, podendo ser necessário o racionamento de energia como em 2001. De acordo com Abbud (2014), dos 42 empreendimentos leiloados de 2000 a 2012, apenas dez hidrelétricas constituem de usinas com reservatórios, ou seja, 32 hidrelétricas são a fio d'água não tendo qualquer capacidade de armazenar água para geração de eletricidade nos períodos secos.

A Agência Nacional de Energia Elétrica (ANEEL) diz que em novembro de 2008, as usinas hidrelétricas, independentemente de seu porte, respondiam por $75,68 \%$ da geração de energia elétrica no país, no passado, o parque hidrelétrico chegou a 
representar 90\% da capacidade instalada.

A ANEEL ainda diz que Esta redução tem três razões, a necessidade da diversificação da matriz elétrica prevista no planejamento do setor elétrico de forma a aumentar a segurança do abastecimento; dificuldade em ofertar novos empreendimentos hidráulicos pela ausência da oferta de estudos e inventários; o aumento de entraves jurídicos que protelam o licenciamento ambiental de usinas de fonte hídrica.

Conforme a Itaipu, estima-se que, nos próximos anos, pelo menos $37 \%$ da necessidade de expansão da capacidade de geração seja de origem hídrica, de acordo com o Plano Decenal de Expansão 2014. A tendência é de que haja maiores investimentos em outras fontes de energia renováveis, com menores danos ao meio ambiente.

Vivenciamos no ano de 2015 um grande problema com os recursos hídricos de nosso país, afetando o setor de energia elétrica e o consumidor para diversas finalidades. O baixo nível das barragens faz com que tenhamos de controlar o gasto de energia elétrica.

O uso irracional de energia elétrica significa desperdício de água. Investir em outras fontes de geração de energia elétrica para atender o consumidor tanto em satisfação quanto financeiramente é fundamental para manter e recuperar a rede fluvial em nosso país, degradando da menor forma possível o meio ambiente.

\subsection{ENERGIA SOLAR}

Uma fonte altamente renovável e inesgotável de energia utilizada a vários anos e de diversas formas é a energia solar. O calor do sol sempre foi empregado em diversas atividades como por exemplo o secar das roupas ou secagem do sal a partir da água do mar.

Costa (2009), explica que o Brasil é um dos poucos países no mundo que recebe uma insolação (número de horas de brilho do sol) superior a 3000 horas por ano, colocando o país em destaque no que se refere em potencial solar.

A tecnologia do aquecedor solar já vem sendo usada no Brasil desde a década de 60, época em que surgiram as primeiras pesquisas. Em 1973, empresas passaram a utilizá-la comercialmente. (Associação Brasileira de Refrigeração, Ar Condicionado, Ventilação e Aquecimento, ABRAVA, 2001).

$O$ aquecedor solar consiste em coletores solar, reservatório térmico (Boiler) e tubulações de cobre. O coletor capta o calor do sol aquecendo a água que esta nele, a água quente torna-se menos densa do que a água fria que esta no reservatório térmico, sendo assim, a água fria "empurra" a água quente tonando este ciclo contínuo, este sistema é conhecido como termofissão ou circulação natural. A água quente utilizada em chuveiros ou torneiras sai do reservatório térmico.

Figura 2 - Aquecedor Solar

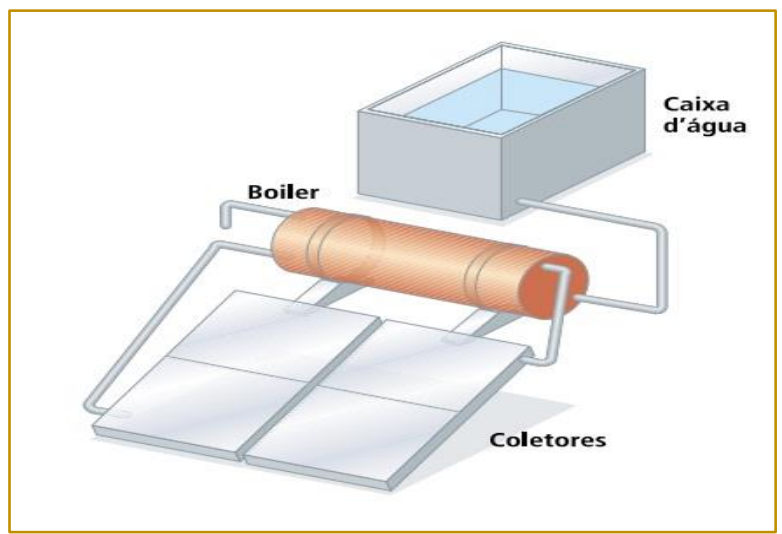

Fonte: ANEEL (2000)

São gastos bilhões de Kwh de energia elétrica para o uso de banhos, que geralmente são consumidos em horas específicas do dia sobrecarregando o sistema elétrico. Energia esta que pode ser suprida pela energia solar, não tendo danos ambientais e com vantagens socioeconômicas. 
Conforme Branco (2009), grandes investimentos tem sido feitos na pesquisa de métodos para transformar energia solar em energia elétrica, convertendo a radiação solar diretamente em energia elétrica com o uso de células fotovoltaicas.

Branco (2009) ainda informa que este é um sistema altamente interessante, mas ainda pouco desenvolvido, e que tem sido empregado com grande sucesso em satélites artificiais dispondo de uma fonte permanente de energia atendendo as necessidades de operação, envio de comunicação dentre outros.

Pileggi (2014), informa que a energia solar ainda é $0,01 \%$ da energia no Brasil, tem-se 164 usinas solares. O grande problema é que a capacidade destas usinas é muito pequena, tem-se como maior fonte as usinas hidrelétricas e térmicas.

Pelo dado citado, observa-se que apesar do Brasil estar geograficamente situado em um local com grande abundância em radiação solar, possui pouco aproveitamento desta energia renovável e inesgotável.

Portal e Energia (2009), explica que nos sistemas fotovoltaicos a radiação solar é convertida em energia elétrica por intermédio dos semicondutores, que são configurados em elementos denominados células fotovoltaicas. Os semicondutores feitos de silício são os mais usados na construção das células e o seu rendimento possível razoável é, atualmente, de cerca de $25-30 \%$.

As células fotovoltaicas geram energia elétrica em corrente contínua, sendo assim necessitase de um inversor conectado ao sistema para converte-la em corrente alternada podendo então ser interligada ao sistema elétrico residencial ou empresarial, para por exemplo uso de computadores, televisões dentre diversos equipamentos utilizados pelo homem.

Como todas as outras fontes, a energia solar tem suas desvantagens como, custo de implementação, não produz energia durante a noite, a produção de energia pode ser comprometida de acordo com a situação climática no período, em locais com maior índice de poluição ambiental, a captação de energia solar não é tão eficiente quanto em locais mais "limpos", para se ter maior potência são instaladas um grande número de placas ocupando muito espaço. (CASEIRO).

O Brasil inaugura a primeira central solar flutuante do mundo, figura 3. O projeto consiste em ter placas flutuantes em reservas das hidrelétricas evitando a expropriação de terras. O projeto foi realizado na Hidroelétrica de Balbina, no município de Presidente Figueiredo, no Amazonas em 04 de março de 2016. (PORTAL E ENERGIA, 2016).

Figura 3 - Central Solar Flutuante

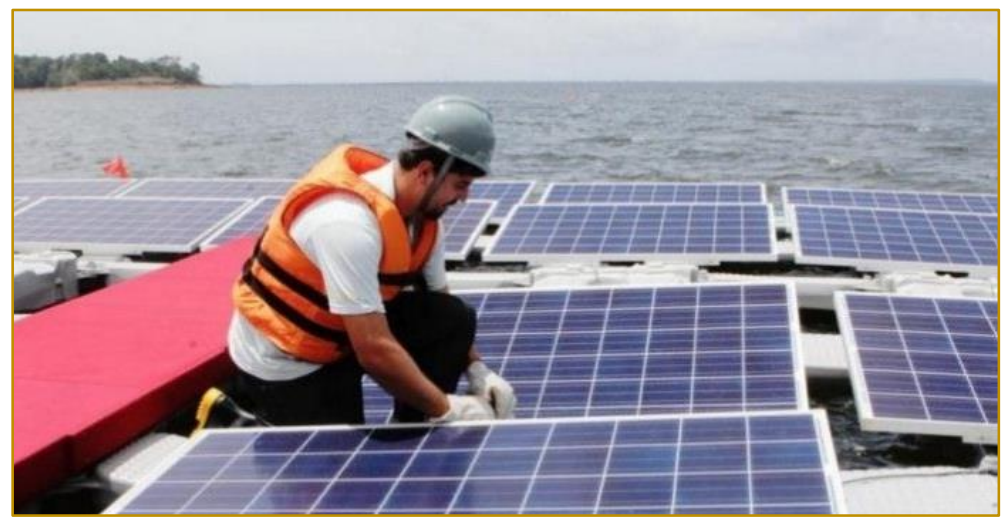

Fonte: Portal e Energia (2016)

Portal e Energia ainda diz que, as principais vantagens da instalação de centrais solares flutuantes na área dos reservatórios de água de centrais hidrelétricas já existentes, é a possibilidade de usar as linhas de transmissão de energia elétrica já existentes nas Hidrelétricas e evitar a expropriação de terras.

Como todas as outras fontes, a energia solar tem suas desvantagens como, custo de 
implementação, não produz energia durante a noite, a produção de energia pode ser comprometida de acordo com a situação climática no período, em locais com maior índice de poluição ambiental, a captação de energia solar não é tão eficiente quanto em locais mais "limpos", a tecnologia precisa de aprimoramentos pois os painéis de captação possuem um redimento de apenas $25 \%$. (CASEIRO).

Possui também grandes vantagens como, as centrais de produção de energia solar requerem uma manutenção mínima, tornandose mais econômica sua produção, com a evolução da tecnologia cada vez mais os painéis solares tem maior potência, o investimento na energia solar é rapidamente recuperado na poupança diária de água, eletriciade e gás, a radiação solar é gratuita e tem um potencial ilimitado. (CASEIRO).

De acordo com a Exame.com (2015), a ANEEL estimula os consumidores residenciais a investirem em projetos de auto geração de energia por meio de paineis solares. Uma forma é permitir que os estados não cobrem duas vezes o ICMS, sobre energia gerada e consumida.

Uma família que consome 200 killowatt-hora de energia por mês e que consiga produzir 120 kWh pagará ICMS apenas sobre a diferença entre o volume gerado e o consumido, ou seja, $80 \mathrm{kWh}$. Caso a produção de energia seja maior que a consumida, o consumidor acumula créditos para o mês seguinte havendo maior desconto na conta de energia. (EXAME.COM, 2015).

Os painéis solares são instalados nos telhados das casas, aproveitando um espaço não utilizado para outra finalidade. São instalados estratégicamente para absorver um maior índice de radiação solar. O inversor converte a energia solar para o formato que pode-se utilizar sem a necessidade de obras ou de alteração nas instalações elétricas. Caso a energia solar produzida não seja totalmente consumida, o excedente é injetado na rede havendo créditos para consumir energia da concessionária através de um medidor bidimensional, como exemplifica a figura 4. (SOLARGRID).

Figura 4 - Painel Solar

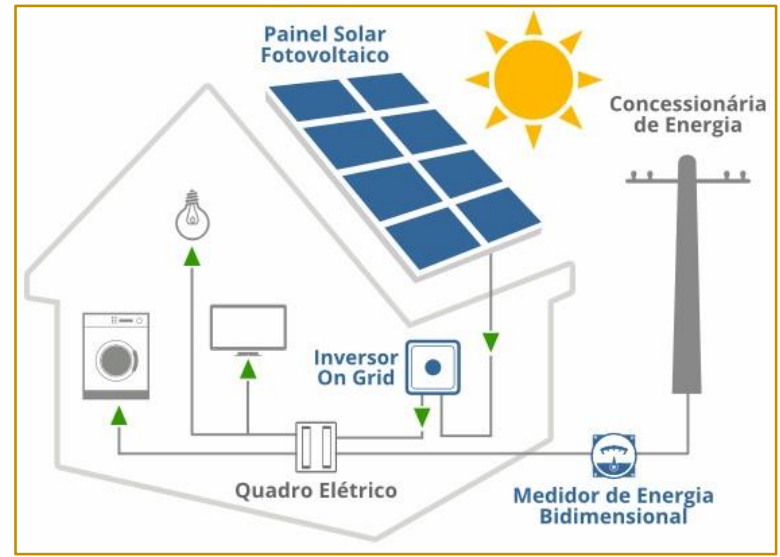

Fonte: Solar Energy

Segundo o relator do processo, diretor Tiago de Barros Correia, o foco do projeto são os consumidores residenciais com consumo médio mensal de 200 kWh. Para esses consumidores, o investimento em painéis solares para produzir o suficiente para gerar toda a energia que gastam seria de $R \$ 12$ mil. Apesar do custo do investimento, a ANEEL informa que o custo do investimento se dá em cinco anos. (EXAME.COM, 2015).

\section{CONCLUSÃO}

Pode-se concluir com esse artigo que o uso da energia elétrica é essencial para o homem, para criação de novas tecnologias, trabalho ou lazer cabendo a ele utilizá-la da melhor forma possível.

É de extrema importância gerar energia elétrica através de fontes renováveis de forma sustentável amenizando os impactos sobre o meio ambiente, 
conscientemente os recursos que natureza nos oferece.

Apesar de a água ser uma fonte renovável, é essencial alternar por outras fontes, já que esta é uma fonte vital para o ser humano e utilizá-la de forma irracional, além de não favorecer a geração de energia, terá grandes consequências para o meio ambiente.

Mesmo sendo de grande importância a contrução de barragens para as hidrelétricas e sendo a maior fonte de geração no Brasil, ela afeta de algumas formas a fauna e pode gerar grandes impactos sobre a sociedade em casos de enchentes ou desapropriação de povoados.

O Brasil presenciou em 2015 a o baixo nível de água nos reservatórios das hidrelétricas, e a falta de água afeta diretamente a geração de energia. Para não vivermos novamente o racionamento de energia elétrica foram ligadas as usinas térmicas, o que encareceu a conta de energia do consumidor.

Desde os tempos primórdios o homem utiliza a energia solar de alguma forma, e com a passar do tempo vem aprimorando este uso a fim de grantir sua sobrevivência da melhor maneira possivel.

Mesmo com alta incidência de radiação solar,

\section{REFERÊNCIAS}

[1] Abbud, O. Por que o Brasil está correndo risco de racionamento de energia. In Brasil economia. Disponível em: http://www.brasileconomia-governo.org.br/2014/04/23/por-que-obrasil-esta-correndo-risco-deracionamento-deenergia-eletrica/. Acessado em 12/04/2016.

[2] A inovação: definição, conceitos e exemplos. In: http://inventta.net/radar-inovacao/ainovacao/. Acessado em 05/03/2016.

[3] Atlas da energia elétrica no Brasil. Disponível em: http://www.aneel.gov.br/arquivos/pdf/atlas_par2_ca p3.pdf acesso em 10/03/2016.

[4] Brasil inaugura primeira central solar flutuante do mundo. In; Portal energia: energies renováveis.Disponível em: http://www.portalenergia.com/brasil-inaugura-primeira-central-solarflutuante-do-mundo.Acessado em 25 mar. 2016.

[5] Branco; S. M. Energia e Meio ambiente. Editora Moderna $2^{\circ}$ edição; 2009 São Paulo Brasil.

[6] Costa, H. S. Por que a energia solar não deslancha no Brasil. In: Carta Capital. Disponível em:http://www.cartacapital.com.br/blogs/outras- o Brasil ainda utiliza pouco esta alternativa para geração, que é uma fonte altamente renovável e inesgotável de energia, mas investimentos tem sido realizados para obter usinas mais potentes garantindo a confiabilidade do sistema para o consumidor.

A ANELL incentiva o uso da microgeração solar é isto é um grande passo para o Brasil, apesar do custo a princípio ser elevado, mas o incentivo para o uso de fontes renováveis faz com que a humanidade se conscientize e pesquise sobre os impactos que diversas fontes podem gerar e concluir sobre qual melhor forma de utilizar.

É de claro entendimento que o homem ainda não conseguiu uma forma de gerar energia elétrica sem agredir completamente o meio ambiente, todas possuem vantagens e desvantagens, mas constantemente estudos são realizados a fim de melhorar este índice.

Cabe ao ser humano utilizar a tecnologia para a geração de energia a seu favor de forma consciente, aproveitando da melhor maneira possível as fontes que a natureza nos oferece minimizando os impactos gerados sobre ela, já que nela, se busca todas as fontes para melhorar, apreciar e solucionar problemas, obtendo como resultado melhor qualidade de vida do homem.

palavras/por-que-a-energia-solar-nao-deslanchano-brasil-3402.html - acessado em 18/12/2015.

[7] Caseiro, A. Quais as vantagens e desvantagens do uso da energia solar. In: Tempo livre. Disponível em:http://tempolivre.umcomo.com.br/articulo/quaisas-vantagens-e-desvantagens-do-uso-da-energiasolar-8754.html. Acessado em 25 mar. 2016

[8] Energia hídrica vantagem e desvantagens. In: Portal energia: energias renováveis. Disponível em:http://www. portal-energia.com/energia-hidricavantagens-e-desvantagens/. Acessado em 04/04/2016

[9] Energia hídrica. In: ITAIPU binacional. Disponível em: Https://www.itaipu.gov.br/energia/energiahidraulica . Acesso em 10/03/2016

[10] Energia solar. In: Aneel. Disponível em: http://www2.aneel.gov.br/aplicacoes/atlas/pdf/03[11] Energia_Solar(3).pdf $\quad-$ Acessado em
16/12/2015

[12] Fontes. In : Camara de comercialização de energia elétrica. Disponível em:http://www.ccee.org.br/portal/faces/pages_publ ico/onde- 
atuamos/fontes?_adf.ctrlstate $=40 z z k 1 a c l \_4 \&$ afrLo $o p=1539170327528947$. Acesso em 12/03/2016 as 17:00h

[13] Esteves,S. O que é inovação? In: Exame.com Disponivel em: http://exame.abril.com.br/rede-deblogs/carreiraem-geracoes/2014/05/24/o-que-e-inovacao/ acessado em 05/03/2016.

[14] Mari Júnior, A. Et. Al. Vantagens e desvantagens da energia hidráulica - Acta Iguazu, Cascavel, v.2, n.4,p. 20-28, 2013.

[15] Mendonça, L. Inovação tecnológica no Brasil. In: Portal o setor elétrico. Disponível em:http://www.osetoreletrico.com.br/web/aempresa/783-inovacao-tecnologica-no-brasil.htmlacessado em 05/03/2016.

[16] Pileggi, M. Usina que produz 25\% da energia solar do país começa operação comercial. In: UOL

[17] economia. Disponível em: http://economia.uol.com.br/noticias/redacao/2014/0 8/29/usina-que-produz-25-daenergia-solar-do-paiscomeca-operacao-comercial.htm. Acessado em 29/08/2014.

[18] RECURSOS Hídricos. In : Portal Cemig. Disponível em: https://www.cemig.com.br/ptbr/

[19] A_Cemig_e_o_Futuro/sustentabilidade/Re cursos_Hidricos/Paginas/default.aspx. acesso em $12 / 03 / 2016$

[20] Teoria do funcionamento energia solar fotovoltaica. In: Portal energia: energia renováveis. Disponivel em:http://www.portalenergia.com/teoria-funcionamento-energia-solarfotovoltaic/ - acessado 26/01/2016.

[21] Warth, A. Aneel quer que consumidor invista em autogeração de energia. In: Exame.com Disponível em:http://exame.abril.com.br/economia/noticias/an eel-quer-que-consumidor-invista-em-autogeracaode-energia.Acessado em 27/01/2016. 


\section{Capítulo 6}

\section{INSTALAÇÕES COMO FATOR-CHAVE NA CADEIA DE SUPRIMENTOS, PARA O EQUILIBRIO ENTRE RESPONSIVIDADE E EFICIENNCIA: UM ESTUDO DE CASO}

\section{Jessika Kauanny de Souza Eurico}

\section{Luiza Albuquerque Santos}

\section{Priscila Pereira Suzart de Carvalho}

Resumo: Com o mercado cada vez mais competitivo, exigem-se das organizações um alto investimento dos seus esforços em suas respectivas cadeia de suprimentos, considerando todos os fatores-chaves que impactam em seu desempenho. Esse estudo de caso faz parte de um projeto para compreensão aprofundada do fator-chave de desempenho da cadeia de suprimentos, instalações, com o objetivo de realizar um diagnóstico do empreendimento do setor de marketing olfativo, de uma fábrica de médio porte localizada no município de Ilhéus demonstrando a influência do panorama por possuir uma única instalação fabril. A metodologia utilizada foi uma pesquisa do tipo descritivo e exploratório, de natureza qualitativa, através de uma visita a instalação e entrevista a representante da empresa. A partir da análise dos dados coletados, em conjunto com a análise teórica, a empresa do setor olfativo poderá ser caracterizada de acordo com o fator-chave instalação.

Palavras-Chave: (Instalações, Cadeia de Suprimentos, Estratégia). 


\section{INTRODUÇÃO}

Esse estudo de caso faz parte de um projeto para compreensão aprofundada do fatorchave de desempenho da cadeia de suprimentos, instalações, com o objetivo de realizar um diagnóstico do empreendimento do setor de marketing olfativo, a fábrica de médio porte, demonstra a influência do panorama de possuir uma única instalação fabril.

$\mathrm{Na}$ Gestão da Cadeia de Suprimentos, os fatores-chaves podem ser utilizados para definir direcionamentos estratégicos, tomadas de decisões além de serem indicadores de desempenho. Eles são quatro ao todo, divididos em dois grupos, os fatores logísticos e os fatores interfuncionais - estes são utilizados para unir responsividade à eficiência (customização e entrega eficaz a baixos custos).

A valorização do fator-chave como decisório coloca os outros fatores como indicadores de desempenho para analisar e realinhar caso necessário às estratégias da empresa e consequentemente da cadeia de suprimentos como um todo. Essa prática leva a uma melhor ambientação no mercado, uma busca constante de desenvolvimento e melhorias alinhando a responsividade aos baixos custos.

O fato de a organização possuir uma única instalação fabril a diferencia por muitos motivos que serão elencados abaixo como tomadas de decisões e suas influências nos outros fatores-chaves como também na estratégia competitiva. É interessante destacar que vislumbrando novas formas de investimentos focaram em uma produção sustentável para a produção de aromatizantes de ambientes, o grande interesse mundial neste modelo de produção consciente possibilitou a empresa desenvolver-se e ampliar para outros tipos de produtos.

A escolha da região para instalação é estratégica sofrendo influências internas e externas, as lojas da empresa, franqueadas e representantes da marca que a fábrica abastece se concentram na região Nordeste e Sudeste, na qual os municípios de Itabuna e de Ilhéus estão conectados pelas suas malhas rodoviárias, possui isenções fiscais e a propriedade permite possíveis ampliações.

\section{REFERENCIAL TEORICO}

\subsection{CADEIA DE SUPRIMENTOS}

Tradicionalmente em uma cadeia de suprimentos, as matérias primas são obtidas, subsequentemente transportadas momentaneamente em depósitos, aguardando seu direcionamento para os clientes finais. Dessa forma, atesta-se que a cadeia de suprimentos está vinculada aos fornecedores, produção, depósitos, distribuidores, varejistas e consumidor final (SIMCHI-LEVI, 2012).

Rockford Consulting Group - RCG (2001) afirmou que a velocidade em cada um desses processos é o segredo o êxito de uma cadeia de suprimentos. Dessa forma a organização deve considerar a coordenação de todos os diversos processos da cadeia, com a maior agilidade possível, sem comprometer a qualidade ou a satisfação do cliente.

Constata-se assim, que o gerenciamento da cadeia de suprimentos procura acentuar, somar e ampliar as vantagens de um gerenciamento integrado. De tal modo as estratégias e as decisões passam a pertencer à cadeia como um todo e não mais elaboradas sob o ângulo de uma única organização (PARRA \& PIRES, 2003). Ainda é citado que cada elemento da cadeia precisa, principalmente, dar importância à competitividade do produto diante do consumidor final e com o desempenho da cadeia produtiva no geral.

Segundo Dornier et al (2000), os obstáculos do gerenciamento da cadeia de suprimentos podem ser correspondentes a atribuição desorganizada e fragmentada de responsabilidades dos processos da cadeia.

Devido a grande competitividade, a principal estratégia da cadeia de suprimentos volta-se ao atendimento e ao interesse do cliente. Procura-se oferecer produtos e serviços adequados no lugar e no momento exato e com menores custos, sendo assim faz-se necessária um atendimento de forma geral respondendo as demandas locais e mundiais. Com o objetivo das empresas de ganhar e absorver a demanda, é preciso que se tenha uma estrutura coordenada e criar uma rede interna, com seus integrantes alinhados a objetivos comuns onde haverá a manutenção dos negócios (AMICUCCI e ALVES, 2012). 


\subsection{OS FATORES CHAVES NA CADEIA DE SUPRIMENTOS}

Nessa sessão serão mencionados os quatro fatores chaves encontrado na literatura: estoque, transporte, informação, instalações, e mais responsividade e eficiência.

Os fatores-chave na cadeia de suprimentos, segundo Pédia (2014) determinam além do desempenho, se o alinhamento estratégico é ou não alcançado em toda a cadeia. De modo que ajude a alcançar o equilíbrio entre responsividade e eficiência, assim as empresas utilizam esses fatores para alcançar o nível de desempenho estabelecido pela estratégia definida.

Segundo Amicucci e Alves (2012) há estoque em todos os processos da cadeia de suprimento desde a obtenção da matéria prima, até o produto final. $\mathrm{O}$ avaliam como o principal fator de geração de custos em uma cadeia.

O transporte é o que movimenta o produto nos diferentes processos na cadeia de suprimento. Assim como os outros fatores, o transporte, possui bastante influência tanto na responsividade, quanto na eficiência. O seu tipo escolhido pela organização também influencia os estoques e as instalações na cadeia (MARIEN, 2000).

Amicucci e Alves (2012) afirmam que a informação às vezes não é classificada como um fundamental condutor da cadeia de suprimento, somente por não ser tangível. Porém, a informação afeta de diferentes formas todos os processos da cadeia de suprimento.

A informação se comporta como uma união entre os processos da cadeia, possibilitando assim gerenciar suas ações e colocar em prática algumas vantagens da maximização da lucratividade total da cadeia (MARIEN, 2000).

Já no quesito responsividade e eficiência Stalk (1990) afirma que quando a cadeia de suprimentos opta por trabalhar de forma responsiva, as organizações geralmente procuram instalar suas fabricas próximas aos seus clientes. Com o aumento de instalação a cadeia torna-se mais responsiva, e com a diminuição instalações mais centrais geram maior eficiência. Contrariamente, se optar ser eficiente exige trabalhar com uma cadeia enxuta, diminuindo ao máximo os custos operacionais e mantendo estoques baixos.

Segundo os autores na literatura, sobre a cadeia de suprimentos, a localização das instalações é um problema comum, entretanto não menos importante. Assim, Fleury; Wanke e Figueiredo (2000) citam que as decisões relacionadas à localização têm altos investimentos envolvidos e provocam impactos sobre os custos logísticos. Uma etapa chave no processo decisório para a seleção de uma localidade é a avaliação das alternativas potenciais disponíveis para a instalação fabril, combinadas com os fatores mais significativos e seus atributos qualitativos e/ou quantitativos (ALVES e ALVES, 2012).

As instalações são pontos nodais na rede logística, tais pontos sendo caracterizados por fábricas, portos, vendedores, armazéns, pontos de varejo e pontos centrais de serviços na rede em que os consumidores finais recebem seus produtos que foram encaminhados rapidamente sem "longas paradas" (BALLOU, 2004).

Assim, Chopra e Meindl (2003) definem instalações como local para ou de onde o estoque é transportado sendo que dentro das instalações esse estoque pode ser transformado em outro estado (fabricado) ou armazenado antes de ser despachado para um próximo estágio (armazenagem). A fabricação e armazenagem em um mesmo local podem proporcionar economias de escala no produto, aumentando também sua eficiência promovida por essa centralização. Muitas instalações reduzem a eficiência, porém, podem aumentar a responsividade se a demanda dos clientes assim exigir.

Segundo Pédia (2014), produzir e armazenar o produto no mesmo local a empresa obtém economia de escala. Essa centralização aumenta a eficiência, no entanto reduz a responsividade, que é alcançada quando a produção é descentralizada, mas que atende o cliente instantaneamente, o que gera altos custos.

\section{METODOLOGIA}

Foi realizada uma pesquisa do tipo descritivo e exploratório, de natureza qualitativa. O processo de investigação aconteceu através de um estudo exploratório em uma empresa fabricante de produtos aromáticos. Uma visita técnica foi feita à fábrica de produtos de perfumaria, na qual foram observados todos 
os fatores relacionados com a gestão da cadeia de suprimentos de instalação.

A coleta de dados aconteceu também por meio de entrevista e de uma aplicação de questionário à assistente de qualidade da empresa, realizada na própria sede desta. Os dados obtidos com a entrevista e com a aplicação do questionário foram analisados e verificados tendo por base o referencial teórico realizado e conhecimento tácito das integrantes do grupo, e estão apresentados no presente trabalho.

\section{ESTUDO DE CASO}

\subsection{CARACTERIZAÇÃO DA EMPRESA}

A fábrica estudada é uma empresa que atua no ramo de Marketing Sensorial (olfativa) está localizada na Rodovia Ilhéus/Itabuna. Fundada em abril de 2002, a empresa iniciou seus trabalhos com consultoria olfativa e aromatizantes de ambientes. Em seu estado atual fábrica, com cerca de 120 funcionários, comercializa produtos de perfumaria, ambiência, higiene pessoal e acessórios, tendo mais de 450 diferentes itens em seu portfólio. Os produtos estão dispostos em duas linhas, uma linha de produto e uma linha especial. Na Tabela 1 abaixo é apresentada a relação dos produtos fabricados pela empresa separada por estas duas linhas. Dentre estes produtos, o óleo em creme e os aromatizantes representam o maior volume produtivo.

A empresa nasceu a partir da aspiração de dois amigos, que perceberam nesse ramo a oportunidade de investir em um próprio negócio, assim conseguiram construir uma marca sólida e diferenciada. Pioneira no mercado de aromatizantes, a organização, agraciada pela sua localização, busca na biodiversidade da Mata Atlântica o estímulo e recursos necessários para a criação de um grande leque de fragrâncias. A missão da empresa é despertar a consciência do consumo sustentável aliado ao prazer de manter corpo e mente revigorado.

Tabela 1: Relação de Produtos da fábrica por linha

\begin{tabular}{|l|l|}
\hline \multicolumn{1}{|c|}{ Linhas de Produtos } & Alecrim \\
\hline Perfumaria para interiores & Âmbar \\
\hline Pout-pourri e difusores & Boníssimo Especiais \\
\hline Sachets perfumados & Cascas \& Folhas \\
\hline Velas aromáticas & Casual Spa (Cupuaçu \& Castanha Do Brasil) \\
\hline Incensos perfumados & Casual Spa (Buquê de Peônias) \\
\hline Água perfumada para roupas & Casual Spa (Creme de Manteigas) \\
\hline Sabonete líquido e gel espumante & Cedro \& Cipreste \\
\hline Sabonetes em barra & Curumim \\
\hline Sais de banho \& espuma & Flor de Algodão \\
\hline Óleo de banho corporal & Marruá \\
\hline Acessórios & Provence \\
\hline Dispersores de fragrâncias & Terra Madre e Vintage \\
\hline Kits & Fonte: \\
\hline
\end{tabular}

Segundo o artigo no Bahia de Valor (2017), os empresários baianos vêm transformando as empresas em redes franqueadas como um meio para ampliar os negócios sem gastar muito e com segurança. Uma vez que o investimento e risco são assumidos pelos franqueados. De acordo com a $\vee$ isão da sócia fundadora da empresa em questão, para o sucesso do franqueamento, são necessários dois fatores: a criação de regras e a padronização.

Sendo assim, os produtos são distribuídos principalmente nas regiões Sudeste e
Nordeste através de lojas próprias e da rede de franquias. com mais de 90 lojas em 22 estados. Há também pontos de vendas e fornecedores autorizados, somando cerca de 1000 revendedores. No estado da Bahia os seus principais representantes estão localizados nas cidades de Itabuna, Feira de Santana, Ilhéus, Porto Seguro, Salvador, Teixeira de Freitas e Vitória da Conquista, totalizando cerca de 23 lojas. 


\subsection{DESCRIÇÃO GERAL DO PROCESSO}

O processo produtivo da fábrica é definido por quatro processos independentes, de acordo com o estado físico da matéria prima (sólido, líquidos, pastoso e granular). A produção é realizada em quatro áreas de produção, como demonstrado na Figura 1, que apesar de serem independentes entre si, executam as ordens de produção de modo simultâneo, mas com apenas um tipo de produto

cada

Figura 1: Fluxograma do processo produtivo

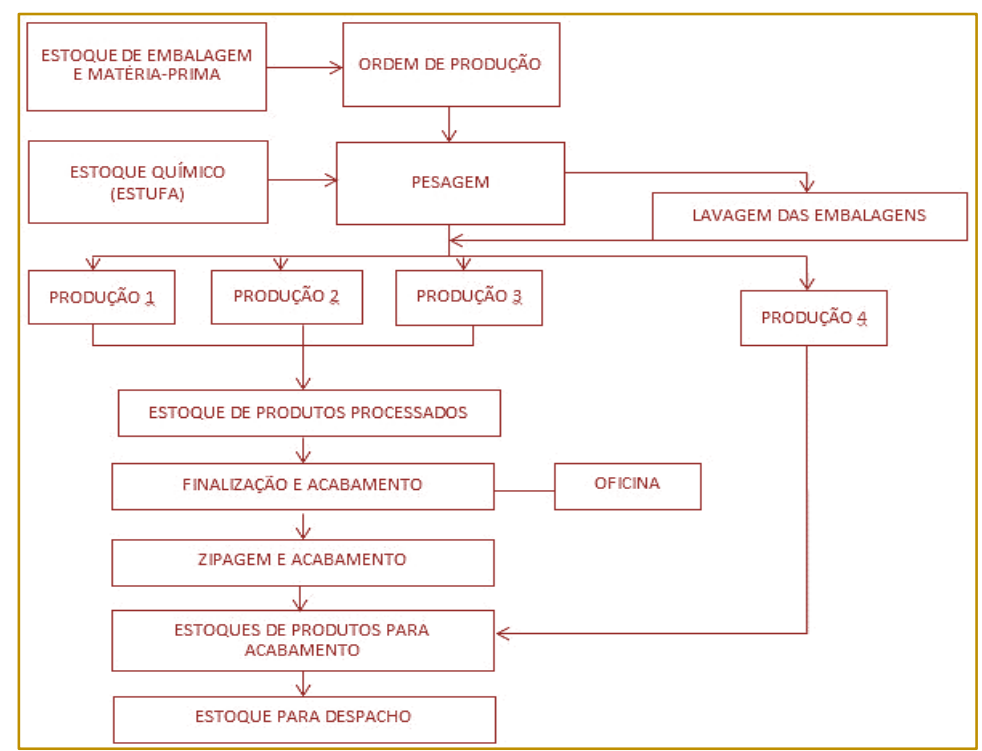

Fonte: Dados da organização

Na Figura 1 está demonstrado como as áreas de produção estão coordenadas com todo o processo de fabricação. Desse modo é possível observar que as quatro áreas de produção são abastecidas por matériasprimas que passaram pelo processo de pesagem e pela seleção das embalagens. Somente a produção 4 (granular), que corresponde a produção de sais de banho, velas e óleos, após passar pelo processo de produção, é encaminhada diretamente para o estoque de produtos e faturamento. Essa especificidade é atribuída a produção 4, pois é a única produção que sai da sala de produção já com código de barras, o que possibilita seu rastreamento mesmo antes de ser estocada.

No entanto, como observado no fluxograma de processos os outros tipos de produtos passam juntos pelas etapas que sucedem a produção, em que depois de produzidos são encaminhados para o estoque de produtos processados, onde a equipe de qualidade faz novamente a verificação das características organolépticas apesar deste controle já ter sido executado na fase inicial ao processamento da matéria-prima.
As fases de finalização e acabamento seguem as especificidades de cada tipo de produto. Em seguida são conduzidos em lotes para o estoque responsável pela liberação de nota fiscal e só assim os lotes seguem para sala de despacho onde a transportadora faz o recolhimento para realizar as entrega aos seus revendedores. Importante mencionar que ao longo do processo produtivo, as áreas de produção possuem restrita quantidade de mão de obra em cada setor. Apenas na sala de oficina, na qual são realizados trabalhos totalmente artesanais (confecção de embalagens diferenciadas) o número de pessoas em atividade é o maior - 15 pessoas em média.

\subsection{COMPONENTES DA TOMADA DE DECISÃO: INSTALAÇÕES}

Analisando a fábrica no quesito instalações como fator chave da cadeia de suprimentos a empresa é considerada flexível devido a sua gama de produtos. Como já mencionado a empresa começou só com Perfumes Para Interior, mas atualmente a produção se expandiu. A instalação tem foco no produto já que eles fabricam desde a base até a 
embalagem. Com um portfólio variado de produtos, é exigida uma grande quantidade de matéria-prima diversificada. Em geral, para a fabricação de seus produtos são utilizadas: essências, químicos, água, álcool e embalagens, os principais fornecedores são os de embalagens, que se encontram na China e os de essências que estão em São Paulo, mas importam produtos da Alemanha, da Suíça e dos Estados Unidos da América.

O Centro de Distribuição é na própria organização. Percebe-se que na empresa há um planejamento de entregas do tipo milk run, no qual um caminhão faz várias entregas sem cruzar rotas, assim maximiza-se a capacidade dos veículos utilizados para o transporte, no sentido da otimização das rotas e da redução dos custos de transporte da operação.

A localização é de forma centralizada, pois só há essa fábrica no Brasil que consegue atender diversos pontos no país inteiro. Foi escolhido ser em llhéus, com base nos fatores externos e internos, onde a empresa aponta como fundamental para a localização atual: a abundância de recursos naturais, o acesso fácil ao terreno, a possibilidade para futuras ampliações, o transporte público, o acesso a rodovias, a mão de obra, a isenção de imposto, o custo da construção, o custo de vida, os impostos locais, a topografia, a imagem da empresa, etc.

No quesito capacidade, após a referência bibliográfica e a análise da empresa, percebe-se que é uma fábrica relativamente pequena para atender uma demanda grande. Com o serviço de Personalização, há a oportunidade de ter uma linha de produtos com marca e rótulo com design exclusivo. Há também a possibilidade de desenvolver fragrâncias exclusivas, de acordo com suas necessidades específicas e nicho de mercado atendido por qualquer pedido, caracterizando assim o sistema make to order. Há os estoques de produtos acabados que são programados para reabastecer as lojas, caracterizando assim o sistema push. E por fim o estoque do tipo work in progress, pois cada produto específico necessita de um tempo de maturação da base.

Portanto, a empresa se mostra eficiente por ter uma única instalação, ou seja, com uma maior centralização significa ser mais eficiente, e assim usando o máximo de sua capacidade. Percebe-se a responsividade da empresa no quesito de possuir mais de 400 pontos no país inteiro e assim conseguindo atender a todos clientes de forma rápida.

\section{CONSIDERAÇÕES FINAIS}

Por vários fatores considera-se a fábrica como eficiente: a utilização máxima da capacidade, centralização da produção e estoques com volume alto ocasionado pelas peculiaridades do produto. Mas também possuem inúmeras facetas responsivas: a flexibilidade produtiva e a capacidade de adaptar-se a pedidos personalizados.

No entanto, diante das informações disponibilizadas para o estudo de caso podese avaliar a empresa como eficiente buscando a maior responsividade, quando se refere ao fator-chave instalações. E concluir que o fator-chave da cadeia de suprimentos que culminou neste estudo de caso foi decisório em toda a estratégia da cadeia e no modelo que a empresa segue e seguirá para que tenha o futuro almejado.

A empresa avaliada vem tomando ações para aumentar a eficiência, um investimento de $\mathrm{R} \$ 3$ milhões em sua unidade industrial. Os recursos estão sendo empregados na ampliação da linha de produção, na compra de equipamentos e também em treinamento de pessoal. Além disso, segundo o Jornal Grande Bahia, serão contratados cerca de mais 30 funcionários.

Além disso, ao final de 2016 foi criado um cheiro para Salvador, cuja ideia foi aprovada pelo prefeito e foi utilizado no Carnaval de São Paulo. Firmando assim a identidade da empresa e reconhecimento, pelo fato da capital baiana ser a primeira cidade do mundo a ter uma identidade olfativa própria. 


\section{REFERÊNCIAS}

[1] Alves, José. R. X; Alves, João. M. Definição de localidade para instalação industrial com o apoio do método de análise hierárquica (AHP). ITA, São José dos Campos, SP, Brasil. 2012.

[2] Amicucci, Dailton C.; Alves Eduardo T. A importância dos fatores chave da cadeia de suprimentos para gestão do segmento farmacêutico: estudo de caso múltiplo na cidade de Lins. Trabalho de conclusão de curso. Faculdade de Tecnologia de Lins Prof. Antonio Seabra. Lins, 2012.

[3] Avatim vence Oscar da perfumaria latinoamericana; empresa tem sede em Ilhéus. Jornal Grande Bahia. 2017. Disponível em <http://www.jornalgrandebahia.com.br/2017/11/ava tim-vence-oscar-da-perfumaria-latino-americanaempresa-tem-sede-em-ilheus/> Acesso em 29 jan. 2018.

[4] Ballou, Ronald $H$. Business Logistics/supply Chain Management: Planning, Organizing, and Controlling the Supply Chain. Estados Unidos: Pearson Education. 2004. 789 p. 5믈ição.

[5] Baiana Avatim apresenta modelos de franquia na 26 a ABF. Bahia de Valor. 2017. Disponível em:

https://www.bahiadevalor.com.br/2017/06/avatimapresenta-modelos-de-franquia-na-26a-abf/> Acesso em 27 jan. 2018.

[6] Chopra, Sunil; Meindl, Peter. Gerenciamento da Cadeia de Suprimentos: estratégia, planejamento e operação. São Paulo: Pearson Prentice Hall, 2003.
[7] Dornier, P.P; Ernst, R.; Fender, M.; Kouvelis, P. Logística e Operações Globais; Texto e Casos, São Paulo; Atlas; 2000.

[8] Fleury, Fernando; WANKE, Peter; Figueiredo, Kleber F. Logística empresarial: a perspectiva brasileira. São Paulo: Ed. Atlas, 2000.

[9] Marcas baianas viram franquias para acelerar crescimento. A Tarde - BA. 2016. Disponivel em <http://sbvc.com.br/marcasbaianas-viram-franquias-para-acelerarcrescimento/> Acesso em: 27 jan. 2018.

[10] Marien, Edward J. The four supply chain enablers. Supply Chain Management Review, março-abril de 2000, p.60-6S.

[11] Parra, Paulo H.; Pires, Silvio R. I. Análise da Gestão da Cadeia de Suprimentos na Indústria de computadores, 2003.

[12] Pédia, Porto. Cadeia de Suprimentos Responsiva. 2014. Disponível em: <http://www.omcconsult.com.br/noticias/cadeia-desuprimentos-responsiva/> Acesso em: 28 jan. 2018.

[13] Levi, David, S. WEI, Yehua. Understanding the Performance of the Long Chain and Sparse Designs in Process Flexibility. 2012.

[14] Rcg Supply Chain Management Definition - Rockford Consulting Group. New York, USA, 1999. Disponível em: <http://logistics.about.com/gi/dynamic/offsite.htm?z $i=1 / X J \& s d n=$ logistics\&zu=http\%3A\%2F\%2Fwww.ro ckfor dconsulting.com\%2Fscm.htm> Acesso em: 28 jan. 2018. 


\section{Capítulo 7}

\section{ANÁLISE DO PROCESSO DE IMPLANTAÇÃO DE UM SISTEMA DE GESTÃO DA QUALIDADE NUMA INDÚSTRIA DE CONFECÇÕES DO ESTADO DO CEARÁ}

\section{Sandro Italo de Oliveira}

\section{Iasmin Alexandrino de Miranda}

Resumo:Com os consumidores cada vez mais exigentes e uma atmosfera competitiva, as organizações necessitam de novas ferramentas de gestão com diretrizes capazes de atender as necessidades dos consumidores. Neste contexto, encontram-se as indústrias de confecção, que tem sentido fortemente os efeitos da competição global, tendo que oferecer um mix de produtos com qualidade, e cada vez mais atraentes aos olhos do consumidor, com muito mais informação de moda. Uma gestão de qualidade apresenta-se como pilar essencial, criando condições internas que possibilitam às organizações um diferencial estratégico e garantem a sobrevivência das empresas a longo prazo, através de uma abordagem na melhoria dos processos com intuito de melhorar a qualidade de seus produtos. Nesse sentido o presente trabalho tem como objetivo analisar o processo de implantação de um sistema de gestão da qualidade em uma indústria de confecções, desde seu nível de planejamento na alta gestão até o nível operacional, apontando os principais desafios e resultados obtidos.

Palavras-Chave: Gestão da qualidade, processos, indústria de confecção. 


\section{INTRODUÇÃO}

O mercado de produtos e serviços passa por mudanças muito rápidas, reflexo da rápida evolução social e tecnológica na humanidade. O consumidor busca encontrar nos produtos não somente sua funcionalidade, mas também busca obter uma grande experiência. $\mathrm{E}$ com isso a elevação nos padrões de qualidade aumentam, advindas de um mercado com clientes cada vez mais exigentes. Isso faz com que algumas empresas até então aparentemente inexpugnáveis, podem devido às rápidas mudanças, ter sua sobrevivência ameaçada (VICENTE FALCONI, 2014).

$\mathrm{Na}$ indústria têxtil e de confecção as empresas estão trabalhando para lançarem produtos cada vez mais rápido, mas neste cenário de crescente oferta, o produto será atraente se estiver adequado às exigências dos clientes. Nesse contexto, uma gestão da qualidade contribui diretamente para esse propósito.

Para Paladini (2006), a necessidade pela qualidade de produtos e serviços, decorrente quase sempre do aumento de concorrências de variadas naturezas, motivou uma transformação radical no cenário. Diante desses novos desafios as organizações buscam diferencias estratégicos, adotando novos modelos de gestão, onde normalmente alteram suas estruturas organizacionais.

O objetivo de estudo desse trabalho é analisar o processo de implantação de um sistema de gestão de qualidade em uma indústria de confecções, que ocorre através de uma abordagem crescente para 0 desenvolvimento dos recursos humanos, implementação de procedimentos e melhoria dos processos, com o objetivo de crescer em produtividade e qualidade de seus produtos, através da confiabilidade e eficiência dos processos internos da organização.

\section{REFERENCIAL TEÓRICO}

\subsection{CONCEITO DE QUALIDADE}

O conceito de qualidade evoluiu substancialmente ao longo das últimas décadas. Antes pensava-se em qualidade apenas com relação ao produto final com uma abordagem de controle da qualidade através de inspeção, agora este conceito é direcionado também aos processos gerenciais, interligando todas as áreas da organização.

Vicente Falconi (2014), define qualidade como um produto ou serviço que atende perfeitamente, de forma confiável, de forma acessível, de forma segura e no tempo certo, as necessidades do cliente.

Qualidade: Está diretamente ligada à satisfação do cliente interno ou externo. Medida por meio das características da qualidade dos produtos ou serviços finais ou intermediários da empresa. Inclui a qualidade do produto ou serviço (ausência de defeito e presença de características que irão agradar o consumidor), a qualidade da rotina da empresa (previsibilidade e confiabilidade em todas as operações), a qualidade do treinamento, qualidade da informação, a qualidade da administração, etc; (FALCONI, 2014).

Contudo, o mercado precisou se adequar ao que o seu cliente pede, ou seja, teve que oferecer produtos e serviços de qualidade à medida em que seu público ficava cada vez mais exigente. Qualidade vai além de um produto de excelência. Qualidade é o resultado de todo um processo produtivo, onde todos os envolvidos estão conscientes da importância de levar aos clientes um produto de qualidade e à empresa um processo mais eficiente.

Para Juran (1990), chegar a um acordo sobre o que se entende por qualidade não é simples. Para os gerentes, nenhuma definição sucinta é realmente precisa, mas uma dessas definições obteve larga aceitação: qualidade é adequação ao uso.

Com essa definição, podemos observar que a qualidade sempre vai ser definida pelo cliente, já que o mesmo é quem faz o "uso" e a última análise do produto ou serviço, definindo ou não sua qualidade segundo a sua satisfação.

Paladini (2006), ainda explica esse conceito afirmando que tudo que contribui para essa "adequação" é relevante. Do ponto de vista do produto, isso significa toda à diversidade de itens que ele possa dispor para melhor se ajustar a sua efetiva utilização. 


\subsection{IMPORTÂNCIA DE UMA GESTÃO DA QUALIDADE}

Uma empresa honesta só pode sobreviver dentro de uma sociedade se for para contribuir para a satisfação das necessidades das pessoas. Esse é o seu objetivo principal. Sabendo disso, as empresas sentem-se pressionadas a buscar modelos de gestão capazes de atender as exigências do mercado atual, nesse sentido um sistema de gestão da qualidade apresenta-se como uma oportunidade de gerar diferencial estratégico nas empresas.

Segundo Falconi (2014) o objetivo da utilização de uma gestão da qualidade total como abordagem gerencial nas empresas, é justamente criar condições internas que garantam a sobrevivência das organizações a longo prazo. Uma empresa com uma cultura voltada para à qualidade de seus produtos e serviços assegura uma melhor experiência e satisfação para o cliente, pois o cliente é a razão de uma empresa existir.

Não é mais possível garantir a sobrevivência da empresa apenas exigindo que as pessoas façam o melhor que puderem, e depois apenas cobrar o resultado. O princípio da abordagem de uma gestão da qualidade, baseia-se em métodos, onde todos sejam capazes de aprender e praticar, utilizando-os na direção dos objetivos da empresa.

\subsection{CULTURA ORGANIZACIONAL}

Tratando-se de cultura organizacional, Chiavenato (2010), afirma que a cultura organizacional é o conjunto de hábitos e crenças, estabelecidos por normas, valores, atitudes e expectativas, compartilhadas por todos os membros da organização. Ela se refere ao sistema de significados compartilhados por todos os membros e que distingue uma organização das demais.

A implantação de um SGQ em uma organização tem um dos seus maiores desafios no âmbito cultural. Ao tentar estabelecer uma cultura voltada para qualidade, encontra nas organizações resistência a mudanças, que por sua vez é uma reação natural do indivíduo.

"Os recursos humanos devem ser considerados como um dos principais fatores para melhoria da qualidade em organizações. As empresas devem estar atentas aos instrumentos metodológicos disponíveis para a captação e interpretação das necessidades de seus funcionários e utilizar essas informações como diferencial competitivo." (Vários autores, 2006)

Dessa forma, a introdução da nova cultura deve ser estudada e trabalhada junto ao departamento de Recursos Humanos, para que sejam evitados resultados negativos advindos da resistência, pois, de certa forma, haverá uma mudança na personalidade da organização.

\section{METODOLOGIA}

A abordagem utilizada neste trabalho foi a qualitativa, de natureza básica com o objetivo exploratório de tornar um problema ou uma visão mais explícita envolvendo um levantamento bibliográfico.

Nesse contexto, Gil (2010), afirma que, o estudo de caso consiste no estudo profundo e exaustivo de um ou poucos objetos de maneira que permita seu amplo e detalhado conhecimento, tarefa praticamente impossivel mediante outros delineamentos já considerados. Yin (2005), ainda afirma que deve haver estudos de caso exploratórios, estudo de caso descritivos ou estudos de caso explanatórios.

Nesse sentido, o presente artigo caracterizase por uma pesquisa bibliográfica e estudo de caso simples.

Este método foi selecionado por permitir aos pesquisadores responder à complexidade da pergunta adotada no contexto deste trabalho: quais os desafios no processo de implantação do sistema de gestão da qualidade em uma indústria de confecção de grande porte?

A coleta de dados para estudo ocorreu a partir de uma revisão prévia de literatura, embasando os pesquisadores para analisar o caso, explorando os desafios decorrentes do processo de implementação da gestão da qualidade.

No caso constituiu-se a análise do campo em estudo e a coleta de dados em diferentes fontes de forma que sustente o objeto de estudo em questão, que deu-se a partir de entrevista com o gestor e observação aos agentes entrevistados. 


\section{CARACTERIZAÇÃO DO CASO}

De acordo com dados atualizados em 2017 da Associação Brasileira da Indústria Têxtil e de Confecção (ABIT) o setor têxtil e de confecção emprega 1,4 milhões de empregados diretos, dos quais $75 \%$ são mulheres. A indústria da moda é o segundo maior empregador na indústria de transformação e também segundo maior gerador do primeiro emprego, tendo quase 200 anos de atuação no Brasil.

O trabalho foi realizado em uma indústria de confecção de roupas, visto a grande importância do setor na economia nacional. Por motivos de sua política, esta não poderá ser mencionada. A empresa se encontra hoje como a maior indústria de confecções da América Latina, e investe continuamente em inovações e melhorias. Além da valorização dos colaboradores a organização também visa 0 melhor desempenho de seus processos, com o intuito de proporcionar produtos de excelência.

Nesse contexto, a empresa procurou implantar um sistema de gestão da qualidade, afim de garantir o aperfeiçoamento de seus processos de forma a garantir uma melhoria contínua da organização.

\section{DISCUSSÃO E ANÁLISE DOS RESUTADOS}

\subsection{PLANEJAMENTO E IMPLANTAÇÃO DA GESTÃO DA QUALIDADE}

O planejamento para implantação do sistema de gestão da qualidade concentra-se nos níveis mais altos da gestão da organização. Sabendo que interfere diretamente na estrutura organizacional.

Para iniciar com o processo de mudança e implantação da gestão da qualidade, o gestor da área tomou como estratégia aceitar o desafio respondendo diretamente à gestão corporativa, garantindo que seu trabalho fosse melhor aceito, possibilitando melhores resultados.

Nessa fase do planejamento, foi feito uma análise organizacional, onde foram levantados questionamento para entender a cultura da empresa, perguntas como: tempo de atuação da empresa no mercado, tipo de produto, estratégia de produção utilizada, qual o cliente, qual a expectativa do cliente, etc. Sabendo disso, foi possível estabelecer um panorama da empresa. Esses questionamentos possibilitam definir uma diretriz para obter sucesso na implantação, e consequentemente no mercado.

Sendo assim, de acordo com a pesquisa observou-se que a empresa passava por um processo migratório, onde mudava a estratégia de fabricar produtos para diferentes lojas, para ter um cliente (loja) único, sendo esse cliente parte do mesmo grupo de empresas. Com isso, a oportunidade de implantar o sistema de gestão da qualidade na empresa, iniciou-se com o conhecimento da organização e do processo fabril. Encontrando desafios e oportunidades de melhoria em uma organização de mais de 70 anos de mercado onde no seu operacional, muitas pessoas para execução dos processos, pois trata-se de um modelo de negócio, em parte expressiva, artesanal.

Portanto a gestão da área junto com as demais áreas da empresa atuaram juntos no processo de implantação do novo sistema, porém encontrou-se um desafio dentro da alta administração, onde a mesma se mostrou resistente ao processo de mudanças e com vícios culturais, não atendendo as expectativas da governança corporativa. Para a implantação da gestão da qualidade foram realizadas etapas seguindo a necessidade de resposta rápida da empresa, não seguindo um modelo teórico geralmente recomendado.

\subsubsection{ANÁLISE ORGANIZACIONAL}

A organização em estudo estabelecia sua qualidade de forma empírica, ou seja, baseada em experiência, não media e consequentemente não tinha dados que pudessem fornecer informações e apontar pontos de melhoria dentro do processo produtivo.

A medida que a organização não pensava sobre qualidade, as pessoas lá inseridas não eram habituadas a tratar qualidade como um dos pontos principais para um produto de excelência, ou seja não tratavam pontos de melhoria no produto de forma efetiva, evitando que voltassem a aparecer. Como consequência, existe um desafio ao inserir uma cultura voltada para qualidade.

Portanto, a nova cultura tem por objetivo inserir a percepção da qualidade e sua importância por toda à organização aos envolvidos com 0 processo produtivo, 
internamente e externamente, de forma que todos estejam orientados para qualidade e melhoria contínua dos processos.

\subsubsection{MAPEAMENTO DO PROCESSO PRODUTIVO}

A estratégia nessa etapa foi mapear a organização, identificando as principais entradas e saídas do processos e fazer o diagnóstico, encontrando os pontos críticos e priorizando os mesmos.

Tendo dado andamento com o mapeamento dos processos, implantou-se indicadores com meta não definida nas principais áreas de atendimento da organização. A não definição da meta observou-se necessária devido a rapidez de resposta que se esperava e as diferentes percepções de qualidade dentro da cultura anterior, sendo assim, mostrando pontos de melhoria nas principais entradas e saídas do processo fabril, matéria prima, costura e lavanderia.

Desse modo, podemos observar que o processo de implantação passa por um ciclo, onde conseguimos enxergar o fluxo através da ferramenta conhecida como PDCA.

Figura. 1 Ciclo PDCA.

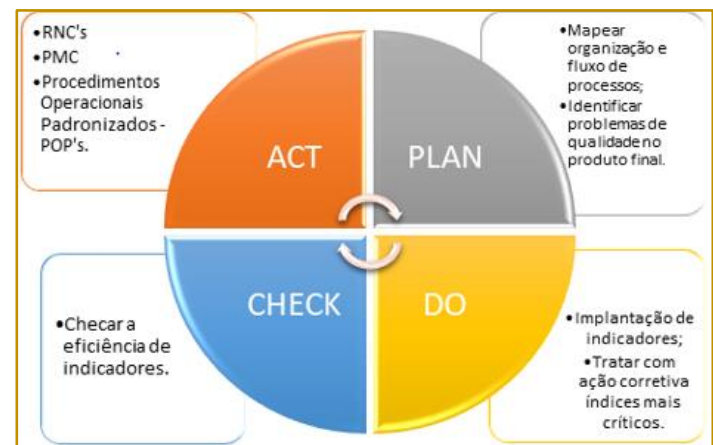

Fonte: Autor.

Em conversa com o gestor, foi possível observar que o processo hoje se encontra na etapa do, ou seja, tratando com ação corretiva os índices mais críticos encontrados a partir dos indicadores estabelecidos. E está iniciando a etapa check, onde está checando a eficiência dos processos, identificando quais os de menor eficiência, caminhando para a etapa act, onde serão tomadas ações para tratar desses indicadores, adiantando que o Registro de Não Conformidades (RNC), Processo de Melhoria Contínua (PMC), e a produção de Procedimentos Operacionais Padronizados (POP), serão uma das principais ações.

\subsubsection{ESTABELECIMENTO DE METAS}

Para estabelecer as metas foram utilizados tanto informações mercadológicas, observando como está a concorrência, o público alvo, expectativas do público, como o conhecimento do próprio gestor responsável pela gestão da qualidade entraram na pesquisa. Nessa etapa, foi de grande importância o conhecimento do gestor no varejo de confecção, que serviu como base para o estabelecimento de metas como: redução do percentual de peças produzidas de segunda qualidade e percentual de retrabalho nos setores de costura. Tendo em vista o conhecimento de mercado e levando em consideração o tipo de produto fabricado.

A percepção do cliente sobre o produto da empresa foi outro ponto chave no estabelecimento das metas, a resposta do cliente foi importante para definir parâmetros da qualidade do produto, sendo possível gerar planos de melhoria contínua, baseados nos novos padrões estabelecidos.

\subsubsection{RECURSOS HUMANOS}

O setor de recursos humanos atuou de forma intensa desde o início do processo de implantação. Atuando de maneira que possibilitou a integração das áreas da empresa, mostrando o objetivo da organização com a introdução de uma cultura voltada para qualidade. 
Nesse sentido, a gestão de pessoas foi muito importante, sabendo que numa empresa com mais de 70 anos de atuação no mercado existe uma cultura comportamental muito forte. E para que as áreas trabalhassem de forma harmônica com o mesmo propósito, algumas ações foram determinantes como, exigência de acompanhamento dos indicadores por parte dos gestores, treinamento dos colaboradores, conscientização da importância da melhoria dos processos e melhoria da qualidade nos processos e produtos.

Com isso foi possível observar a evolução do colaborador dentro da organização, atuando com os mesmos objetivos da empresa, onde houve uma percepção de desenvolvimento profissional, através de capacitação, engajamento, e conhecimento da importância da estratégia adotada pela organização.

\subsubsection{OPERACIONAL}

Ao se tratar de nível operacional, o desafio foi em relação a mudança cultural. Muitos dos colaboradores estavam acomodados ao antigo modelo de gestão, então era notória a preocupação dos mesmos em relação à mudança.

No entanto, existiram profissionais dispostos a enfrentar o desafio junto com a empresa, onde a mesma sempre esteve disposta a investir nesse perfil de colaborador, que foram se adequando ao novo modelo de gestão.

Portanto, a gestão de pessoas foi um fator crucial nessa etapa do processo junto a gestão da qualidade, desde que o mesmo atuou junto a todos colaboradores da empresa no processo de engajamento e treinamento quando necessário. No entanto o desafio é constante, à medida que novos colaboradores entram na empresa existe a necessidade de integração ao processo de mudança junto aos objetivos da organização.

\section{CONCLUSÃO}

O artigo tem por finalidade analisar a implantação de um sistema de gestão da qualidade e seus principais desafios em uma indústria de confecções, visto a grande importância do setor têxtil e de vestuário na economia nacional.

Em virtude dos fatos e estudos apresentados, é seguro afirmar que perante um cenário de crise e alta competitividade no mercado, é imprescindivel a busca por ferramentas inovadoras que auxiliem no desempenho das empresas. Dessa forma, a adoção de uma Gestão de Qualidade apresenta-se como diferencial estratégico.

O trabalho foi desenvolvido através de um estudo caso simples, onde acompanhou-se uma observação durante a implementação do sistema de gestão da qualidade dentro da organização, assim como a reação dos colaboradores no que diz respeito a mudança organizacional.

Através das informações expostas, visualizase como um Sistema de Gestão da Qualidade está interligado com a cultura organizacional de uma empresa, alterando a maneira de pensar e agir dos membros da organização.

Constata-se que a gestão da qualidade buscou modificar o sistema gerencial como um todo, atuando nos processos afim de obter eficiência e confiabilidade, seguido de uma maior produtividade e aumento da qualidade no produto final, buscando a satisfação do cliente.

Portanto conclui-se que a implantação do Sistema de Gestão da Qualidade é de fundamental importância para organização, e que o envolvimento de gestores e lideranças é imprescindível para a aceitação de uma cultura voltada para qualidade. Ainda concluise que é de grande importância o entendimento e conscientização de todos da organização para que a gestão da qualidade possa interagir com todas as áreas, possibilitando o alcance do objetivo principal de satisfazer as necessidades das pessoas. 


\section{REFERÊNCIAS}

[1] Abit - Associação Brasileira da Indústria Têxtil e de Confecção. Dados gerais do setor referentes a 2017 (atualizados em dezembro 2017). Disponível em: http://www.abit.org.br/cont/perfil-dosetor. Acesso em: 03 de fev. 2018.

[2] Campos, Vicente Falconi. TQC: Controle da qualidade total (no estilo japonês). Nova Lima: Falconi Editora, 2014. 286p.

[3] Chiavenato, Idalberto. Administração nos novos tempos. $2^{\underline{a}}$ ed. Rio de Janeiro: Elsevier, 2010.

[4] Chiavenato, Idalberto. Gestão de Pessoas: o novo papel dos recursos humanos nas organizações. 3aㅡ ed. Rio de Janeiro: Elsevier, 2010.
[5] Dias, Reinaldo. Cultura organizacional: construção, consolidação e mudanças. São Paulo: Atlas, 2013.

[6] Gil, A. C. Como elaborar projetos de pesquisa. 5 ed. São Paulo, 2010.

[7] Juran, J.M. Juran na liderança pela qualidade - Um guia para executivos. Livraria pioneira editora, SP. 1990.

[8] Paladini, Edson Pacheco. Gestão da qualidade: teoria e prática. 2 Ed. 3 Reimp. Editora Atlas, SP. 2006.

[9] Yin, R. K. Estudo de Caso. 3. Ed. Porto Alegre: Bookman, 2005, p. 212. 


\section{Bapítulo 8}

\section{GERENCIAMENTO DA INCERTEZA APLICADO A UMA STARTUP}

\section{Jonatas dos Santos Welte \\ Rodrigo Linhares Lauria \\ Marcos dos Santos \\ Joana Marcelino Gomes}

Resumo: Com as novas tecnologias e a mudança da sociedade o mundo tornou-se cheio de riscos, incertezas e imprevistos. É necessário que os atuais empreendedores tenham uma atitude ativa quanto a instabilidade no mercado e neste contexto estão as startups. É preciso conhecer não só as ferramentas que irão ajudar, como a forma estratégica de utilizá-las. Perder tempo com atividades que não geram o resultado esperado é fatal. Este trabalho explora conceitos existentes na literatura acerca dessas ferramentas e faz uso de uma pesquisa feita pelo SEBRAE e pela CB Insights que descreve as principais fraquezas encontradas nas stratups. E tem objetivo apontar as principais incertezas ligadas a essas empresas e alguns caminhos para soluciona-las. Como resultado, econtrou-se que a falta de um bom modelo de negócio, a má escolha das equipes, a falta de financiamento e um produto que não se mostra necessário aos clientes se mostraram como as principais causas de insucesso das startups.

Palavras-chave: Startup; Empreendedorismo; Modelo de Negócios; Incertezas 


\section{INTRODUÇÃO}

O empreendedorismo vem mudando a forma de se pensar de muitos, com mudanças constantes de mercado e o desenvolvimento rápido do mundo e das pessoas. Muitos são atraídos à essa esfera para trazer suas grandes ideias. A competitividade dos empreendedores trouxe uma conhecida, mas ainda considerada recente forma de se empreender: as empresas Startup. As Startups se popularizaram no Brasil entre os anos 1990 e 2001, quando surgiu a bolha da Internet, segundo o especialista Gitahy (2011). O mundo empresarial tem diferentes opiniões sobre quais empresas podem ser consideradas startups, mas a definição que se destaca é que Startups são um modelo de negócio de valor, repetível e escalável (BLANK 2010). Um exemplo muito comum de negócio repetitivo é a empresa Netflix, que com os direitos autorais em cima de um único filme faz sua distribuição a milhões de usuários de uma só vez.

Startups são referência para todo empreendedor pelo fato de possuírem grande potencial, e muitas dessas empresas necessitam de pouquíssimo investimento. Algumas como a Perestroika iniciaram com apenas $\mathrm{R} \$ 300$ e estão a mais de 5 anos no mercado dando cursos sobre criatividade. Este modelo é favorável ao Brasil, não só pela baixa necessidade de capital, mas pelo fato de que este ramo tem atraído investidores e profissionais em todo lugar na busca do próximo negócio de sucesso. Entretanto, um grande número de empresas Startup tem seu fim em estado ainda embrionário.

O risco é um fator comum em todas as atividades, seja de negócio ou do cotidiano. Brigham e Houston (1999) definem o risco como a "chance de que ocorra um evento desfavorável". Uma área de grandes expectativas como as Startups, tem integrada a incerteza. Um estudo feito pela Época (2016) aponta que 74\% das startups no Brasil fecham após cinco anos, enquanto 67\% encerram suas atividades entre dois a cinco anos de funcionamento.

Com esse crescimento constante das startups e a grande quantidade que morrem devido à incerteza de mercado e a má gestão dos riscos envolvidos, se faz necessário um bom gerenciamento dos mesmos para seu desenvolvimento.

Este trabalho visa não somente apontar as incertezas e riscos mais comuns ligadas à essas novas empresas, mas também identificar algumas estratégias mais utilizadas quando se inicia uma startup e descrever possíveis soluções para as dificuldades encontradas, como suavizar, ou até mesmo, contorná-las.

\section{REVISÃO DE LITERATURA}

\subsection{EMPREENDEDORISMO}

O empreendedorismo é a arte de tornar algo realizável com motivação e criatividade. Consiste em assumir um comportamento proativo e um aproveitamento total das competências racionais e intuitivas de um empreendedor.

Foi em 1942 que o economista Joseph Schumpeter utilizou esta palavra para associar o empreendedor ao desenvolvimento econômico. Os economistas sabem que o empreendedor é vital para este desenvolvimento. Segundo Francisco e Knebel (2014) há duas teorias ligadas ao empreendedorismo: a teoria econômica e a teoria comportamentalista. A teoria econômica é também conhecida como Schumpeteriana, onde ela afirma que foram os economistas que viram como o empreendedorismo era importante para a economia do país. A teoria comportamentalista está relacionada ao comportamento do ser humano; Max Weber viu que empreendedores tinham ideias inovadoras e independentes.

A expressão "empreendedorismo" foi originada da tradução da expressão entrepreneurship da língua inglesa que, é composta da palavra francesa entrepreneur e do sufixo inglês ship. E as definições podem ser descritas: Para Barreto (1998, p. 190) "empreendedorismo é habilidade de criar e constituir algo a partir de muito pouco ou de quase nada"; Para Dornelas (2008) o empreendedorismo significa fazer algo novo, diferente, mudar a situação atual e buscar, de forma incessante, novas oportunidades de negócio, tendo como foco a inovação e a criação de valor; Para Chiavenato (2004), "O empreendedor é a pessoa que inicia e/ou opera um negócio para realizar uma ideia ou projeto pessoal, assumindo riscos e responsabilidades e inovando continuamente"; Para Schumpeter (1988), é um processo de "destruição criativa", através da qual produtos ou métodos de produção existentes são destruídos e substituídos por 
novos

\subsection{PERFIL DE EMPREENDEDOR}

Ainda hoje se tem divergências de opiniões sobre porque o empreendedor surge, mas as diferentes opiniões chegam geralmente a duas opções: da necessidade do mercado ou necessidade de sobrevivência. Antigamente haviam três modelos de empreendedor: corporativo, startup e social definidos por Pessoa (2005), porém hoje há mais dois que são o ecoemprendedor segundo Bennet (1992) e o empreendedor tecnológico segundo o Instituto Euvaldo Lodi (2010).

a) Corporativo: usa de suas habilidades como empreendedor dentro de um negócio já existente, é também o mais comum dos empreendedore.

b) Startup: diferente do anterior cria novos modelos de negócio. Analisa o mercado e diante uma oportunidade cria sua própria versão de um negócio muitas vezes existente, porém de forma diferenciada. Tornando-se competitivo e superando a concorrência em diversos quesitos.

c) Social: suas habilidades vêm em busca não necessariamente de capital financeiro, mas para solucionar um problema social. É o tipo de empreendedor que muitas vezes fica entre o governo e a empresa privada, sendo um mediador para que suas ações impactem de forma positiva.

d) Ecoempreendedor: um elemento novo dessa classificação, e seu campo é nos modelos de negócio sustentáveis para o meio ambiente. Além disso, ele também encontra utilidade para as "sobras" dentro das empresas e gerando receita.

e) Tecnológico: o último e também muito parecido com o de startup, seu foco é a busca de um negócio dentro do mundo digital. Com o atual crescimento do mercado de tecnologia, as oportunidades são muitas, porém sua chance de sobrevivência nesse nicho não é maior eu a dos outros.

Ainda dentro do perfil empreendedor é preciso lembrar um nome de difícil tradução e sua real referência. O autor do livro Seth Godin comenta que a tradução literal de bootstrap é a alça de couro da bota que se usa para puxar. O Bootstrapping é aquele empreendedor corajoso, que decide seguir com sua empresa sem ajuda financeira externa, usando somente o capital próprio ou aquele que o negócio gerar. O tipo de empreendedor que opta pela própria paixão a sua sobrevivência. Um termo que faz todo sentido quando se fala de um empreendedor que puxa sua propria empresa. Ter sucesso sozinho já é dificil, quando se trata de startup é ainda mais desafiador. Em geral os bootstrappers são empreendedores experientes, de capacidade muito acima do comum e na maioria das vezes são outliers, pontos fora da curva. Casos famosos de bootstrappers são a Microsoft e a Dell. Apesar de parecer quase imposível ser um bootstrapper, o ideal é que no inicio de uma empresa, seja ela qual for, deve-se arriscar e tentar se tornar sustentável sozinho.

\subsection{MODELO DE NEGÓCIOS (CANVAS)}

Antes de falar sobre modelo de negócios, é necessário falar sobre plano de negócios, que é uma ferramenta detalhada sobre a empresa e facilita a tomada de decisão já que proporciona uma visão muito maior do mercado e possíveis ameaças ou oportunidades. Uma desvantagem clara é o seu tamanho, por ser muito especifico tornase denso e pode levar até meses para ser concluído, tempo este que para algumas empresas não apresenta ser nenhuma vantagem, sendo startup ou não.

O Canvas foi idealizado em 2004 por Alexander Osterwalder, mas foi em 2009 com a publicação do seu livro Business Model Generation (BMG) que ganhou destaque mundial e foi aderido por diversas empresas. O modelo de negócio auxilia sob condições de incerteza no mercado, ferramenta ideal para as startups que sempre se desenvolvem sob esta perspectiva. Todo modelo permite que se tenha uma visão ampla e dentro de uma única página de todo o negócio, tornando mais fácil sua leitura. Ela também gera compartilhamento de ideias e fornece um campo propicio para inovação. É dividido em nove etapas, são elas:

a) Segmento de Clientes: Uma vez que o objetivo é agradar ao cliente, é preciso definir o nicho de atendimento neste primeiro momento, agrupa-los segundo as necessidades e comportamentos similares. Um modelo de negócio pode se prender a um único tipo de cliente ou vários, cabe a organização decidir e ignorar aquilo que não condiz com a escolha.

b) Proposta de Valor: O valor está intimamente ligado aos benefícios que o serviço ou 
produto irá gerar. De acordo com as necessidades dos clientes cria-se um conjunto de características para satisfazer essas vontades.

c) Canais: É através dele que a empresa define por qual caminho irá entregar o valor ao cliente. Ele expande o conhecimento do cliente sobre os benefícios, auxilia na avaliação da empresa e dá suporte estratégico. Para Osterwalder e Pigneur (2011), os canais possuem cinco fases (conhecimento, avaliação, compra, entrega e pós-venda), além disso, podem possuir canais próprios ou de parceiros.

d) Relacionamento com o cliente: Neste bloco se define as estratégias para que os clientes não procurem os concorrentes por diversos motivos. Um dos pontos mais difíceis para se definir, já que cada cliente pensa de uma forma diferente. Algumas empresas optam por autoatendimento, onde o cliente tem controle sobre tudo, porém ter um contato mais próximo com o cliente garante melhores reações.

e) Fontes de receita: Forma que o cliente irá pagar pelo benefício adquirido. Dois tipos são conhecidos: receita de transação que é feita através de um único pagamento ou receitas recorrentes, onde se englobam assinaturas, aluguéis e etc. Dentro deste bloco é muito comum haver diversas formas de pagamento, há sete categorias de fonte de renda: venda de ativos, taxas de uso, taxa de inscrição, empréstimo, licenciamento, taxa de corretagem e propaganda (OSTERWALDER \& PIGNEUR, 2011).

a) Recurso-chave: São os ativos fundamentais para o modelo de negócios funcionar. Descreve-se aquilo que realmente é significativo dentro da empresa.

b) Atividades-chave: Similar aos recursos, são as ações mais significativas para que 0 modelo de negócio tenha êxito.

c) Parcerias-chaves: Alianças feitas com competidores ou não, visando o crescimento do negócio e a força entre comprador e fornecedor, garantindo confiança, menor custo e otimização do serviço.

d) Estrutura de custos: Principal função é avaliar o modelo de negócio e estimar os principais custos na geração do valor pretendido.

Figura 1 - Modelo Estrutural Canvas.

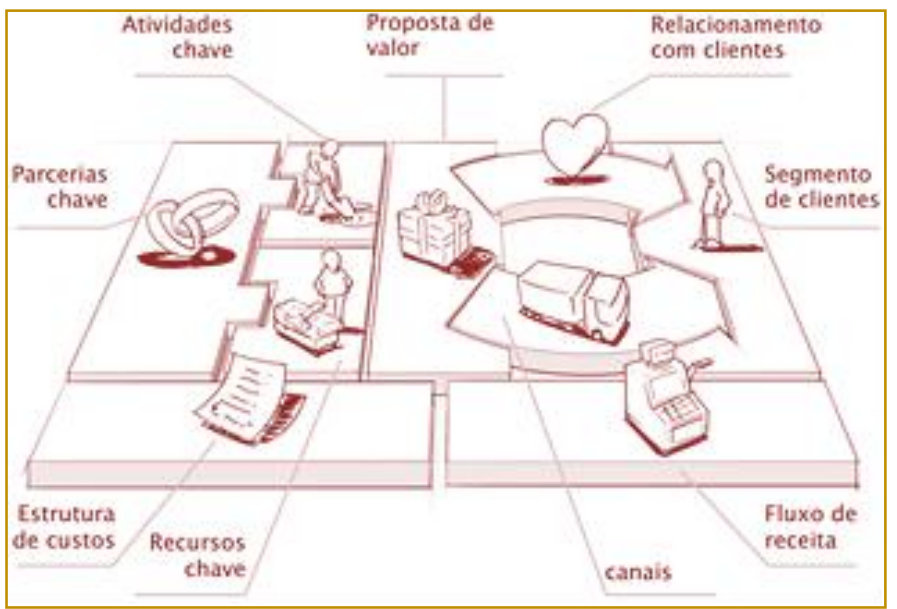

Fonte: Osterwalder (2009).

\subsection{LEAN STARTUP}

O Lean Startup foi criado por Eric Ries em 2011, é um conjunto de práticas para auxiliar diversos empreendedores a terem maiores chances de sucesso durante 0 desenvolvimento de suas empresas. Traz em sua essência as primícias que aumentar a frequência de contato com os clientes permite que a empresa siga pelo rumo correto, diminuindo os riscos e custos desnecessários. O conceito se divide em três partes fundamentais: Visão, Direção e Aceleração. Onde a visão vem definir o que é uma startup e como medir seu progresso. A segunda parte é identificar o ciclo básico de feedback construir-medir-aprender, com o objetivo de construir algo minimamente viável e verificar a reação dos clientes. Por último ele levanta 
técnicas que permitirão acelerar o processo de feedback, além de analisar conceitos com o poder de pequenos lotes.

Dentro do tópico medir vem o grande diferencial dessa prática, pois em seu início as startups não conhecem de fato os clientes e em como seus produtos podem satisfazêlos. É comum se criar uma estratégia que iria, a princípio, solucionar um problema ou satisfazer uma necessidade, mas se não for baseada nos clientes, o mercado não o receberá com grandes expectativas. Quando o cliente interage com o produto, gera um feedback qualitativo e quantitativo, alimentando um banco de dados para correções futuras.

Figura 2 - Ciclo de Feedback Lean Startup.

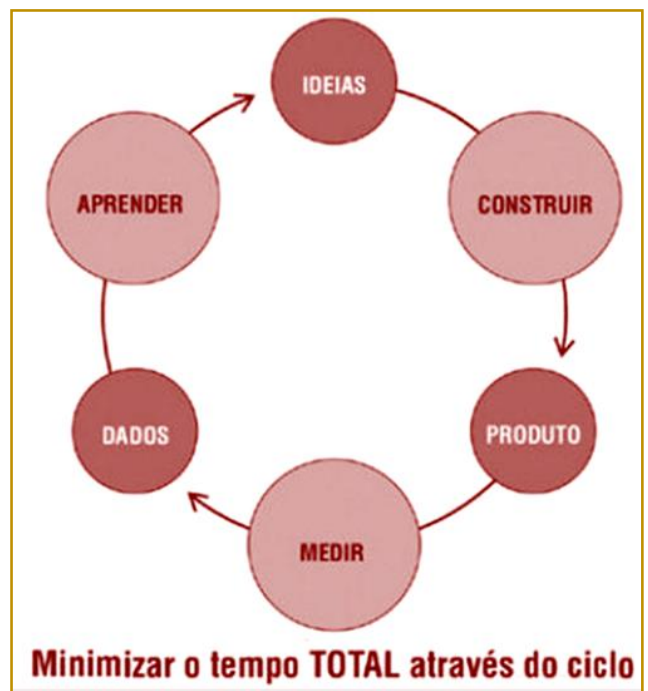

Fonte: Ries (2012).

A pratica do Lean Startup se baseia em se ter a ideia, construir um produto mínimo viável, medir, avaliar os resultados e novamente inserir ao ciclo para novas medições, é algo contínuo. Estas avaliações constantes acabam por reformular a ideia diversas vezes, mas garantem a redução de desperdícios e eliminam expectativas imprecisas do mercado.

Por fim e extremamente importante, o MVP (produto mínimo viável), permite a realização de testes rápidos dentro do mercado. O cliente quase sempre não sabe tudo que realmente quer num produto até ter o contato com o protótipo. A entrega de um pequeno lote para o cliente é a forma ideal para diminuir o risco da obsolescência precoce num mercado que não se interessou pelo produto ou serviço. A ideação é um processo muito utilizado quando se constrói um modelo de negócio, pois ele visa encontrar a novidade onde ninguém mais vê possibilidade de avanço, através do brainstorming. A Prototipagem é tornar aquilo que antes era abstrato em algo físico e simples para validar a ideia e acompanhar resultados.
Ries (2012) quando fala sobre crescer, descreve que todo crescimento deve ser sustentável, no sentido de que o crescimento não deve ser uma única explosão de sucesso, mas um crescimento constante não isolado e de longo prazo. Ele define que há quatro principais maneiras de crescimento: boca a boca, efeito colateral na utilização do produto, publicidade financiada e compra ou uso repetido. As fontes que alimentam o ciclo ele chama de motores, que é como um motor de combustão, girando repetidas vezes, quanto mais rápido o ciclo é completado, mais rápido a empresa crescerá. O cliente é peça principal e está conectado a três classificações de motores: recorrente, viral e pago.

Recorrente: A taxa de aquisição de novos clientes deve sempre superar a taxa de rotatividade dos mesmos, ou seja, além de buscar por novos clientes a empresa deve procurar fazer de tudo para manter os clientes já conquistados.

Viral: A pessoa transmite a outra sem perceber, pelo simples fato de usá-lo, por exemplo o Facebook, uma vez que a pessoa 
se torna usuário do produto, ele automaticamente envia convites a seus colegas como um vírus.

Pago: Quando a receita gerada for superior ao custo de adquirir um novo cliente, se reinveste em publicidade e os novos clientes financiam o ciclo. Para aumentar sua taxa de crescimento basta aumentar a receita ou reduzir o custo de aquisição.

Deste modo a startup pode definir medições especificas para seus motores de negócio e acompanhar o real crescimento da mesma. Geralmente investe-se em um único motor para não causar confusão, mas a mudança de motores pode ocorrer sempre que a empresa necessitar. Através desta prática que é o Lean Startup pode definir um ritmo de crescimento, criar padrões de desenvolvimento, estabelecer prioridades quanto ao feedback, otimizar entregas para avaliações e focar no cliente que é o verdadeiro potencializador da empresa, além de é claro, reduzir custos significativos.

\subsection{INCUBADORAS}

A incubação é um processo onde empresas fornecem infraestrutura física, técnica e administrativa em prol do desenvolvimento da startup e que pode ser ativado sempre que necessário. Entretanto, este dinheiro no Brasil é geralmente dinheiro público, então para conseguir financiamento das mesmas, é necessário passar por um processo mais burocrático, além de ter um produto mais próximo da realização do que algum ainda em desenvolvimento.

Existem três estágios de incubação:

A pré-incubação diz respeito às atividades gerais necessárias para apoiar o empreendedor em desenvolvimento de sua ideia, modelo de negócio e plano de negócio, para aumentar as chances de chegar a uma criação de startup eficaz. Geralmente, implica uma primeira avaliação da ideia e treinamento direto, além da assistência necessária para colocar o cliente nas condições de escrever um plano de negócios totalmente completo. As incubadoras associadas à universidade geralmente são pré-incubadoras.

A incubação diz respeito ao apoio dado ao empresário desde o início até a expansão. Normalmente, é um processo de médio prazo e durante os três primeiros anos de atividade da empresa. Que são os anos em que é seguro dizer se o novo empreendimento é bem-sucedido e tem uma boa chance de se tornar uma empresa totalmente madura. As ações ativadas geralmente são o acesso aos serviços de finanças, coaching direto e mentoria, bem como serviços de hospedagem e treinamento específico. Portanto, a incubação física, embora um serviço muito importante, é um subconjunto dos processos gerais de incubação.

Pós-incubação, refere-se às atividades a serem realizadas quando a empresa atingiu a fase de maturidade e, está pronto para caminhar com seus próprios pés. É o momento em que foi fisicamente incubado, e a empresa deixa de ter suporte da incubadora. Vários serviços ainda podem ser prestados para incrementar suas vendas ou melhorar seus processos produtivos, como serviços de internacionalização ou introdução de inovação através de atividades de pesquisa e detecção. As incubadoras posicionadas como "pós incubadoras" em algum momento se renomeiam como "aceleradoras".

\subsection{ACELERADORAS}

O modelo de aceleradoras é um exemplo da recente mudança para o foco intangível, com conhecimento intensivo e serviços de suporte em incubação. Uma aceleradora é uma organização, que visa acelerar a criação de novos empreendimentos, proporcionando educação e orientação para empreendimentos durante um período Cohene \& Hochberg, 2014. Embora o modelo da aceleradora inclua serviços intangíveis, como mentoria e networking, tem um número significativo de outros recursos específicos que o separam dos modelos de incubação. Primeiro, eles não são principalmente projetados para fornecer recursos físicos e serviços de suporte de escritório durante um longo período. Em segundo lugar, eles normalmente oferecem um pré investimento, geralmente em troca de equivalência patrimonial. Em terceiro lugar, eles são menos focados em capitalismo de risco, mas são mais estreitamente ligados aos investidores anjos e a uma pequena escala individual de investidores.

Existem algumas similaridades ou atividades realizadas pelas aceleradoras que também são desempenhadas pelas incubadoras ou pelos investidores anjos. Isto porque todas 
ajudam a desenvolver novos empreendimentos. No entanto, a diferença crucial seria a duração limitada dos programas de aceleração em comparação à natureza contínua dos programas oferecidos por incubadoras ou investidores anjo. Esta diferença conduz a muitas outras.

Tabela 1 - Diferenças Chaves entre Incubadoras, Investidores e Aceleradoras.

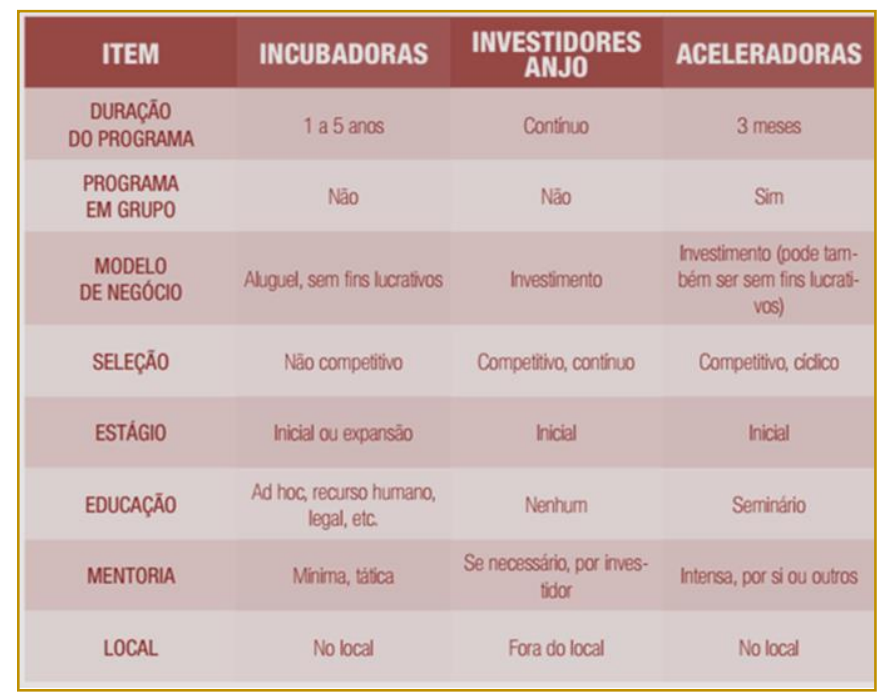

Fonte: COHEN 2013 (ADAPTADO).

\section{APRESENTAÇÃO E DISCUSSÃO DOS RESULTADOS}

O maior risco que uma Startup pode sofrer é criar um produto que ninguém tenha interesse, um problema muito comum.

Uma publicação do site Grandes Empresas \& Pequenos Negócios em março de 2017 mostra que a meta do SEBRAE, SESI e SENAI era dar apoio financeiro para 284 negócios inovadores. Isto significa que centenas de novos negócios estão surgindo a todo instante e a grande maioria quer fazer do seu negócio um sucesso o mais rápido possível.

Existe hoje um ranking mundial, feito por um grupo de experts que acompanham as novas tendências e fazem um relatório para curiosos e investidores: a Startup Genome, que é um esforço colaborativo global para ajudar todos os lugares do planeta a nutrir e manter estes ecossistemas prósperos na inicialização tecnológica. Seus insights, reunidos com mais de 10 mil empresas iniciantes e 300 organizações parceiras, fornecem um ponto de partida para fundadores, empregadores e líderes locais em mais de 50 cidades em todo o mundo para tomar decisões precisas e oportunas que impulsionem a inovação e o crescimento econômico.

Para que mais startups prosperem, é preciso entender as influências subjacentes ao sucesso. O Startup Genome faz referência aos ecossistemas de inicialização, combinando a análise de dados com insumos dos fundadores, para fornecer conhecimento que capacitará as regiões a construir um consenso para ação e atrair comunidades de inicialização saudáveis.

Em 2015, o SEBRAE fez uma pesquisa para avaliar as principais dificuldades que 0 ecossistema sofre numa busca de encontrar melhorias para o crescimento saudável das startups paulistas. Para o objetivo deste trabalho iremos focar nas principais dificuldades encontradas. Foram entrevistados diversos empreendedores e investidores. Segundo a pesquisa, do ponto de vista dos empreendedores o maior problema era em relação ao modelo de negócio, seguido pelas relações com recursos humanos, finanças, ao produto e outros. 
Tabela 2 - Porcentagens Relacionadas as Dificuldades.

\begin{tabular}{|l|}
\hline $79 \%$ Relacionadas ao modelo de negócio \\
$44 \%$ Dificuldade de planejamento e execução \\
$41 \%$ Validar a ideia com o mercado \\
$39 \%$ Estruturar a ideia no papel \\
$38 \%$ Dificuldade para vender a ideia \\
$62 \%$ Relacionadas aos Recursos Humanos \\
$56 \%$ Reunir pessoas "experts" e comprometidas \\
$60 \%$ Relacionadas a finanças \\
$59 \%$ Dificuldade de financiamento \\
$42 \%$ Relacionadas ao produto e serviço \\
$39 \%$ Como construir um protótipo \\
$4 \%$ Relacionadas ao mercado \\
$8 \%$ Relacionadas ao marketing \\
$6 \%$ Relacionadas à aspectos pessoais \\
$2 \%$ Gestão do Negócio
\end{tabular}

Fonte: Sebrae (2015)

Dentre as mais diversas ferramentas existentes, o CANVAS é o mais utilizado pelas startups, principalmente pelo fato de ser rápido e prático, podendo ser alterado sem dificuldades .

Figura 3 - Top 20 Reasons Startups Fail.

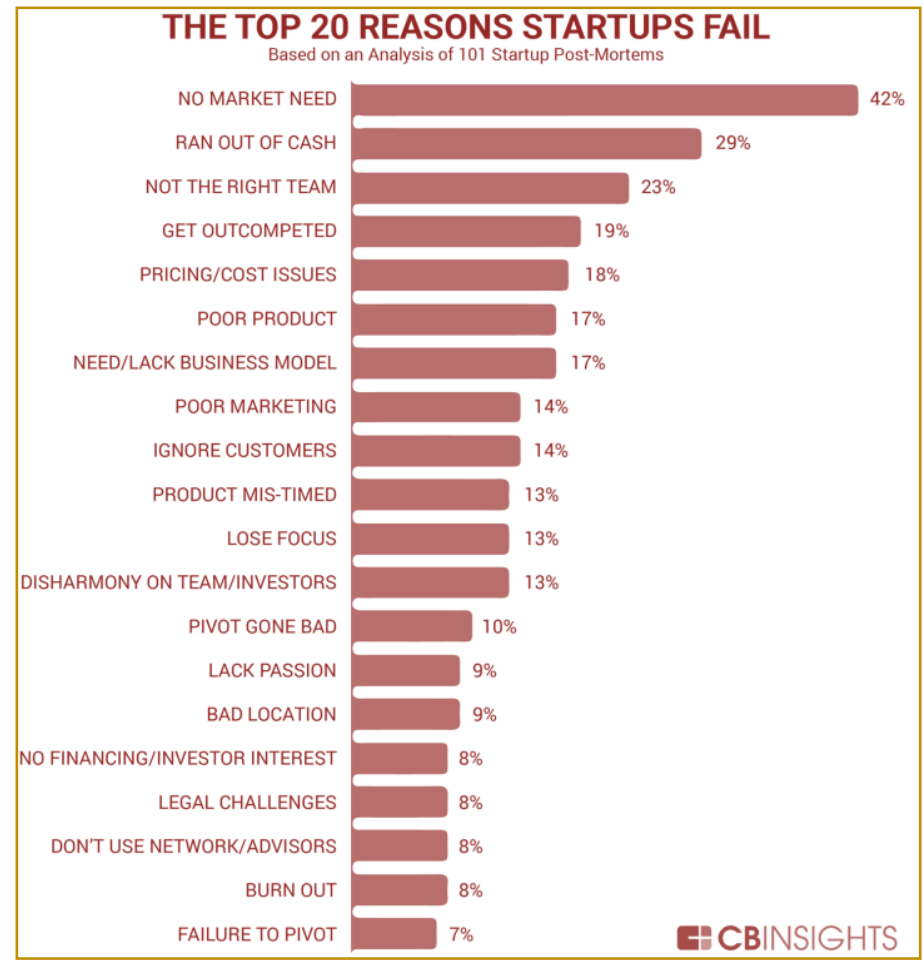

Fonte: CB Insights (2017)

A FGV também foi responsável por fazer um levantamento de dados quanto as startups brasileiras e dentro de sua pesquisa fez um levantamento dos principais pontos buscados por aceleradoras antes de selecionarem uma startup para investir. 
Figura 4 - Relevância dos Componentes do Bussines Model Canvas para as Aceleradoras.

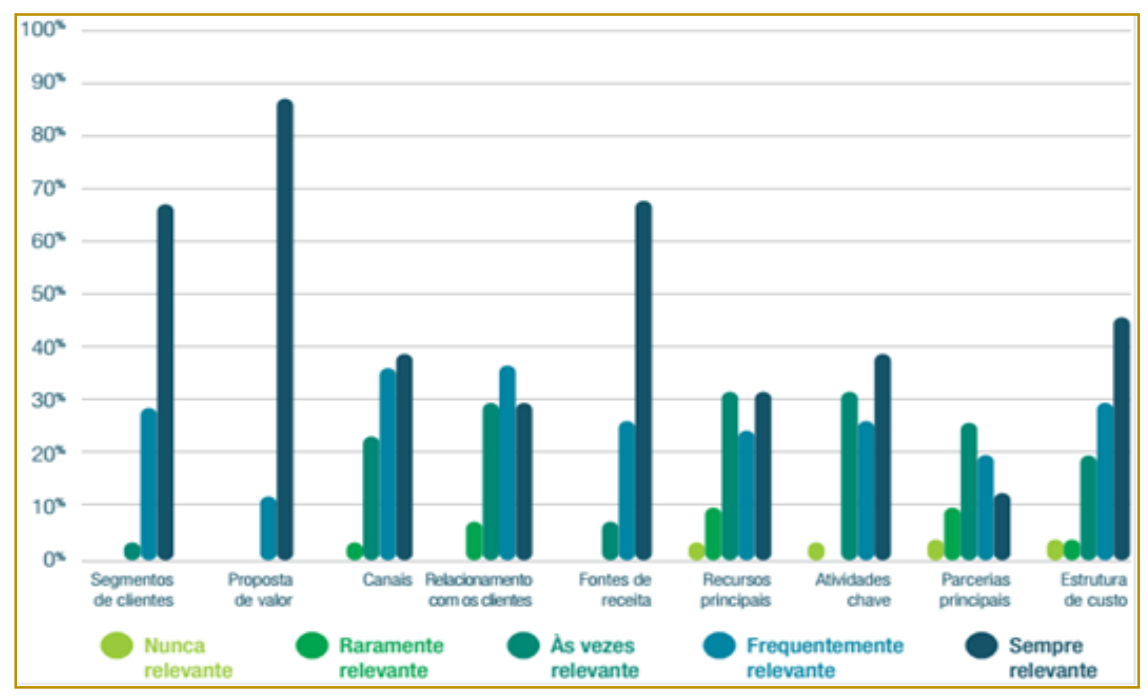

Fonte: FGV (2016).

As aceleradoras que são em muitos casos essenciais para o crescimento, têm foco proposta de valor, fonte de receita e segmento de cliente como principais componentes, além disso, canais e relacionamentos com o cliente, os dados mostram que jamais são considerados como "nunca relevantes". E na prática as aceleradoras têm preferência por startups que já possuam um protótipo funcional, diferente das no exterior segundo Campos, 2015.

Quando comparados os dados da FGV com os do SEBRAE, percebe-se que $O$ planejamento sofre dificuldades de desenvolvimento logo no início da montagem do modelo, algumas metodologias iniciam o CANVAS pelo segmento de cliente, enquanto outros pela proposta de valor, ou seja, os empreendedores têm uma boa ideia, mas no momento de descrever a proposta no papel a ideia já começa a apresentar problemas.

A segunda dificuldade identificada pelo SEBRAE é quanto aos recursos humanos, ou seja, os profissionais que estão envolvidos no projeto. São Paulo é um ecossistema mundialmente conhecido e ainda sim é comum encontrar equipes mal organizadas. No momento de selecionar equipes é necessário que a mesma seja multidisciplinar e proativa.

Figura 5 - Principais Fatores de não Seleção das Aceleradoras.

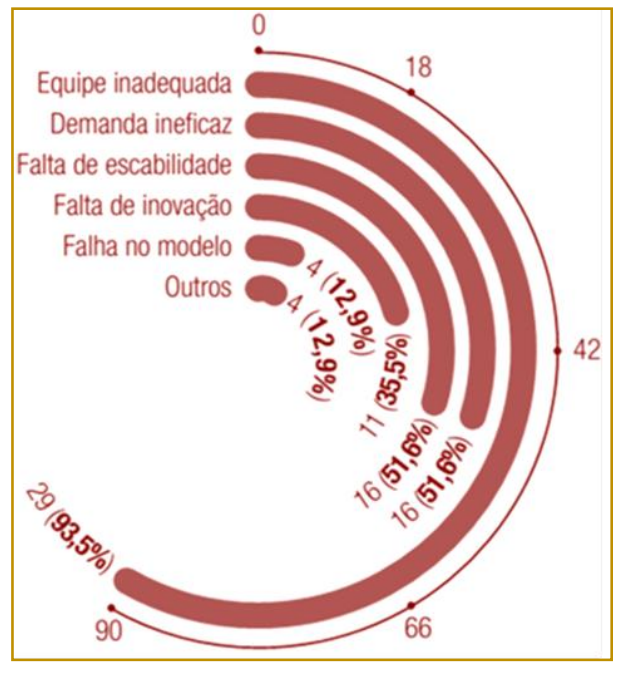

Fonte: FGV (2016). 
Parece um problema brasileiro, mas é um problema também mundial, ocupa o terceiro lugar, de acordo com a CB Insights, uma aceleradora privada em New York.

O próximo item levantado pelo SEBRAE são as finanças, e neste processo tem-se opções de levantar capital como um bootstarpping, procurar um investidor anjo ou como Miller e Bound (2011) comentam, uma incubadora ou aceleradora. A execução de um arranque está associada a elevados riscos e muitas vezes requer mais financiamento do que os fundadores da startup podem providenciar. Portanto, eles precisam se conectar com os investidores que podem fornecer capital conforme diz Arundale 2012, pois cedo ou tarde o negócio vai necessitar de investimento para alavancar. Importante destacar ainda que os investimentos têm valores bem diferentes quando comparados de forma global. Uma pesquisa feita pela aceleradora Global Accelerator Report 2016, que fornece informações para investidores e curiosos, cede um olhar interno exclusivo dos programas de aceleração em todo o mundo. Mesmo em projetos sem um produto mínimo viável, consegue-se um investimento entre 5 mil a 20 mil dólares em média, e as aceleradoras brasileiras investem de $\mathrm{R} \$ 45$ mil a $R \$ 255$ mil nas startups segundo Campos (2015). O verdadeiro problema apontado nas startups externas é o investimento não ser suficiente para se alcançar um produto escalável.

Há ainda segundo o SEBRAE, problemas menos significativos relacionados ao mercado, ao marketing, aspectos pessoais e gestão de negócio. Estes não tiveram o mesmo impacto que os anteriormente comentados, porém foram adicionados a pesquisa.

\section{REFERÊNCIAS}

[1] Arundale, K (2010) Guide to Private Equity. London: BVCA.

[2] Barreto, L. O, (1998). Educação para o empreendedorismo. Educação Brasileira.

[3] Blank, Steve. Customer Development at Startup2Startup. Disponível em $<$ https://www.slideshare.net/sblank/customerdevelopment-at-startup2startup $>$. Acesso em 01/05/2017.

[4] Brigham, E. F.; Houston, J. F. Fundamentos da moderna administração

\section{CONSIDERAÇÕES FINAIS}

O trabalho apresentou de forma breve as principais dificulades encontradas pelas startups para o seu desenvolvimento sustentável. Dentre todas as dificuldades encontradas, a maior foi a falta da necessidade do mercado para o produto. Infelizmente muitas startups constroem coisas que as pessoas não querem com a esperança irracional de que elas as convencerão. É preciso avaliar seu produto corretamente, identificar os hábitos do mercado e então suprir a real necessidade presente, estas são ações mínimas para qualquer arranque de sucesso. Com essas informações, pode-se perceber que é necessário um planejamento minucioso, além de uma pesquisa quanto aos clientes, colaboradores e fornecedores.

O conhecimento em diversos processos torna o empreendedor mais criativo e com uma visão maior do próprio mercado. A engenharia de produção sai um passo à frente neste quesito por dar ao aluno ainda na graduação uma visão global de uma empresa, levando-o ainda na universidade a reconhecer o fluxo do desenvolvimento no mercado industrial, financeiro, sustentável e inovador.

O empreendedorismo é dentre as mais diversas profissões a que mais impacta a sociedade. Aqueles que buscam ter sua própria startup terão um longo caminho a percorrer, não só pela dificuldade e riscos comum em se empreender no país, mas por estar num segmento relativamente novo e com muitas incertezas, mas o verdadeiro empreendedor não se abala por estáticas, ele dribla os obstáculos um a um e continua até alcançar o tão desejado sucesso.

financeira. Tradução Maria Imilda da Costa e Silva. Rio de Janeiro: Campus, 1999.

[5] Bootstrappers. Disponível em $<$ http://www.sethgodin.com/sg/docs/bootstrap. pdf> . Acesso 22/10/2017.

[6] Campos, Newton M. The myth of the idea: and the upsidedown startup. Charleston, SC: Createspace, 2015

[7] CB Insight. Disponível em <http://www.earlypad.com/7-reasons-startupsrequire-market-research/>. Acesso 30/10/2017.

[8] CB Insight. Disponível em 
<http://www.earlypad.com/7-reasons-startupsrequire-market-research/>. Acesso 30/10/2017.

[9] Cohen, S., Hochberg, Y.V., 2014 Accelerating startups: The Seed Accelerator Phenomenon. Disponível em $<$ http://seedrankings.com/pdf/seed-acceleratorphenomenon.pdf>. Acesso 25/10/2017.

[10] Cohen, Susan. What Do Accelerators Do? Insights from Incubators and Angels, 2013. Disponível http://www.mitpressjournals.org/doi/pdf/10.1162/IN OV_a_00184>. Acesso 25/10/2017.

[11] Chiavenato, I. (2004). Empreendedorismo: dando asas ao espírito empreendedor. São Paulo: Saraiva.

[12] Dornelas, J. C. A. (2008). Empreendedorismo: transformando ideias em negócios. Rio de Janeiro: Elsevier .

[13] Gitahy, Yuri. O que é uma startup? Empreendedor Online - Empreendedorismo na Internet e negócios online, 2011. Disponível em $<$ http://www.empreendedoronline.net.br/o-que-euma-startup/>. Acesso em: 20/04/2017.

[14] Grandes Empresas \& Pequenos Negocios. Disponível

<http://revistapegn.globo.com/Startups/noticia/201 7/03/startups-terao-r-536-milhoes-do-senai-dosebrae-e-do-sesi.html>. Acesso 17/10/2017.

[15] GUST. Disponível em < http://gust.com/accelerator_reports/2016/global/>. Acesso 11/11/2017.

[16] Instituto Euvaldo Lodi (2010). Empreendedorismo: ciência, técnica e arte.
Brasília: CNI.IEL. Nacional .

[17] Miller, Paul And Bound, Kirsten (2011). Disponível em <https://www. nesta.org.uk/publications/startup-factories>. Acesso 24/10/2017.

[18] Osterwalder, Alexander; Pigneur, Yves. Business Model Generation. Hoboken, USA: John Wiley \& Sons, 2011.

[19] Pessoa, E (2005). Tipos de Empreendedorismo: semelhanças e diferenças. Disponível em $<$ http://www.administradores.com.br/informese/artigos/tipos-deempreendedorismosemelhancas-ediferencas/10993 >. Acesso em: 01/05/2017.

[20] Ries, Eric. A Startup Enxuta: como os empreendedores atuais utilizam a inovação contínua para criar empresas extremamente bemsucedidas. 1a. São Paulo: Leya, 2012.

[21] Sebrae. Disponível em <http://www.sebrae.com.br/sites/PortalSebrae/cana is_ adicionais/conheca_quemsomos $>$. Acesso $1 \overline{7} / 10 / 2017$

[22] Schumpeter, J. A. (1988). A teoria do desenvolvimento econômico. São Paulo, Nova Cultura .

[23] ZOOB. Disponível em <https://imagesna.ssl-images-amazon.com/images /G/15/aplusautomation/vendorimages/d8e3b4d1e111-4092-8bbde49b65ac8c5e.jpg ._CB281990229_.jpg>. Acesso 22/10/2017. 


\section{Capítulo 9}

\section{ASPECTOS DA GESTÃO DA QUALIDADE NO BENEFICIAMENTO DO CAFE: ESTUDO DE CASO SOBRE A APLICAĊ̃̃O DA GESTÃO DA QUALIDADE TOTAL}

\section{Dayane Menezes Bessa}

Paulo Renato Pakes

Guilherme Mendes de Souza

Aline Okumoto Gomes

Brena Bezerra Silva

Vivian Karina Bianchini

Resumo: A Gestão de Qualidade Total (GQT) ou Total Quality Management (TQM), é uma das maiores preocupações das empresas na atualidade, sejam elas de produtos ou serviços. A conscientização e o reconhecimento de sua importância tornou-a indispensável para as empresas de todo o mundo. Indispensável esta, pois, aumenta a satisfação e a confiança dos clientes, reduz custos, aumenta a produtividade, melhora a imagem da empresa, além de possibilitar a conquista de novos mercados. Deste modo, esta pesquisa buscou verificar como se estruturam as práticas da gestão da qualidade total adotados a uma empresa que tem como enfoque a Torrefação de café. Com os resultados coletados através de um estudo de caso foi possível analisar a importância dos princípios e ferramentas do TQM para a empresa, verificar a classificação da empresa em relação ao mercado e propor possíveis melhorias.

Palavras-chave:Produtividade, Gestão,Qualidade, Produção,Café. 


\section{INTRODUÇÃO}

Atualmente há uma grande demanda por produtos práticos e saudáveis pelos consumidores, e o principal requisito para a compra de produtos e a fidelidade dos clientes, é sem duvida a qualidade entregue pelas empresas. Portanto, as empresas vivem se preocupando quanto à qualidade de seus produtos e serviços prestados, utilizando de estratégias, técnicas e ferramentas do TQM com intuito de estar sempre um passo a frente de seus concorrentes e melhor satisfazer os clientes.

Ao se tratar do café, essa realidade não é diferente. Introduzido no Brasil no inicio do século XVIII, o processo da torra do café era realizada em propriedades pessoais, principalmente em fogões a lenha. Qualquer pessoa podia fazer esse trabalho sem se preocupar com a fiscalização. Por essa razão os Sindicatos das Indústrias de Café de diversos estados viram na formação de uma entidade nacional, uma melhor forma de negociar com o governo o estabelecimento de políticas de real interesse do setor. Dessa forma em 1973 foi criada a Associação Brasileira de Indústria de Café - ABIC, que representa as indústrias de torrefação $e$ moagem de café de todo o país. Em 1989 a ABIC lançou o Programa de Autofiscalização da Indústria de Café, mais conhecido como Selo de Pureza $A B I C$, tendo como principal missão o compromisso com a qualidade do produto (ABIC, 2018).

Toledo et al. (2014) relata que a Gestão da Qualidade Total (GQT), se desenvolveu a partir do momento em que a gestão da qualidade em uma organização como um todo começou a ter importância. Os autores ainda definem a TQM como uma filosofia de gestão baseada no princípio de melhoria contínua de produtos e processos com a finalidade de atender as necessidades de todos os clientes, independente das fases do ciclo de vida dos produtos, com relação a qualidade, custos, entrega, serviços etc., conforme passa-se a considerar a qualidade total e não somente a qualidade strictu senso do produto.

A importância da gestão da qualidade da organização levou ao desenvolvimento das teorias e práticas mais evoluídas, denominada Gestão da Qualidade Total (GQT) ou, em inglês, Total Quality Management (TQM).
Inicialmente o termo qualidade era associado aos termos técnicos dentro da produção, e posteriormente foi voltado para a satisfação total do cliente. O surgimento deste conceito deu-se durante o período do Fordismo no início dos anos 50.

Com base nesse contexto, este artigo tem como objetivo explorar os processos de uma indústria de café no interior do estado em Minas Gerais, evidenciando quais são os conceitos da Gestão de Qualidade Total adotados pela empresa. Para isso, foi realizado um estudo de caso único.

\section{QUALIDADE}

$\mathrm{Na}$ qualidade existem duas dimensões. A qualidade de dimensões objetivas, voltada para a especificação do elemento e a qualidade de dimensões subjetivas, referente à percepção das pessoas em relação às características objetivas e subjetivas da entidade (SHEWHART, 1931).

Durante a década de 50, o conceito de qualidade era crucial, pois os técnicos e engenheiros associavam suas visões na dimensão objetiva, para obter máxima qualidade em seu desempenho, priorizando sempre o desempenho técnico, durabilidade, ausência de defeitos, fazendo assim com que tanto as empresas, como clientes, se beneficiem dos produtos produzidos, tendo em mente que para a satisfação de ambas as partes são necessárias a aniquilação de todos os defeitos (TOLEDO et al., 2014).

Em meados dos anos 50 e 60, houve mudanças no conceito de qualidade. Com o surgimento de autores que propuseram novas visões sobre o termo qualidade - os famosos "Gurus da Qualidade" transformaram as ideias e pensamentos dos conceitos de qualidade apresentados até aquele momento, e influenciaram de maneira positiva em como melhora-la consideravelmente. Agora a ideia de qualidade não era somente a produção de produtos de alto desempenho sem falhas, nem produtos com alto conforto ou de alta tecnologia, muito menos de designs bonitos e estilosos, porque em muitas das vezes isso não era uma necessidade a ser saciada na visão dos clientes, sua nova meta e visão de qualidade era visar a pura necessidade e satisfação dos clientes, tendo por base na figura 1 abaixo. 
Figura 1: Definições dos Gurus da Gestão da Qualidade

\begin{tabular}{|l|l|}
\hline Deming & $\begin{array}{l}\text { Qualidade é um termo relativo que vai mudando de significado à } \\
\text { medida que as necessidades dos clientes evoluem }\end{array}$ \\
\hline Juran & $\begin{array}{l}\text { Associa à ideia de "adequação ao uso" e satisfação das necessidades } \\
\text { do cliente }\end{array}$ \\
\hline Crosby & $\begin{array}{l}\text { Conformidade com especificações; zero defeitos e fazer certo da } \\
\text { primeira vez }\end{array}$ \\
\hline Feigenbaum & $\begin{array}{l}\text { Caracteristica do produto que proporciona a satisfação total do } \\
\text { consumidor durante seu uso }\end{array}$ \\
\hline Ishikawa & $\begin{array}{l}\text { Qualidade é processo no qual envolve o produto de qualidade de } \\
\text { forma que seja econômico, útil e traz satisfação ao consumidor }\end{array}$ \\
\hline
\end{tabular}

Fonte: Elaborado a partir de Toledo et al. 2014

Garvin (1992) em seus conhecimentos defende a tese de que existem cinco conceitos para que se alcance o nível superior da qualidade, que são eles: Transcendental, baseado no produto, baseado no usuário, baseado na fabricação e baseado no valor, como é exemplificado na figura 2 abaixo.

Figura 2: Abordagens da qualidade

\begin{tabular}{|c|c|}
\hline Enfoque & Definição \\
\hline Transcedental & $\begin{array}{l}\text { Qualidade é sinônimo de "excelência nata". É absoluta e universalmente reconhecível. } \\
\text { Entretanto, a qualidade não poderia ser precisamente definida, pois ela é uma propriedade } \\
\text { simples e não analisável, que aprendemos a reconhecer somente através de experiência. }\end{array}$ \\
\hline $\begin{array}{ll}\text { Baseado } & \text { no } \\
\text { Produto } & \end{array}$ & $\begin{array}{l}\text { A qualidade é definida como uma variável precisa, mensurável e dependente do conteúdo } \\
\text { de uma ou mais características do produto. As diferenças na qualidade entre produtos } \\
\text { concorrentes seriam reflexo de diferenças qualitativas e quantitativas nas características } \\
\text { desses produtos, não no sentido da variedade de características, mas do valor intrínseco da } \\
\text { característica. }\end{array}$ \\
\hline $\begin{array}{l}\text { Baseado } \\
\text { Usuário }\end{array}$ & $\begin{array}{l}\text { Este enfoque parte da premissa, oposta à anterior, de que a qualidade está nos "olhos" e } \\
\text { preferências do consumidor. A qualidade estaria associada a uma visão subjetiva, baseada } \\
\text { em preferências pessoais. }\end{array}$ \\
\hline $\begin{array}{l}\text { Baseado na } \\
\text { Fabricação }\end{array}$ & $\begin{array}{l}\text { O enfoque baseado na fabricação identifica a qualidade como "conformidade com as } \\
\text { especificações". Uma vez que uma especificação de projeto tenha sido estabelecida, } \\
\text { qualquer desvio significa redução na qualidade. }\end{array}$ \\
\hline $\begin{array}{l}\text { Baseado no } \\
\text { Valor }\end{array}$ & $\begin{array}{l}\text { Aqui se define qualidade em termos de custos e preços. De acordo com esse enfoque, um } \\
\text { produto de qualidade é aquele que no mercado apresenta desempenho esperado a um preço } \\
\text { aceitável, e internamente à empresa apresenta conformidade a um custo aceitável. }\end{array}$ \\
\hline
\end{tabular}

Fonte: Garvin, 2002

Toledo (2014) diz que de acordo como enfoque transcendental, qualidade é sinônimo de "excelência nata", e que a qualidade de determinado objeto apenas deveria ser definida após realizar intensivamente a aplicação do mesmo, demonstrando suas reais características no decorrer do tempo e para muitos usuários. Para o enfoque Baseado no Produto, o autor afirma que a qualidade é descrita como uma variável precisa, mensurável, além de ser dependente de uma ou mais características do produto. Esse enfoque possibilita a classificação segundo as características desejadas que possuam dos produtos concorrentes. Já o enfoque baseado no usuário, associa a qualidade a uma visão mais subjetiva, baseada em preferências pessoais, supondo que os produtos que mais atendem as necessidades dos clientes, são aqueles considerados como tendo alta qualidade. O enfoque baseado na produção ou (fabricação) é descrito pelo autor como a identificação da qualidade como "conformidade com especificações", encontrando excelência em qualidade com o atendimento de especificações e com "fazer certo a primeira vez", ou seja, produzir dentro das especificações sem precisar de retrabalho ou recuperação do produto. Por fim, o enfoque baseado no valor, onde o autor define que qualidade está relacionada aos custos e preços. Ainda com relação a este enfoque, um produto que possua qualidade, é aquele que perante o mercado realiza as funções esperadas e que possui um preço acessível, e internamente à organização apresenta conformidade a um custo acessivel.

\section{ERAS DA GESTÃO DA QUALIDADE}

O desenvolvimento do TQM surgiu da necessidade de resolver problemas relativos a discrepâncias entre os processos de pesquisa, má interpretação das necessidades de consumidores em termos de projetos, documentações inadequadas de projetos, 
desvios de planejamento de processos, falta de informações precisas para fornecedores e produção e a falta de sintonia entre as funções produção, marketing e vendas (MIRANDA, 1994).

Para Toledo (2014), a gestão de qualidade, aborda a adoção de conjuntos de práticas utilizadas pela empresa na obtenção de lucro, sendo de forma eficiente e eficaz, ou seja, a qualidade desejada para o produto.

As definições e abordagens atuais sobre gestão de qualidade são os frutos de décadas de aperfeiçoamento das práticas de gerenciamento, que foram discutidas na época por grandes autores nos Estados Unidos e no Japão, tendo assim a obtenção de resultados naturais na evolução dos objetivos, foco e métodos para a qualidade.

Segundo Toledo et al. (2014), houve uma evolução no modo de verificar a qualidade do produto, o que antes passava por verificações de qualidade, somente ao fundar o produto, por decorrência das inspeções e controle de qualidade, observou-se que havia necessidade de adicionar mais verificações ao longo do processo de fabricação sendo assim baseado nos conceitos de A Era das Qualidades descrita por Gavin, definindo quatro fases de verificação, que são elas: $A$ Era da Inspeção da qualidade; A Era do Controle de Qualidade do Processo; A Era da Garantia da Qualidade; A Era do Gerenciamento Estratégico.

Figura 3- Eras da Qualidade.

\begin{tabular}{|c|c|c|c|c|c|}
\hline \multirow{2}{*}{$\begin{array}{l}\text { IDENTIFICAÇ̃̃o DAS } \\
\text { CARACTERISTICAS }\end{array}$} & \multicolumn{5}{|c|}{ ERAS DA QUALIDADE E DESCRIÇÃO DAS CARACTERÍSTICAS } \\
\hline & $\begin{array}{l}\text { Inspeção do } \\
\text { Produto }\end{array}$ & Controle do processo & Sistema de gestão/garantia & Gerenciamento estratégico & Futuro \\
\hline $\begin{array}{l}\text { Período da Era da } \\
\text { Qualidade }\end{array}$ & \begin{tabular}{|l|}
$\begin{array}{l}\text { Décadas de } 1910 \text { a } \\
1930\end{array}$ \\
\end{tabular} & Décadas de 1940 e 1950 & Décadas de 1960 e 1970 & Décadas de 1980 e 1990 & Década de 2000 em diante \\
\hline Objetivo da Qualidade & $\begin{array}{l}\text { Deteç̧̃̃o de não } \\
\text { conformidades }\end{array}$ & $\begin{array}{l}\text { Controle de processos de } \\
\text { fabricação }\end{array}$ & $\begin{array}{l}\text { Coordenação dos processos de } \\
\text { fabricação, confiabilidade e } \\
\text { manutenabilidade }\end{array}$ & Impacto estratégico da qualidade & $\begin{array}{l}\text { Impacto social, econômico e } \\
\text { ambiental. }\end{array}$ \\
\hline $\begin{array}{l}\text { Preocupação básica ou } \\
\text { visão da Qualidade }\end{array}$ & $\begin{array}{l}\text { Verificação/Um } \\
\text { problema a ser } \\
\text { resolvido }\end{array}$ & $\begin{array}{l}\begin{array}{l}\text { Controle/Um problema a } \\
\text { ser resolvido }\end{array} \\
\end{array}$ & $\begin{array}{l}\text { Coordenação/Um problema a ser } \\
\text { resolvido, mas que seja enfrentado } \\
\text { pró-ativamente }\end{array}$ & $\begin{array}{l}\text { Impacto estratésico/Uma } \\
\text { oportunidade de concorrência }\end{array}$ & $\begin{array}{l}\text { Impacto social, econômico e } \\
\text { ambiental/Uma oportunidade de } \\
\text { diferenciação }\end{array}$ \\
\hline Ênfase da Qualidade & $\begin{array}{l}\text { Uniformidade do } \\
\text { produto }\end{array}$ & $\begin{array}{l}\text { Uniformidade do produto } \\
\text { com menos inspeçãoe } \\
\text { fornecimentode peças } \\
\text { uniformes }\end{array}$ & 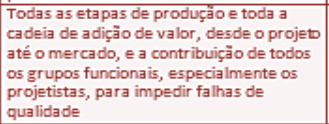 & $\begin{array}{l}\text { As necessidades de mercado e do } \\
\text { consumidor }\end{array}$ & $\begin{array}{l}\text { As necessidades da sociedade, do } \\
\text { mercado e do consumidor }\end{array}$ \\
\hline Métodos da Qualidade & \begin{tabular}{|l|} 
Inspeção da \\
produção e \\
Instrumentos de \\
medição \\
\end{tabular} & $\begin{array}{l}\text { Instrumentos e técnicas } \\
\text { estatisticas }\end{array}$ & Programa e sistemas & $\begin{array}{l}\text { Planejamentoestratégico, } \\
\text { estabelecimento de objetivos e a } \\
\text { mobilização da organização }\end{array}$ & $\begin{array}{l}\text { Métodos e ferramentas } \\
\text { estatísticas sofisticadas, prática da } \\
\text { inovação e capacitação de pessoal }\end{array}$ \\
\hline $\begin{array}{l}\text { Papel dos profissionais } \\
\text { da Qualidade }\end{array}$ & $\begin{array}{l}\text { Inspeção, } \\
\text { classificação, } \\
\text { contagem e } \\
\text { avaliaçã̃o }\end{array}$ & $\begin{array}{l}\text { Solução de problemas e a } \\
\text { aplicaçãa }\end{array}$ & $\begin{array}{l}\text { Mensuração da qualidade, } \\
\text { planejamento da qualidade e projeto } \\
\text { de programas }\end{array}$ & $\begin{array}{l}\text { Esta belecimento de objetivos, educaçäo } \\
\text { e treinamento, traba lho consultivo com } \\
\text { outros departamentos e delineamento } \\
\text { de programas }\end{array}$ & $\begin{array}{l}\text { Estabelecimento de objetivos, } \\
\text { educaçąo e treinamento, trabalho } \\
\text { consultivo com outros atores da } \\
\text { cadeia produtiva }\end{array}$ \\
\hline $\begin{array}{l}\text { Quem é o responsável } \\
\text { pela qualidade }\end{array}$ & $\begin{array}{l}\text { O departamentode } \\
\text { inspeção }\end{array}$ & $\begin{array}{l}\text { Os departamentos de } \\
\text { produção e engenharia }\end{array}$ & $\begin{array}{l}\text { Todos os departamentos, embora a alta } \\
\text { gerência só se envolva perifericamente } \\
\text { com o projeto, op planejamento e a } \\
\text { execuçăo das polticas da qualidade }\end{array}$ & $\begin{array}{l}\text { Todos na empresa, com alta } \\
\text { gerência exercendo forte liderança }\end{array}$ & Todos na cadeia de produção \\
\hline $\begin{array}{l}\text { Orientação da } \\
\text { Qualidade }\end{array}$ & $\begin{array}{l}\text { Em direção ao } \\
\text { produto }\end{array}$ & Em direção ao processo & Em direção ao sistema & $\begin{array}{l}\text { Humanistica, em direção à } \\
\text { sociedade, ao custo e ao } \\
\text { consumidor }\end{array}$ & $\begin{array}{l}\text { Relacional entre atores da cadeia } \\
\text { de produção }\end{array}$ \\
\hline $\begin{array}{l}\text { Caráter ou base de } \\
\text { atuação da Qualidade }\end{array}$ & Técnico & Técnico & Técnico & Estratégico e humano & Humano e social \\
\hline $\begin{array}{l}\text { Abordagem ou enfoque } \\
\text { da Qualidade }\end{array}$ & $\begin{array}{l}\text { Inspeciona, } \\
\text { comprovaa } \\
\text { qualidade }\end{array}$ & Controla a qualidade & Constrói ou produz a qualidade & Gerencia a qualidade & $\begin{array}{l}\text { Coordena a qualidade na cadeia } \\
\text { de produção }\end{array}$ \\
\hline Função comprometida & $\begin{array}{l}\text { Produção e } \\
\text { controle do } \\
\text { produto acabado }\end{array}$ & $\begin{array}{l}\text { Produção e projetos do } \\
\text { produto e do processo }\end{array}$ & Projetos e outras funções & $\begin{array}{l}\text { Toda a organização e gestão da } \\
\text { empresa e da cadeia de produção }\end{array}$ & $\begin{array}{l}\text { Gestão da integrada da cadeia de } \\
\text { produção e do relacionamento } \\
\text { com a sociedade }\end{array}$ \\
\hline
\end{tabular}

Fonte: Toledo et al. (2014).

De acordo com Bon e Mustafa (2013), a GQT se refere a um conjunto de métodos e técnicas para sustentar a melhoria contínua e satisfazer as demandas dos clientes. Já para Sadikoglu e Olcay (2014), a GQT é um sistema de gestão com a filosofia de melhorar continuamente a qualidade dos produtos, serviços e processos, focando a atenção nos clientes, atendendo as necessidades e expectativas para melhorar a satisfação do cliente e o desempenho da empresa.

Destacam-se então os princípios fundamentais do TQM, para o sucesso na gestão da qualidade total da empresa. 
Figura 4- Quadro de princípios do TQM

\begin{tabular}{|c|c|}
\hline \multicolumn{2}{|r|}{ PRINCÍPIOS DO TQM (Total Quality Management) } \\
\hline Príncipio & Descrição \\
\hline Foco no Cliente & $\begin{array}{l}\text { As organizaçốes dependem de seus clientes e, portanto, precisam identificar as } \\
\text { necesidades atuais e futuras dos cliente }\end{array}$ \\
\hline $\begin{array}{l}\text { Liderança e apoio } \\
\text { da alta } \\
\text { administração }\end{array}$ & $\begin{array}{l}\text { Os líderes estabelecem unidade de propósito e o rumo da organização. Convém } \\
\text { que eles criem e mantenham um ambiente interno, no qual as pessoas possam } \\
\text { estar totalmente envolvidas no propósito de atingir os objetivos da organização }\end{array}$ \\
\hline $\begin{array}{l}\text { Envolvimento das } \\
\text { pessoas }\end{array}$ & $\begin{array}{l}\text { As pessoas são a essência de uma organização. Deve-se buscar o total } \\
\text { envolvimento das pessoas para a satisfação das expectativas das partes } \\
\text { interessadas na organização }\end{array}$ \\
\hline $\begin{array}{l}\text { Abordagem de } \\
\text { processo }\end{array}$ & $\begin{array}{l}\text { Um resultado desejado é alcançado mais eficientemnte quando as atividades e os } \\
\text { recursos relacionados são gerenciados como um processo }\end{array}$ \\
\hline Melhoria Contínua & Deve-se buscar a melhoria contínua do desempenho global da organização \\
\hline \begin{tabular}{|l|}
$\begin{array}{l}\text { Abordagem factual } \\
\text { para tomada de } \\
\text { decisão }\end{array}$ \\
\end{tabular} & Decisões eficazes são balanceadas na análise de dados e informações \\
\hline $\begin{array}{l}\text { Relação com os } \\
\text { fornecedores }\end{array}$ & $\begin{array}{l}\text { Uma organização e seus fornecedores são interdependentes. Portanto, devem } \\
\text { estabelecer uma relação de benefícios mútuos para aumentar a capacidade de } \\
\text { ambam para agregar valor }\end{array}$ \\
\hline
\end{tabular}

Fonte: Toledo et al. (2014) adaptada pelo autor

Conforme Aquilani et al. (2017), a ideia central da abordagem de GQT é que a qualidade esteja presente no gerenciamento organizacional como um todo, não se limitando às atividades inerentes ao controle da qualidade. Além disso, compreende o gerenciamento das relações entre todos os envolvidos com a existência da empresa, não se restringindo ao relacionamento com o cliente, o que inclui os colaboradores, os fornecedores e a própria sociedade, em sentido local e amplo.

\section{MÉTODO DE PESQUISA}

Os métodos de pesquisa devem serpensados como uma estrutura e orientação geral para condução de uma investigação (BRYMAN,
1989). Para esta pesquisa o método escolhido em função de sua adequação com a abordagem e contingências da pesquisa foi o estudo de caso.

Segundo Yin (2010), o estudo de caso é uma forma de investigação empírica que busca responder as perguntas "Como" ou "Porque" sobre um conjunto contemporâneo de acontecimentos. A essência de um estudo de caso é esclarecer uma decisão ou um conjunto de decisões.

Ainda segundo Yin (2010), o estudo de caso é uma forma de se fazer pesquisa social empírica ao investigar-se um fenômeno atual dentro do contexto de vida-real, onde as fronteiras entre o fenômeno e o contexto são claramente definidas na situação em que fontes de evidências são usadas.

Figura 5 - Etapas realizadas no estudo de caso

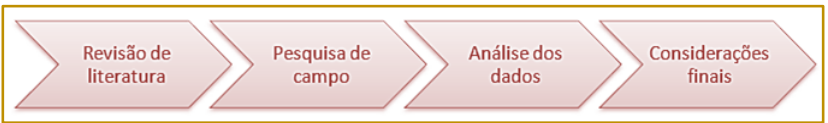

Fonte: Elaboraçãoprópria

\subsection{REVISÕES DE LITERATURA}

Para a construção deste artigo, houve o estudo sobre teorias existentes a respeito da qualidade, gestão da qualidade e gestão da qualidade total e sua implementação em ambientes empresariais, com base em artigos, livros e dados online.

O objetivo principal deste artigo é entender a teoria e verificar a eficácia de sua aplicação através do estudo de caso.

\subsection{PESQUISA DE CAMPO}

Após a revisão de literatura, foram abordados os tópicos na empresa para a pesquisa de campo. As informações foram obtidas por meio de entrevistas aplicadas aos funcionários da empresa, onde as mesmas foram realizadas com o auxílio do responsável do setor de qualidade. 


\subsection{ANÁLISE DOS RESULTADOS}

Após a coleta dos dados, foram realizadas comparações com a teoria escolhida para a elaboração do estudo de caso. Com base em Toledo et al. (2014), elaboraram-se sete proposições acerca da prática da GQT:

> H1: Se a empresa adotou a GQT, é provável que tenha adotado práticas de gestão voltadas ao foco no cliente;

\section{$>$}

H2: Se a empresa adotou a GQT, é provável que tenha adotado práticas voltadas à liderança e apoio da alta administração;

> H3: Se a empresa adotou a GQT, é provável que tenha adotado práticas voltadas ao envolvimento de pessoas;

> H4: Se a empresa adotou a GQT, é provável que tenha adotado a abordagem de processos;

> H5: Se a empresa adotou a GQT, é provável que tenha adotado a melhoria contínua;
> H6: Se a empresa adotou a GQT, é provável que tenha adotado a abordagem factual de tomada de decisão;

> H7: Se a empresa adotou a GQT, é provável que tenha adotado práticas na relação com fornecedores.

\subsection{CONSIDERAÇÕES}

Nessa etapa, foram feitas as considerações relevantes sobre o resultado do trabalho, elaboração e publicação do artigo.

\section{RESULTADOS}

\subsection{APRESENTAÇÃO DE CASO}

A empresa escolhida como alvo de estudo está inserida no setor alimentício, com atividades voltadas ao processamento e comercialização de café, sendo uma das pioneiras no ramo, estando a mais de 30 anos no mercado.

A empresa conta com um quadro de sete funcionários, como mostra a tabela 1 abaixo:

Tabela 1 - Quadro de funcionários

\begin{tabular}{|c|c|}
\hline Quantidade & Função \\
\hline 1 & Auxiliar Administrativo \\
\hline 2 & Vendedor \\
\hline 2 & Preparação \\
\hline 2 & Produção \\
\hline \multicolumn{2}{|c|}{ Fonte: Elaboração própria } \\
\hline
\end{tabular}

Seus principais clientes são supermercados, hotéis, padarias, ou qualquer outro tipo de comercio da cidade ou região.

\subsection{ANÁLISE DAS PROPOSIÇÕES}

H1: Se a empresa adotou a GQT é provável que tenha adotado práticas de gestão voltadas ao foco no cliente.

Foi possível verificar esta hipótese e constatála como válida. No intuito de "ouvir" seus clientes, a empresa possui um canal virtual de sugestões e reclamações onde é possível receber um feedback, tanto de seus clientes (supermercados, padarias), quanto dos consumidores finais, no que tange a percepção de qualidade do seu produto (café). Além do mais, a empresa previne insatisfação de consumidores, no que se refere ao sabor do produto, utilizando como estratégia a compra dos grãos de café durante o período de colheita, nos meses de abril a junho, quando os grãos são de melhor qualidade, e realizando inspeção criteriosa destes grãos. Nesse sentido, a empresa mantém uma padronização de seus produtos.Desta forma, um cliente que toma o café hoje, sentirá o mesmo sabor ao tomá-lo em 10 anos.

H2: Se a empresa adotou a GQT, é provável que tenha adotado práticas voltadas à liderança e apoio da alta administração.

Foi possível verificar esta hipótese e constatála como válida. Considerando que a empresa é por natureza familiar e de pequeno porte e considerando também que os proprietários criaram uma cultura de participação de seus funcionários foi possível analisar o comprometimento da equipe, no que se refere às práticas de qualidade e sobre a importância de fazê-las presentes em toda a empresa. Os proprietários disseminaram a 
importância da qualidade na empresa. Estão sempre próximos do processo de fabricação, levantando os problemas de qualidade e propondo soluções de como eliminá-los.

H3: Se a empresa adotou a GQT, é provável que tenha adotado práticas voltadas ao envolvimento de pessoas.

Foi possível verificar esta hipótese e constatála como válida. Os funcionários, conhecedores de todo o processo de fabricação, são conscientizados sobre a importância da qualidade dos produtos e capazes de opinar e sugerir melhorias de qualidade. Os mesmos registram diariamente o que é feito pelo setor e os problemas surgidos durante os processos de fabricação café. Este registro permite aos demais funcionários o acesso ao que foi feito em um período de trabalho, tal como as atividades desenvolvidas e informações para tomada de decisões. Ademais, a aproximação com fornecedores também permite confiabilidade de entrega e qualidade do produto. Nesse sentido, o gerenciamento e controle sistêmico da qualidade associado à participação e competência de todos os envolvidos na empresa permite a melhoria contínua do produto, diminuição de custos de não qualidade, redução de variabilidades e aumento da qualidade do produto.

H4: Se a empresa adotou a GQT, é provável que tenha adotado a abordagem de processos.

Foi possível verificar esta hipótese e constatála como válida. A empresa possui processos bem definidos. Inicialmente é feito a aquisição da matéria prima. Neste momento já é realizado uma pequena seleção do produto. Posteriormente é encaminhada para separação de impurezas (pedras, cascas, etc.) onde é feito o beneficiamento do café. Após esse processo o café é encaminhado para a torra, onde é submetido a altos graus de temperatura até atingir a torra desejada. Depois esse grão é resfriado, moído e embalado. Desta forma o alimento é separado por lotes e estocado para venda. Cada processo é acompanhado de forma criteriosa para garantir a qualidade do produto.

H5: Se a empresa adotou a GQT, é provável que tenha adotado a melhoria contínua.

Foi possível verificar esta hipótese e constatála como válida. Atualmente, a empresa está buscando adquirir um novo maquinário. Ademais, preocupada com a qualidade de seu produto, a empresa buscou o selo ABIC (Associação Brasileira da Indústria de Café). Nesta associação o produto é monitorado continuamente, e qualquer alteração é comunicada a empresa para manter sua qualidade.

H6: Se a empresa adotou a GQT, é provável que tenha adotado a abordagem factual de tomada de decisão.

Foi possível verificar esta hipótese e constatála como válida. A principal decisão da empresa está relacionada a um relatório, de periodicidade semestral, contendo dados de inspeção do produto final que será comercializado. Para inspeção do produto é retirada uma amostra escolhida aleatoriamente, onde é encaminhada para centros de análise, no caso a ABIC e também a NUGAP (Núcleo Global de Análise e Pesquisa). Os dados são registrados e comparados com os anteriores para definir planos de melhoria da qualidade do produto e tomar decisões estratégicas coerentes com a situação atual da empresa.

H7: Se a empresa adotou a GQT, é provável que tenha adotado práticas em qualidade na relação com fornecedores.

Foi possível verificar esta hipótese e constatála como válida. Verificou-se a importância dos fornecedores para empresa, responsáveis em fornecer a matéria-prima principal: os grãos de café. A empresa mantém parceria com seus fornecedores, existindo nesta parceria confiabilidade na entrega e na qualidade dos grãos de café. No entanto, a empresa não exige certificação e também não preocupa conhecer as etapas do ciclo do café, visto que existem várias maneiras de identificar a qualidade. Avaliadores conseguem identificar a qualidade apenas pela cor ou pelo cheiro dos grãos.

\section{CONSIDERAÇÕES FINAIS}

O objetivo deste estudo foi identificar as práticas de qualidade de uma empresa de torrefação de café e relacioná-las à Gestão da Qualidade Total - GQT.

Através da pesquisa in locus, descobriu-se que há uma grande aplicação de práticas voltadas para a GQT. A empresa está em processo de melhoria e adequação no tangente ao controle de qualidade desde a aquisição da matéria prima até a elaboração do produto final, para que as condições do 
café nas diferentes fases do seu ciclo: matéria prima, processamento e produto final assegurem um padrão de identidade do alimento fornecido ao consumidor, culminando em um vinculo de credibilidade e confiabilidade, repercutindo numa situação de crescimento, sobrevivência e adequação ao processo da competição globalizada: minimizar desperdícios, promover qualidade e incentivar a capacidade criativa a conquistar o consumidor, assegurando o mercado. O envolvimento dos colaboradores, como os fornecedores e funcionários auxilia a empresa a alcançar melhores resultados dentro e fora do ambiente corporativo, principalmente quanto às estratégias de qualidade. Os proprietários criaram uma cultura de participação e disseminaram a importância da qualidade na empresa. A empresa possui processos bem definidos. Ademais, informações diárias sobre as atividades

\section{REFERÊNCIAS}

[1] Aquilani, B.; Silvestri, C.; Ruggieri, A.; Gatti, C.A systematic literature review on total quality management critical success factors and the identification of new avenues of research ",The TQM Journal,v. 29, n. 1, p. $184-213,2017$.

[2] Bryman, A. Research methods and organization studies. London: Unwin Hyman, London, 1989. 283 p.

[3] Bon, A. T.; Mustafa, E. M. A. Impact of total quality management on innovation in service organizations: Literature review and new conceptual framework. Elsevier: Malaysia, 2013.

[4] Garvin, D. Gerenciando a qualidade. Rio de Janeiro: Qualitymark, 1992. desenvolvidas e os problemas surgidos são registradas, os quais são importantes para tomada de decisão. No entanto, semestralmente um relatório de monitoramento da qualidade do produto é analisado e este é o principal contexto que gera decisões importantes para empresa.

Verificou-se que ainda há espaço para se trabalhar e ajustar fatores da empresa no quesito de qualidade. Dentre elas, seria interessante para a empresa saber a procedência de sua matéria prima, pois é impossível identificar se essa produção segue com a legislação determinada, como a Lei $n^{\circ}$ 10.831 que tem como objetivo a sustentabilidade ecológica, a minimização da dependência de energias não renováveis, dentre outros.

Colocar estudos futuros.

[5] Miranda, Roberto Lira. Qualidade total: rompendo as barreiras entre a teoria e a prática.2 ed. São Paulo: Makron Books, 1994.

[6] Shewhart, W. Economic Control of Quality of Manufactured Product, 1931.

[7] AssociaçãoBrasileira de Industria de Café, histórico institucional.Disponívelem: <http://abic.com.br/institucional/abic/>Acessoem 02/04/2018

[8] Toledo, J.C.; Borrás, M.Á.; Mergulhão, R.C.; Mendes, G.H.S. Qualidade: Gestão e Métodos. Rio de Janeiro: LTC, 2014.

[9] Yin, R. K. Estudo de caso: Planejamentos e Métodos. 3르. Porto Alegre: Bookman, 2010. 


\section{Gapítulo 10}

\section{APLICACÃO DA FILOSOFIA LEAN MANUFACTURING PARA MELHORIA DA PRODUTIVIDADE NA INDÚSTRIA DO SETOR AUTOMOBILISTICO.}

\section{Euclides Fernandes dos Reis \\ Marcio do Carmo Boareto \\ Luciana Vieira de Melo \\ Vagner Rosalem}

\section{Sara da Costa Fernandes}

Resumo: O Lean Manufacturing consolida uma abordagem abrangente que alinha à implementação de estratégias promovendo a melhoria dos processos e desempenho organizacional que direciona redução de custos e maximização de lucro. Neste contexto, o setor automobilístico possui uma grande importância, pois a produção enxuta através do Lean Manufacturing proporciona a melhoria na produtividade, qualidade e desenvolvimento de produtos. Este estudo possui o objetivo principal de discutir quais resultados foram alcançados, após a implementação de uma melhoria de processo na montadora de veículos no estado do Goiás. Para isto foi feito um estudo de caso através de uma análise documental que permitiu realizar uma análise comparativa relacionada a melhoria de processo na organização pesquisada. Identifica-se que houve sucesso na aplicação do pensamento Lean na montadora de veículos, pois sem nenhum investimento inicial, a aplicação do Lean trouxe redução no custo de pintura do veículo. A partir dessa melhoria, entende- se que a presente filosofia pode ser estendida para outras áreas da organização, o que consequentemente trará mais resultados dentro do processo produtivo.

Palavras chave: custos, veículos, produção. 


\section{INTRODUÇÃO}

É crescente a busca das organizações pela qualidade de produtos, serviços, processos e também a possibilidade de incremento significativo no desempenho organizacional, na mudança de cultura e no aumento do capital humano. Nesta perspectiva, as organizações buscam "a diminuição dos custos de produção a eliminação de desperdícios e a redução da variabilidade nos processos críticos para o negócio" (SANTOS e MARTINS, 2008, p. 43).

Relacionado a isto, o Lean Manufacturing desde a década de 1980 vem ganhando a apreciação das organizações na busca da competitividade através da "redução do tempo entre o pedido do cliente e a entrega por meio da eliminação de desperdícios". Isto ocorre através da identificação do que agrega ou não valor na expectativa do cliente: "a interligação das etapas necessárias à produção de bens no fluxo do valor, de tal modo que este avance sem interrupções, desvios, retornos, esperas ou refugos; e a operação deste fluxo puxada pela demanda" (SILVA, MIYAKE, BATOCCHIO e AGOSTINHO, 2011, p. 689). Isto direciona ao objetivo gerencial da organização na busca de processos eficientes e eficazes, com foco na criação de valor, redução de desperdícios e consequentemente de custos (MANN, 2005).

Sendo assim, o conceito Lean Manufacturing consolida uma abordagem abrangente que alinha à implementação de estratégias promovendo a melhoria do desempenho do negócio priorizando a melhoria contínua da qualidade de produtos e serviços, incremento da capacidade de inovação, reduzindo custos e desperdícios. Considerando suas implicações, essas ações organizacionais vêm ganhando cada vez mais destaque em todos os setores econômicos empresariais (SCHROEDER et al., 2002; SANTOS, 2006; SANTOS E MARTINS, 2008).

Neste contexto, o setor automobilístico é um importante segmento a ser estudado. Relacionado a isto, de acordo com Ghinato (1996), o sistema Toyota de Produção é uma referência como um sistema de produção enxuta. Um estudo de Womack, Jones e Ross (1992) sobre a indústria automobilística mundial evidencia que a produção enxuta através do Lean Manufacturing, proporciona a melhoria na produtividade, qualidade, desenvolvimento de produtos e explica o sucesso da indústria japonesa e de outras indústrias do mundo.

Considerando a representatividade da indústria automobilística para o cenário empresarial mundial e a abordagem do pensamento enxuto em diferentes processos como forma de melhoria de produtividade e redução de custos, identifica-se o interesse e a oportunidade deste estudo propor a seguinte questão: quais são os resultados alcançados após a implementação de um processo mais enxuto em uma montadora de veículos no estado de Goiás?

Neste sentido, este estudo possui o objetivo principal de discutir quais resultados foram alcançados, após a implementação de uma melhoria de processo na montadora de veículos em Goiás. O processo estudado está relacionado à pintura de carrocerias de veículos que pode ter direcionado o aumento de produtividade e consequentes reduções de custos de produção (TIGRE, 2006). Visando atingir este objetivo será feita análise documental que permitirá realizar uma análise comparativa relacionada a melhoria de processo na organização pesquisada.

\section{REFERENCIAL TEÓRICO}

\subsection{LEAN MANUFACTURING}

O termo "Lean" foi definido originalmente no livro "A Máquina que Mudou o Mundo" de Womack, Jones e Ross (1990), em um estudo sobre a indústria automobilística no mundo e o uso das práticas de produção enxuta do Sistema Toyota de Produção. De acordo com Womack e Jones (1996), os 5 princípios do Lean são:

1) Precisamente definir o que é valor, por produto e sob ótica do cliente;

2) Identificar o fluxo de valor para cada produto;

3) Fazer o valor fluir sem interrupções;

4) Puxar;

5) Buscar a perfeição.

As origens do Lean remetem ao Sistema Toyota de Produção, e para Ohno (1997), os pilares do SPT são: (i) automação, entendida como automação do toque humano, que se trata de direcionar máquinas, equipamentos e pessoas de autonomia necessária de parar a produção sempre que uma condição já estabelecida ou normal for atingida, como por 
exemplo, a quantidade produzida. Ou em condição anormal, como por exemplo, os desvios de padrão de qualidade desejado; (ii) Just-in-time: geração de estoque em níveis estritamente necessários ao sistema, de forma a produzir no tempo exato apenas a quantidade necessária de produtos.

Liker e Meier (2007) apontam os 4Ps que explicam os princípios da produção enxuta:

i) Philosophy (Filosofia): filosofia enxuta em que os líderes enxergam a empresa como uma forma de agregar valor aos clientes, à sociedade, comunidade e funcionários;

ii) Process (Processo): processos certos que geram resultados certos; iii) People \& Partners (Pessoas e Parcerias): pessoas e parcerias em desenvolvimento a longo prazo direcionando a geração de valor aos clientes; uma forma de gerar valor aos clientes é a organização desafiar seus funcionários a crescerem;

iv) Problem Solving (Solução de problemas): solução contínua da raiz dos problemas direciona à aprendizagem organizacional e à melhoria contínua.

Liker (2006) adiciona 14 reconhecidos princípios do Lean norteados pelos 4Ps apresentados, conforme demonstra a figura (1).

Figura 1: Os 4Ps e os 14 Princípios Lean

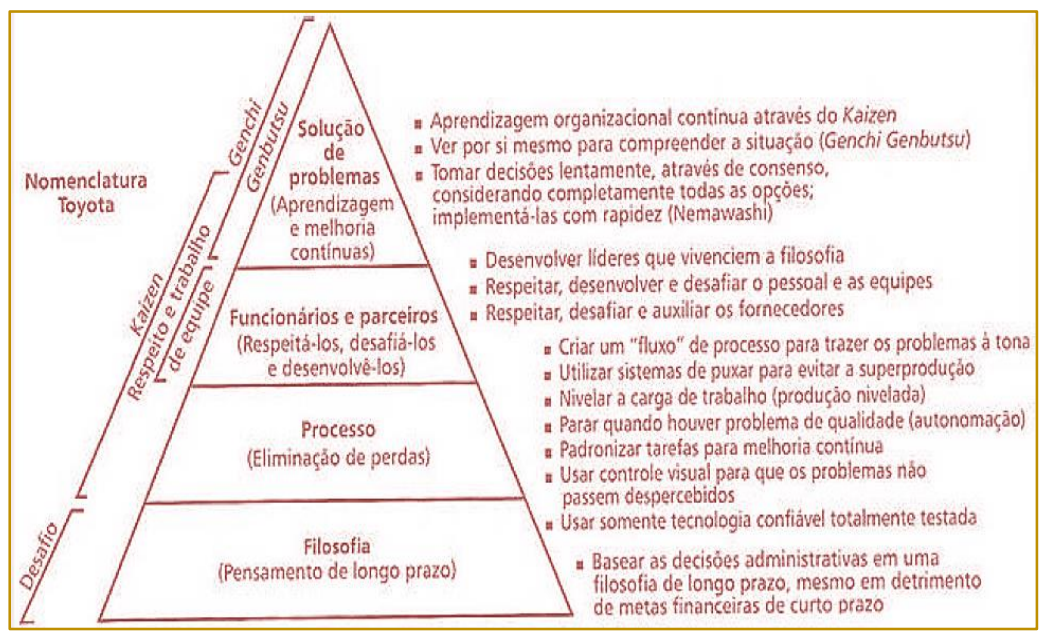

Fonte: Liker, 2006

Para Hopp e Spearman (2004), o Lean é um sistema que integra e realiza a produção de uma determinada organização usando o mínimo de estoques e baixos custos. Shah e Ward (2007) salientam que o Lean é um sistema sócio-técnico integrado com o principal objetivo de eliminar o desperdício com a simultânea redução da variabilidade em fornecedores, clientes ou dentro da empresa

Godinho e Fernandes (2004) definem a Manufatura Enxuta uma estratégia integrada de gestão que direciona a organização a certas situações do mercado e ajuda no alcance dos objetivos organizacionais de desempenho (qualidade e produtividade), sendo um modelo comporto por uma série de princípios (ideias, fundamentos e regras organizacionais) capacitores (ferramentas, tecnologias e metodologias utilizadas).

\section{METODOLOGIA}

Visando atingir o objetivo proposto, o presente trabalho apresenta um estudo de caso e demonstra o pensamento enxuto através do Lean Manufacturing aplicado dentro de uma montadora automobilística localizada no estado de Goiás. O estudo de caso é apropriado para investigar fenômenos in loco, e acontecimentos reais que tornam as características de um estudo evidentes. Sendo assim é a investigação dentro de um contexto da vida real em que os limites entre fenômeno e contexto são bem claros (YIN, 2015)

O estudo foi de caráter exploratório e natureza descritiva. Para Gil, (2012) a pesquisa exploratória proporciona uma visão geral do caso estudado aproximando-se assim de determinado fato. Para Malhotra (2011) a 
pesquisa descritiva estabelece relações com um determinado fenômeno sendo possível descrevê-los proporcionando uma visão especifica de algum problema.

A pesquisa possui uma abordagem qualitativa, pois pode proporcionar uma visão e compreensão melhor do problema em que a coleta de dados é analisada de forma interpretativa possibilitando uma aproximação da fonte de coleta de dados (MALHOTRA, 2011). Neste sentido, a pesquisa constitui um estudo de caso único com abordagem descritivo qualitativa.

Para análise de dados foi realizada a análise documental. Os documentos analisados foram planilhas eletrônicas (Excel 2010), descrições de layout, tempos de processo e custos de produção. Para Yin (2015) o uso de documentos colabora e valorizam as evidências, provenientes de uma determinada fonte.

Assim, será apresentada através da documentação, a fonte de evidências e informações possibilitando demonstrar como ocorreu a melhoria no processo através do Lean Manufacturing na montadora automobilística localizada no estado de Goiás.

\section{RESULTADOS E DISCUSSÕES}

A empresa sob investigação atua no mercado automobilístico, e possui os processos de Body- Shop (Solda de Carrocerias) Paint-Shop (Pintura de Carrocerias) e Trim-Shop (Montagem de Veículos). A empresa tem unidade de negócio no estado de Goiás, onde atua a mais de uma década. As transformações ocorridas no cenário industrial provocadas pela globalização impuseram a respectiva organização, novas maneiras, novos rearranjos produtivos, a fim de enfrentar a competividade imposta pelo atual mercado (HAYES et al., 2005).
Diante também de uma globalização que impacta no acirramento entre as organizações, a montadora BETA baseada no pensamento fundamentado no Lean Manufacturing: buscou realizar uma melhoria com objetivo de aperfeiçoar a eficiência do seu processo produtivo e que necessariamente provocasse redução nos custos operacionais e assim manter-se competitiva no mercado. Inserida neste contexto foi solicitado pela diretoria industrial da organização BETA à formação de uma equipe de trabalho de engenheiros, para investigar possíveis desperdícios no processo na área de pintura de carrocerias, que pudessem ser eliminados e assim reduzir o custo de fabricação do veículo.

O setor de pintura foi eleito por representar dentro do processo, o maior custo de fabricação do veículo. A equipe formada por engenheiros de produção, por sua vez, delimitou alguns equipamentos a serem investigados dentro do processo de pintura, que neste trabalho de Lean Manufacturing contemplou às estufas de primer e base/verniz por representar dentro do processo de pintura o maior custo com energia elétrica e gás liquefeito de petróleo (GLP).

O processo de pintura de carrocerias possui inicialmente a aplicação de primer, que consiste em fundo preparador de superfícies sobre a carroceria, e posteriormente o veículo segue para estufa de secagem para receber a cura do material aplicado sobre o automóvel. Ainda, na sequência do mesmo processo, logo após a secagem do primer é realizado a aplicação da base/verniz sobre a superfície metálica e novamente o veículo entra em uma nova estufa para secagem da base/verniz. Este processo possui duas estufas de primer e duas estufas de verniz, conforme apresentado na Figura (2).

Figura 2: Processo de aplicação de Primer e Base/Verniz

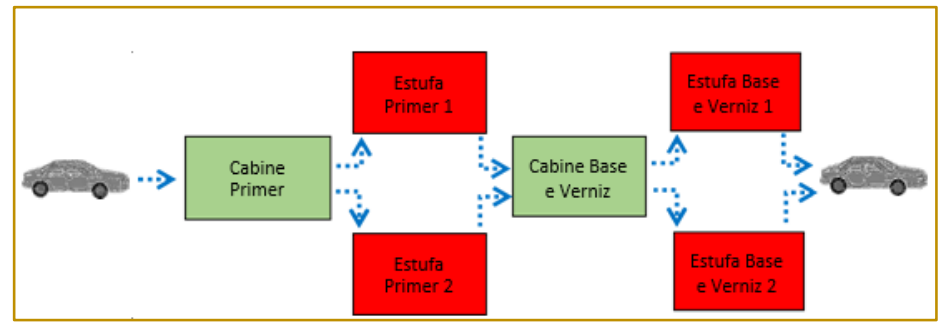

Fonte: Elaborado pelos autores 
A jornada da produção inicia a 07 horas e 20 minutos com término as 17 horas e 08 minutos. Contudo o início do processo das estufas ocorre antes das 07 horas, pois elas devem ser aquecidas para atingir o valor de temperatura nominal de processo. A tabela (1) apresenta os horários de funcionamento das estufas de Primer e Base/Verniz antes da melhoria.

Tabela 1: Horário de funcionamento das estufas

\begin{tabular}{l|c|c|c|c|c|c|}
\multicolumn{1}{c}{ Equipam. } & Start & $\begin{array}{c}\text { Tempo de } \\
\text { Aquecimento }\end{array}$ & $\begin{array}{c}\text { Início do } \\
\text { Processo }\end{array}$ & $\begin{array}{c}\text { Término do } \\
\text { Processo } \\
\text { / Início do } \\
\text { Resfriamento }\end{array}$ & $\begin{array}{c}\text { Tempo de } \\
\text { Resf. }\end{array}$ & $\begin{array}{c}\text { Término do } \\
\text { Resf. }\end{array}$ \\
\hline Estufa Primer & $05: 20$ & $02: 00$ & $07: 20$ & $15: 50$ & $01: 20$ & $17: 10$ \\
\hline Estufa Base/ Verniz & $05: 30$ & $01: 50$ & $07: 20$ & $15: 50$ & $01: 20$ & $17: 10$ \\
\hline
\end{tabular}

As estufas possuem controlador lógico programável (CLP), responsável pelo controle de todas as etapas do processo. Cada equipamento estava ajustado para 6 veículos por hora, totalizando 12 veículos por hora, com uma produção diária de 100 veículos. A tabela (2) apresenta a capacidade de processamento das estufas de pintura.

Tabela 2: Capacidade de processamento das estufas de pintura

\begin{tabular}{|c|c|c|c|}
\hline Equipamento & Veículos/ Hora & Horas / dia & Total de Veículos \\
\hline Estufas Primer & 12 & 8,5 & 102 \\
\hline Estufas Base/Verniz & 12 & 8,5 & 102 \\
\hline \multicolumn{3}{|c}{ Fonte: Elaborado pelos autores }
\end{tabular}

Para que haja o pleno funcionamento das estufas algumas fontes de energia são necessárias para operacionalizar os equipamentos em questão: energia elétrica e gás liquefeito de petróleo (GLP). $\mathrm{Na}$ organização objeto de estudo, o Quilowatthora (KWh) possui tarifas diferenciadas ao longo do dia,

sendo $R \$ 0,20$ das 00:00 ás 17 horas e 59 minutos e das 21 horas ás 23 horas e 59 minutos. O horário compreendido das 18 ás 21 horas, também denominado de Horário de
Ponta (HP) possui tarifa de $R \$ 1,50$. Já o GLP possui o custo de $\mathrm{R} \$ 3,50 \mathrm{Kg}$

O horário de Ponta sempre foi uma premissa para a organização não utilizar equipamentos de produção em função do custo. Neste horário basicamente apenas iluminação do pátio de veículos permanece ligada. A variável energia elétrica possuía assim relevância na análise. O custo mensal gerado pelo consumo de energia elétrica e GLP é descrito na tabela (3).

Tabela 3: Custo Mensal com Energia Elétrica e GLP

\begin{tabular}{|c|c|c|c|c|c|c|c|c|c|}
\hline Variável & Equipamento & Quant. & KWh & $\mathrm{KG} / \mathrm{h}$ & Hs. & $\begin{array}{l}\text { Dias } \\
\text { (Mês) }\end{array}$ & $\begin{array}{l}\mathrm{KWh} \\
(\mathrm{R} \$)\end{array}$ & $\begin{array}{l}\mathrm{Kg} / \mathrm{h} \\
(\mathrm{R} \$)\end{array}$ & $\begin{array}{c}\text { Custo Mensal } \\
(R \$)\end{array}$ \\
\hline \multirow[b]{2}{*}{$\begin{array}{l}\text { Energia } \\
\text { Elétrica }\end{array}$} & Estufa Primer & 2 & 250 & - & 12 & 20 & 0,2 & - & 24000 \\
\hline & $\begin{array}{c}\text { Estufa } \\
\text { Base/Verniz }\end{array}$ & 2 & 250 & - & 12 & 20 & 0,2 & - & 24000 \\
\hline \multirow[b]{2}{*}{ Gás (GLP) } & Estufa Primer & 2 & - & 48 & 10,5 & 20 & - & 3,5 & 70560 \\
\hline & $\begin{array}{c}\text { Estufa } \\
\text { Base/Verniz }\end{array}$ & 2 & - & 48 & 10,5 & 20 & - & 3,5 & 70560 \\
\hline \multicolumn{9}{|c|}{ TOTAL } & $\mathrm{R} \$ 189.120$ \\
\hline
\end{tabular}

Fonte: Elaborado pelos autores 
Em função de um volume diário menor que o projetado para o processo e que consequentemente ocasionava ociosidade dos equipamentos, os engenheiros de produção, investigaram a possibilidade de desligar uma estufa de primer e uma estufa de Base/Verniz. Para isso foi necessário duas ações: aumentar a velocidade do transportador de piso responsável pelo arraste dos veículos dentro das estufas elevando quantidade veículos processados de 6 para 9 veículos por hora e aumentar o tempo de processo, que anteriormente finalizava as 17 horas e 10 minutos e que após a melhoria de processo, o término passou a ser as 20 horas e 10 minutos. A tabela (4) ilustra os novos horários de funcionamento das estufas após a realização do pensamento Lean Manufacturing.

Tabela 4: Horário de funcionamento das estufas

\begin{tabular}{|c|c|c|c|c|c|c|}
\hline Equip. & Start & $\begin{array}{c}\text { Tempo de } \\
\text { Aquecimento }\end{array}$ & $\begin{array}{l}\text { Início do } \\
\text { Processo }\end{array}$ & $\begin{array}{c}\text { Término Processo } \\
\text { / Inicio do } \\
\text { Resfriamento }\end{array}$ & $\begin{array}{l}\text { Tempo de } \\
\text { Resf. }\end{array}$ & $\begin{array}{l}\text { Término do } \\
\text { Resf. }\end{array}$ \\
\hline Estufa Primer & $05: 20$ & 02:00 & $07: 20$ & $18: 50$ & 01:20 & 20:10 \\
\hline $\begin{array}{c}\text { Estufa } \\
\text { Base/Verniz }\end{array}$ & $05: 30$ & $01: 50$ & $07: 20$ & $18: 50$ & 01:20 & 20:10 \\
\hline
\end{tabular}

Fonte: Elaborado pelos autores

Após a melhoria fundamentada no pensamento Lean Manufacturing houve uma diminuição no custo de energia elétrica e gás
GLP de $R \$ 29.400$ ao mês. A tabela (5) demonstra os novos custos.

Tabela 5: Custo Mensal com Energia Elétrica e GLP

\begin{tabular}{|c|c|c|c|c|c|c|c|c|c|}
\hline Variável & Equipamento & Quant. & $\mathrm{KWh}$ & $\mathrm{KG} / \mathrm{h}$ & Hs. & $\begin{array}{l}\text { Dias } \\
\text { (Mês) }\end{array}$ & $\begin{array}{l}\mathrm{KWh} \\
(\mathrm{R} \$)\end{array}$ & $\begin{array}{l}\mathrm{Kg} / \mathrm{h} \\
(\mathrm{R} \$)\end{array}$ & $\begin{array}{l}\text { Custo Mensal } \\
\qquad(R \$)\end{array}$ \\
\hline \multirow{4}{*}{$\begin{array}{l}\text { Energia } \\
\text { Elétrica }\end{array}$} & \multirow{2}{*}{ Estufa Primer } & \multirow[t]{2}{*}{1} & \multirow[t]{2}{*}{250} & \multirow[t]{2}{*}{ - } & 12 & \multirow[t]{2}{*}{20} & 0,2 & \multirow[t]{2}{*}{-} & 12000 \\
\hline & & & & & 3 & & 1,5 & & 22500 \\
\hline & \multirow{2}{*}{$\begin{array}{c}\text { Estufa } \\
\text { Base/Verniz }\end{array}$} & \multirow[t]{2}{*}{1} & \multirow[t]{2}{*}{250} & \multirow[t]{2}{*}{-} & 12 & \multirow[t]{2}{*}{20} & 0,2 & \multirow[t]{2}{*}{ - } & 12000 \\
\hline & & & & & 3 & & 1,5 & & 22500 \\
\hline \multirow[t]{2}{*}{ Gás (GLP) } & $\begin{array}{l}\text { Estufa } \\
\text { Primer }\end{array}$ & 1 & - & 48 & 13,5 & 20 & - & 3,5 & 45360 \\
\hline & $\begin{array}{c}\text { Estufa } \\
\text { Base/Verniz }\end{array}$ & 1 & - & 48 & 13,5 & 20 & - & 3,5 & 45360 \\
\hline \multicolumn{9}{|c|}{ TOTAL } & $R \$ 159.720$ \\
\hline
\end{tabular}

Fonte: Elaborado pelos autores

A Figura (3) ilustra a nova configuração de processo após a retirada de uma estufa de primer e outra estufa de base/verniz.

Figura 3: Processo de aplicação de Primer e Base/Verniz

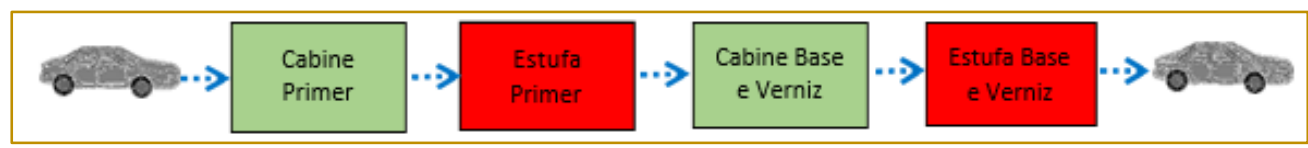

Fonte: Elaborado pelos autores

A Figura (4) ilustra o ganho acumulado no

2018. período de 11 meses entre os anos de 2017 e 
Figura 4: Ganho acumulado

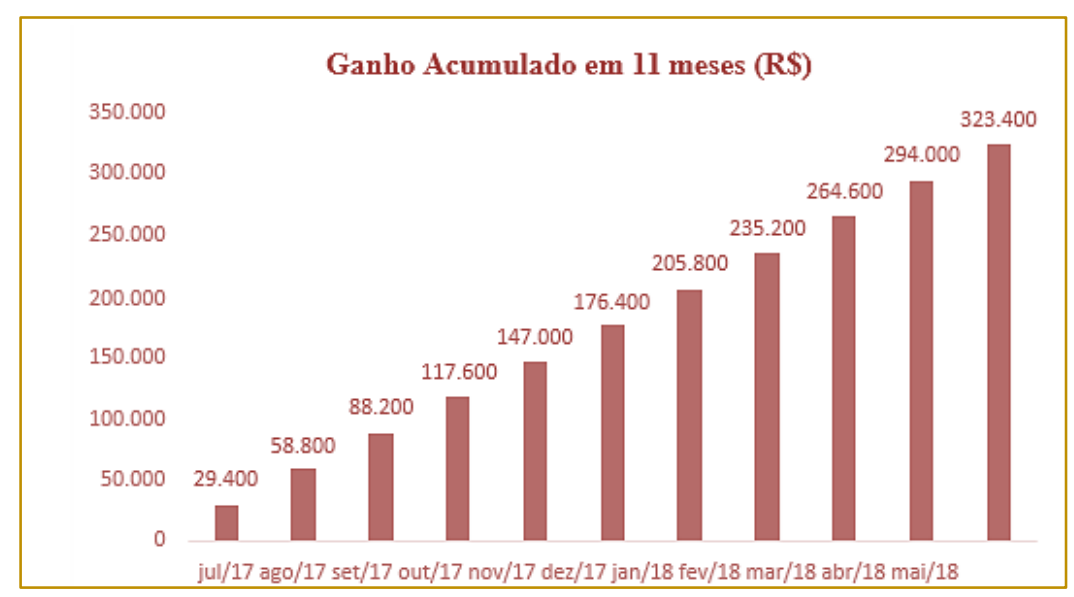

Fonte: Elaborado pelos autores

\section{CONSIDERAÇÕES FINAIS}

O Lean Manufacturing tem como essência a redução de desperdícios por meio da aplicação de métodos, como os já citados Jidoka e Just-In-Time, lançando mão do uso de diversas ferramentas de gestão. Isso se dá a partir da instauração de uma filosofia voltada para o desenvolvimento de uma

produção mais enxuta possível, em busca de uma cultura que aumenta a produtividade da organização.

O desperdício que foi constatado neste estudo está relacionado à utilização inadequada dos equipamentos do setor de pintura da indústria automobilística objeto de estudo, conforme apesentado nas discussões. Isso porque, ao não utilizar de maneira eficiente à completa capacidade dos equipamentos, gerava-se desperdício, que não era tão nítido, porem ao se aplicar o pensamento enxuto, foi possível descobrir o quanto e onde pode se obter resultados satisfatórios no processo produtivo.

Ao final desta pesquisa ficou evidente, que o

\section{REFERÊNCIAS}

[1] Gil, A. C. Didática do ensino superior. São Paulo: Atlas, 2012.

[2] Ghinato, P. Sistema Toyota de produção: mais do que simplesmente Just-In-Time. Caxias do Sul: Ed. Universidade de Caxias do Sul, 1996.

[3] Hayes, R.; Pisano, G.; Upton, D.; Wheelwright, S. Operations, Strategy, and

[4] Technology: Pursuing the Competitive Edge. Hoboken: John Wiley \& Sons, 2005. pensamento Lean Manufacturing, é realmente uma metodologia muito valiosa para as organizações que se preocupam em atender de maneira eficiente seus clientes. Observase que houve sucesso na aplicação do pensamento Lean na montadora de veículos, pois sem nenhum investimento inicial, a aplicação do Lean trouxe redução no custo de pintura do veiculo. A partir dessa melhoria, entende-se que a presente filosofia pode ser estendida para outras áreas da organização, - que consequentemente trará mais resultados dentro do processo produtivo.

Diante deste contexto, entende-se que é possível a organização BETA reproduza o pensamento Lean para restante da planta com objetivo de eliminar o desperdício ao longo de todo o fluxo de valor, em vez de pontos isolados, criar processos com menos esforço humano, menos espaço, menos capital e menos tempo para fabricar produtos e serviços a custos muito menores e com muito menos defeitos, em comparação com sistemas tradicionais de negócios. Com certeza o gerenciamento de informações se tornará muito mais simples e preciso.

[5] Hopp, W. J.; Spearman, M. L. To pull or not to pull: what is the question? Manufacturing \& Service Operations Management, 6(2), 133-148, 2004.

[6] Liker, J. O modelo Toyota, 14 Princípios de Gestão do Maior Fabricante do Mundo. Porto Alegre: Bookman, 2006.

[7] Liker, J.; Meier, D. Modelo Toyota - Manual de Aplicação: Um Guia Prático Para a Implementação dos 4Ps da Toyota. Porto Alegre: Bookman, 2007. 
[8] Malhotra, N. K. Pesquisa de marketing: foco na decisão. 3. ed. São Paulo: Pearson Prentice Hall, 2011.

[9] Mann, D. W. Creating a lean culture: tools to sustain lean conversions. New York: Productivity Press, 2005. 224p.

[10] Ohno, T. O Sistema Toyota de Produção: além da produção em larga escala. Porto Alegre: Bokman, 1997

[11] Shah, R.; Ward, P. T. Defining and developing measures of Lean production. Journal of Operations Management, 25(4), 785-805, 2007.

[12] Santos, A. B. Modelo de Referência para estruturar o programa de qualidade seis sigma: proposta e avaliação. São Carlos, 2006. v.1. Tese (Doutorado em Engenharia de Produção). Universidade Federal de São Carlos.

[13] Santos, A. B.; Martins, M. F. Modelo de referência para estruturar o Seis Sigma nas organizações. Gestão \& Produção, v. 15, n. 1, p. 43-56, jan.-abr. 2008.

[14] Schroeder, R. G.; Linderman, K.; Liedtke, C.; Choo, A. S. Six sigma: old wine in
[15] new bottles? Working Paper, Carlson School of Management, University of Minnesota, Dec., 2002.

[16] Silva, I. B.; Miyake, D. I.; Batocchio, A.; Agostinho, O. L. Integrando a promoção das

[17] metodologias Lean Manufacturing e Six Sigma na busca de produtividade e qualidade numa empresa fabricante de autopeças. Gest. Prod., São Carlos, v. 18, n. 4, p. 687-704, 2011.

[18] Tigre. P. B. Gestão da Inovação - A Economia da Tecnologia no Brasil. Rio de Janeiro: Elsevier, 2006

[19] YIN, R. K. Estudo de caso: planejamento e métodos. 2. ed. Porto Alegre: Bookman, 2015. Wheelwright, S.; HAYES, R. Competing through manufacturing. Harvard Business Review, v. 63, n. 1, p. 99-109, 1985.

[20] Womack, J. P., Jones, D. T., \& Ross, D. A máquina que mudou o mundo. Rio de Janeiro: Campus, 1992.

[21] Womack. J. P.; Jones, D. A Mentalidade Enxuta. Editora Campus, 1996. 


\section{Bapítulo 11}

\section{APLICACÃO DO ALGORITMO DO CAMINHO MINIMO EM UMA EMPRESA PROCESSADORA DE MIÚDOS NO SUDESTE GOIANO}

\section{Pedro Henrique Borges Xavier}

\section{Laura Teixiera Hohl}

\section{Anderson Clayton Lima Alencar}

Thainara Danielle Barbosa Marçal

\section{Naiara Faiad Sebba Calife Garcia}

Resumo: A rapidez na entrega do produto final é um diferencial para que os clientes optem por determinado produtor/fornecedor, agregado a minimização dos custos e consequentemente a maximização dos lucros empresariais as organizações buscam meios para gerenciar os fatos que podem influenciar seu processo decisório. Neste contexto, o objetivo deste trabalho é aplicar a Otimização em Redes, utilizando o problema do caminho mais curto, considerando uma origem e um destino pré-estabelecido, para encontra a rota ótima de uma processadora de miúdos até seu cliente de maior distância. Para tal, foi realizada uma abordagem de pesquisa quantitativa com procedimento experimental, utilizando modelagem matemática resolvida na ferramenta Solver do Excel, onde foi acompanhado a perspectiva de Hillier e Lieberman (2013) que sugerem seis passos para auxiliar no planejamento e procedimentos que poderão ser desenvolvidos. Como resultado pode-se observar o menor caminho entre a processadora de miúdos e seu cliente de maior distância, obtendo uma distância ótima de 21,4 km. O trabalho traz não só contribuições empresariais, mas também pode ser utilizado como fonte bibliográfica para aplicação desta técnica de pesquisa operacional.

Palavras-chave: otimização em redes,problema do caminho mais curto, pesquisa operacional. 


\section{INTRODUÇÃO}

Dentre as atividades econômicas desenvolvidas no Brasil, a agropecuária representa um setor decisivo na balança comercial do país. No ano de 2017, seu crescimento acumulado de $14,5 \%$ impulsionou o Produto Interno Bruto, enquanto outros setores como o da indústria e de serviços obtiveram resultados negativos, segundo dados do Ministério da Agricultura, Pecuária e Abastecimento.

A Pecuária Brasileira é considerada uma das mais produtivas em todo o mundo. De acordo com o Serviço Agrícola Estrangeiro do Departamento de Agricultura dos Estados Unidos (FAS/USDA) o Brasil detém 22,64\% do rebanho bovino mundial, representando 226,03 milhões de animais, o que torna o país o segundo maior produtor de carne bovina do mundo, atrás apenas da Índia. O país é também o quarto maior produtor de carne suína, com 3725 mil toneladas, e o segundo maior produtor mundial de aves, com 13.250 mil toneladas no ano de 2017.

Este setor agropecuário continua a apresentar um crescimento expressivo. No 30 trimestre de 2017, foram abatidas 7,98 milhões de cabeças de bovinos, 11,03 milhões de cabeças de suínos e 1,47 bilhão de cabeças de frangos, sob algum tipo de serviço de inspeção sanitária, dados do Instituto Brasileiro de Geografia e Estatística.

Como esfera primária da economia, a pecuária além de abastecer o mercado interno, também tem um papel considerável nas exportações do país, no entanto, mesmo com a vasta variedade de cortes existentes, nem sempre toda a carne do animal é aproveitada no abate, por falta de interesse por parte dos frigoríficos em investir no mercado de miúdos, cortes de carne que incluem rins, coração, fígado, língua dentre outros. Este desinteresse se deve sobretudo em relação a desinformação sobre a existência de restaurantes, açougues, e supermercados que veem vantagem na comercialização deste tipo de carne. Tendo em vista este cenário, empresas que realizam este tipo de distribuição tem ainda mais barreiras para se manter no mercado, logo estas buscam métodos para manter-se com lucros, com um grande custo em transporte uma boa forma de realizar o aumento de sua receita é a redução.

Caixeta Filho e Martins (2001) também afirmam que o transporte é o principal componente da logística, e este é a última fronteira para a redução de custos de uma empresa, Logo, como o transporte não agrega valor ao produto, porém é um gasto inevitável, programar rotas mais inteligentes é essencial para enxugar estes custos e melhorar o tráfego de mercadorias, sem que isso implique em prejuízos no nível de serviço oferecido pela empresa.

Desta forma, o intuito desta pesquisa é determinar o menor caminho entre um centro de distribuição de miúdos bovinos, suínos e de aves, localizado no município de Goiandira e seu consumidor de maior distância. Para esta finalidade, foi utilizado o algoritmo do caminho mínimo, que visa determinar a menor distância percorrida entre uma origem e um destino, e consequentemente encontrar uma rota que minimize os custos de transportes, os quais são responsáveis por $60 \%$ dos custos logísticos na maioria das empresas (GOMES, 2004).

\section{REVISÃO BIBLIOGRÁFICA}

\subsection{OTIMIZAÇÃO DE REDES - PROBLEMA DO CAMINHO MAIS CURTO}

Segundo Moreira (2010), a pesquisa operacional surgiu durante a Segunda Guerra Mundial, a partir da necessidade de alocar recursos escassos às operações militares e as atividades de cada operação, sendo impulsionada com a melhoria das técnicas na formulação de problemas e a popularização dos computadores. Assim a pesquisa operacional utiliza técnicas de modelagem, considerando todas as alternativas possíveis, auxiliando na tomada de decisão.

Arenales et al. (2007) salientam que a pesquisa operacional se tornou ainda mais importante com a economia eletrônica, globalização, internet, onde é cada vez maior a necessidade de decisões rápidas e estratégicas, fundamentais nas relações entre empresas, clientes e fornecedores. Logo possui um vasto campo de aplicação, que vai desde a agricultura, finanças ao setor público. Assim a pesquisa operacional pode ser compreendida como uma ciência e tecnologia de decisão, que a partir da formulação de modelos, considerando suas particularidades, fornecem respostas que auxiliam ao gestor na tomada de decisão.

Determinar um objetivo, as restrições do 
problema, possíveis caminhos alternativos limites de tempo, etc., fazem parte do processo de definição do problema, após esse processo, inicia-se a formulação do modelo matemático que incluem as variáveis de decisão, a função objetivo, as restrições e os parâmetros do modelo, um tipo particularmente importante é o modelo de programação linear, em que tanto as funções matemáticas da função objetivo e das restrições, são lineares (HILLIER; LIEBERMAN, 2013).

Além da programação linear, existem outras técnicas, que permitem solucionar os modelos matemáticos, de acordo com a complexidade e o tipo do modelo, como a programação linear inteira, onde todas as variáveis devem possuir valores inteiros, programação dinâmica, que é um método para a construção de algoritmos para a resolução de problemas computacionais, em especial os de otimização combinatória e a otimização em redes, que é baseada na interligação de pontos e linhas, utilizada principalmente na solução de problemas de roteamento (TAHA, 2008).

De acordo com Hillier e Lieberman (2013), a representação em redes é uma ferramenta muito importante para descrever a relação entre componentes de um sistema, principalmente considerando o vasto campo de aplicação da mesma, como redes de transporte, elétricas, de comunicação, além de áreas como produção, distribuição, planejamento de projetos, posicionamento de instalações, administração de recursos e planejamento financeiro.

Assim podemos definir uma rede, como um conjunto de pontos que são conectados por retas, os quais mantém uma relação entre si, como a ligação entre duas cidades, por meio de estradas, assim Arenales et al. (2007), define $\mathrm{N}$ como um conjunto finito, cujos elementos são chamados nós e $\mathrm{E}$ um conjunto de pares de nós, onde grafo é o par $G=(N, E)$ e rede é um grafo cujos nós têm valores associados. Um grafo $G=(N, E)$ pode ser representado graficamente, onde cada nó i é representado por um círculo com o rótulo i, e cada aresta (i, j) por uma linha conectando os dois círculos rotulados de $\mathrm{i}$ e $\mathrm{j}$.

Além disso, outras definições são empregadas por Taha (2008), por exemplo, se um arco permite fluxo em uma direção e na direção oposta o fluxo é nulo, o mesmo é dito como arco orientado, quando todos os arcos são orientados, tem-se uma rede orientada, onde dois nós são ligados por uma sequência de arcos diferentes, que passam por outros nós, logo em uma rede conectada todos os nós estão ligados por pelo menos um caminho. Além disso, quando uma rede é conectada sem ciclos, trata-se de uma arvore, que é composta pelo subconjunto de todos os nós e a árvore que liga todos os nós da rede é a árvore geradora.

Logo existem inúmeras aplicações práticas que podem ser solucionadas por meio da otimização em redes, Arenales et al. (2007) introduz alguns algoritmos que permitem identificar soluções para problemas de otimização em redes, como o algoritmo de Dijkstra, que a partir de comprimentos não negativos do arco, fornece o menor caminho entre dois nós da rede, já o algoritmo de Ford mesmo com comprimentos negativos, é capaz de encontrar o caminho mais curto entre dois nós, assim como o algoritmo de Floyd, que mesmo com comprimentos negativos, encontra caminhos mínimos entre todos os pares de nós do grafo, desde que não haja circuitos com comprimentos negativos, há outros exemplos como o problema da árvore geradora mínima, entretanto, o foco deste estudo é o problema do caminho mais curto.

A partir de uma rede conectada por dois nós, que estão a uma distância não-negativa, é possível encontrar um caminho mínimo entre esses nós, origem e destino. Hillier e Lieberman (2013), apresentam o algoritmo do caminho mais curto, onde é identificada a menor distância entre todos os nós, a partir da origem até o nó de destino. O algoritmo se inicia com o objetivo da n-ésima iteração, onde se encontra o n-ésimo nó mais próximo da origem, posteriormente, ocorre a entrada para a n-ésima iteração, n-1 nós mais próximos da origem, o próximo passo é encontrar os candidatos ao n-ésimo nó mais próximo, que são fornecidos pelos nós já solucionados, e por fim o cálculo do n-ésimo nó mais próximo, a distância entre os nós solucionados e seus candidatos é adicionada, assim o candidato com a menor distância total é o n-ésimo nó mais próximo e seu caminho mais curto é aquele gerando essa distância. 


\section{MÉTODO E PROCEDIMENTO DE} PESQUISA

O trabalho em questão tem uma abordagem quantitativa, pois foi utilizado modelos matemáticos para resolução do problema e os dados foram coletados de forma quantitativa. Segundo Mattar (2001) a pesquisa quantitativa busca a validação das hipóteses mediante a utilização de dados estruturados, estatísticos, com análise de um grande número de casos representativos, recomendando um curso final da ação.

Quanto ao procedimento de pesquisa foi utilizado a pesquisa experimental, já que se utilizou estudos e recursos existentes como o algoritmo do caminho mínimo. Segundo Fonseca (2002) A pesquisa experimental opta por grupos de objetos coincidentes, submeteos a tratamentos distintos, examinando as variáveis estranhas e checando se as diferenças notadas nas respostas são estatisticamente significantes.

Para a realização da pesquisa de pesquisa operacional foi utilizada as diretrizes de Hiller e Lieberman (2010). Que são: 1) definir o problema e coletar dados; 2) formular o problema matemático para representar o problema; 3) desenvolver um procedimento computacional para a solução do problema; 4) testar o modelo e aprimorá-lo se necessário; 5) preparar para a implementação do modelo; 6) e implementar o modelo.

A coleta de dados ocorreu no mês de janeiro de 2018 em uma empresa que distribui miúdos. Para a obtenção dos dados utilizou uma pesquisa semiestruturada com os funcionários durante uma visita in-loco. Durante a entrevista foi coletado dados sobre os clientes para o cálculo da distância. Foi escolhido o cliente com maior distância para aplicação do algoritmo do caminho mínimo.

O modelo matemático foi elaborado com auxílio do Google Maps $®$, para determinar os pontos, da ferramenta Solver do Excel $\AA$, para a resolução do problema de caminho mínimo, e do softaware de desenho DIA Diagram Editor ${ }^{\circledR}$, para a elaboração da rede. Os passos 5 e 6 não correspondem ao escopo do trabalho.
A empresa objeto de estudo está localizada na cidade de Goiandira - Goiás, ela teve início de suas atividades em 2014 com sete funcionários, atualmente possui dez. A empresa é responsável por receber e armazenar os miúdos de bovinos, suínos e aves, pelo processamento dos mesmos e pela sua distribuição aos clientes, que em sua maioria são localizados na cidade de Catalão - Goiás.

\section{RESULTADOS E DISCUSSÕES}

Para maior compreensão dos resultados obtidos essa seção será dividida em subseções, com o objetivo de especificar cada etapa do processo de resolução do problema proposto, sendo a primeira delas justamente a apresentação e definição deste, seguindo pela construção do modelo, onde serão apresentados os dados. A subseção 5.3 é composta pelos resultados e analises obtidas em relatórios dados pelos softwares utilizados, apresentando assim a solução do modelo. A quanta e última seção, é composta pelas soluções e validação do modelo em estudo.

\subsection{DEFINIÇÃO DO PROBLEMA E COLETA DE DADOS}

Com os dados coletados e auxílio do Google MAPS® foi possível analisar dentre os doze clientes o consumidor com maior distância geográfica em relação a empresa, sendo este, o Supermercado Santa Maria. Assim foram definidos os pontos iniciais (empresa) e destino. Após esta definição, foram obtidas novamente através do Google MAPS $®$ as possíveis rotas entre estes 2 pontos e suas respectivas distancias. De posse dessas informações foram criados pontos de acesso (B a G). Para a emulação dos dados, elaborou-se uma planilha no Software Excel $($, apresentada na Tab. (1), onde pode-se verificar a distância entre os pontos e suas possíveis rotas, que também chegam ao destino final, sendo A o início e $\mathrm{K}$ o ponto final. 
Tabela 1 - Distâncias entre a empresa e os pontos de acesso

\begin{tabular}{|c|c|c|}
\hline De & Para & Distância $(\mathrm{Km})$ \\
\hline A & B & 12,8 \\
\hline B & C & 1,18 \\
\hline B & D & 3,05 \\
\hline C & D & 2,4 \\
\hline C & E & 0,8 \\
\hline E & I & 0,82 \\
\hline E & H & 0,12 \\
\hline D & F & 1,13 \\
\hline H & D & 2,3 \\
\hline H & F & 2,0 \\
\hline I & F & 2,2 \\
\hline I & J & 1,47 \\
\hline F & G & 0,35 \\
\hline J & G & 0,75 \\
\hline G & K & 4,15 \\
\hline
\end{tabular}

Elaborada pelos autores (2018)

A representação de cada ponto (nó) pode ser vista na Tab. (2), onde é especificado

detalhadamente sua localização:

Tabela 2 -Especificações dos pontos (nós)

\begin{tabular}{|c|l|}
\hline Pontos & \multicolumn{1}{|c|}{ Acesso as Possiveis Rotas } \\
\hline A & Empresa Estudada \\
\hline B & Ponto de Acesso à Rua São Luiz com Avenida Ricardo Paranhos \\
\hline C & Cruzamento da Avenida Ricardo Paranhos com a Avenida Margon \\
\hline D & Ponto de Acesso para Rua L-1 \\
\hline E & Cruzamento da Rua Ênio Metsavat com a Avenida Farid \\
\hline F & Cruzamento da Rua L-2 com a Rua Mandaguari \\
\hline G & Cruzamento da Rua Antônio Sebba com a Rua L-2 \\
\hline H & Cruzamento da Rua Ênio Metsavat com a Rua Firminópolis \\
\hline I & Cruzamento da Avenida Farid Gomes com a José Marcelino \\
\hline J & Cruzamento da Rua Juscelino Gomes com a Rua L-2 \\
\hline K & Destino \\
\hline
\end{tabular}

Elaborada pelos autores (2018)

\subsection{FORMULAÇÃO DO MODELO MATEMÁTICO PARA REPRESENTAR O PROBLEMA}

Com a definição de todos os pontos, foi possível criar uma rede com os caminhos viáveis para chegar ao destino final, como pode ser visto da Fig. (1) abaixo. Sendo que os círculos (nós) representados por letras indicam as prováveis entradas de caminhos ótimos, e as ligações entre os pontos representadas por retas assinalam suas respectivas distancias (em Quilômetros).

Figura 1 - Representação do problema em rede em Km. Fonte:

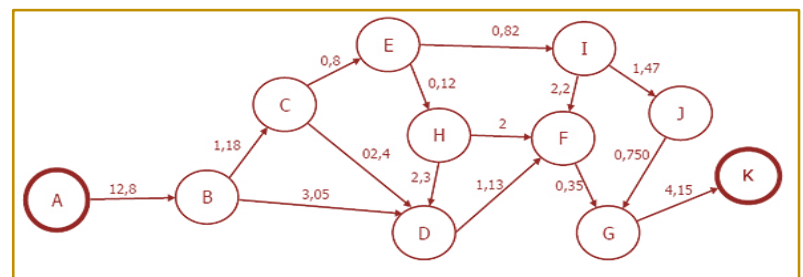

Elaborada pelos autores (2018) 


\subsection{SOLUÇÃO DO MODELO}

Com a rede finalizada, utilizou-se o Software Excel® para a criação de uma planilha onde os dados a serem analisados foram dispostos, como pode ser observado na Fig.(3) onde também é demostrado que nas colunas $\mathrm{B}$ e $\mathrm{C}$ são representadas as interligações (arcos direcionados) da rede. Os nós de partida são representados nas células B4 a B18, já os nós de destino pelas células C4 a C18. A distância entre um caminho e outro é disposto na coluna $D$, os nós são representados na coluna G. Por sua vez, na coluna H são representados os fluxos líquidos, onde um arco incluso no fluxo é dado pelo número $1 \mathrm{e}$ um arco não incluso pelo número 0 , sendo estas as variáveis de decisão para cada ligação, estes valores são dispostos na célula E que representa a Rota Selecionada, especificadamente nas células E4 até E18.

Figura 3 - Tabulação dos dados no Software Excel.

\begin{tabular}{|c|c|c|c|c|c|c|c|c|c|}
\hline 4 & A & B & c & D & $E$ & $\mathrm{~F}$ & G & $\mathrm{H}$ & 1 \\
\hline \multicolumn{10}{|l|}{2} \\
\hline 3 & & De & Para & Distância (Km) & Rota Selecionada & & Nós & Fluxo Liquido & Oferta/Demanda \\
\hline 4 & & A & B & 12,8 & 1 & & $\mathrm{~A}$ & -1 & -1 \\
\hline 5 & & B & C & 1,18 & 1 & & B & 0 & 0 \\
\hline 6 & & $\mathrm{~B}$ & D & 3,05 & 0 & & $\mathrm{C}$ & 0 & 0 \\
\hline 7 & & C & D & 2,4 & 0 & & D & 0 & 0 \\
\hline 8 & & C & $\mathrm{E}$ & 0,8 & 1 & & $E$ & 0 & 0 \\
\hline 9 & & $\mathrm{E}$ & I & 0,82 & 0 & & $\mathrm{~F}$ & 0 & 0 \\
\hline 10 & & $\mathrm{E}$ & $\mathrm{H}$ & 0,12 & 1 & & G & 0 & 0 \\
\hline 11 & & $\mathrm{D}$ & $\mathrm{F}$ & 1,13 & 0 & & $\mathbf{H}$ & 0 & 0 \\
\hline 12 & & $\mathrm{H}$ & D & 2,3 & 0 & & I & 0 & 0 \\
\hline 13 & & $\mathrm{H}$ & $F$ & 2 & 1 & & $J$ & 0 & 0 \\
\hline 14 & & 1 & $\mathrm{~F}$ & 2,2 & 0 & & K & 1 & 1 \\
\hline 15 & & $I$ & $J$ & 1,47 & 0 & & & & \\
\hline 16 & & $\mathbf{F}$ & G & 0,35 & 1 & & & & Caminho Ótímo \\
\hline 17 & & $\mathrm{~J}$ & G & 0,75 & 0 & & & & A-B \\
\hline 18 & & G & $\mathrm{K}$ & 4,15 & 1 & & & & $B-C$ \\
\hline 19 & & & & & & & & & $C-E$ \\
\hline 20 & & \multicolumn{3}{|c|}{ Distância Total (Km) } & 21,4 & & & & $\mathrm{E}-\mathrm{H}$ \\
\hline 21 & & & & & & & & & $\mathrm{H}-\mathrm{F}$ \\
\hline 22 & & & & & & & & & F-G \\
\hline 23 & & & & & & & & & G-K \\
\hline
\end{tabular}

Elaborada pelos autores (2018)

Hillier e Lieberman (2013) explicita que o fluxo liquido dado em um nó é o fluxo que sai menos o fluxo que entra, deste modo como especificado na coluna $\mathrm{H}$ (linhas $\mathrm{H} 4$ até $\mathrm{H} 14$ ) o fluxo líquido 1 seja na origem e 0 -1 no destino, tendo o restante dos nós o valor de 0 , sendo então a coluna I (Oferta/Demanda) feita especificadamente para atender essa exigência. As equações especificas para o fluxo liquido podem ser vistas na figura 5 do APÊNDICE A.

A solução ideal é apresentada na célula E20, a qual nos exibe o caminho mínimo entre os pontos $A$ e $\mathrm{K}$, vale ressaltar que o objetivo especificado na caixa de diálogo da ferramenta solver é minimizar esta célula, já que deve ser demonstrado o menos caminhos entre os nós, também é demostrado na caixa de diálogo do solver as restrições, como pode ser visto da Figura 8 do APÉNDICE A. O caminho ótimo apresentado deve assumir valor irrestrito e não negativo, tendo como método de solução o LP Simples, proporcionando um valor de solução ótimo.

A solução ótima apresentada, resultando assim no menor caminho entre a empresa estudada $(A)$ e o Supermercado Santa Maria (K) passa pelos nós : B - Ponto de Acesso à Rua São Luiz, seguindo para os nós (C) Cruzamento da Avenida Ricardo Paranhos com a Avenida Margon , (E) - Cruzamento da Rua Enio Metsavat com a Avenida Farid, $(\mathrm{H})$ Cruzamento da Rua Enio Metsavat com a Rua Firminopolis, (F) - Cruzamento da Rua L-2 com a Rua Mandaguari, (G) - Cruzamento da Rua Antônio Sebba com a Rua I-2 ,chegando assim ao destino (K) - Supermercado Santa Maria.

Seguindo a rota de menor caminho apresentada, o veículo que realiza a entrega irá percorrer uma distância de 21,4km, o caminho mínimo é demostrado na Fig. (2): 
Figura 2 - Rede com o caminho mínimo.

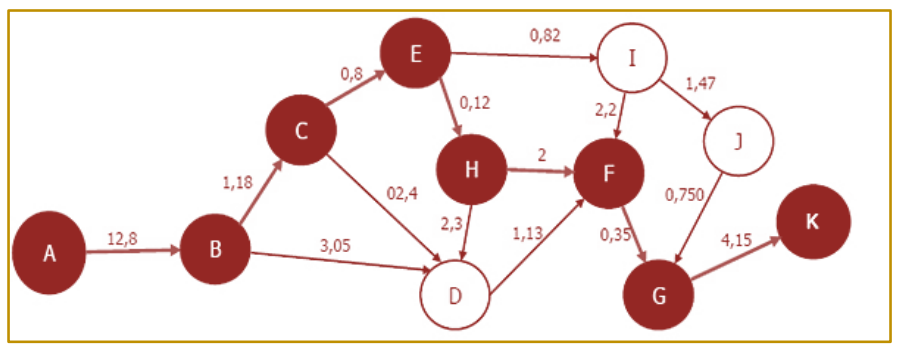

Fonte: Elaborado pelos autores (2018)

As distâncias entre cada nó são de: $(A)$ à $(B)$ $12,8 \mathrm{~km}$; $(\mathrm{B})$ à $(C) 1,18 \mathrm{~km}$; $(\mathrm{C})$ à $(\mathrm{E}) 0,8 \mathrm{~km}$; $(E)$ à $(H) 0,12 \mathrm{~km} ;(H)$ à $(F) 2 \mathrm{~km} ;(F)$ à $(G) 0,35$ $\mathrm{km}$ e $(\mathrm{G})$ à $(\mathrm{K})$ 4,15 km.

No Relatório de Reposta 1 dado pela ferramenta solver, pode-se analisar que para a resolução do problema foram necessárias 12 iterações. O resultado ótimo da minimização é apresentado na Tabela Célula do Objetivo (Min), que pode ser visualizado na Fig. (3) assim como também é indicada a Tabela de Células Variáveis, que apresenta os valores de 1 ou 0 , ou seja quais caminho foram selecionados (1) e quais não foram (0), por fim a Tabela de Restrições registra a relação entre o fluxo liquido oferta demanda, com os valores dados em literatura de -1,0 e 1 para indicar o nó de origem e nó de destino.

\subsection{TESTAR O MODELO E APRIMORÁ-LO SE NECESSÁRIO}

O modelo foi valido primeiramente manualmente, realizando a somatória de todos os caminhos possíveis, onde foi constatado que o caminho o obtido é ótimo, outra de verificação utilizada foi a ferramenta Google Maps ${ }^{\circledR}$ que também forneceu o menor caminho entre a empresa estudada e o destino.

\section{CONSIDERAÇÕES FINAIS}

A pesquisa teve como objetivo determinar 0 menor caminho entre empresa estudada e seu consumidor de maior distância. Além da Pesquisa Operacional, o presente trabalho também abrange outra subárea da Engenharia de Produção, a Logística. Logo, a interdisciplinaridade entre estas elas teve sua importância comprovada através da análise de artigos demonstrando a grande importância e aplicabilidade da Pesquisa Operacional aliada a Otimização de Redes no processo de roteirização e tomada de decisão de empresas.

Analisando os resultados obtidos, observouse que a utilização da ferramenta cumpre a proposta de apresentar o menor caminho entre a empresa estuda (nó A) e seu cliente de maior distância (nó K), proporcionando um caminho mínimo de 21,4km.

Como sugestões futuras para aprimoramento na análise realizada, pode-se expandir a aplicação da ferramenta para outros clientes (nós) ou até mesmo, traçar um caminho ótimo que atenda os demais clientes distintos de uma única vez, justapondo um algoritmo abrangendo um novo objetivo de trabalho. Outro ponto a ser aperfeiçoado é a utilização de uma ferramenta para medir com maior exatidão a distância entre a empresa e seus clientes, além de melhorias no modelo, e caso seja interesse da empresa uma futura implementação 


\section{REFERENCIAS}

[1] Arenales, M.; Armentano, V.; Morabito, R.; Yanasse, $\mathrm{H}$. Pesquisa Operacional para cursos de engenharia. 3. ed. Rio de Janeiro: Elsevier, 2007.

[2] Caixeta Filho, J. V.; Martins, R. S. Gestão Logística do Transporte de Cargas. São Paulo: Atlas, 2001.

[3] Embrapa - Empresa Brasileira de Pesquisa Agropecuária. Estatísticas/Desempenho da produção [Internet] disponível em: < https://www.embrapa.br/suinos-e-

aves/cias/estatisticas> Acesso em 15/02/2018.

[4] Fonseca, J. J. S. Metodologia da pesquisa científica. Fortaleza: UEC, 2002.

[5] Fortes, Bianca Jupiara; Ribeiro, Roberto Portes; Mülle, Felipe Martins. Programação Linear: Uma aplicação para a otimização na distribuição de uma empresa de nutrição animal. 2014. Disponível em: <http://www.revistaespacios.com/a14v35n11/14351 112.html >. Acesso em: 02/02/2018.

[6] Gomes, C. F. S.; Ribeiro, P. C. C. Gestão da Cadeia de Suprimentos integrada à Tecnologia da Informação. São Paulo: Thomson, 2004.

[7] Hillier, F. S.; Lieberman, G. J. Introdução à Pesquisa Operacional. 8. ed. Porto Alegre: AMGH, 2010.

[8] Ibge-Instituto Brasileiro de Geografia e Estatística. Indicadores IBGE - Estatística da Produção Pecuária. Dezembro de 2017. [Internet] disponível em: $<$ https://biblioteca.ibge.gov.br/visualizacao/periodi cos/2380/epp_2017_dez.pdf > Acesso em 10/02/2018

[9] Kinochita, Celia Kazuko; Maiellaro, Joao Roberto. Modelos para roteirização e programação de veículos aplicados a uma empresa de transporte escolar. 2011. Disponível em: <http://www.abepro.org.br/biblioteca/enegep2011_ TN_STO_140_888_18482.pdf >. Acesso em: 07/02/2018.

[10] Mapa- Ministério da Agricultura, Pecuária e Abastecimento [Internet] disponível em <http://www.agricultura.gov.br/noticias/agropecuari a-puxa-o-pib-de-2017> Acesso em 15/02/2018.

[11] Mattar, F. N. Pesquisa de marketing. 3. ed. São Paulo: Atlas, 2001.
[12] Matos Junior, Carlos Alberto de et al. O papel da roteirização na redução de custos logísticos e melhoria do nível de serviço em uma empresa do segmento alimentício no Ceará. 2013. Disponível

em: $<$ https://anaiscbc.emnuvens.com.br/anais/article/vi ewFile/186/186>. Acesso em: 07/02/2018.

[13] Méndez, Yasmín Salazar; Guardia, Luis Ernesto Torres. Problema do caminho mais curto algoritmo de dijkstra. 2008. Disponível em: $<$ https://www.marinha.mil.br/spolm/sites/www.marin ha.mil.br.spolm/files/006_1.pdf>. Acesso em: 07/02/2018

[14] Moreira, D. A. Pesquisa Operacional Curso Introdutório. 2. ed rev. São Paulo: Cenage Learning, 2010.

[15] Oliveira, Igor Henrique Inácio de et al. Utilização da pesquisa operacional para otimização de rotas de um motorista autonomo na região de são paulo. 2015. Disponível em: <https://www.aedb.br/seget/arquivos/artigos 15/762 2273. pdf>. Acesso em: 30/02/2018.

[16] Peixoto, Gabriela et al. Aplicação do problema do caminho mais curto para otimização de rota de um frigorífico. In: Simpósio de Engenharia de Produção - SIENPRO,1.,2017, Catalão. Anais eletrônicos... Catalão: UFG - RC, 2017 p. 1 - 10. Disponível em :< http://sienpro.catalao.ufg.br/up/1012/o/Sarah_Arag \%C3\%A3o_Vasconcelos.pdf>. Acesso em: 19/02/2018.

[17] Silva, André Luís; Oliveira, Lucas Machado de; Andrade, Rafael Quintão de. Metodologia baseada no Algoritmo de Dijkstra para roteirização de pontos turísticos em Ouro Preto. 2010. Disponível em: <http://www.saepro.ufv.br/wpcontent/uploads/2010.2.pdf $>$. Acesso em: 02/02/2018

[18] Taha, H. A. Pesquisa operacional: uma visão geral. 8. ed. São Paulo: Pearson Prentice Hall, 2008.

[19] Usda/Fao - United States Department of Agriculture / Foreign Agricultural Service. Livestock and Poultry: World Markets and Trade [Internet] $<$ https://apps.fas.usda.gov/psdonline/circulars/lives tock_poultry.pdf> Acesso em 15/02/2018. 


\title{
Gapítulo 12
}

\section{DISCUSSÕES INICIAIS SOBRE SUSTENTABILIDADE DA BIOENERGIA E DAS BIOMASSAS BRASILEIRAS E SUAS ROTAS DE CONVERSÃO ENERGÉTICA}

\author{
Herbert Carneiro Rangel \\ Luiz Lúcio de Aragão Pedroso \\ Igor Cassiano Rangel \\ Milton Erthal Júnior \\ Claudio Luiz Melo de Souza
}

Resumo: As sociedades modernas têm um estilo de vida muito dependente de energia, sendo que, os combustíveis fósseis são os principais geradores dessa energia primária. Entretanto, eles são responsáveis por grande parte das emissões de gases de efeito estufa no mundo. A busca por fontes de energias renováveis tem crescido, principalmente devido aos novos paradigmas de sustentabilidade socioambiental. A biomassa apresenta relevante papel nesse contexto, por causa da sua abundância no planeta e devido ao grande potencial para a sua produção. As biomassas são consideradas renováveis devido ao ciclo do carbono, pois quando queimadas elas liberam $\mathrm{CO}_{2}$, porém ao serem formadas pela fotossíntese, sequestram o carbono e liberam o oxigênio. A bioenergia é aquela que tem por matéria-prima a biomassa, que de acordo com suas transformações, podem resultar em biocombustíveis líquidos, gasosos ou sólidos. Dentre muitos exemplos, destacamos o biodiesel e o bioetanol, dentre os biocombustíveis líquidos, obtidos por meio de cultivos energéticos lignocelulósicos, amiláceos, oleaginosos ou sacarinos. O biometano é um importante gás gerado em biodigestores alimentados com resíduos animais ou em aterros sanitários planejados. São importantes ainda os biocombustíveis sólidos, tais como o carvão vegetal, a lenha, os briquetes e péletes fabricados pela compactação da biomassa de resíduos de cultivos, de madeireiras e de podas urbanas. Destacamos ainda o licor negro, residual da indústria de celulose, que é usado em altos-fornos e os biocombustíveis obtidos de microalgas. O Brasil tem grande potencial para a produção de biomassas devido ao seu clima, incidência solar, extensão territorial e boa estrutura de agronegócio. Contudo, o setor das biomassas, ainda necessita de avanços tecnológicos e de incentivos. Portanto, o propósito desse artigo foi contribuir com o debate nacional tão relevante para a diversificação da matriz energética brasileira.

Palavras chave: Biomassa, Bioenergia, Sustentabilidade 


\section{INTRODUÇÃO}

O desenvolvimento das sociedades no campo social e econômico requer uma maior demanda por energia e grande parte destas provém de combustíveis fósseis. Este tipo de fonte de energia tem trazido preocupações para a sociedade mundial em função da provável escassez do petróleo, que é a principal fonte de energia do mundo e somado a isso, as pressões mundiais para a preservação ambiental e diminuição dos gases de efeito estufa (GEEs). Esses são os motivos principais para que governos mundiais busquem maior produção e consumo de combustíveis renováveis, inclusive de bioenergia da biomassa (LAL, R., 2004; GOLDEMBERG, 2009; CARBONARI, 2012).

Seguindo diretrizes internacionais, o Brasil têm realizado esforços públicos e privados para a adoção de fontes renováveis de energia em vários setores produtivos a fim de diversificar a sua matriz energética. $\mathrm{O}$ uso e produção de biomassa para fins energéticos é uma potencial proposta para que setor agroindustrial brasileiro alcance maior grau de sustentabilidade. Além de mitigar as emissões de GEEs do setor, a diversificação da matriz é fundamental para a segurança energética nacional, que requer menor dependência do petróleo com suas variações cambiais e da energia hidrelétrica que cada vez mais é atingida por períodos prolongados de estiagens. A utilização da bioenergia brasileira pode ser realizada inicialmente por meio do aproveitamento das várias fontes de biomassa já disponíveis e pouco aproveitadas, bem como pelo incentivo a produção de novas fontes de matéria-prima para a geração de bioenergia em cadeias produtivas bem estruturadas (PHILIPPI; DOS REIS, 2016).

Os biocombustíveis brasileiros já constituem uma identidade nacional e abriram caminhos para a bioenergia em geral que vem crescendo nas últimas décadas, principalmente com a criação de novas legislações para o setor, quanto à produção, logística reversa, distribuição, incentivos tributários fiscais, incentivo ao associativismo, as inovações tecnológicas de conversão energética (pirólise, biodigestão anaeróbica, gaseificação, hidrólise enzimática, torrefação, etc.), melhoramento genético de culturas, principalmente gramíneas com o capimelefante e o sorgo biomassa, e florestas energéticas de eucalipto e pinus, dentre tantas iniciativas (RUIZ, 2015; MARAFON et al., 2017; ROCHA et al., 2017, PEDROSO et al., 2018)

O objetivo deste artigo é contribuir para o debate nacional sobre o setor de geração de bioenergia, copilando e descrevendo informações sobre os tipos de transformações da biomassa em biocombustível e os principais tratamentos e tecnologias usados, redução de custos e expansão da produção de bioenergia.

\section{BIOMASSA}

Biomassa é a matéria orgânica que pode ser utilizada na produção de energia. As vantagens do uso da biomassa na produção de energia são o baixo custo, o fato de ser renovável, de permitir o reaproveitamento de resíduos e de ser bem menos poluente que as outras fontes de energia como o petróleo ou o carvão (BERMANN, 2008).

A biomassa é o elemento principal de diversos novos tipos de combustíveis e fontes de energia como o BTL, o biodiesel, o bioóleo e o biogás. O BTL, também chamado de Biomass-to-Liquids, consiste em um combustível líquido obtido através da pirólise rápida, que consiste em uma reação química de decomposição por meio de calor. Esse método é responsável pela transformação da biomassa em gás e, em seguida, através de um processo químico, transformado em líquido, dando origem ao biocombustível denominado BTL (BOERRIGTER, 2006).

A mais abundante fonte renovável de recurso biológico da natureza é a da biomassa. $\mathrm{Na}$ natureza pode-se explorar a biomassa açucarada, a biomassa lignocelulósica e biomassa amilácea bem como as oleaginosas. A biomassa açucarada é proveniente de produtos vegetais e tubérculos tais como cana de açúcar e beterraba. A biomassa lignocelulósica é o nome dado para um conjunto de macromoléculas orgânicas complexas constituídas muitas vezes de pectinas, ligninas, hemicelulose e celuloses, as quais podem estar ligadas ou não entre si (VASSILIEV ET al., 2010). Estão presentes na madeira, bagaço de cana, resíduos agrícolas, gramíneas, resíduos de celulose (Tabela 1). A biomassa amilácea é proveniente dos produtos contendo amidos como exemplo o milho, a mandioca e a batata. As biomassas 
oleaginosas são as usadas para biodiesel e os principais exemplos são soja, algodão, milho, dentre outras (SANTOS, 2012)

A biomassa é renovada através do ciclo do carbono. Uma vez queimada, ela libera $\mathrm{CO} 2$ na atmosfera. A fotossíntese das plantas transforma o $\mathrm{CO} 2 \mathrm{em}$ hidratos de carbono e libera $\mathrm{O}_{2}$. Desta forma, a atmosfera não é alterada com o uso da biomassa, desde que seja realizada de forma controlada e não predatória. (BNDS, 2010)
Segundo Lal (2004), a queima de combustíveis fósseis representa aproximadamente $82 \%$ das emissões dos gases causadores do efeito estufa. Então, seja pela questão ambiental global, seja pela importância em reduzir a dependência externa de energia de outros países, o uso de biocombustíveis representa uma alternativa viável na substituição de combustíveis fósseis, e assim, há uma busca bem apropriada pela bioenergia proveniente de biomassas.

Tabela 1. Composição (\%) da biomassa lignocelulósica.

\begin{tabular}{|l|c|c|c|}
\hline \multicolumn{1}{|c|}{ Biomassa } & Celulose & Hemicelulose & Lignina \\
\hline Palha de Cana & $40-44$ & $30-32$ & $22-25$ \\
\hline Bagaço de Cana & $32-48$ & $19-24$ & $23-32$ \\
\hline Madeira Dura & $43-47$ & $25-35$ & $16-24$ \\
\hline Madeira Mole & $40-44$ & $25-29$ & $25-31$ \\
\hline Talo de Milho & 35 & 25 & 35 \\
\hline Espiga de Milho & 45 & 35 & 15 \\
\hline Algodão & 95 & 2 & 0,3 \\
\hline Palha de Trigo & 30 & 50 & 15 \\
\hline Sisal & 73,1 & 14,2 & 11 \\
\hline Palha de Arroz & 43,3 & 26,4 & 16,3 \\
\hline Forragem de Milho & $38-40$ & 28 & $7-21$ \\
\hline Fibra de Coco & $36-43$ & $0,15-0,25$ & $41-45$ \\
\hline Fibra de Bananeira & $60-65$ & $6-8$ & $5-10$ \\
\hline Palha de Cevada & $31-45$ & $27-38$ & $14-19$ \\
\hline
\end{tabular}

A biomassa tem destaque pela abundância, alta densidade energética, pelas facilidades de armazenamento, conversão e transporte, maturidade tecnológica tanto para plantio e colheita quanto para geração em bioenergia, maior competitividade comparada às outras fontes de energias, além da vantagem da utilização na permuta dos combustíveis fósseis pelo combustível da biomassa entre equipamentos das indústrias. Dessa maneira, a substituição das formas de obtenção de energia não teria impacto tão grande nas indústrias. (CASTRO; DANTAS, 2008)

A utilização da biomassa como combustível pode ser feita na sua forma bruta ou através de seus derivados. Madeira de reflorestamento, produtos e resíduos agrícolas que antes não eram aproveitados e sim descartados e queimados, como é o caso da casca de arroz, de café, bagaço da cana e muitos outros, resíduos florestais como eucalipto e pinus, excrementos animais, carvão vegetal, álcool, óleos animais, óleos vegetais, gás pobre, biogás são formas de biomassa utilizadas como combustível ( PACHECO, 2006)
Parte considerável de um vegetal não é amido nem açúcar, mas sim fibras que não são digeridas pelos fermentos tradicionais, como é o caso da cana-de-açúcar, que apresenta $2 / 3$ de sua massa na forma de fibra não fermentável (Tabela 2 e 3). Desta forma, grande porcentagem da massa desse tipo de substrato é desperdiçada em termos de geração de etanol (LEITE; CORTEZ, 2013).

A oferta de biomassa no Brasil tem um potencial enorme devido a extensão do país bem como sua característica tropical, área agricultável, incidência solar, clima, agroindústria consolidada, etc. O Brasil já possui um destaque na produção de biocombustível, especificamente o biodiesel e etanol, porém, há ainda um grande potencial ainda não utilizado de produção de bioenergias proveniente de biomassas, além de poder se tornar uma fonte energética para produção de energia elétrica. Conforme dados do Balanço Energético Nacional 2017 (dados de 2016), as fontes de energia elétrica no Brasil são representadas por $81,7 \%$ de renováveis e a biomassa atende com 8,2 \%, 
sendo basicamente utilizadas lenha, óleos vegetais e carvão vegetal.

Tabela 2. Composição (\%) de biomassa sacarina.

\begin{tabular}{c|c|c|c|c|c|c|}
\hline Biomassa & \multicolumn{1}{c}{ Água Total } & \multicolumn{2}{c}{ Sacarose } & Fibras & \multicolumn{2}{c}{ Sacarose na Água } \\
Cana & $73-76$ & $10-15$ & $15-20$ & $70-88$ & $2-4$ & $2-4$ \\
\hline Beterraba & 85 & 11 & 3,4 & 97 & - & - \\
\hline
\end{tabular}

Fonte: TACO - Tabela Brasileira de Composição de Alimentos - 2011

Tabela 3. Composição (\%) de biomassa amilácea.

\begin{tabular}{|c|c|c|c|}
\hline Biomassa & Água Total & Amido & Fibras \\
\hline Milho & 63,5 & $70-75$ & 3,9 \\
\hline Batata & $73-83$ & $14,7-28,2$ & $1,2-2,6$ \\
\hline Mandioca & 61,8 & 36,2 & 1,9 \\
\hline
\end{tabular}

\section{BIOENERGIA}

A bioenergia é o nome dado para a energia obtida através da biomassa. Esta energia pode ser usada para se gerar calor, eletricidade ou combustível para motores de combustão em geral. Também é considerada a energia quimicamente armazenada na biomassa, ou seja, pode ser interpretada como energia solar aprisionada por se originar nos processos de fotossínteses. As principais fontes de bioenergia são provenientes de matérias primas renováveis, como madeira, produtos agrícolas e dejetos orgânicos. Dentre os combustíveis bioenergéticos destaca-se o etanol, o metanol, o biodiesel, entre outros. Estes representam uma fonte alternativa de combustível, perante aos combustíveis fósseis. (LEMOS; STRADIOTO, 2012)

Conforme Zhang ( 2008 ), um bilhão de toneladas de biomassa seca produz entre 80130 bilhões de galões de etanol celulósico. Porém, é necessário utilizar de forma eficaz todas as frações das matérias-primas, especialmente, a celulose, hemicelulose e lignina, para obter sistemas que sejam sustentáveis e economicamente viáveis.

De acordo com Ripoli (2000), uma tonelada de palha equivale a algo entre 1,28 bpe (barris de petróleo equivalentes). Consequentemente, a não utilização dessa biomassa é um grande desperdício energético.

A crescente demanda energética, principalmente de combustíveis para a indústria, associada aos problemas relacionados a uso de combustíveis fósseis e ao meio ambiente, tem direcionado o foco para muitos estudos relacionados a uso de bioenergia e principalmente para os biocombustíveis. Os biocombustíveis apresentam as vantagens de serem obtidos a partir de biomassas abundantes e baratas, redução da emissão de $\mathrm{CO} 2$, uma vez que a produção da biomassa reduz a quantidade deste gás e os biocombustíveis são também biodegradáveis (BRASIL, 2018).

De acordo com Zheng, et al. (2009), há um grande esforço da comunidade científica para o desenvolvimento de novos processos economicamente viáveis para o aproveitamento da componente lignocelulósica da biomassa. Como exemplo o caso dos resíduos agrícolas (palha e bagaço de cana-de-açúcar, palha de trigo e resíduos de milho) e resíduos florestais (pó e restos de madeira), assim como o capim elefante para produção de etanol combustível (etanol de segunda geração).

Outro ponto de destaque é a produção do biocombustível denominado biodiesel que são provenientes das plantas oleaginosas tais como soja, milho, algodão, dendê, palma, mamona, dentre outros, bem como também gordura animal. As matérias primas possuem características diferentes em relação à disponibilidade, produção dos óleos, absorção do CO2 da atmosfera, custos e produção (BRASIL, 2018).

Segundo a Agência Nacional de Petróleo, Gás Natural e Bicombustível (ANP, 2012) o biodiesel tem por definição um composto de ésteres de ácidos carboxílicos de cadeia longa, produzido a partir da transesterificação e ou/esterificação de matérias graxas, de 
gorduras de origem vegetal (oleaginosas) ou animal.

O biodiesel apresenta uma vantagem enorme em relação ao diesel derivado de petróleo em virtude da importância para a indústria, para o setor agrícola, setor econômico do país, valorização de mão de obra rural e de profissionais na área química, e vantagens para o meio ambiente e principalmente para a saúde humana. Durante sua reação de combustão a quantidade de dióxido de carbono liberada pela queima é menor em relação aos combustíveis fósseis. Porém, o biodiesel também possui algumas desvantagens que precisam ser minimizadas para a sua produção. As principais são a dificuldade de produção, adaptações mecânicas em equipamentos para sua utilização, custo de produção maior que os combustíveis normais, profissionais especializados, equipamentos sofisticados, além da questão da segurança na manipulação dos produtos para sua produção, pois envolvem o uso do metanol e bases fortes, bem como tratamento dos rejeitos. (BIODIESELBR.COM)

O Brasil possui lei desde 2005 que obriga a mistura do biodiesel ao óleo diesel proveniente de fóssil. Segundo o Conselho Nacional de Política Energética (CNPE), haverá um aumento gradativo periódico. As misturas entre o biodiesel e o diesel mineral é conhecida pela letra $\mathrm{B}$ seguido do número que corresponde a quantidade de biodiesel na mistura. Segundo o CNPE, houve um aumento em março de 2018 para $10 \%$ de biodiesel no diesel mineral assim, a mistura está sendo denominada B10 (BRASIL, 2018).

\section{ROTAS DE TRANSFORMAÇÃO}

Em termos energéticos, a Biomassa é a matéria-prima para a produção de bioenergia, portanto são produtos energéticos e renováveis, originados a partir da matéria orgânica de vegetais e animais, que pode ser utilizado para produção de energia (BERMANN, 2008).

Quanto à tipologia existem dois grandes grupos de biomassa, o primeiro refere-se à biomassa tradicional, composta pela lenha e resíduos naturais. $O$ segundo grupo, chamado de biomassa moderna, é aquela produzida em processos tecnológicos, tais como biocombustíveis líquidos, briquetes e pellets, cogeração termelétrica e cultivos energéticos, a exemplo das florestas plantadas e gramíneas geneticamente melhoradas para esse fim (BERMANN, 2008).

Os seus principais usos como insumo energético são: produção de biocombustíveis sólidos para geração de energia térmica (carvão e resíduos agroflorestais), biocombustíveis líquidos (álcool combustível e biodiesel utilizados em motores a combustão) e geração de energia elétrica (combustão direta, gaseificação, queima de gases, entre outras tecnologias). A biomassa pode ser obtida de vegetais lenhosos, não lenhosos e/ou de resíduos orgânicos, e transformados em energia mediante diferentes processos de conversão (MARAFON, et al., 2017).

Algumas são as formas de transformação das biomassas em bioenergias passando por processos químicos, físicos, biológicos e térmicos. Podemos verificar na Figura 10 diagrama para conversão da biomassa em bioenergia.

Figura 1 - Conversão da Biomassa em Bioenergia

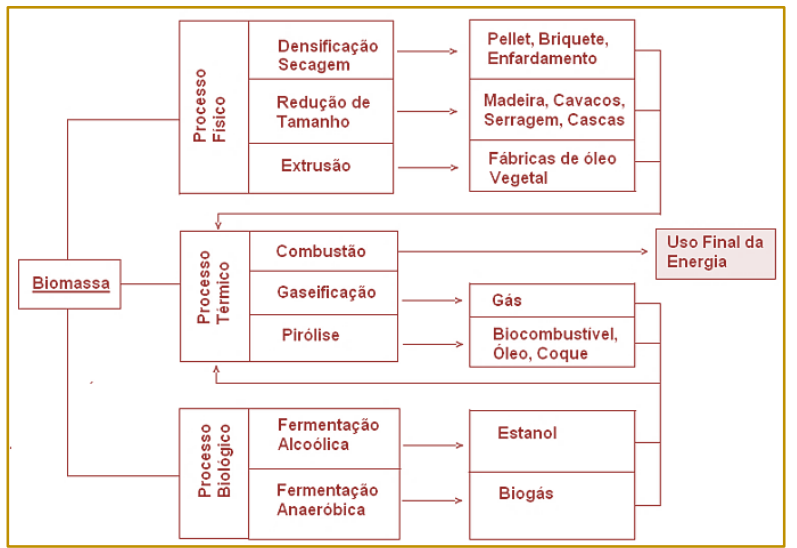

Fonte: www.lippel.com.br 
A produção do biocombustível proveniente da biomassa açucarada passa por um processo de fermentação com leveduras num meio aquoso açucarado onde as leveduras transformam o açúcar em etanol.

Os açucares já estão disponíveis na biomassa como é o caso da cana de açúcar e da beterraba. O processo de obtenção do açúcar da cana se dá através da extração do caldo da cana de açúcar por meio de moagem. No caso da beterraba a extração do açúcar se dá através da lavagem com água quente da beterraba cortada em fatia bem finas. Estas são tecnologias muito conhecidas e dominadas há muitos anos (MANOCHIO, 2014).

Na Figura 2 podemos verificar um fluxograma com os diversos tipos de biomassas e a forma para se produzir o biocombustível.

Figura 2 - Tipos de Biomassas e suas transformações em biocombustível

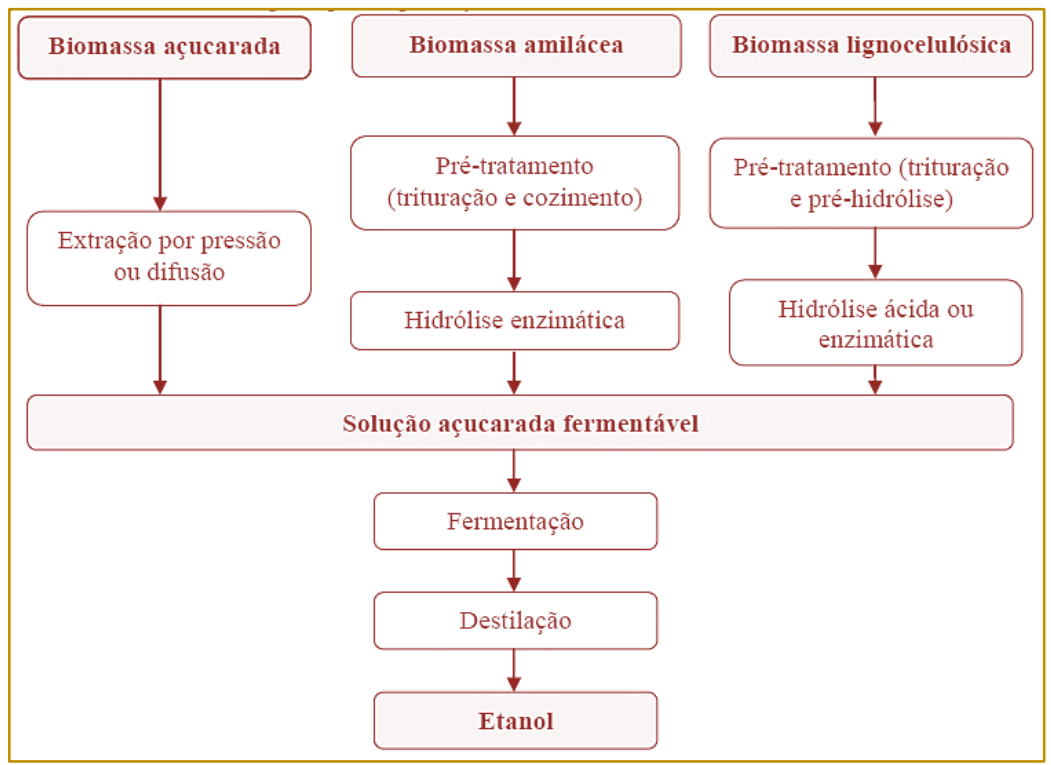

Fonte: Adaptado pelo autor

A produção do biocombustível proveniente da biomassa lignocelulósica passa por um processo físico-químico e biológico de fracionamento dos componentes químicos para transformação em açucares mais simples para posterior fermentação. É necessário desmontar a parede celular para transformar a celulose, hemicelulose e lignina em açucares fermentáveis, isto é, glicose, através de hidrólises com ácidos ou enzimas, uma vez que a estrutura lignocelulósica é muito resistente a bioconversão. As tecnologias atuais são caras e desfavoráveis, neste momento. Uma vez se obtendo açucares fermentáveis, o processo de obtenção do etanol é semelhante ao processo da biomassa açucarada. (SILVA, 2014)

A produção do biocombustível proveniente da biomassa amelace também passa por um processo de moagem, cozimentos e de hidrólise do amido para transformação em cadeias menores de açucares fermentáveis. Esse processo está também muito dominado pois muitos países no mundo produzem etanol de milho. Uma vez obtido o açúcar fermentável, o processo é semelhante aos outros. (MANOCHIO, 2014)

O biodiesel é um biocombustível obtido através da transesterificação de triglicerídeos (Figura 3). Transesterificação é uma reação química entre um éster e um álcool da qual resulta um novo éster e um novo álcool. Significa dizer que é um processo de reação entre as gorduras dos óleos e gorduras em geral com um álcool e um catalisador e assim, a reação química de transesterificação produz dois produtos, o glicerol e uns ésteres que é designado de biodiesel. (LEMOS \& STRADIOTO, 2012) 
Figura 3 - Processo básico de transformação de óleos em biodiesel

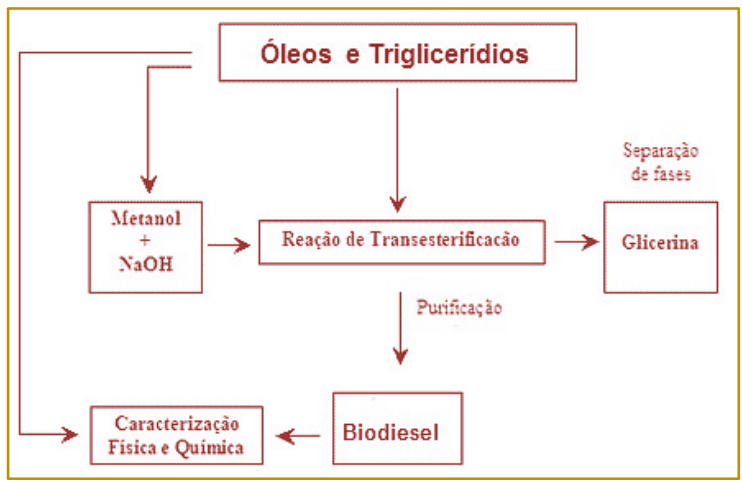

Fonte: Santos et al (2012).

\section{CONSIDERAÇÕES FINAIS}

O uso da biomassa, em especial de biocombustíveis, é muito importante para substituição gradual de combustíveis fósseis na matriz energética brasileira e consequente diminuição da geração dos gases de efeito estufa. O Brasil já possui um destaque neste assunto, pois domina a produção do etanol e do biodiesel. Porém há muito ainda por se fazer, pois há um desperdício enorme de biomassas que são descartadas durante colheita de produtos agroflorestais.

A combustão direta da biomassa e o consumo de gás natural, muito comuns para a sobrevivência de populações rurais e de países subdesenvolvidos, é uma prática também adotada em diversas indústrias brasileiras, mas que tende a diminuir devido às novas tecnologias de transformação da biomassa. Como exemplo a utilização de briquetes e péletes é uma forte tendência como madeira artificial, assim como o bioetanol na substituição de gás natural em

\section{REFERÊNCIAS}

[1] Anp, 2010- Agencia Nacional de Petróleo, Gás Natural e Biocombustíveis. BRASIL. BIODIESEL. 2012. Disponível em: <anp.gov.br/>.

[2] Berman, C., Crise Ambiental e as Energias Renováveis, 2008. Ciência e Cultura, volume 60 № 3.

[3] Bioetanol de cana de açúcar: energia para o desenvolvimento sustentável. Rio de Janeiro: Bnds, 2008. 316p.

[4] Boerrigter, H., Economy of Biomass-toLiquids (BTL) plants - An engineering assessment 2006.

[5] Bnds Setorial- Papel e Celulose, 2010, Perspectivas do setor de biomassa de madeira para a geração de energia residências, cogeração termelétrica e em veículos.

Há significativas vantagens na produção de energia proveniente de biomassas, são ganhos socioambientais e econômicos, mas o setor carece de estudos científicos para inovação tecnológica em toda cadeia produtiva. Também há grandes dificuldades para cumprimentos de legislações, mitigação de impactos ao meio ambiente e cuidados para a saúde humana.

A biomassa e a bioenergia são ferramentas propulsoras de desenvolvimento sustentável da indústria em geral, inclusive a agroindústria, proporcionando desenvolvimento do homem do campo, o cumprimentos dos protocolos de acordo mundiais sobre clima, redução do desmatamento, utilização de Mecanismo de Desenvolvimento Limpo (MDL) por meio de florestas energéticas, além da utilização dos créditos de carbono entre nações.

[6] Brasil, 2016. Ministério de Minas e Energia. Balanço energético nacional. Brasília, DF: MME, $1982 . \quad$ Disponível em: <http://www.iee.usp.br/gbio/?q=livro/fontes-debiomassa>. Acesso: 12 mai. 2018

[7] Carbonari, A. C., et al, Livro Bioenergia Desenvolvimento, Pesquisa e Inovação. Parte 1, capítulo 3, pag-54, 2012.

[8] Castro, N. J., Dantas, G. A., Bioenergia no Brasil e na Europa: uma análise comparativa, 2008.

[9] Goldemberg, J. Biomassa e energia. Química Nova, São Paulo, v. 32, n. 3, p. 582-587, 2009.

[10] Lal, R.; Science 2004, 304, 1623

[11] Leite, R.C.; Cortez, A.B. O etanol combustível no Brasil. 2004 Disponível em < 
http://www.agencia.cnptia.embrapa.br/Repositorio/ etanol3_000g7gq2cz702wx5ok0wtedt3xdr mftk.pdf> Acesso em: 03 nov. 2013

[12] Lemos, E. G. M, Stradioto, N. R., Bioenergia- Desenvolvimento, pesquisa e inovação, 2012

[13] Manochio, C. , TCC- produção de bioetanol de cana-de-açúcar, milho e beterraba: uma comparação dos indicadores tecnológicos, ambientais e econômicos, 2014

[14] Pacheco, F., Energias renováveis: breves conceitos. Revista Conjuntura e Planejamento, 2006.

[15] Pedroso, L.L.A.; Silva, F.F; Silva, F.F.F; Melo. A.M.; Erthal JR., M.; Shymoia, A.; Matias, I.O. Souza, C.L.M. Demandas atuais e futuras da biomassa e da energia renovável no Brasil e no mundo Braz. J. of Develop., Curitiba, v. 4, n. 5, p. 1980-1996, 2018.

[16] Rocha, J. R. A. S. C.; Machado, J. C.; Carneiro, P. C. S.; Carneiro, J. C.; Resende, M. D. V.; Pereira, A. V.; Carneiro, J. E. S. Elephant grass ecotypes for bioenergy production via direct combustion of biomass. Industrial Crops and Products, Amsterdã, v. 95, p. 27-32, 2017.
[17] Ripoli, T. C. C.; Scientia Agricola. 2000, vol. $57 \mathrm{n} \div 4$

[18] Santos, F.A., et al, Potencial da palha de cana-de-açúcar para produção de etanol, 2012

[19] Silva, V. F. N., Tese- Avaliação dos parâmetros experimentais do fracionamento do bagaço da cana de açúcar na obtenção do etanol celulósico e lignina, 2014.

[20] Vassiliev, S. V.; Baxter, D.; Andersen, K. K.; Vassileva, C. G. An overview of the chemical composition of biomass. Fuel, Amisterdam, v. 89, n. 5, p. 913-933, 2010

[21] Marafon, A.C.; Santiago, A.D.; Amaral, A.F.C.; Bierhals, A.N.; Paiva, H. L.; GUIMARÃES; V.S. Uso da biomassa para a geração de energia. Ed. Anderson Carlos Marafon et al., Aracaju: documentos Embrapa Tabuleiros Costeiros, 2016. 28 p. (ISSN 1678-1953; 211).

[22] Zhang, Y. H. P.; J. Ind. Microbiol Biotechnol. 2008, 35, 367.

[23] Zheng, Y. I.; PAN, Z.; ZHANG, R.; WANG, D.; Appl. Energy 2009, 86, 2459.: 10.1590/S010040422012000500025

[24] Www.Lippel.Com.Br, Acesso Março,2018

[25] Www. Biodieselbr.com, Acesso Abril, 2018 


\section{Gapítulo 13}

\section{ESTRATEGIAS DE INOVAÇÃO E MODOS DE GESTÃO DA PESQUISA EMPRESARIAL}

\section{Omar Ouro-Salim}

\section{Karine de Jesus Santana}

\section{José Eduardo Machado Barroso}

\section{Marcela Cabral Mendes Barroso}

Fausto Teodoro Neves

\section{Elcimara Rabelo de Oliveira}

Resumo: Desde meados da década de 1990, a pesquisa corporativa foi desafiada em suas formas tradicionais pelo surgimento de um regime competitivo de inovação, que agora afeta um número crescente de indústrias. As expectativas para alcançar os resultados da pesquisa são mais urgentes quando se trata de inovar as empresas de forma repetida e radical, enquanto, ao mesmo tempo, a pesquisa está experimentando uma racionalização de seus orçamentos e seus processos. Embora nem todas as inovações exigem a incorporação de um novo e significativo conteúdo de conhecimento, algumas são baseadas em avanços científicos e técnicos. É o caso das inovações de produtos. O presente trabalho tem como objetivo aprofundar os conhecimentos sobre inovação, identificando e analisando fatores determinantes e necessários em seu processo, no meio da organização até a consolidação tecnológica. Do ponto de vista metodológico, quanto aos fins à pesquisa caracteriza-se como descritiva, quanto aos procedimentos, bibliográfica quanto à análise do problema, qualitativa. Atualmente o caminho de sucesso para as organizações encontra-se na inovação.

Palavras-chave: Inovação, Pesquisa, Organização. 


\section{INTRODUÇÃO}

Perante à intensificação da concorrência e à rápida evolução dos mercados, a inovação tornou-se um dos componentes primordiais da competitividade das empresas. Assim, para lidar contra as importações têxteis chineses beneficentes dos custos de mão-deobra, as empresas ocidentais, investem massivamente na inovação tecnológica, afim de permanecer e sobreviver no mercado cada vez competitivo. Nessa globalização, a necessidade de inovar é cada vez elevada. Fenômenos como a globalização dos mercados, a revolução científica e tecnológica e o desenvolvimento dos meios de comunicação fazem com que a competitividade entre as organizações e a busca pela perfeição de produtos e processos aumentem cada vez mais, tornando-se necessária a criação de produtos e processos novos para a sobrevivência das organizações (WEIL, 2003).

O papel da inovação, como sinônimo de crescimento foi enfatizado ao nível macroeconômico por Kondratiev (1892-1938) e depois pela análise de Schumpeter (18831950). Os autores expliquem as fases ascendentes de ciclos econômicos pelo avanço da inovação, traduzindo pela aplicação de novas tecnologias e sua difusão na sociedade. Assim, as novas tecnologias de informação e de comunicação (NTIC) poderiam refletir uma nova economia, fundada em um novo paradigma de crescimento. Portanto, há vinte anos atrás, o foco da empresa era reduzir custos e controlar canais de produção em torno de produtos padronizados. Na década de 1990, o choque da globalização arruinou os benefícios das empresas. Nesse sentido, torna-se essencial para as empresas inovarem para não desaparecerem. A inovação é uma condição essencial para a sobrevivência e o desenvolvimento de muitas empresas. Além disso, a inovação pode ser definida como a transição para a aplicação industrial ou comercial de uma invenção dentro de uma empresa. Distingue-se entre a inovação de produtos (novos produtos ou um produto que incorpora um novo processo), inovação de processo (novo processo de fabricação na empresa). Embora a inovação seja um dos impulsos de crescimento para a empresa, as pesquisas na área de marketing mostram que o processo de inovação é complexo e cheio de incertezas (WEIL, 2003).

Isso nos leva à seguinte questão: em que medida a inovação é um fator chave no sucesso empresarial?

Para responder a esta pergunta, mostra-se oportuno falar primeiramente da definição da inovação em vários aspectos, da gestão da inovação, da gestão das equipes, da inovação e suas vantagens, da rentabilidade da inovação, dos ênfases estratégicos, da mobilização das competências dos atores, e da consolidação tecnológica, além das conclusões.

\section{DEFINIÇÃO DA INOVAÇÃO}

O conceito da inovação é bastante variado e depende, principalmente, da sua aplicação. A inovação é então uma iniciativa, modesta ou revolucionária, que apareça como uma novidade para as organizações e mercados e que, aplicada na prática, traz resultados econômicos para as organizações. Outros tipos de inovações podem se relacionar a novos mercados, novos processos, novos produtos, novos modelos de negócio e métodos organizacionais ou até mesmo novas fontes de cadeias de suprimentos (INSTITUTO INOVAÇÃO, 2008).

Houve várias definições dos autores sobre o significado "inovação". Logo seguida apresentaremos as definições dos autores de acordo com a tabela 1. 
Tabela 1: Autores e sua percepção da inovação

\begin{tabular}{|c|c|}
\hline Autores & Definição \\
\hline $\begin{array}{l}\text { Martin Bell e Keith } \\
\text { Pavitt }\end{array}$ & A inovação pode ser vista como um processo de aprendizagem organizacional. \\
\hline C.K. Prahalad & $\begin{array}{l}\text { Inovação é adotar novas tecnologias que permitem aumentar a competitividade da } \\
\text { companhia. }\end{array}$ \\
\hline Ernest Gundling & $\begin{array}{l}\text { Inovação é uma nova ideia implementada com sucesso, que produz resultados } \\
\text { econômicos. }\end{array}$ \\
\hline Fritjof Capra & As organizações inovadoras são aquelas que se aproximam do limite do caos. \\
\hline Giovanni Dosi & $\begin{array}{l}\text { Inovação é a busca, descoberta, experimentação, desenvolvimento, imitação e } \\
\text { adoção de novos produtos, novos processos e novas técnicas organizacionais. }\end{array}$ \\
\hline Gary Hamel & A inovação caracteriza-se pela abertura de um novo mercado. \\
\hline Guilherme Ary Plonski & $\begin{array}{l}\text { Inovação pode ter vários significados e a sua compreensão depende do contexto } \\
\text { em que ela for aplicada. Pode ser ao mesmo tempo resultado e processo ou ser } \\
\text { associada à tecnologia ou marketing. }\end{array}$ \\
\hline Peter Drucker & $\begin{array}{l}\text { Inovação é o ato de atribuir novas capacidades aos recursos (pessoas e } \\
\text { processos) existentes na empresa para gerar riqueza. }\end{array}$ \\
\hline Price Pritchett & $\begin{array}{l}\text { Inovação é como nós nos mantemos à frente do nosso ambiente. As inovações } \\
\text { fora da nossa organização vão acontecer "quando elas quiserem" estejamos } \\
\text { prontos ou não. }\end{array}$ \\
\hline $\begin{array}{l}\text { Ronald Jonash e Tom } \\
\text { Sommerlatte }\end{array}$ & $\begin{array}{l}\text { Inovação é um processo de alavancar a criatividade para criar valor de novas } \\
\text { maneiras, através de novos produtos, novos serviços e novos negócios. }\end{array}$ \\
\hline Tom Kelley & Inovação é o resultado de um esforço de time. \\
\hline
\end{tabular}

\section{GESTÃO DA INOVAÇÃO}

No contexto da globalização e do mercado livre em que a competição é, de certo modo, inevitável, a dinâmica de qualquer empreendimento econômico pode ser analiticamente interpretada por meio da lógica criativa, onde a força motriz do progresso é a inovação, evidenciada por produtos novos, processos novos e/ou modelos de negócios novos (CRIBB, 2007).

Portanto, a gestão da inovação vai muito além do alcance das equipes de produção $e$ desenvolvimento. Muitas inovações não vêm da tecnologia, embora sua implementação possa exigir a solução de problemas técnicos complexos. Isso pode ser a prestação de novos serviços em torno de um produto ou serviço (como o serviço de provisão de veículos), uma nova arquitetura de entrega (como as vendas de computadores montados sob demanda e entregues prontamente após uma encomenda por correio ou compra pela internet, ou a oferta de um serviço "interno" em 48 horas por empresas, por correspondência, ou por distribuição de livros através da Internet). Novas ideias para produtos ou serviços podem vir de um departamento de marketing ou emergir em qualquer lugar dentro da empresa, especialmente entre funcionários que estão em contato com o cliente ou enfrentam um problema particular (WEIL, 2003).
A gestão da inovação assume várias formas de acordo com o contexto particular da empresa e implementa vários dispositivos para conscientizar os funcionários referente a necessidade de inovar, encorajá-los a expressar suas ideias, observações em relação aos comportamentos de clientes, fornecedores, ou concorrentes, e acima de tudo, empurra a hierarquia intermediária e superior para avaliar essas contribuições, respondendo rapidamente às sugestões, seja estudá-las ou explicando por que elas não são mantidas, para fins de valorizar os inovadores. Porém, a gestão da tecnologia, representa apenas a parte do dispositivo. Contudo, a palavra tecnologia em um sentido amplo, inclui tudo que está organizado em habilidades e alguns dos quais podem ser aplicados em uma área mais ampla. Considere-se sucessivamente os problemas tradicionais da gestão de equipes dos produtos e desenvolvimento, em seguida, a necessidade de uma gestão integrada de tecnologia baseada em capacitação de a empresa detectar e integrar técnicas exógenas, a fim de gerenciar as habilidades, estratégias, capitalização e gestão do conhecimento, para melhorar o know-how além do seu campo de atividade (WEIL, 2003). 


\section{GESTÃO DE RECURSOS HUMANOS NAS ORGANIZAÇÕES}

Durante muito tempo, a literatura sobre o gerenciamento da tecnologia se concentrou na gestão da pesquisa e desenvolvimento (P\&D) esquecendo da gestão de equipes trabalhadores. Uma série de problemas pode acontecer no desenvolvimento da inovação nas organizações. Por exemplo, como gerenciar uma atividade cujos os resultados são incertos, distantes e ambíguos? Se na farmácia (exceto biotecnologia) é necessário sintetizar dez mil moléculas para encontrar uma droga, como julgar então os resultados dos pesquisadores? Será que a sorte tem um papel importante nos resultados das pesquisas? Outra dificuldade é como gerenciar indivíduos mais competentes do que aqueles que os supervisionam e avaliam? Todas essas perguntas permitem refletir em relação à gestão de recursos humanos nas organizações (WEIL, 2003).

No entanto, o desafio da gestão de recursos humanos tem sido estudado em pesquisa, bem como o impacto e os efeitos perversos de certos dispositivos de gerenciamento, como a escala dupla (reconhecimento da contribuição dos especialistas em paralelo com os gerentes) (ALLEN; KATZ, 1988).

Um pesquisador que frequentemente pergunta sobre os resultados da pesquisa, não é confiável ou preguiçoso. A admiração de pares é um motor poderoso e Steve Jobs usou isso para estimular os desenvolvedores da Apple, que poderiam ser aplaudidos ou silenciados de acordo com a impressão dada por suas atitudes (SCULLEY, 1988).

Bailyn (1996), por sua vez, mostra a má interpretação dos gerentes ou dos orientadores que geralmente oferecem pouca orientação sobre os objetivos de uma pesquisa, acreditando que os pesquisadores compreendam melhor as questões em seu campo, mas impõem trabalho bastante rígido, enquanto os pesquisadores esperem o contrário, desejando ter uma grande margem de manobra tática na forma de se organizar, justificada pela sua competência profissional (BAILYN, 1996).

Gerenciar os horizontes de conflitos de operações e pesquisas é um desafio adicional dos gerentes. Assim, o gerente de uma equipe de pesquisadores se comporta como um empresário: ele resolve os problemas materiais para permitir que o pesquisador "se concentra em sua arte", ele promove os resultados do pesquisador externamente e a relevância do seu trabalho, ele reforça o status do pesquisador, fazendo-o sentir-se apreciado. Este tradutor de empresários infla a atenção de seus diversos interlocutores, fazendo com que o pesquisador esteja ciente das prioridades estratégicas da organização e, portanto, dos temas relevantes e permitindo que os colaboradores da empresa apreciem a contribuição do pesquisador. Além disso, o gerente desempenha um papel de tela ou tampão entre as diferentes lógicas e, em particular, entre os horizontes temporais em conflito: o da empresa que deseja uma grande reatividade e a do pesquisador que precisa de tempo para construir uma competência (WEIL, 2003).

\section{INOVAÇÃO E SUAS VANTAGENS}

Em um ambiente competitivo e diante das mudanças estruturais, as organizações estão empenhando na inovação que é um ativo essencial para o crescimento e 0 desenvolvimento das organizações. Portanto, graças à inovação, as organizações podem desenvolver uma competitividade sustentável. Assim, as organizações procuram desenvolver inovações levando em consideração os riscos associados nela (WEIL, 2003).

A inovação permite que as empresas fortaleçam sua posição competitiva nos mercados. Ela permite que às empresas aumentem suas produtividades, melhorem a qualidade de seus produtos e serviços, e desenvolvem consequentemente suas competências-chave. Além disso, ela permite que as empresas melhorem sua competitividade sem preço. Porter (1991) enfatiza que a inovação é a chave para a competitividade das empresas pois fortalece sua capacidade de se manter competitivas nos mercados nacionais como internacionais.

A inovação é um fator determinante na competitividade e na rentabilidade das organizações, e portanto, é a parte essencial da estratégia da organização. Assim, inovar permite que a empresa tenha vantagem competitiva em termos de custo ou oferta de produtos. Nesse contexto, a empresa pode aplicar uma estratégia de preços mais baixos ou uma estratégia de aumento das margens. Quando a inovação relaciona-se aos produtos, a empresa diferencia-se dos seus 
concorrentes. A estratégia de diferenciação é muitas vezes adotada por grandes empresas inovadoras que podem coexistir lado a lado com grandes grupos (WEIL, 2003).

\subsection{A RENTABILIDADE DA INOVAÇÃO}

Embora a inovação ofereça uma vantagem competitiva, sua rentabilidade permanece incerta, e pode dificultar o desenvolvimento da empresa. No entanto, a rentabilidade da inovação é incerta devida aos seus efeitos anticoncorrenciais. A inovação tem um impacto na estrutura dos concorrentes e dos preços. Isso pode levar a distorções em relação ao modelo competitivo tradicional (concorrência pura e perfeita) e, também, às situações de otimização de Pareto. Portanto, com a preocupação de otimizar a alocação de recursos, as empresas poderão projetar uma política para monitorar os efeitos anticoncorrenciais da inovação, eliminando os benefícios adicionais da inovação. É o caso do maior fabricante de software do mundo, Microsoft. Inicialmente beneficiando de uma vantagem tecnológica, o Microsoft, por um lado, conseguiu impor aos fabricantes de microcomputadores seus sistemas operacionais (MS-DOS e Windows) e, por outro lado, assinou contratos com eles com base um sistema chamado "processador" que forçou os fabricantes a equipar seu hardware com o software do Microsoft. A empresa do Bill Gates foi, assim, construída nos anos 80 como um monopólio virtual no mercado de softwares de aplicação (WEIL, 2003).

\section{2 ÊNFASES ESTRATÉGICOS DA INOVAÇÃO}

Esta parte, centra-se na gestão das atividades de pesquisa dentro das empresas que são implantadas em um contexto competitivo marcado por um peso muito forte da inovação. Certas indústrias pensam em computadores, eletrônicos, automóveis ou nas indústrias criativas em torno da moda e do design e estão hoje envolvidas em uma competição por meio da inovação (WEIL, 2003).
Autores como Chapel (1997), Hatchuel et al. (1998), Hatchuel (2001), afirmam que as indústrias (eletrônicas, automóveis), entraram em um regime real de "inovação intensiva", que refere-se à frequência de inovação. A inovação afeta todas as dimensões da oferta (produto/serviço, distribuição, etc.). Para as empresas que operam no setor mercadológico, a capacidade de suportar a alta taxa de inovações, traz novas funções, novos valores de uso para os clientes e até mesmo sua sobrevivência no mercado (BROWN; EISENHARDT, 1998).

As organizações de pesquisas em empresas industriais estão passando por uma grande reestruturação, em particular com o enfraquecimento ou mesmo a desestruturação de grandes laboratórios centrais, longos emblemas do poder científico das grandes empresas ocidentais (BERGER, 2006).

Para responder à questão referente a utilidade ou a inutilidade da pesquisa em relação à inovação, é necessário especificar o que se entende por inovação, já que, por trás desse mesmo termo extremamente diferente das inovações de marketing para o desenvolvimento de novos produtos para satisfazer os clientes cada vez exigentes. 0 trabalho de Hatchuel (1996), Hatchuel e Weil (2003) e Le Masson et al. (2006), são muito úteis para o conhecimento da noção de inovação. Esses autores desenvolveram uma teoria chamada "C-K" que apresenta o raciocínio do design como uma jornada de dois sentidos entre dois espaços: o espaço conceitual "C" e o espaço de conhecimento "K" (ver Tabela 2). Eles caracterizam as inovações de acordo com duas dimensões: a diferença mais ou menos importante entre o conceito em que se baseia uma inovação e os conceitos já existentes e o fosso mais ou menos importante entre o conhecimento que a inovação incorpora e o estoque de conhecimento existente. O pequeno desvio notado " $\delta$ " representa (pequeno delta) e o grande desvio notado " $\Delta$ " representa (grande delta). Por meio dessas duas dimensões, é possível distinguir quatro tipos de situações de inovação (ver Tabela 2). 
Tabela 2: As quatro situações de inovação, de acordo com a teoria

\begin{tabular}{|c|c|c|c|}
\multicolumn{2}{c|}{} & \multicolumn{2}{c|}{ Conhecimentos $\mathrm{K}$} \\
\hline \multirow{2}{*}{ Concepções } & $\delta \mathrm{C}$ & $\begin{array}{c}\text { Não mobilize pesquisa e pouco } \\
\text { desenvolvimento }\end{array}$ & Novo processo químico reduzindo custos \\
\cline { 2 - 4 } & $\Delta \mathrm{C}$ & Tampa-prego & Nylon \\
\hline
\end{tabular}

Fonte: Le Masson et al, 2006

Algumas inovações exigem pouco conhecimento (coluna de pequeno delta $(K)$ da Tabela 2). São inovações que representam uma baixa expansão conceitual (de acordo com os termos da teoria C-K): por exemplo modificações menores de um modelo de veículo; essas inovações incrementais não necessitam de pesquisas e são menos desenvolvidas. Essas inovações não exigem novos conhecimentos, mas introduzem um conceito inovador, por exemplo, o "suporte prego", que consiste em um dispositivo muito simples para manter um prego na posição desejada além de segurá-lo entre os dedos, o que torna possível evitar esmagar esses últimos com golpes de martelo.

Por outro lado, algumas inovações exigem uma criação significativa de conhecimento (coluna grande delta (K) da Tabela 2). Portanto, essas inovações não representam uma expansão conceitual significativa. É O caso do desenvolvimento de um novo processo químico para reduzir custos, mas sem alterar as propriedades do produto. Outras inovações combinam uma forte expansão conceitual e uma importante criação de novos conhecimentos. Restando no campo da química, este é, por exemplo, o caso da invenção do nylon por DuPont Nemours, que abriu imensas perspectivas no campo dos têxteis e que decorreu dos esforços das pesquisas prolongadas.

No ambiente competitivo atual, a competitividade das empresas é principalmente focalizada na capacidade de inovar com novas funcionalidades; oferecendo novos produtos/serviços para os clientes que a empresa pode esperar para se destacar por um tempo de seus concorrentes, sem ser obrigada a entrar em guerras de preços extremamente caros. Na maioria das vezes, requer-se uma importante criação de conhecimento científico e técnico. As inovações do tipo $(\Delta C-\Delta K)$, são alavancas muito poderosas para a competitividade das empresas pertencentes a esse tipo de indústria.
As dificuldades que a inovação tecnológica encontra nas empresas, atualmente, são devidas às vezes a uma insatisfação das direções das empresas, quanto à sua eficiência. A pesquisa seria útil para inovar, mas ineficaz, ou pelo menos julgada como insuficientemente efetiva por seus financiadores. A noção de eficiência refere-se tanto à definição clássica de controle de gestão (capacidade de alcançar os objetivos estabelecidos) quanto à aceitação por Barnard (1938), ou mais tarde às teorias de controle externo (especialmente a teoria da dependência de recursos de Pfeffer e Salancik (1978), a capacidade de atender às expectativas, as demandas de grupos que dominam recursos escassos e cruciais para a sustentabilidade da organização.

\section{A MOBILIZAÇÃO DAS COMPETÊNCIAS DOS ATORES}

A inovação e a produção de conhecimento dependem da criatividade de todos os atores da empresa e de sua capacidade de assumir riscos. As inovações radicais exigem daqueles que estão na origem dela uma capacidade de convencer sua hierarquia, de se impor em relação a estratégias e estruturas, muitas vezes sinônimo de inércia e conformidade. O empresário desempenha um papel fundamental, já que a criação da empresa é muitas vezes o resultado da inovação. Em seguida, deve espalhar dentro da organização uma cultura de mudança, valorizando as iniciativas, mesmo que falhem (WEIL, 2003).

Em grandes empresas, os empresários foram substituídos por gerentes que não têm uma cultura de risco, o que dificulta a inovação, de forma inerente segue uma lógica de desordem: não deve ser canalizada, mas guiada por uma partilha de valores comuns. A gestão geral da empresa, o principal detentor do poder de decisão, tem um papel fundamental a desempenhar na mobilização e envolvimento de todos os funcionários em 
todos os níveis da hierarquia, facilitando a transição da lógica de planejamento para uma lógica de "intraempreendedorismo" (WEIL, 2003).

Os pesquisadores da inovação estão na origem da maioria das inovações na empresa. Eles devem implementar uma determinada gestão que atenda suas expectativas para atraí-las e mantê-las. Essas expectativas são específicas e não podem ser comparadas com os fatores motivacionais dos funcionários. A maioria das empresas atribui importância à atmosfera cooperativa e amigável em que ela trabalha, o que não é surpreendente quando sabe-se que as inovações atuais não são mais o trabalho de um único homem e uma feliz coincidência, mas um esforço em equipe para criar sinergias entre diferentes níveis da organização. No entanto, é importante fidelizar os pesquisadores inovadores, pois a perda de um deles às vezes pode ser catastrófica para a empresa (WEIL, 2003).

\section{CONSOLIDAÇÃO TECNOLÓGICA}

Organizações inteligentes sempre reconheceram a importância de ligações e conexões, aproximando-se de clientes ou consumidores para melhor compreender suas necessidades, junto com fornecedores para que disponibilizem soluções inovadoras, criando vínculos com colaboradores, stackholders, centros de pesquisas, e até concorrentes, com vistas à construção e operação de sistemas em inovação. (BESSANT; TIDD, 2009).

A concorrência nos mercados internacionais aumentou significativamente a globalização das informações e das comunicações. A concorrência não implica mais apenas custos e preços, mas engloba de forma geral a conquista de novas cotas de mercado, diversificação dos modelos e dos produtos entre outros. As mudanças levam a uma larga gama de alianças entre empresas, formalizadas contratualmente ou informais. De acordo com Feitosa (2008), essas relações contratuais consolidadas assumem novo papel e adquirem maior relevância no panorama econômico contemporâneo, onde inovar tecnologicamente significa manter a posição no mercado e crescer.

A consolidação e o comprometimento entre organizações podem representar uma alternativa viável na defesa de sua competitividade no mercado, desde que conduzida de modo eficaz, no momento oportuno e com o parceiro adequado. Boa parte das alianças entre organizações de menor potencial compreende a comercialização dos novos produtos e serviços no mercado, a integração dos próprios produtos com algumas linhas de oferta e a permuta de faixas de utilização por produtos ou serviços complementares (FEITOSA, 2008).

Os acordos de consolidação tecnológica, na concepção de Feitosa (2008), visam algumas vantagens como transferência de tecnologias entre organizações, cessão de licença, pesquisa de complementação tecnológica. Para ser exercida de maneira eficiente, a consolidação construtiva entre organizações requer uma atenta avaliação dos proveitos e dos riscos; das vantagens e desvantagens econômicas que pode comportar.

\section{CONCLUSÕES}

A inovação tornou-se uma abordagem estratégica em seu próprio direito de enfrentar a intensificação da concorrência e a evolução perpétua do mercado. Isso se traduz no desejo de manter e aumentar a participação no mercado e reduzir custos e maior flexibilidade de produção.

O domínio da inovação permite que algumas empresas entrem no mercado enquanto outras desaparecem por falta de modernização. O grau de inovação de um setor, portanto, condiciona o nível de barreiras à entrada de novos concorrentes. No entanto, o empresário deve ter em mente que a inovação requer estruturas capazes de assumir os riscos técnicos, financeiros, comerciais, humanos e legais associados a ela.

As empresas procuram inovações em todas as suas formas, porque lhes permitem aumentar sua competitividade, seja por um melhor controle de custos, seja por terem um monopólio (temporário ou sustentável) no mercado. A inovação, portanto, determina a estratégia da empresa.

No entanto, esse processo de inovação gera restrições financeiras, técnicas e outras. A inovação e a organização são dois conceitos antagônicos, o primeiro baseado na instabilidade, liberdade e flexibilidade e outro que requer estruturas estáveis. Além disso, a 
empresa se esforça para implementar estruturas flexíveis com objetivo de produzir resultados acionáveis.

O financiamento cada vez mais pesado tende a direcionar as empresas para uma estratégia

\section{REFERÊNCIAS}

[1] Allen, J.; Katz, R. The dual ladder: motivational solution or managerial delusion? R\&D Management. Cambridge. 1998.

[2] Bailyn, L. Autonomy in the Industrial R\&D Lab, Human Resource Management Summer, ed. 24, n-2, p.129-146. 1996

[3] Barnard, C. I. The Functions of the Executive, Harvard University Press, Cambridge. 1938.

[4] Berger, S. Les nouvelles frontières de l'économie mondiale, Seuil, Paris. 2006.

[5] Bessant, J.; Tidd, J. Inovação e Empreendedorismo. Porto Alegre: Bookman, 2009.

[6] Brown, S. L.; Eisenhardt, K. M. Competing on the edge: Strategy as structured chaos, Harvard Business Scholl Press. 1998

[7] Chapel, V. La croissance par l'innovation intensive, de la dynamique d'apprentissage à la révélation d'un modèle industriel, le cas Tefal, Thèse de doctorat, spécialité : Ingénierie et gestion, École des Mines de Paris, Paris. 1997.

[8] Cribb, A. Y. Artigo Mudança cultural coletiva: o pré-requisito da inovação no Brasil. Publicação Jornal da Ciência em 27 nov.2007. Disponível em:<http://www.protec.org.br/ artigos.asp?cod=106 >. Acesso em 12 mar. 2008.

[9] Feitosa, M. L. P. A. M. Acordos de cooperação entre empresas e o efeito rede. Disponível em:< http://jus2.uol.com.br/doutrina/ texto.asp?id=3098 > . Acesso em 14 abr.2008.

[10] Hatchuel, A. \& Weil, B. A new approach of innovative design: an introduction to C-K theory, Iced'03, Stockholm, Sweden, August 2003.

[11] Hatchuel, A. « Changement et apprentissage en organisation: les défis d'une économie de conception ", in Ruano-Borbalan J.C. (ed.) Changement et innovation en formation et interativa de inovação que supõe que a empresa estabeleça novas relações com o meio ambiente (fornecedores, clientes, ect.), para constituir uma verdadeira rede de inovação.

organisation, Sciences Humaines, Les Éditions Demos, Paris. 2001

[12] Hatchuel, A. « Comment penser l'action collective ? Théorie des mythes rationnels », In : Damien R. \& Tosel, A. (eds.), Les annales littéraires de Besançon, Besançon. 1996.

[13] Hatchuel, A., Chapel, V. Deroy, X. \& Le Masson, $P$. Innovation répétée et croissance de la firme, rapport de recherche, Cnrs, septembre. 1998.

[14] Hatchuel, A., Le Masson, P. \& Weil, B. From R\&D to RID: Design Strategies and the Management of Innovation Fields. 8th International Product Development Management Conference, Enschede, the Netherlands, June. 2001.

[15] Instituto Inovação. A inovação: Conceitos, a importância de inovar, a dinâmica da inovação. Disponível em:< http://www.institutoinovacao.com.br/inovacao.php >. Acesso em 07 de abril de 2008.

[16] LE Masson, P.; Weil, B. \& Hatchuel, A. Les processus d'innovation, conception innovante et croissance des entreprises, Lavoisier, Hermès, Paris. 2006.

[17] Pfeffer, J. \& Salancik, G.R. The External Control of Organizations, A Resource Dependence Perspective, Harper and Row, New York. 1978.

[18] Porter, M. Estratégia competitiva: técnicas para análise das indústrias e da concorrência. 7 . ed. Rio de Janeiro: Campus. 1991.

[19] Sculley, J. De Pepsi à Apple, Grasset. Oxford, Usa. 1988.

[20] Weil, T. Le management de I' innovation dans les entreprises. Annales des Mines. Paris, 2003. 


\section{Gapítulo 14}

\section{GREEN IT: UMA ANÁLISE DE COCITAÇÃO EM MÚLTIPLAS PERSPECTIVAS}

\section{Carulina Marques}

Nelson Dias da Costa Júnior

Dalton Matsuo Tavares

\section{Stella Jacyszyn Bachega}

Resumo: A Green IT refere-se à adoção de práticas que minimizam o impacto causado pelas atividades da tecnologia de informação ao meio ambiente. Para melhor entendimento destas medidas, faz-se necessária uma revisão sobre os assuntos que os pesquisadores estão estudando relacionados a este tema. Visando este melhor entendimento, a pesquisa aqui realizada utilizou a metodologia conhecida como análise de cocitações em múltiplas perspectivas. Esta técnica refere-se a análise de padrões estruturais, temporais e, também, ao uso de citações para interpretar a natureza dos clusters obtidos por meio do software CiteSpace ${ }^{\circledR}$. Por meio deste estudo foram obtidos relatórios que forneceram dados como os principais pesquisadores do tema, quais autores são os mais citados, quais foram as palavras-chave utilizadas ao se pesquisar sobre Green IT, qual foi a linha do tempo, mostrando o período em que os principais estudos foram realizados e quais são os países que mais pesquisaram sobre o tema.

Palavras-chave: Green IT, CiteSpace ${ }^{\circledR}$, análise de cocitações em múltiplas perspectivas 


\section{INTRODUÇÃO}

Os conceitos relacionados a sustentabilidade ainda estão em processo de maturidade no mundo moderno. Isso ocorre por esta ser uma preocupação recente e, ainda, por não se possuir um conjunto de teorias e experimentos consolidados em termos científicos e práticos, tal como em áreas como ciências matemáticas e física, por exemplo.

Sendo assim, um dos primeiros passos é entender $O$ que é sustentabilidade e desenvolvimento sustentável (BLACKBURN, 2007), além de se averiguar o que há de mais moderno relacionado a esse tema. Neste aspecto, encontra-se o conceito de Green IT que, segundo Murugesan e Gangadharan (2012), refere-se a tecnologias e sistemas de informação sustentáveis e práticas ambientalmente corretas no âmbito da tecnologia da informação. A importância de Green IT se intensifica se for observado o que foi exposto por Kumar e Kannegala (2012), os quais apontam a questão da obsolescência programada dos mais diversos produtos de caráter tecnológico como sendo um dos motivos para o aumento dos possíveis impactos ambientais oriundos de tecnologia da informação.

Considerando que diversas pesquisas dentro dessa temática têm sido realizadas nas últimas décadas, é importante proceder com a identificação de material bibliográfico relevante e dos principais pesquisadores dessa área. Para isso, esse trabalho lança mão de software especializado para realizar o processo de mapeamento bibliográfico e entender o perfil da pesquisa científica na área de Green IT.

Presoto, Souza e Thurler (2013) adotaram uma abordagem sistemática para revisão bibliográfica e incorporaram a utilização do software CiteSpace ${ }^{\circledR}$ para realização de uma análise bibliométrica e para apresentar a construção de um referencial teórico mais robusto. Valerio e Silva (2016) também utilizaram esse software para a obtenção de redes de bibliometria e entenderam que as análises utilizadas permitiram a estruturação de uma literatura capaz de orientar pesquisadores e gestores da área estudada.

Este trabalho tem o objetivo de realizar uma análise da bibliografia relacionada a Green IT a partir da utilização do software CiteSpace ${ }^{\circledR}$, bem como da análise de cocitação em múltiplas perspectivas. Este método foi desenvolvido por Chen (2006) e sugerido para este tipo de estudo. O artigo foi estruturado da seguinte forma: na seção 2 é feita uma breve introdução ao tema; na seção 3 é denotada a metodologia utilizada na pesquisa; na seção 4 são apresentados os resultados obtidos pelo software e suas respectivas análises; e a seção 5 apresenta as considerações finais acerca do que foi discutido e uma proposta de continuidade para o trabalho.

\section{GREEN IT}

Murugesan (2008) afirma que a TI causa impactos ambientais durante diversos estágios. Cada fase da "vida" de um computador, ou de qualquer outro dispositivo, é responsável por danos ambientais, seja durante a produção, uso ou descarte. Portanto, existe a necessidade de atitudes, como a adoção de técnicas de Green IT (ou Tecnologia da Informação Verde), para minimizar estes danos. A Green IT pode ser definida como o estudo e prática de projeto, produção, uso e descarte de computadores, servidores e subsistemas associados de forma eficiente e eficaz com o mínimo ou nenhum impacto sobre o meio ambiente (MURUGESAN; 2008).

Considerando o tema em estudo, é possível estabelecer duas tendências. A primeira tem como foco repensar os produtos e processos, aplicando a reengenharia em busca de aprimorar a eficiência energética e o uso e requisitos de conformidade. A segunda busca dar um incentivo ao se reduzir a destruição do meio ambiente e a emissão de gases que contribuem para o efeito estufa. Sobre o enfoque, o mesmo é pautado em transformar o ambiente de negócios por meio de inovação em TI com foco em sustentabilidade (MURUGESAN; GANGADHARAN, 2012).

\section{METODOLOGIA}

Para a realização do presente estudo utilizouse o método desenvolvido por Chen (2006), conhecido como análise de cocitações em múltiplas perspectivas (ou multipleperspective co-citation analysis). Esta técnica refere-se a análise de padrões estruturais, temporais e também ao uso de citações, para se interpretar a natureza dos clusters, obtidos por meio do software CiteSpace ${ }^{\circledR}$. 
Li, Ma e Qu (2017) descrevem três passos para que seja desenvolvido o método de análise de cocitações em múltiplas perspectivas, a saber:

Construir um banco de dados que atenda aos requisitos do tema a ser pesquisado: para isso, faz-se necessário selecionar uma base de pesquisa que possua artigos de qualidade. A base de dados utilizada para a pesquisa foi a Web of Science (WOS), pois esta é integrada a ferramenta CiteSpace ${ }^{\circledR}$. Além disso, a mesma possui reconhecimento internacional.

Utilizar as palavras-chave corretas durante a realização da pesquisa: o pesquisador deve ter especial atenção em relação a validade e representatividade das palavras e conferir a relevância dos artigos apresentados mediante
- uso de tais palavras. A palavra-chave utilizada para a pesquisa foi 'Green IT. Foram selecionados artigos publicados entre os anos de 2009 a 2018. Tal período foi escolhido devido ao fato de que, segundo gráfico fornecido pela WOS, e apresentado na Fig. (1), foi no ano de 2009 que ocorreu o crescimento em relação ao número de estudos sobre o tema. A continuidade até o ano de 2018 torna possível o alcance de publicações atualizadas.

Estender a base de dados: para tanto, faz-se necessário que a mesma possua a maior cobertura possível em relação aos estudos já realizados. Após a análise dos estudos apresentados pela WOS, foram selecionados 451 artigos. Os mesmos foram exportados para a base de dados do CiteSpace ${ }^{\circledR}$.

Figura 1: Ritmo de publicações referentes a metodologia de Green IT

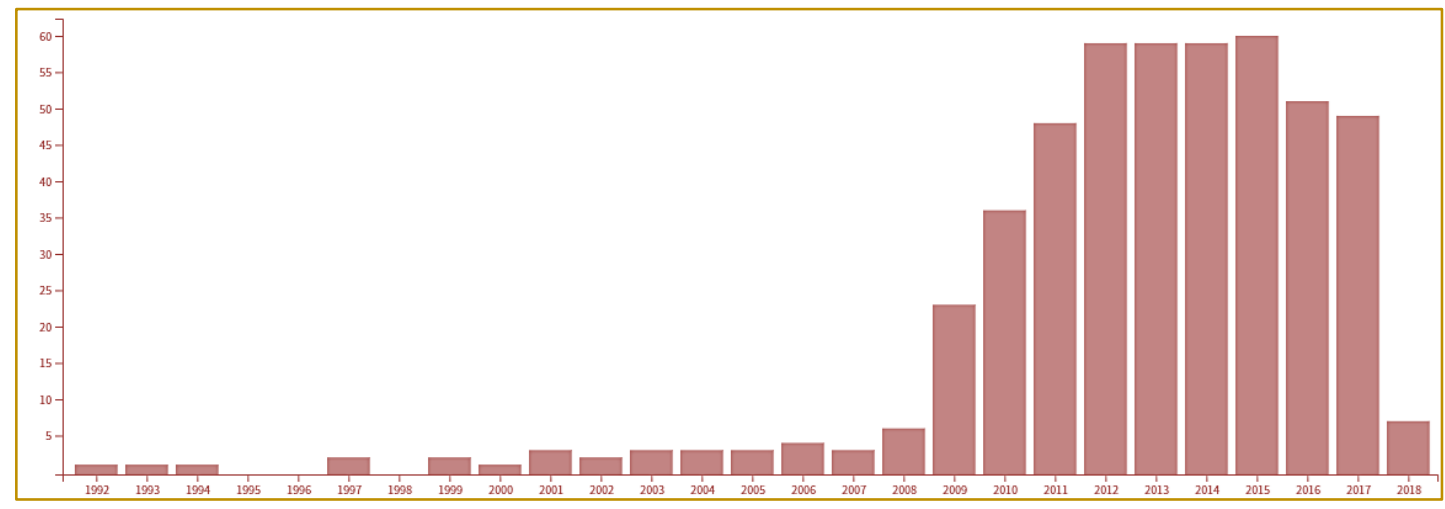

(Fonte: Adaptado de Web of Science)

Os parâmetros utilizados para fazer o mapeamento no software levaram em conta o período (estudos publicados entre 2009 e 2018) e os termos (Term Source) título, resumo, autor e palavras-chave, os quais foram utilizados para a busca e selecionados no CiteSpace ${ }^{\circledR}$. Quanto ao tipo de nó (Node Type), foi selecionado o que se refere as referências citadas.

\section{RESULTADOS}

Abaixo estão descritas as métricas obtidas com o mapeamento feito pelo CiteSpace ${ }^{\circledR}$. Os dados foram obtidos por meio de relatórios fornecidos pelo software.

\section{MAPEAMENTO}

Após a conclusão de todos os passos citados, o CiteSpace ${ }^{\circledR}$ apresentou o mapa que pode ser visto na Fig. (2). Neste, foram identificados 90 conjuntos de referências cocitadas (ou c/usters), ressaltando que cada grupo corresponde a uma linha de pesquisa (o painel onde consta essa informação foi omitido para reduzir o tamanho da figura). Para caracterizar a natureza de um cluster, o CiteSpace ${ }^{\circledR}$ pode extrair frases nominais dos títulos, obtendo assim um agrupamento de estudos que possuem semelhança. Posteriormente ocorre a rotulação dos mesmos. Os clusters são classificados na ordem decrescente do seu tamanho, começando pelo maior cluster (\# 0), para o menor cluster (\#4). Mediante tais parâmetros obteve-se, de acordo com a base de dados aqui analisada, o total de cinco agrupamentos. Para efeitos deste trabalho, foram analisados os agrupamentos contendo a maior quantidade de citações e o seu extremo oposto, o qual contém a menor quantidade de citações, nomeados como \#0 
sustainability e \#4 energy efficient, conforme visto na Fig. (3).

\section{MODULARIDADE E SILHUETA}

Existem algumas medidas utilizadas para caracterizar o mapeamento, as mesmas são fornecidas pelo próprio CiteSpace ${ }^{\circledR}$. Para que ocorra a visualização destes valores, foi acessada a função 'métrica' presente no próprio software. Feito isso, tais parâmetros são mostrados no canto superior esquerdo da tela, conforme Fig. (3). A modularidade Q deve possuir valores entre 0 e 1. Quanto mais próximo de 1, maior é a conexão entre os clusters, ressaltando que valores entre 0,4 e 0,8 são aceitáveis. No caso em análise, o valor de $Q=0,8352$, indica a boa qualidade do cluster apresentado.

Em relação a silhueta, a mesma deve estar compreendida entre -1 e 1. No mapeamento feito sobre Green IT, o valor da silhueta foi de 0,276 . Portanto a mesma encontra-se dentro do escopo admissível.

Figura 2: Mapeamento dos artigos

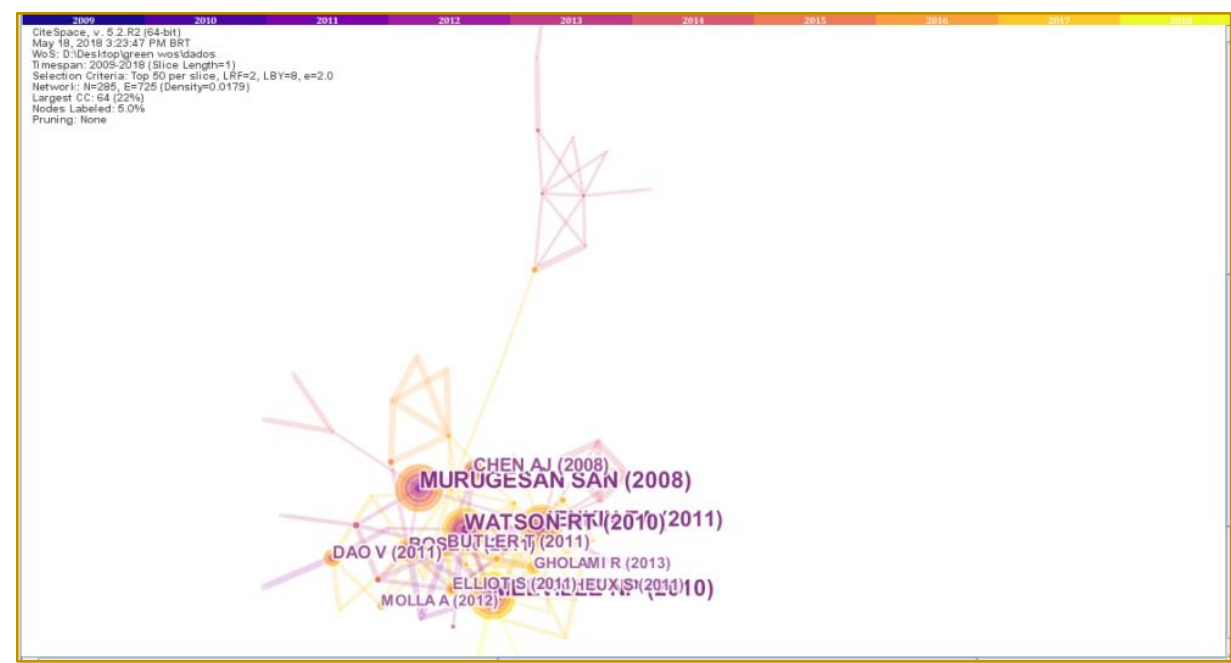

(Fonte: CiteSpace ${ }^{\circledR}$ )

Figura 3: Agrupamentos de citações estudados (\#0 e \#4)

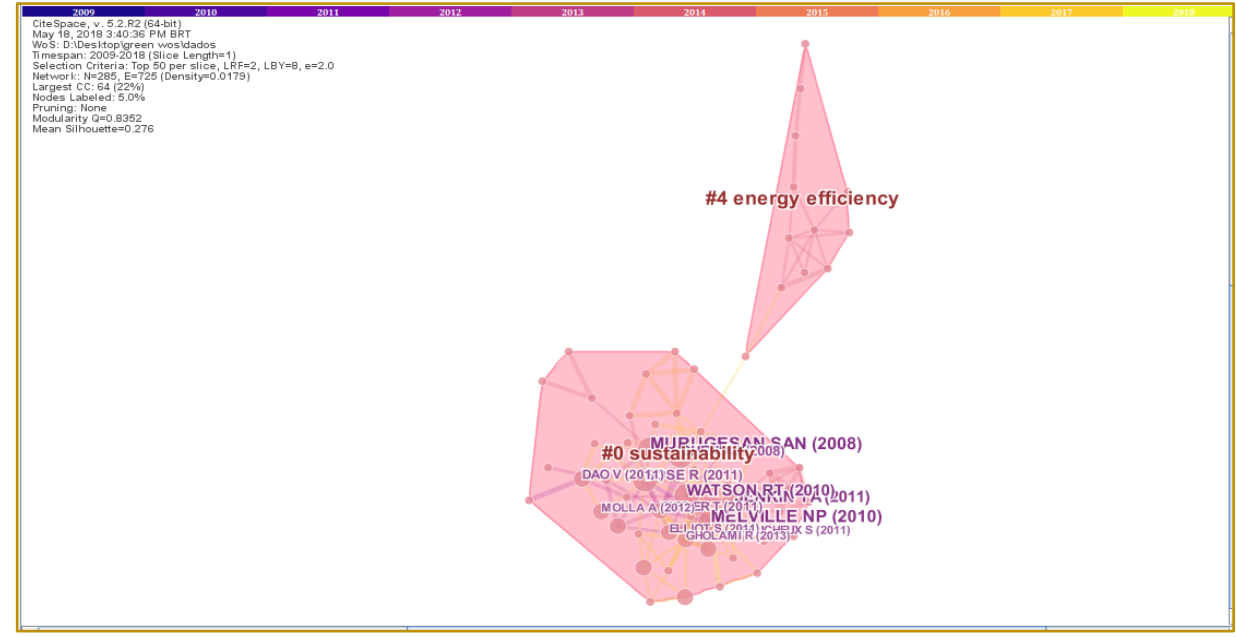

(Fonte: CiteSpace ${ }^{\circledR}$ ) 


\section{DETECÇÃO DE EXPLOSÃO (BURST)}

A detecção de explosão refere-se a um indicativo de uma área de pesquisa mais ativa. Este indicador fornece evidências de que uma publicação tem atraído significativo grau de atenção da comunidade científica e em quais períodos de tempo isso ocorreu. Percebe-se pelos dados apresentados na Tab. (1) que o estudo de Biachini e Rajamony (2004) teve a explosão de citação mais forte
(Força $=3,8775$ ), tendo ocorrido durante um período de dois anos. Observe que as citações da Tab. (1) e demais tabelas, aparecem no formato do relatório automático gerado pelo CiteSpace ${ }^{\circledR}$. Neste, há a indicação do primeiro autor, ano e fonte de publicação, volume e primeira página do artigo.

Tabela 1: Referências com explosão de citações referente a autores

\begin{tabular}{|c|c|c|c|c|}
\hline Referências & Força & Inicio & Fim & 2009-2018 \\
\hline Heath T, 2005, 10 Acm Sigplan S P, 391, 186 & 2,7015 & 2010 & 2013 & \\
\hline $\begin{array}{l}\text { Koomey J, 2007, Estimating Total Pow, 35, } \\
5630\end{array}$ & 2,6271 & 2010 & 2011 & - \\
\hline Bianchini R, 2004, COMPUTER, 37, 68 & 3,8775 & 2010 & 2012 & \\
\hline Orsato RJ, 2006, Calif Manage Rev, 48, 127 & 2,8307 & 2012 & 2013 & \\
\hline $\begin{array}{l}\text { Enokido T, 2010, INT CON ADV INFO NET, 0, } \\
142\end{array}$ & 2,8307 & 2012 & 2013 & \\
\hline $\begin{array}{l}\text { Waluyo AB, 2011, ieee T Ind Electron, 58, } \\
2173\end{array}$ & 2,8307 & 2012 & 2013 & \\
\hline $\begin{array}{l}\text { Koomey JG, 2011, GROWTH DATA CTR } \\
\text { ELEC, 33, } 46\end{array}$ & 2,994 & 2013 & 2014 & \\
\hline Barolli L, 2011, leee T Ind Electron, 58, 2163 & 2,4987 & 2014 & 2015 & \\
\hline $\begin{array}{l}\text { Gracia-Tinedo R, 2013, P } 6 \text { Int C Cloud Comp, } \\
0,621\end{array}$ & 2,4987 & 2014 & 2015 & a \\
\hline Enokido T, 2013, leee T Ind Electron, 60, 824 & 2,9191 & 2014 & 2015 & \\
\hline Molla A, 2012, J COMPUT Inform Syst, 52, 92 & 2,4295 & 2015 & 2018 & \\
\hline
\end{tabular}

Fonte: Adaptado do CiteSpace ${ }^{\circledR}$

Analisando-se publicações mais recentes, nota-se que o estudo de Molla e Abareshi (2012) possui explosão de citações significativa, sendo considerado relevante para a condução de pesquisas mais recentes relacionadas ao tema. Também é possível fazer essa mesma análise considerando-se as palavras-chave. De acordo com a Tab. (2), percebe-se que a palavra mais citada é Green IT. Esta também foi importante para o levantamento realizado no decorrer deste trabalho. Vale ressaltar que existem outros termos relevantes, conforme ilustrado na Tab. (2).

Tabela 2: Explosão de citações por palavras-chave

\begin{tabular}{|l|c|c|c|c|}
\multicolumn{2}{c|}{ Palavras-chave } & Força & Inicio & 2009-2018 \\
\hline Green IT & 9,4222 & 2009 & 2010 & \\
\hline Green IT Technology & 2,672 & 2011 & 2013 & \\
\hline Strategy & 3,516 & 2012 & 2013 & \\
\hline Data Center & 3,0628 & 2014 & 2016 & \\
\hline Model & 2,4777 & 2014 & 2016 & \\
\hline
\end{tabular}

Fonte: Adaptado do CiteSpace ${ }^{\circledR}$ 


\section{CENTRALIDADE}

A Tabela (3) apresenta, de acordo com dados fornecidos pelo CiteSpace ${ }^{\circledR}$, os valores de Centralidade. Esta métrica relaciona-se aos artigos que possuem alto grau de relevância em cada cluster. Em geral, estudos que possuem centralidade igual ou maior a 0,1 são considerados estudos chave.

Tabela 3: Valores de Centralidade

\begin{tabular}{|c|l|c|}
\hline Centralidade & \multicolumn{1}{|c|}{ Referência } & Cluster \# \\
\hline 0,3 & Bose R, 2011, J STRATEGIC INF SYST, 20, 38 & 0 \\
\hline 0,3 & Beloglazov A, 2012, FUTURE GENER COMP SY, 28, 755 & 0 \\
\hline 0,3 & Bai CG, 2013, INFORM SYST FRONT, 15, 831 & 4 \\
\hline 0,3 & Moyer JD, 2012, TECHNOL FORECAST SOC, 79, 919 & 0 \\
\hline 0,3 & Jenkin TA, 2011, INFORM ORGAN-UK, 21, 17 & 0 \\
\hline 0,1 & Murugesan San, 2008, IT PROFESSIONAL, 10, 24 & 0 \\
\hline 0,1 & Melville NP, 2010, MIS QUART, 34, 1 & 0 \\
\hline 0,1 & Watson RT, 2010, MIS QUART, 34, 23 & 0 \\
\hline 0,1 & Butler T, 2011, J STRATEGIC INF SYST, 20, 6 & 0 \\
\hline
\end{tabular}

Fonte: Adaptado do CiteSpace ${ }^{\circledR}$

Percebe-se pelos dados apresentados na Tab. (3) que os estudos apresentados possuem valores satisfatórios de centralidade. Assim, podem ser considerados relevantes quando se deseja realizar uma pesquisa referente a Green IT.

\section{RANKING DE CITAÇÕES}

Também são fornecidos dados referentes ao número de citações que os autores receberam dentro de seus respectivos clusters. Conforme visto na Tab. (4), o autor mais citado foi Muregesan (2008), seguido de Melville (2010).

Tabela 4: Autores mais citados

\begin{tabular}{|c|l|c|}
$\begin{array}{c}\text { Contagem de } \\
\text { Citações }\end{array}$ & \multicolumn{1}{c|}{ Autores } & Cluster \# \\
\hline 43 & Murugesan San, 2008, IT Professional, 10, 24 & 0 \\
\hline 42 & Melville NP, 2010, MIS Quart, 34, 1 & 0 \\
\hline 39 & Jenkin TA, 2011, Inform Organ-UK, 21, 17 & 0 \\
\hline 38 & Watson RT, 2010, MIS Quart, 34, 23 & 0 \\
\hline 21 & Bose R, 2011, J Strategic inf Syst, 20, 38 & 0 \\
\hline 18 & Dao V, 2011, J Strategic InF Syst, 20, 63 & 0 \\
\hline 17 & Butler T, 2011, J Strategic INF Syst, 20, 6 & 4 \\
\hline 15 & Enokido T, 2010, leee Syst J, 4, 221 & 0 \\
\hline
\end{tabular}

Fonte: Adaptado do CiteSpace ${ }^{\circledR}$

Vale observar que também figuram Enokido, Aikebaier e Takizawa (2010), pertencentes ao cluster \#4, o qual seria aquele com menor quantidade de citações. Mesmo assim, esta referência não ocupa a última posição da Tab. (4), o que revela a importância pela análise de todos os clusters identificados de modo a não se perder referências relevantes. Esta observação torna-se mais forte na avaliação da Tab. (5) discutida na próxima seção.

\section{SIGMA}

O valor de sigma faz uma combinação entre duas métricas citadas anteriormente, sendo elas, a detecção de explosão e a centralidade. Por meio deste uso combinado obteve-se os dados apresentados na Tab. (5). É possível observar a ordem dos estudos que atraíram atenção da comunidade científica e que possuem relevância para a área em estudo. 
Tabela 5: Sigma

\begin{tabular}{|c|c|c|}
\hline Sigma & Referências & Cluster \# \\
\hline 1 & Bose R, 2011, J STRATEGIC INF SYST, 20, 38 & 0 \\
\hline 1 & Beloglazov A, 2012, FUTURE GENER COMP SY, 28, 755 & 4 \\
\hline 1 & Bai CG, 2013, INFORM SYST FRONT, 15, 831 & 0 \\
\hline 1 & Moyer JD, 2012, TECHNOL FORECAST SOC, 79, 919 & 4 \\
\hline 1 & Jenkin TA, 2011, INFORM ORGAN-UK, 21, 17 & 0 \\
\hline 1 & Murugesan San, 2008, IT PROFESSIONAL, 10, 24 & 0 \\
\hline 1 & Melville NP, 2010, MIS QUART, 34, 1 & 0 \\
\hline 1 & Watson RT, 2010, MIS QUART, 34, 23 & 0 \\
\hline 1 & Butler T, 2011, J STRATEGIC INF SYST, 20, 6 & 0 \\
\hline 1 & Gholami R, 2013, INFORM MANAGE-AMSTER, 50, 431 & 0 \\
\hline
\end{tabular}

\section{LINHA DO TEMPO}

Para que os estudos referentes a Green IT sejam melhores analisados, o CiteSpace ${ }^{\circledR}$ faz o mapeamento de acordo com a linha do tempo. Fazer a identificação de quando os estudos mais relevantes foram publicados proporciona aos pesquisadores acesso aos períodos que possuem maior número de pesquisas e também conhecimento sobre a relevância das mesmas. A Figura (4) apresenta a linha do tempo para os clusters considerados.

Figura 4: Linha do tempo

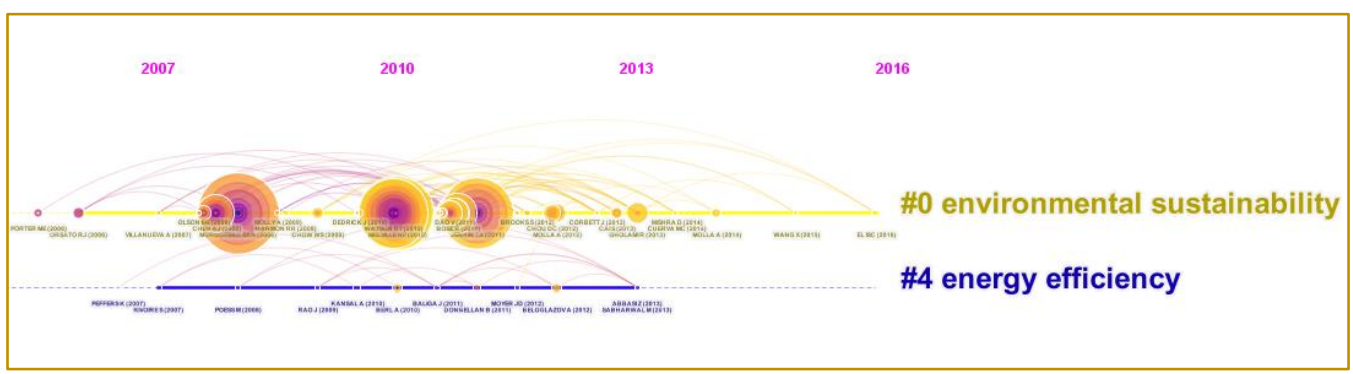

Fonte: CiteSpace ${ }^{\circledR}$

Pela linha apresentada, no período de 2008 a 2011 houve um grande fluxo de publicações relacionados ao tema. O tamanho dos círculos representa o índice de centralidade. Logo, é possível concluir que durante o período citado, os artigos publicados que fazem parte do cluster \#0 environmental sustainability, possuem relevância para pesquisadores que desejam realizar estudos referentes a Green IT. De forma análoga, no caso do cluster \#4 energy efficiency, pode-se concluir que as pesquisas presentes neste cluster apresentaram baixa relevância, comparado aos anteriores. Entretanto, pesquisadores interessados podem se atentar ao tema da eficiência energética como forma de inovar, pesquisando áreas importantes e pouco exploradas.

\section{RANKING DE PAÍSES}

O CiteSpace ${ }^{\circledR}$ também fornece relatório constando quais são os países que possuem maior número de pesquisas referentes ao tema em estudo. Percebe-se pela Fig. (5) que em primeiro lugar estão os Estados Unidos da América, seguidos da Alemanha. O Japão aparece na terceira colocação. 
Figura 5: Países líderes em citações

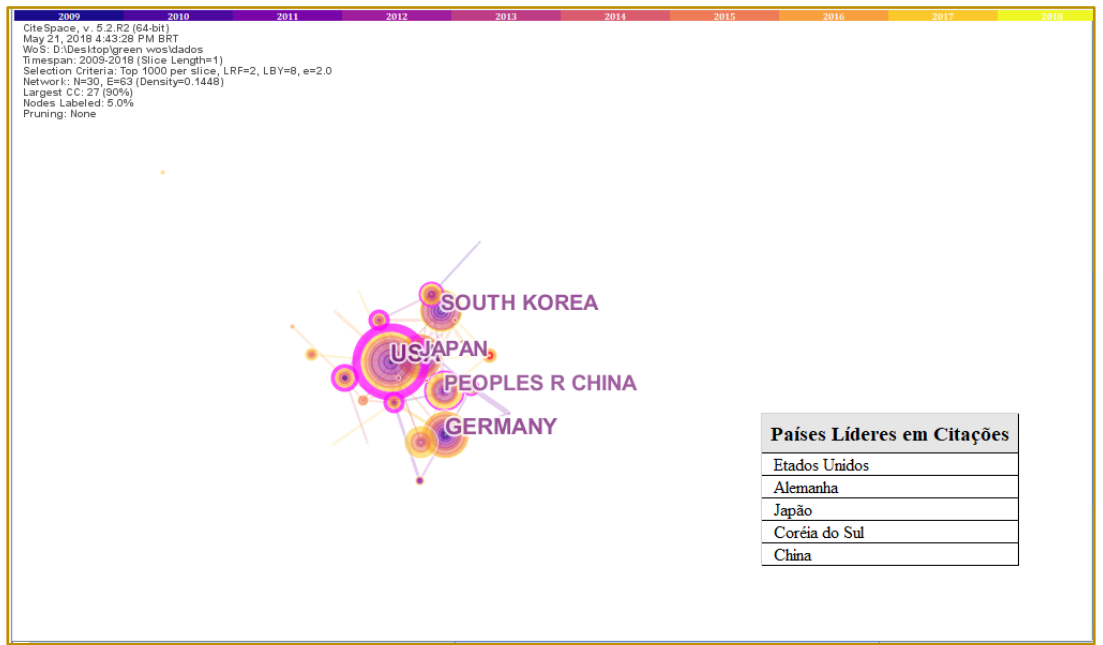

Fonte: CiteSpace ${ }^{\circledR}$

\section{CONSIDERAÇÕES FINAIS}

As pesquisas referentes a Green IT, conforme visto na Fig. (1), tem apresentado crescimento significativo. Diversas áreas de conhecimento estão adotando esta prática visando tornar suas atividades menos agressivas ao meio ambiente. O objetivo deste trabalho foi fazer um mapeamento, com o auxílio do software CiteSpace ${ }^{\circledR}$, sobre os temas abordados quando se trata da Tecnologia da Informação Verde.

Por meio dos dados apresentados, foi possível concluir que o objetivo foi alcançado. Estes são apresentados na seção 4, onde pode-se verificar o mapeamento dos relatórios apresentados pelo CiteSpace ${ }^{\circledR}$, em figuras e tabelas. A metodologia adotada foi a análise de cocitação em múltiplas perspectivas, utilizando medidas como a modularidade e silhueta para demostrar que os clusters obtidos (Fig.(3)) podem ser considerados de boa qualidade. O contraste entre os clusters com maior quantidade de citações (\#0 environmental sustainability) e com menor quantidade de citações (\#4 energy efficiency), demonstra a importância de ambos, muito

\section{REFERÊNCIAS}

[1] Bai, C. J. S. Green information technology strategic justification and evaluation. Information Systems Frontiers, vol. 15, p. 831-847, 2013.

[2] Barolli, L.; Xhafa, F. Jxta-Overlay: A P2P platform for distribute, collaborative, and ubiquitous computing. IEEE Transactions on Industrial Electronics, vol. 58, n. 6, p. 2163-2172, 2011. embora o cluster \#O, conforme foi demonstrado, seja o mais relevante. Outra métrica utilizada foi a detecção de explosão, a qual apresentou os estudos que atraíram mais atenção dos pesquisadores, os autores e o período em que ocorreram (Tab. (1)). Também foram analisadas quais palavraschave são mais utilizadas ao se tratar de pesquisas sobre Green IT (Tab. (2)). Foram expostas tabelas contendo as referências dos autores que apresentaram pesquisas que possuem relevância para a área em estudo (Tab. (3) e Tab. (4)). Por fim, foram apontados quais são os países líderes de pesquisas relacionadas a Tecnologia da Informação Verde (Fig. (5)).

Os dados fornecidos pelo CiteSpace ${ }^{\circledR}$ podem ser usados de forma satisfatória por pesquisadores que estão estudando a área de Green IT. As diretrizes dadas pelo software servem como embasamento para as mais diversas pesquisas relacionadas ao tema. Sugere-se que pesquisas futuras considerem uma base de dados maior para analisar o tema abordado, além de realizar uma análise mais ampla envolvendo todos os clusters obtidos.

[3] Beloglazov, A.; Abawajy, J.; Buyya, R. Energy-aware resource allocation heuristics for efficient management of data centers for cloud computing. Future Generation Computer Systems, vol. 28, p. 755-768, 2012.

[4] Bianchini, R.; Rajamony, R. Power and energy management for server systems. IEEE Computer Society, vol. 37, n. 11, p. 68-76, 2004. 
[5] Blackburn, W. R. The Sustainability Handbook: The Complete Management Guide to Achieving Social, Economic and Environmental Responsibility. London: Earthscan, 2007.

[6] Bose, R.; Luo. X. Integrative framework for assessing firms potential to undertake Green IT initiatives via virtualization - A theoretical perspective. Journal of Strategic Information Systems, vol. 20, p. 38-54, 2011.

[7] Butler, T. Compliance with institucional imperatives on environmental sustainability: Building theory on the role of Green IS. Journal of Strategic Information Systems, vol. 20, p. 6-26, 2011.

[8] Chen, C. CiteSpace II: Detecting and Visualizing Emerging Trends and Transient Patterns in Scientific Literature. Journal of the American Society for Information Science and Technology, v. 57, n. 3, p. 359-377, 2006.

[9] Dao, V.; Langella, I.; Carbo, J. From green to sustainability: Information technology and na integrated sustainability framework. Journal of Strategic Information Systems, vol. 20, p. 63-79, 2011.

[10] Enokido, T.; Aikebaier, A.; Takizawa, M. A model for reducing power consumpition in peer-topeer systems. IEEE Systems Journal, vol. 4, p. 221229, 2010

[11] Enokido, T.; Suzuki, K.; Aikebaier, A.; Takizawa, M. Algorithms for reducing de total power consuption in data communication-based applications. IEEE International Conference on Advanced Information Networking and Applications, p. 142-149, 2010.

[12] Enokido, T.; Takizawa, M. An integrated power consumption model for distributed systems. IEEE Transactions on Industrial Eletronics, vol. 60, p. 824-836, 2013.

[13] Faucheux, S.; Nicolai, I. IT for green and Green IT: A proposed typology of eco-innovation. Ecological Ecnomics, vol. 70, p. 2020-2027, 2011.

[14] Gholami, R.; Sulaiman, A. B.; Ramayah, T.; Molla, A. Senior managers percepcion om green information systems (IS) adoption and environmental performance: Results from a field survey. Information \& Management, vol. 50, p. 431438, 2013

[15] Gracia-Tinedo, R.; Artigas, Sanchez Artiga, M.; Lopez, P. G. Cloud-as-a-gift: Effectively exploiting personal cloud free accounts vis REST APIs. IEEE Sixth International Conference on Cloud Computing, p. 621-628, 2013.

[16] Heath, T. D. Methodology and experimental design for the study of liposomedepedent drugs. Methods in Enzymology, vol. 391, p. 186-199, 2005.

[17] Jenkin, T. A; Webster, J.; MCSHANE, L. An agenda for "Green" information technology and systems research. Information and Organizaton, vol. 21, p. 17-40, 2011.

[18] Koomey, J. G.; Berad, S.; Sanchez, M.; WONG, H. Implications of historical trends in the eletrical efficiency of computing. IEEE Annals of the history of computing, vol. 33, p. 46-54, 2011.

[19] Koomey, J.; Hultman, N. E. A reactor-level analysis of busbar costs for US nuclear plants, 1970-2005. Energy Police, vol. 35, p. 5630-5642, 2007.

[20] Kumar, A. P.; Kannegala, S. S. Green Devices and Hardware. In: Murugesan, S.; Gangadharan, G. R. (Org.). Harnessing Green IT: Principles and Practices. 1 ed. West Sussex: John Wiley and Sons Ltd, 2012, p. 23-38.

[21] LI, X.; MA, E.; QU, H. Knowledge mapping of hospitality research - A visual analysis using CiteSpace. International Journal of Hospitality Management, vol. 60, p. 77-93, 2017.

[22] Melville, N. P. Information systems innovation for enviromental sustainability. MIS Quartely, vol. 34, p. 1-21, 2010.

[23] Molla, A.; Abareshi, A. Organizational green motivations for informatoin technology: Emprical study. Journal of Computer Information Systems, vol. 52, p. 92-102, 2012.

[24] Moyer, J. D.; Hughes, B. B. ICT,s: Do they contribute to increase carbono emissions? Technological Forecasting \& Social Change, vol. 79, p. 919-931, 2012.

[25] Murugesan, S. Harnessing green IT: principles and practices. IEEE IT Professional, $v$. 10, n.1, p. 24-33, 2008.

[26] Murugesan, S.; Gangadharan, G. R. Green IT: An Overview. In: Murugesan, S.; Gangadharan, G. R. (Org.). Harnessing Green IT: Principles and Practices. 1 ed. West Sussex: John Wiley and Sons Ltd, 2012, p. 1-22.

[27] Orsato, R. J. Competitive environmental strategies: When does it pay to be green? California Review Management, vol. 48, n. 2, p. 127-143, 2006.

[28] Presoto, A. E.; Souza, R. C.; Thurler, J. H. F. Um estudo bibliométrico sobre cadeias de suprimentos sustentáveis. In: XXXIII Encontro Nacional de Engenharia de Produção (Enegep), 2013, Salvador, BA. Anais... Salvador: Abepro, out. 2013.

[29] Valerio, K. G. O.; Silva, C. E. S. Expandindo a visão sobre o gerenciamento de riscos: O risco de oportunidade. In: XXXVI Encontro Nacional de Engenharia de Produção (Enegep), 2016, João Pessoa, PB. Anais... João Pessoa: ABEPRO, out. 2016

[30] Waluyo, A. B.; Rahayo, W.; Taniar, D.; Srinivasan, B. A novel structure and access mechanism for mobile data broadcast in digital 
ecosystems. IEEE Transactions on Industrial Eletronics, vol. 58, n. 6, p. 2173-2182, 2011.

[31] Watson, R. T.; Broudeau, M, C.; Chen, A. J. Information systems and environmentally sustainable development: Energy informatics and new directions for the IS commnity. MIS Quartely, vol. 34, p. 23-38, 2010. 


\section{Capítulo 15}

\section{INDÚSTRIA 4.0 E SEUS PRESSUPOSTOS: ESTUDO DE CASO DE ADERENNCIA AO CONTEÚDO PROGRAMÁTICO DO CURSO DE ENGENHARIA DE MECATRÔNICA DE UM INSTITUTO FEDERAL DO NORDESTE BRASILEIRO}

\section{Hector Leonardo Mota Moreira}

Matheus Araújo dos Santos

Isadora Costa Vasconcelos Vieira

Daniel Xavier Sousa

Cícero Roberto de Oliveira Moura

Karine Bessa Porto Pinheiro Vasques

Resumo: O presente artigo trata do tema Indústria 4.0 e do curso de Engenharia de Mecatrônica ofertado por um Instituto Federal do nordeste brasileiro, com o objetivo de qualificar a aderência entre os conteúdos vistos ao longo do curso com os principais pressupostos da Indústria 4.0. Trata-se de uma pesquisa que se enquadra como estudo de caso. Realizado um estudo bibliográfico sobre dos principais conceitos envolvendo a Indústria 4.0 e seus pressupostos e determinado alguns termos-chave que foram utilizados na verificação das ementas de disciplinas do curso de engenharia mecatrônica, observando suas semelhanças com pressupostos estudados. O trabalho também contou com a aplicação de uma pesquisa com os docentes e coordenadores do curso, por meio de questionários, visando identificar a relação entre os pressupostos e o conteúdo praticado no curso. Com base nos resultados analisados, concluiu-se que, Sistemas CiberFísicos, Robótica Avançada e Manufatura Aditiva são os pressupostos da Indústria 4.0 que apresentaram maior aderência ao curso de engenharia de mecatrônica, enquanto que os demais, Big Data, Inteligência Artificial e Internet das Coisas (IoT) apresentaram aderência um pouco abaixo da média geral.

Palavras-chave: Indústria 4.0, Engenharia de Mecatrônica, Instituto Federal. 


\section{INTRODUÇÃO}

Nos últimos séculos, vivem-se, de tempos em tempos, as chamadas Revoluções Industriais. As três passadas revolucionaram a indústria de diversas formas, tornando a obsoleta produção manual em uma sofisticada produção autônoma, com máquinas fazendo o papel repetitivo que antes era feito pelos operários.

Segundo Dombrowski e Wagner (2014 apud OLIVEIRA; SIMÕES, 2017) um conjunto de inovações tecnológicas que ocasiona desdobramentos no âmbito social, político e econômico é denominado de revolução industrial. A Primeira Revolução Industrial ocorreu em meados do século XVIII, na Inglaterra, e introduziu as máquinas a vapor que seriam usadas nas fábricas produtoras de fios e tecidos, a indústria têxtil. Durante os séculos XIX e XX, o mundo viu uma ascensão de aparelhos que se utilizavam da recémdescoberta energia elétrica, como rádios e telefones. Era a Segunda Revolução Industrial, que se utilizou também do petróleo para abastecer automóveis e aviões, que passaram a ser confeccionados. Por fim, a Terceira Revolução Industrial foi marcada pela computação e rápido compartilhamento de dados. A informação era a chave de sucesso de empresas que surgiam, como a Apple e a Microsoft.

Hodiernamente, está em acelerado ritmo de expansão a Quarta Revolução Industrial, também chamada de Indústria 4.0, que tem como preceito a incorporação da digitalização à atividade industrial, acrescendo novos conceitos inovadores para a indústria, como a Inteligência Artificial, os Sistemas CiberFísicos, o Big Data, a Internet das Coisas (IoT), a Robótica Avançada, dentre outros (CNI, 2016).

Nesse contexto, tem-se uma nova indústria em ascensão, modernizada e inovadora, e, com base nisso, o Brasil deve se modernizar em paralelo com as grandes empresas multinacionais. Para isso, é necessária uma intensa formação profissional, com vasto conhecimento nos pressupostos da Indústria 4.0. Dessa forma, esse artigo tem como objetivo analisar o conteúdo programático do curso de Engenharia de Mecatrônica ofertado por um Instituto Federal do nordeste brasileiro, verificando o nível de aderência de suas disciplinas curriculares com os conceitos e pressupostos da Indústria 4.0. A pesquisa de termos-chave, baseados nos conceitos da
Indústria 4.0 e seus pressupostos, foi utilizada na verificação das ementas de disciplinas do curso de engenharia de mecatrônica, além da aplicação de questionários com os docentes e coordenadores do curso.

\section{INDÚSTRIA 4.0}

O conceito "Indústria 4.0" surgiu na Feira de Hannover (Alemanha) de 2011, para descrever uma revolução que vem impactando organizações mundiais com o advento da digitalização industrial. Consistindo na cooperação entre sistemas físicos e virtuais de fabricação, a Indústria 4.0 possibilita fábricas inteligentes e flexíveis com a criação de novos modelos operacionais, sustentados por uma gama de novas tecnologias (SCHWAB, 2016).

No entanto, a quarta revolução industrial não diz respeito apenas à indústria inteligente, abrangendo também áreas da biologia, computação quântica, nanotecnologia, energias renováveis e novos materiais, entre outros. Aqui, serão abordados somente conceitos mais próximos da Indústria 4.0 e da Engenharia Mecatrônica.

De acordo com Schwab (2016), há divergências se esse conceito seria, de fato, uma nova revolução industrial, ou apenas uma continuação das inovações decorrentes da terceira. Nesse contexto, três razões principais evidenciam que a Indústria 4.0 é única perante as três anteriores revoluções:

a) Acelerado ritmo de crescimento, de tal forma que cada vez mais novas tecnologias originam outras, em um processo que se repete constantemente, e em intervalos de tempo cada vez menores.

b) Novos conceitos estão surgindo e ganhando espaço no campo social e industrial, que aparecem como resultado dessa revolução.

c) Mudanças no sistema estão acontecendo em países, indústrias e em toda sociedade.

Dessa forma, a sociedade atual tem necessidade de adequar-se o mais rápido possível a essas transformações. No campo do ensino, as instituições devem modificar seus conteúdos disciplinares, de modo a adequar os futuros profissionais da área da indústria e tecnologia às inovações desse campo, para que possam disputar o mercado de trabalho, cada vez mais qualificado. 
Outrossim, os trabalhadores devem adequarse, tanto em formação acadêmica, como em competências como: criatividade, inovação, comunicação, solução de problemas e conhecimentos técnicos (AIRES; MOREIRA; FREIRE, 2017).

No que diz respeito às fábricas brasileiras, segundo a CNI (2016), o conhecimento sobre as tecnologias necessárias e sua incorporação na produção para a formação básica da indústria 4.0 era pouco difundido no país: $42 \%$ das empresas desconheciam sua importância e 52\% não utilizavam ferramentas como manufatura aditiva, incorporação de serviços digitais nos produtos, automação digital sem sensores e projetos de manufatura por CAD/CAM.

Com foco em melhorar o processo de produção e aumentar a produtividade, o Brasil se mantém em um caminho positivo, porém limitado, pois deixa de lado oportunidades na exploração de novos modelos de negócios e desenvolvimento da cadeia produtiva. Apesar do rumo natural de foco em aumento da eficiência e em seguida a busca pelo desenvolvimento de novos produtos e modelos de negócios, na posição competitiva em que o país se encontra, o ideal seria que o movimento de digitalização fosse realizado, simultaneamente, em todas as dimensões (CNI, 2016).

Esta mesma pesquisa da CNI de 2016, afirma que para se manter competitivo a nível global, é essencial que o Brasil tenha uma estratégia de incorporação das novas tecnologias em sua indústria. Há exemplos de países em que a indústria 4.0 já é foco da sua política industrial, o que leva a necessidade de não apenas buscar a incorporação das novas tecnologias, mas fazê-lo de forma veloz, afim de evitar o gap para seus competidores.

\subsection{PRESSUPOSTOS DA INDÚSTRIA 4.0}

Existem algumas divergências quanto ao conceito de Indústria 4.0 em relação à uma quarta revolução industrial mas é evidente que novas e avançadas tecnologias surgiram nestes últimos anos, e que impactaram a indústria e a sociedade como um todo. Aqui serão abordados alguns pressupostos da Indústria 4.0: Inteligência Artificial, Robótica Avançada, Sistemas Ciber-Físicos (CyberPhysical Systems - CPS), Internet das Coisas (Internet of Things - IoT), Big Data e Manufatura Aditiva.
De acordo com Luger e Stubblefield (1993 apud LUSTOSA, 2004), a Inteligência Artificial (IA) é um ramo da ciência da computação que se dedica à automação de comportamento inteligente. É difícil considerar apenas uma definição, sendo assim, ao longo do tempo ela adquiriu várias linhas de pensamento. Há vertentes que se referem ao processo de pensamento e raciocínio, enquanto outras dão foco às ações e comportamento. Além disso, há linhas de pensamento que comparam as ações da máquina com as possíveis ações humanas e que comparam com as ações humanas ideais, as que seriam consideradas racionais (GOMES, 2010).

\subsubsection{ROBÓTICA AVANÇADA}

Segundo Othman et al (2016), robôs desempenham um importante papel na indústria manufatureira moderna. Uma face essencial da indústria 4.0 são métodos de produção autônomos alimentados por robôs que podem executar tarefas de maneira inteligente, com foco em segurança, flexibilidade, versatilidade e colaboração com humanos. Na indústria 4.0, robôs e humanos trabalharão lado a lado, em tarefas interligadas e usando interfaces homemmáquina com sensores inteligentes.

Para Schwab (2016), os avanços dos sensores permitem aos robôs uma melhor compreensão e resposta ao ambiente. Além disso, os robôs podem acessar informações remotas da nuvem, rompendo com a necessidade de programação prévia. Isso permite que o uso de robôs seja ampliado para abranger várias funções, como: produção, logística e distribuição de documentos.

\subsection{SISTEMAS CIBER-FÍSICOS (CYBER- PHYSICAL SYSTEMS - CPS)}

Os Sistemas Ciber-Físicos, (Cyber-Physical Systems - CPS), segundo Lee (2008), são integrações de processos computacionais e físicos em que computadores embarcados monitoram e controlam, geralmente com feedback contínuo, processos físicos.

De acordo com Bauernhansl (2014 apud HERMANN, 2016), o desenvolvimento dos CPS é caracterizado por três fases. $\mathrm{Na}$ primeira geração dos CPS estão inclusas as tecnologias de identificação, como etiquetas 
de RFID, que permitem identificação única. A segunda geração dos CPS está munida de sensores e atuadores com um escopo de funções limitado. Os Sistemas Ciber-Físicos da terceira geração se diferem por serem capazes de armazenar e analisar dados, equipados com múltiplos sensores e atuadores e compatíveis com o funcionamento em rede.

\subsubsection{INTERNET DAS COISAS (INTERNET OF THINGS - IOT)}

Segundo Deidmar, Sobreira e Lima (2017) a Internet das Coisas (Internet of Things - 10T) se refere a uma revolução tecnológica que em breve conectará equipamentos como eletrodomésticos, meios de transporte, roupas e maçanetas conectadas à internet e a outros dispositivos, como computadores e smartphones.

No contexto da indústria 4.0, a internet das coisas (no ramo industrial adota-se Industrial Internet of Things - I/OT) torna-se um importante pilar devido à possibilidade de conexão entre máquinas por meio de sensores e dispositivos eletrônicos, o que permite e facilita a troca de dados em tempo real, como por exemplo, o monitoramento remoto, que propicia que as empresas rastreiem onde estão e como são movimentados seus objetos. Do outro lado, têm-se o consumidor, que pode acompanhar o seu pedido em tempo real, ajudando-a a tornar-se uma indústria inteligente (SADIKU et al 2017).

\subsubsection{BIG DATA}

Para Taurion (2015) o Big Data representa não só uma grande quantidade de dados, mas um montante de dados que seja volumétrico e variado, além de verossímil e valoroso para o negócio. Esse conceito tem surgido nos últimos anos devido ao crescente número de informações que as organizações têm de processar de forma rápida e consistente. Isso gera uma constante preocupação com a segurança desses dados, principalmente para as empresas de grande e médio porte, uma vez que o banco de dados de uma instituição é o que passa a dar sustentação aos seus processos produtivos.

Entretanto, o Big Data, nos termos da indústria 4.0, não trata apenas das variáveis, mas relaciona esses dados entre si por meio de um algoritmo que tende a encontrar um padrão para essas informações, de forma a mitigar possíveis erros futuros. Nesse ponto, as fábricas se beneficiam do Big Data para lidar com a criação de novas variáveis todos os dias e relacioná-las da melhor maneira, agilizando e otimizando seus processos (TAURION, 2015)

\subsubsection{MANUFATURA ADITIVA}

De acordo com Volpato e Costa (2013) a manufatura aditiva consiste na fabricação de peças com a impressão 3D. Esse processo é feito acrescentando material em perfis complexos. Esse meio possui vantagens comparado apenas com o processo de usinagem como: economia de material para produção, fabricação de peças mais complexas e precisão no acabamento.

A manufatura aditiva tem tornado a indústria mais inteligente e sofisticada, sobrepujando as técnicas de usinagem, ou unindo-se a essa. Considerando a indústria 4.0, esse método pode ser usado em conjunto com os Sistemas Ciber-Físicos, em concomitância com softwares de CAD/CAM para ter maior eficiência no projeto e um produto final de qualidade, seja ele: peça, componente, protótipo, entre outros. Em breve, acredita-se que a impressão $3 \mathrm{D}$ se tornará mais difundida, incluindo placas de circuito, microchips, células e órgãos humanos (SCHWAB, 2016).

\section{FORMAÇÃO EM MECATRÔNICA E O INSTITUTO FEDERAL}

Segundo Rosário (2006), o termo "Mecatrônica" foi utilizado pela primeira vez no fim dos anos 70, no Japão, como resultado da junção bem-sucedida entre mecânica, eletrônica e processos digitais na feitura de produtos de consumo. A Engenharia de Mecatrônica pode ser compreendida como a interseção da Engenharia Mecânica, a Engenharia Elétrica (eletrônica) e o controle por computador no projeto e manufatura de produtos e processos

Em meados da década de 80, países como Austrália, Japão e Coreia do Sul implementaram cursos de graduação e pósgraduação voltados ao ensino de mecatrônica. No Brasil, os primeiros cursos de graduação em mecatrônica surgiram no 
fim da década de 80 e foram denominados pelo Ministério da Educação de curso de Engenharia de Controle e Automação, sendo implementados em algumas universidades e faculdades de tecnologia (ROSÁRIO, 2006).

Ainda segundo o autor supracitado, o caráter multidisciplinar de sua formação permite ao profissional de controle e automação elaborar estudos e projetos, assim como participar da direção e fiscalização de atividades relacionadas ao controle de processos e automação de sistemas industriais. Por ter cunho generalista, a formação do engenheiro de controle e automação requer um esforço notável do corpo docente e discente, mas findará suprindo uma lacuna existente no mercado, provendo uma capacitação profissional interessante.

O curso de graduação em Engenharia de Mecatrônica do Instituto Federal em estudo, visa preparar profissionais para o desempenho de atividades ligadas ao controle e automação de sistemas a variáveis contínuas ou discretas, principalmente no ambiente industrial. Teve sua criação aprovada em 2006 e teve seu reconhecimento pelo MEC em 2011. Apresenta uma duração de cinco anos (10 semestres letivos) com 70 disciplinas (propedêuticas e técnicas). A matriz curricular do curso envolve conteúdos do núcleo de formação básica, num total 1260 horas; conteúdos do núcleo de formação profissional, num total de 1000 horas e do núcleo de conteúdos específicos, com o total de 1820 horas, que se constituem em extensões e, aprofundamentos dos conteúdos profissionalizantes, bem como de outros conteúdos destinados a caracterizar a ênfase do Curso.

De acordo com documentos institucionais, o Instituto Federal tem sua história se iniciando no limiar do século XX, quando o então Presidente Nilo Peçanha, inspirado nas escolas vocacionais francesas, cria em 1909, as Escolas de Aprendizes Artífices, destinadas a prover de formação profissional os pobres e desvalidos da sorte. Em 1968 recebe a denominação de Escola Técnica Federal do Estado, demarcando o início de uma trajetória de consolidação de sua imagem como instituição de educação profissional de elevada qualidade, responsável pela oferta de cursos técnicos de nível médio nas áreas de edificações, estradas, eletrotécnica, mecânica, química industrial, telecomunicações e turismo.
Somente em 1994, juntamente com as demais Escolas Técnicas da rede federal, é transformada em Centro Federal de Educação Tecnológica, que estabeleceu uma nova missão institucional, a partir da ampliação das possibilidades de atuação no ensino, na pesquisa e na extensão.

O Governo Federal, em 2008, cria 38 Institutos Federais de Educação, Ciência e Tecnologia, com 312 campi espalhados por todo o país, cada um deles constituindo-se uma autarquia educacional vinculada ao Ministério da Educação (MEC).

\section{METODOLOGIA APLICADA}

A partir das pesquisas bibliográficas realizadas sobre os principais conceitos e pressupostos da Indústria 4.0, foram selecionados termoschave que melhor representam cada um desses pressupostos, atentando para os conceitos de maior relevância e de maior frequência no contexto geral da literatura.

A partir desses termos-chave foram feitas buscas nos programas da matriz curricular do curso de Engenharia de Mecatrônica do Instituto Federal em estudo, que consta de 70 (setenta) disciplinas ao todo, incluindo disciplinas propedêuticas e técnicas. As disciplinas que tiveram suas ementas apresentando pelo menos um dos termoschave, em um contexto relacionado aos pressupostos, foram selecionadas como aderentes à Indústria 4.0.

Para cada uma das disciplinas técnicas do curso, foi aplicado um questionário com o respectivo professor da disciplina. O questionário abordava os subtópicos dos pressupostos da Indústria 4.0. Além disso, o questionário permitia que o docente pudesse expor sua opinião sobre qual disciplina aborda cada subtópico e pressuposto, além de um espaço para comentários.

Do total de 70 (setenta) disciplinas, foram retiradas 10 (dez) por serem propedêuticas e 14 (quatorze) por não terem nenhum dos termos-chave em suas ementas. Restando um total de 46 (quarenta e seis) disciplinas técnicas, ministradas por aproximadamente vinte professores.

A pesquisa foi realizada com uma amostra de 12 (doze) professores (60\% do total), que ministram mais de uma disciplina para os estudantes de Engenharia de Mecatrônica do campus. 
No questionário aplicado na pesquisa constavam os 6 (seis) pressupostos abordados no item 2, com 18 (dezoito) subtópicos principais (três subtópicos por pressuposto), para que os professores avaliassem a relação, ou aderência, de cada tópico com as disciplinas do curso.

A avaliação constava de uma escala de "0" a "5" (0-1-2-3-4-5), onde 0 indica não haver relacionamento algum entre o pressuposto analisado e a disciplina em questão, e "5" indicando total aderência entre a disciplina e o pressuposto.

Com esta metodologia atotada, foi possível obter resultados qualitativos que foram quantificados em uma pontuação, por subtópico, permitindo um tratamento estatístico da aderência dos pressupostos da Indústria $4.0 \mathrm{com}$ o curso de Engenharia Mecatrônica. Os resultados obtidos são abordados no item seguinte.

\section{RESULTADOS}

\subsection{RESULTADOS POR DISCIPLINAS}

Com o tratamento e análise dos dados teve-se que apenas $30 \%$ da totalidade de disciplinas ofertadas durante o curso de Engenharia de Mecatrônica estudado foram relacionadas, pelos professores que responderam o questionário, aos pressupostos da Indústria 4.0. A Figura (1) mostra a distribuição das disciplinas ofertadas pelo curso associadas aos termos-chave dos pressupostos da Indústria 4.0.

Considerando a metodologia adotada e análise dos dados obtidos, conforme representados na Figura (1), aproximadamente $66 \%$ (sessenta e seis porcento) das ementas de disciplinas constantes na matriz curricular do curso apresentam aderência com os pressupostos da Indústria 4.0, através dos termos-chave. Somente 20\% (vinte porcento) não apresenta aderência, considerando os 14\% (quatorze porcento) de disciplinas propedêuticas, aproximadamente. Se for considerado para a análise somente as disciplinas técnicas (70 menos 10 propedêuticas), tem como resultado uma aderência de 76,7\% (setenta e seis virgula sete porcento).

Figura 1: Aderência das ementas de disciplinas do curso com os pressupostos da Indústria 4.0.

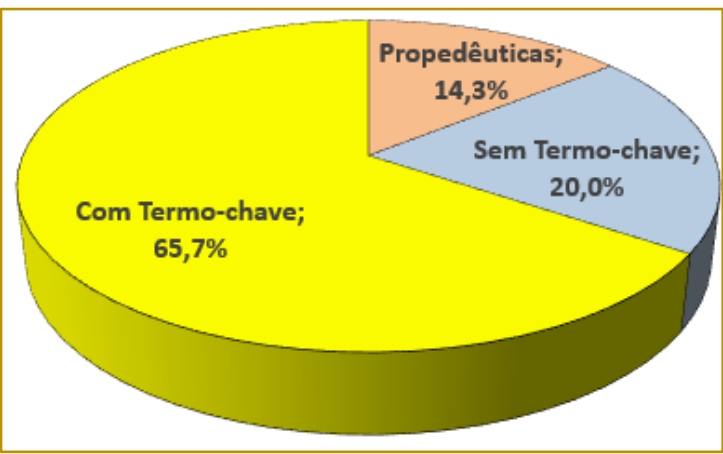

Fonte: Dados da pesquisa (2018).

\subsection{RESULTADOS POR SUBTÓPICO DOS PRESSUPOSTOS}

Analisando a aderência dos subtópicos dos pressupostos da Indústria $4.0 \mathrm{com}$ as disciplinas, através da pesquisa com os questionários aplicados com os professores do curso, conforme registrado na Tabela (1), observa-se que 14 (quatorze) dos 18 (dezoito) subtópicos apresentam aderência acima de $50 \%$, com cinco acima de $70 \%$ (setenta porcento) de aderência (sensores, robôs autônomos, automação, integração de sistemas e projeto assistido por computador). Somente três com pontuação menor ou igual a $40 \%$ (quarenta porcento) de aderência (armazenamento de dados, segurança de dados e computação em nuvem). 
Tabela 1: Resultados por subtópico dos pressupostos da Industria 4.0

\begin{tabular}{|c|c|c|c|}
\hline Pressupostos e subtópicos da indústria 4.0 & $\begin{array}{c}\text { Pontuação } \\
\text { possível }\end{array}$ & $\begin{array}{c}\text { Pontuação } \\
\text { obtida }\end{array}$ & $\begin{array}{l}\text { Percentual } \\
\text { aderência }\end{array}$ \\
\hline 1. Robótica Avançada & & & 74,9 \\
\hline Robótica colaborativa & 35 & 23 & 65,7 \\
\hline 1.2. Sensores & 45 & 40 & 88,9 \\
\hline 1.3. Robôs autônomos & 40 & 28 & 70,0 \\
\hline 2. Big Data & & & 45,0 \\
\hline 2.1. Armazenamento de dados & 45 & 18 & 40,0 \\
\hline 2.2. Processamento de dados & 50 & 29 & 58,0 \\
\hline 2.3. Segurança dos dados & 35 & 13 & 37,1 \\
\hline 3. Inteligência Artificial & & & 53,1 \\
\hline 3.1. Robô racional & 30 & 12 & 40,0 \\
\hline 3.2. Aprendizado de máquina & 40 & 26 & 65,0 \\
\hline 3.3. Agente Inteligente & 35 & 19 & 54,3 \\
\hline 4. Sistema Cyber-Físico & & & 78,0 \\
\hline 4.1. Automação & 50 & 43 & 86,0 \\
\hline 4.2. Integração de sistemas & 30 & 24 & 80,0 \\
\hline 4.3. Objeto inteligente & 25 & 17 & 68,0 \\
\hline 5. Manufatura Aditiva & & & 69,1 \\
\hline 5.1. Impressão 3D & 40 & 22 & 55,0 \\
\hline 5.2. Projeto assistido por computador & 55 & 46 & 83,6 \\
\hline 5.3. Prototipagem & 35 & 24 & 68,6 \\
\hline 6. Internet das Coisas & & & 59,3 \\
\hline 6.1. Computação em nuvem & 40 & 16 & 40,0 \\
\hline 6.2. Sistemas em rede & 45 & 31 & 68,9 \\
\hline 6.3. Controle de dispositivos remotamente & 45 & 31 & 68,9 \\
\hline
\end{tabular}

\subsection{RESULTADOS POR PRESSUPOSTO}

A Figura (2) apresenta os percentuais de aderência dos pressupostos em estudo. Através de um Gráfico de Pareto, observa-se que os pressupostos com maior aderência foram os Sistemas Ciber-Físicos, seguido por Robótica Avançada e Manufatura Aditiva, com percentuais acima de 60\% (sessenta porcento). Mesmo com resultados inferiores aos citados, os três outros pressupostos aprestaram aderência acima de $40 \%$ (quarenta porcento). A média geral de aderência ficou em 63,2\% (sessenta e três vírgula dois porcento).

Figura 2: Percentual de aderência dos pressupostos ao curso de Engenharia Mecatrônica.

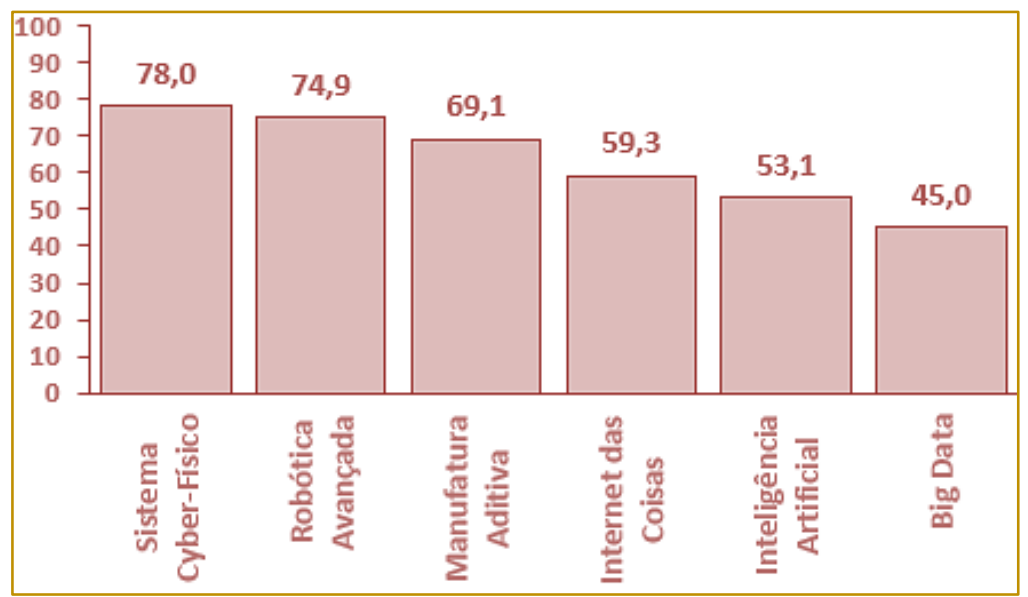




\section{CONCLUSÕES}

Este trabalho de pesquisa permitiu chegar ao seu término com as seguintes conclusões relativas aos objetivos propostos e sua metodologia aplicada:

a) A revisão bibliográfica sobre a Indústria 4.0 e seus pressupostos foi realizada com sucesso, pois permitiu uma análise consistente para o propósito do trabalho;

b) Um levantamento de dados e informações detalhadas do Instituto Federal do nordeste brasileiro e do curso de Engenharia de Mecatrônica em estudo, foi muito importante para a obtenção dos resultados de aderência aos pressupostos da Indústria 4.0;

c) A utilização da metodologia de pesquisa aplicada se apresentou viável ao processo de avaliação dos objetivos propostos;

d) A aplicação adequada da metodologia no processo de tratamento e análise dos dados permitiram resultados que consolidaram a validação da metodologia.

\section{REFERÊNCIAS}

[1] Aires, R. W. A.; Moreira, F. K.; Freire, P. S. Indústria 4.0: Competências requeridas os profissionais da Quarta Revolução Industrial. Congresso Internacional de Conhecimento e Inovação - CIKI, [S.I.], v. 1, n. 1, 2017. Disponível em:

$<$ http://proceeding.ciki.ufsc.br/index.php/ciki/article /view/314>. Acesso em: 04 jun. 2018.

[2] Bauernhansl, Thomas. Die vierte industrielle Revolution. Der Weg in ein wertschaffendes Produktionsparadigma. In: Bauernhansl, Thomas.; Hompel, Michael ten.; Vogel- Heuser, Birgit. Industrie 4.0 in Produktion, Automatisierung und Logistik: anwendung, technologie, migration. Wiesbaden: Springer Vieweg, 2014.

[3]

CNI, Confederação Nacional da Indústria. Desafios para a indústria 4.0 no Brasil. Brasília: CNI, 2016. 34p. Disponível em: <https://bucket-gw-cni-static-cms-

si.s3.amazonaws.com/media/filer_public/d6/cb/d6c bfbba-4d7e-43a0-9784-

86365061a366/desafios_para_industria_40_no_bra sil.pdf>. Acesso em: 18 mai. 2018.

[4] Deidmar, G. L. C.; Sobreira, D. S.; Lima, W. D. Internet das coisas na educação. Revista Tecnologias em Projeção. Brasília, v. 8, n. 2, p. 78, 2017.

[5] Dombrowski, U.; Wagner, T. Mental strain
A partir desses resultados, percebe-se que o curso de Engenharia de Mecatrônica do Instituto Federal em estudo apresenta considerável aderência aos pressupostos da Indústria 4.0, com uma média geral acima de $60 \%$ (sessenta porcento). Considerando que o curso tem somente 12 anos de criação e 7 anos de reconhecimento pelo MEC. Porém alguns pressupostos, como Sistemas CyberFísicos, Robótica Avançada e Manufatura Aditiva apresentam aderência acima da média geral.

Apesar destes resultados positivos com relação à aderência pesquisada neste trabalho, sugere-se um estudo mais detalhado e abrangente da matriz curricular do curso de Engenharia de Mecatrônica em questão, buscando adequação constante às realidades atuais e futuras das empresas, no que diz respeito aos pressupostos da Indústria 4.0, permitindo uma importante atualização da capacitação do profissional para a conjuntura atual da sociedade do futuro.

as field of action in the 4th industrial revolution. In: Variety Managementin Manufacturing. Proceedings of the Cirp Conference of Manufacturing Systems, 47., 2014. Anais... Braunschweig: Technische Universität Braunschweig, 2014. p. 100-105.

[6] Gomes, D. S. Inteligência Artificial: Conceitos e Aplicações. Olhar Científico - Revista de Publicações da FAAr, Ariquemes, v. 1, n. 2, $2010 . \quad$ Disponivel em: <http://www.olharcientifico.kinghost.net/index.php/ olhar/article/download/49/37>. Acesso em: 30 abr. 2018.

[7] LEE, E. A. Cyber Physical Systems: Design Challenges. In: IEEE International Symposium on Object and Component-Oriented Real-Time Distributed Computing (ISORC), 11., 2008. Anais... Orlando: IEEE, 2008. p. 363-369.

[8] Hermann, M.; Pentek, T.; Otto, B. Design Principles for Industrie 4.0 Scenarios. In: Hawaii International Conference on System Sciences (HICSS), 49., 2016. Anais... Koloa: IEEE, 2016. p. 3928-3937.

[9] Luger, G. F.; Stubblefield, W. A. Artificial Intelligence: Structures and Strategies for Complex Problem Solving. 2. ed. Redwood City: Pearson, 1993. $740 \mathrm{p}$.

[10]

Lustosa, V. G. O estado da arte em inteligência artificial. Colabor@ - Revista Digital de CVA - Ricesu, v. 2, n. 8, 2004. Disponível em:

$<$ revista.faculdadeprojecao.edu.br/index.php/Proje 
cao4/

[11] article/download/1007/840>. Acesso em: 04 jun. 2018.

[12] Oliveira, F. T.; Simões, W. L. A indústria 4.0 e a produção no contexto dos estudantes da engenharia. In: Simpósio de Engenharia de Produção, 1., 2017. Anais... Catalão: UFG, 2017.

[13] Othman, Mohd Fauzi; AZLI, Nor Hayati Nor; TALIB, Muhamad Farihin; BAHRIN, Mohd Auman Kamarul. Industry 4.0: a review on industrial automation and robotic. Journal Teknologi, Kuala Lumpur, v. 78 n. 6-13, 2016. Disponível em: <https://jurnalteknologi.utm.my/index.php/jurnaltekn ologi/article/view/9285/5537>. Acesso em: 18 mai. 2018.

[14] Rosario, João Maurício. Princípios de mecatrônica. São Paulo: Pearson Prentice Hall, 2005

[15] Sadiku, Matthew N. O.; Wang, Yonghui;
CUI, Suxia; MUSA, Sarhan M. Industrial Internet of Things. International Journal of Advances in Scientific Research and Engineering (IJASRE), Prairie View, v. 3, n. 11, 2017. Disponível em: $<w w w . i j a s r e . n e t / a b s t r a c t$. php?article_id=3482\&title $=$

INDUSTRIAL \%20INTERNET\%200F\%20THINGS>. Acesso em: 19 mai. 2018.

[16] Schwab, Klaus. A quarta revolução industrial. São Paulo: Edipro, 2016.

[17] Taurion, Cezar. Big Data. Rio de Janeiro: Brasport, 2013.

[18] Volpato, N.; Costa, C. A. Competências e recursos da rede de manutenção aditiva (RMA) no Brasil. In: Congresso Brasileiro de Engenharia de Fabricação, 7, 2013. Anais... Itatiaia: ABCM, 2013. Disponível

em: <http://www.swge.inf.br/siteCOBEF2013/anais/PDF S/COBEF2013-0287.PDF>. Acesso em: 25 mai. 2018 


\section{Capítulo 16}

\section{O GOVERNO ELETRONICO: ASPECTOS GERAIS SOBRE A MODERNIZAÇÃO ADMINISTRATIVA DA GESTÃO PUBLICA BRASILEIRA}

Fernando Cerutti Aguiar

Fabricio Freitas da Silva

Julio Cezar Negri Ramos

Claudio Luiz Melo de Souza

Milton Erthal Junior

Resumo: A utilização de ferramentas eletrônicas como estratégia de Governança Digital para o desenvolvimento de uma gestão pública mais eficiente, moderna, desburocratizada e participativa, já é uma realidade no âmbito da Administração Pública Brasileira. Este artigo faz uma breve análise sobre os principais programas nacionais do Governo Digital que impulsionarão eficiência administrativa aos órgãos públicos, indicando seus estágios de implantação, suas potencialidades e os principais desafios enfrentados. O processo utilizado foi o de pesquisa documental e bibliográfica em portais governamentais, artigos científicos e legislações específicas. Os resultados indicam que os programas em fase de implantação irão representar grandes avanços para modernização da Gestão Pública Nacional, contribuindo para redução de desperdícios financeiros e facilitando o desenvolvimento de políticas públicas. 


\section{INTRODUÇÃO}

Adaptar-se ao mundo globalizado e a era da informação é crucial para o desenvolvimento de qualquer nação nos dias atuais. As tecnologias de informação e comunicação (TICs) promoveram sistemas complexos de informação que fomentam o ambiente público e privado do século XXI. Adequar-se as constantes inovações tecnológicas não é só uma questão de sobrevivência para o setor privado, mas também para as organizações públicas. A eficiência administrativa está diretamente relacionada ao bom uso das novas tecnologias e que sem elas, torna-se impossível gerir uma empresa de forma competitiva ou até mesmo um país de modo consciente, participativo e democrático.

Associando-se 0 desenvolvimento das tecnologias de informação à modernização da gestão pública, surge em meados da década de 90, nos Estados Unidos, o denominado "Governo Eletrônico" ou "E-gov". De acordo com a Organização para a Cooperação e Desenvolvimento Económico (OCDE 2014), o Governo digital refere-se ao uso de tecnologias digitais, como parte integrada das estratégias de modernização governamentais, para gerar benefícios para a sociedade. É baseado em um ecossistema governamental digital composto de atores de governo, empresas, organizações da sociedade civil e indivíduos que apoiam a produção e o acesso a dados, serviços e conteúdos mediante interações com o governo.

No âmbito do Governo Federal Brasileiro, o tema tem sido tratado atualmente como Estratégia de Governança Digital (EGD). A EGD define os objetivos estratégicos, metas e indicadores da Política de Governança Digital, estabelecida pelo Decreto no 8.638 , de 15 de janeiro de 2016. A publicação é composta de três eixos, dez objetivos e 51 iniciativas estratégicas com validade até 2019 (BRASIL, 2017). Trata-se do mais recente documento criado para nortear os programas, projetos e serviços do governo, definindo seus objetivos estratégicos e estabelecendo metas e indicadores até 2019.

A Estratégia de Governança Digital proposta pelo governo federal estabelece como prioridade três eixos: acesso à informação, prestação de serviços e participação social. O que propõe a EGD, de maneira simplificada, é promover, através da tecnologia de informação, maneiras de ampliar a participação da sociedade nas ações governamentais, além de aumentar a prestação de serviços digitais e melhorar a eficiência administrativa através do mapeamento e a adequação de todos os processos internos à sua forma eletrônica.

Este artigo tem como objetivo avaliar a implantação dos sistemas de Governo Eletrônico no Brasil, mais especificamente aqueles que envolvem as atividades administrativas e acessórias da Gestão de Governo e não aquelas finalísticas. Serão analisados os programas mais inovadores e relevantes para o atual momento, como o eSocial, o Processo Eletrônico Nacional (PEN) e o sistema de transporte Taxigov.

\section{REVISÃO DA LITERATURA}

\subsection{GOVERNO ELETRÔNICO/ GOVERNANÇA ELETRÔNICA}

A adoção de Tecnologias de Informação e Comunicação (TIC) como suporte à prestação de serviços e informações tem sido um objetivo estratégico por parte de governos em todo o mundo. A combinação do uso de TICs avançadas, especialmente a internet, no suporte de novas formas de trabalho na administração pública, junto com a disponibilização mais abrangente de informações e serviços interativos acessíveis através de diferentes canais, é a base do governo eletrônico. (SANTOS; REINHARD, 2011).

De acordo com Parra Filho e Martins (2007), parte da literatura identifica uma mudança conceitual no debate, de governo eletrônico para governança eletrônica. Em um sentido mais amplo, essa mudança estaria ligada às mudanças nas relações entre Estado e sociedade e da ação governamental. Ainda segundo Parra Filho e Martins (2007), a utilização de TICs pelo setor público, dentro dessa perspectiva de governança eletrônica, passa a se referir ao modo como a internet pode melhorar a capacidade do Estado de formular e implementar suas políticas.

Para Guimarães e Medeiros (2005) a governança eletrônica - também intitulada egovernança ou governança digital -, refere-se ao modo como a Internet pode melhorar a capacidade do Estado de governar e formular suas políticas.

Um conceito importante é a divisão de governança eletrônica em três áreas: eAdministração Pública, melhoria dos 
processos governamentais e do trabalho interno do setor público com a utilização das tecnologias de informação e comunicação; eServiços Públicos, melhoria na prestação de serviços ao cidadão e e-Democracia, maior participação do cidadão, mais ativa, possibilitada pelo uso das tecnologias de informação e comunicação no processo de tomada de decisão. (CUNHA; DUCLÓS; BARBOSA, 2006). De acordo com Cunha e Miranda (2008), esta divisão por áreas é meramente didática, pois as fronteiras entre as três dimensões não são claras, sendo que um determinado projeto de e-gov pode estar associado a mais de uma dimensão.

Outro conceito a se destacar é o que relaciona o governo eletrônico com seus diferentes públicos. Segundo Fernandes et al (2004), a relação entre governo e sociedade pode ser categorizada em quatro tipos distintos:

- G2B (Governo-Empresas) caracterizada pela interação do governo com as empresas do setor privado na troca de informações e processamento de transações eletrônicas, buscando reduzir ao máximo as barreiras para se fazer negócios com o governo;

- G2C (Governo-Cidadão) caracterizada pela interação do governo, de forma ampla e completa, com o cidadão, provendo a ele informações e serviços públicos que atendam às suas necessidades de contribuinte, controlador das ações de governo, beneficiário e usuários dos serviços públicos ao longo de ciclo da vida - infância, adolescência, maioridade e terceira idade;

- G2E (Governo-Servidor Público) caracterizada pela interação do governo com os funcionários do serviço público, provendo informações e prestação de serviços necessários para o desenvolvimento de suas atividades profissionais e benefícios decorrentes da sua relação com o governo;

- G2G (Governo-Governo) caracterizada pela interação dos diferentes agentes governamentais e governos nas diferentes esferas (municipal, estadual e federal), provendo informações, prestação de serviços e processamento de transações para o desenvolvimento de suas atividades.

\subsection{GOVERNO ELETRÔNICO NO BRASIL}

No Brasil, o Governo Eletrônico, de acordo com Diniz et al. (2009), iniciou-se nos anos 2000 durante a gestão do presidente Fernando Henrique Cardoso. Os primeiros estudos para a formulação de uma política federal de governo eletrônico foram elaborados pelo Grupo de Trabalho em Tecnologia da Informação (GTTI), uma comissão interministerial criada pelo decreto presidencial de 3 de abril de 2000, com a finalidade de examinar e propor políticas, diretrizes e normas relacionadas às novas formas eletrônicas de interação.

Desde então, o e-gov vem se transformando e ganhando enorme potencialidade. O documento Estratégia de Gestão Governamental, aponta alguns avanços do egov no Brasil, como a padronização dos portais eletrônicos governamentais, o portal de serviços públicos federais, o portal de dados abertos e outros.

Importante destacar que processos eletrônicos já consagrados no Brasil também foram iniciativas de governo eletrônico, como o sistema de votação nacional com urnas eletrônicas, o sistema de declaração de imposto de renda, a nota fiscal eletrônica e o portal de compras governamentais.

Para Oliveira e Eler (2015), o objetivo do Governo Eletrônico Federal é transformar as relações do Governo com os cidadãos, visando aprimorar a qualidade dos serviços prestados, além de fortalecer a participação cidadã por meio do acesso a informação e uma administração mais eficiente.

Diante disso, o governo precisará enfrentar dificuldades que podem ir além das limitações financeiras, tecnológicas e de infraestrutura. Para Albuquerque, Silva e Souza (2017), existe a necessidade de uma mudança não só tecnológica, mas cultural para o aperfeiçoamento desse mecanismo no âmbito da Administração Pública brasileira, compreendendo de forma simples às relações geradas por essa nova Era Digital, no qual se estabelece em alcançar novas práticas de gestão democrática visando melhorar as condições de desenvolvimento econômico e social do Estado brasileiro.

\section{METODOLOGIA}

Trata-se de uma pesquisa exploratória com abordagem qualitativa. Para Gil (2008), a 
pesquisa exploratória habitualmente envolve levantamento bibliográfico e documental, entrevistas não padronizadas e estudos de caso. Procedimentos de amostragem e técnicas quantitativas de coleta de dados não são costumeiramente aplicados nestas pesquisas.

Em relação à pesquisa qualitativa, Gerhardt e Silveira (2009), destacam que a pesquisa qualitativa não se preocupa com representatividade numérica, mas, sim, com o aprofundamento da compreensão de um grupo social, de uma organização, etc.

Para tanto, utilizou-se a pesquisa bibliográfica e documental referente ao tema, levantando informações em portais do governo federal brasileiro, legislações, artigos científicos, teses e livros relacionados ao governo eletrônico. A proposta é avaliar o estágio de desenvolvimento do e-gov no Brasil de modo a destacar suas potencialidades e perspectivas para um futuro próximo. A proposta não é avaliar amplamente todas as ações que envolvem as TICs em âmbito governamental, mas sim analisar pontualmente alguns projetos de e-gov no Brasil considerados mais relevantes para o atual momento em termos de inovação e que promoverão maiores benefícios à população.

\section{PROGRAMA ESOCIAL}

O Sistema de Escrituração Digital das Obrigações Fiscais, Previdenciárias e Trabalhistas (eSocial) instituído pelo decreto no 8373/2014 é o instrumento de unificação da prestação das informações referentes à escrituração das obrigações fiscais, previdenciárias e trabalhistas. Por meio desse sistema, os empregadores passarão a comunicar ao Governo, de forma unificada, as informações relativas aos trabalhadores, como vínculos, contribuições previdenciárias, folha de pagamento, comunicações de acidente de trabalho, aviso prévio, escriturações fiscais e informações sobre o FGTS (PORTAL DO ESOCIAL, 2018).

Apesar de instituído em 2014, por meio do decreto 8373, a utilização do sistema para empresas foi prorrogada diversas vezes e somente em janeiro de 2018 foi implantado e passa agora a ser obrigatório para empresas com faturamento superior a 78 milhões de reais. O cronograma prevê que a partir de 1 으 de julho de 2018 será estendido as demais empresas e a partir de 14 de janeiro de 2019 será obrigatório também para os órgãos públicos.

De acordo com o portal do eSocial (2018), quando 0 projeto estiver totalmente implementado, reunirá informações de mais de 44 milhões de trabalhadores do setor público e privado do país em um único sistema.

O eSocial é parte e um programa ainda maior, chamado de Sistema Público de Escrituração Digital (SPED). Este sistema, que faz parte do Programa de Aceleração do Crescimento (PAC), foi instituído pelo Governo brasileiro por meio do Decreto no 6.022/2007 e pode ser classificado como uma prática de e-Gov e de Nova Gestão Pública (NGP), que fazem parte do mesmo movimento (VELLUCCl; GRIBL, 2017).

O decreto № 7.979 de 2013 em seu artigo $2^{\circ}$ define o SPED como instrumento que unifica as atividades de recepção, validação, armazenamento e autenticação de livros e documentos que integram a escrituração contábil e fiscal dos empresários e das pessoas jurídicas, inclusive imunes ou isentas, mediante fluxo único, computadorizado, de informações.

A "Nota Fiscal Eletrônica", a "Escrituração Contábil Digital", a "Escrituração Fiscal Digital do ICMS (Imposto sobre Circulação de Mercadorias e Prestação de Serviços), do IPI" (Imposto sobre Produtos Industrializados) e a "Escrituração Fiscal Digital das contribuições para o PIS (Programa de Integração Social), COFINS (Contribuição para o Financiamento da Seguridade Social) e Previdenciárias incidentes sobre a Receita" são exemplos de obrigações acessórias naturais ao ambiente SPED (LIMA et al., 2016).

O eSocial é o módulo do SPED onde serão prestadas as obrigações assessórias das empresas referentes aos seus empregados. De acordo com Gribl e Velucci (2017), além do envio automático das informações que serão transmitidas através de uma única fonte para a Secretaria da Receita Federal, Ministérios do Trabalho e Emprego e da Previdência Social, Instituto Nacional de Seguridade Social (INSS) e Caixa Econômica Federal, a proposta é que o eSocial seja um sistema global, com todas as informações de funcionários, permitindo a análise integrada e abrangente das informações. 
Figura 1: eSocial e órgãos participantes

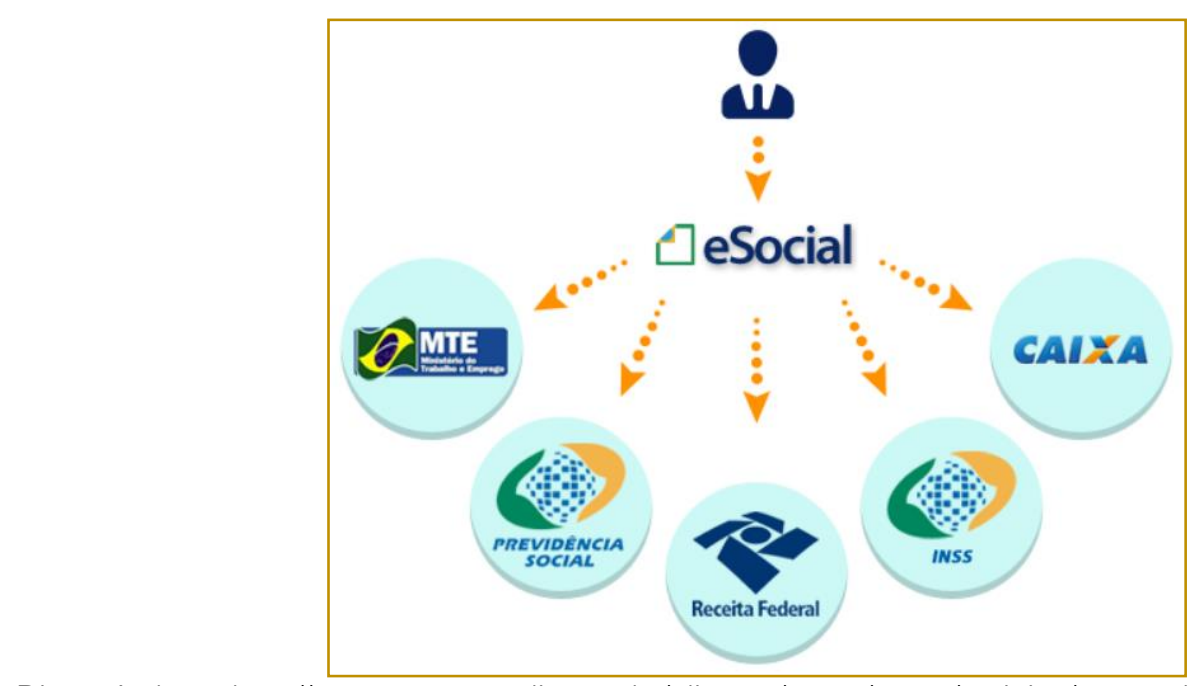

Disponível em: http://www.sempe.mdic.gov.br/clientes/smpe/smpe/noticias/smpe-abre-consulta-publica-paraesocial-da-micro-e-pequena-empresa/esocial.png/view

Vassoler (2016) afirma que as fraudes e a redução no direito trabalhista dos empregados e os prejuízos das arrecadações foram os motivos que levaram o Governo Federal a consolidarem o eSocial, por isso a união dos órgãos envolvidos Receita Federal, a Previdência Social, o Ministério do Trabalho e a Caixa Econômica Federal, permitindo a criação do programa e-Social, dessa maneira haverá melhor arrecadação das informações enviadas.

O portal do eSocial (2018), destaca as diversas vantagens do sistema como a simplificação de processos com consequente ganho de produtividade, além de diminuição de erro nos cálculos na geração de guias. 0 sistema promoverá maior segurança jurídica para as empresas, contribuirá para atuação dos órgãos fiscalizadores e ainda aumentará a efetivação e cumprimento dos direitos trabalhistas.

No entanto, para Vassoler (2016), os empregadores terão que se adaptar as novas regras, que serão mais rígidas, as ocorrências acontecidas na empresa como demissão admissão dentre outros não poderão mais ser adiadas com esse novo sistema, ele não aceitará datas retroativas ou qualquer divergência, assim o empregador deverá estar atento a tudo que ocorre com seus colaboradores diariamente.

$\mathrm{Na}$ prática a legislação trabalhista não será alterada, porém as informações terão que ser prestadas com maior exatidão e de acordo com os prazos estabelecidos por lei, caso contrário as empresas poderão ser multadas.

Mann e Hoffmam destacam que o eSocial provocará uma mudança no cenário com que as organizações públicas e privadas estão inseridas, quebrando novos e velhos paradigmas e buscando novas estratégias de gestão empresarial e principalmente de recursos humanos.

\section{PROCESSO ELETRÔNICO NACIONAL (PEN)}

O projeto Processo Eletrônico Nacional (PEN) é uma iniciativa conjunta de órgãos e entidades de diversas esferas da administração pública para a construção de uma infraestrutura pública de processo administrativo eletrônico. Uma iniciativa de gestão pública, que visa a obtenção de substanciais melhorias no desempenho dos processos da administração pública, com ganhos em agilidade, produtividade, satisfação do público usuário e redução de custos. (PORTAL DE COMPRAS, 2018)

Segundo Höehr (2017), o PEN é uma iniciativa conjunta de entes, órgãos e entidades públicas de diversas esferas, para a construção de uma infraestrutura pública de processo administrativo eletrônico que permite a criação e o trâmite de documentos e processos eletrônicos. 
O projeto é consequência do decreto 8.539 de outubro de 2015 que tornou obrigatório o uso do meio eletrônico para gestão e tramitação de processos administrativos nas instituições públicas no Brasil. O decreto estabeleceu prazo de 02 anos para início da implantação e 03 anos, contados da publicação do decreto para que todas as instituições estejam adaptadas aos meios eletrônicos. Dessa forma, até outubro de 2018, todos os órgãos e entidades da administração pública federal direta, autárquica e fundacional deverão estar inteiramente adaptados ao programa.

De modo a facilitar a enquadramento das instituições ao projeto, o Governo Federal adotou o Sistema Eletrônico de Informações (SEI) como plataforma única de integração entre as diversas instituições federais.

O SEl foi desenvolvido pelo Tribunal Regional

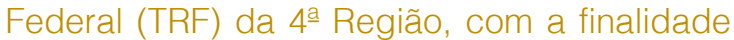
de dar agilidade aos processos e documentos, mais transparência e principalmente na redução de custos, permitindo um sistema que arquivasse, produzisse, tramitasse, avaliasse, usasse e guardasse permanentemente documentos ou os eliminasse, tudo de acordo com o Conselho Nacional de Arquivos (CONARQ), ambos trabalharão no intuito de aparelhar o Processo Eletrônico Nacional (PEN), apresentando como características principal a portabilidade e acesso remoto através de todos os navegadores e aparelhos eletrônicos conectados à rede mundial de computadores (internet). (ALBUQUERQUE; SILVA; SOUSA, 2017)

Trata-se de uma grande revolução na administração pública federal e os benefícios são enormes. Pode-se citar economia de recursos com papel, tinta, pastas, maior celeridade na tramitação de processos, padronização dos documentos, mapeamento de processos, maior segurança e redução de espaço físico quanto ao armazenamento dos mesmos, além de proporcionar mais transparência, já que todos os servidores poderão ter acesso a todos os documentos tramitados dentro da instituição, com exceção dos restritos e sigilosos que são estabelecidos por lei.

Também é possível dizer que a economia de recursos deve ir ainda muito além da redução de gasto com material de expediente se considerarmos que os processos serão tramitados de forma totalmente eletrônica e integrada entre diferentes órgãos, possibilitando grande redução nos custos de transporte de documentos físicos entre diferentes instituições ou até mesmo dentro de um mesmo órgão com várias unidades distintas.

Portanto, o Processo Eletrônico Nacional promoverá grandes mudanças positivas nas instituições brasileiras, indo de encontro a política de desburocratização nacional. No entanto, os órgãos participantes precisarão estar atentos quanto as limitações tecnológicas, sobretudo em relação aos equipamentos eletrônicos necessários a implantação do sistema. Também será preciso investir em treinamento e capacitação dos servidores de todas as áreas e não somente aquelas envolvidas no desenvolvimento dos programas e mapeamento dos processos. A área de Tecnologia de Informação e Comunicação deve passar a ser fundamental e estratégica para o planejamento institucional, recebendo maior aporte de recursos financeiros e de pessoal.

\section{PROJETO TAXIGOV}

De iniciativa do Ministério do Planejamento, Desenvolvimento e Gestão (MPOG), o intitulado TáxiGov é um sistema de transporte de servidores públicos realizado por meio de agendamento de táxis. Similar a outros sistemas como "Uber", o TaxiGov é para uso exclusivo dos servidores do executivo federal que atuam no Distrito Federal. Teve sua implantação iniciada em fevereiro de 2017 no MPOG, hoje já está operando em 22 unidades e até o final do primeiro semestre de 2018 deve estar implantado em todos órgãos da Administração Direta Federal que atuam no Distrito Federal e entorno.

O sistema tende a se tornar referência para todo o setor público, visto que proporciona grande economia de recursos. De acordo com o portal do Mistério do Planejamento (2018), a economia anual prevista com o modelo é de aproximadamente 20 milhões de reais, representando uma redução de $60 \%$ das despesas de deslocamento dos servidores.

O TáxiGov, substitui os modelos antigos de prestação do serviço que utilizam frota própria ou alugada. Basicamente, em vez de comprar veículos que geram muitos custos com manutenção, motoristas e depreciação ou 
alugar, gerando custos de ociosidade, o poder público contrata um fornecedor (empresa de táxi), por meio de licitação, para transportar seus servidores utilizando o sistema de agendamento por aplicativo próprio.

As corridas são solicitadas via aplicativo mobile e web, além de uma Central de Atendimento por telefone. A solução permite, também, que os usuários acompanhem o deslocamento do veículo, desde a solicitação até a finalização da viagem, e recebam por email confirmação e informações sobre a corrida (PORTAL GOVERNO DO BRASIL, 2018).

Marcolino et al. (2017), ressalta que além da redução de custos, destacam-se outros ganhos não financeiros, como a possibilidade de gestores públicos realizarem 0 acompanhamento em tempo real dos deslocamentos, consultando, a qualquer momento, aqueles já realizados. Também permite aos órgãos reduzir o número de pessoas, tempo e outros recursos alocados na execução de atividades antes relacionadas à frota e à gestão contratual.

Gleisson Rubin, atual secretário de gestão do Ministério do planejamento, afirma que desde sua implantação, em fevereiro de 2017, o TáxiGov vem se mostrando como uma estratégia de solução de mobilidade que permite a modernização da gestão pública com uso de recursos tecnológicos de ponta, com significativa redução dos gastos e maior racionalidade e padronização do serviço (PORTAL DO PLANEJAMENTO, 2018).

A perspectiva é de que, em um futuro próximo, o exemplo do Distrito Federal sirva de modelo para as demais regiões do país e que o novo sistema seja adotado por órgãos

\section{REFERÊNCIAS}

[1] Albuquerque, Bruno Marques; Silva, Fernanda Cláudia Araújo Da; Sousa, Thanderson Pereira De. A era eletrônica da administração pública federal. Revista Vianna Sapiens, v. 8, 2017.

[2] Brasil. Ministério do Planejamento, Orçamento e Gestão. Estratégia de Governança Digital, 2017. Disponível em: < https://www.governoeletronico.gov.br/egd >. Acesso: 23 jan. 2018

[3] Decreto no 7.979 , de 8 de abril de 2013. Altera o Decreto no 6.022, de 22 de janeiro de 2007, que instituiu o Sistema Público de Escrituração Digital - Sped. Disponível em: dos três poderes em todo território nacional gerando grande economia e comprovando que as soluções tecnológicas devem ser adotadas para garantir maior eficiência na utilização dos recursos.

\section{CONSIDERAÇÕES FINAIS}

A tecnologia tornou-se uma aliada do poder público. Questões como transparência pública, participação social, controle de gastos e fiscalização são hoje viáveis por meio de avanços tecnológicos como a Internet.

O presente artigo buscou demonstrar de maneira geral como o governo brasileiro está atuando de forma a aplicar as inovações tecnológicas para desburocratizar a Administração Pública, tornando-a mais leve e menos dispendiosa.

O Processo Eletrônico Nacional tende a ser um grande instrumento de transparência, eficiência e integração entre órgãos, podendo ainda viabilizar projetos ainda maiores no futuro. O eSocial será uma ferramenta fundamental para desburocratização, não só do setor público, mais principalmente do privado, facilitando o controle das obrigações assessórias das empresas. Já o TaxiGov deve contribuir principalmente na redução dos gastos públicos, evitando despesas desnecessárias com aquisição e manutenção de veículos.

De forma geral, as ações apresentas demonstram que significativas mudanças estão ocorrendo no governo federal e irão contribuir de forma eficaz para modernização da Gestão Pública Nacional, proporcionando um ambiente menos burocrático e mais capaz de atender aos anseios da população.

<http://www.planalto.gov.br/ccivil_03/_ato20112014/2013/decreto/d7979.htm>. Acesso: 23 jan. 2018

[4] Decreto $\mathrm{n}^{\circ}$ 8.373, de 11 de dezembro de 2014. Institui o Sistema de Escrituração Digital das Obrigações Fiscais, Previdenciárias e Trabalhistas - eSocial e dá outras providências. Disponível em: <http://www.planalto.gov.br/ccivil_03/_ato20112014/2014/decreto/d8373.htm>. Acesso: 23 jan. 2018

[5] Decreto no 8.539, de 08 de outubro de 2015. Dispõe sobre o uso do meio eletrônico para a realização do processo administrativo no âmbito dos órgãos e das 
entidades da administração pública federal direta, autárquica e fundacional. Disponível em: < http://www.planalto.gov.br/ccivil_03/_Ato20152018/2015/Decreto/D8539.htm>. Acesso: 23 jan. 2018

[6] Decreto $\mathrm{n}^{\circ}$ 8.638, de 15 de janeiro de 2016. Institui a Política de Governança Digital no âmbito dos órgãos e das entidades da administração pública federal direta, autárquica e fundacional. Disponível em: <http://www.planalto.gov.br/ccivil_03/_ato20152018/2016/decreto/d8638.htm>. Acesso: 23 jan. 2018

[7] Cunha, M. A. V. C; Miranda, P. R. M. A Pesquisa no Uso e Implicações Sociais das Tecnologias da Informação e Comunicação pelos Governos no Brasil: uma Proposta de Agenda a Partir de Reflexões da Prática e da Produção Acadêmica Nacional. Encontro da Associação Nacional de Pós-graduação e Pesquisa em Administração. Rio de Janeiro: EnANPAD, 2008.

[8] Cunha, Alexandra Viegas Cortez da Maria; Duclós, Luis Carlos; Barbosa, Alexandre Fernandes. Institucionalização do e-governo como Instrumento de Legitimidade da Governança Eletrônica no Setor Público no Brasil, Chile e Peru. Encontro da Associação Nacional de Pósgraduação e Pesquisa em Administração. Salvador: EnANPAD, 2006. Disponível em: <http://www.anpad.org.br/enanpad/2006/dwn/enan pad2006-adic-2856.pdf>. Acesso em: 27 jan. 2018.

[9] Diniz, Eduardo Henrique et al. O governo eletrônico no Brasil: perspectiva histórica a partir de um modelo estruturado de análise. Revista de Administração Pública v. 43, fev. 2009.

[10] Engel Gerhardt, Tatiana; Tolfo Silveira, Denise. Métodos de Pesquisa. Universidade Federal do Rio Grande do Sul. ed. Porto Alegre, 2009

[11] Fernandes, Alexandre et al. Governo eletrônico: Um modelo de referência para a sua implementação governo eletrônico: um modelo de referência para a sua implementação. Congresso Anual de Tecnologia de Informação. 2004.

[12] Gil, Antonio Carlos. Métodos e Técnicas de Pesquisa Social. São Paulo: Editora Atlas S.A., 2008. Disponível em $<$ https://ayanrafael.files.wordpress.com/2011/08/gil -a-c-mc3a9todos-e-tc3a9cnicas-de-pesquisasocial.pdf>. Acesso em: 28 jan. 2018.

[13] Guimarães, Tomás de Aquino; Medeiros, Paulo Henrique Ramos. A relação entre governo eletrônico e governança eletrônica no governo federal brasileiro. Cadernos Ebape.BR v. 3, dez. 2005.

[14] Höehr, Augusta. A contribuição do arquivista na implantação de um sistema de gestão de processos eletrônicos. Universidade Federal do Rio Grande do Sul , 2017. Disponível em: <https://www.lume.ufrgs.br/handle/10183/169448> Acesso em: 14 jan. 2018.

[15] Lima, Edson Sampaio De et al. Contribuição à análise da redução nos custos de conformidade tributária e os investimentos no sistema público de escrituração digital - Sped no brasil. Journal of Information Systems and Technology Management v. 13, n. 1, p. 101-130, 19 abr. 2016.

[16] Mol Marcolino, Daniel et al. Táxigov: inovação no serviço de mobilidade de servidores como modelo de centro de serviços compartilhados no governo federal. X Consad de Gestão Pública , 2017

[17] Oecd. Recommendation of the Council on Digital Government Strategies. Organisation for Economic Co-operation and Development, 2014. Disponível em: <http://www.oecd.org/gov/digitalgovernment/Recommendation-digital-governmentstrategies.pdf>. Acesso em: 23 jan. 2018

[18] Oliveira, Alberto Dumont Alves; Eler, Marcelo Medeiros. Acessibilidade em Governo Eletrônico: um estudo sobre a aplicação de padrões web em sítios gov.br. Universidade de São Paulo, 2015. Disponível em: <http://www.each.usp.br/marceloeler/papers/Oliveir a-Eler-SBSI2015.pdf>. Acesso em: 14 jan. 2018.

[19] Parra Filho, Henrique Carlos Parra; Martins, Ricardo Augusto Poppi. Governança digital como vetor para uma nova geração de tecnologias de participação social no Brasil. Liinc em Revista v. 13, 2017

[20] Portal de Compras Processo Eletrônico Nacional. Disponível em: $<$ https://www.comprasgovernamentais.gov.br/index .php/pen>. Acesso: 23 jan. 2018

[21] Portal DO Planejamento Taxigov. http://www. planejamento.gov.br/taxigov>. Acesso: 23 jan. 2018

[22] Portal Esocial Conheça o eSocial. Disponível em: < http://portal.esocial.gov.br/institucional/conhecao>. Acesso: 23 jan. 2018

[23] Portal Governo do Brasil TáxiGov atinge meta de $60,89 \%$ de economia nas despesas com transporte administrativo. Disponível em: < http://www.brasil.gov.br/governo/2017/06/taxigovatinge-meta-de-60-89-de-economia-nas-despesascom-transporte-administrativo>. Acesso: 23 jan. 2018

[24] Sant, Hudson De; SECAL, Mann. A implantação do E-Social sob a ótica dos profissionais de $\mathrm{RH}$ das cooperativas agropecuárias de Ponta Grossa-Pr. Gestão Estratégica: Tecnologia e o Impacto nas Organizações , 2015. 
[25] Santos, E. M.; Reinhard, N. Usos de Serviços de Governo Eletrônico no Brasil: um estudo exploratório. Encontro da Associação Nacional de Pós-Graduação e Pesquisa em Administração. Rio de Janeiro: ANPAD, 2011. p.115.

[26] Vassoler, Herika Dassoler. O sistema de escrituração fiscal digital das obrigações fiscais previdenciárias e trabalhistas - eSocial.
Universidade do Extremo Sul Catarinense , 2016. Disponível

em: <http://200.18.15.27/handle/1/3637>. Acesso em: 29 jan. 2018.

[27] Vellucci, Rosana Gribl; Gribl, Rosana. Os desafios da implantação do esocial e seus reflexos nas rotinas das organizações, 2017. Disponível em: <http://tede.metodista.br/jspui/handle/tede/1639>. Acesso em: 14 jan. 2018. 


\section{Gapítulo 17}

\section{OTIMIZACẼO DAS ATIVIDADES DIÁRIAS ATRAVÉS DA IMPLANTAÇÃO DO GRD NO SETOR DE MANUTENCC̃O DE UMA UNIVERSIDADE PÚBLICA}

\section{Higor Coimbra Lucindo}

Ana Flavia da Fonseca Barroso

André Luiz Francisco Ferreira

Resumo: A baixa produtividade, falta de motivação no desempenho das atividades rotineiras, forte resistência a mudanças, são fatores prejudiciais a qualquer organização, pois interferem diretamente na qualidade dos serviços prestados. Buscando melhorar a qualidade dos serviços e o melhor desempenho das atividades diárias do setor, através da aplicação da metodologia do Gerenciamento da Rotina do Trabalho do dia a dia ou GRD que é uma ação de verificação diária, que busca criar, preservar ou melhorar a padronização dos procedimentos (CAMPOS, 1998), inicialmente foi feito um estudo das etapas do processo de solicitação e atendimento dos serviços prestados pelo setor e construído o fluxograma do processo que foi exposto em uma reunião com a participação dos colaboradores, com o intuito de eliminar possíveis anomalias no processo, o que desencadeou um novo modelo de atendimento (atendimento setorial) no qual o campus da universidade foi dividido em oito macro setores visando otimizar os atendimentos. Por fim, foram estabelecidos procedimentos operacionais padrões e implantada a padronização em um treinamento com a presença todos os envolvidos. Apesar de enfrentar inúmeras resistências devido à forte cultura organizacional, conclui-se que com o desenvolvimento desse trabalho ocorreu um avanço expressivo no GRD do setor de manutenção gerando expectativas de otimização no atendimento das solicitações, ganhos qualitativos e quantitativos e profissionais mais motivados.

Palavras-chave: GRD, Padronização, Fluxograma, Qualidade dos Serviços. 


\section{INTRODUÇÃO}

Atualmente, visando a satisfação de seus clientes e colaboradores, as empresas, buscam a melhoria contínua de seus serviços e processos. As organizações privadas, devido à alta competitividade, lideram a implantação de programas de qualidade, a fim de manterem-se no mercado; já às organizações públicas, devido à forte cultura organizacional, imprimem uma resistência às mudanças, comprometendo a qualidade dos serviços prestados. A padronização de tarefas rotineiras é uma forma de promover melhorias no ambiente de trabalho e de levar satisfação aos clientes e colaboradores pois faz parte das premissas da qualidade total.

O Gerenciamento da Rotina do Trabalho do Dia a Dia ou GRD é uma ação de verificação diária, objetivando criar, preservar ou melhorar a padronização dos procedimentos. Padronizar é envolver todos os integrantes do processo objetivando um denominador comum em busca da melhoria, sendo necessário analisar o processo e melhorá-lo de forma a corrigir as anomalias, seguidamente introduzir o padrão na organização, treinando as pessoas e assegurando que o processo será executado de acordo com o que foi estabelecido (CAMPOS, 1998).

Este trabalho tem como objetivo mostrar como as atividades diárias podem ser otimizadas através da implantação do GRD em empresas através de um estudo de caso descritivo e exploratório no setor de manutenção de uma universidade pública de Minas Gerais. Para o desenvolvimento deste trabalho, foi feito um estudo das etapas do processo de solicitação e atendimento dos serviços prestados pelo setor, construção do fluxograma, levantamento das atividades críticas e geração de um novo modelo de atendimento que foi padronizado e implantado.

\section{GERENCIAMENTO DO TRABALHO DO DIA- A-DIA}

O gerenciamento da rotina do trabalho do diaa-dia ou GRD é uma ação de verificação diária para criar, preservar ou melhorar a padronização dos procedimentos de fundamental importância visto que através dele, os processos são estabelecidos, alcançando a previsibilidade da qualidade de produtos e serviços. A padronização deve ser iniciada pelos processo e tarefas prioritários, que são aquelas que provocam vigoroso impacto na qualidade do produto ou serviço (CAMPOS, 1998).

As funções operacionais são responsáveis pela ocupação de maior parte do tempo do trabalhador e com o intuito de evitar anomalias no processo, é necessário que que exista a padronização dos procedimentos que devem ser seguidos por cada colaborador. O gerenciamento da rotina, objetiva criar novos padrões, alterar ou respeitar padrões existentes (CAMPOS, 1998).

Padronizar é envolver todos os integrantes do processo objetivando um denominador comum em busca da melhoria, sendo necessário analisar o processo e melhorá-lo de forma a corrigir as anomalias, seguidamente introduzir o padrão na organização, treinando as pessoas e assegurando que o processo será executado de acordo com o que foi estabelecido, para que a padronização seja aplicada corretamente e esteja de acordo com os propósitos da organização. É uma ferramenta fundamental para o gerenciamento da rotina do trabalho do dia-a-dia, visto que promove melhoria na qualidade dos serviços e produção (CAMPOS, 1998).

Fischer (2002) estabelece a padronização através dos seguintes passos: elaboração de fluxograma, seleção dos itens de verificação (causas) e dos itens de controle (efeitos), análise dos padrões no momento de sua aplicação, elaboração da documentação pertinente ao sistema de padronização e revisões do padrão e da documentação pertinentes, em função das melhorias alcançadas.

O padrão autoriza os gestores a instituírem aos seus administrados, responsabilidades atribuídas de forma clara e definida. Conforme Ambrozewicz apud Seleme \& Stadler (2010), deve-se atender a alguns requisitos básicos ao estipular padrões:

1) Ser mensurável: Permitir avaliação a qualquer momento, adquirindo resultados que possibilitem confrontar claramente os dois estados atual e anterior.

2) Ser de fácil compreensão: Por englobar muitos funcionários, o padrão deve ser de fácil compreensão a quem vai utilizá-lo.

3) Ser de fácil aplicação: Simples e fácil utilização. 
4) Ser democrático: Se possível, deve ser estabelecido junto aos usuários, o que permiti uma especialização na execução.

5) Ser baseado na prática: Apresentando essa característica tem como base o ensaio, a realização na prática e tem comprovada sua eficácia.

6) Ser passível de revisão: Deve permitir sofrer alteração visando melhoria sem comprometer o já instituído.

7) Possuir autoridade: Por ser a forma mais clara de chegar ao objetivo é necessário muito rigor no padrão.

8) Possuir informação de vanguarda: Deve ser a parte principal do processo.

9) Ser voltado para o futuro: O padrão deve possuir abertura a processos que levam a resultados ineficientes no momento atual.

10) Fazer parte de um sistema de padronização: Atender as especificidades de cada caso.

Para Campos (1995) uma organização em processo de padronização busca uma unificação dos procedimentos e, evitando comprometer o processo de implantação, é recomendado não buscar a perfeição inicialmente. A perfeição será atingida de médio á longo prazo pelo gerenciamento. São recomendas, as seguintes etapas na implantação: transparência no comprometimento da diretoria; criação de um programa de implantação; extrair informações dos departamentos que compõem 0 processo; determinar padrões prioritários e designar responsáveis para estabelecimento deles; apresentar e discutir os procedimentos do padrão com cada subordinado e repassar aos demais departamentos envolvidos; encaminhar o padrão a ser implantado para aprovação do superior; avaliar periodicamente a eficácia da padronização.

De acordo com Campos (1995) a verificação quanto ao cumprimento dos padrões é função do supervisor, portanto é essencial que esse profissional conheça profundamente todos os postos que estão sob sua conduta. Ao perceber anomalias, é função dele orientar o operador quanto à forma correta de cumprir o padrão estabelecido. A conversa diária com os operadores é fundamental para obter informações de falhas no procedimento, evitando desgastes desnecessários.

De modo geral, a padronização se torna um meio para transmitir informações, viabilizando a informação dos clientes através de procedimentos padrões, a educação e treinamento objetivando conscientizar os envolvidos sobre a importância do cumprimento do padrão estabelecido, promovendo a interação e satisfação de todos. Além disso, ela permite a melhoria e a garantia da confiabilidade, manutenção e melhoria da qualidade, a prevenção da ocorrência de anomalias e o estabelecimento de procedimentos padrões de operação, reduzindo os custos do processo como simplificação de atividades, além de melhorar a produtividade dos funcionários e oferecerIhes maior direcionamento e segurança para a execução de suas atividades diárias (CAMPOS, 1999).

\section{ESTUDO DE CASO}

O estudo de caso foi realizado no setor de manutenção de uma universidade pública localizada em Minas Gerais cuja função é planejar, gerenciar e executar as manutenções do campus universitário.

Através de observações in loco, observou-se que o responsável pelo setor deveria gerenciar todo o processo de atendimento às requisições de serviços encaminhadas ao setor de oficinas, e que não havia padronização e controle dos serviços solicitados, ocasionando desorganização em todo o processo de atendimento.

Conforme a metodologia do GRD, a padronização aponta as seguintes etapas básicas: Elaboração do fluxograma; descrição do procedimento; registro em formato padrão.

\subsection{O FLUXOGRAMA}

A construção do fluxograma foi instaurada em uma reunião com todos os envolvidos no processo que em opinião unânime afirmaram a necessidade de padronização dos processos, visto que, o desconhecimento das etapas a serem seguidas por parte dos envolvidos, provocava prejuízos ao processo.

Para elaborar o fluxograma o gestor percorreu cada etapa que integra o processo, com o intuito de mapear a situação real. Ao percorrer as etapas era comum conversar com os colaboradores objetivando compreender as seguintes informações quanto à realização das tarefas: dificuldades enfrentadas, nível de satisfação, idéias inovadoras e outras possíveis anomalias identificadas pelos colaboradores. 
Ao percorrer todas as etapas, foi gerado o relatório contendo todas as atividades do processo e respeitando a ordem crescente delas, na sequência está disposto em forma de texto o relatório citado:

O processo se inicia, quando é detectado a necessidade de um atendimento pelo usuário, que se dirige a secretaria da unidade acadêmica, descreve a solicitação ao secretário responsável por encaminhar as requisições de serviços internos a gerência, via sistema de informação. A requisição solicitada é encaminhada, chegando via sistema ao gerente de oficinas, que inicialmente verifica se possui equipe especializada para executar o solicitado, possuindo equipe especializada, inseri a requisição na planilha eletrônica de gerenciamento e controle de requisições se não possuir equipe especializada a requisição é recusada via sistema e arquivada.

A requisição inserida na planilha eletrônica de gerenciamento e controle de requisições é liberada para execução via sistema, e encaminhada ao escritório administrativo da empresa terceirizada responsável pela manutenção, que inseri a requisição no controle interno e repassa ao encarregado das oficinas. Ao receber a requisição 0 encarregado respeitando o controle padrão de atendimento encaminha a requisição ao operador que faz uma visita ao local e levanta a quantidade de material necessária para realizar o serviço, se o serviço solicitado for de manutenção o encarregado encaminha a lista de material ao gerente de oficinas, que gera uma requisição via sistema solicitando o material ao almoxarifado do setor, se o serviço for de confecção, a lista de material é encaminhada ao solicitante do serviço, que repassa a secretaria da unidade que gera uma requisição via sistema ao almoxarifado do setor, caso o serviço não seja de manutenção ou confecção é recusado via sistema e arquivado.

O almoxarifado via SMS avisa que o material está liberado, ao receber a mensagem o encarregado da ordem ao operador responsável para retirar o material e executar o serviço, caso não tenha o material, o solicitante é acionado para realizar a compra.

Com o material em mãos, o operador executa - serviço e encaminha a requisição para assinatura do solicitante que obrigatoriamente averigua a conclusão do serviço, se estiver conforme, assina, caso contrário, comunica ao próprio operador a não conformidade e aguarda solução, somente após solucionado, o solicitante assina e devolve ao operador.

A requisição assinada é entregue ao encarregado que se desloca até o local da execução e verifica a conformidade do serviço, se conforme, encaminha a requisição ao escritório administrativo da empresa terceirizada, que irá dar baixa na requisição em seu controle interno e encaminhar ao gerente de oficinas, que confere a execução do serviço e dar baixa no controle padrão, e em seguida dar baixa no sistema, por fim arquiva a requisição.

Foi elaborado o fluxograma do processo conforme Figura 1. Em seguida o fluxograma foi exposto em uma nova reunião com os colaboradores que tinha como objetivo encontrar as atividades críticas e as anormalidades do processo. 
Figura 1 - Fluxograma Funcional

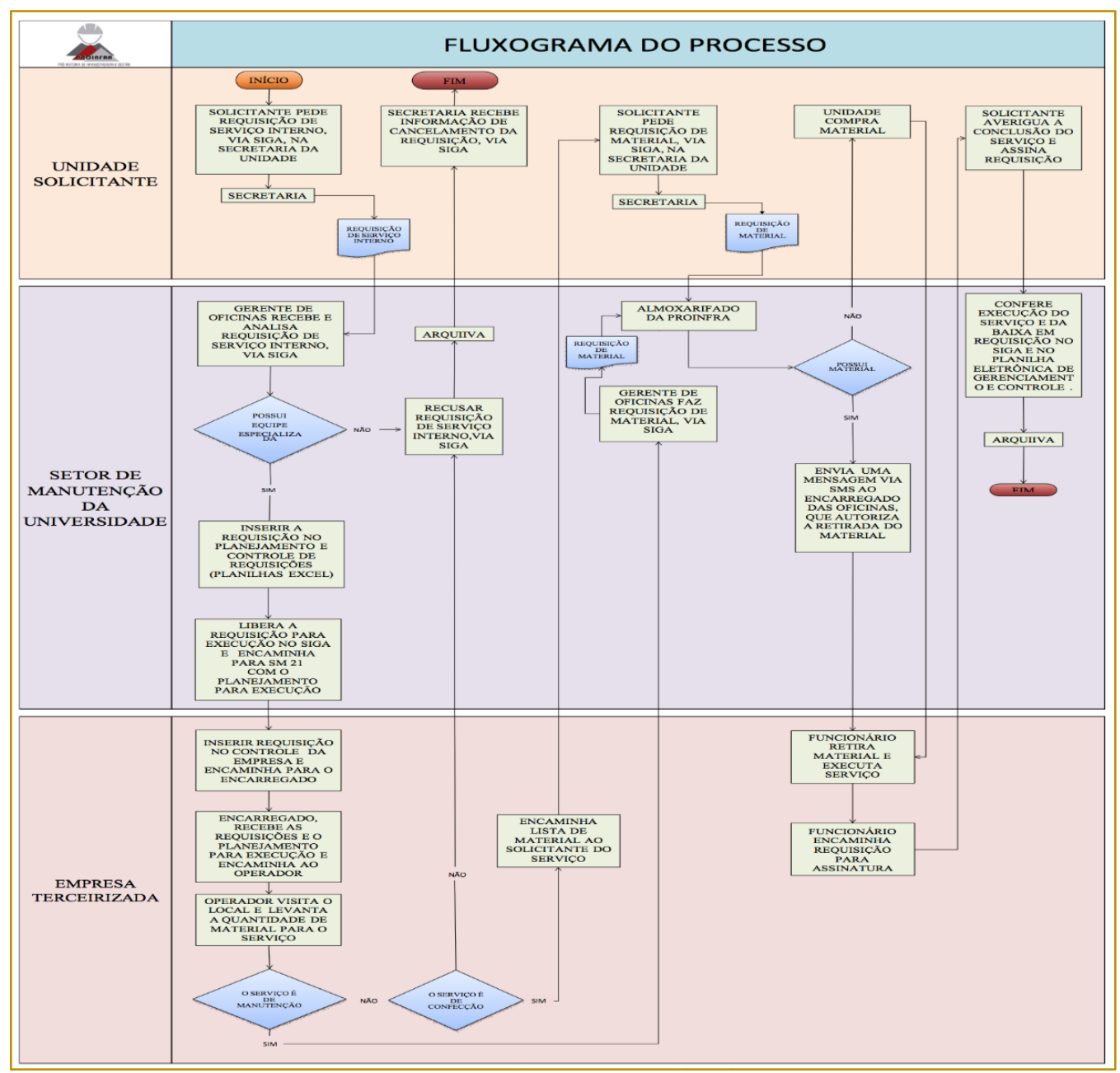

Fonte: O autor (2018)

Durante a reunião detectou-se que, na etapa em que a requisição é solicitada pela unidade, passava somente por uma análise básica. Onde era observado se a equipe de manutenção era capaz de executar o serviço, sendo possível, a requisição era liberada via siga $e$ inserida nas requisições a serem encaminhadas. A análise básica não filtrava requisições simples e complexas, o que provocava um grande acúmulo do principal foco da manutenção que é o atendimento as requisições simples de serem solucionadas, dando abertura ao atendimento das requisições complexas como as de confecção que demoram dias para serem executadas e em sua maioria não são requisições prioritárias.

Na etapa em que as requisições são liberadas e repassadas a empresa terceirizada, a ausência de um procedimento padrão provocava um gargalo na quantidade demandada, pois os serviços eram mal distribuídos aos operadores que passavam grande parte do dia sendo deslocados para atendimentos em setores distantes uns dos outros, além de muitas vezes ficarem ociosos por não conseguirem transporte para deslocamento, visto que são 164 funcionários e por questões de custos elevado é inviável colocar número excessivo de veículos para atendimento. O que exigia uma melhor organização do setor objetivando também minimizar o uso de veículos.

Com a definição das atividades críticas acima citadas, foi realizada uma nova reunião com o coordenador de manutenção e o supervisor, ficando definido a necessidade de criar procedimentos padrões, objetivando: um eficiente gerenciamento rotineiro, otimização 
do atendimento as requisições solicitadas e minimização de anomalias no processo.

O processo iniciou com um estudo da extensa área da universidade, onde foi verificado, a necessidade de dividir as unidades requisitantes em oito macro setores conforme Figura 2.

Figura 2 - Mapa setorial

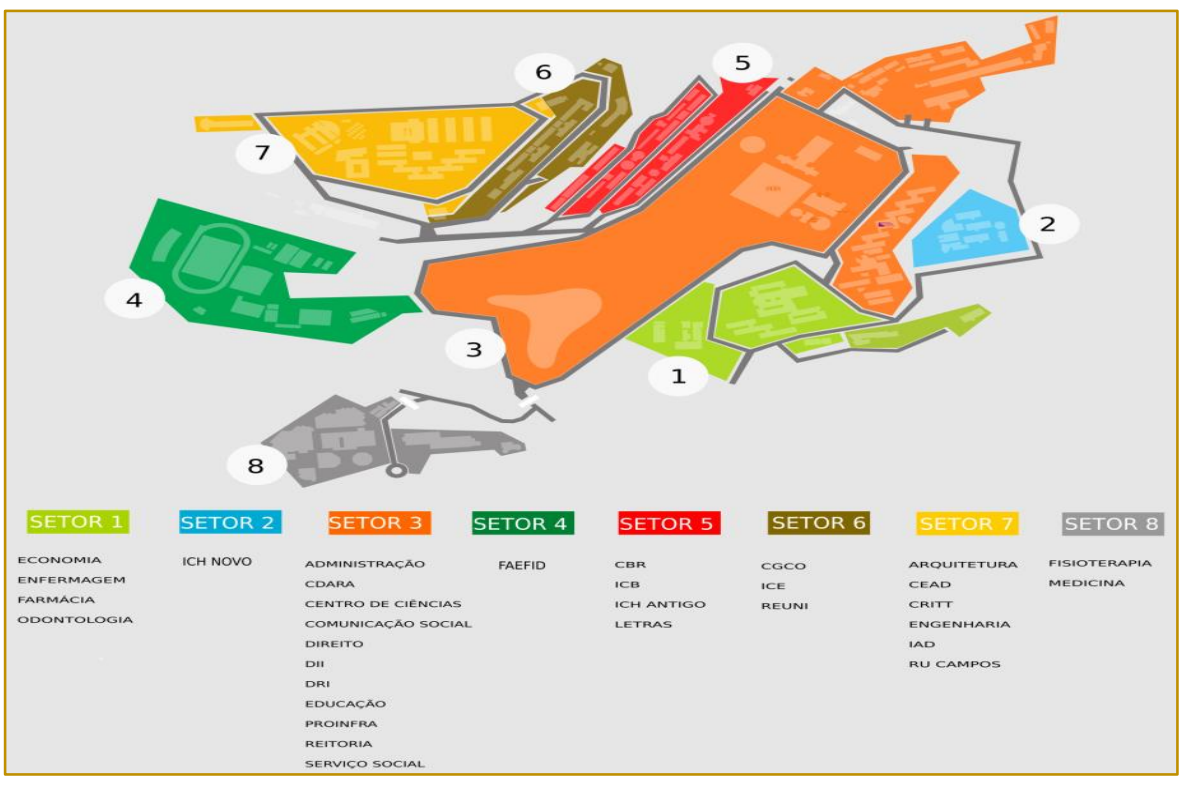

Fonte: O autor (2018)

Além disso as unidades externas que integram a universidade ficaram divididas em dois setores, totalizando dez, macro setores a serem atendidos.
Após a construção do fluxograma e a padronização do novo modelo de atendimento foram elaboradas planilhas eletrônicas para gerenciamento e controle dos atendimentos, conforme Figura 3 e 4.

Figura 3 - Planilha de gerenciamento e controle das requisições

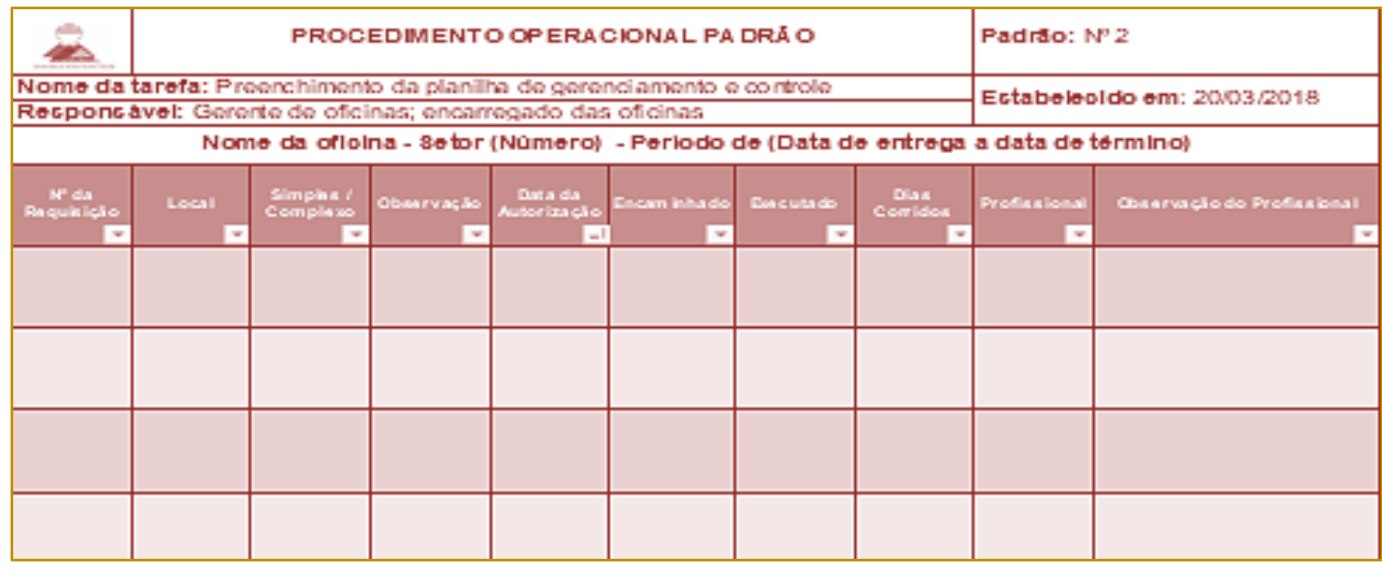

Fonte: O autor (2018)

$\mathrm{Na}$ planilha eletrônica de gerenciamento e controle das requisições conforme Figura 3, constam as atividades a serem seguidas desde a solicitação até o arquivamento da requisição, sendo essas: número de controle da requisição de serviços internos; local, indicando a unidade solicitante; simples ou complexos, indica a característica do serviço; 
observação, é a descrição resumida do serviço; data de autorização, data que o solicitante requisitou; encaminhado, data na qual o gerente encaminhou o serviço para execução; dias corridos, é o número de dias que foram necessários para executar o serviço; observação do profissional, indica as dificuldades enfrentadas para executar o serviço.

Figura 4 - Planilha de gerenciamento e controle das requisições não atendidas

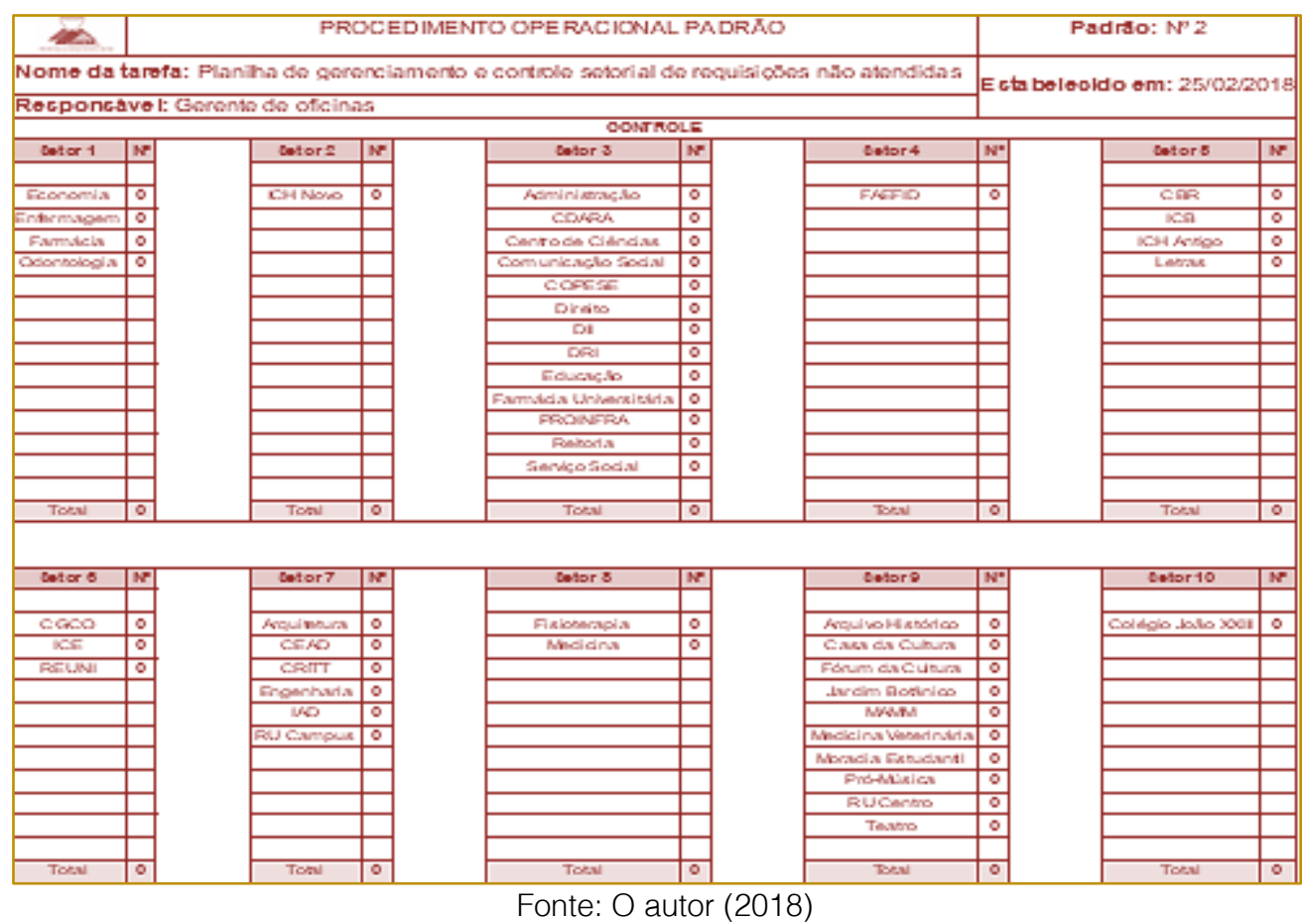

$\mathrm{Na}$ planilha eletrônica de gerenciamento e controle das requisições não atendidas, conforme Figura 4, são demonstrados resumidamente todos os macro setores, constando, o quantitativo de requisições a serem atendidas em cada unidade requisitante cuja soma totaliza o número de requisições pendentes por setor. Vinculado a essas planilhas tem-se um controle no qual consta o somatório de todas as requisições autorizadas, encaminhadas e executadas.

As planilhas de gerenciamento e controle mencionadas acima geram gráficos demonstrativos mensais referentes ao número de requisições autorizadas para a gerência de oficinas, encaminhadas a terceirizada e executadas pela terceirizada, conforme Figuras 5 e 6.

Figura 5 - Gráfico demonstrativo setorial

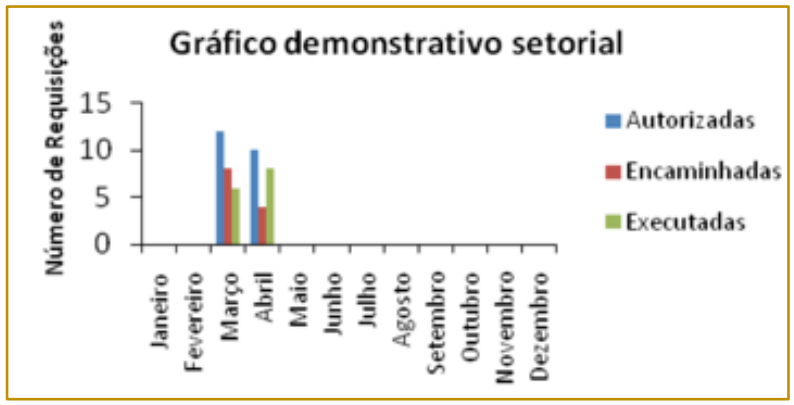

Fonte: O autor (2018) 
O gráfico demonstrativo setorial da Figura 5, gerado através de dados extraídos da planilha eletrônica de gerenciamento e controle de requisições da Figura 6, contém resultados mensais quantitativos setorial das solicitações autorizadas pelo solicitante, encaminhadas para execução e executadas.

Figura 6 - Gráfico demonstrativo total

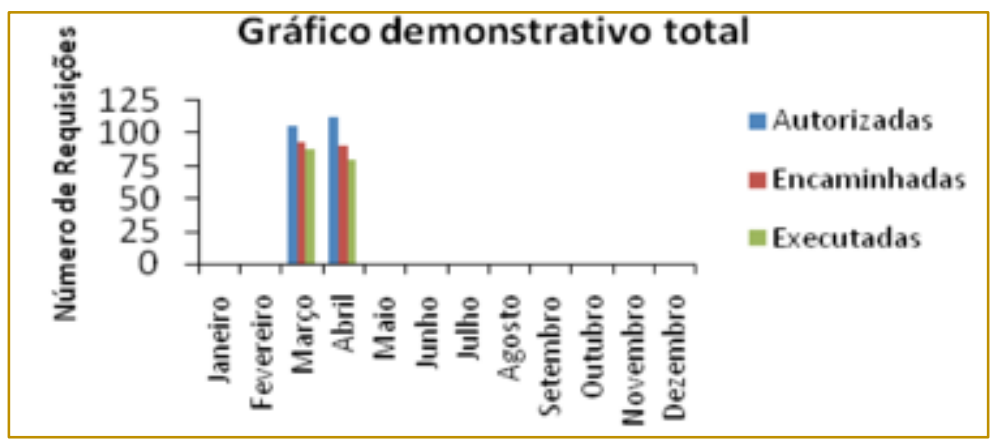

Fonte: O autor (2018)

O gráfico do demonstrativo total da Figura 6, gerado através de dados extraídos da planilha eletrônica de gerenciamento e controle de requisições da Figura 7 , contém resultados quantitativos mensais de todas as solicitações autorizadas pelo solicitante, encaminhadas para execução e executadas.

Concluída a construção das planilhas de gerenciamento e controle foram elaborados os procedimentos operacionais padrão (POP) por meio de uma planilha eletrônica, conforme Figura 7.

Os procedimentos operacionais padrões abrangeram todos os envolvidos. Com os padrões estabelecidos foi realizado a implantação, que contou com um treinamento envolvendo todos colaboradores, objetivando apresentar os padrões estabelecidos e intensificar que os serviços passariam a ser atendidos por setor, e que os serviços de urgência seriam passados na frente somente com a anuência do gerente, caso contrário os operadores seguem a rotina diária, que é o atendimento setorial, que funciona diante de um ciclo que se inicia no setor um e termina no setor dez, foi estabelecido o prazo máximo para permanecer em um setor de 5 dias úteis, caso termine $\mathrm{o}$ atendimento antes disso 0 supervisor deve avisar imediatamente ao gerente, não terminando no prazo estabelecido, as requisições não atendidas ficam sendo as primeiras do próximo ciclo. Além disso, os operadores recebem ordem para permanecer no mesmo setor durante todo um turno, manhã ou tarde, só é permitido voltar antes do término do turno a oficina se executadas todas as requisições do setor. 
Figura 7 - Procedimento operacional padrão 1

\begin{tabular}{|c|c|c|}
\hline ins & PR OCEDIMENTO OPE RACIONAL PADR AO & Padıù̃o: $N^{\infty} 1$ \\
\hline Nome d: & fa: Atunkizçlio dürin da planilha de controle das requisiçōes & \multirow{2}{*}{ F stabelecido em: $200.3 / 2018$} \\
\hline Respon: & Gerente de oficinas & \\
\hline \multicolumn{3}{|c|}{ MATERIAL NECT SSSARIO } \\
\hline \multicolumn{3}{|c|}{ Computudor } \\
\hline \multicolumn{3}{|c|}{ Impressorn } \\
\hline \multicolumn{3}{|c|}{ Internet } \\
\hline \multicolumn{3}{|c|}{ Folha $\wedge 4$} \\
\hline \multicolumn{3}{|c|}{ ATIVIDADES CRITICAS } \\
\hline \multicolumn{3}{|c|}{ 01- Entrar no sistema } \\
\hline \multicolumn{3}{|c|}{ CL- Inserir login e serhn. } \\
\hline \multicolumn{3}{|c|}{ Q3- Clicnr em Sistemn 3.} \\
\hline \multicolumn{3}{|c|}{ 04- Clicar em ndministrativa } \\
\hline \multicolumn{3}{|c|}{ Q8- Clicar em requisiçobes. } \\
\hline \multicolumn{3}{|c|}{ 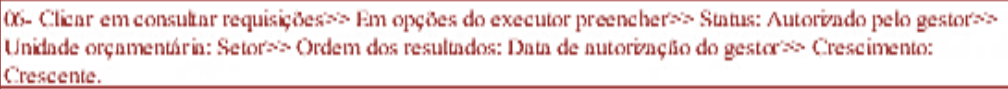 } \\
\hline \multicolumn{3}{|c|}{ (T/- Imprimir ns requisiçóss correspondentes no din acesend. } \\
\hline \multicolumn{3}{|c|}{ Cos- Extrnir das requisiçoes os dados necessários parn alinerzar a planilha de controle. } \\
\hline \multicolumn{3}{|c|}{ (9)- Alunentar planillan de controle de requisiçöes. } \\
\hline \multicolumn{3}{|c|}{ 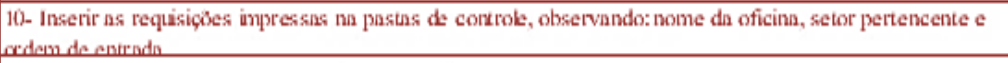 } \\
\hline \multicolumn{3}{|c|}{ RESULTADOS F SPERADOS } \\
\hline \multicolumn{3}{|c|}{ 01- Mnnter a orgnniunçlio dórín dos serviços solicitudos. } \\
\hline \multicolumn{3}{|c|}{ ó- Facilidade para verificar ostatus do serviço soliciudo } \\
\hline \multicolumn{3}{|c|}{ AC̣ÖES CORRFTIVAS } \\
\hline \multicolumn{3}{|c|}{ 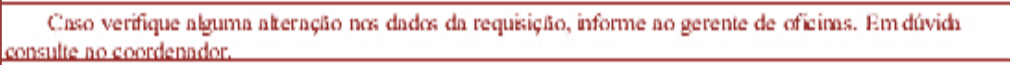 } \\
\hline Criado $\mathrm{p}$ & ferene de Oficims & \\
\hline
\end{tabular}

Fonte: O autor (2018)

Com o padrão implantado, à verificação do cumprimento dos padrões estabelecidos e presença de anomalias no processo, tornouse atividades diárias objetivando manter a qualidade dos serviços e a melhoria contínua. Além de Mensalmente, o gerente das oficinas promover um treinamento com o intuito de motivar os profissionais no cumprimento dos padrões e garantir a qualidade dos serviços. Durante o treinamento os colaboradores indicam pontos positivos e negativos do padrão, quando constatados a negatividade essas são tratadas para melhor cumprimento e melhoria contínua dos atendimentos.

As Figuras 8 e 9, confirmam ganhos quantitativos no número de atendimentos, comparando os meses de março, abril e maio dos anos de 2017 e 2018 (após a implantação) nas oficinas de vidraçaria e marcenaria.

Figura 8 - Comparativo mensal da vidraçaria

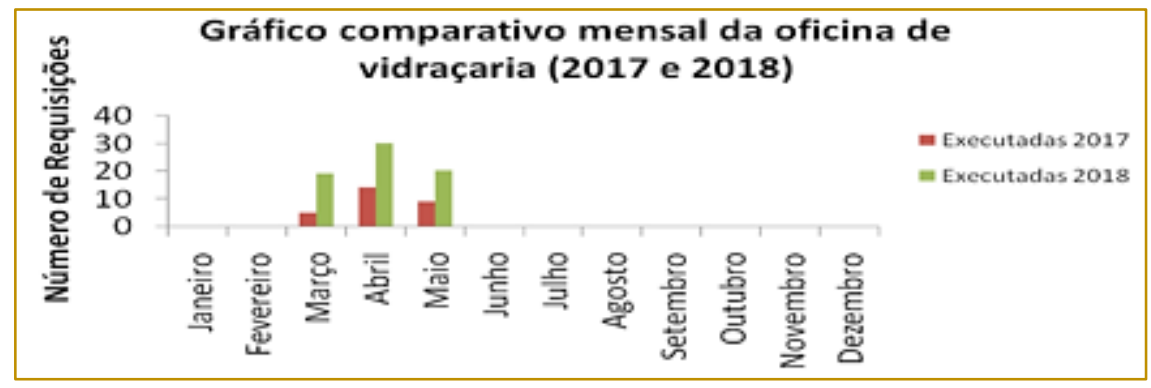

Fonte: O autor (2018) 
Conforme a Figura 8, nos meses de março, abril e maio de 2018 o número de atendimentos superou em grande escala o quantitativo do ano de 2017 na oficina de vidraçaria.

Figura 9 - Comparativo mensal da marcenaria

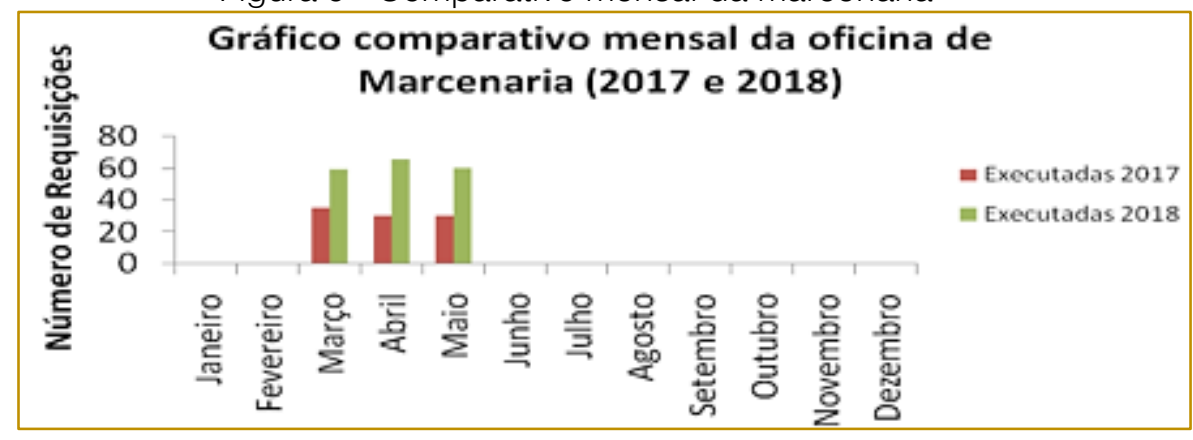

Fonte: O autor (2018)

Conforme a Figura 8, nos meses de março, abril e maio de 2018 o número de atendimentos superou em grande escala o quantitativo do ano de 2017 na oficina de marcenaria.

Como a implantação é recente não foi possível quantificar os resultados de todas as oficinas.

\section{CONCLUSÃO}

Através da metodologia do gerenciamento da rotina do trabalho do dia a dia, ao elaborar o fluxograma, foi possível diagnosticar as anomalias do processo e as etapas que necessitavam serem melhoradas, etapas que foram fundamentais para criação do modelo de atendimento setorial.

Para facilitar o gerenciamento rotineiro e o controle dos atendimentos, foram elaboradas planilhas eletrônicas de gerenciamento e

\section{REFERÊNCIAS}

[1] Abreu, V.B.L.; Lock, F.N. O controle e o gerenciamento da rotina de trabalho na busca pela qualidade em prestação de serviços, Santa MariaRS, $2007 . \quad$ Disponível em:<https://periodicos.ufsm.br/sociaisehumanas/ar ticle/view/829 > . Acesso em: 10 março 2018.

[2] Bergue, S. T. Gestão de pessoas em organizações públicas. 3. ed. Caxias do Sul, RS: Educs, 2010.

[3] Campos, V. F. Qualidade total: padronização de empresas. 4. Ed. Belo Horizonte: Fundação Christiano Ottoni, 1995. controle das requisições e procedimentos operacionais padrões. Com as ações implantadas foi possível concluir que houve uma melhora significativa no GRD, sendo essas: otimização no atendimento das solicitações, visto que os operadores não ficam mais ociosos, ganhos qualitativos e quantitativos devido à centralização do atendimento por setor, profissionais mais motivados e respeitando os padrões implantados, além de grande expectativa de redução de custos com transporte de colaboradores.

Apesar de enfrentar inúmeras resistências devido à forte cultura organizacional, concluise que com o desenvolvimento desse trabalho ocorreu um avanço expressivo no GRD do setor de manutenção gerando expectativas de otimização no atendimento das solicitações, ganhos qualitativos e quantitativos e profissionais mais motivados.

[4] Campos, V. F. Gerenciamento da rotina do trabalho do dia-a-dia. 2. ed. Belo Horizonte: Fundação Christiano Ottoni, 1998.

[5] Campos, V. F. Qualidade total: padronização de empresas. Belo Horizonte: EDG, 1999.

[6] Campos, V. F. Controle da Qualidade total. 8. ed. Nova Lima-MG: INDG TecS 2004.

[7] Carvalho, M. M.; Paladini, E. P. Gestão da Qualidade: teoria e casos. Rio de Janeiro: Elsevier, 2005.

[8] Fischer, A. Sistematização de processo de padronização de detalhes construtivos em projeto.2002 p. 87. Dissertação (Mestrado em 
Engenharia de Produção) Disponível em: $<$ https://repositorio.ufsc.br/bitstream/handle/12345 6789/83717/PEPS2479D.pdf?sequence=1\&isAllow ed=y > . Acesso em: 17 março 2018.

[9] Gianesi, I. G. N.; Corrêa, H. L. Administração estratégica de serviços: operações para a satisfação do cliente. São Paulo: Atlas, 1996.

[10] Harrington, H. J. Aperfeiçoando processos empresariais. 1. ed. São Paulo: Makron Books, 1993.

[11] Juran, J.M. A qualidade desde o projeto: Os novos passos para o planejamento da qualidade em produtos e serviços. 3 ed. São Paulo: Ed. Pinoneira, 1992.

[12] Lucas, V.L e Silveira, J.O.B. A qualidade do atendimento no setor público, 2012, Disponível em: $\quad<w w w$.amog.org.br/amogarquivos/TccposTurma-2012/Vera-Lucia-Lucas.pdf>. Acesso em: 10 março 2018.
[13] Monteiro, E.C. Qualidade dos serviços terceirizados no setor público, 2010, Monografia (graduação em administração) Disponível em: <repositorio.favip.edu.br:8080/bitstream/12345678 9/1164/1/TCC.pdf>. Acesso em: 15 março 2018.

[14] Moraes, I.S. et al.Terceirização: moldando o futuro das empresas. Disponível em: <http://revistas.unifacs.br/index.php/rgb/article/vie wFile/130/130 > . Acesso em: 15 fevereiro 2018.

[15] Schmenner, Roger W. Administração de operações de serviços. Trad. de Lenke Peres. Revisão técnica de Petrônio Garcia Martins. Editora Futura, São Paulo, 419p, 1999.

[16] Seleme, R. e Stadler, H. Controle da qualidade as ferramentas essenciais.2. ed. Curitiba: Ibpex, 2010. 


\title{
Capítulo 18
}

\section{POTENCIAL DE ECONOMIA DE ENERGIA ELETRICA NA ILUMINAÇÃO E REFRIGERAÇÃO DA UNIVERSO/JF}

\author{
Brehme Rezende de Oliveira \\ Ana Flavia da Fonseca Barroso \\ Élcio Barreira da Silva Castro \\ Robert Alexandre de Ávila
}

Resumo: A necessidade em reduzir ao máximo o consumo de energia elétrica se torna cada vez importante devido à escassez dos recursos naturais e danos ambientais causados durante o processo de geração. Redução de custos com energia elétrica é um importante fator que os gestores devem estar atentos, pois a utilização de novos produtos/tecnologias possibilita o alcance deste objetivo. A eficiência energética de iluminação pode ser alcançada com a substituição das lâmpadas atuais por outras mais eficientes (LED - Diodos Emissores de Luz). Além disso, o sistema de refrigeração pode ter seu consumo reduzido, com a utilização de uma nova tecnologia chamada Inverter. O objetivo do estudo foi analisar o consumo de energia elétrica e seus custos, no sistema de iluminação e refrigeração (ar condicionado), da Universidade Salgado de Oliveira - UNIVERSO campus Juiz de Fora. O artigo apresenta o cálculo do atual consumo desses sistemas, e apresenta o potencial de economia a ser alcançado com utilização de novas tecnologias. Apresenta ainda, uma análise econômica, demonstrando em que período de tempo às novas tecnologias torna-se financeiramente viável. O sistema de iluminação, através da utilização de lâmpadas LED apresentou menor tempo de retorno do investimento, enquanto a substituição total do sistema de refrigeração, apesar da utilização de tecnologia Inverter, o tempo de retorno do investimento é longo, porém, ao realizar a análise por ambiente, observam-se setores que esse retorno acontece em um curto período de tempo, tornando-se economicamente viável.

Palavras-chave: Eficiência Energética, Economia de Energia, Lâmpadas LED, Ar Condicionado Split Inverter, Redução de Custos. 


\section{INTRODUÇÃO}

As empresas têm um papel importante a desempenhar em busca do desenvolvimento sustentável. Pode-se destacar que o uso racional e eficiente de energia elétrica, deve estar presente no seu dia a dia. Eliminando o desperdício, a necessidade de geração de energia diminui $e$, consequentemente, a pressão sobre os recursos naturais é reduzida, e ainda há um retorno financeiro, com economia na conta de energia elétrica (SILVA e NASSAR, 2016). Eficiência energética refere-se à utilização de menos energia para produzir a mesma quantidade de serviços e é amplamente definida pela razão entre os produtos ou serviços úteis de um processo pela quantidade de energia (PATTERSON,1996). Existe uma forte relação entre eficiência energética e impacto ambiental (DINCER, 2000).

O objetivo do estudo foi fazer uma análise do consumo de energia elétrica no sistema de iluminação e refrigeração em uma empresa, e apresentar uma proposta de potencial de economia viável, com base em novas tecnologias existentes.

\section{METODOLOGIA}

No desenvolvimento do trabalho foi realizado um estudo de caso na instituição de ensino Universidade Salgado de Oliveira, UNIVERSO/JF. Realizou-se um levantamento quantitativo das lâmpadas e dos equipamentos de ar condicionado existente no Campus, por ambiente, assim como a especificação técnica dos modelos. O tempo de uso por dia (horas), e dias úteis de consumo mensal, foi coletado através de uma pesquisa com os colaboradores dos setores. Por fim, foi realizada uma análise dos resultados através da construção de tabelas comparativas.

\section{EFICIÊNCIA ENERGÉTICA X ECONOMIA DE ENERGIA}

Grande parte da energia elétrica do Brasil é proveniente de usinas hidrelétricas (FRANCISCO, 2009), as quais dependem de um recurso natural limitado para geração de energia, tornando assim a redução do consumo energético muito importante para a preservação deste recurso (SANTOS ET AL 2015).
A dependência de aparelhos elétricos para o desenvolvimento de atividades diárias nas empresas acarreta em custos elevados nos orçamentos corporativos, sendo os sistemas de iluminação e refrigeração ambiental os principais responsáveis pelo consumo de energia. Estão surgindo novas tecnologias que fornecem ao mercado produtos com grande eficiência energética, tornando-se alternativa para atualização nas instalações.

Segundo Silva \& Nassar (2016) a eficiência energética se mostra importante no processo de diminuição de consumo de duas maneiras: a primeira na questão ambiental, com possível redução do impacto causado pelos processos que levam ao fornecimento de energia, iniciando na captura de recursos naturais, passando pelos processos de geração e transmissão até seu uso final pelos consumidores, e a segunda com a redução de custos para o consumidor.

O desenvolvimento energético sustentável envolve três grandes mudanças tecnológicas: a poupança de energia no lado da demanda, a melhoria da eficiência na produção de energia e a substituição de combustíveis fósseis por diversas fontes renováveis (LUND, 2007).

Ações de eficiência energética contribuem para diminuir o consumo e o desperdício de energia. Cada quilowatt (KW) economizado ajuda evitar a construção de novas fontes geradoras de energia elétrica, contribuindo para preservar o meio ambiente. É importante utilizar de forma racional e eficiente a energia, para que evitar a necessidade de diminuir a qualidade de vida, bem como o conforto e a segurança do usuário (SILVA \& NASSAR, 2016).

Nas instituições de Ensino Superior, o consumo de energia elétrica é evidenciado, entre outros, pela necessidade de uso para iluminação e refrigeração constante, impactando diretamente nos custos operacionais. Devido ao caráter de pesquisa, as Instituições de Ensino Superior têm um papel importante a desempenhar em busca do desenvolvimento sustentável, princípios e práticas de sustentabilidade devem ser vistos como valores. Pode-se destacar que o uso racional e eficiente de energia elétrica, deve estar presente em todas as ações diárias. Eliminando 0 desperdício, diminui-se a necessidade de geração de energia e, consequentemente, a pressão sobre os recursos naturais é reduzida, existindo ainda 
um retorno financeiro, com economia na conta de energia elétrica (SILVA \& NASSAR, 2016).

Neste trabalho, foi estudada a questão de sistemas iluminação, apresentando como alternativa de economia de energia elétrica a tecnologia LED, e sistema de refrigeração, através de aparelhos de ar condicionado, demonstrando a explicação de funcionamento, modelos instalados e modelos desenvolvidos por meio de novas tecnologias existentes, destacando-se o modelo split inverter.

Ar condicionado é um equipamento com a finalidade de climatizar o ar em um ambiente fechado, mantendo sua temperatura controlada de acordo com a preferência do usuário.

Os sistemas de condicionamento de ar podem ser divididos, de acordo com Creder (1997), em sistemas de expansão direta (quando o condicionador recebe diretamente do recinto ou através de dutos a carga de ar frio ou quente) e de expansão indireta (quando o condicionador utiliza um meio intermediário para retirar a carga térmica transmitida pelo ar frio ou quente).

Vargas (2015) diz que os mais conhecidos no mercado são os de expansão direta que tem como principais representantes os do tipo janela e split. Um inconveniente desse tipo de equipamento, principalmente do tipo janela, é o desconforto acústico provocado pelos seus componentes. Devido a esse problema, os fabricantes investiram em pesquisa para que a unidade evaporadora ficasse separada da unidade condensadora, reduzindo o ruído proveniente do processo de compressão. Assim, surgiram os aparelhos do tipo split. Destacam-se dois modelos de ar condicionado split: os aparelhos split convencional e split inverter.

No ar condicionado convencional, o compressor funciona no sistema liga - desliga para manter o ambiente climatizado, o que causa grande variação de temperatura e picos de energia, consumindo grande quantidade de eletricidade. No sistema inverter, o compressor varia a rotação de acordo com a temperatura desejada, fazendo com que a climatização aconteça gradativamente. Existe um circuito inteligente que faz com que o aparelho mantenha a temperatura ambiente constante e pouca oscilação. Como o compressor do inverter não gera picos de energia, seu consumo é menor que o convencional

O ar-condicionado do tipo inverter funciona de maneira similar ao split convencional, porém o seu compressor nunca é desligado durante o uso. Isso se deve ao fato da presença de um inversor de frequência que controla a velocidade do motor do compressor fazendo com que ele gire a velocidades baixas para manter a temperatura constante no ambiente (VARGAS, 2015).

Desta forma, podem-se destacar algumas vantagens do split inverter sobre o split convencional, dentre elas: o pico de energia é menor, a variação de temperatura no ambiente é menor assim como o nível de ruído. A economia de energia pode variar de $40 \%$ a $60 \%$, de acordo com a tecnologia de cada fabricante (VARGAS, 2015).

A dependência de um sistema de iluminação eficaz gera-se para uma empresa gastos expressivos na conta de energia elétrica. Como alternativa, a busca por produtos mais eficientes, possibilita redução no consumo elétrico, consequentemente redução de custos.

Como alternativa viável, a lâmpada de Light Emitter Diode (Diodo Emissor de Luz - LED) é uma evolução tecnológica que vem ganhando cada vez mais destaque no mercado de lâmpadas. Lâmpadas de LED são dispositivos semicondutores preenchidos com gases e revestidos com diferentes materiais de fósforo (SANTOS et al, 2011).

A utilização do LED em forma de lâmpada, além de ser um avanço tecnológico, é muito interessante do ponto de vista dos benefícios ambientais, pois seu consumo de energia é consideravelmente inferior às lâmpadas convencionais, como as incandescentes e as fluorescentes compactas. Outros benefícios ambientais das lâmpadas de LED são as características e possibilidades de descarte final de resíduos, além da sua durabilidade. Sua durabilidade é outro aspecto interessante, pois demanda menos trocas o que, consequentemente, gera menos descartes no ambiente. Já a lâmpada fluorescente, por exemplo, contém Mercúrio, o que exige maiores cuidados quanto ao descarte, devido às características nocivas deste elemento. (SANTOS et al., 2011 p.595602).

De acordo com Aman et al. (2013), a vida útil de uma lâmpada LED é de aproximadamente 
50.000 horas.

Lâmpadas de LED equivalentes a $60 \mathrm{~W}$ da incandescente e a $15 \mathrm{~W}$ da fluorescente necessitam de apenas de 8 Watts para emitir luz, gerando um gasto bem menor que as demais, cerca de $1.000 \mathrm{kWh}$ (ENERGIA LIMPA, 2009).

Existem diversas maneiras para reduzir 0 consumo de energia, uma delas é a substituição de lâmpadas ineficientes (lâmpadas incandescentes) por lâmpadas eficientes (Light Emitter Diode - LED) (SAIDUR, 2009). Estudos revelam que o consumo com iluminação artificial é uma parte significante para o consumo total de energia de um país (BLADH \& KRANTZ, 2008).

\section{ESTUDO DE CASO}

Foi realizado um levantamento quantitativo e qualitativo do sistema de iluminação e refrigeração da UNIVERSO/JF no período de 01/09/2017 à 30/09/2017. De posse dos dados coletados foi calculado o consumo mensal de energia elétrica destes sistemas, sendo apresentado um comparativo entre consumo atual e consumo de uma proposta para potencial de economia, além de destacar mudanças já implementadas e tempo de retorno do investimento para a execução da proposta.

\subsection{SISTEMA DE REFRIGERAÇÃO}

O sistema de refrigeração da UNIVERSO/JF é composto por 135 máquinas de ar condicionado, modelo split convencional, com potência (BTU's) de 9.000, 12.000, 18.000, $24.000, \quad 36.000,48.000$ e 58.000, cuja especificação depende da área e destinação de uso do ambiente. São distribuídas entre os setores administrativos, laboratórios e salas de aula. A proposta apresentada, a fim de alcançar economia de energia elétrica e redução de custos, é a de substituir os atuais equipamentos pelo modelo split inverter, mais eficiente e econômico.

\subsubsection{SISTEMA DE REFRIGERAÇÃO ATUAL: SPLITCONVENCIONAL, CONSUMO MENSAL (KWH) E CUSTO MENSAL (R\$)}

Nesta etapa, realizou-se uma visitação em todos os ambientes do campus, a fim de identificar quais ambientes são equipados com aparelho de ar condicionado, assim como a especificação técnica do modelo instalado.

Após o levantamento quantitativo e qualitativo de todos os aparelhos, a próxima etapa foi realizar uma pesquisa com os responsáveis pelos setores, para chegar ao tempo de uso mensal (em horas) do equipamento instalado em cada ambiente para realização do cálculo de energia elétrica consumida. A planilha detalhada com as informações (tipo equipamento, potência, consumo mensal de KWh, custo) se encontra nos apêndices deste trabalho.

Os cálculos demonstram o consumo no mês de outubro de 2017, com base na atual demanda. Foi convencionado para fins de cálculo, o custo de $\mathrm{R} \$ 0,58$ por kWh (valor retirado da fatura de energia elétrica no mês de setembro 2017 desta empresa). O consumo (kWh) de energia dos aparelhos de ar condicionado split convencional, foi retirado da tabela do INMETRO (selo PROCEL de Eficiência Energética), o cálculo é obtido através do produto entre Consumo (kWh) e Tempo de uso (horas).

O Quadro 1 informa o consumo mensal de KWh e o custo mensal do sistema de refrigeração atual, com a utilização dos modelos split convencional:

Quadro 1: Consumo Mensal Atual Sistema de Refrigeração, Split Convencional.

\begin{tabular}{|c|c|c|}
\hline \multicolumn{2}{|c|}{ CONSUMO AR CONDICIONADO SPLIT CONVENCIONAL } \\
\hline Modelo & $\begin{array}{c}\text { Consumo de } \\
\text { Ene rgia (KWh/M ês) }\end{array}$ & Custo (R\$/Mês) \\
\hline SPLIT CONVENCIONAL (ATUAL) & $58.204,72$ & $\mathrm{R} \$ 33.758,74$ \\
\hline
\end{tabular}

Fonte: O autor (2017) 
4.1.2 SISTEMA DE REFRIGERAÇÃO PROPOSTO: SPLIT INVERTER, CONSUMO MENSAL (KWH) E CUSTO MENSAL (R\$)

Para o cálculo do consumo (kWh) de energia dos aparelhos de ar condicionado split inverter, foi considerada uma redução de $40 \%$ sobre os valores consumidos nos modelos convencionais, economia propiciada devido a tecnologia presente neste tipo de equipamento, sendo que o consumo (kWh) de energia dos aparelhos de ar condicionado split convencional, foi retirado da tabela do INMETRO (selo PROCEL de Eficiência Energética). O cálculo é obtido através do produto entre Consumo (kWh) e Tempo de uso (horas).

O Quadro 2 informa quanto seria o consumo mensal de KWh e o custo mensal do sistema de refrigeração, com a utilização dos modelos split inverter.

Quadro 2: Consumo Mensal Sistema de Refrigeração, Split Inverter.

\begin{tabular}{|c|c|c|}
\hline \multicolumn{3}{|c|}{ CONSUMO AR CONDICIONADO SPLIT INVERTER } \\
\hline Modelo & $\begin{array}{c}\text { Consumo de } \\
\text { Energia (KWh/Mês) }\end{array}$ & Custo (R\$/Mês) \\
\hline SPUT INVERTER (PROPOSTA) & $35.314,92$ & R\$ 20.482,65 \\
\hline
\end{tabular}

Fonte: O autor (2017)

\subsubsection{ANÁLISE DO POTENCIAL DE ECONOMIA E TEMPO DE RETORNO DO INVESTIMENTO}

O potencial de economia a ser alcançado, pode ser observado através do comparativo do consumo dos modelos atuais de refrigeração (SPLIT Convencional), e proposta de substituição para o modelo SPLIT Inverter.

Os atuais equipamentos de refrigeração, devido ao tempo de uso (14 anos), apresentam problemas constantes, (necessitando manutenção contínua), gera-se alto custo de mão de obra e peças de reposição. Com os aparelhos indicados, além da economia gerada, tendem a não precisar de manutenção frequente, apenas conservação, consequentemente pode-se fazer uma renegociação do contrato de manutenção mensal do sistema de refrigeração.

O Quadro 3 mostra que essa substituição geraria uma economia mensal de 22.889,80 kWh, o equivalente a $R \$ 13.276,08 /$ mês.

Quadro 3: Comparativo de Consumo e Potencial de Economia.

\begin{tabular}{|c|c|c|c|c|c|}
\hline \multicolumn{1}{|c|}{ COMPARATIVO CONSUMO / POTENCIAL DE ECONOMIA AR CONDICIONADO (PROPOSTA 40\% ECONOMIA) } \\
\hline & $\begin{array}{c}\text { Consumo de } \\
\text { Energla (KWh/Me̊s) }\end{array}$ & Custo (R\$/Me̊s) & $\begin{array}{c}\text { Economla } \\
\text { (KWh/Me̊s) }\end{array}$ & $\begin{array}{c}\text { Economla } \\
\text { (R\$/Me̊s) }\end{array}$ \\
\hline SPLIT CONVENCIONAL (ATUAL) & 58.204 .72 & RS 33.758 .74 & --- & -- \\
\hline SPLIT INVERTER (PROPOSTA) & $35.314,92$ & RS 20.482 .65 & $\mathbf{2 2 . 8 8 9 , 8 0}$ & R\$ & $13.276,08$ \\
\hline
\end{tabular}

O tempo de retorno do investimento foi calculado através do sistema Payback Simplificado, que consiste em dividir a economia mensal, pelo custo do investimento inicial, a fim de descobrir em quanto tempo o investimento inicial é resgatado.

O Quadro 4 demonstra o cálculo do tempo de retorno do investimento, assim como a economia mensal, e o custo do investimento inicial. 
Quadro 4: Tempo de Retorno Investimento.

\begin{tabular}{|c|c|c|c|}
\hline \multicolumn{1}{|c|}{ PAYBACK - RETORNO INVE STIMENTO (AR CONDICIONADO INVERTER) } \\
\hline Aquisição de Ar Condicionado modelo INVERTER & $\begin{array}{c}\text { Investimento } \\
\text { Inicial (R\$) }\end{array}$ & $\begin{array}{c}\text { Economia } \\
\text { (R } \$ \text { /Mês) }\end{array}$ & $\begin{array}{c}\text { Retorno } \\
\text { Investimento } \\
\text { (Anos) }\end{array}$ \\
\cline { 2 - 5 } & $\mathrm{R} \$ 1.308 .000,00$ & $\mathrm{R} \$ 13.276,08$ & 8,21 \\
\hline
\end{tabular}

Fonte: O autor (2017)

Observa-se que o custo elevado e o longo tempo de retorno do investimento inicial, indica que a substituição total do sistema de refrigeração, pode não ser viável, porém, ao analisar esse retorno por ambiente, conclui-se que existem determinados lugares, em que o tempo de retorno diminui consideravelmente, pois quanto maior o tempo de uso, mais rápido se torna o retorno do investimento inicial (tabela de retorno do investimento inicial detalhada por ambiente encontra-se anexa no apêndice deste trabalho). O custo do KWh também infere no resultado, quanto maior o custo, menor será o tempo de retorno.

\subsection{SISTEMA DE ILUMINAÇÃO}

O sistema de iluminação da UNIVERSO/JF é composto por um total de 4.320 lâmpadas, e a especificação do tipo de lâmpada utilizada é bastante variada, sendo estas determinadas por ambiente. A iluminação esta presente principalmente nas salas de aula, laboratórios, setores administrativos, banheiros, escadas e estacionamento.

O sistema de iluminação possui três cenários a serem analisados:

a) Sistema antigo: sistema de iluminação totalmente composto por lâmpadas modelo fluorescentes, entre tubulares e compactas.

b) Sistema atual: realizada a substituição parcial de lâmpadas fluorescentes para lâmpadas LED. c) Sistema proposto: sistema de iluminação totalmente composto por lâmpadas modelo LED.

\subsubsection{SISTEMA DE ILUMINAÇÃO ANTIGO}

Nesta etapa, realizou-se uma visitação em todos os ambientes do campus, a fim de identificar o quantitativo de lâmpadas, assim como a especificação técnica do modelo instalado em cada ambiente.

Após o levantamento quantitativo e qualitativo de todos os ambientes, a próxima etapa foi realizar uma pesquisa com os responsáveis pelos setores, a fim de chegar ao tempo de uso mensal (em horas) do sistema de iluminação, para realização do cálculo de energia elétrica consumida. A planilha detalhada com as informações (tipo de lâmpada, quantidade, potência, consumo mensal de KWh, custo) se encontra no apêndice deste trabalho.

Os cálculos demonstram o consumo no mês de Outubro de 2017, com base na atual demanda. Foi convencionado para fins de cálculo, o custo de $\mathrm{R} \$ 0,58$ por kWh (valor retirado da fatura de energia elétrica no mês de Setembro 2017 desta empresa). O consumo das lâmpadas é obtido através do produto entre Potência (W) e Tempo de uso (horas).

O Quadro 5 mostra o consumo e custo mensal do sistema antigo de iluminação, onde todas a lâmpadas são fluorescentes:

Quadro 5: Consumo e Custo do Sistema de lluminação Antigo.

\begin{tabular}{|c|c|cc|}
\hline \multicolumn{2}{|c|}{ CONSUMO E CUSTO SISTEMADE ILUMINACÃO (ANTIGO) } \\
\hline Modelo & $\begin{array}{c}\text { Consumo de } \\
\text { Energia (KWh/Mês) }\end{array}$ & Custo (R \$/Mês) \\
\hline LÂMPADAS FLUORESCENTES & 17.461 .12 & RS 10.127 .45 \\
\hline
\end{tabular}

Fonte: O autor (2017) 


\subsubsection{SISTEMA DE ILUMINAÇÃO ATUAL}

Atualmente, após a substituição parcial do sistema de iluminação em alguns ambientes do campus, através da instalação de lâmpadas modelo LED, pode-se observar a economia no consumo de energia elétrica, e a redução de custos mensais já alcançados.
No Quadro 6, observa-se o comparativo do consumo com iluminação, antes e após a substituição parcial (atuais), dos modelos convencionais (fluorescente), para LED. Essa substituição gerou uma economia mensal de $2.917,97$ kWh, equivalente a $R \$ 1.692,42 /$ mês.

Quadro 6: Consumo e Custo do Sistema de lluminação Antigo/Atual e Economia Mensal.

\begin{tabular}{|c|c|cc|c|c|}
\hline \multicolumn{6}{|c|}{ COMPARATIVO CONSUMO E ECONOMIAILUMINAÇÃO (ATUAL) } \\
\hline Modelo & $\begin{array}{c}\text { Consumo de } \\
\text { Energia (KWh/Mês) }\end{array}$ & Custo (R\$/Mês) & $\begin{array}{c}\text { Economia } \\
\text { (KWh/Mês) }\end{array}$ & $\begin{array}{c}\text { Economia } \\
\text { (R\$/Mês) }\end{array}$ \\
\hline LÂMPADAS FLUORESCENTES (ANTES) & $17.461,12$ & $\mathrm{R} \$$ & $10.127,45$ & --- & --- \\
\hline LÂMPADAS FLUORESCENTES + LED & $14.543,15$ & $\mathrm{R} \$$ & $8.435,03$ & $\mathbf{2 . 9 1 7 , 9 7}$ & $\mathrm{R} \$$ \\
\hline
\end{tabular}

Fonte: O autor (2017)

\subsubsection{SISTEMA DE ILUMINAÇÃO PROPOSTO}

A proposta apresentada a seguir, seria a de substituir totalmente o sistema de iluminação do campus, atingindo assim uma considerável economia mensal no consumo de energia elétrica, além da redução de custos. No
Quadro 7, observa-se o comparativo do consumo atual com iluminação, e proposta de potencial de economia, com a substituição total do sistema de iluminação para o modelo LED. Essa substituição geraria uma economia mensal de 5.021,09 kWh, equivalente a $\mathrm{R} \$ 2.912,23 / \mathrm{mês}$.

Quadro 7: Consumo e Custo do Sistema de lluminação Atual e Proposta de Economia Mensal

\begin{tabular}{|c|c|c|c|c|c|}
\hline \multicolumn{6}{|c|}{ COMPARATIVO CONSUMO E POTENCIAL DE ECONOMIA ILUMINAÇÃO (PROPOSTA) } \\
\hline Modelo & $\begin{array}{c}\text { Consumo de } \\
\text { Energia (KWh/Mês) }\end{array}$ & Custo (R\$/Mês) & $\begin{array}{l}\text { Economia } \\
\text { (KWh/Mês) }\end{array}$ & & $\begin{array}{l}\text { nomia } \\
\text { Mês) }\end{array}$ \\
\hline LÂMPADAS FLUORESCENTES + LED & $14.543,15$ & $8.435,03$ & $2.917,97$ & $\mathrm{R} \$$ & $1.692,42$ \\
\hline LÂMPADAS LED & $9.522,06$ & $5.522,79$ & $5.021,09$ & $\mathrm{R} \$$ & $2.912,23$ \\
\hline
\end{tabular}

\subsubsection{ANÁLISE DO POTENCIAL DE ECONOMIA E TEMPO DE RETORNO DO INVESTIMENTO \\ O tempo de retorno do investimento foi calculado através do sistema Payback Simplificado, que consiste em dividir a economia mensal, pelo custo do investimento}

inicial, a fim de descobrir em quanto tempo o investimento inicial é resgatado.

O Quadro 8 demonstra o cálculo do tempo de retorno do investimento, assim como a economia mensal, e o custo do investimento inicial.

Quadro 8: Tempo de Retorno Investimento Lâmpadas LED.

\begin{tabular}{|c|c|c|c|}
\hline \multicolumn{4}{|c|}{ PAYBACK - RETORNO INVESTIMENTO (ILUMINAÇÃO LED) } \\
\hline \multirow{2}{*}{ Aquisição de Lâmpadas modelo LED } & $\begin{array}{c}\text { Investimento } \\
\text { Inicial (R\$) }\end{array}$ & $\begin{array}{c}\text { Economia } \\
\text { (R\$/Mês) }\end{array}$ & $\begin{array}{c}\text { Retorno } \\
\text { Investimento } \\
\text { (Anos) }\end{array}$ \\
\cline { 2 - 5 } & $\mathrm{R} \$ \mathbf{6 2 . 1 7 7 , 0 0}$ & $\mathrm{R} \$ 2.912,23$ & 1,78 \\
\hline
\end{tabular}

Fonte: O autor (2017)

Observa-se que o curto tempo de retorno do investimento inicial, indica que a substituição total do sistema de iluminação é viável. Ao analisar esse retorno por ambiente, conclui-se 
que existem determinados lugares, em que o tempo de retorno é ainda menor, pois quanto maior o tempo de uso, mais rápido será o retorno do investimento inicial. O custo do kWh também infere no resultado, quanto maior o custo, menor será o tempo de retorno.

\section{CONCLUSÃO}

Em virtude dos problemas hídricos e, consequentemente, elétricos, eficiência energética é um tema bastante abordado atualmente no Brasil, devido a isso, optou-se por fazer a análise proposta neste trabalho para enfatizar a importância da utilização racional de energia.

A substituição das lâmpadas e equipamentos de refrigeração, gera uma considerável redução no consumo e custos de energia elétrica, consequentemente auxilia na preservação de recursos naturais necessários na geração de energia, além de evitar a queima de combustíveis fósseis, diminuindo o impacto ambiental.

\section{REFERÊNCIAS}

[1] Aman, M.M.; Jasmon, G.B.; Mokhlis, H.; \& Bakar, A.H.A. Analysis of The Performance of Domestic Lighting Lamps. 2013. Energy Policy, v. 52, p. $482-500$.

[2] Bladh, M. \& Krantz, H. Towards a Bright Future? Household use of Electric Light: a Microlevel Study. 2008. Energy Policy, v. 36, p. 3521 - 3530

[3] Creder, $H$. Instalações de arcondicionado. LTC. 1997.

[4] Dincer, I. Renewable energy and sustainable development: a crucial review. Renewable and Sustainable Energy Reviews, 2000. 4(2) 157-175

[5] Energia Limpa. A Reinvenção da Luz. Revista Veja. Edição 2145 - ano 42 - n 52.30 de dezembro de 2009. Disponível em: <https://goo.gl/N8YFMH>. Acesso em: 20 Out. 2017.

[6] Francisco, W.C. Energia Hidrelétrica. Disponível em: <https://goo.gl/rZsRyz>. Acesso em: 20 Out. 2017.

[7] Lund, H. Renewable Energy Strategies for Sustainable Development. Energy. 2007. 32(6),
Neste trabalho percebemos que a nova tecnologia de lâmpadas utilizando LED apresenta um grande potencial de redução de consumo de energia elétrica. $\mathrm{Na}$ análise econômica fica evidente a eficiência da tecnologia LED, sendo apresentada a economia já alcançada, e ainda o potencial que poderá ser alcançado. No arcondicionado, split inverter, verificamos um excelente potencial de economia de energia elétrica, porém o longo período de retorno do investimento pode ser um fator negativo. Analisando por ambiente, aqueles que apresentam uma maior demanda de uso, o retorno do investimento diminui consideravelmente, tornando-se uma boa opção.

O constante crescimento no consumo de energia elétrica Brasil nas últimas décadas desencadeou a busca por meios eficazes de economizar energia elétrica. Nas empresas em que a iluminação e o ar condicionado têm uma parcela significativa neste consumo, deve atentar por inserir meios que permita diminuir o consumo e diminuição de custos.

912-919.

[8] Patterson, M. G. What is energy efficiency? Concepts, indicators and methodological issues. Energy policy, 1996. 24(5), 377-390

[9] Saidur, R. Energy Consumption, Energy Savings, and Emission Analysis in Malaysian Office Buildings. 2009. Energy Policy, v. 37, p. 4104 4113.

[10] Santos, T.S.; Batista, M. C.; Pozza, S. A.; \& Rossi, L. S. Análise da Eficiência Energética, Ambiental e Econômica Entre Lâmpadas de LED e Convencionais. Benefícios Econômicos e Ambientais das Lâmpadas LED e Domésticas. Eng Sanit Ambient I v.20 n.4 I out/dez 2015 | 595-602.

[11] Silva, C. O. S.; Nassar, C. A. G. Análise do Uso da Energia Elétrica no Instituto Federal Fluminense Campus Campos Guarus. Revista de Gestão Ambiental e Sustentabilidade - GeAS. Vol. 5, N. 3. Setembro. / Dezembro 2016.

[12] Vargas, M. C. Eficiência Energética em Edificações Residenciais: lluminação e Refrigeração. XXXV Encontro de Engenharia de Produção (Enegep) - Perspectivas Globais para a Engenharia de Produção, Fortaleza, CE, Brasil, 2015. 


\section{Gapítulo 19}

\section{UTILIZAÇÃO DE RESÍDUOS DE CONCRETEIRA PARA A FABRICAÇÃO DE PAVERS}

Roberto Fernandes dos Reis Filho,

Ed Carlo Rosa Paiva

José Waldo Martínez Espinosa,

Resumo: A construção civil tem provocado grandes modificações no meio ambiente devido as construções, pelas enormes quantidades de recursos extraídos e pela grande quantidade de resíduos gerados. A reciclagem entra nesse cenário como uma forma de tentar amenizar esses problemas, fazendo com que menos recursos sejam extraídos e que os resíduos gerados sejam aproveitados, proporcionando mais vida útil aos aterros onde são depositados. O aproveitamento de resíduos é o foco deste trabalho, que buscou produzir blocos intertravados de concreto, denominados Pavers, utilizando resíduos sólidos das concreteiras, provenientes da lavagem dos caminhões betoneiras, como substituto parcial do cimento. Foram feitos traços contendo cimento, pó de pedra e água (traço de referência), sendo que nos demais ocorreram substituição do cimento por resíduos nos percentuais de 5, 10 e 15\%. Foram confeccionados seis pavers para cada um dos traços, que passaram pelo ensaio de compressão nas idades de cura de 7, 14 e 28 dias, respectivamente, e mais seis pavers de cada traço que foram utilizados para o ensaio de absorção aos 28 dias de cura. Nenhum traço alcançou resultados compatíveis ao que a NBR 9781 - 2013 exigiam, até o traço de referência apresentou resultados tanto de resistência à compressão quanto de absorção fora dos padrões da norma. Entre os traços com resíduo o de 10\% foi o que apresentou melhores resultados.

Palavras-chave: Reciclagem, blocos intertravados de concreto, resistência a compressão. 


\section{INTRODUÇÃO}

O concreto é o produto mais utilizado no mundo segundo a Associação Brasileira de Cimento Portland (ABCP, 2013), devido a isso, ele tem sido foco de muitos estudos $e$ pesquisas que procuram melhores formas de usá-lo, assim como novas tecnologias que possibilitem seu maior rendimento, eficiência e a diminuição de danos ao meio ambiente. No Brasil o uso desse insumo vem aumentando devido ao grande crescimento da construção civil, principalmente, nas áreas de infraestrutura e obras de habitação que tiveram um grande avanço devido ao Programa de Aceleração do Crescimento (PAC) promovido pelo governo (ABCP, 2013). $O$ crescimento da construção civil também marcou, de forma positiva, o crescimento das concreteiras devido à substituição do concreto usinado por aquele produzido na própria obra.

O crescimento da produção de concreto, em concreteiras, foi de 180\% entre 2005 e 2012, mostrando-se superior ao avanço do consumo de cimento de $80 \%$ no mesmo período. Estima-se que em 2012 foram produzidos 51 milhões de metros cúbicos de concreto pelas concreteiras em todo o país (ABCP, 2013). Um dos grandes problemas causados por esse crescimento da construção civil e, consequentemente, das concreteiras são as grandes quantidades de recursos naturais utilizados, no caso para a produção de concreto, como a areia, rochas que dão origem as pedras britadas, água, calcário e argila, que fazem parte da composição do cimento. Uma das formas de tentar amenizar um pouco essa degradação ambiental é o aproveitamento dos resíduos da indústria da construção civil beneficiando e utilizando-os como agregado graúdo para a fabricação de um novo concreto, como material de base ou de sub-base dos pavimentos, ou até mesmo utilizados como agregado miúdo para a fabricação de pavers ou blocos de concreto utilizados na pavimentação.

Os pavers, segundo a NBR 9781(ABNT, 2013), são blocos pré-moldados de concreto utilizados como revestimento de pavimento intertravado. São peças que se encaixam umas às outras e que, devido seu formato e material de rejuntamento (areia), não necessitam de argamassa ou de mão de obra especializada. A sua colocação é fácil, assim como sua retirada, podendo ser feitos reparos e manutenções no subsolo sem haver prejuízo de peças, após a conclusão do serviço, basta colocá-los de volta no lugar (CASTRO, 2011). Essa facilidade de colocação e remoção do piso torna-se uma grande vantagem desse tipo de pavimento, chamado pavimento intertravado, em relação aos pavimentos asfálticos e de concreto, evitando assim desconfortos aos moradores vizinhos de onde se precisa de manutenção ou da própria construção do pavimento, como barulho e sujeira, assim como a rápida liberação para o tráfego (AMADEI, 2011).

Segundo Hallack (2001), o revestimento de peças pré-moldadas de concreto (PPC) possui, simultaneamente, grande capacidade estrutural e valor paisagístico, devido à possibilidade de utilização de peças coloridas que melhoram a estética, como podem facilitar a incorporação de sinalização horizontal das vias. Esse tipo de revestimento também propicia visibilidade superior à das superfícies de asfalto, tanto à luz do dia quanto à luz artificial no período noturno, além de apresentar menor absorção de luz solar, oferecendo melhor conforto térmico, não tendo grandes elevações de temperatura como ocorrem em pavimentos escuros.

A capacidade estrutural do revestimento de PPC, de acordo com Shackel (1990), está inteiramente ligada a sua forma de assentamento. O arranjo do tipo "espinha-depeixe", por exemplo, apresenta menor valor de deformação permanente quando comparado com o assentamento em fileira, principalmente quando dispostos paralelamente ao sentido do tráfego. Os pavers assim como os bloquetes permitem a infiltração da água de chuva para o solo. O espaço entre as peças é permeável permitindo que a água infiltre para os lençóis subterrâneos, diminuindo as chances de ocorrerem enchentes e a diminuição da lamina de água na superfície do pavimento, deixando o piso menos escorregadio, garantindo mais segurança aos usuários (CASTRO, 2011).

Devido às inúmeras vantagens apresentadas sobre a utilização de PPC, como revestimento, bem como a grande quantidade de estudos sobre a fabricação de pavers com o uso de resíduos se mostrando eficientes, buscou-se avaliar o uso de resíduo proveniente de concreteiras para a produção de pavers. Esse resíduo é gerado pela decantação da água usada para lavar os caminhões betoneiras após transportarem o concreto. Essa água contendo o resto de concreto que fica no caminhão é depositada em tanques, e o material decantado é o resíduo que foi 
utilizado neste trabalho. Nesse sentido, o objetivo deste trabalho foi avaliar a viabilidade técnica da utilização de resíduos sólidos de concreteira, como substituto parcial do cimento, na fabricação de pavers.

\section{REVISÃO DA LITERATURA}

\subsection{REVESTIMENTO - PAVER}

Paver é um tipo de revestimento, que é assentado sobre uma camada de areia que já trabalha também como rejunte lhe proporcionando porosidade e permeabilidade, capaz de resistir a diferentes tipos de tráfegos (VIRGILIIS, 2009). As PPCs são de grande resistência proporcionando maior vida útil ao pavimento, proporcionado uma boa relação ao custo beneficio. Elas devem possuir dimensões uniformes, juntas de aproximadamente 3 milímetros preenchidas por areia fina e a compactação deve ser adequada em todo o revestimento (ABCP, 2010). O revestimento é a camada que é capaz de suportar as cargas e tensões provenientes dos carregamentos provocados pelo tráfego, protegendo a base de possíveis desgastes provocados pela abrasão (CRUZ, 2003).

\subsection{PEÇAS PRÉ-MOLDADAS DE CONCRETO OU PAVERS}

\subsubsection{PROCESSO DE FABRICAÇÃO DOS PAVERS}

Os pavers são fabricados principalmente em máquinas do tipo vibroprensa que podem ser manuais, pneumáticas ou hidráulicas, que variam de acordo com a forma, tamanho, tipo de motor, formas de alimentação, quantidade de produção, e outros fatores (PURIFICAÇÃO, 2009).

$\mathrm{Na}$ fabricação manual, ocorre o lançamento manual do concreto, que possui uma consistência mais seca, a força de prensagem também é manual, o que faz ter uma diferenciação de pressão no decorrer da produção das peças (PURIFICAÇÃO, 2009). Esse processo é totalmente dependente do serviço braçal dos funcionários, o que influencia diretamente na produtividade e qualidade do produto. Outra forma de fabricação é utilizando vibroprensas com desforma sobre paletes, elas podem ser pneumáticas ou hidráulicas, sua capacidade produtiva depende de seu tamanho, da forma de acionamento, de sua potência, tipo de vibradores e também da forma de alimentação da máquina.

Após a moldagem das peças nas vibroprensas as mesmas passam por um processo de cura em câmaras que mantêm a umidade relativa do ar acima de $95 \%$, isso faz com que a hidratação do cimento seja garantida e que a absorção de água pela peça seja menor, em torno de $6 \%$. O período de cura nas câmaras leva 24 horas e é continuado nos pátios podendo variar de 7 a 28 dias, dependendo das condições do fabricante. Assim, as peças chegam às obras prontas para o uso (PURIFICAÇÃO, 2009). Outra forma de produção dos pavers é por meio de betoneiras para fazer a mistura da massa e, posteriormente, colocá-la em formas sobre uma mesa vibratória. Depois disso os blocos os mesmos são levados para local plano para passar pelo período de cura e de desforma.

\subsubsection{NORMA BRASILEIRA PARA AS PEÇAS DE CONCRETO (PAVER)}

Os pavers são blocos pré-moldados de concreto utilizados como revestimento de pavimento intertravado. O concreto para a produção dos pavers deve ser constituído de cimento Portland, podendo ser qualquer tipo e classe, agregados e água, podendo ser utilizados aditivos e pigmentos (NBR 9781 ABNT, 2013). A mesma norma preconiza que os blocos devem atender a certos limites e tolerâncias nas dimensões. Para o comprimento eles não devem superar os 250 $\mathrm{mm}$, a sua largura útil deve ser de no mínimo $97 \mathrm{~mm}$ na área da peça destinada à aplicação da carga no teste de compressão, e sua espessura deve ser de no mínimo 60 $\mathrm{mm}$, especificada em múltiplos de $20 \mathrm{~mm}$. A tolerância especificada, nas medidas dos blocos de concreto é $\pm 3 \mathrm{~mm}$ para as dimensões: comprimento, largura e espessura. Outra verificação, realizada nos pavers, é a absorção de água, que consiste em verificar o acréscimo de massa no corpo devido à água em relação à massa desse mesmo corpo seco, sendo expresso em porcentagem. A absorção média não pode ser maior do que $6 \%$ não se admitindo nenhum valor individual maior que $7 \%$. Com relação a sua resistência, os blocos de concreto devem atender às especificações da Tab. (1). 
Tabela 1: Resistência característica à compressão

\begin{tabular}{|c|c|}
\hline Solicitação & $\begin{array}{l}\text { Resistência característica a compressão (fpk) aos } \\
\qquad 28 \text { dias }\end{array}$ \\
\hline $\begin{array}{l}\text { Tráfego de pedestres, veículos leves e veículos } \\
\text { comerciais de linha. }\end{array}$ & $\geq 35 \mathrm{MPa}$ \\
\hline $\begin{array}{l}\text { Tráfego de veículos especiais e solicitações capazes de } \\
\text { produzir efeitos de abrasão acentuados }\end{array}$ & $\geq 50 \mathrm{MPa}$ \\
\hline
\end{tabular}

Fonte: NBR 9781 (ABNT, 2013)

\subsection{PAVERS PRODUZIDOS COM MATERIAIS REAPROVEITÁVEIS E RECICLADOS}

\subsubsection{PAVERS FABRICADOS COM CINZA DE BAGAÇO DE CANA-DE-AÇÚCAR}

A cinza de bagaço de cana-de-açúcar (CBC) é um resíduo gerado em grande quantidade na produção de álcool e açúcar e, devido a suas características, estudos têm sido realizados visando sua utilização na fabricação de blocos de concreto para pavimento intertravado. Altoé et al. (2011) utilizaram CBC como substituto parcial do agregado fino (areia natural), na fabricação de pavers com diferentes porcentagens de substituição. O traço utilizado foi de 1:2,40:1,3:0,65 (cimento : areia/cinza : pedrisco : água/cimento), houve substituição de 5, 10, 15, 20, 25 e 30\% de areia por cinza. Nesse trabalho foi observado que pavers com $15 \%$ de substituição de CBC em relação a areia apresentaram os melhores resultados nos ensaios de compressão aos 28 dias atingindo $35 \mathrm{MPa}$.

\subsubsection{PAVERS FABRICADOS COM RESÍDUOS DA CONSTRUÇÃO E DEMOLIÇÃO}

Outro método sustentável de fabricar pavers é utilizando os resíduos de construção e demolição $(R C D)$ que, através da reciclagem desses resíduos, pode-se obter tanto o agregado miúdo (areia reciclada) quanto o agregado graúdo (pedrisco reciclado) para a fabricação dos blocos de concreto (CAVALCANTI et al., 2011). O traço utilizado foi de 1:2:3 (cimento : areia reciclada : pedrisco reciclado) e os pavers atingiram resistência de 14,5 $\mathrm{MPa}$, sendo que a resistência mínima a compressão deveria ser de $35 \mathrm{MPa}$. Mesmo assim, podem ser aproveitados para o calçamento de calçadas e estacionamentos que possuam tráfego leve, sendo uma boa alternativa para amenizar a enorme quantidade de RCD que é gerado pela construção civil.

\section{MATERIAIS E MÉTODOS}

\subsection{MATERIAIS}

Os materiais que foram utilizados para a confecção dos pavers foram pó-de-pedra, cimento, água e o resíduo sólido de concreteira.

\subsubsection{PÓ-DE-PEDRA}

O pó-de-pedra utilizado é um agregado com uma granulometria bastante variada, fazendo papel tanto de agregado fino como o do graúdo. O ensaio de granulometria foi realizado no laboratório da Geografia da UFG, onde a amostra do agregado foi seca em estufa a temperatura de $110 \pm 5^{\circ} \mathrm{C}$ por um período de 24 horas para retirar a umidade, para assim ser passado pelas peneiras de diferentes aberturas. A presença de material em todas as bandejas das peneiras de diferentes aberturas mostraram a grande variedade granulométrica do material. Segundo a NBR 7211 (2005) o agregado miúdo deve atender certos limites de finura, passando pela peneira de 4,8 milímetros e sendo retido pela peneira de 0,15 milímetros. Para conhecer melhor o agregado e saber sua composição química foi feito um ensaio chamado de EDX que por meio de raios- $X$ identifica quais os elementos que estão presentes na amostra. Na Tabela (2) está mostrada a proporção de cada elemento que compõe a amostra em relação a toda a amostra. 
Tabela 2: EDX dos materiais

\begin{tabular}{|c|c|c|c|}
\hline \multirow{2}{*}{ Elementos } & $\begin{array}{c}\text { Pó-de-pedra } \\
\text { Resultado }(\%)\end{array}$ & $\begin{array}{c}\text { Cimento } \\
\text { Resultado } \%)\end{array}$ & $\begin{array}{c}\text { Resíduo } \\
\text { Resultado }(\%)\end{array}$ \\
\hline $\mathrm{Ca}$ & 4,997 & 82,235 & 72,792 \\
\hline $\mathrm{Si}$ & 60,996 & 8,807 & 15,867 \\
\hline $\mathrm{K}$ & 15,691 & 0,569 & 1,144 \\
\hline $\mathrm{Al}$ & 12,115 & - & - \\
\hline $\mathrm{Fe}$ & 4,997 & 4,986 & 7,433 \\
\hline $\mathrm{Ti}$ & 0,541 & 0,414 & 0,828 \\
\hline $\mathrm{Rb}$ & 0,265 & - & 0,018 \\
\hline $\mathrm{Mn}$ & 0,194 & 0,093 & 0,181 \\
\hline $\mathrm{Ir}$ & 0,043 & - & - \\
\hline $\mathrm{Cu}$ & 0,041 & 0,036 & 0,058 \\
\hline $\mathrm{Zr}$ & 0,04 & - & 0,035 \\
\hline $\mathrm{Sr}$ & 0,038 & 0,73 & 0,626 \\
\hline $\mathrm{Zn}$ & 0,028 & 0,11 & 0,125 \\
\hline $\mathrm{Nb}$ & 0,014 & - & - \\
\hline $\mathrm{S}$ & - & 1,948 & 0,823 \\
\hline $\mathrm{V}$ & - & 0,035 & 0,028 \\
\hline $\mathrm{Cr}$ & - & 0,033 & 0,042 \\
\hline $\mathrm{Ni}$ & - & 0,004 & - \\
\hline & Fonte: Próprio autor $(2016)$ & \\
\hline
\end{tabular}

\subsubsection{CIMENTO}

O cimento utilizado para a fabricação dos pavers foi O CP \|| $32 \mathrm{E}$, cuja resistência recomendada é de $32 \mathrm{MPa}$ aos 28 dias. Para melhor caracterizá-lo foi feita a sua granulometria e a realização do EDX para descobrir sua composição química (Tab. 2).

\subsubsection{RESÍDUO DE CONCRETEIRA}

O resíduo de concreteira utilizado foi proveniente de uma concreteira situada na cidade de Catalão. O material é proveniente do processo de decantação realizado com a água que foi utilizada na lavagem dos caminhões betoneiras. A água residuária é armazenada em tanques para que as partículas sólidas se depositem no fundo. O material decantado é retirado na forma de um lodo e é acomodado nos arredores da concreteira até que se tenha a quantidade de levá-lo para o aterro sanitário. Este resíduo também passou por teste de granulometria e pelo ensaio de EDX (Tab. 2). Esta análise possibilitou perceber que a sua composição se assemelhava mais à composição do cimento do que do agregado, justificando, assim, a substituição parcial do cimento pelo resíduo.

\subsection{EQUIPAMENTOS}

Os ensaios de compressão foram realizados no Laboratório de Estruturas do curso de Engenharia Civil - Faculdade de Engenharia (FENG) da Universidade Federal de Goiás Regional Catalão com o auxílio de uma prensa hidráulica modelo YAW classe 1, seu controle é efetuado por computador, onde há um software chamado Máquina Universal de Ensaios - Sistema Hidráulico - Versão V1.62. O ensaio de absorção foi realizado no Laboratório da Geografia com o auxilio de uma balança com precisão de 0,1 gramas e de uma estufa para a secagem dos corpos de prova temperatura de $110 \pm 5^{\circ} \mathrm{C}$ por um período de 24 horas.

\subsection{MÉTODO}

A confecção dos pavers foi feita em uma fábrica de pré-moldados situada na cidade de Catalão. Para a produção dos pavers foram utilizados pó-de-pedra, cimento Portland CP II $32 \mathrm{E}$, água e resíduo de concreteira. Os pavers foram moldados em formas

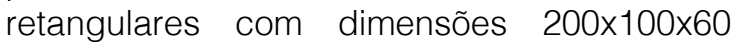
$(\mathrm{mm})$, que se adéquam as dimensões especificadas pela NBR 9781 (2013).

Foi feito um traço de referência, sem o resíduo, objetivando atender a resistência à compressão mínima exigida pela norma NBR 9781 de $35 \mathrm{MPa}$ aos 28 dias (ABNT, 2013). O traço de referência utilizado foi o mesmo 
empregado pela fábrica de pré-moldados que consistiu em 10 latas de pó-de-pedra, 1 saco de cimento e 2 latas de água. A lata utilizada possuia volume de 20 litros, obtendo uma relação água/cimento de 0,8 . A partir do traço de referência foram feitos outros com proporções diferentes de resíduo em substituição ao cimento, tendo um traço com $5 \%$ de substituição, outro com $10 \%$ e outro com 15\%. Foram confeccionadas 24 peças para cada traço, sendo que 18 foram separadas em três grupos e passaram por ensaio de compressão em três idades diferentes, aos 7, 14 e 28 dias, ou seja, seis pavers de cada traço para cada idade e os 6 restantes foram para o ensaio de absorção que foi realizado apenas com 28 dias. Os valores de resistência à compressão e absorção obtidos foram comparados à aqueles recomendados pela NBR 9781 (2013).

A dosagem do pó-de-pedra e da água foi realizada usando latas, tal como na fábrica, e para a dosagem do cimento e do resíduo foi utilizada uma balança digital com precisão de
10 gramas. As misturas de todos os traços foram feitas em betoneira, os materiais foram misturados a seco durante 90 segundos. Em seguida foi adicionada a água e misturados por mais 90 segundos. As peças foram moldadas em formas e o adensamento foi realizado por meio de uma mesa vibratória. Após passarem pela mesa vibratória, as formas foram levadas para uma área plana e coberta. As peças permaneceram cobertas com plástico, durante 24 horas, sendo depois molhadas periodicamente por 6 dias. Depois da primeira semana de cura elas ficaram em local aberto até atingirem as datas de ensaio.

A realização dos ensaios de resistência a compressão seguiram rigorosamente as recomendações da NBR 9781 (ABNT, 2013). O resultado do ensaio de compressão é dado em megapascals (MPa), que é encontrado pela divisão do valor da carga de ruptura expresso em newtons ( $\mathrm{N}$ ) pela área de carregamento em milímetros quadrados $\left(\mathrm{mm}^{2}\right)$, multiplicado pelo fator $\mathrm{p}$ que é encontrado em função da espessura da peça, como mostrado na Tab. (3).

Tabela 3: Fator multiplicativo $p$

\begin{tabular}{|c|c|}
\hline Espessura nominal da peça $(\mathrm{mm})$ & $p$ \\
\hline 60 & 0,95 \\
\hline 80 & 1,00 \\
\hline 100 & 1,05 \\
\hline
\end{tabular}

Fonte: NBR 9781 (ABNT, 2013)

Com os dados do ensaio de compressão de cada peça determina-se a resistência a compressão estimada do conjunto de peças que é encontrado pelas eq. (1) e (2):

$$
\begin{array}{r}
\quad f_{p k, e s t}=f_{p}-t \times s \\
s=\sqrt{\frac{\sum\left(f_{p}-f_{p i}\right)^{2}}{n-1}}
\end{array}
$$

Em que,

$f_{p}$ : é a resistência média das peças, expressa em megapascal (MPa);

$f_{p i}$ : é a resistência individual das peças, expressa em megapascal (MPa);

$f_{p k, e s t}$ : é a resistência característica estimada

à compressão, expressa em megapascal(MPa);

n: é o número de peças da amostra; s: é o desvio padrão da amostra, expresso em megapascals (MPa);

t: é o coeficiente de Student, fornecido em função do tamanho da amostra.

A primeira amostra, contendo 6 peças de cada traço, passou pelo ensaio de compressão com 7 dias, de acordo com a NBR 9781. Na realização do ensaio foram utilizadas 2 lâminas de borracha com espessura de 2 milímetros para regularizar as 
superfícies da peça para a colocação de carga.

Ao se observar que a borracha utilizada no primeiro ensaio estava prejudicando os resultados, absorvendo a carga com sua deformação, optou-se pela sua retirada nos ensaios de compressão de 14 e 28 dias. $\mathrm{Na}$ prensa utilizada, nos ensaios de compressão, a velocidade de carregamento difere da pedida em norma em relação à unidade, sendo a velocidade empregada de $2 \mathrm{~mm} / \mathrm{min}$, possuindo um carregamento constante como requer a norma.

O ensaio de absorção foi realizado com os pavers de 28 dias de idade em 6 peças de cada traço, conforme preconizado pela NBR -
9781 (2013). Depois da primeira pesagem repetiu-se o processo a cada 2 horas até que duas pesagens sucessivas não apresentassem diferença de massa superior a $0,5 \%$ em relação ao valor anterior. Após a pesagem dos pavers saturados eles foram levados à estufa na temperatura de $110 \pm 5^{\circ} \mathrm{C}$ por um período de 24 horas. Com os pavers secos foram realizadas novas pesagens, efetuando o mesmo processo de repetição a cada 2 horas realizado com os pavers saturados. Com os valores de massa dos pavers saturados e secos calculou-se a capacidade de absorção de cada traço, de acordo com a Eq. (3):

$$
A=\frac{m_{2}-m_{1}}{m_{1}} \times 100
$$

Em que,
A: é a absorção de cada corpo de prova, expressa em porcentagem (\%)
$m_{1}$ : é a massa do corpo de prova seco, expressa em gramas (g);
$m_{2}$ : é a massa do corpo de prova saturado, expressa em gramas (g).

Para facilitar a visualização, bem como a discussão dos resultados, eles foram agrupados na forma de gráficos e quadros, sendo que todos os dados coletados estão apresentados nos Apêndices.

A análise estatística foi realizada com base no teste de médias Tukey, utilizando o software Sisvar.

\section{RESULTADOS E DISCUSSÕES.}

$\mathrm{Na}$ Tab. 4 estão mostrados os valores de resistência característica à compressão dos pavers nas idades de 7, 14 e 28 dias, bem como os resultados obtidos para o teste de médias Tukey com nível de significância de $5 \%$ para a resistência característica à compressão dos pavers.

Tabela 4: Resultado das resistências obtidas nos corpos de prova para diferentes idades e do teste Tukey.

\begin{tabular}{|c|c|c|c|c|c|c|}
\hline \multirow{3}{*}{$\begin{array}{l}\text { Cps } \\
\text { Ref. }\end{array}$} & \multicolumn{6}{|c|}{ Idade } \\
\hline & \multicolumn{2}{|c|}{7} & \multicolumn{2}{|c|}{14} & \multicolumn{2}{|c|}{28} \\
\hline & 5,95 & $\mathrm{Aa}$ & 15,13 & $A b$ & 18,29 & $A c$ \\
\hline Res.05\% & 4,52 & $\mathrm{Aa}$ & 9,48 & $\mathrm{Bb}$ & 10,38 & $\mathrm{Bb}$ \\
\hline Res. $10 \%$ & 4,99 & $\mathrm{Aa}$ & 10,28 & $\mathrm{Bb}$ & 11,83 & $\mathrm{Bb}$ \\
\hline Res. $15 \%$ & 3,91 & $\mathrm{Aa}$ & 8,43 & $\mathrm{Bb}$ & 8,70 & $\mathrm{Bb}$ \\
\hline
\end{tabular}

As letras maiúsculas iguais indicam resultados estatisticamente iguais na coluna. As letras minúsculas iguais indicam resultados estatisticamente iguais na linha.

Conforme pode ser observado na Tab. (4), os resultados obtidos em todos os traços, inclusive no de referência, que não apresenta adição de resíduo, não atingiram a resistência à compressão de $35 \mathrm{MPa}$ aos 28 dias, conforme é exigido pela norma NBR 9781 (ABNT, 2013). Acredita-se que isso seja devido a algum erro de dosagem em relação ao traço utilizado pela empresa. Uma das prováveis causas deve ter sido o fator água/cimento (a/c), uma vez que a adição de duas latas de água, que corresponde a $40 \mathrm{~kg}$, para um saco de cimento de $50 \mathrm{~kg}$ deu uma relação a/c de 0,8 , que é muito alta tendo em 
vista que em outros estudos de fabricação de pavers, com diferentes resíduos, a relação a/c variava de 0,2 a 0,7. Como no estudo de Purificação (2009) onde a relação a/c variou de 0,45 a 0,64 e no estudo de Cruz (2003) variou de 0,2 a 0,48.

Outra característica do traço, que pode ter dado problema na resistência, é que o agregado utilizado possuía mais finos do que os limites permitidos para agregado miúdo para a fabricação de concreto segundo a norma de agregados a NBR 7211 (ABNT, 2005), podendo assim ter influenciado para que a resistência ficasse baixa. Ainda nesse sentido, outro fator que pode ter prejudicado o resultado do ensaio de compressão foi a falta de regularidade da superfície inferior, concentrando a carga em pontos diferentes da peça ao invés de ter uma carga aplicada uniformemente na face do paver. Para tentar suprir a falta de nivelamento da peça foram utilizadas duas laminas de borracha, uma em sua superfície superior e outra na inferior, mas observou que no decorrer dos ensaios a borracha estava absorvendo parte da carga com sua deformação, prejudicando os resultados. Um fator que pode corroborar com a suspeita da influência da falta de regularidade da superfície dos pavers, na resistência à compressão, foi a forma de ruptura ocasionada em quase todas as amostras.

Observo-se durante os ensaios, que inicialmente, ocorreu a fissuração das laterais das peças e um desplacamento das laterais, diminuindo a área de aplicação de carga do paver, diminuindo então a resistência. Acredita-se que, com a superfície plana, a carga atingiria uniformemente todos os pontos do pavers ocorrendo uma fissuração uniforme pela peça e não em pontos específicos como ocorreu. Esse fato fez com que a curva carga $x$ deformação apresentasse um comportamento quase horizontal antes de se obter uma curva mais inclinada, que significa um aumento de carga aplicada. Isso se refere a uma acomodação da peça devido à irregularidade de sua superfície.

Mesmo sem atingir a resistência exigida, o estudo mostrou que entre os pavers que tinham resíduo em sua composição os de traço com $10 \%$ de resíduo foram os que apresentaram melhores resultados com relação a resistência à compressão, isto baseado apenas pelos dados de resistência característica à compressão, de acordo com a NBR 9781. Mas, indo além da norma, notase que pelo teste de Tukey todos os traços de resíduo apresentam resultados estatisticamente iguais. Acredita-se que esses valores podem atingir valores maiores, uma vez que se corrija a relação água/cimento, reduzindo a porosidade dos paver e se faça a regularização da superfície inferior do paver. O valor da resistência do traço de 10 \% aos 28 dias correspondeu a aproximadamente $65 \%$ da resistência do traço de referência na mesma idade. Acredita-se que ao fazer o traço de referência atingir os $35 \mathrm{MPa}$ exigidos pela norma e, uma vez mantida essa mesma proporção, o traço com $10 \%$ de resíduo alcançaria uma resistência maior. Ainda que não se alcance os valores recomendados pela NBR 9187 (ABNT, 2013), acredita-se que esses pavers possam ser utilizados em calçadas, praças e até para pisos de pavimentos de tráfego leve.

Outros trabalhos que seguem essa idéia de fabricação de pavers com resíduos mostram que é possível alcançar resultados satisfatórios de resistência, sendo que trabalhos como de Altoé et al. (2011), que fez substituição parcial de agregado por cinza de bagaço de cana-de-açúcar utilizando vibroprensa, atingiu resultados dentro dos exigidos pela norma, como também o trabalho de Moura et al. (2006) que fez uso de resíduo de serragem de rochas ornamentais como substituto parcial do cimento, também fazendo uso de vibroprensa, atingindo resultados até melhores dos pedidos pela NBR 9781 (ABNT, 2013) alcançando resultados de até $42,6 \mathrm{MPa}$ aos 28 dias, com uma substituição de $15 \%$. Mas há também trabalhos que não conseguiram resultados satisfatórios como o de Cavalcanti et al., (2011), em que houve a utilização de agregados reciclados provenientes dos RCD para a fabricação dos pavers. O método adotado por Cavalcanti et al., (2011) foi igual ao realizado neste trabalho, não foi utilizado vibroprensa e sim um concreto mais plástico para facilitar seu adensamento, e também não alcançou resultados como a norma exige.

Com esse comparativo entre trabalhos tornou possível perceber que o método utilizado para a fabricação dos pavers pode também vir a influenciar a sua resistência final, já que os trabalhos que fizeram uso de vibroprensa alcançaram melhores resultados. Uma forma de tentar melhorar a resistência dos que fazem uso da massa mais plástica para facilitar o adensamento é utilizar aditivo superplastificante, para diminuir a quantidade de água no traço. 
Conforme foi observado nenhum traço apresentou resultados satisfatórios. Segundo a NBR 9781 (ABNT, 2013) não se pode ter absorção superior a $6 \%$ e todos os traços obtiveram absorção média superior a esse valor. Esses resultados corroboram com a suspeita de que a relação água/cimento de 0,8 tenha sido elevada. Esse fato proporcionou uma grande quantidade de vazios presentes nas peças, evidenciando ainda mais a necessidade de rever o traço de referência utilizado pela empresa. Nesse sentido, verifica-se uma relação direta entre os parâmetros de resistência a compressão e a absorção. Assim, ou se aumenta a quantidade de cimento com o objetivo que o mesmo ajude a preencher esses espaços vazios e melhorando as ligações entre as partículas diminuindo a absorção e também aumentando a resistência à compressão, ou se reduz a quantidade de água de modo a ajustar a relação água/cimento a patamares aceitáveis. É notório que a primeira opção, do ponto de vista econômico não é a mais adequada, visto que isso aumentaria os

\section{REFERÊNCIAS}

[1] Abcp - Associação Brasileira de Cimento Pontland. Pesquisa inédita e exclusiva revela cenário do mercado brasileiro de concreto. 2013.Disponível

em:<http://www.abcp.org.br/conteudo/imprensa/pe squisa-inedita-e-exclusiva-revela-cenario-domercado-brasileiro-de-concreto\#.VRChS_nF-Sg>. Acesso em: 08 jun. 2015.

[2] Abcp - Associação Brasileira de Cimento Portland. Manual de Pavimento Intertravado: Passeio Público. São Paulo: ABCP, 2010. 36 p.

[3] Abnt - Associação Brasileira de Normas Técnicas. NBR 9781: Peças de concreto para pavimentação-Especificação e métodos de ensaio. 2.ed. Rio de Janeiro: ABNT, 2013. 21 p.

[4] Abnt -Associação Brasileira DE NORMAS TÉCNICAS. NBR 7211: Agregados para concreto Especificação. 2. ed. Rio de Janeiro: ABNT, 2005. $11 \mathrm{p}$.

[5] Altoé, S. P. S.; Francisco, A. D.; Martins, C. $\mathrm{H}$. Análise do comportamento quanto à resistência mecânica de pavers fabricados com cinza de bagaço de cana-de-açúcar como agregado miúdo. Anais Eletrônicos do Encontro Internacional de Produção Científica. Maringá: CESUMAR, 2011,5 p.

[6] Amadei, D. I. B.; Avaliação de blocos de concreto para pavimentação produzidos com resíduos de construção e demolição do município de Juranda / PR.2011. 153 f. Dissertação custos de produção, sendo assim, só restaria a segunda opção.

\section{CONSIDERAÇÕES FINAIS.}

Embora o trabalho não tenha apresentado resultados satisfatórios, no que se refere às recomendações da NBR 9781 (ABNT, 2013), acredita-se que com algumas correções pode-se sim alcançar melhores resultados, viabilizando a utilização do resíduo de concreteira para a fabricação de pavers para pisos de calçadas, praças e estacionamentos de veículos leves. Em trabalhos futuros se realizarão ensaios com essas modificações.

A resistência à compressão não deve ser o único parâmetro a ser considerado quando se avalia a incorporação de resíduos na confecção de novos materiais, deve ser levado em consideração fatores relacionado ao meio ambiente e até mesmo econômico, sendo que com a utilização do resíduo diminui a quantidade levada aos aterros ou até locais inadequados e também barateando o produto devido à diminuição de cimento na sua produção.

(Mestrado em Engenharia Urbana) - Universidade Estadual de Maringá, Maringá, 2011.

[7] Cavalcanti, E .C. M.; Amorim, R. P. F.; Junior, G. S. A. Pavimentação intertravada: utilização de resíduos de construção e demolição para fabricação de e assentamento de pavers.Anais do XV INIC.Jacareí: UNIVAP, 2011. 6 p.

[8] Castro, C. R. Piso intertravado: vantagens que vão muito além da estética. Disponível em: <http://tecparpavimentos.com.br/goto/store/texto/6 5/piso-intertravado-vantagens-que-vao-muito-alemda-estetica>. Acesso em: 09 jun. 2015.

[9] Cruz, L. O. M. Pavimento Intertravado de Concreto: Estudos dos elementos e métodos de dimensionamento. 2003. 281 f. Dissertação (Mestrado em Ciências em Engenharia Civil) Universidade Federal do Rio de Janeiro, Rio de Janeiro, 2003.

[10] Hallack, A.Pavimento intertravado: uma solução universal. Disponível em: <http://www.revistaprisma.com.br/novosite/noticia.a sp?cod=107>. Acesso em 14 ago. 2015.

[11] Moura, W. A.; Lima, M. L.; Gama, J. L. C. N.; Moratti, M.; Souza, F. L. C. Produção de pisos intertravados comutilização de resíduos de serragem de rochas ornamentais. Anais do XI Encontro Nacional de Tecnologia no Ambiente Construído. Florianópolis: Entac, 2006, 10 p. 
[12] Purificação, E. B. Estudo do uso de agregados reciclados de concreto e substituição do cimento por resíduo de polimento de porcelanato na produção de piso intertravado de concreto. 2009. 104 f. Dissertação (Mestrado em Construção Civil) - Escola de Engenharia da Universidade Federal de Minas Gerais. Belo Horizonte, 2009.

[13] Shackel, B.Design and Construction of Interlocking Concrete Block Pavement.1st Edition. Elsevier, Nova lorque e Londres. 1990.
[14] Virgiliis, A, L, C., Procedimentos de projetos e execução de pavimentos permeáveis visando retenção e amortecimento de picos de cheias. 2009. 213 f. Dissertação (Mestrado em Engenharia) - Escola Politécnica da USP. São Paulo, 2009. 


\section{Gapítulo 20}

\section{PROJETO DE TERCEIRIZACEÃO DO GERENCIAMENTO DE MANUTENCÃO DE UMA PLANTA DE LUBRIFICANTES DO SEGMENTO DE ÓLEO \& GÁS}

\section{Fábio Esperança}

\section{João Luiz Cesarino Ferreira}

Nélio Domingues Pizzolato

Resumo: Este trabalho, baseado em gerenciamento de projetos, examina um projeto de terceirização da gestão de manutenção de uma planta de lubrificantes em uma empresa de grande porte. Devido ao baixo investimento em manutenção, a justificativa para o estudo da planta decorre da deterioração ocorrida nos últimos anos. O objetivo principal deste artigo é de contribuir com o conhecimento prático sobre terceirização de manutenção de empresa de lubrificantes, tanto para a comunidade acadêmica, quanto para os trabalhadores e empresários do ramo. A metodologia aplicada foi a pesquisa descritiva e exploratória, e, posteriormente, foi feito os levantamentos de dados dos estudos, com os resultados e as conclusões da terceirização, utilizando a metodologia do PMBOK (Project Management Body of Knowledge) para o gerenciamento de projetos de manutenção na planta de lubrificantes de um grupo internacional do segmento de Óleo \& Gás. Um programa de confiabilidade define a estrutura organizacional, responsabilidades, procedimentos, processos e recursos utilizados no gerenciamento de projetos para a aplicação do conhecimento, com suas habilidades, ferramentas e técnicas às atividades. Os resultados foram auspiciosos, como serão descritos, em particular o esforço do programa Fault Tree Analysis (FTA) deve ser mantido pela direção de engenharia, que, periodicamente, deve verificar a pertinência das ações de correção e melhoria, a efetiva implantação das ações e os resultados alcançados com as ações.

Palavras-chave: Confiabilidade, gerenciamento de projetos, visão estratégica. 


\section{INTRODUÇÃO}

Este trabalho descreve um projeto de terceirização em gestão de todo o escopo da manutenção em uma planta de lubrificantes de uma empresa de grande porte. Mais especificamente, um grupo internacional. $\mathrm{O}$ escopo do projeto incluía assumir toda a manutenção da planta, e também o desenvolvimento das competências dos profissionais de manutenção a alcançarem maior produtividade, e mais a operação e manutenção das utilidades, vapor, água e ar comprimido, a operação do almoxarifado de peças de manutenção, a criação da célula do planejamento e a manutenção de empilhadeiras a gás.

$\mathrm{Na}$ fase de iniciação do projeto, após pesquisas junto a diversas empresas que haviam adotado procedimento análogo, e que, diante de maus resultados, se arrependeram, foram percebidas falhas na contratação destas empresas terceirizadas de manutenção e, então, foi decidido inovar. Foi criado um contrato de incentivos para melhorar os indicadores de desempenho e redução de custos, após um período de doze meses de carência, onde foi reconhecido que o parceiro terceirizado, teria que fazer um investimento em estrutura, implantação de procedimentos, planejamento e treinamento de pessoal, além de inovação com as medições da manutenção preditiva, entendendo que o custo iria subir ligeiramente no primeiro ano, mas cairia de forma progressiva nos anos subsequentes (NBR 9325, 1986).

O projeto foi desenhado para ter fluxo de caixa positivo no terceiro ano, mas no segundo ano foi observada a redução dos custos. Um dos fornecedores préselecionados, aqui identificada como empresa CEMAN, aceitou trabalhar sem remuneração, afim de levantar todos os custos de manutenção da planta de lubrificantes, junto com a empresa, aqui denominada EPTO $^{1}$ e este trabalho durou três meses, para que a citada empresa pudesse comparar o antes e depois da terceirização e, também, ter um valor de referência no processo de licitação.

Este trabalho de levantamento de custos foi aprovado pelo setor de auditoria da empresa

\footnotetext{
${ }^{1}$ NOTA 1: Por questões de confidencialidade não mencionaremos aqui o nome da empresa de Óleo \& Gás, esta terá um nome fictício: EPTO.
}

EPTO e serviu de parâmetro de referência para o processo de licitação final, em que a empresa terceirizada foi aprovada por uma comissão de contratação. Houve o convencimento do comitê de contratação e de auditoria a criar parâmetros de escolha da melhor empresa, não somente pelo menor preço final, mas também pelo valor agregado ao projeto.

Foi identificado que um fator crítico de sucesso do projeto seria a aceitação do projeto, por parte dos colaboradores da área de manutenção da empresa EPTO, pois era entendido que poderia haver resistência, por parte destes colaboradores, na contratação da empresa, pois poderiam perder benefícios. Um dos colaboradores não quis efetivar a mudança de empresa e continuou funcionário da empresa multinacional. Dois meses depois da mudança, este mesmo colaborador, percebendo o sucesso do projeto, solicitou que naquele momento preferia mudar, pois havia sido direcionado a uma função operacional e não havia se adaptado, e preferiria trabalhar mesmo na área de manutenção.

A justificativa para o projeto de terceirização desta planta de lubrificantes da empresa EPTO tem-se a deterioração da planta nos últimos tempos resultante do baixo investimento em manutenção, devido à falta de treinamento, competências e habilidades técnicas dos funcionários que faziam este trabalho há anos, pois o core business da empresa nunca foi manutenção e enxergou-se então uma oportunidade de melhoria, transformando a manutenção de um centro de custo em uma oportunidade de investimento para obter retorno em produtividade e menores custos no futuro, com o aumento de volume de lubrificantes produzido.

O objetivo principal deste artigo é de contribuir com o conhecimento prático sobre terceirização de área de manutenção industrial de uma planta de lubrificantes do segmento de óleo \& gás, tanto para a comunidade acadêmica, quanto para os trabalhadores e empresários deste ramo. O objetivo analítico do projeto era selecionar e contratar uma empresa especializada em gerenciamento de projetos de manutenção que pudesse agregar valor com tecnologia, bem como em planejamento dos serviços a serem programados, prevenindo possíveis falhas e quebras de equipamentos de forma antecipada, reduzindo o tempo de parada de 
máquinas e equipamentos de forma repentina, comprometendo o volume de produção.

\section{METODOLOGIA}

A metodologia aplicada foi a pesquisa descritiva e exploratória. No desenvolvimento deste trabalho foi feita uma revisão bibliográfica para a fundamentação teórica, a fim de se obter o levantamento do estado da arte do tema, através de coleta de dados científicos, além de documentos e textos em meio virtual, assim como da fundamentação teórica ou, ainda, para justificar os limites e contribuições da própria pesquisa sobre a relação da visão estratégica da manutenção centrada na confiabilidade. Posteriormente, foi feito o levantamento de dados dos estudos, com seus resultados e as conclusões da terceirização, utilizando a abordagem recomendada pelo $\mathrm{PMBOK}$ para $\mathrm{O}$ gerenciamento de projetos de manutenção na planta de lubrificantes de um grupo internacional do segmento de Óleo \& Gás. Foram utilizados os cinco processos descritos no PMBOK (iniciação, planejamento, execução, controle e encerramento) e as oitenta e cinco atividades de gerenciamento contidos nestes cinco processos. $\mathrm{Na}$ fase de iniciação os mais importantes foram: escolha do gerente do projeto; elaboração do termo de abertura; levantamento dos custos reais de manutenção da empresa EPTO; e as reuniões de pré-requisitos que deram origem ao escopo real a ser contratado, além da identificação das Partes Interessadas, certamente menos relevante no caso presente, pois as possíveis Partes seriam estritamente internas, sem reflexos externos, mas abordado na Seção 4.1, mais adiante. Os custos foram relevantes como referência na concorrência da melhor empresa, além da identificação dos stakeholders, como previsto no processo de iniciação, menos fundamental no presente caso, mas que será objeto de discussão mais adiante, na Seção 4.1. Na fase de planejamento, o mais importante foi a criação da Estrutura Analítica de Projeto (EAP). Na fase de monitoramento e controle, as ações mais importantes foram as medições de performance e dos KPI's (key performance indicators) estabelecidos para o projeto (MTBF - mean time between failures, e o índice de retrabalho) em um primeiro momento e, na fase do encerramento, o ponto de destaque foi o compartilhamento das lições aprendidas.

\section{GESTÃO DA MANUTENÇÃO}

Diante das condições atuais do mercado, as palavras de ordem são: investir, desenvolver e buscar reter os colaboradores. O investimento em pessoas fará com que o colaborador possa se sentir motivado e, assim, produzir melhores resultados e se preparar para os desafios futuros dentro da organização. O investimento em gestão de pessoas, por meio de treinamentos, desenvolvimentos e melhorias da qualidade de vida fará com que a organização economize dinheiro em outras frentes, como recrutamento e seleção, afastamentos e desligamentos. Formar equipes de alta performance é algo que todas as empresas almejam, mas que poucas conseguem, pois para isso são necessários investimentos, tanto de tempo quanto de dinheiro (PMBOK, 2014).

Um programa de confiabilidade define a estrutura organizacional, responsabilidades, procedimentos, processos e recursos utilizados na gestão da confiabilidade. As tarefas em um programa de confiabilidade formam um conjunto de atividades relacionadas a aspectos da confiabilidade de uma unidade ou o apoio para produção de um resultado pré-estabelecido. Os elementos de um programa de confiabilidade incluem uma tarefa ou um conjunto de tarefas realizadas por um indivíduo ou equipe (BASTOS, 2017). 
Figura 1: Fluxograma de processo de manutenção baseado na confiabilidade

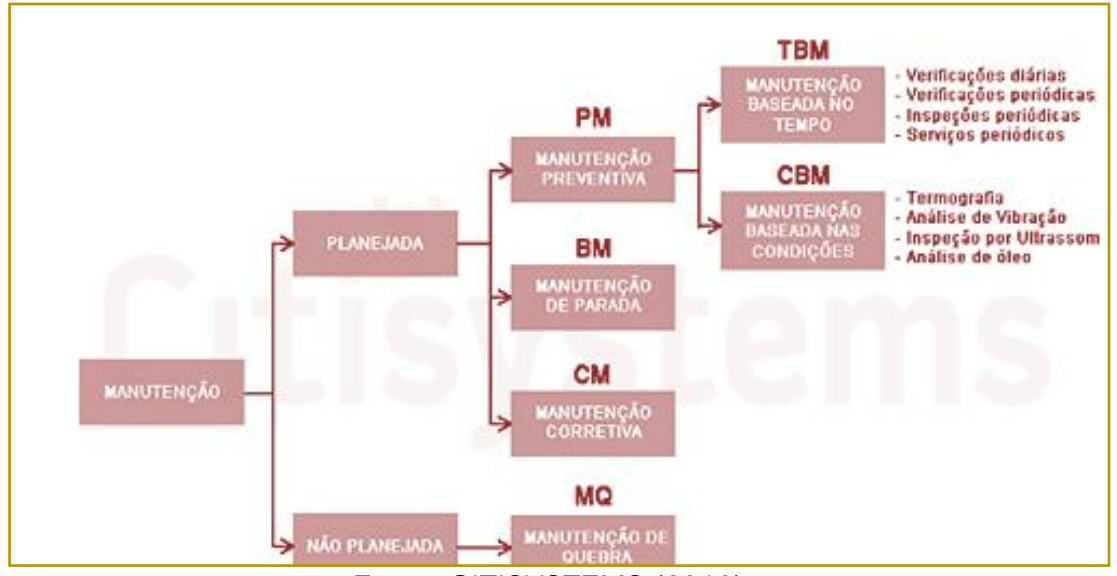

Fonte: CITISYSTEMS (2016).

A Figura 1 indica um fluxograma do processo de manutenção baseado na confiabilidade. $O$ perfil característico da empresa EPTO, antes da terceirização, era: $20 \%$ de manutenção preventiva (PM), $40 \%$ de manutenção corretiva $(\mathrm{CM})$ e $40 \%$ manutenção de quebra (MQ).

\subsection{MANUTENÇÃO PREDITIVA}

Segundo Lafraia (2001), a manutenção preditiva é o acompanhamento periódico de equipamentos ou máquinas, através de dados coletados por meio de monitoração ou inspeções. As técnicas mais utilizadas para manutenção preditiva são: análise de vibração e técnicas de análise não destrutivas, como a termografia e a análise de óleo, dentre outras. A empresa EPTO
Lubrificantes S.A. implementou a análise de vibração, a termografia e a análise de óleo, em seu planejamento de manutenção, técnicas discutidas a seguir:

\subsubsection{ANÁLISE DE VIBRAÇÃO}

Segundo Jordán (2016), a análise de vibração é um processo capaz de identificar possíveis falhas nos componentes móveis de um equipamento. Vários motores elétricos e bombas foram cadastrados no sistema de gerenciamento de manutenção da EPTO e estas inspeções foram fatores determinantes para alcançar os objetivos do projeto e os indicadores de desempenho. O equipamento da Figura 2 mostra um coletor de dados de vibração.

Figura 2: Coletor de dados de vibração.

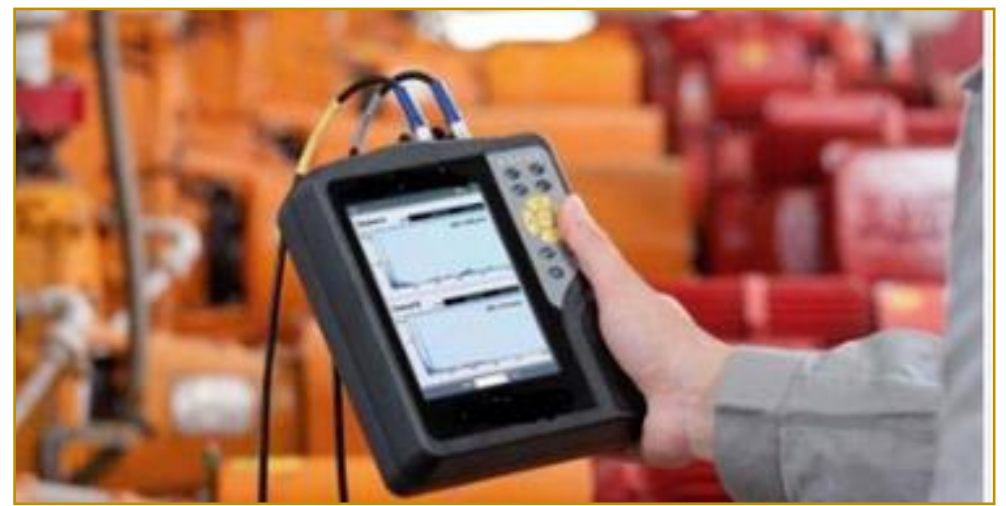




\subsubsection{TERMOGRAFIA}

É uma técnica que permite mapear um corpo ou uma região com o intento de distinguir áreas de diferentes temperaturas, sendo portanto uma técnica que permite a visualização artificial da luz dentro do espectro infravermelho. A termografia hoje tem um papel muito importante na área de manutenção preditiva. Por meio da sua utilização, é possível eliminar muitos problemas de produção, evitando falhas elétricas, mecânicas e fadiga de materiais (JORDÁN, 2016). A Figura 3 mostra uma análise de um painel elétrico através da termografia.

Figura 3: Emissão de um painél elétrico.

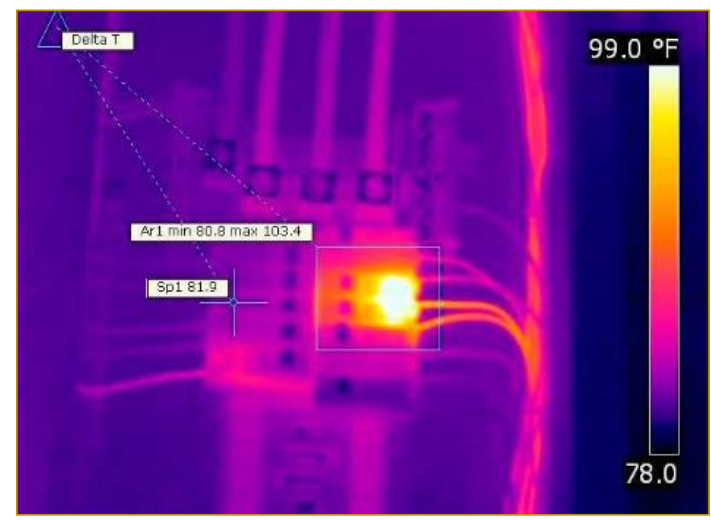

Fonte: JORDÁN (2016).

\subsubsection{ANÁLISE DE ÓLEO}

A análise de óleo é uma ferramenta de manutenção preditiva de diagnóstico para monitorar e avaliar as condições dos fluidos e equipamentos. Ela permite que se maximize o desempenho e confiabilidade de ativos por meio da identificação de problemas antes que se tornem falhas. Essa ferramenta gera assertividade e segurança na tomada de decisões dos gestores, economizando tempo e reduzindo custos de manutenção (NBR 5462, 1994).

Com indicadores e informações, as decisões irão gerar menor impacto no custo de manutenção. A análise de óleo gera intervenções programadas, previsibilidade e maior disponibilidade física dos equipamentos (JORDÁN, 2016). A Figura 4 demonstra a coleta de óleo de um equipamento.

Figura 4: Coleta do óleo do equipamento para fazer testes.

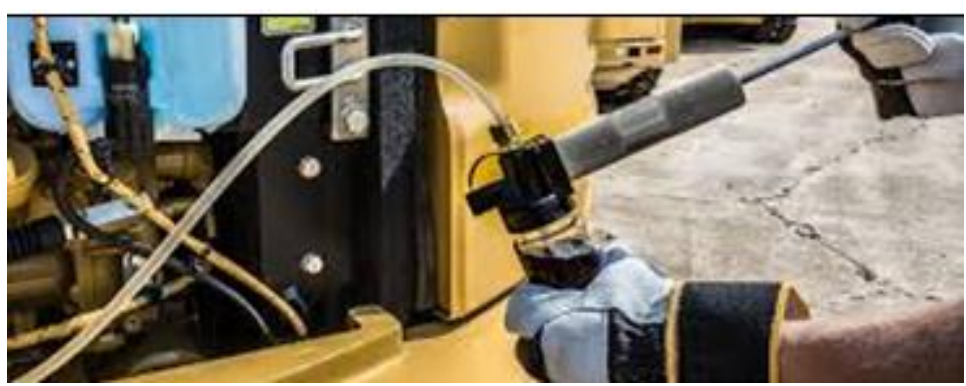

Fonte: Jordán (2016).

\section{GERENCIAMENTO DE PROJETOS}

De acordo com o PMBOK, o gerenciamento de projetos é a aplicação do conhecimento, habilidades, ferramentas e técnicas às atividades do projeto para atender aos seus requisitos. O gerenciamento de projetos é realizado através da aplicação e integração apropriadas das 85 atividades de gerenciamento de projetos, logicamente agrupados em cinco grupos de processos já citados, que são: iniciação; planejamento; execução; monitoramento e controle; encerramento (PMBOK, 2014). 
O gerenciamento de um projeto normalmente inclui, mas não se limita à: identificação dos requisitos, abordagem das diferentes necessidades, preocupações e expectativas das partes interessadas no planejamento e execução do projeto, estabelecimento, manutenção e execução de comunicações ativas, eficazes e colaborativas entre as partes interessadas, gerenciamento das partes interessadas (os stakeholders), visando ao atendimento aos requisitos do projeto e à criação das suas entregas, equilíbrio das restrições conflitantes do projeto que incluem, mas não se limitam ao escopo, qualidade, cronograma, orçamento, recursos e riscos (MULCAHY, et al., 2014).

\subsection{PARTES INTERESSADAS NO PROJETO}

Importante ressaltar a importância das Partes Interessadas no projeto, que podem determinar e/ou contribuir para o sucesso ou o insucesso do projeto. Uma Parte Interessada pode ser um indivíduo, grupo ou organização, que pode afetar, ou sentir-se afetada por uma decisão, atividade ou resultado de um projeto. De acordo com Mitchell et al., 1997, cada parte interessada tem sua influência, poder, legitimidade e urgência.

A equipe do projeto deve identificar as partes interessadas internas e externas, positivas e negativas, $e$ as partes executoras e orientadoras a fim de determinar os requisitos do projeto e as expectativas de todas as partes envolvidas. O gerente de projetos precisa gerenciar a influência de todas essas partes interessadas em relação aos requisitos do projeto a fim de garantir um resultado bem sucedido (PMBOK, 2014).

\subsubsection{RELAÇÃO ENTRE AS PARTES INTERESSADAS E O PROJETO}

Usando a classificação proposta por Mitchell et al., 1997, as Partes Interessadas têm diversos níveis de responsabilidade, autoridade e urgência, quando se envolvem em um projeto. Esses níveis podem mudar ao longo do ciclo de vida do projeto. Seu envolvimento pode variar, desde contribuições ocasionais em pesquisas e grupos de discussão até o patrocínio total do projeto, que inclui o fornecimento de apoio financeiro, político ou outro tipo de apoio. Algumas Partes Interessadas também podem limitar o sucesso do projeto, de forma passiva ou ativa. Essas Partes Interessadas, igualmente, exigem a atenção do gerente de projetos no decorrer de todo o ciclo de vida do projeto, bem como um plano de ação e abordagem de quaisquer questionamentos que possam levantar (MULCAHY, et al., 2014).

A identificação das Partes Interessadas é um processo contínuo em todo o ciclo de vida do projeto. Caso isso não seja feito, podem ocorrer atrasos, aumento de custos, problemas inesperados e outras consequências negativas, incluindo o cancelamento do projeto.

\section{GERENCIAMENTO DO ESCOPO DO PROJETO}

O gerenciamento do escopo é o processo que define qual o trabalho é necessário e garante que todo esse trabalho, e apenas este trabalho, seja realizado. Para realizar o projeto de terceirização foi aplicada a abordagem de gerenciamento de projetos proposta pelo PMBOK.

\subsection{O ESCOPO DO PROJETO DE TERCEIRIZAÇÃO DA MANUTENÇÃO}

A empresa EPTO precisava reduzir seu headcount em 24 pessoas, pois a lucratividade do negócio de lubrificantes vinha caindo ano a ano e os investimentos em manutenção também vinham decaindo com o tempo, fazendo com que o índice de disponibilidade se encontrava na casa dos $75 \%$ no final dos anos 90. O setor de manutenção englobava fazer manutenção em toda a planta, que contava com a seguintes áreas/equipamentos da indústria:

a) Enchimento de óleos lubrificantes, dos embalados de 1 litro, 5 litros, 20 litros e 200 litros e mais aproximadamente todas as 1000 válvulas de controle, de retenção, lançadores e aparadores de $\mathrm{PIG}^{2}$, esse sistema para limpeza de linha de óleo;

b) Área de paletizadores das embalagens;

c) Unidade de fabricação de graxas lubrificantes, tachos, válvulas, bombas e

\footnotetext{
${ }^{2}$ NOTA 2: PIG - é um dispositivo de plástico, em forma de sanfona que fica dentro da tubulação de óleo, empurrado por ar comprimido para limpeza da tubulação, na troca de um óleo lubrificante para outro.
} 
tanques de espera (hopers) e o sistema de transporte pneumático de matéria-prima;

a) Unidade de descarregamento de carro tanque;

b) Área de tancagem de óleos básicos e aditivos, com suas respectivas bombas e válvulas;

c) Manifold de distribuição dos óleos desde a fabricação até o setor das máquinas de enchimento;

d) Operação de empilhadeiras a gás para produção e manutenção;

e) Unidade de fabricação dos óleos lubrificantes (o setor da mistura);

f) Equipamentos do sistema de combate a incêndio para toda a planta, bomba jóquei, bomba a diesel e outros;

g) Área de compressores, secadores de ar comprimido e gerador diesel;

h) Área das caldeiras de vapor e aquecimento de fluido térmico para a unidade fabricação das graxas lubrificantes;

i) Área das ETES, estações de tratamento de efluentes;

j) Área de estoque de peças sobressalentes para operação e manutenção da planta (menos a produção);

h) Unidade de fabricação de produto a base de asfalto, ligado à chefia de fabricação da unidade de graxa, que tinha um aquecedor e bomba específicos para essa unidade;

I) Nove (09) subestações, toda parte elétrica dentro das unidades industriais, iluminação e ventilação;

m) Manutenção das utilidades, vapor, água potável e industrial e ar comprimido.

Eram 24 pessoas, entre mecânicos, soldadores e eletricistas e um supervisor de manutenção, perfazendo um total de 25 pessoas. Além das áreas acima, o escopo previa mais o seguinte: implementação da manutenção preditiva nos equipamentos, medição de vibração, análise de óleo e termografia, a partir de um plano de manutenção em software de gestão de manutenção; preventivas programadas; corretiva quando necessário, segundo a Figura 1.

\subsection{FORA DO ESCOPO}

Este tema também é muito importante, principalmente para a elaboração da Estrutura Analítica de Projeto (EAP), e para determinar o real escopo de serviços da empresa terceirizada e o custo final dos serviços. Alguns dos trabalhos previstos ocorrem em pequenas manutenções no maquinário de produção, nas unidades da fábrica de graxas, mistura e enchimento dos óleos, e outras unidades, tais como: aperto de parafusos, troca de lâmpadas, conserto em tomadas elétricas, lubrificação das máquinas de produção, desmontagem de motores elétricos, troca de botoeiras de comando; pintura de tanques, e máquinas em geral; desmontagem e montagem de algum dispositivo do maquinário de produção; desmontagem e montagem de tubulação e aparadores de PIG na área do enchimento de óleos; troca de revestimento de isolamento de vapor nas tubulações; troca de válvulas em qualquer linha de óleo, graxa, ar comprimido, água, aditivo e vapor; qualquer manutenção na unidade de fabricação de embalagens plásticas e, também, manutenção por obras civis nas unidades industriais acima.

Uma vez que as causas básicas tenham sido priorizadas através da sua criticidade, as ações de correção e melhoria devem se dirigir às causas com maior criticidade. $A$ intenção das ações de correção e melhoria deve reduzir a probabilidade de ocorrência do evento de topo (NBR 9325, 1986).

A FTA (Failure Tree Analysis ou Análise de Árvores de Falha) é uma técnica de confiabilidade que tem como objetivos (FOGLIATTO, 2011):

i) Partindo de um evento de topo, indesejável, identificar todas as combinações de causas que podem originá-lo;

ii) Estudar a probabilidade de ocorrência dessas causas e, em função disso, do evento de topo;

iii) Priorizar ações que visam bloquear essas causas.

Essas técnicas revelam os pontos fracos do sistema e, assim, fornecem subsídios para as atividades de melhoria contínua. As técnicas FTA têm a vantagem de sistematizarem o diagnóstico de produtos e processos, as quais auxiliam a detectar e eliminar possíveis ocorrências de falhas e fornecem uma hierarquia de prioridades para as ações. A responsabilidade pela condução de um estudo de FTA deve ser delegada a um indivíduo, mas o estudo em si deve ser feito por uma equipe.

A aplicação da FTA nas fases iniciais do projeto de terceirização do gerenciamento de projetos permite que eventuais mudanças 
sejam implementadas com maior facilidade, bloqueando crises futuras. Além disso, os estudos da FTA reduzem a possibilidade de implementar alterações que venham a criar problemas no futuro. Idealmente, os estudos de FTA têm uma natureza cíclica, acompanhando as atividades de melhoria contínua de produtos e processos (FOGLIATTO, 2011).

Todo o esforço da FTA terá pouco valor se as ações planejadas não forem efetuadas. É responsabilidade de todos os participantes da equipe fornecerem o acompanhamento necessário à concretização das ações planejadas. As ações de correção e melhoria podem contemplar a revisão do desenho de partes do projeto, revisão de especificações de materiais, revisão dos procedimentos de manufatura e montagem, a incorporação de novos procedimentos, a incorporação de novos controles, o uso de tecnologias alternativas, a intensificação das atividades de manutenção preventiva ou preditiva etc. (FOGLIATTO, 2011). A Figura 5 é uma foto ilustrativa da planta de lubrificantes da empresa EPTO lubrificantes.

Figura 5: Foto ilustrativa da planta de lubrificantes da empresa EPTO Lubrificantes.

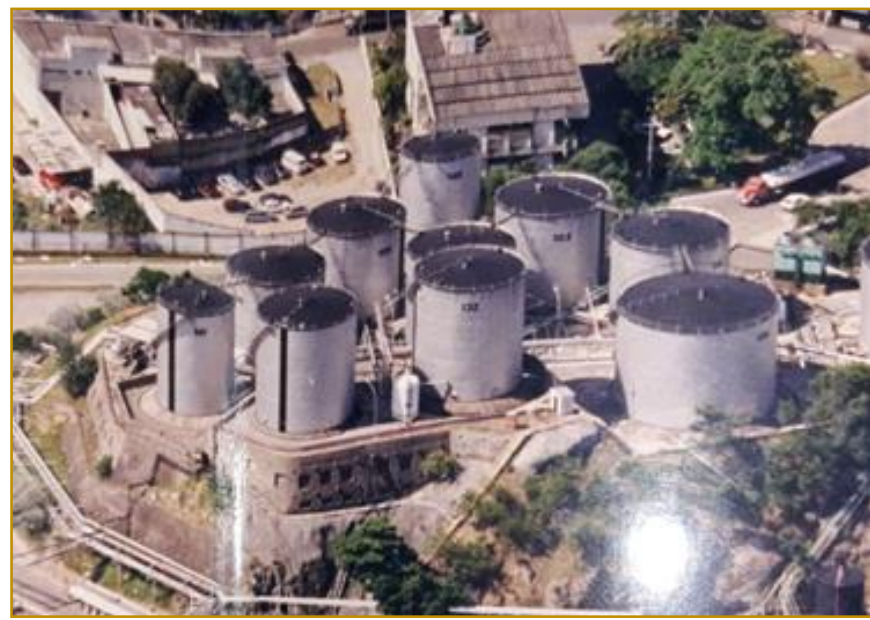

Fonte: Os autores (2018).

\section{DISCUSSÕES E RESULTADOS}

\subsection{DEFINIÇÃO DO GERENCIAMENTO DE PROJETOS DA EMPRESA DE LUBRIFICANTES}

Para o gerenciamento de projetos foi utilizada a aplicação de ferramentas e técnicas para atender aos seus requisitos, de acordo com os cinco processos: iniciação, planejamento, execução, monitoramento e controle, encerramento.

\subsubsection{INICIAÇÃO}

Selecionar o gerente de projetos; determinar a cultura e os sistemas existentes da empresa; reunir processos, procedimentos e informações históricas; dividir projetos grandes em fases; compreender o caso de negócios; identificar requisitos, premissas, riscos e restrições iniciais, além dos acordos existentes; avaliar a viabilidade dos projetos e de produtos com as restrições determinadas; criar objetivos mensuráveis; desenvolver o termo de abertura do projeto; identificar as partes interessadas e determinar suas expectativas, influência e impacto.

\subsubsection{PLANEJAMENTO}

Determinar como você vai planejar para cada área de atuação; determinar requisitos detalhados; criar a declaração de escopo do projeto; determinar o que adquirir e preparar documentos de aquisição; determinar a equipe de planejamento; criar a EAP e o dicionário da EAP; criar a lista de atividades; criar o diagrama de rede; estimar o requisito de recursos; estimar o tempo e os custos; determinar o caminho crítico; desenvolver o cronograma; desenvolver o orçamento; determinar padrões, processos e métricas da qualidade; criar o plano de melhoria de processos; determinar todos os papéis e responsabilidades; planejar as comunicações e engajamento das partes interessadas; voltar - iterações; finalizar os documentos de aquisição; criar o plano de gerenciamento de 
mudanças; concluir a parte de "como executar e controlar" de todos os planos de gerenciamento; desenvolver uma linha de base de desempenho e um plano de GP realista e final; obter a aprovação formal do plano; organizar uma reunião de partida (kickoff).

\subsubsection{EXECUÇÃO}

Executar o trabalho de acordo com o plano do GP(gerenciamento do projeto); produzir as entregas do produto (escopo do produto); reunir dados de desempenho do trabalho (NBR 13533, 1995). Solicitar mudanças; implementar somente as mudanças aprovadas; melhorar continuamente; seguir os processos; determinar se os processos estão corretos e são eficazes (garantia da qualidade); mobilizar a equipe final; gerenciar pessoas; avaliar o desempenho individual e de equipe; realizar atividades de desenvolvimento da equipe; oferecer reconhecimento e recompensa; usar registro de questões; facilitar a resolução de conflitos; liberar recursos conforme o trabalho for terminando; enviar e receber informações e solicitar feedback, reportar o desempenho do projeto; gerenciar o engajamento e a expectativa das partes interessadas; realizar reuniões; selecionar fornecedores.

\subsubsection{MONITORAMENTO E CONTROLE}

Tomar medidas para controlar o projeto; medir o desempenho pela linha de base; medir o desempenho por outras métricas do plano de GP; analisar e avaliar o desempenho; determinar se as variações requerem ações corretivas ou outra solicitação de mudanças; influenciar os fatores que causam mudanças; solicitar mudanças; realizar o controle integrado de mudanças; aprovar ou rejeitar mudanças; atualizar o plano do GP e os documentos do projeto; informar as partes interessadas sobre os resultados de solicitações de mudança; monitorar o engajamento das partes interessadas; gerenciar a configuração; criar as previsões; obter o aceite do cliente de entregas parciais; realizar o controle da qualidade; realizar as reavaliações e auditorias de risco; gerenciar as reservas; controlar as aquisições.

\subsubsection{ENCERRAMENTO}

Confirmar que o trabalho é realizado de acordo com os requisitos; terminar 0 encerramento das aquisições; obter a aceitação final do produto; terminar o encerramento financeiro; entregar o produto completo; solicitar feedback do cliente sobre o projeto; concluir relatórios finais de desempenho; registros de índices e acervo; coletar as lições aprendidas finais e atualizar a base de conhecimento.

\subsection{ESTRUTURA ANALÍTICA DE PROJETOS (EAP)}

A Estrutura Analítica de Projetos foi definida em 5 fases para performance da empresa. A EAP é a representação gráfica da decomposição do projeto em suas partes constituintes

\subsubsection{DEFINIÇÃO E CLASSIFICAÇÃO DOS CUSTOS DE MANUTENÇÃO QUE ENTRARIAM NO FUTURO ESCOPO - FASE 1}

- Convite feito à empresa de manutenção CEMAN, e aceito por esta empresa, com a missão de levantar os custos de manutenção reais da EPTO Lubrificantes;

- Entrevistas de pré-requisitos com as diversas áreas;

- $\quad$ Apresentação e definição dos custos finais às Partes Interessadas;

- Obter autorização formal por escrito do setor de auditoria corporativa sobre o material levantado a quatro mãos com a CEMAN que seria objeto do trabalho e escopo para o setor de aquisições e contratações licitar e contratar o fornecedor;

- Fim da Fase 1.

\subsubsection{DEFINIÇÃO DE ESCOPO E NÃO ESCOPO - FASE 2}

- $\quad$ Apresentar definições de escopo para as diversas partes interessadas e obter o aceite final para prosseguir com as próximas fases;

- $\quad$ Fim da Fase 2 


\subsubsection{ESCOLHA DE FORNECEDORES - FASE 3 \\ Escolha dos melhores fornecedores da época;}

- Visita a três contratos de cada fornecedor em andamento ou encerrado, e entrevista com os clientes destes fornecedores de forma a obter feedback sobre os contratos destas empresas com os futuros fornecedores possíveis da EPTO;

- Definição dos fornecedores que participariam da concorrência/licitação e envio da relação final dos fornecedores e justificativa ao setor de aquisições;

- Fim da Fase 3.

\subsubsection{LICITAÇÃO E COMITÊ DE CONTRATAÇÃO - FASE 4}

- Escrever e enviar solicitação do escopo final para que o setor de aquisições e contratações possa realizar o processo de licitação e contratação;

- Determinar junto com o setor de aquisições os critérios da contratação para análise do comitê;

- Reunião do Comitê de Contratação e definição do fornecedor ganhador;

- Assinatura do contrato de serviços com a CEMAN, a empresa ganhadora;

- $\quad$ Fim da Fase 4.

\subsubsection{DESLIGAMENTO DAS PESSOAS DA EMPRESA EPTO E ADMISSÃO NA EMPRESA CEMAN E START-UP DA EXECUÇÃO DO PROJETO - FASE 5}

- Reuniões da empresa CEMAN com as diversas partes interessadas da empresa EPTO para alinhar as fases de implementação nas diversas áreas da planta (passagem de serviço);

- Início efetivo dos trabalhos da CEMAN;

- Determinar as lições aprendidas, compartilhar as lições aprendidas com todas as partes interessadas e fechar toda a documentação de encerramento do projeto;

- $\quad$ Encerramento e FIM do projeto.

\section{CONCLUSÃO}

Uma das maiores missões deste projeto de terceirização é aplicar o aprendizado de outros contratos que não deram certo, pois não houve uma continuidade do projeto. Esse projeto de terceirização da empresa EPTO vive até hoje, com um escopo menor devido à demanda de produção, mas a empresa CEMAN, adquirida pela ABB Service, ainda está trabalhando na empresa EPTO Lubrificantes com bons índices de desempenho, e isto certamente é uma evidência objetiva que o caminho traçado foi o melhor possível.

Esse caminho traçado não poderia ter tido este sucesso continuado sem a aplicação de ferramentas de gestão de performance, e um deles, que se pode citar, é o programa de FTA que deve ser mantido pela direção de engenharia, que, periodicamente, deve verificar a pertinência das ações de correção e melhoria, na efetiva implantação destas ações, compartilhando sempre as lições aprendidas entre todos os envolvidos. Isso pode ser feito na forma de auditorias periódicas no programa, visando confirmar a sua eficácia.

Segundo Mulcahy et al. (2014), todo projeto precisa medir, medir e medir sempre seu desempenho. O grande pilar deste artigo de terceirização certamente foi a manutenção centrada na confiabilidade e nenhum trabalho desta natureza poderia ser realizado sem uma parceria forte entre contratante e contratada. Em nenhum momento se buscou o contrato de serviços assinado entre as partes, o sucesso do projeto foi construído no dia a dia.

A partir do processo de transição, contratante e contratada começaram a promover discussões em todos os níveis, buscando estratégias que se reforçaram em posturas de convivência mútua e que resultaram em fatores positivos para ambas as organizações. A empresa contratada promoveu vários treinamentos que tiveram a participação de ambas as empresas, contratada e contratante, de forma a agregar valor ao contrato e aumentar a produtividade. Esse projeto, como qualquer outro, precisa ser retroalimentado na busca incessante por medir a performance e resultados planejados e buscar muitas vezes outros indicadores que possam manter viva a chama do desempenho de excelência. 


\section{REFERÊNCIAS}

[1] Bastos, Paulo R. F. de Moura; Oliveira, Denise Freitas S. De. Redes Bayesianas: Aplicações em Confiabilidade e no Diagnóstico de Perdas não Técnicas, Appris Editora, 2017.

[2] Citisystems. Os 6 tipos de manutenção na indústria. Disponível em: <https://www.citisystems.com.br/tipos-manutencaoindustria/>, 2016. Acesso em 09/09/2018.

[3] Fogliatto, Flávio Sanson; Ribeiro, José Luis Duarte. Confiabilidade e Manutenção Industrial. Rio de Janeiro: Elsevier: Abepro, 2011.

[4] Jordán, Paúl Rodriguez. Processos de Confiabilidade na Indústria de Óleo e Gás, Interciência Editora, 2016.

[5] Lafraia, João Ricardo Barusso. Manual de Confiabilidade Mantenabilidade e Disponibilidade. Qualitymark Editora, 2001.

[6] Mitchell, R. K., Agle, B. R., Wood, D. J. Theory of Stakeholder Identification And Salience. The Academy of Management Review, 1997.

[7] Mulcahy, Rita; Brandt, Rose; Giotis Theofanis C.; Kirwin, Margo; Kusay, Ursula; Lofsness, Mary; Marans, Elaine, Nielsen, Jeffrey S.;
Yang Nah Wee; Mulcahy, Tim; Rudolf, Eric. Rita's Course in a Book@ para passar no Exame de PMP. Alinhado ao Guia Pmbok da $5^{\text {a }}$ Ed, Rmc Publications Inc, EUA, 2014.

[8] NBR 5462. Confiabilidade e mantenabilidade. Rio de Janeiro: ABNT Associação Brasileira de Normas Técnicas, 1994.

[9] NBR 9325. Confiabilidade de equipamentos - planos de ensaio de conformidade para taxa de falhas e tempo médio entre falhas admitindo-se taxa de falhas constantes. São Paulo: ABNT - Associação Brasileira de Normas Técnicas, 1986.

[10] NBR 13533. Coleta de dados de campo relativos à confiabilidade, mantenabilidade, disponibilidade e suporte a manutenção. Rio de Janeiro: ABNT - Associação Brasileira de Normas Técnicas, 1995.

[11] Pmbok. Guia do Conhecimento em Gerenciamento de Projetos (Guia PMBOK). Project Management Institute, 5a ed. Inc. 14 Campus Boulevard Newtown Square, Pensilvania, EUA, 2014. 


\section{Bapítulo 21}

PREVISÃO DE DEMANDA: APLICAÇÃO DA TÉCNICA DE AJUSTAMENTO EXPONENCIAL COM TENDENCIA EM UMA EMPRESA DE MONTAGEM DE EQUIPAMENTOS PARA BELEZA

\section{João Lucas Ferreira dos Santos}

Afonso José Lemos

Jessycka Brandão Santana

\section{Rony Peterson da Rocha}

Resumo: A utilização de métodos matemáticos para a previsão de demanda tem ganhado importância em várias empresas, uma vez que esses são fundamentais para à tomada de descisão em atividades da área de Planejamento e Controle da Produção (PCP), tais como: gestão da capacidade produtiva, planejamento agregado, planejamento mestre, programação da produção e gestão de estoques. Diante disso, o objetivo desse estudo foi de aplicar a técnica de ajustamento exponencial para tendência para a previsão de demanda de uma família de produtos de uma empresa de montagem de equipamentos para beleza. Os resultados da previsão de demanda foram obtidos para o primeiro semestre de 2017. Para a empresa em questão, destaca-se a importância da impregabibilidade das técnicas de previsões de demanda, visto que a maior parte da matéria prima da empresa é oriunda da China.

Palavra chave: PCP, estudo de caso, ajustamento exponencial com tendência. 


\section{INTRODUÇÃO}

O mundo dos negócios exige cada vez mais das empresas, fazendo com que o planejamento tenha um papel fundamental, principalmente em relação a função produção. O Planejamento e Controle da Produção (PCP), segundo a ABEPRO (2008), é uma importante subárea que contribui para o desenvolvimento dos negócios de uma empresa. Contudo, conforme Martins e Laugeni (2006) a realização de um bom planejamento depende muitas vezes de uma previsão de demanda.

A previsão de demanda é uma sequencia de passos lógicos como apresentado por Moreira (2011) que tem por objetivo buscar informações sobre valores relacionados a vendas futuras, de um produto ou um conjunto de produtos. Para realizar a previsão de demanda, Slack; Chambers e Johnston (2009) é necessário a utilização de alguma técnica, sendo que essas podem ser do tipo: quantitativo ou qualitativo.

As técnicas qualitativas levam em consideração a experiência ou conhecimento acumulado pelo especialista para predizer a probabilidade do resultado de eventos (REID; SANDERS, 2005).

As técnicas quantitativas são métodos estruturados que podem ser utilizados por outros analistas e as previsões obtidas são idênticas as originais. Esta técnica é dividida em séries temporais, correlações e regressões (métodos causais) (STEVENSON, 2001).

Lustosa et al., (2008) e Chase; Jacobs e Aquilano (2006) ressaltam a importância do nível de detalhamento da informação de demanda para tomada de decisões em diversas atividades da área de Planejamento e Controle da Produção (PCP). A previsão de demanda no nível estratégico impactará em decisões relacionadas ao Planejamento da Capacidade de Produção, no nível tático em informações que dizem respeito ao Programa Mestre de Produção (PMP) e o planejamento das necessidades dos materiais, por fim, no nível operacional em decisões referente a programação da produção e estoques.

Neste trabalho busca-se aplicar uma técnica quantitativa para a previsão de demanda de uma família de produtos de uma empresa do setor de beleza. O objetivo foi de aplicar a técnica de previsão a partir da análise do histórico de vendas da empresa, com o intuito de encontrar a previsão de demanda para o primeiro semestre de 2017.

Este estudo esta estruturado da seguinte forma: Introdução; fundamentação teórica; metodologia; estudo de caso; considerações finais e referencias.

\section{PREVISÃO DE DEMANDAS}

A previsão de demanda segundo Tubino (2000) é uma informação relevante na gestão de um sistema de produção, em especial para as funções desenvolvidas pelo Planejamento e Controle da Produção (PCP). Assim às demandas são do tipo dependente ou independente. Dependente para às demandas que dependem de outros produtos; ou independente para uma demanda que não pode ser obtida diretamente de outros produtos. Essa previsão é utilizada como um dado de entrada para decisões de planejamento, em relação aos horizontes de planejamentos, sendo eles: longo; médio e curto prazo (CHASE; JACOBS e AQUILANO, 2006).

As decisões de longo prazo em relação as informações de previsão de demanda são inversas as decisões de curto prazo, ou seja, elas envolvem segundo Slack; Chambers e Johnston (2009), maior volume de recursos, por este motivo devem ser tomadas com maior antecedência. Diante deste pressuposto, nota-se que as previsões de demanda são utilizadas em dois momentos. Segundo Tubino (2009) o primeiro momento refere-se: às previsões agregadas, já no segundo momento, refere-se a utilização das previsões desagregadas. Desta forma Martins e Laugeni (2006) afirmam que a demanda agregada é a quantidade de vendas para uma família de produtos que representam substancialmente um todo da amostra. Em relação as previsões desagregadas Lustosa et al., (2008) afirmam que são informações relacionadas a cada produto.

Em relação ao médio prazo, Tubino (2009) destaca que estes são estabelecidos de acordo com às necessidades de definir os recursos disponíveis como plano mestre de produção e programação da produção.

Para o curto prazo, Correa (2009) afirma que este tipo de decisão é de magnitude pequena, envolvendo baixos recursos. Em contra partida permitem alta flexibilidade do 
volume produzido como apresentado por Slack; Chambers e Johnston (2009).

Para se obter uma previsão de demanda é necessário compreender os modelos de previsões que serão determinados. A escolha desses modelos, como afirma Chopra e Meindl (2003) é apenas um componente de uma abordagem ampla de passos à ser seguido.

\subsection{ETAPAS PARA MODELAGEM DE PREVISÃO DE DEMANDA}

De acordo com Tubino (2009) a modelagem de previsão de demanda segue cinco etapas básicas: objetivo do modelo; coleta e análise de dados; seleção da temática de previsão; obtenção das previsões; e por fim, monitoração do modelo, tal como apresentado no quadro 1.

Quadro 1 : Etapas para Modelagem de Previsão de Demanda

\begin{tabular}{|l|l|}
\hline \multicolumn{1}{|c}{ Etapa } & \multicolumn{1}{c|}{ Descrição } \\
objetivo do modelo & $\begin{array}{l}\text { Essociada a necessidade da previsão, ou seja, de acordo com a finalidade deve ser } \\
\text { considerado seu nível de precisão, como, reposição de estoques ou previsão para } \\
\text { planejar a capacidade de uma nova linha de produção (LUSTOSA et al.,. 2008) }\end{array}$ \\
\hline $\begin{array}{l}\text { coleta e analise de } \\
\text { dados }\end{array}$ & $\begin{array}{l}\text { Deve-se coletar e analisar os dados históricos do produto, com o intuito de identificar e } \\
\text { desenvolver a técnica de previsão de demanda que melhor se adaptam (TUBINO, } \\
\text { 2009). }\end{array}$ \\
\hline $\begin{array}{l}\text { seleção da } \\
\text { temática de } \\
\text { previsão }\end{array}$ & $\begin{array}{l}\text { Levando em consideração o objetivo desejado com a previsão de demanda e } \\
\text { característica dos dados, deve-se escolher a técnica mais adequada a essas } \\
\text { necessidades. (LUSTOSA et al.,. 2008) }\end{array}$ \\
\hline $\begin{array}{l}\text { obtenção das } \\
\text { previsões }\end{array}$ & $\begin{array}{l}\text { A realização da previsão de demanda fornece dados sobre as demandas futuras, estes } \\
\text { dados devem ser posteriormente incorporados à rotina de planejamento e controle da } \\
\text { produção (LUSTOSA et al.,. 2008) }\end{array}$ \\
\hline $\begin{array}{l}\text { monitoração do } \\
\text { modelo }\end{array}$ & $\begin{array}{l}\text { a diferença entre as previsões e as vendas efetuadas deve ser monitorada, com isso, é } \\
\text { possível implementar melhorias a técnica de previsão de demanda aproximando cada } \\
\text { vez mais os números previstos da demanda real (TUBINO, 2009). }\end{array}$ \\
\hline
\end{tabular}

Fonte: Adaptado pelos Autores

A previsão de demanda pode ser compreendida como um processo metodológico para determinar dados futuros. Segundo Martins e Laugeni (2006) a previsão, poderá abordar os dados e trabalhá-los de duas formas distintas, sendo elas: métodos estatísticos ou subjetivos.

Os modelos de previsões de demanda em geral são definidos em dois grandes grupos: quantitativos (métodos estatísticos) e qualitativos (métodos subjetivos). O método quantitativo é empregado quando possui dados amostrais históricos de demandas. $\mathrm{O}$ método qualitativo é empregada quando o analista não dispõem de tempo para coletar e analisar os dados de demandas passadas. (SLACK, 2009; TUBINO, 2009; CORRÊA, 2009; BALLOU, 2001)

\subsection{MÉTODOS QUALITATIVOS DE PREVISÃO DE DEMANDA}

Os métodos qualitativos segundo Moreira (2003) são baseados no julgamento e na experiência de pessoas com experiência que possam emitir opiniões sobre eventos futuros de interesse. Alguns desses métodos são apresentados no Quadro 2. 
Quadro 2 : Métodos Qualitativos

\begin{tabular}{|c|c|}
\hline Categorias & Subgrupos e Definição \\
\hline Senso Comum & $\begin{array}{l}\text { "Obtêm-se uma previsão mediante à compilação de opiniões daqueles no final da } \\
\text { hierarquia que lida com o que está sendo previsto" (CHASE; JACOBS e AQUILANO, 2006, } \\
\text { p.454); Além do apresentado, complementa-se, ..."o método procura capturar opiniões de } \\
\text { pequenos grupos sobre alguma variável que se pretende prever " (CORREA, 2009, } \\
\text { p.264). }\end{array}$ \\
\hline $\begin{array}{l}\text { Pesquisa de } \\
\text { Mercado }\end{array}$ & $\begin{array}{l}\text { "Propõe-se coletar dados de várias maneiras (pesquisas, entrevistas, e assim por diante) } \\
\text { para testar às hipóteses sobre o mercado" (CHASE; JACOBS e AQUILANO, 2006, p.454) ; } \\
\text { semelhante a esta afirmação, ..." pode-se recorrer ao método para avaliar o potencial } \\
\text { consumo de um determinado produto" (LUSTOSA et al., 2008, p.57) e (CORREA, 2009, } \\
\text { p.264). }\end{array}$ \\
\hline $\begin{array}{l}\text { Analogia } \\
\text { Histórica }\end{array}$ & $\begin{array}{l}\text { "Liga o que está sendo previsto a um item similar. É importante no planejamento de } \\
\text { produtos novos, onde uma previsão poderá ser obtida pelo uso da história de um produto } \\
\text { similar " (CHASE; JACOBS e AQUILANO, 2006, p.454); Além desta afirmação, ..." este } \\
\text { método também é utilizado para identificar a demanda de novos produtos" (CORREA, } \\
\text { 2009, p.264). }\end{array}$ \\
\hline Método Delphi & $\begin{array}{l}\text { "Grupos de especialistas respondem ao questionário. Um moderador compila os } \\
\text { resultados e formula um novo questionário que é submetido para o grupo" (CHASE; } \\
\text { JACOBS e AQUILANO, 2006, p.454); complementando esta afirmação...," é utilizado para } \\
\text { solução de problemas técnicos" (LUSTOSAet al., 2008, p.57) e (CORREA, 2009, p.264). }\end{array}$ \\
\hline
\end{tabular}

Fonte: Adaptado pelos Autores

Nota-se que estes métodos não se apoiam em nenhum modelo específico, embora possam ser conduzidos de maneira sistemática. São úteis na ausência de dados, até mesmo quando os dados não apresentam veracidade, ou quando pretende-se trabalhar com o lançamento de algum novo produto (CHOPRA e MEINDL, 2003).

\subsection{MÉTODOS QUANTITATIVOS DE PREVISÃO DE DEMANDA}

Observa-se que os métodos quantitativos são divididos em dois grandes grupos, como apresentado por Lustosa et al., (2008): i) Projeção de Séries Temporais ou ii) Correlação e Regressão (modelo causal). O quadro 3 apresenta um esboço sobre estes métodos.

Quadro 3 - Métodos Quantitativos para Modelos de Series Temporais e Correlação e Regressão

\begin{tabular}{|c|c|c|}
\hline \multicolumn{3}{|l|}{ Modelo } \\
\hline \multirow{3}{*}{ Séries Temporais } & $\begin{array}{l}\text { Tentativa ou Solução } \\
\text { Simples }\end{array}$ & $\begin{array}{l}\text { "é o movimento gradual dos dados para cima ou para baixo ao longo do } \\
\text { tempo" (HEIZER e RENDER, 2001, p.106). Além desta colocação, ..." } \\
\text { Pondera-se um período de tempo contendo um número de ponto } \\
\text { dividindo a soma dos valores dos pontos pelo número de pontos } \\
\text { "(CHASE; JACOBS e AQUILANO, 2006, p.454). }\end{array}$ \\
\hline & Médias Móveis & $\begin{array}{l}\text { "Sazonalidade é um padrão de dados que se repete depois de um } \\
\text { período de dias, semanas, meses ou trimestres" (HEIZER e RENDER, } \\
2001 \text {, p.106). Neste mesmo sentido, ..." o método de média móvel } \\
\text { simples, cada demanda tem o mesmo peso a média, ou seja, cada } \\
\text { demanda histórica pode ter o seu próprio peso" (KRAJEWSKI; RITSMAN e } \\
\text { MALHOTRA, 2009, p.446). }\end{array}$ \\
\hline & $\begin{array}{l}\text { Suavização } \\
\text { Exponencial }\end{array}$ & $\begin{array}{l}\text { "Pontos recentes são ponderados mais com o peso, declinando } \\
\text { exponencialmente à medida que os dados se tornam mais antigos" } \\
\text { (CHASE; JACOBS e AQUILANO, 2006, p.454). Complementando, ..." } \\
\text { Ciclos são padrões entre os dados que ocorrem a cada alguns anos. Eles } \\
\text { costumam ser vinculados aos ciclos de negócios e são da maior } \\
\text { importância na análise e no ciclos de negócios a curto prazo" (HEIZER e } \\
\text { RENDER, 2001, p.106) }\end{array}$ \\
\hline \multicolumn{2}{|c|}{ Correlação e Regressão(modelo causal) } & $\begin{array}{l}\text { "É um dos modelos causais mais conhecidos e utilizados, que consiste } \\
\text { em uma variável dependente esta relacionada a uma ou mais variável por } \\
\text { uma equação linear" (KRAJEWSKI; RITSMAN e MALHOTRA, 2009, } \\
\text { p.448). Complementando, ..." A regressão é útil para a previsão de longo } \\
\text { prazo das principais ocorrências e planejamento agregado" (CHASE; } \\
\text { JACOBS e AQUILANO, 2006, p.467). }\end{array}$ \\
\hline
\end{tabular}

Fonte: Adaptado pelos Autores 
Os métodos do tipo séries temporais, utilizam um conjunto de valores ao longo de um período. Segundo Gaither e Fraizer (2006) esses métodos têm como objetivos definir valores futuros baseados em históricos passados. Os modelos de correlação e regressão buscam como apresentado por Tubino (2009) prever as demandas com base em previsão de outra variável que esteja interligada com o produto em análise.

\subsection{COMPORTAMENTO GRÁFICO DO HISTÓRICO DE VENDAS (OU DAS DEMANDAS)}

O comportamento da demanda de um determinado produto pode ser caracterizado como demanda pontual ou demanda repetitiva. A demanda pontual é quando ocorre de forma concentrada ou apenas uma vez, e posteriormente diminui drasticamente. Para este tipo de demanda, a previsão possui dificuldades no sentindo da falta de histórico em demandas confiáveis (LUSTOSA et al., 2008).

Para os produtos que possuem demanda repetitiva, nota-se que existe uma subdivisão em dois grupos, a demanda repetitiva e a demanda independente. A demanda com característica dependente é previsível, pois esta associada a fatores conhecidos. $\mathrm{Na}$ figura 1 tem a representação dos gráficos que cada demanda forma ao longo de um ciclo (SLACK 2009; TUBINO 2009; CORRÊA 2009).

Figura 1- Comportamentos gráficos dos padrões de demandas.

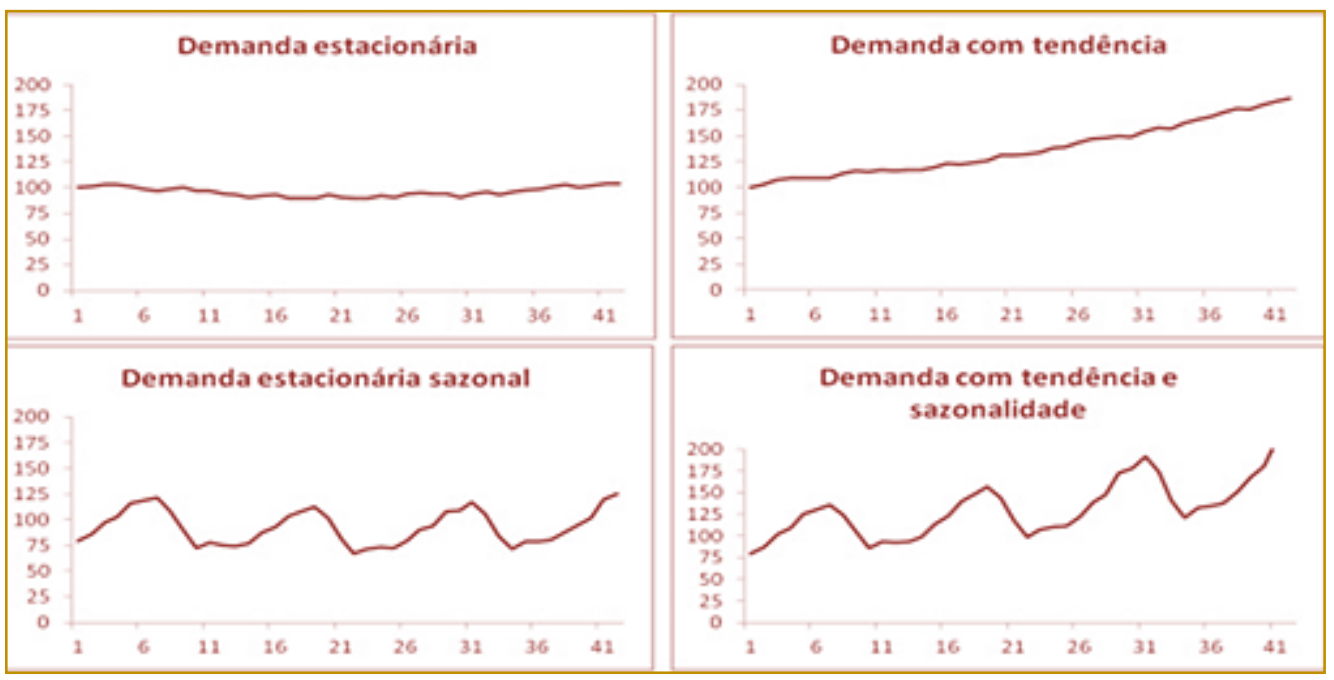

Fonte: adaptado de Lustosa et al., (2008)

Para os produtos que possuem demandas independentes pode-se observar que eles se dividem entre demanda estacionária e com tendência como apresentado na figura 1 , primeira e constante com pequenas variações. A demanda com tendência são as que possuem crescimento ou declínio nas vendas. Outra característica é a sazonalidade, que representa às variações que são regulares ao longo de um período (LUSTOSA, et al., 2008).

A escolha do método por meio do gráfico como ilustrado na Figura 1, pode ser observado que as demandas estacionárias e demandas com tendências indicam a direção ao longo da distancia da série, incluindo qualquer quantidade constante de demanda nos dados. Para a variação sazonal nota-se flutuações regulares que se repetem em períodos, mensal ou semanal (RITZMAN e KRAJEWSKI, 2004).

\section{METODOLOGIA}

A pesquisa se classifica quanto aos resultados como aplicada, quanto aos fins, como, descritiva e explicativa; se enquadra na abordagem de pesquisa como qualiquantitativo em função das descrições dos métodos e processos; quantitativa quanto às quantidades vendidas e as demandas. Em relação às coletas de dados se enquadra, como, bibliográfica, documental e estudo de caso (VERGARA, 2013). 
A coleta de dados foi realizada por meio de visitas. Coletou-se informações sobre o histórico de vendas de uma família de produtos, referente aos exercícios do ano de: 2014; 2015; 2016 e; primeiro semestre de 2017.

O método de pesquisa utilizado foi o qualiquantitativo. Para escolha da técnica de previsão, foi utilizado o Excel 2003 para manipulação dos dados referentes aos anos coletados, posteriormente observou-se o comportamento destes históricos de vendas ao longo destes anos. A partir do comportamento gráfico do histórico de vendas foi possível determinar as características que auxiliaram na escolha, como por exemplo: o declínio das vendas ao longo do tempo, ou seja, foi possível observar uma tendência. Desta forma, determinou-se o método do ajustamento exponencial.

Para os cálculos do método de ajustamento exponencial por tendência utilizou-se às equações (1); (2) e (3) segundo (TUBINO, 2009):

$$
P_{t+1}=M_{t}+T_{t}
$$

Sendo que $M_{t}$ e $T_{t}$ são obtidos pelas equações (2) e (3) respectivamente.

$$
\begin{aligned}
& M_{t}=P_{t}+\alpha_{1}\left(D_{t}-P_{t}\right) \\
& T_{t}=T_{t-1}+\alpha_{2}\left(\left(P_{t}-P_{t-1}\right)-T_{t-1}\right)
\end{aligned}
$$

Onde: $\mathrm{P}_{\mathrm{t}+1}$ : previsão da demanda para $\mathrm{O}$ período $t_{+1} ; P_{t}$ : Previsão da demanda para $o$ período t; $\mathrm{P}_{\mathrm{t}-1}$ : Previsão de demanda para o período $t_{-1} ; M_{t}$ : Previsão média exponencial móvel da demanda para o período $t ; T_{t}$ : Previsão da Tendência para o período $t ; T_{t-1}$ : Previsão da Tendência para o período $t_{-1} ; \alpha_{1}$ : coeficiente de ponderação da média; $\alpha_{2}$ : coeficiente de ponderação da tendência; $D_{t}$ : Demanda do período t.

Para determinar a relação entre o valor da demanda real e a demanda prevista, calculou-se o erro entre às mesmas.
A ferramenta solver do software Microsoft Exce/ foi utilizada para determinar o valor ideal para os coeficientes de ponderação sujeito a $0 \leq \alpha_{1} \leq 1$ e $0 \leq \alpha_{2} \leq 1$, assim determinou-se uma função objetivo para o menor desvio médio absoluto ou MAD (Mean Absolute Deviation). O MAD é a média da somatória da diferença da demanda real pela demanda prevista em módulo, que foi otimizada utilizando o método de solução de regressão não linear. Otimizou-se estes valores dos coeficientes e, determinou-se o menor MAD, como pode ser apresentada à seguir:

$$
\operatorname{Min} M A D=\frac{\sum\left|D_{a t u a l}-P_{t}\right|}{n}
$$

Em que:

$$
\begin{aligned}
& D_{\text {atual }} \text { : é a demanda real para o período } \\
& P_{t}: \text { é ademanda prevista para o período } \\
& \mathrm{t}=\text { períodos e } n \text { é o numero de períodos. }
\end{aligned}
$$


A empresa objeto de estudo localizada na mesorregião centro ocidental do Paraná, possui um mix de produtos compostos por três famílias, sendo elas: Prancha Alisadora; Maquina de Corte e Secador de Cabelo. Atualmente a família de prancha alisadora representa maior número de vendas correspondentes a cerca de 50\% dos produtos comercializados pela empresa. Neste estudo optou-se por realizar a previsão de demanda para a família de produtos prancha alisadora pois, esta representa maior número de vendas.

\section{ESTUDO DE CASO}

A empresa de estudo, esta inserida no setor de produtos eletroeletrônicos com foco na produção de equipamentos para salão de beleza e também para uso domestico. O mix de produtos da empresa é divido em três famílias, são elas, pranchas alisadoras, máquinas de corte de cabelo e secadores de cabelo.
Não há na empresa um departamento de PCP formalizado. As funções do PCP são divididas entres os departamentos de compras e produção, É de responsabilidade do departamento de compras a manutenção dos estoques e a emissão das ordens de serviço. A empresa realiza a previsão de demanda de forma qualitativa, utilizando a experiência dos colaboradores e sua intuição.

A previsão de demanda foi aplicada apenas na família de produtos das pranchas de cabelo. Eesta família foi escolhida por representar 0 principal produto comercializado pela empresa, correspondendo aproximadamente 53\% dos produtos comercializados no período entre os anos de 2014, 2015 e 2016.

A partir dos dados fornecidos pela empresa referente as vendas mensais das pranchas no período de 2014 a 2016, foi gerado um gráfico utilizando o software Microsoft Excel. Este gráfico é apresentado na figura 2.

Figura 2: Gráfico de vendas das pranchas, mês a mês, no intervalo de Janeiro de 2014 a Dezembro de 2016.

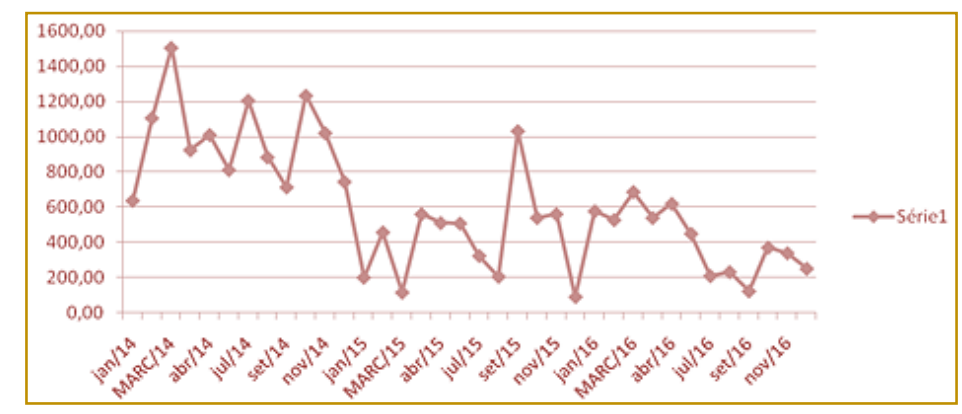

Para o ano 2014 observa-se que as vendas são maiores em relação ao ano de 2016 e 2015. O período de 2015 apresenta-se como intermediário em relação aos outros dois anos. Nota-se que o fator econômico, sobre tudo as oscilações no dólar corroboraram substancialmente para o declínio das vendas dos produtos da empresa, pois a matéria prima utilizada para a montagem dos produtos é importada da China.

Com a abertura de uma filial da empresa estudada na zona franca de Manaus, a produção dos itens foi dividida entre as duas linhas de montagem. Desta forma as vendas caíram como apresenta a figura 2. Com isso optou-se por utilizar a técnica de previsão mais de ajustamento exponencial com tendência.

Para calcular as demandas do primeiro semestre de 2017 foram utilizadas às equações (1), (2) e (3) apresentadas anteriormente na metodologia. Os cálculos foram feitos individualmente para cada mês. Um esboço desses cálculos é apresentado para Janeiro de 2017 no quadro 4. 
Quadro 4 - Esboço do cálculo de ajustamento por tendência

\begin{tabular}{|c|c|}
\hline$M_{t}=P_{t}+\alpha_{1}\left(D_{t}-P_{t}\right)$ & $T_{t}=T_{t-1}+\alpha_{2}\left(\left(P_{t-} P_{t-1}\right)-T_{t-1}\right)$ \\
\hline $\begin{array}{c}M_{t}=271,33+0,515008 *(251-271,33) \\
M_{t}=271,33+0,515008 *(-20,33) \\
M_{t}=271,33+(-10,47) \\
M_{t}=260,86\end{array}$ & $\begin{array}{c}T_{t}=-30,9868+0,321425 *((241,4-271,33)- \\
(-30,9868)) \quad T_{t}=-30,65\end{array}$ \\
\hline \multicolumn{2}{|c|}{$P_{t+1}=M_{t}+T_{t}$} \\
\hline \multicolumn{2}{|c|}{$\begin{array}{c}P_{t+1}=260,86+(-30,65) \\
P_{t+1}=230,21\end{array}$} \\
\hline
\end{tabular}

Pela possibilidade de utilização de dados de vendas reais da empresa, para o primeiro semestre de 2017, foi gerada a previsão utilizando-se do software Microsoft Exce/ para plotar os dados, e a ferramenta solver para encontrar o valor de $\alpha_{1}$ (coeficiente de ponderação da média) e $\alpha_{2}$ (coeficiente de ponderação da tendência), que gerassem o menor erro possível, assim otimizando os valores para estes coeficientes.
Com a utilização do solver foi possível encontrar os valores de $\alpha_{1}$ e $\alpha_{2}$ com menor erro para a previsão de demanda do período entre março de 2014 e dezembro de 2016. Com isso, foi indicado $\alpha_{1}=0,515008$ e $\alpha_{2}=$ 0,321425 . O desenvolvimento dos cálculos do MAD para o período entre março de 2014 e dezembro de 2016 é apresentado utilizando a equação 4.

$$
\begin{gathered}
M A D=\frac{\sum\left|D_{\text {atual }}-P_{t}\right|}{n}(4) \\
M A D=\frac{\sum|18592-23807,55|}{32} \\
M A D=163
\end{gathered}
$$

Os dados obtido pelas previsões para o primeiro semestre de 2017 e o erro em relação a demanda real são apresentados na tabela 1.

Tabela 1 : Demandas Reais e Previstas

\begin{tabular}{|l|c|c|c|}
\multicolumn{1}{|c|}{ Período } & Demanda Real & Demanda Prevista & Erro \\
\hline Janeiro 2017 & 1266 & 242 & 1024 \\
\hline Fevereiro 2017 & 918 & 766 & 152 \\
\hline Março 2017 & 1268 & 1201 & 67 \\
\hline Abril 2017 & 1962 & 1527 & 435 \\
\hline Maio 2017 & 1874 & 2016 & 242 \\
\hline Junho 2017 & 2448 & 2205 & 243 \\
\hline
\end{tabular}

O método de previsão empregado neste estudo é voltado para o horizonte de planejamento de curto prazo, tendo em vista que gera previsões para o mês seguinte. Previsão de curto prazo torna-se interessante para a empresa, pois, possibilita uma capacidade rápida de resposta em relação ao método utilizado, logo, se às previsões feitas forem imprecisas, ou seja com um maior Erro, - programador poderá tomar medidas imediatamente calibrando a técnica de previsão, aumentando assim sua precisão e diminuindo os prejuízos. A figura 3 apresenta os valores das demandas previstas, das demandas reais e do erro. 
Figura 3: Gráfico de linhas, representando Demanda atual (P. atual), a previsão para o período (Pt) e o erro.

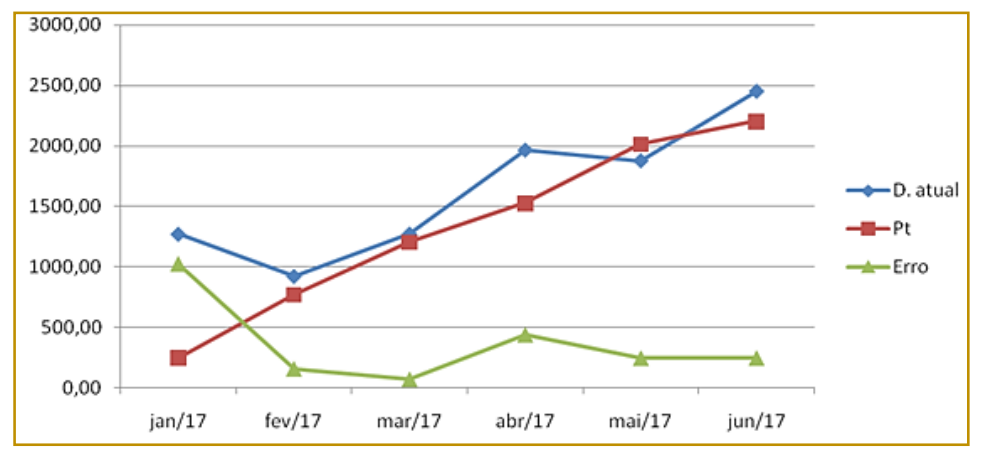

Partir das previsões reais e previstas foi possível compará-las, como ilustra a Figura 3. É possível observar, que a previsão de demanda para Janeiro de 2017 é a com menor precisão, portanto maior erro, isso ocorre em função dos recessos de fim de ano e da necessidade de suprir em janeiro as datas de dezembro em que não houve produção. Observa-se também, que a partir de fevereiro de 2017 as previsões, e as demandas reais apresentam tendência de crescimento, enquanto o erro se mantém contínuo, com isso, o método de previsão mostra-se estável, gerando valores próximos as demandas reais.

\section{CONSIDERAÇÕES FINAIS}

O artigo apresentou a previsão de demanda agregada de um dentre o mix de produtos de uma empresa. Essa previsão é uma variável importantíssima, porque contribui para uma melhor projeção do futuro, respondendo questões como: quanto comprar de matéria

\section{REFERÊNCIAS}

[1] Abepro. Associação Brasileira de Engenharia de Produção.Áreas e Subáreas da Engenharia de Produção. Disponível em:<http://www.abepro.org.br/internasub.asp?ss=2 $7 \& c=846>$. Acesso 18 de junho de 2017.

[2] Ballou, R, H.: Gerenciamento da cadeia de suprimentos: planejamento, organização e logística empresarial. 4. Ed. Porto Alegre: Bookman, 2001.

[3] Basseto,C.L.A; BORGES, R; Vincenzi, L.S.: Previsão de demanda em uma empresa de produção de peças para implementos agrícolas. $V$ Congresso brasileiro de Engenharia de Produção (CONBEPRO). Ponta Grossa, PR, Brasil.2015.

[4] Chase, R.B; Jacobs, R.F; Aquilano, N.T.: Administração da Produção para a vantagem competitiva. 10ed.Porto Alegre: Bookman, 2006. prima e; quanto poderá ser vendido de um produto.

Com esse estudo foi possível prever a demanda para o primeiro semestre de 2017 e posteriormente compara-la com os resultados fornecidos pela organização. Desta forma sugere-se que os responsáveis por essa atividade busquem trabalharem com ferramentas matemáticas de previsão de demandas.

Após a determinação dos métodos a serem utilizados é fundamental que sejam realizados um monitoramento do mesmo, de forma a mensurar a eficiência do método empregado. O mesmo procedimento deve ser realizado para os demais produtos da empresa. Também cabe ressaltar que essas previsões são fundamentais para a empresa em questão, uma vez que boa parte da sua cadeia de suprimentos é oriunda do mercado internacional, especialmente da China.

[5] Chopra, S.; e Meindl, P.: Gerenciamento da Cadeia de Suprimentos: estratégia, planejamento e operações. São Paulo: Prentice Hall, 2003.

[6] Consul, F, B.; e Werner, L.: Avaliação de técnicas de previsão de demandas utilizadas por um software de gerenciamento de estoques no setor farmacêutico. XXX Encontro Nacional de Engenharia de Produção (Enegep). São Paulo, SP.2010. Disponível em:< http://www.abepro.org.br/biblioteca/enegep2010_tn _sto_113_740_15746.pdf\%3C>. Acesso em 15 de junho de 2017.

[7] Corrêa, H. L., Corrêa,C.A.: Administração de produção e operações: manufatura e serviços: uma abordagem estratégica. Atlas, 2009.

[8] Gaither, N; Frazier, G.: Administração da produção e Operações. São Paulo. Pioneira. 2001. 
[9] Heizer, Jay; Render, Barry.: Administração de Operações: Bens e Serviços. $5^{\underline{a}}$ edição, Rio de Janeiro: LTC, 2001

[10] Krajewski, L.; Ritzman, L.; Malhotra, M.: Administração de produção e operações. 8. ed. São Paulo: Pearson, 2009.

[11] Lustosa, L.J.; Mesquita, M.A.; Quelhas, O. L. G.; Oliveiras, R.J.: Planejamento e controle da produção. Rio de Janeiro: Elsevier, 2008.

[12] Martins; Laugeni.: Administração da Produção. São Paulo . Saraiva. 2006.

[13] Medeiros, B.S.F; e Bianchi, C. R.: A aplicação do método regressão linear simples na demanda de produtos sazonais: um estudo de caso. Disciplinar um Scientia. Serie: Ciências Sociais Aplicadas. V.5, n.1, p.35-53,2009.
[14] Moreira, D.A.: Administração da Produção e Operações. 2ed.São Paulo: Cengage Learning, 2011.

[15] Ritzman, L; Krajewski, L. J.:Administração da produção e operações. São Paulo. Prentice Hall. 2004.

[16] Slack,N. Administração da produção. 3.ed.São Paulo: Atlas, 2009.

[17] Tubino, D. F.: Manual de Planejamento e Controle da Produção.2 Ed. São Paulo: Atlas, 2000.

[18] Tubino, D.F.: Planejamento e controle da produção. São Paulo: Atlas,2009.

[19] Vergara, S.C.: Projeto e relatórios de pesquisa em administração. São Paulo, Editora, 2003. 


\section{Gapítulo 22}

\section{UTILIZACÃO DE FERRAMENTAS DA QUALIDADE NO PROCESSO PRODUTIVO DA CASA DAS FRALDAS DE CAMPO MOURÃO/PR PARA A IDENTIFICAÇÃO DE POSSIVEIS MELHORIAS}

Francisco Costa Machado Neto

\section{Igor de Prince}

Matheus Felipe Pires

Gustavo Henrique Marques

Rubya Vieira de Mello Campos

Resumo: As ferramentas da qualidade são importantes instrumentos para o auxílio no controle da qualidade e na identificação e análise de problemas, bem como,para o planejamento e implementação de uma solução de melhorias nas empresas. O objetivo desse estudofoi identificar possíveis gargalos no processo produtivo de fraldas na Casa das Fraldas São José de Campo Mourão e apresentar a análise esugestões de melhorias no ambiente produtivo. Esta pesquisa classificase como descritiva, onde, para seu desenvolvimento,foi utilizada uma abordagem qualitativa e quantitativa, assim como também foi realizado uma revisão de literatura e um estudo de caso.Para organização dos dados e informações, foram utilizadas as ferramentas Diagrama de Ishikawa, Brainstorming e $5 \mathrm{~W} 1 \mathrm{H}$. Os resultados obtidosforam satisfatórios, sendo possível identificar possíveis pontos de melhoria na produção e qualidade. Assim, acredita-se que a implantação das ideias sugeridas nesse estudo, poderão facilitar os procedimentos de fabricação e padronização de fraldas, além de melhorar a qualidade dos processos e consequentemente do produto final.

Palavras chave: Produtividade; Qualidade; Melhoria; Ferramentas

* Artigo apresentado no XI Encontro Nacional de Engenharia de Produção Agroindustrial 


\section{INTRODUÇÃO}

A melhoria de desempenho das atividades e a produtividade possuem impacto significativo nas organizações, o que faz com que empresas as busquem constantemente. Conforme Slack et al (2009) todos os procedimentos, mesmo quando bem planejados e controlados, ainda podem ser melhorados.

Para Laugeni; Martins (2005), os índices de produtividade são baseados em alguns fatores, sejam estes, determinados pela empresa ou envolvidos na produção. O aumento da produtividade traz grandes benefícios para as organizações, como aumento nos lucros e diminuições de retrabalho.

Vidal (1997, apud ROTH, 2011, p.49) afirma que a organização do trabalho define a atividade a ser realizada, proporcionando maneiras e padrões de procedimentos da produção. Para Laugeni; Martins (2005), os padrões podem ser modificados e aperfeiçoados a fim de elevar seu rendimento, trazendo otimização na qualidade e no tempo em que as atividades são realizadas. Tais mudanças podem ser aplicadas por meio de ferramentas de qualidade, como a melhoria contínua, entre outros.

As ferramentas de qualidade são importantes instrumentos para o auxílio no controle da qualidade e na identificação e análise de problemas, bem como o planejamento e implementação de uma solução (PEINADO; GRAEMI, 2007).

Slack et al (2009) ainda afirmam que produtos e serviços produzidos com qualidade são consideravelmente vantajosos para as organizações, fazendo com que esse fator seja de grande preocupação por parte destas, isto é, quanto mais atributos de qualidade um produto ou serviço apresentar, maior será sua aceitação. A preocupação em manter a qualidade aumenta à medida que a produção cresce, o que gera a necessidade e mostra a importância de sempre melhorar a forma como os produtos e serviços são produzidos.

O objetivo desse estudo consiste em identificar possíveis gargalos erealizar uma análise do ambiente produtivoe apresentação de sugestões de melhoriasem uma organização de cunho voluntário, localizada na cidade de Campo Mourão/PR, utilizando conceitos existentes para melhoria de processos com o auxílio de determinadas ferramentas de qualidade.

Vale destacar que o estudo não apresenta uma crítica aos meios de produção adotados pela organização, e sim medidas e métodos simples e de fácil aplicação para auxiliar os voluntários, e colaborar com a melhoria da qualidade e produtividade.

\section{REFERENCIAL TEÓRICO}

\subsection{QUALIDADE}

O crescimento populacional no mundo e Revolução Industrial no século XVIII tornou a imagem do artesão quase obsoleta, dando origem a produção em massa, o que permitiu a redução nos preços,ocasionando o aumento na procura e então a necessidade de melhorar continuamente, recorrendo a métodos e processos de qualidade(SILVA, 2009).

Slack et al (2009) define o conceito de qualidade como "consistente conformidade com as expectativas dos consumidores", isto é, atender e garantir que o produto possua as especificações de fabricação e ainda satisfaça as necessidades e/ou exigências dos consumidores.

Acreditava-se em uma antiga e tradicional visão de controle de qualidade que, para obter uma mercadoria de maior qualidade, o custo era elevado, porém, atualmente essa perspectiva não prevalece mais. O conceito de que a qualidade impulsiona a produtividade, advinda dos fabricantes japoneses, determina que, se a produção for executada

corretamente desde o primeiro processo e o produto e/ou serviço vier sem defeito, os custos são reduzidos e o desperdício eliminado (GAITHER, N.; FRAZIER, G. 2001).

\subsection{PRODUTIVIDADE}

Segundo Sandroni (1999), o termo produtividade pode ser expressado como o uso eficiente dos recursos produtivos, afim de alcançar o máximo de produção com o menor quantidade de tempo e custos possíveis, ou seja, elevar o nível de produtividade é muito importante e benéfico para as empresas.

Conforme Gaither; Frazier (2002), quando se trabalha para diminuir as falhas de uma linha de produção a produtividade tende a 
melhorar. Como consequência, quanto maior a qualidade no produto e/ou serviço, menor é o custo, pois menos produtos são sucateados, menor é a quantidade de produtos devolvidos na garantia e a produção dificilmente é interrompida.Dessa forma, os programas de gerenciamento são considerados um meio de melhorar aprodutividade da empresa.

São muitos os fatores que são associados e que podem influenciar a produtividade de uma empresa, como a eficiência, qualidade, lucro e ambiente de trabalho. Torna-se de extrema importância para as organizações saber gerir e controlar esse fator que, por sua amplitude e eficácia, pode ser aplicado de diferentes formas (REGGIANI et al, 2005).

\subsection{CICLO PDCA}

Segundo Chiavenato (2009), o ciclo PDCA, também denominado ciclo da melhoria contínua, visa principalmente maximizar a eficiência, analisando todos os processos com o intuito de otimizar a forma como são realizados e focando na obtenção da excelência. Conforme Peinado; Graemi (2007), essa metodologia foi criada por WalterShewhart e popularizada por Edwards Deming, sendo uma sigla com inicias das palavras de origem inglesa plan (planejar), do (fazer), check (checar) e act(agir).

Para Fitzsimmons; Fitzsimmons (2014), verificar/inspecionar a qualidade é uma ação tardia, e que se deve focar nos processos. O PDCA é importante pela possibilidade de padronizar a solução e aprender o que deu certo e errado durante o ciclo. Para que isso ocorra usam-se muitas ferramentas que ajudam na análise dos dados na formulação para a tomada de decisão.
É muito difícil alcançar altos índices de qualidade ou implantar uma filosofia sem o uso de alguns instrumentos que orientem a identificação e a resolução dos problemas que podem surgir. Alguns especialistas afirmam que grande parte dos problemas podem ser analisados e resolvidos com o auxílio de ferramentas de qualidade(PEINADO; GRAEMI, 2007).

Mariani et al (2005) afirmam que para se conseguir dispensar o empirismo e controlar mais precisamente os processos qualitativos, utiliza-se instrumentos e técnicas eficazes, chamadas de ferramentas da qualidade. Segundo Corrêa; Corrêa (2004), existem 7 ferramentas básicas que podem ser usadas para auxiliar no encontro, entendimento e solução dos problemas que são: Fluxograma; Diagrama de Pareto; Diagrama de Ishikawa; Folhas de Verificação; Histograma; Diagrama de Dispersão; Controle Estatístico de Processo. Para Carpinetti (2010) existem outras ferramentas conhecidas como gerenciais e organizacionais, comoBrainstorming, $5 \mathrm{~W} 1 \mathrm{H}$, Diagramas de Processo, Matrizes entre outros.

\section{- Diagrama de Ishikawa}

O Diagrama de Ishikawa, também conhecido como diagrama espinha de peixe ou de causa e efeito, busca a partir dos sintomas dos problemas (efeitos) mensurar as todas probabilidades que motivam as suas causas, isto é, procura a causa inicial do efeito final (CHIAVENATO, 2009).O diagrama se mostra muito eficaz e permite o encontro da raiz do problema apresentado, sendo organizado e estrutura a base do chamada "seis M", onde são apontadas seis possíveis áreas onde possuem causas que levaram ao problema (PEINADO; GRAEMI, 2007).

Figura 1 - Diagrama de Ishikawa.

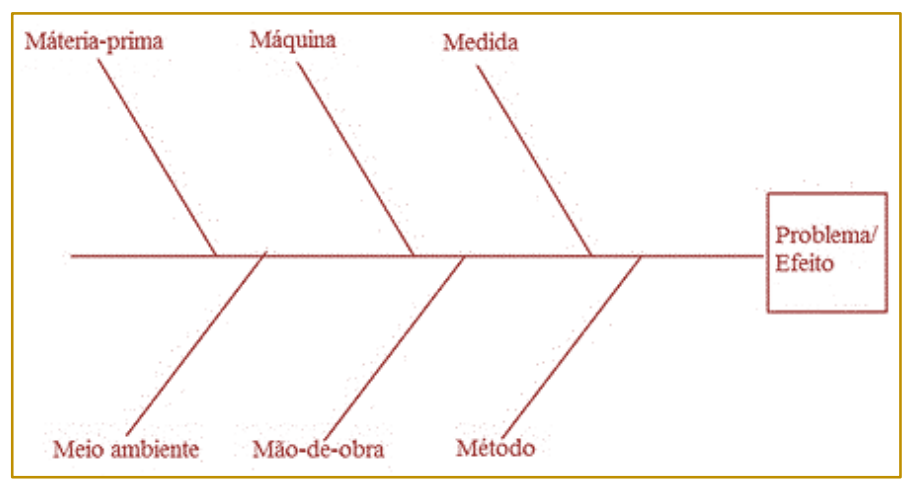

Fonte: Adaptado de Chiavenato (2009) 


\section{- Brainstorming}

O Brainstormingé uma técnica usada para gerar o maior número de ideias possíveis sobre determinado assunto em um espaço definido de tempo. Esse método consiste na reunião do grupo envolvido no assunto para, no tempo estimado, apresentar as ideias pensadas naquele momento, as quais são listadas conforme são produzidas. Todas as ideias não devem ser descartadas logo de cara, para que se incentive o fluxo de ideias. (PEINADO; GRAEMI, 2007)

\section{$5 \mathrm{~W} 1 \mathrm{H}$}

A ferramenta $5 \mathrm{~W} 1 \mathrm{H}$ tem esse nome devido a quantidade de palavras de origem inglesa com as inicias "W" e "H". Esse instrumento auxilia a execução de uma operação sem que haja dúvidas, já que estabelece qual tarefa será feita, por quem, quando, de que forma e o motivo que gerou a necessidade da tarefa (PEINADO; GRAEMI, 2007).

Segundo Laugeni; Martins (2005) a ferramenta $5 \mathrm{~W} 1 \mathrm{H}$ é um método conceitual, onde as vezes o foco não é melhorar, mas eliminar algum processo. Cada uma das iniciais possui um fundamento, que significa:

- What? (o que?): O que será feito para resolver o problema;

- Who? (quem?): Quem será designado para tentar resolver o problema;

- How? (como?): A forma/método como será executada a resolução;

- Where? (onde?): O local onde será executado;

- When? (quando?): O período/tempo em que será feito;

- Why? (por quê?): A razão/motivo de ser executado.

Esse método expressa-se em ponderar o problema, descrevê-lo em como ele afeta o processo, os trabalhadores e o que ele causa. O 5W1H torna-se parte de um plano de ação para implementar as soluções que forem definidas (AGUIAR, 2004).

\section{METODOLOGIA}

A Instituição em estudo foi a Casa das Fraldas São José, localizada no município de Campo Mourão, Paraná. O estudo em questão foi desenvolvido durante os meses de fevereiro a abril do ano de 2017 e teve como foco a análise do ambiente produtivo e a sugestão de melhorias.
Para a coleta das informações necessárias para o desenvolvimento do trabalho em questão foi realizada uma visita no ambiente, onde mediante uma pesquisa participante que, segundo Gil (2002), caracteriza-se pela interação entre pesquisadores e membros das situações investigadas, foi possível identificar alguns pontos de melhoria na produção, podendo assim, buscar alternativas para a redução das perdas e melhorias no processo produtivo, por meio da aplicação de ferramentas da qualidade.

A pesquisa adotou o método de abordagem qualitativa e quantitativa, pois além da atribuição de significados e interpretação dos fenômenos, também apresenta certos valores numéricos, e quanto aos fins classifica-se como descritivaem razão de descrever a importância do processo de melhoria contínua nas organizações, por intermédio de trabalhos já desenvolvidos que dão suporte para obter uma visão geral sobre o assunto. O estudo é de cunho bibliográfico e virtual, pois se baseia em livros, artigos científicos e sites especializados sobre o tema.

Quanto aos meios caracteriza-se como estudo de caso, pois se baseia na participação direta no processo produtivo da instituição juntamente com o levantamento de informações sobre melhoria contínua da qualidade e produtividade. Gil (2002) afirma que o estudo de caso consiste no estudo aprofundado de um oupoucos objetos, de maneira que permita seu amplo e detalhado conhecimento, tarefa que seria praticamente impossível mediante outros pontos de vistas de procedimentos técnicos.

\section{ESTUDO DE CASO}

A Casa das Fraldas São José de Campo Mourão surgiu a partir de um desafio quando Marta Kaiser, como exigência parcial para conclusão do trabalho de curso, propôs aos seus alunos do curso de Direito da Faculdade Integrado de Campo Mourão a tarefa de desenvolver uma atividade de responsabilidade social que atendesse a comunidade para o cumprimento de horas extracurriculares. No mês de maio de 2008 em uma sala cedida pela Associação Comercial e Industrial de Campo Mourão (ACICAM), com suporte financeiro inicial dos alunos, professores e empresários da cidade, teve início então a produção de fraldas. Foram produzidas um total de 20.830 fraldas, as 
quais foram entregues em lares de idosos e em um hospital da cidade (CASA DAS FRALDAS, 2017).

O resultado e repercussão obtidos por essa ação motivaram a diretora da Faculdade Integrado e o Presidente da ACICAM a proporem a produção de fraldas como uma ação permanente. No dia 13 de novembro de 2008 a Casa das Fraldas São José foi então inaugurada e a coordenação ficou por conta da idealizadora do projeto inicial, a professora e advogada Marta Kaiser. Atualmente a produção das fraldas é feita diariamente pelos alunos da Faculdade Integrado e comunidade de Campo Mourão, através de voluntários. A Casa das Fraldas também conta com o apoio, parceria e suporte financeiro de importantes instituições da cidade (CASA DAS FRALDAS, 2017).

Para a produção, a Casa das Fraldas disponibiliza três salas, onde em duas delas são divididos os processos de fabricação, como mostra a Figura 2. O local ainda conta com outras salas para fins de armazenagem do material produzido.

Figura 2 - Sala de produção

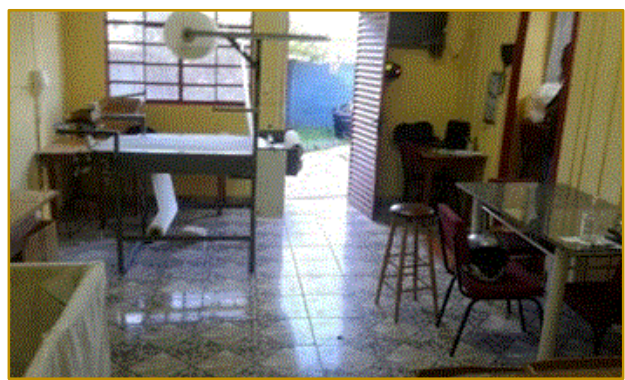

\subsection{PROCESSO DE FABRICAÇÃO DAS FRALDAS}

O processo de fabricação das fraldas é realizado de forma voluntária, não possuindo funcionários, metas e nem remuneração para as pessoas que se propõem a participar da produção.A Casa das Fraldas possui uma máquina (figura 3) que faz a colagem do tecido permeável com o polietileno (plástico), no qual estes possuem o "recheio" de uma mantade celulose e gel.

Figura 3 - Máquina de colagem

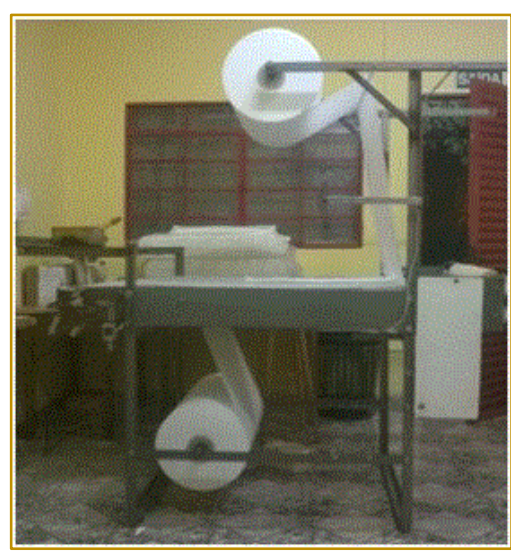

A fralda é colada e segue direto para um reservatório (figura 4). Em seguida, quando o reservatório está cheio, as fraldas são transportadas para uma espécie de cesto grande e aberto que está localizado na mesma sala e fica próximo das mesas onde é feito o corte das fraldas. 
Figura 4 - Cesto com fralda pré corte.

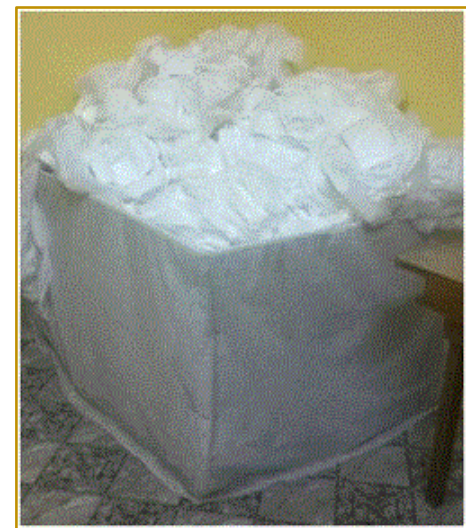

O corte é feito com um estilete seguindo o contorno dos moldes de vidro conforme mostra a Figura 5.

Figura 5 - Fralda pós corte

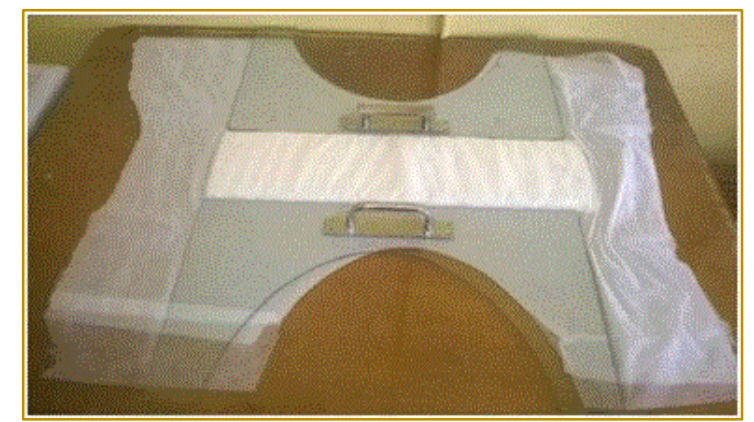

Após esse processo, as fraldas seguem para outra sala onde são esticadas sobre uma mesa (figura 6) e colados adesivos por fim são enroladas e presas por um elástico (figura7).

Figura 6 - Processo de etiquetar e finalizar as fraldas

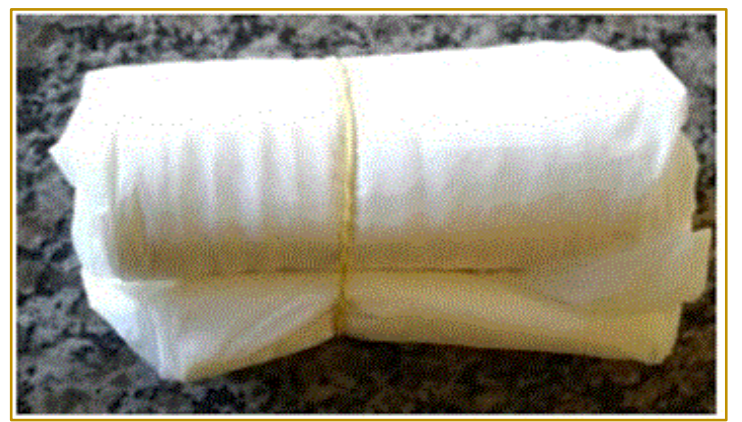


Figura 7 - Produto final

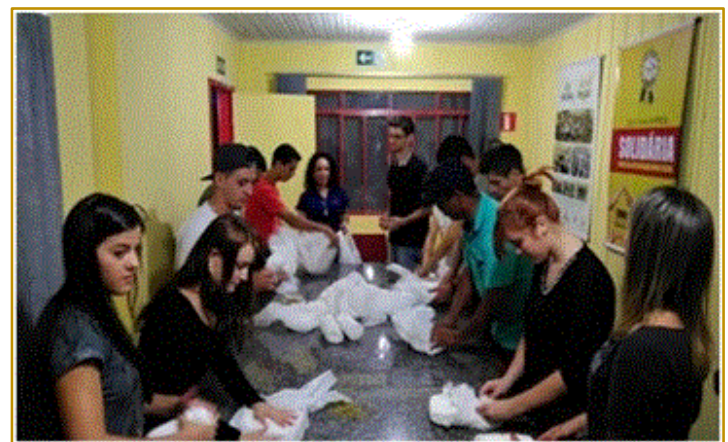

Os procedimentos são ensinados rapidamentepelo responsável do local e não se tem um número determinado de quantas pessoas são necessárias para a produçãodas fraldas,porém, nas visitas realizadas pelos acadêmicos e professores para a realização da pesquisa, foi possível notar que, para facilitar o processo, eram necessários no mínimo quatro pessoas somente para a realização do corte das fraldas.

\subsection{OTIMIZAÇÃO DO PROCESSO}

Para o levantamento de dados e informações, foram utilizadas as ferramentasBrainstorming para encontrar as melhores ideias; oDiagrama de Ishikawa, para encontrar as raízes do que motivou o planejamento e o $5 \mathrm{~W} 1 \mathrm{H}$ para traçar a melhor forma de executá-las.Tais ferramentas constituem afase $P$ (planejar) do ciclo PDCA, já que, por serem sugestões, as etapas D (fazer), C (chegar) e A (agir) não foram aplicadas e conferidas de imediato.

\section{- Armazenamento da fralda depois de colada}

Com o auxílio do Diagrama de Ishikawa, foram analisados todos os aspectos da forma como as fraldas são depositadas na caixa/cesto. Conclui-se que, de certa forma, é um tempo considerável que se perde desenrolando e, às vezes, procurando a ponta da fralda para encaminhá-la até a mesa de corte. Para tanto, a Tabela 1 mostra o plano de ação definido com o auxílio do Brainstorming do que poderá ser feito para otimização destes processos.

Tabela 1 - Plano de ação

\begin{tabular}{c|c|c|c|c|c|}
$\begin{array}{c}\text { O que fazer? } \\
\text { (What?) }\end{array}$ & $\begin{array}{c}\text { Como fazer? } \\
\text { (How?) }\end{array}$ & $\begin{array}{c}\text { Onde fazer? } \\
\text { (Where?) }\end{array}$ & $\begin{array}{c}\text { Quem irá fazer? } \\
\text { (Who?) }\end{array}$ & $\begin{array}{c}\text { Quando será } \\
\text { feito? (When?) }\end{array}$ & $\begin{array}{c}\text { Por que? } \\
\text { (Why?) }\end{array}$ \\
\hline $\begin{array}{c}\text { Implementar uma } \\
\text { bobina para } \\
\text { enrolar as fraldas } \\
\text { ao saírem da } \\
\text { máquina }\end{array}$ & $\begin{array}{c}\text { Criar um } \\
\text { protótipo }\end{array}$ & $\begin{array}{c}\text { Na saída } \\
\text { das fraldas } \\
\text { depois da } \\
\text { colagem }\end{array}$ & $\begin{array}{c}\text { Acadêmicos do } \\
\text { curso de } \\
\text { Engenharia de } \\
\text { Produção }\end{array}$ & $\begin{array}{c}\text { Entre março e } \\
\text { maio/2017 }\end{array}$ & $\begin{array}{c}\text { Redua deseno tempo } \\
\text { fralda antes de ser } \\
\text { cortada }\end{array}$ \\
\hline
\end{tabular}

A proposta para implantação dos suportes para as bobinas será da seguinte forma: uma será posicionada de frente para a máquinade colagem para enrolar as fraldas e ficará sob um suporte com rodízios com freios, como mostra a ilustração da Figura 8,0 que facilitará a movimentação até as mesas de corte e os freios travarão o suporte para não correr o risco de se mover durante o processo.Terá uma manivela para girar a bobina, e facilitar o manuseio. 
Figura 8 - Ilustração do protótipo da bobina com manivela (medidas em cm)

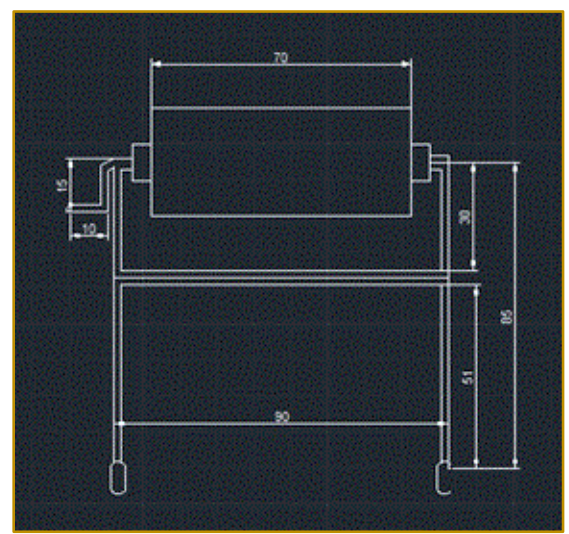

No procedimento atual, as fraldas vão da máquina de colagem para uma caixa e em seguida são transportadas para um reservatório maior, perto das mesas de corte. Já com o sistema de bobina, após o carregamentodas fraldas,esta será transportada até as mesas de corte e a bobina que estiver vazia retornará para a máquina de colagem. Para que não corra o risco de um posto de trabalho (mesa) esperar o outro terminar de enrolar para fazer o mesmo procedimento, deve-se deixar por volta de três bobinas cheias sem suporte como estoque, pois, quando uma for usada, a mesma será colocada no suporte à frente da máquina de colagem para ser abastecida novamente, enquanto os voluntários usarão apenas as bobinas disponíveis no estoque, totalizando assim, duas bobinas para as mesas de corte, três para estoque e uma para a máquina de colagem.
Depois de desenrolada, a fralda é esticada sobre uma mesa de madeira e vidro temperado que facilita o processo. Em seguida dois suportes de vidro (como pôde ser visto na Figura 5) são colocados sobre a fralda para o corte destas.

\section{- Corte das fraldas}

Com o auxílio do Diagrama de Ishikawaforam analisados todos os aspectos e definiu-se que a principal causa que motivou a busca por uma melhoria no processo foram os suportes de corte. Estes instrumentos usados não indicam o tamanho correto da fralda e apenas delimitam o ângulo do corte. Os suportes também indicam a necessidade de duas pessoas por período para a realização da tarefa.Para tanto a Tabela 2 mostra o plano de ação definido com o auxílio do Brainstorming, que poderá ser feito para otimizar o processo de corte das fraldas.

Tabela $2-5 \mathrm{~W} 1 \mathrm{H}$ para o corte das fraldas

\begin{tabular}{|c|c|c|c|c|c|}
\hline $\begin{array}{c}\text { que fazer? } \\
\text { (What?) }\end{array}$ & Como fazer? (How?) & $\begin{array}{c}\text { Onde fazer? } \\
\text { (Where?) }\end{array}$ & $\begin{array}{c}\text { Quem irá } \\
\text { fazer? (Who?) }\end{array}$ & $\begin{array}{c}\text { Quando será } \\
\text { feito? } \\
\text { (When?) }\end{array}$ & Por que? (Why?) \\
$\begin{array}{c}\text { Trocar o } \\
\text { equipamento } \\
\text { de corte }\end{array}$ & $\begin{array}{c}\text { Criar um protótipo } \\
\text { individual que faça o o } \\
\text { mesmo trabalho dos } \\
\text { dois suportes atuais }\end{array}$ & $\begin{array}{c}\text { Nas mesas de } \\
\text { corte }\end{array}$ & $\begin{array}{c}\text { Acadêmicos do } \\
\text { curso de } \\
\text { Engenharia de } \\
\text { Produção }\end{array}$ & $\begin{array}{c}\text { Entre março } \\
\text { e maio/2017 }\end{array}$ & $\begin{array}{c}\text { Para otimizar o } \\
\text { tempo e o número } \\
\text { de pessoas na etapa } \\
\text { de corte das fraldas }\end{array}$ \\
\hline
\end{tabular}

Com o novo suporte, que pode ser visualizado na Figura9 o tamanho do corte poderáser mantido, porém, as fraldas terão um tamanho padrão e assim poderá ser desenvolvida individualmente. 
Figura 9- Protótipo em MDF para corte das fraldas

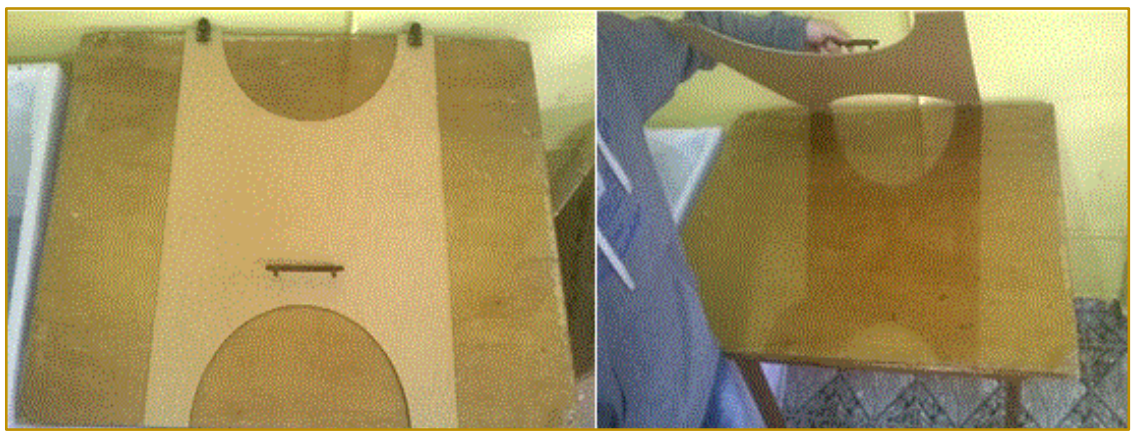

O novo suporte poderá ser fixado na mesa por meio de dobradiças e será do mesmo material transparente dos suportes anteriores, porém, com marcações no centro a fim de posicionar a fralda corretamente. Dessa forma a atividade poderá ser feita de forma mais simples, podendo ser executada por uma ou duas pessoas. ,

\section{CONSIDERAÇÕES FINAIS}

Com a elaboração do estudo de caso, foi possível constatar que a Casa das Fraldas São José de Campo Mourão é uma instituição com grande importância social para a comunidade, e, com seus quase 9 anos de existência, distribui gratuitamente fraldas geriátricas para organizações que cuidam de idosos.

A principal finalidade deste estudo foi identificar e posteriormente sugerir melhorias no processo de fabricação das fraldas, para que seja possível facilitar os procedimentos, melhorar a produtividade e a qualidade do produto final na produção de fraldas.

\section{REFERÊNCIAS}

[1] Aguiar, Paulo Celso Gonçalves. Aplicação da Metodologia, de Análise e Solução de Problemas na Célula Lateral de uma Linha de Produção Automotiva. Taubaté: Universidade de Taubaté, 2004. 65p. Trabalho de Conclusão de Curso em Especialização em Gestão Industrial, Universidade de Taubaté, 2004.

[2] Carpinetti, Luiz Cesar Ribeiro, Gestão da Qualidade - Conceitos e Técnicas, 4aㅡ ed. São Paulo, Atlas, 2011.

[3] Casa das Fraldas. Um Projeto Bem Sucedido. Disponível em $<$ http://www.casadasfraldas.org.br/?pagina=histori a> Acesso dia 20/04/2017 às 17h e 08min.
O processo de fabricação possui alguns pontos que podem ser aperfeiçoados, a fim de facilitar a execução das atividades e proporcionar para um único indivíduo a mesma facilidade que um grupo de vinte pessoas, por exemplo,encontra para produzir as fraldas.

O uso das ferramentas Diagrama de Ishikawa e 5W1H para o início da abordagem do Ciclo PDCA foram importantíssimas para o encontro dos principais pontosa seremmelhorados e também para a definição da melhor sugestão para que a melhoria fosse possível.

Sendo assim, acredita-se que a implantação das ideias sugeridas neste estudo poderá facilitar os procedimentos de fabricação das fraldas, sendo possíveldefinir um tamanho padrão para as fraldas, melhorar a qualidade dos processos e do produto final, e assim, aumentar a produtividade, o que, por consequência, poderá atender mais idosos e pessoas que precisam e dependem das fraldas.

[4] Chiavenato, Idalberto. Administração Geral e Pública. $2^{\underline{a}}$ ed. Rio de Janeiro: Elsevier, 2009. 531 p.

[5] Corrêa, Henrique L.; Corrêa, Carlos A. Administração de Produção e Operações Manufatura e Serviços: Uma abordagem estratégica. São Paulo: Atlas, 2004.690p.

[6] Fitzsimmons, James A.; Fitzsimmons, Mona J. Administração De Serviços: Operações, Estratégia e Tecnologia da Informação. 7a ed. São Paulo: McGraw Hill Education, 2014. 535p.

[7] Gaither, Norman; Frazier Greg. Administração da Produção e Operações. 8ª ed. Rio de Janeiro: Thomson, 2001. 598 p. 
[8] Gil, Antônio Carlos. Como Elaborar Projetos de Pesquisa. 4aㅡ ed. São Paulo: Atlas S.A., 2002. $176 p$.

[9] Laugeni, Fernando P.; Martins, Petrônio G. Administração da Produção. $2^{\underline{a}}$ ed. São Paulo: Saraiva, 2005. 562 p.

[10] Mariani. C. M.; Pizzinatto. N. K.; Farah. O. E. Método PDCA e Ferramentas da Qualidade no Gerenciamento de Processos Industriais: Um Estudo de Caso. XII Simpósio de Engenharia de Produção (SIMPEP). Bauru, 2005.

[11] Peinado, Jurandir; Graemi, Alexandre Reis. Administração da Produção (Operações Industrias e de Serviços). 1aㅡ ed. Curitiba: UniceP, 2007. 750p.

[12] Reggiani, Gibson Barcelos, et al.Gestão da produtividade: metodologia aplicada a uma indústria de bebidas. XII Simpósio de Engenharia de Produção (SIMPEP). Bauru, 2005. 9 p.

[13] Roth, Claudio Weiss. Qualidade e Produtividade. $3^{\mathrm{a} e d .}$ Santa Maria: Colégio Técnico Industrial de Santa Maria, 2011. 74p.

[14] Sandroni, Paulo. Novíssimo Dicionário de Economia. São Paulo: Best seller, 1999. 650 p.

[15] SILVA, Miguel Ângelo Gomes e. Desenvolvimento e Implementação de um Sistema de Gestão da Qualidade. Aveiro: Universidade Aveiro, 2009. 154p. Dissertação de Mestrado em Engenharia e Gestão Industrial, Universidade Aveiro, 2009

[16] Slack, Nigel et al. Administração da Produção. 3aㅡ ed. São Paulo: Atlas, 2009. 728 p. 


\section{Gapítulo 23}

\section{INOVAÇÃO DO PROCESSO PRODUTIVO DA CERVEJA ARTESANAL: ALGUMAS REFLEXÕES}

\section{Fernanda Batista Hagge}

Antonio Oscar Santos Goes

Resumo: A inovação tem sido admitida como a máquina que impulsiona o desenvolvimento econômico, além de configurar um fator determinante para a competitividade das empresas. A cerveja artesanal também está inserida nesse contexto. Diante do exposto, este artigo analisa os processos inovativos da cadeia de suprimentos da cerveja de cacau no Brasil-Bahia, particularmente a cerveja artesanal. Para o alcance desse propósito, escolheram-se dois objetivos específicos: a) expor métodos de produção da cerveja entre dois períodos da história; b) analisar os procedimentos da manufatura cervejeira artesanal. $O$ referencial teórico abordou a questão do conceito de inovação e como é produzida a cerveja artesanal. A metodologia foi básica, exploratória, qualitativa, bibliográfica, telematizada, iconográfica e documental. Os resultados refletiram o processo de fabricação da cerveja artesanal: cacau, na cidade de Ilhéus, na Universidade Estadual de Santa Cruz. Com a expansão mais recente do consumo e sua sofisticação, tornou-se relevante o desenvolvimento de produtos mais refinados e diferentes do que se encontra no mercado. No Brasil, as cervejarias especializadas apostam em sabores característicos da região, aproveitando toda a diversidade de frutos e especiarias encontrados no país, trazendo inovação ao produto final, através do sabor cacau e adicionais de nib.

Palavras-chave: Cerveja; Diferenciação; Produção; Cacau. 


\section{INTRODUÇÃO}

Deu-se início, no Brasil do final da década de 80, uma vertente para empreendedores com ideias inovadoras e mentes capazes de executá-las. O novo segmento, que nos Estados Unidos recebeu o nome de Craft Brewing, ficou conhecido como "Produção Alternativa de Cerveja", e carrega consigo um imenso diferencial inovativo. O objetivo não é a competição direta com as cervejarias então existentes no mercado global, ou até mesmo no mercado doméstico, mas um aproveitamento das lacunas deixadas por estes. Na tentativa de descobrir o que ainda não foi explorado pelo mercado, surge a possibilidade da inovação no empório cervejeiro. O objetivo principal é direcionar o enfoque para as prioridades do consumidor, que se sentirá degustando um produto exclusivo, dificilmente encontrado.

A inovação tem sido admitida como a máquina que impulsiona o desenvolvimento econômico, além de configurar um fator determinante para a competitividade das empresas e, por conseguinte, dos países, de acordo com as publicações realizadas por Robert Solow (1987) e Schumpeter (1911). Em consonância com o que foi citado, o mercado de cervejas artesanais veio a apresentar sólido crescimento, com números que aumentam de 30\% a 40\% anualmente, segundo Angela Klinke (2016). Este fator possibilita chegar a conclusão de que a recente popularização do consumo de cervejas artesanais não é passageira. Certamente, não é modismo de negócios, provavelmente, uma demanda constante para o futuro.

Os esforços para caracterizar-se como inovativo estão relacionados ao modo que as empresas utilizam para criar, adquirir ou combinar seus recursos disponíveis com o objetivo de inovar. Dito isso, o processo produtivo da cerveja básica depende, essencialmente, de 4 insumos, sendo estes: a cevada, o lúpulo, a água e a levedura. O obstáculo da produção em território brasileiro é a dificuldade de obtenção destes elementos. Dos que foram supracitados, apenas a água e, mais recentemente, algumas leveduras, são conseguidas localmente, as demais matérias-primas não são ofertadas de maneira fácil.

A perspectiva da inovação na produção artesanal brasileira encontra-se na diversidade de adjuntos aqui disponíveis, já que outros países não dispõem de um número tão alto de possibilidades de espécies. Entre os mais variados tipos de frutos, flores e especiarias que podem ser acrescentados ao produto final, dar-se-á ênfase ao cacau, cuja cerveja já é demandada internacionalmente. A região de Ilhéus, na Bahia, é a responsável pelo fornecimento dos nibs de cacau para algumas cervejarias brasileiras, como a paranaense Bodebrown e a cervejaria Mistura Clássica, localizada no Rio de Janeiro. Esta última nomeou seu produto de "Porreta", em homenagem à região originária do seu ingrediente diferencial.

A inovação é um processo desordenado: difícil de mensurar e difícil de administrar. A maioria das pessoas o identifica quando gera uma onda de crescimento (KOTLER; DE BES, 2011). No presente caso, foi perceptível a grande aceitação da cerveja de cacau pelo universo cervejeiro, sendo que alguns dos produtos desta categoria chegaram a ser premiados.

De acordo com o que foi dito, compreende-se que a análise do processo produtivo de cervejas artesanais, dando ênfase a cerveja de cacau, tem como objetivo a investigação para posterior levantamento de respostas sobre o processo de inovação no ramo industrial, tanto em pequenas empresas como em grandes organizações.

Para desenvolvimento deste artigo, explanouse toda a produção da cerveja do cacau, desde a moagem do malte, passando pela mostura, filtragem, fervura e fermentação, até que a cerveja seja envasada e esteja pronta para ser consumida.

Sob esta perspectiva objetivam-se analisar os processos inovativos da cadeia de suprimentos da cerveja de cacau no Brasil, enfatizando o estado da Bahia, com a finalidade de investigar os diferentes tipos de processo que ocorrem neste âmbito. A metodologia foi básica, exploratória, qualitativa, bibliográfica, telematizada e documental. Os resultados refletiram o processo de fabricação da cerveja artesanal: cacau, na cidade de Ilhéus, na Universidade Estadual de Santa Cruz.

\section{DESENVOLVIMENTO}

O referencial teórico abordado neste trabalho é um recorte do artigo intitulado: O processo inovador através de um estudo de caso no 
Porto Digital - Recife: a tecnologia como vantagem competitiva, do $X$ Congresso Nacional de Excelência em Gestão, 2014. Resgata de forma semelhante com algumas complementaridades para $\mathrm{o}$ entendimento básico do que é inovação, em sendo assim é um desdobramento do artigo anterior direcionado nesse trabalho, a questão da cerveja do cacau.

Segundo a Bíblia da Inovação, Kotler e De Bes (2011) afirmam que a inovação nem sempre acarreta em grandes saltos adiante. De fato, a inovação radical é mais visível e reconhecível, porém, esta demanda mais criatividade e pode implicar em um número muito maior de riscos. Por outro lado, a inovação gradual é tão necessária quanto a anterior, e dá ao negócio uma maior segurança e sustentabilidade. Esta forma de inovação, também chamada incremental, consegue inclusive levar à inovação radical, ao longo do tempo. Pelo visto, entende-se que a inovação segundo esses pensadores acontecem de forma radical ou incremental.

Outro autor que aborda a inovação é o austríaco Schumpeter. Assim, nas palavras Ipsis litteris desse teórico, citado por Góes (2012) o "desenvolvimento" é definido pela realização de novas combinações e caracterizado em cinco casos:

1 - Introdução de um novo bem - ou seja, um bem com que os consumidores ainda não tiveram familiaridade - ou de uma nova qualidade de um bem. 2 - Introdução de um novo método de produção, ou seja, um método que ainda não tenha sido testado pela experiência no ramo próprio da indústria de transformação, que de modo algum precisa ser baseada numa descoberta cientificamente nova, e pode consistir também em nova maneira de manejar comercialmente uma mercadoria. 3 - Abertura de um novo mercado, ou seja, de um mercado em que o ramo particular da indústria de transformação do país em questão não tenha ainda entrado, quer esse mercado tenha existido antes ou não. 4 - Conquista de uma nova fonte de oferta de matérias-primas ou de bens semimanufaturados, mais uma vez independentemente do fato de que essa fonte já existia ou teve que ser criada. 5 Estabelecimentos de uma nova organização de qualquer indústria, como de uma posição de monopólio (por exemplo, pela trustificação) ou a fragmentação de uma posição de monopólio (SCHUMPETER, 1985).
No embasamento schumpeteriano, o desenvolvimento se caracteriza pela inclusão de novas combinações de forma descontinuada, fazer as coisas de forma diferente, por meio da introdução de um novo bem ou de uma nova qualidade, por meio da introdução de um novo método de produção, com a abertura de novos mercados, a descoberta de uma nova fonte de matéria prima ou produtos semiacabados, ou a reorganização de uma indústria. Essa definição pode servir como ponto de partida para uma discussão atual sobre a inovação e sua importância para o desenvolvimento econômico (SCHUMPETER, 1942).

A inovação é conceituada por diversos pontos de vista, suas características e condicionantes. Por isso, para que esta pesquisa sobre a cerveja de cacau possa alcançar o seu objetivo, é preciso entender e refletir o que é inovação.

\section{A Organização para Cooperação e} Desenvolvimento Econômico - OCDE (2007), através do Manual de Oslo, diz que a inovação como a programação e execução de um produto, seja bem ou serviço, novo ou melhorado significativamente, ou ainda, um processo, um novo método organizacional na forma ou práticas de negócios, na organização do ambiente produtivo ou nas relações com o ambiente externo.

Para o especialista Tigre (2006), a inovação é a aplicação vivencial e efetiva de uma determinada criação original, que pode ser processo, técnica ou produto. Essas alterações acontecem em qualquer tipo de produto e serviços, especificamente, na cerveja. As inovações de processo envolvemse ao aprimoramento ocorrido pela introdução de novas tecnologias de produção, novos métodos de manuseio e entrega de produtos. No caso específico de mudanças na estrutura gerencial da organização, da interligação e articulação entre suas áreas funcionais, da especialização do seu quadro de funcionários, dos relacionamentos existentes com os seus clientes e fornecedores e, ainda, das técnicas utilizadas para organizar os processos de negócios, denomina-se de inovações organizacionais (GÓES, 2012).

Contribuindo para esclarecer o que seja inovação, Mattos e Guimarães (2005) registram que a forma básica de classificar as inovações é a que as define como: incrementais, radicais e fundamentais. Nas inovações incrementais há um 
aperfeiçoamento através de pequenas melhorias nos produtos ou processos. Já nas inovações radicais, os princípios básicos de funcionamento do produto ou serviço são alterados. A última definição, inovação fundamental, ocorre quando uma inovação promove tamanha mudança nos produtos ou processos, que acarreta em muitas outras inovações.

Essa classificação das inovações a partir do seu impacto na economia não é nova, como pode ser visto nos estudos de Schumpeter: Produzir significa combinar materiais e forças que estão ao nosso alcance. Produzir outras coisas, ou as mesmas coisas com método diferente, significa combinar diferentemente esses materiais e forças. Na medida em que as 'novas combinações' podem, com o tempo, originar-se das antigas por ajuste contínuo mediante pequenas etapas, há certamente mudança, possivelmente há crescimento. (...) (SCHUMPETER, 1911)

Compreende-se que a gestão da organização deve estar alinhada com o propósito da inovação no sentido de criar condições para que esta exista de fato e gere frutos. Neste sentido, entende-se a inovação como algo que ultrapasse uma visão simplória de instrumentos, equipamentos ou máquinas usadas em um sistema de produção. Assim, nesta visão, a inovação ocorre quando produtos, processos ou serviços, sendo novos, são criados em um ambiente de negócio. (HALL, 1984). Tudo isso pode ser direcionado para o processo inovativo da cerveja de cacau.
Destaca-se, ainda, que o processo de inovação aberta, que vem destacada na literatura, está voltada à gestão. $\mathrm{Na}$ concepção de Chesbrough e Vanhaverbeke (2006), a inovação aberta compreende fluxos intencionais de entrada e saída de conhecimentos com objetivo de acelerar a inovação interna e consecutivamente expandir mercados para o uso externo de inovação. A inovação aberta permite às organizações enfrentarem a competição globalizada através do acesso a conhecimentos de fora da organização por meio da interação com agentes externos como universidades e institutos de pesquisa e redes de empresas, possibilitando a ampliação dos limites de atuação da firma, criando e captando valor para a organização possibilitando o acompanhamento e proatividade frente às constantes transformações do ambiente externo e consecutivamente de suas oportunidades e desafios.

O manual de Oslo (2004) define quatro tipos de inovações que colaboram com um amplo conjunto de mudanças nas atividades das empresas: a) inovações de produto; b) inovações de processo; c) inovações organizacionais; e d) inovações de marketing.

Para ampliar o debate da inovação, refletir-seão, agora, as cinco gerações de Rothwell para Modelos de Inovação. Na tabela 1 Tidd (2008) na visão de Rothwell observa a natureza do processo de inovação no qual realiza uma síntese das cinco gerações de modelos que progrediram a partir de modelos lineares para mais interativos.

Tabela 1- Modelos de Inovação - As Cinco Gerações de Rothwell

\begin{tabular}{|c|c|}
\hline $\begin{array}{l}\text { Primeira e } \\
\text { segunda } \\
\text { geração }\end{array}$ & Modelos lineares simples - influxo de necessidade, estímulo de tecnologia. \\
\hline $\begin{array}{l}\text { Terceira } \\
\text { Geração }\end{array}$ & $\begin{array}{c}\text { Modelo de ligação, destaca da a relação entre diferentes elementos e } \\
\text { feedback entre os mesmos. }\end{array}$ \\
\hline Quarta geração & $\begin{array}{c}\text { Modelo paralelo, integração dentro da empresa, tanto para cima na cadeia de } \\
\text { valor como fornecedores fundamentais, quanto para baixo com consumidores } \\
\text { exigentes e ativos, ênfase em parcerias e alianças. }\end{array}$ \\
\hline Quinta Geração & $\begin{array}{l}\text { Integração entre sistemas e networking abrangente, reações customizadas e } \\
\text { flexíveis, inovação contínua. }\end{array}$ \\
\hline
\end{tabular}

Fonte: Góes apud Tidd (2008) 


\section{RESULTADOS E DISCUSSÕES}

A cerveja como se conhece é composta basicamente de quatro ingredientes fundamentais, sendo estes a água, a cevada, - lúpulo e a levedura. Cada um destes elementos desempenha uma determinada função na composição do sabor e demais características da cerveja e, portanto, precisam ser tratados de maneiras específicas para que se atinja um produto final de boa qualidade.

Por outro lado, a produção em massa de cerveja pode incluir insumos como milho e arroz, além de aditivos químicos, como corantes, estabilizantes e conservantes (SIQUEIRA, 2008), o que resulta em uma experiência inferior para o consumidor mais exigente e seletivo. Surge aí o espaço para uma produção mais tradicional e independente, que tem compromisso com o perfil sensorial do que está sendo produzido. São estas as cervejas artesanais, que tem suas receitas cuidadosamente elaboradas $e$ seu processo controlado do começo ao fim.

As cervejas artesanais são produzidas em pequena escala, principalmente pelo cuidado exigido ao longo de sua produção. Isso não significa que não possam ser feitas industrialmente, mas a preocupação com a essência da bebida e a busca pelos melhores ingredientes possíveis tornam difícil uma produção nas proporções das grandes marcas produzidas aos milhões.

Além da preocupação com os ingredientes básicos da cerveja, as cervejas artesanais podem incluir em suas receitas ingredientes inovadores, agregando ainda mais valor $e$ diferenciação em seus produtos. Estes componentes extras podem ser frutas, especiarias e ervas que podem resultar num produto nunca antes visto. Existem hoje no mercado cervejas com tons mais cítricos, doces, ou até com sabores totalmente inusitados e regionais, como a cerveja de rapadura. A vasta opção de sabores novos e a alta especialização empregada na produção destas cervejas deixa evidente que os padrões conhecidos são muito limitados em questão de diversidade, além de abrir margem para novas experiências de consumo, como a harmonização de cervejas com o alimento, que antes era realizado apenas com produtos como o vinho.

A adição do cacau nas cervejas artesanais inclui-se na inovação incremental. Para sua produção, o nibs do cacau é adicionado durante as etapas de fervura e a maturação da produção da cerveja, conferindo ao produto final um aroma cítrico e sabor intenso, o que proporciona à bebida um resultado inovador.

A bebida como é conhecida hoje sofreu muitas mudanças desde que foi descoberta, há aproximadamente 10 mil anos. Especulase que a cerveja tenha sido criada de maneira acidental, proveniente da fermentação não induzida de algum cereal. Abaixo, está exposto um quadro comparativo, que verifica as diferenças entre a produção de cerveja naqueles tempos e atualmente.

Tabela 1 - Comparativo da produção de cerveja na Idade Média vs Tempos Atuais

\begin{tabular}{|c|c|c|}
\hline & Idade Média & Tempos Atuais \\
\hline Quem produz? & Padeiros & $\begin{array}{l}\text { Grandes e pequenas fábricas } \\
\text { especializadas }\end{array}$ \\
\hline $\begin{array}{l}\text { Quais os } \\
\text { insumos? }\end{array}$ & Grãos de cereais, leveduras, água & Água, cevada, lúpulo, leveduras \\
\hline Como é feito? & $\begin{array}{l}\text { A cevada é deixada de molho, moída, } \\
\text { moldada em bolos e adiciona-se a } \\
\text { levedura. Estes eram colocados em } \\
\text { jarras de água para fermentar. Podiam } \\
\text { ser adicionadas ervas para a correção } \\
\text { de sabores. }\end{array}$ & $\begin{array}{l}\text { A cerveja passa pela malteação, } \\
\text { moagem, brassagem, } \\
\text { clarificação, fervura, } \\
\text { resfriamento, fermentação e } \\
\text { envase. }\end{array}$ \\
\hline
\end{tabular}

Fonte: Adaptado de Rebello (2009); Silva \& Leite (2016). 
É possível notar a evolução drástica que esse processo sofreu ao longo dos anos. A produção de uma boa cerveja agora ocorre seguindo etapas rigorosas, que são controladas para garantir a boa qualidade do produto final. Como mostrado na tabela, a fabricação começa com a malteação, que consiste em iniciar o processo de germinação dos grãos dos cereais. Nesta etapa, surge a diferenciação entre os diversos grãos. A escolha do tipo de malte que definirá os aromas e sabores advindos do malte e principalmente a cor da cerveja.

Com os maltes definidos e a quantidade de cada tipo, a cerveja segue para a moagem. A ideia da moagem é quebrar a casca do grão. As condições da moagem implicam diretamente na etapa seguinte. Uma vez que o grão tenha sido "aberto", é preciso fazer com que enzimas presentes nele quebrem os açúcares não fermentáveis em açúcares fermentáveis. Esta etapa é a brassagem.

Em seguida, a cerveja segue para a clarificação. Durante a clarificação o mosto circula, sendo tirado do fundo da panela e percorrendo por um caminho que passe pelas cascas do malte. Quando isto é feito, impurezas presentes no mosto vão ficando presas nas cascas, e açúcares ainda não extraídos acabam por serem extraídos nesta etapa. Depois do mosto clarificado e sem cascas, ele é fervido. Durante a fervura ocorre a evaporação de substâncias indesejadas. Também acontece a adição do lúpulo e são eliminadas as bactérias ou microorganismos que possa estar presentes. O lúpulo tem dois papeis importantes na cerveja, o primeiro é conferir amargor, equilibrando o doce do malte, e o segundo é ser conservante natural.

Após estes processos, ocorre o resfriamento. Se o mosto resfriasse naturalmente, o tempo que ele tem contato com o ambiente cresceria, aumentando o risco de contaminálo. Por este motivo, o ideal é resfriar todo o mosto até a temperatura de inoculação da levedura o mais rápido possível. Agora, ocorrerá o processo de fermentação onde a levedura irá consumir os açúcares e produzir álcool e gás carbônico. Por fim, a cerveja segue para o envase. Todo este processo está demonstrado no fluxograma a seguir.

Figura 1 - Processos da fabricação da cerveja.

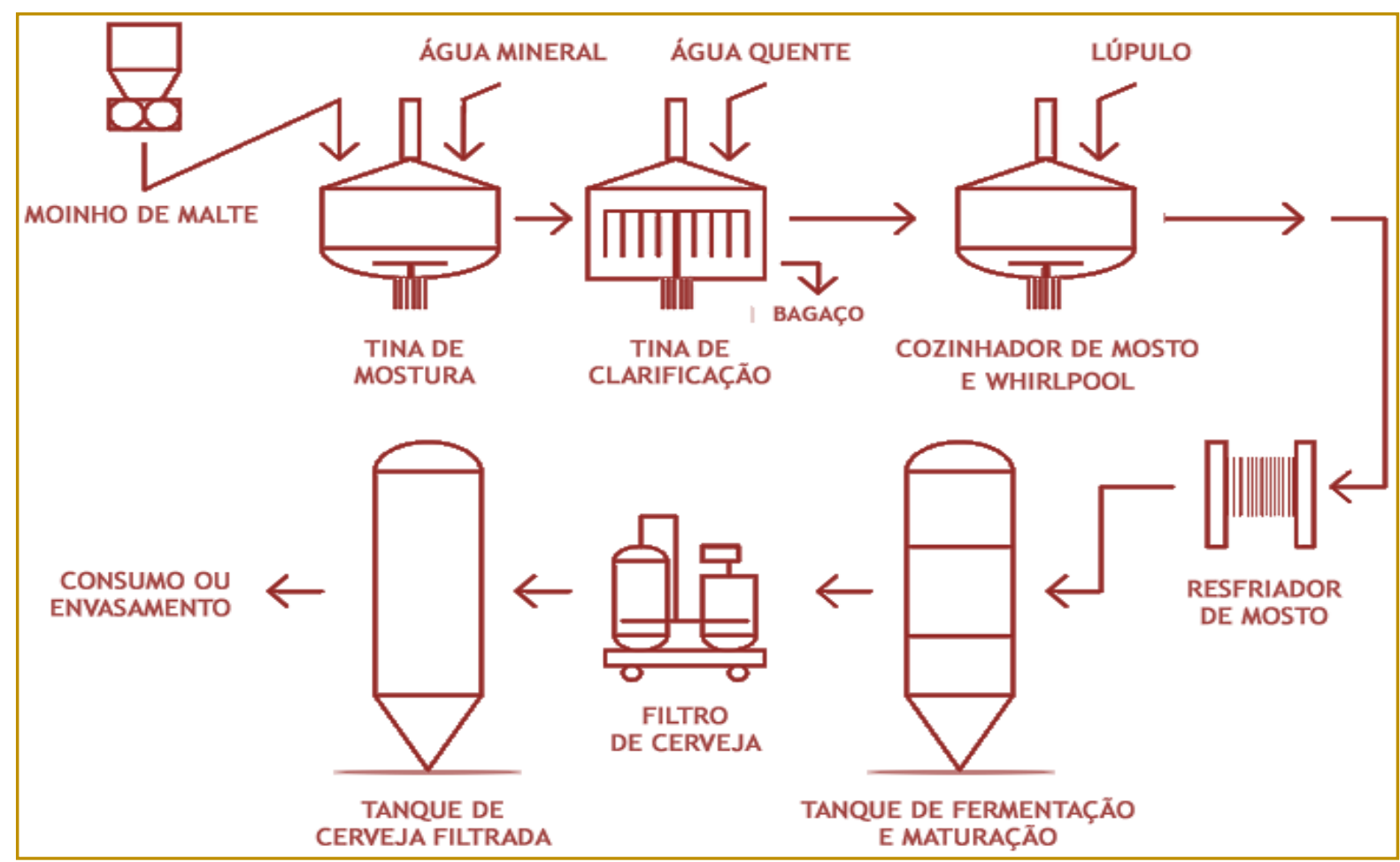

Fonte: Cervejaria Dortmund (2017), site da empresa. 
Tudo que foi exposto anteriormente descreve o processo produtivo da cervejaria artesanal detalhadamente além de um recorte histórico da cerveja. Para um entendimento restrito, a seguir um comentário sobre grandes corporações cervejeiras.

As grandes fábricas cervejeiras realizam este processo em grandiosas quantidades, com o propósito de produzir lotes gigantescos de uma só vez. Como consequência, cada etapa do procedimento é minuciosamente monitorada para possibilitar o controle da qualidade da cerveja, já que um simples erro pode prejudicar milhares de litros da produção. Abaixo, vemos uma imagem da fábrica da cervejaria Corona, no México, que produz 20 milhões de garrafas de cerveja por dia.

Figura 2- Fábrica da cerveja Corona.

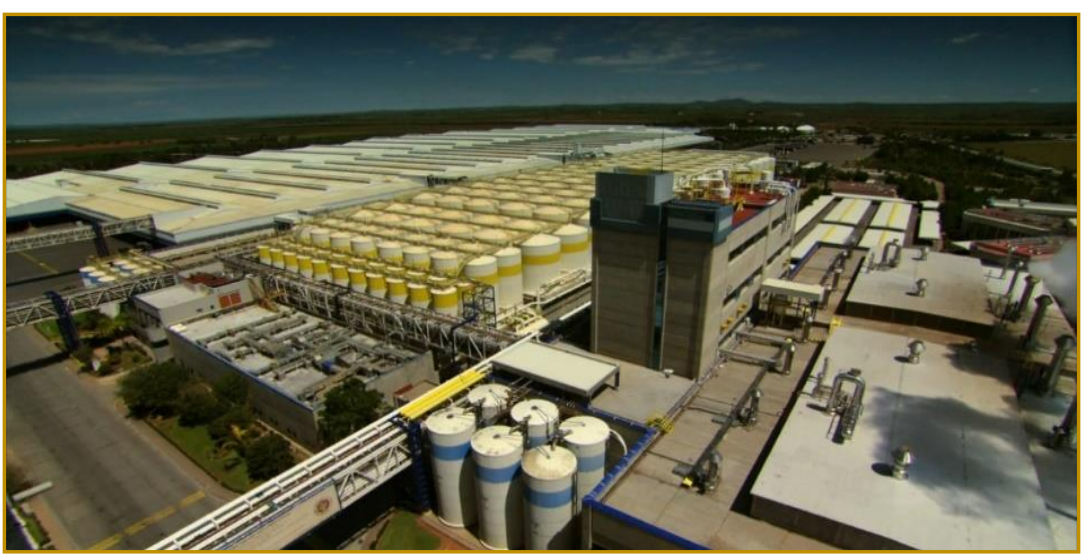

Fonte: Documentário Mega Fábricas, National Geographic (2016)

Nesse momento, alguns procedimentos da cerveja artesanal. Com o desenvolvimento e a grande aprovação das cervejas artesanais, foram criadas premiações para estimular as produções e honrar aquelas que realmente se destacam. As cervejas de cacau aparecem nessas listas. No Concurso Brasileiro de Cerveja, a Brazilian Cacau Ale, da cervejaria Bodebrown, levou medalha de bronze. Esta mesma ainda foi premiada internacionalmente, conquistando o ouro no festival Mondial de La Bière, no Canadá. A cerveja Cacau IPA, da mesma cervejaria, também foi premiada no MBeer Contest Brazil.

Além da cerveja de cacau, o mercado de cervejas artesanais tem trazido outros sabores inesperados. Já são lançadas no mercado cervejas com acerola e abacaxi na sua composição, além de cervejas com mel, açaí e até rapadura. Dentre as diversas variações existentes, vale destacar a Tupiniquim Funky Framboesa, uma cerveja frutada e leve, que ganhou medalha de ouro no Festival Brasileiro da Cerveja, e a Seasons Dubble Dragon: Honey Revenge, que conquistou duas medalhas no mesmo evento.
Recentemente, a Universidade Estadual de Santa Cruz, localizada em Ilhéus, inaugurou a primeira microcervejaria da Bahia. Considerando a rica diversidade existente no sul do estado, objetiva-se a realização de experimentos de novos sabores de cerveja, usando frutas e microorganismos pertencentes à região. Estes últimos são usados como leveduras, tendo a função de fermentação na produção da bebida. Já as frutas são usadas para conferir sabores e aromas diferentes de todos já lançados no mercado.

De acordo com o professor Antonio Reis (2017), o processo de fabricação do produto na microcervejaria passa pela brassagem, fermentação e maturação. Atualmente, está sendo usado o cacau como elemento inovativo. A diferença aparece na parte do fruto utilizada na produção, já que aqui é utilizada a polpa do cacau, enquanto nas cervejas de cacau que já são produzidas, trabalha-se com o nibs. 
Figura 3 - Microcervejaria da UESC.

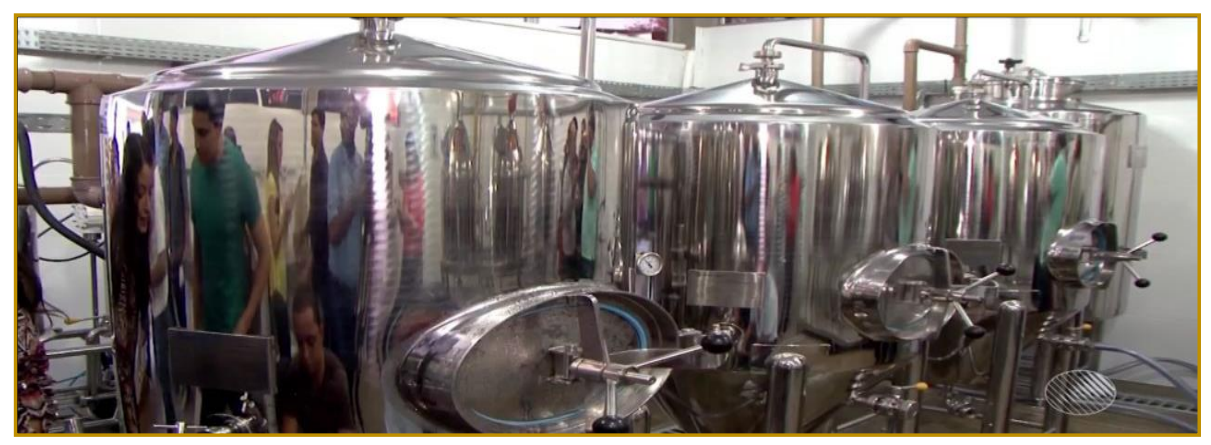

Fonte: Reportagem transmitida pelo G1 (2016)

Figura 4 - Microcervejaria da UESC.

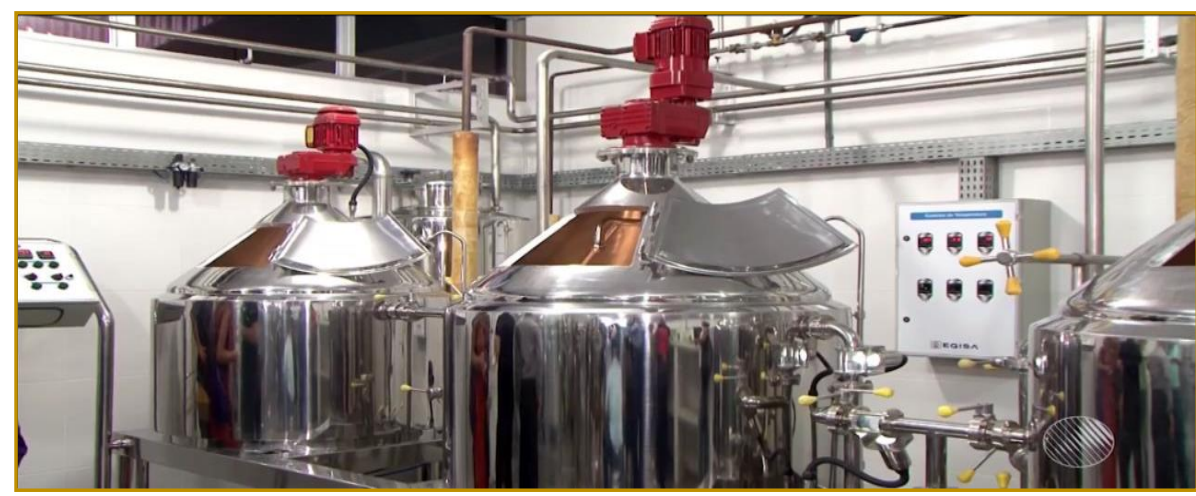

Fonte: Reportagem transmitida pelo G1 (2016)

O maquinário de produção é semelhante ao usado nas grandes fábricas, exceto pelas suas dimensões, que na microcervejaria, são reduzidas de maneira radical. Ainda assim, são usados toneis de fermentação e maturação, o que aponta para um processo parecido com o usual. A capacidade de produção é de 600 litros por ciclo, muito pouco se comparado à cervejaria Corona, citada anteriormente.

\section{CONSIDERAÇÕES FINAIS}

A cerveja se configura como um produto de alta relevância no mercado mundial. Com a expansão mais recente do consumo e sofisticação do mesmo, tornou-se relevante o desenvolvimento de produtos mais refinados e diferentes do que se encontra no mercado. No Brasil, as cervejarias especializadas apostam em sabores característicos da região, aproveitando toda a diversidade de frutos e especiarias encontrados no país, trazendo inovação ao produto final.

A cerveja de cacau surge nesse âmbito, e tem como atrativos um sabor acentuado e um aroma cítrico. A adição do cacau, que se caracteriza como inovação incremental, é feita geralmente no processo de fervura e maturação da cerveja, a partir do uso dos nibs. No sul da Bahia, onde fica localizada a microcervejaria da UESC, este processo passa ainda por mais inovações, já que a polpa do fruto é usada na fabricação.

Apesar do comentado anteriormente, o processo produtivo, que passa por brassagem, fermentação e maturação, não apresenta inovação, seguindo as etapas comumente usadas nas fábricas de cerveja pelo mundo. Chama-se, pois, de inovação incremental. O caráter revolucionário permanece apenas nos ingredientes utilizados, sendo estes frutos ou leveduras encontradas na região, assim, considera-se, atendendo o embasamento de Schumpeter como inovação radical.

O cacau cultivado no sul da Bahia é utilizado, ainda, na fabricação de outras cervejas produzidas em outros estados do país. Seus nibs são exportados para a paranaense Bodebrown, cuja cerveja de cacau foi reconhecida em diversos festivais cervejeiros no Brasil e no mundo, além da carioca Mistura Clássica, que também desenvolveu um 
produto usando os ingredientes da região. A adição do nibs confere à cerveja um novo sabor e aroma que agradam os amantes da bebida.

Por termo, este trabalho expôs o processo produtivo da cervejaria artesanal atrelado com

\section{REFERENCIAS}

[1] BA, G1. Uesc inaugura 1a microcervejaria da Bahia e planeja bebida feita com frutas. Disponível

em:<http://g1.globo.com/bahia/noticia/2016/07/ues c-inaugura-1-micro-cervejaria-da-bahia-e-planejabebida-feita-com-frutas.html>. Acesso em: 15 abr. 2017.

[2] Chesbrough, H.W. Open Innovation: The new imperative for creating and profiting From. Harvard Business, 2006.

[3] Conde, Mariza Velloso Fernandez; AraujoJorge, Tania Cremonini de. Modelos e concepções de inovação: a transição de paradigmas, a reforma da C\&T brasileira e as concepções de gestores de uma instituição pública de pesquisa em saúde. Ciênc. saúde coletiva, São Paulo, v. 8, n. 3, p. 727-741, 2003. Disponível em: $<$ http://www.scielo.br/scielo.php?script=sci_arttext \&pid=S1413-

$81232003000300007 \&$ lng =en\&nrm=iso $>$. Acesso em: 19 Apr. 2017.

[4] DE BES, Fernando Trías; Kotler, Philip. A Bíblia da Inovação. [S.I.]: Casa da Palavra, 2011. $352 \mathrm{p}$.

[5] Ferreira, Artur de Souza; Benka, Cleiton Luis. Produção de cerveja artesanal a partir de malte germinado pelo método convencional e tempo reduzido de germinação. 2014. 42 p. Trabalho de Conclusão de Curso (Curso superior de tecnologia em alimentos)- Universidade Tecnológica Federal do Paraná, Francisco Beltrão, 2014. Disponivel em:<http://repositorio.roca.utfpr.edu.br/jspui/bitstre am/1/3455/1/FB_COALM_2014_2_06.pdf>. Acesso em: 16 abr. 2017.

[6] Góes, A., Yoshida, L. And Trindade, L. (2016). A inovação como estratégia empresarial: algumas perspectivas teóricas. Doutor. Universidade Estadual de Santa Cruz.

[7] Hall, Richard H. Organizações: Estrutura e Processos. 3. ed. Rio de Janeiro: Prentice-Hall, 1984.

[8] Klinke, Angela. Cerveja artesanal não é moda. Disponível em: $<$ http://www.valor.com.br/cultura/blue-

chip/4418136/cerveja-artesanal-nao-e-moda>.

Acesso em: 30 mar. 2017.

[9] Mattos, João Roberto Loureiro de; GUIMARÃES, Leonam dos Santos. Gestão da o processo de inovação direcionado para a cervejaria artesanal, considera-se que o processo não apresenta atributos da inovação, somente o sabor e o aroma devem ser considerados como processo inovativo.

tecnologia e inovação: uma abordagem prática. São Paulo: Saraiva, 2005.

[10] Mega Fábricas - Cervejaria Corona. [S.I.]: National Geographic, 2016.

[11] Ocde. Manual de Oslo: diretrizes para coleta e interpretação de dados sobre inovação (2007). 3. ed. Brasília: Ocde; Eurostat; Finep, 2007.

[12] Paranhos, Pedro. Concurso Brasileiro de Cervejas 2017: Cervejas premiadas. Disponível em: <http://www.mestre-cervejeiro.com/concursobrasileiro-de-cervejas-2017-cervejas-premiadas/>. Acesso em: 15 abr. 2017.

[13] Processo de fabricação. Disponível em: <http://www.dortmund.com.br/fabricacao.php> Acesso em: 20 abr. 2017.

[14] Rebello, Flávia De Floriani Pozza. Produção de cerveja. Revista Agrogeoambiental, [S.I.], p. 145-155, dez. 2009. Disponível em:<https://agrogeoambiental.ifsuldeminas.edu.br/i ndex.php/Agrogeoambiental/article/viewFile/224/22 0>. Acesso em: 16 abr. 2017.

[15] Sartori, Simone. Características da Inovação: Uma Revisão de Literatura. INGEPRO Inovação, Gestão e Produção, [S.I.], v. 03, n. 09, p. 52-64, set. 2011. Disponível em: <http://www.ingepro.com.br/Publ_2011/Set/481\%2 0pg\%2052\%20-\%2064.pdf>. Acesso em: 16 abr. 2017.

[16] Schumpeter, J. A. Capitalismo, Socialismo e Democracia. Rio de Janeiro: Fundo de Cultura, 1961. Publicado pela primeira vez em 1942.

[17] Schumpeter, Joseph A. (1985), Teoria do Desenvolvimento Econômico: uma investigação sobre lucros, capital, crédito o ciclo econômico. São Paulo: Nova Cultura.

[18] Silva, Hiury Araújo; Leite, Maria Alvim; Paula, Arlete Rodrigues Vieira de. Cerveja e sociedade. Contextos da Alimentação - Revista de Comportamento, Cultura e Sociedade, São Paulo: Centro Universitário Senac, v. 4, n. 2, p. 85-91, mar. $2016 . \quad$ Disponível em: <http://www3.sp.senac.br/hotsites/blogs/revistacon textos/wpcontent/uploads/2016/03/73_CA_artigo_revisado.p df>. Acesso em: 16 abr. 2017.

[19] Siqueira, Priscila Becker; Bolini, Helena Maria André; Macedo, Gabriela Alves . O PROCESSO DE Fabricação da cerveja E Seus Efeitos na Presença de Polifenóis. Alimentos e Nutrição, Araraquara, out. 2008. v. 19, p. 491-498. 
Disponível em: <http://servbib.fcfar.unesp.br/seer/index.php/alimentos/article/ viewFile/660/556>. Acesso em: 24 mar. 2017.

[20] Tidd, J. et al. Gestão da Inovação. Porto Alegre: Bookman, 3ed, 2008.

[21] Tigre, P. B. Gestão da inovação: a economia da tecnologia no Brasil. Rio de Janeiro: Elsevier Campus, 2006.
[22] Trindade, L. X. ; GÓES, A. O. S. O processo inovador através de um estudo de caso no Porto Digital - Recife: a tecnologia como vantagem competitiva. In: X Congresso Nacional de Excelência em Gestão, 2014, Rio de Janeiro. X Congresso Nacional de Excelência em Gestão Anais. Rio de Janeiro, 2014. 


\section{Bapítulo 24}

\section{ANALISE DA MATRIZ CURRICULAR DO CURSO DE ENGENHARIA DE PRODUÇÃO AGROINDUSTRIAL - ESTUDO DE CASO}

\section{Guilherme Fernando Ribeiro}

Andréa Machado Groff

Resumo: O ensino das Engenharias tem acompanhado a demanda histórica pelos processos industriais. A evolução do conhecimento na área de Engenharia ocasionou a sua subdivisão em diversos ramos, entre eles o de Engenharia de Produção, que apresenta diversas áreas de atuação. As Diretrizes Curriculares Nacionais para cursos de Engenharia definem os princípios, fundamentos, condições e procedimentos da formação de Engenheiros a serem considerados para a elaboração do Projeto Político Pedagógico do curso. De acordo com as Diretrizes os cursos devem possuir três núcleos de conteúdos: o núcleo de conteúdos básicos, o núcleo de conteúdos profissionalizantes e o núcleo de conteúdos específicos. Este estudo teve como objetivo analisar a matriz curricular de um Curso de Engenharia de Produção Agroindustrial e como objetivos específicos: identificar o número de horas aulas dedicadas a cada uma das áreas e subáreas da Engenharia de Produção e aos núcleos de conteúdos básicos, de conteúdos profissionalizantes e de conteúdos específicos e propor reestruturação curricular do Curso. Para a análise, primeiramente, as disciplinas em vigor no ano de 2014, foram classificadas de acordo com o núcleo de conteúdos. Posteriormente, foram identificados e quantificados os totais de horas aulas dedicados às áreas e subáreas da Engenharia de Produção. Observou-se que o núcleo de conteúdos básicos representou 35,39\% da carga horária total do Curso, o núcleo de conteúdos profissionalizantes $32,38 \%$ e o núcleo de conteúdos específicos 30,72\%. Assim, há necessidade de reestruturação curricular com atenção às disciplinas dos núcleos de conteúdos profissionalizantes e de conteúdos específicos. Com relação às áreas verificou-se que as mais trabalhadas foram Engenharia de Operações e Processos da Produção, Pesquisa Operacional e Engenharia Organizacional e, as menos abordadas, Educação em Engenharia de Produção, Engenharia do Trabalho e Engenharia Econômica.

Palavras-chave: Educação em engenharia. Ensino de engenharia. Avaliação de curso. 


\section{INTRODUÇÃO}

Pode-se dizer que a Engenharia existe desde a antiguidade e teve início com os homens primitivos, quando os mesmos passaram a elaborar instrumentos e invenções que permitiam suprir suas necessidades. Ao desenvolver ferramentas e objetos eles estavam explorando princípios básicos que estudamos hoje nas Engenharias (CARVALHO; PORTO; BELHOT, 2001; CUNHA, 2002).

A Engenharia propriamente dita nasceu nos exércitos, pois, a descoberta da pólvora, os progressos da artilharia, a construção de estradas, pontes e portos para fins militares forçou o surgimento de profissionais habilitados para o planejamento e realização dessas obras (TELLES, 1984).

O ensino das Engenharias tem acompanhado a demanda histórica pelos processos industriais. Conforme apresentado por Cunha (2002), até o advento da Revolução Industrial, a Engenharia subdividia-se em apenas dois ramos: o militar e o civil. A evolução do conhecimento na área de Engenharia ocasionou a subdivisão em outros ramos: mecânico, elétrico, minas, telecomunicações, alimentos, produção entre outros.

Conforme apresentado por Laudares e Batista (2003) e Fleury (2008), a Engenharia de Produção nasceu sob as inspirações taylorista e fordista, que defendiam a otimização do trabalho e a qualidade dos produtos, visando atender a demanda de mercado. A Engenharia de Produção visa analisar, medir e melhorar os métodos de execução de tarefas e projetos, promovendo a implantação de melhores sistemas de produção (FLEURY, 2008), e veio em resposta às necessidades de desenvolvimento de métodos e técnicas de gestão dos meios produtivos.

Segundo Oliveira (2004), a modalidade de Engenharia de Produção é relativamente recente se comparada às demais Engenharias. No Brasil, o curso de Engenharia de Produção teve início na Escola Politécnica da Universidade de São Paulo (USP) na década de 1950, época em que o país passava por um forte processo de industrialização (SANTOS, 2008). O curso de Engenharia de Produção foi criado com base nas matrizes curriculares dos cursos de Administração de Empresas e de Engenharia Mecânica, almejando os conhecimentos técnicos e as habilidades de gestão (CUNHA, 2002).

A Associação Brasileira de Engenharia de Produção (ABEPRO), constituída em 09 de Outubro de 1987, atua representando os docentes, discentes e profissionais de Engenharia de Produção e visa esclarecer o papel do Engenheiro de Produção na sociedade $e$ as suas áreas de atuação (ABEPRO, 2010). As áreas de atuação listadas pela ABEPRO (2008) são: Engenharia de Operações e Processos da Produção; Logística; Pesquisa Operacional; Engenharia da Qualidade; Engenharia do Produto; Engenharia Organizacional; Engenharia Econômica; Engenharia do Trabalho; Engenharia da Sustentabilidade e; Educação em Engenharia de Produção.

De acordo com a ABEPRO (1998), o curso de Engenharia de Produção possibilita aos profissionais sólida formação científica, capacitação para identificar, formular e solucionar problemas ligados às atividades de projeto, operação e gerenciamento do trabalho e de sistemas de produção de bens e/ou serviços, considerando seus aspectos humanos, econômicos, sociais e ambientais, com visão ética e humanística, em atendimento às demandas da sociedade.

Além da ABEPRO, os cursos de Engenharia contam com a Resolução $\mathrm{n}$ 11 do Conselho Nacional de Educação (CNE) e Câmara de Educação Superior (CES), de 11 de março de 2002, que institui as Diretrizes Curriculares Nacionais do Curso de Graduação em Engenharia (BRASIL, 2002). As Diretrizes definem os princípios, fundamentos, condições e procedimentos da formação de Engenheiros a serem considerados para a elaboração do Projeto Político Pedagógico do curso. Ainda de acordo com esse documento os cursos de Engenharia, devem possuir em sua matriz curricular um núcleo de conteúdos básicos, um núcleo de conteúdos profissionalizantes e um núcleo de conteúdos específicos, que incluam atividades complementares, disciplinas optativas, trabalho de conclusão de curso e estágio.

O presente artigo tem como objetivo geral: analisar a matriz curricular de um Curso de Engenharia de Produção Agroindustrial e como objetivos específicos: identificar o número de horas aulas dedicadas a cada uma das áreas e subáreas da Engenharia de Produção e aos núcleos de conteúdos básicos, de conteúdos profissionalizantes e 
de conteúdos específicos e propor a reestruturação curricular do Curso.

Este artigo enquadra-se na área de Educação em Engenharia de Produção e na subárea do conhecimento que trata da Gestão e Avaliação de Sistemas Educacionais de Cursos de Engenharia de Produção.

\section{ENGENHARIA DE PRODUÇÃO: MODALIDADE, DIRETRIZES E CONTEÚDOS}

A Engenharia de Produção no ensino de graduação apresenta duas formas de inserção: por meio de cursos na modalidade plena e cursos que figuram como habilitação específica (ênfases) de um dos ramos clássicos da Engenharia. Segundo Cunha (2002), a modalidade plena é a que proporciona a habilitação do egresso como Engenheiro de Produção. É a modalidade atualmente mais em voga, havendo, conforme o autor, o surgimento de um grande número de cursos nesta modalidade no País. Os cursos estabelecidos como habilitações específicas (ênfases) facultam o estudo em conteúdos específicos da habilitação escolhida.

Segundo a ABEPRO (2003), nos cursos de modalidade plena, além da base tecnológica da Engenharia de Produção, o egresso deverá ter conhecimento dos principais processos de produção, especificamente os mecânicos e os químicos. Para os cursos de habilitações específicas, além dos conteúdos definidos para os cursos de modalidade plena, o egresso deverá ter o aprofundamento de conteúdos profissionalizantes na habilitação.

De acordo comas Diretrizes Curriculares Nacionais do Curso de Graduação em Engenharia (BRASIL, 2002), os cursos de Engenharia, independente da sua modalidade, devem possuir em sua matriz núcleos de conteúdos básicos, de conteúdos profissionalizantes e de conteúdos específicos, que caracterizem a modalidade. O núcleo de conteúdos básicos deve contemplar cerca de $30 \%$ da carga horária total do curso, o núcleo de conteúdos profissionalizantes cerca de $15 \%$ e o núcleo de conteúdos específicos cerca de 55\% (BRASIL, 2002).

De acordo com a ABEPRO (2003), o núcleo de conteúdos básicos visa desenvolver o raciocínio lógico, constituir a base para a formação tecnológica e possibilitar a qualificação de competências e habilidades gerais necessárias ao Engenheiro.

O núcleo de conteúdos profissionalizantes inclui as disciplinas essenciais para a formação do Engenheiro de Produção e deve contemplar as áreas e subáreas da Engenharia de Produção listadas pela ABEPRO (2008).

O núcleo de conteúdos específicos deve fornecer os conhecimentos técnicos requeridos para a compreensão dos diversos tipos de sistemas de produção, além de possibilitar a intervenção do profissional no projeto e na operação dos sistemas agroindustriais (ABEPRO, 2003), que é o caso do Curso em estudo. Santos (2004) destaca como elementos desse núcleo o trabalho de conclusão de curso, o estágio curricular e as disciplinas optativas para os aprofundamentos e extensões necessários.

De acordo com a Resolução no 2 do CNE e CES (BRASIL, 2007), de 18 de junho de 2007, que dispõe sobre a carga horária mínima dos cursos de graduação, bacharelados, na modalidade presencial, os cursos de Engenharia, independente da sua modalidade, devem possuir carga horária mínima de 3.600 horas, cumpridas em um prazo não inferior a quatro anos e carga horária mínima de estágio de 160 horas.

\section{METODOLOGIA}

\subsection{CARACTERIZAÇÃO DA PESQUISA}

A pesquisa classifica-se, quanto aos fins, como exploratória e aplicada. Exploratória, pois, visa familiarizar-se com um assunto pouco conhecido e pouco explorado. Aplicada, cujo objetivo é resolver necessidades concretas em curto e médio prazos. Quanto aos meios, classifica-se como pesquisa bibliográfica, documental e estudo de caso. Bibliográfica, pelo uso de fontes literárias para a elaboração da teoria de base, documental pelo uso de documentos normativos e estudo de caso, pois foi realizado em um contexto real. Quanto à abordagem, classifica-se como qualitativa e quantitativa, pois, os resultados podem ser quantificados por meio de análise dos dados e as amostras são representativas e qualitativas. Para caracterização da pesquisa utilizou-se Gil (2008). 


\subsection{UNIVERSO DA PESQUISA}

Para o estudo foi utilizada a matriz curricular do Curso de Engenharia de Produção Agroindustrial de uma Universidade, em vigor no ano de 2014. Essa matriz apresenta carga horária total de disciplinas de 4.148 horas aula e de Estágio Curricular Supervisionado 306 horas (aproximadamente 367 horas aula).

\subsection{IDENTIFICAÇÃO DAS DISCIPLINAS POR NÚCLEO DE CONTEÚDOS}

Para a avaliação da matriz curricular, primeiramente, as disciplinas foram classificadas por núcleo de conteúdos (básicos, profissionalizantes ou específicos), com base nas Diretrizes Curriculares Nacionais do Curso de Graduação em Engenharia (BRASIL, 2002). Foram consultados os respectivos Planos de Ensino, aprovados pelo Colegiado do Curso no ano de 2014 e, posteriormente, determinadas as porcentagens de horas aulas dedicadas a cada núcleo.

\subsection{IDENTIFICAÇÃO DAS ÁREAS E SUBÁREAS DA ENGENHARIA DE PRODUÇÃO}

Para a identificação das horas aulas dedicadas às áreas e subáreas da Engenharia de Produção, primeiramente, foi consultado o documento Áreas e Subáreas da Engenharia de Produção da ABEPRO (2008). Posteriormente, foi estruturado um questionário do tipo misto, com as seguintes perguntas: A) Utiliza essa área e subárea em seu Plano de Ensino? B) Se sim, qual o número de horas dedicadas em cada uma delas. O questionário foi enviado (via e-main) aos professores das disciplinas. Não foi considerada a carga horária destinada ao Estágio Curricular Supervisionado (306 horas), pois, cada aluno pode realizar o Estágio em uma ou mais áreas.

Visando identificar a importância das áreas e subáreas da Engenharia de Produção na formação dos acadêmicos do Curso foram também enviados questionários (via e-mail) ao Presidente da ABEPRO Gestão 2014/2015 e ao Presidente da ABEPRO Gestão 2012/2013.

O questionário, do tipo aberto, foi elaborado com as seguintes perguntas: A) Em sua opinião, qual a importância do envolvimento das áreas e subáreas da Engenharia de
Produção na formação dos acadêmicos deste curso? B) É necessário que todas as áreas e subáreas da Engenharia de Produção, bem como suas respectivas subáreas, listadas pela ABEPRO (2008), estejam presentes na matriz curricular e sejam aplicadas com os alunos visando garantir as competências e habilidades de um Engenheiro de Produção?

Ao receber os questionários respondidos iniciou-se a tabulação e a análise dos dados. Para organização dos dados e elaboração das representações gráficas foi utilizado o programa Microsoft Office Excel 2010.

\section{RESULTADOS E DISCUSSÃO}

\subsection{HORAS DEDICADAS AOS NÚCLEOS DE CONTEÚDOS}

O Curso apresenta em sua matriz curricular conteúdos básicos, profissionalizantes e específicos, conforme estabelecem as Diretrizes Curriculares Nacionais do Curso de Graduação em Engenharia (BRASIL, 2002). As horas dedicadas a cada núcleo de conteúdos estão apresentadas na Figura 1.

No primeiro e no segundo ano do Curso predominam os conteúdos básicos, 748 e 646 horas aula, respectivamente, o que corresponde a 78,5 e $65,5 \%$ da carga horária total desses anos. Esses conteúdos decrescem ao longo do Curso, no terceiro ano, a carga horária cai para 136 horas aula, no quarto para 68 horas aula e no quinto não há conteúdos básicos.

De acordo com a ABEPRO (2003), os conteúdos básicos são fundamentais à compreensão e expressão de ideias e conceitos e ao desenvolvimento em qualquer modalidade de Engenharia.

Os conteúdos profissionalizantes são abordados, principalmente, no terceiro e quarto anos do Curso, 578 e 612 horas aula, respectivamente. Há aumento na carga horária desses conteúdos do primeiro ao quarto ano (de 68 para 612 horas aula), não havendo conteúdos profissionalizantes no quinto ano.

Os conteúdos específicos são abordados, principalmente, no quarto e quinto anos, $306 \mathrm{e}$ 605 horas aula, respectivamente. Observa-se - aumento na carga horária desses conteúdos, do primeiro ao quinto ano, de 68 para 605 horas aula, totalizando $100 \%$ dos conteúdos abordados no último ano do Curso. 
Figura 1 - Horas aulas dedicadas aos núcleos de conteúdos básicos, profissionalizantes, específicos e outros

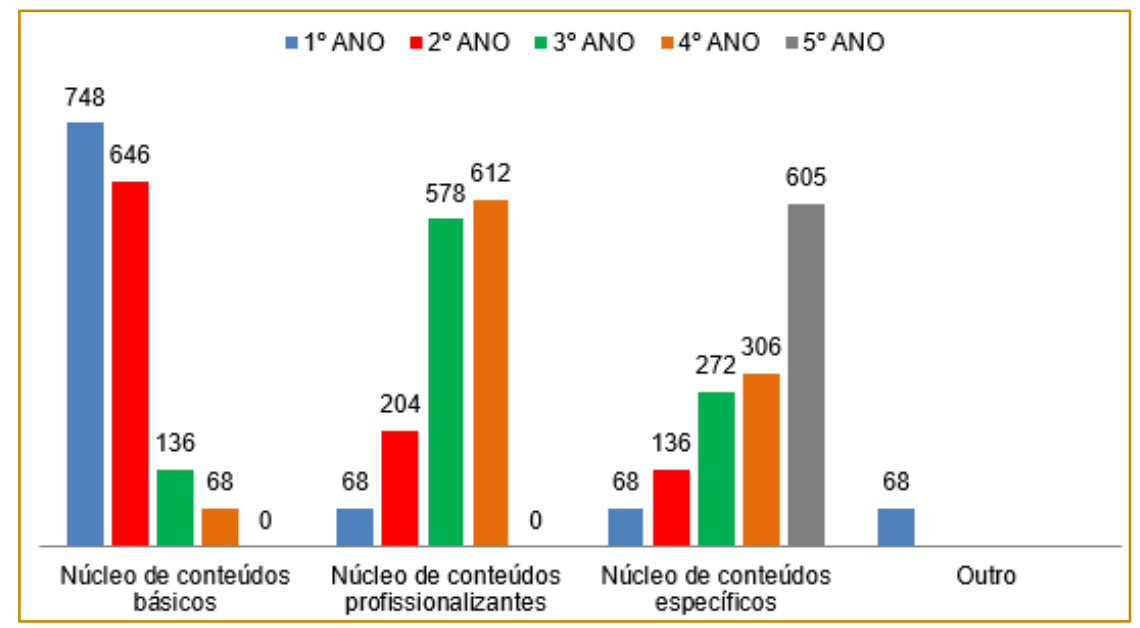

Fonte: Elaborado pelos autores

Quanto ao total de horas em cada núcleo de conteúdos, observou-se que o núcleo de conteúdos básicos totaliza 1.598 horas aula, o núcleo de conteúdos profissionalizantes 1.462 horas aula e o núcleo de conteúdos específicos 1.387 horas aula (Figura 2). A disciplina de Prática Desportiva (68 horas aula) não se enquadrou em nenhum dos núcleos de conteúdos descritos nas Diretrizes.

Figura 2 - Horas aulas e percentual da carga horária do Curso dedicados aos núcleos de conteúdos básicos, profissionalizantes, específicos e outros

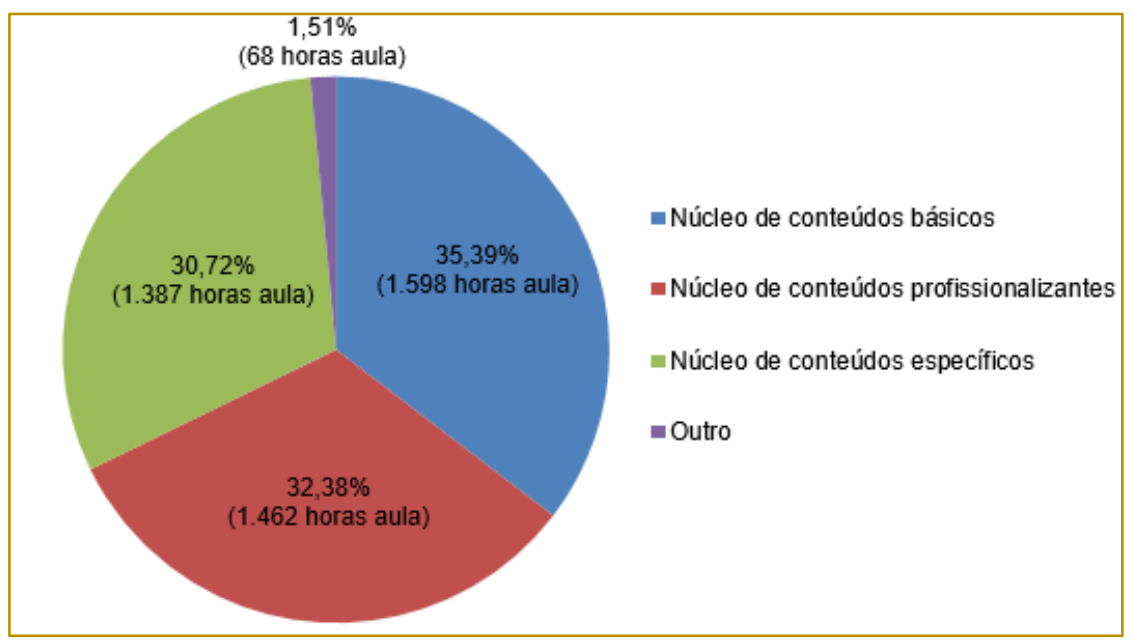

Fonte: Elaborado pelos autores

Os núcleos de conteúdos básicos, profissionalizantes e específicos corresponderam, respectivamente, a 35,39, 32,38 e $30,72 \%$ da carga horária total do Curso e $1,51 \%$ correspondeu a outros conteúdos, referentes à disciplina de Prática Desportiva (Figura 2).

Conforme as Diretrizes Curriculares Nacionais do Curso de Graduação em Engenharia
(BRASIL, 2002), o núcleo de conteúdos básicos deve contemplar cerca de 30\% da carga horária total do curso, o núcleo de conteúdos profissionalizantes cerca de $15 \%$ e o núcleo de conteúdos específicos cerca de $55 \%$. Observa-se que o núcleo de conteúdos básicos e o núcleo de conteúdos profissionalizantes estão acima das porcentagens descritas nas Diretrizes já o 
núcleo de conteúdos específicos apresenta carga horária inferior, conforme apresentado na Figura 3.

Visando adequar a matriz curricular do Curso às Diretrizes Curriculares Nacionais há necessidade de reestruturação a fim de trabalhar conteúdos específicos em disciplinas profissionalizantes e correlacionar conteúdos de disciplinas do núcleo de conteúdos básicos com disciplinas dos núcleos de conteúdos profissionalizantes e específicos.

Figura 3 - Percentuais da carga horária total do Curso em cada núcleo de conteúdos comparados aos estabelecidos nas Diretrizes

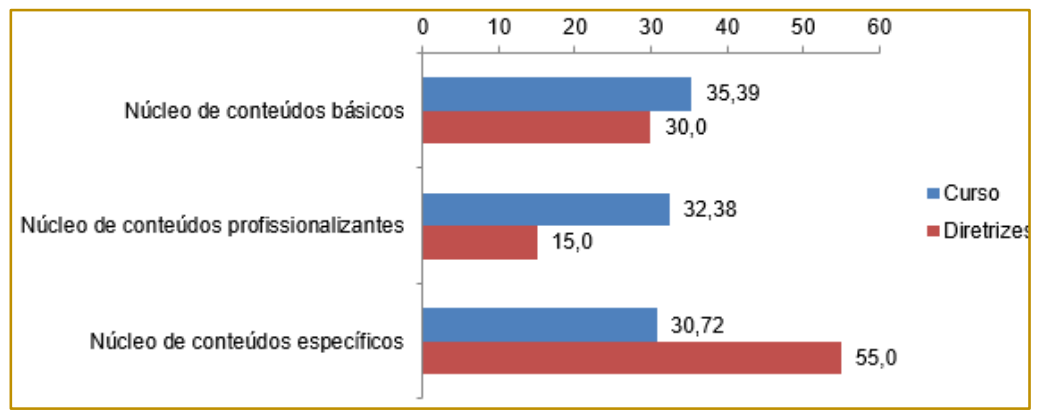

Fonte: Elaborado pelos autores

Observou-se também que das dezenove disciplinas optativas apresentadas no Projeto Político Pedagógico do Curso, três delas pertencem ao núcleo de conteúdos básicos, três ao núcleo de conteúdos específicos e treze ao núcleo de conteúdos profissionalizantes. De acordo com Santos (2004), as disciplinas optativas devem ser do núcleo de conteúdos específicos, o que evidencia a necessidade de reestruturação dessas ou a inclusão de novas disciplinas optativas na próxima matriz curricular.

\subsection{CARGA HORÁRIA DEDICADAS ÀS ÁREAS E SUBÁREAS DA ENGENHARIA DE PRODUÇÃO}

A Figura 4 apresenta a carga horária dedicada às áreas da Engenharia de Produção. As principais áreas da Engenharia de Produção abordadas nas disciplinas foram: Engenharia de Operações e Processos da Produção (507 horas aula), Pesquisa Operacional (349 horas aula) e Engenharia Organizacional (303 horas aula) e as menos abordadas Educação em Engenharia de Produção (68 horas aula), Engenharia do Trabalho (101 horas aula) e Engenharia Econômica (136 horas aula).

Figura 4 - Carga horária dedicada a cada área da Engenharia de Produção

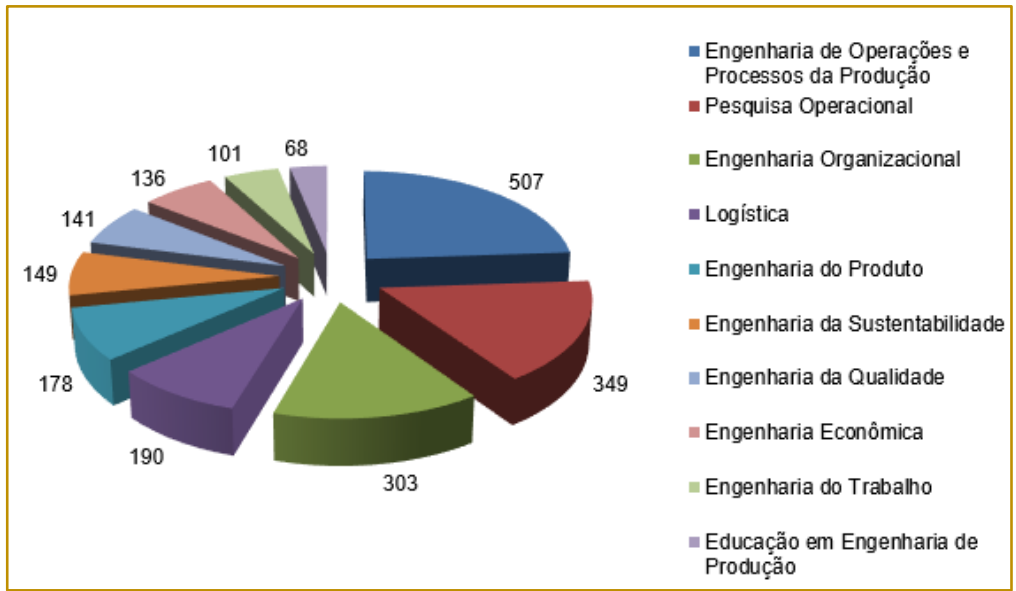

Fonte: Elaborado pelos autores 
Quanto às subáreas, as principais foram: Gestão de Sistemas de Produção e Operações (185 horas aula), Planejamento, Programação e Controle da Produção (158 horas aula) e Modelagem, Simulação e Otimização (148 horas aula). As subáreas menos abordadas foram Produção Mais Limpa e Ecoeficiência (9 horas aula) e Processos Estocásticos (2 horas aula). A subárea Gestão e Avaliação de Sistemas Educacionais de Cursos de Engenharia de Produção, foco desse estudo, não foi abordada no Curso.

Observou-se que 2.122 horas aula foram dedicadas às áreas e subáreas da Engenharia de Produção, o que corresponde a $51,16 \%$ da carga horária total de disciplinas (4.148 horas aula). Considerando-se que o Estágio Curricular Supervisionado, de 306 horas (aproximadamente 367 horas aula), é realizado somente em áreas e subáreas da Engenharia de Produção o número de horas aumenta para, aproximadamente, 2.489 horas aula, o que corresponde a aproximadamente $55,13 \%$ da carga horária total do Curso.

É importante destacar que apenas uma disciplina do núcleo de conteúdos básicos apresentou horas dedicadas à áreas/subáreas da Engenharia de Produção, devido à realização de atividades nas subáreas de Processo de Desenvolvimento do Produto e Planejamento e Projeto do Produto. Além disso, algumas disciplinas do núcleo de conteúdos específicos também apresentaram horas dedicadas às áreas e subáreas da Engenharia de Produção.

Grassano et al. (2010) ao compararem a Matriz do Conhecimento e de Competências, proposta pelo Conselho Federal de Engenharia e Agronomia (CONFEA) e pelo Conselho Regional de Engenharia e Agronomia (CREA), e as áreas e subáreas da Engenharia de Produção abordadas no Exame Nacional de Desempenho dos Estudantes (realizados nos anos de 2005 e 2008), às matrizes curriculares de Cursos de Engenharia de Produção, verificaram que as subáreas mais trabalhadas foram: Matemática (13,38\%), Física (9,64\%) e Métodos e Processos de Produção (8,03\%). Estes valores foram baseados em uma matriz curricular de 3.735 horas. Os autores observaram que as subáreas menos estudadas foram Comunicação e Expressão e Ergonomia e Segurança do Trabalho, ambas com $0,80 \%$ e constataram que algumas subáreas não foram abordadas.

De acordo com o Presidente da ABEPRO Gestão 2012/2013: Para o Engenheiro de Produção, o conhecimento em cada uma das áreas e subáreas da Engenharia de Produção é muito importante para ajudá-lo na solução das questões profissionais com que estará envolvido na sua carreira. Cada área mostrase capaz de melhorar os processos de qualquer tipo de organização. Saber utilizar esses conhecimentos com certeza irá agregar muito valor nas tomadas de decisões.

Para o Presidente da ABEPRO Gestão 2014/2015, o conjunto das áreas da Engenharia de Produção é importante, pois, compõe os conhecimentos mínimos necessários para que se forme um profissional de Engenharia de Produção que atenda à definição de Engenharia de Produção e aos objetivos propostos nos documentos da ABEPRO. A ausência de um mínimo de alguma dessas áreas pode comprometer a consecução de algum dos objetivos e deixar o profissional sem conhecimentos que o possibilitem desenvolver alguma habilidade e/ou competência.

Ao serem questionados se todas as áreas de conhecimento da Engenharia de Produção, bem como suas respectivas subáreas, devem estar presentes na matriz curricular, visando garantir as competências e habilidades de um Engenheiro de Produção, o Presidente da ABEPRO Gestão 2012/2013 afirmou que: as dez áreas devem sempre estar presentes na estrutura curricular de um curso de graduação em Engenharia de Produção. É muito importante para a formação do Engenheiro de Produção. No entanto as subáreas são aprofundamentos focados em alguns aspectos que levam a uma especialização. Nenhum curso conseguirá abordar todas as subáreas em um período normal de graduação em cinco anos. O que é aconselhável que um curso desenvolva a sua identidade desenvolvendo o aprofundamento de conteúdo em algumas subáreas.

\section{CONSIDERAÇÕES FINAIS}

$\mathrm{Na}$ matriz curricular do Curso foram destinadas maiores cargas horárias aos núcleos de conteúdos básicos e de conteúdos profissionalizantes, assim, há necessidade de reestruturação curricular a 
fim de aumentar a carga horária de conteúdos específicos, o que pode ser realizado abordando esses conteúdos em disciplinas profissionalizantes e correlacionando-se disciplinas do núcleo de conteúdos básicos às disciplinas dos núcleos de conteúdos profissionalizantes e específicos.

Cabe destacar que das dezenove disciplinas optativas apresentadas no Projeto Político Pedagógico do Curso treze delas devem ser reestruturadas, por não se enquadrarem no núcleo de conteúdos específicos.

As áreas da Engenharia de Produção mais trabalhadas no Curso foram Engenharia de Operações e Processos da Produção, Pesquisa Operacional e Engenharia Organizacional e as subáreas foram Gestão de Sistemas de Produção e Operações, Planejamento, Programação e Controle da

\section{REFERÊNCIAS}

[1] Abepro, Associação Brasileira de Engenharia de Produção. Grande Área e Diretrizes Curriculares. Rio de Janeiro/RJ, 1998. Disponível em:

$<$ www.abepro.org.br/arquivos/websites/1/DiretrCurr 19981.pdf>. Acesso em: 24 set. 2014.

[2] Abepro, Associação Brasileira de Engenharia de Produção. Referências Curriculares da Engenharia de Produção. Santa Bárbara d'Oeste/SP, 2003. Disponível em: $<$ www.abepro.org.br/arquivos/websites/1/DocStaB arbara2003.pdf>. Acesso em: 24 set. 2014.

[3] Abepro, Associação Brasileira de Engenharia de Produção. Áreas e Sub-áreas de Engenharia de Produção. Rio de Janeiro/RJ, 2008. Disponível em: $<w w w$.abepro.org. br/interna.asp? $p=399 \& m=424 \& s$ $=1 \& c=362>$. Acesso em: 24 set. 2014.

[4] Abepro, Associação Brasileira de Engenharia de Produção. Estatuto. São Carlos/SP, $2010 . \quad$ Disponível em: $<w w w$.abepro.org.br/interna.asp? $p=332 \& m=635 \& s$ $s=1 \& c=364>$. Acesso em: 24 set. 2014.

[5] Brasil, Conselho Nacional de Educação. Diretrizes Curriculares Nacionais do Curso de Graduação em Engenharia. Resolução CNE/CES 11/2002. Diário Oficial da União, Brasília, 9 de abril de 2002. Disponível em:<>. Acesso em: 9 out. 2014.

[6] Brasil, Conselho Nacional de Educação. Carga horária mínima e procedimentos relativos à integralização e duração dos cursos de graduação, bacharelados, na modalidade presencial. Resolução CNE/CES 2/2007. Diário Oficial da União, Brasília, 19 de junho de 2007. Disponível
Produção e Modelagem, Simulação e Otimização.

As áreas menos estudadas foram Educação em Engenharia de Produção, Engenharia do Trabalho e Engenharia Econômica e as subáreas Produção Mais Limpa e Ecoeficiência e Processos Estocásticos. A subárea de Gestão e Avaliação de Sistemas Educacionais de Cursos de Engenharia de Produção, foco desse estudo, não foi abordada. Há necessidade de abordar esses conteúdos no próximo Projeto Político Pedagógico do Curso, a fim de desenvolver essas competências e habilidades.

Este artigo servirá de referência para futuras mudanças no Projeto Político Pedagógico do Curso e como material de apoio ao Núcleo Docente Estruturante.

em:<portal.mec.gov.br/cne/arquivos/pdf/2007/rces 002_07.pdf>. Acesso em: 12 out. 2014.

[7] Carvalho, Anna Cristina Barbosa Dias de; Porto, Arthur José Vieira; Belhot, Renato Vairo. Aprendizagem significativa em Engenharia. Revista Produção, v. 11, n. 1, p. 81-90, 2001.

[8] Cunha, Gilberto Dias da. Um panorama atual da Engenharia de Produção. Porto Alegre, $2002 . \quad$ Disponível em:<www.abepro.org.br/arquivos/websites/1/Panor amaAtualEP4.pdf>. Acesso em: 30 set. 2014.

[9] Fleury, Afonso. O que é Engenharia de Produção. In. BATALHA, Mario Otávio (Org.). Introdução a Engenharia de Produção. Rio de Janeiro: Elsevier, 2008.

[10] Gil, Antonio Carlos. Métodos e técnicas de pesquisa social. 6. Ed. São Paulo: Atlas, 2008.

[11] Grassano, Dayanni Rossi; LIMA, Larissa Faria de; Mendes, Ramon Freitas; Ferraz, Thais Cristina Pereira; Oliveira, Vanderli Fava. Estudo da representatividade das áreas e subáreas da Engenharia de Produção segundo a matriz do conhecimento e o Enade. Encontro Nacional de Engenharia de Produção (XXX ENEGEP), 30, 2010. São Carlos, SP. Anais...

[12] Laudares, João Bosco; Batista, José de Paula. Um estudo comparativo dos currículos dos cursos de Engenharia Civil e de Engenharia de Produção Civil de escolas de engenharia mineiras. Congresso Brasileiro DE educação em Engenharia (XXXI Cobenge), 31, 2003. Rio de Janeiro, RJ. Anais..

[13] Oliveira, Vanderli Fava de. Um estudo sobre a avaliação dos cursos de Engenharia de Produção. Encontro Nacional de Engenharia de Produção (XXIV Enegep), 24, 2004. Florianópolis, SC. Anais... 
[14] Santos, Fernando César Almada. A incorporação do núcleo de conteúdos específicos na graduação em Engenharia de Produção da EESC-USP. CONGRESSO BRASILEIRO DE Educação em Engenharia (XXXII Cobenge), 32, 2004. Brasília, DF. Anais...

[15] Santos, Fernando César Almada. O que é Engenharia de Produção. In. BATALHA, Mario
Otávio (Org.). Introdução a Engenharia de Produção. Rio de Janeiro: Elsevier, 2008.

[16] Telles, Pedro Carlos da Silva. História da Engenharia no Brasil: século XX. 1. Ed. V. 2. Rio de Janeiro: Clavero, 1984. 


\title{
Gapítulo 25
}

\section{ADEQUAÇÃO DO MANEJO PRÉ-ABATE DE FRANGOS AO PROGRAMA NACIONAL DE ABATE HUMANITÁRIO - STEPS - ESTUDO DE CASO EM UMA INDÚSTRIA FRIGORIFICA}

\author{
Gabriel Andrian Gentilin
}

Andréa Machado Groff

Resumo: O crescente aumento da preocupação dos consumidores com a produção de alimentos cárneos, que garanta o bem-estar animal, vem aumentando em escala global, fazendo com que indústrias frigoríficas passem por mudanças a fim de satisfazer os consumidores. Além disso, protocolos de cooperação foram firmados entre países reforçando práticas que prezem pelo bemestar animal, o que evidencia a importância de adequações no processo produtivo como forma de adquirir credibilidade com o mercado externo. As operações do manejo pré-abate, se não realizadas adequadamente, comprometem o bem-estar animal e causam muitos prejuízos às indústrias avícolas, em decorrência de reduções no rendimento de carcaça e na qualidade da carne. O manejo pré-abate de frangos envolve as etapas realizadas antes da chegada dos animais à indústria frigorífica (jejum, captura, carregamento e transporte) e as realizadas na indústria frigorífica (descanso, descarregamento, pendura e insensibilização). Como meio de propiciar o bem-estar dos animais de produção, a World Society of the Protection of Animals (WSPA) elaborou e implantou no Brasil, em conjunto com o Ministério da Agricultura, Pecuária e Abastecimento (MAPA), - Programa Nacional de Abate Humanitário - Steps. O Programa Steps tem diretrizes e recomendações internacionalmente aceitas de boas práticas de abate humanitário e um dos seus pilares é o treinamento de fiscais e de profissionais das indústrias frigoríficas. Com o objetivo de verificar se as operações de manejo pré-abate de frangos estavam em conformidade com o Programa Steps o presente estudo foi realizado em uma indústria frigorífica, localizada no estado do Paraná. Para a avaliação do bem-estar animal durante o manejo pré-abate, primeiramente, foram consultadas as recomendações descritas no Programa e, no frigorífico, observadas as etapas de descanso, descarregamento, pendura e insensibilização dos frangos. Posteriormente, as causas de não atendimento às recomendações do Programa foram identificadas e priorizadas, utilizando-se a Matriz GUT, e o plano de ação elaborado. Nenhuma das etapas do manejo pré-abate avaliadas atendeu a todas as recomendações do Programa Steps. A causa de maior grau crítico foi o tempo inadequado de descanso, seguido da utilização de parâmetros incorretos de insensibilização, acúmulo e colisão de gaiolas na etapa de descarregamento, falta de treinamento de colaboradores da pendura, falhas na realização do abate emergencial na área de recepção e, na etapa de insensibilização, falta de monitoramento do comportamento dos frangos depois de insensibilizados. Para a adequação do tempo de descanso sugeriu-se considerar o horário previsto para o abate e os tempos de apanha e de transporte. Para a adequação dos parâmetros de insensibilização sugeriuse a capacitação dos colaboradores e maiores rapidez e eficácia na comunicação entre colaboradores da recepção e da insensibilização, para que os parâmetros sejam adequados ao lote. Na etapa de descarregamento, para diminuir o acúmulo e a colisão de gaiolas foi proposta a aquisição e instalação de um sensor ótico na esteira. Para a adequação da pendura sugeriu-se, primeiramente, a realização de estudos sobre os impactos de realizar o procedimento de acalmar os frangos com as mãos sobre o ritmo de pendura estabelecido pelo frigorífico. Para a adequação do abate emergencial recomenda-se o treinamento de dois colaboradores. Para o adequado monitoramento do comportamento dos frangos depois de insensibilizados recomenda-se a capacitação dos colaboradores sobre os comportamentos que não devem ser apresentados após a insensibilização. Para estudos futuros, sugere-se que as perdas ocasionadas pelo não cumprimento do Programa Steps ao rendimento de carcaças e à qualidade da carne de frangos sejam quantificadas e avaliadas.

Palavras-chave: Insensibilização; Matriz GUT; Pendura; Tempo de descanso; Bem-estar animal. 


\section{INTRODUÇÃO}

A exigência por produtos cárneos produzidos assegurando 0 bem-estar animal vem crescendo em escala global e faz com que as indústrias, cada vez mais, adotem os procedimentos necessários para atender tal exigência (OLIVO, 2006).

Grandin (2014) afirma que, para as indústrias frigoríficas, a preocupação com a origem de suas matérias-primas, os animais, e a forma como estes são abatidos impactam, de forma direta, na opinião dos consumidores. Tal preocupação vem, gradativamente, ganhando força devido à grande disponibilidade de informações trazidas pelos diversos meios de comunicação e, de acordo com Grandin (2014) e Rodrigues et al. (2016), os consumidores estão dispostos a pagar mais por um produto em que os processos que assegurem o bem-estar animal tenham sido adotados.

As operações de manejo pré-abate, se não realizadas adequadamente, comprometem o bem-estar animal e causam muitos prejuízos às indústrias frigoríficas, em decorrência de reduções no rendimento de carcaça e na qualidade da carne (RUI; ANGRIMANI; SILVA, 2011; GRANDIN, 2014).

O manejo pré-abate de frangos envolve as operações realizadas antes da chegada dos animais à indústria frigorífica (jejum, captura, carregamento e transporte) e aquelas realizadas na indústria frigorífica (descanso, descarregamento,
insensibilização).

Como medida para propiciar o bem-estar dos animais de produção foi criado o Programa Nacional de Abate Humanitário - Steps (etapas em português), elaborado e implantado no Brasil pela World Society of the Protection of Animals - WSPA, em conjunto com o Ministério da Agricultura, Pecuária e Abastecimento - MAPA (LUDTKE et al., 2010). O Programa Steps apresenta uma série de recomendações a serem consideradas nas diversas etapas do manejo pré-abate de frangos.

Para a correta avaliação do bem-estar animal, algumas variáveis devem ser levadas em consideração, como o conceito das cinco liberdades, definido pelo Comitê Brambell e aperfeiçoado pelo Conselho de Bem-Estar na Produção Animal do Reino Unido, que é utilizado mundialmente (LUDTKE et al., 2010). Segundo o conceito, o animal deve estar livre de fome, sede e má nutrição; livre de desconforto; livre de dor, injúria e doença; livre para expressar seu comportamento normal e livre de medo (SILVA; MIRANDA, 2009).

Existem vários fatores que podem comprometer o bem-estar dos frangos nas etapas de manejo pré-abate como: desconforto térmico, tempo excessivo de espera pré-abate, dor nas pernas ou canelas devido à compressão do gancho, uso de força excessiva na etapa de pendura, medo e estresse ocasionados por posição desconfortável, lesões provocadas pelo bater de asas e parâmetros de insensibilização inadequados (LUDTKE et al., 2010).

O Programa Steps tem diretrizes e recomendações internacionalmente aceitas de boas práticas de abate humanitário e um dos seus pilares é o treinamento de fiscais e de profissionais das indústrias frigoríficas (ABIPECS, 2010).

Sendo assim, a fim de avaliar se as operações de manejo pré-abate, realizadas nas etapas de descanso, descarregamento, pendura e insensibilização, estavam de acordo com o Programa Steps, o presente estudo foi realizado em um frigorífico de frangos, localizado no estado do Paraná.

\section{FUNDAMENTAÇÃO TEÓRICA}

\subsection{ENGENHARIA DE PROCESSOS E OPERAÇÕES DA PRODUÇÃO}

Esta pesquisa se enquadra na área de Engenharia de Processos e Operações da Produção, tendo como subárea a Engenharia de Métodos. A Engenharia de Processos e Operações da Produção é uma das áreas da Engenharia de Produção e compreende projetos, operações e melhorias dos sistemas que criam e entregam os produtos (bens ou serviços) primários da empresa (ABEPRO, 2008). A subárea Engenharia de Métodos, de acordo com Souto (2002) busca a padronização do processo, por meio do estudo e análise do trabalho, de forma sistemática, a fim de encontrar o melhor método para a realização de uma tarefa com maior produtividade.

Segundo Takashina e Flores (1996), o estudo de tempos e de métodos fornece formas para a obtenção de dados reais e de indicadores confiáveis, modificando a maneira de gerir 
questões como a produtividade e a qualidade.

Os protocolos de bem-estar animal apresentam métodos que propiciam, além do bem-estar animal, o aumento da produtividade e a melhoria da qualidade e servem como guias norteadores, possibilitando assim, atender às exigências dos consumidores.

A seguir serão apresentadas as recomendações para o manejo pré-abate nas etapas avaliadas no presente estudo: descanso, descarregamento, pendura e insensibilização dos frangos.

\subsection{RECOMENDAÇÕES PARA O MANEJO PRÉ-ABATE DE FRANGOS}

\subsubsection{DESCANSO}

O descanso deve ser realizado em galpão de espera e propiciar condição térmica adequada aos frangos, o que contribui para a menor ocorrência de carne de qualidade inferior devido ao estresse térmico e também para a minimização da taxa de mortalidade (VIEIRA, 2008)

De acordo com o Programa Steps o caminhão de frangos deve ser direcionado para o local de descanso sem delongas (LUDTKE et al., 2010). Sandercock et al. (2001) afirmam que frangos que sofrem estresse térmico agudo antes do abate apresentam carne de qualidade inferior podendo comprometer também a produtividade. Estresse térmico agudo pode ser caracterizado por condições intensas de calor e acontecer tanto no transporte como no galpão de espera (MITCHELL; KETTLEWELL, 1998).

De acordo com o Programa Steps o galpão de espera deve ser coberto, arejado, possuir sistemas eficientes de nebulização, distribuição uniforme de ventiladores, termo higrômetro e colaborador treinado para realizar o monitoramento e a coleta de dados referentes à temperatura e umidade relativa do ar, a fim de proporcionar um ambiente onde $\mathrm{o}$ frango consiga se acalmar e se recuperar do estresse causado pelo transporte, em um tempo de, no mínimo, uma hora e, no máximo, duas horas (LUDTKE et al., 2010).

\subsubsection{DESCARREGAMENTO}

Após o descanso, os frangos são direcionados para a área de recepção, que consiste no descarregamento das gaiolas, de forma manual ou automática (TAVERNARI; ALBINO; ARAÚJO, 2012).

De acordo com o Programa Steps a área de recepção deve dispor de esteira móvel ou elevador para auxiliar no descarregamento das gaiolas, que deve ser feito sem causar agitação desnecessária (LUDTKE et al., 2010)

Nessa etapa o número de frangos mortos por caminhão deve ser registrado e os frangos em estado de sofrimento devem ser abatidos imediatamente, por meio do destroncamento do pescoço, por um colaborador devidamente treinado (LUDTKE et al., 2010).

\subsubsection{PENDURA}

Posteriormente, os frangos são direcionados, por meio de esteiras, até a linha de pendura. De acordo com o Programa Steps (LUDTKE et al., 2010), a pendura deve ser realizada, pelo colaborador, por ambos os pés do frango na nórea (linha contínua provida de ganchos), que deve ser dotada de um parapeito ao longo de toda a sua linha e apresentar o mínimo de curvas e variações de altura. Ainda de acordo com as recomendações do Programa, ao final da linha de pendura deve haver uma luz direcionada às gaiolas para averiguar se essas estão vazias.

O ambiente de pendura deve apresentar baixa intensidade luminosa, as portas de acesso devem ser abertas o mínimo possível e os colaboradores devem evitar a movimentação desnecessária próxima à linha de pendura (LUDTKE et al., 2010). O Programa recomenda ainda que os colaboradores mantenham as suas mãos sobre o frango após a pendura por um período de 1 a 2 segundos a fim de acalmálos.

O tempo compreendido entre a pendura e a insensibilização não deve ser inferior a 12 segundos ou superior a 60 segundos e, caso ocorram situações emergenciais como queda de energia ou parada de funcionamento, é recomendada a remoção dos frangos dos ganchos até que o processo normalize (LUDTKE et al., 2010). 


\subsubsection{INSENSIBILIZAÇÃO}

O método mais utilizado para a insensibilização é a eletronarcose, em que os frangos são imersos em uma cuba com água eletrificada de maneira que a corrente elétrica flua da cuba para os frangos e se dissipe nos ganchos da nórea, que devem estar molhados (LUDTKE et al., 2010). A insensibilização adequada pode otimizar o processo de sangria uma vez que a imobilidade proporcionada anula possíveis contusões (LUDTKE et al., 2010).

A eletronarcose atua nos frangos em um tempo de 15 milésimos de segundo, se realizada corretamente, promove perda de consciência imediata minimizando o sofrimento além de causar o mínimo dano à carcaça, porém, caso realizada inadequadamente, pode ocasionar sofrimento e perdas devido à fraturas e manchas na carcaça (LUDTKE et al., 2010).

O Programa recomenda que o frango seja imerso na cuba de insensibilização até a base de suas asas e que a sua cabeça fique o mais próximo possível do eletrodo - eletrodos afastados há mais de $5 \mathrm{~cm}$ da parede da cuba podem não contribuir para a perda imediata de consciência por apresentarem corrente elétrica menor que a mínima recomendada, que é de 0,12 ampères/frango (com frequência entre 400 a $1500 \mathrm{~Hz}$ ) - devese buscar também maior uniformidade de lotes uma vez que o diâmetro das pernas do frango influencia, de forma direta, a condutividade da corrente elétrica (LUDTKE et al., 2010).

Os parâmetros de insensibilização devem ser dispostos em um visor para facilitar o monitoramento e a modificação quando necessária, além disso, o monitoramento dos frangos deve ser realizado a fim de verificar a eficácia da insensibilização (LUDTKE et al., 2010). Na fase tônica, caracterizada pela perda da consciência e enrijecimento do corpo, o frango deve apresentar pescoço arqueado, asas fechadas, tremor involuntário, olhos abertos, pernas estendidas e ausência de respiração rítmica, posteriormente, a fase clônica, é caracterizada por contração e contorcimento das extremidades do corpo e movimentos descoordenados das asas e, por fim há ausência de reflexos oculares e da terceira pálpebra (LUDTKE et al., 2010).

\section{REVISÃO DE LITERATURA}

Nesta seção estão apresentados dois trabalhos realizados com objetivos similares ao desse estudo.

Silveira (2013) realizou um estudo em um frigorífico de frangos com o objetivo analisar as condições relacionadas ao bem-estar animal e abate humanitário e estabelecer ações corretivas. Foram analisados 29 lotes e definidos os pontos de controle e os pontos críticos de controle. Constatou-se que apenas três pontos de controle e um ponto crítico de controle apresentavam 100\% de conformidade. Ações corretivas foram sugeridas a fim de minimizar as não conformidades encontradas.

Jorge (2008) avaliou os procedimentos relacionados à distância de transporte, tempo de transporte, tempo de espera, tempo de engradamento, densidade relativa de cada caminhão, incidência de mortalidade e de contusões em 992.036 frangos. Observou índices elevados de hematomas, contusões, mortalidade, aerossaculite e $\mathrm{pH}$ da carne alterado. O autor atribuiu tais índices à falta de cuidados em relação ao bem-estar animal, acarretando grandes perdas para o frigorífico.

\section{METODOLOGIA}

\subsection{CARACTERIZAÇÃO DA EMPRESA}

O presente estudo foi realizado no período de Agosto a Novembro de 2016 em uma unidade frigorífica de frangos, localizada no estado do Paraná. A unidade pertence a uma cooperativa que atua no processamento e comercialização de carnes suínas e de frangos, lácteos, massas, vegetais e rações.

No período de realização do estudo, a unidade abatia, em média, 155 mil frangos/dia em dois turnos. Os dados utilizados para a realização desse estudo foram coletados no primeiro turno, com início às 04h:05min e término às 13h:35min.

\subsection{AVALIAÇÃO DO BEM-ESTAR ANIMAL}

Para a avaliação do bem-estar animal foram consideradas as recomendações apresentadas no Programa Nacional de Abate Humanitário - Steps, elaborado pela World Society for the Protection of the Animals em conjunto com o MAPA (LUDTKE et al., 2010), e observadas as operações de manejo pré- 
abate realizadas nas etapas de descanso, descarregamento, pendura e insensibilização dos frangos.

$\mathrm{Na}$ etapa de descanso, durante 15 dias, foram coletados: o tempo de espera dos caminhões (compreendido entre a chegada do caminhão e o descarregamento das gaiolas na plataforma de recepção), a temperatura e a umidade relativa do ar, três vezes ao dia, ambas com o auxílio de um termo higrômetro. Foram também observadas as características do galpão de espera, o funcionamento dos nebulizadores e ventiladores e se havia um colaborador treinado para monitorar a temperatura e a umidade relativa do ar no local.

$\mathrm{Na}$ etapa de descarregamento, durante 15 dias, foram observados: os procedimentos utilizados no abate emergencial, a ocorrência de diferenças significativas no tamanho e no peso dos frangos, a forma de descarregamento das gaiolas (se havia esteira ou elevador para tal fim) e os dados referentes ao registro de frangos mortos (retirados da planilha de controle de abate diário).

$\mathrm{Na}$ etapa de pendura, durante 15 dias, foi verificado se os colaboradores evitavam movimentação desnecessária próxima à linha de pendura e também se mantinham suas mãos sobre o frango após a pendura e por quanto tempo, com a finalidade de acalmálos. Foram observadas também as características da nórea, a intensidade de iluminação no local e se havia luz direcionada às gaiolas, no fim da esteira, para verificar se essas estavam vazias. Além disso, o tempo entre a pendura e a insensibilização foi mensurado (com o auxílio de um cronômetro) e os procedimentos adotados durante situações emergenciais identificados.

$\mathrm{Na}$ etapa de insensibilização, primeiramente, foi determinada a amostra necessária para observação, realizando-se o cálculo de amostragem aleatória simples, caracterizado pela igualdade de chances de qualquer frango ser selecionado. Para o cálculo, foi utilizada a Equação 1, descrita por Correa (2003).

Em que:

$$
n=\frac{Z^{2} \cdot p \cdot(1-p)}{e^{2}}
$$

$$
\begin{aligned}
& n=\text { amostra calculada; } \\
& Z \text { = variável normal padronizada associada ao nível de confiança; } \\
& \mathrm{p}=\text { verdadeira probabilidade do evento; } \\
& \mathrm{e}=\text { erro amostral. }
\end{aligned}
$$

Assim, foi obtido o número necessário de frangos insensibilizados a serem observados (663). Por meio da velocidade da nórea obteve-se o tempo necessário requerido para observar os 663 frangos.

A coleta foi realizada uma vez por dia durante 15 dias e em diferentes horários. Foram anotados dados referentes ao peso médio e sexo dos frangos, corrente utilizada e frequência. Também foi observado se os ganchos estavam molhados e se havia diferença significativa no tamanho e no peso dos frangos. Para a identificação da má insensibilização foram avaliados 0 bater coordenado de asas e os reflexos oculares e da terceira pálpebra. Além disso, foram observadas as características da cuba de imersão, a localização dos eletrodos e o visor dos parâmetros de insensibilização.

\subsection{ELABORAÇÃO DO PLANO DE AÇÃO}

Para a priorização das causas e elaboração do plano de ação, utilizou-se a Matriz GUT. Conforme descrito por Kepner e Tregoe (1981), a Matriz auxilia na gestão de projetos e também na definição de estratégias para decisão de qual causa do problema deverá ser priorizada levando em consideração a gravidade (G), a urgência $(U)$ e a tendência (T) da causa a partir da atribuição de pontuação para cada um desses itens. A atribuição da pontuação foi realizada da seguinte maneira: Para $G$ foram atribuídas as pontuações $5,4,3,2,1$ para causas 
extremamente graves, muito graves, graves, pouco graves e sem gravidade, respectivamente. Para $U$ foram atribuídas as pontuações 5,4 , 3, 2, 1 para necessidade de ação imediata, muito urgente, urgente, pouco urgente e sem urgência, respectivamente. Por fim, para $T$ a referida pontuação foi atribuída da seguinte maneira: irá piorar rapidamente, irá piorar em curto prazo, irá piorar em médio prazo, irá piorar em longo prazo e não irá piorar, respectivamente. A causa do problema que apresentou maior pontuação, considerando-se a multiplicação $G \times \cup \times T$, foi priorizada.

Posteriormente, foi elaborado um plano de ação para minimizar as causas do problema que levaram ao não atendimento das recomendações apresentadas no Programa Steps.

\subsection{CARACTERIZAÇÃO DA PESQUISA}

A pesquisa classifica-se, quanto ao método de abordagem, como mista (qualiquantitativa), qualitativa por descrever os requisitos de bem-estar e identificar as causas do não atendimento às recomendações do Programa Steps e quantitativa por apontar percentuais de falhas a partir da observação das operações de manejo pré-abate nas etapas de descanso, descarregamento, pendura e insensibilização.
Quanto aos fins classifica-se como exploratória, descritiva e explicativa uma vez que identifica e descreve as causas de não atendimento às recomendações do Programa. Quanto aos meios, classifica-se como bibliográfica, documental e estudo de caso.

\section{ESTUDO DE CASO}

\subsection{BEM-ESTAR NA ETAPA DE DESCANSO}

O Quadro 1 apresenta as principais recomendações do Programa Steps para a etapa de descanso e se as práticas adotadas pelo frigorífico atendiam ou não essas recomendações.

Nesta etapa foi observado que, logo após a chegada ao frigorífico, o caminhão era direcionado ao galpão de espera sem delongas e que o galpão de espera era coberto e aberto nas laterais, para facilitar a circulação de ar. O sistema de controle de temperatura compreendia ventiladores, nebulizadores e termo higrômetro, que apresentaram funcionamento adequado. O monitoramento desse sistema era realizado a cada duas horas por colaborador devidamente treinado. Os dados referentes ao monitoramento eram anotados em uma planilha de controle do bem-estar-animal. Todos estes aspectos estavam em conformidade com as recomendações do Programa Steps.

Quadro 1. Atendimento às recomendações do Programa Nacional de Abate Humanitário - Steps Etapa de descanso.

\begin{tabular}{|c|c|c|}
\hline Fatores a serem considerados & Recomendações & $\begin{array}{l}\text { Atende as } \\
\text { recomendações? }\end{array}$ \\
\hline $\begin{array}{l}\text { Condução do caminhão ao galpão de } \\
\text { espera }\end{array}$ & $\begin{array}{l}\text { O caminhão deve ser direcionado para o galpão } \\
\text { de espera sem delongas }\end{array}$ & Sim \\
\hline Características do galpão de espera & $\begin{array}{l}\text { Coberto e arejado, com sistemas eficientes de } \\
\text { nebulização e distribuição uniforme de } \\
\text { ventiladores }\end{array}$ & Sim \\
\hline \multirow[b]{2}{*}{$\begin{array}{l}\text { Controle da temperatura e da umidade } \\
\text { relativa do ar no galpão de espera }\end{array}$} & $\begin{array}{l}\text { Controle de temperatura e umidade relativa do } \\
\text { ar deve ser realizado com termo higrômetro }\end{array}$ & Sim \\
\hline & $\begin{array}{l}\text { Umidade relativa deve ser variável em função da } \\
\text { temperatura e, quando a temperatura for inferior } \\
\text { a } 10^{\circ} \mathrm{C} \text {, todos os sistemas de controle de } \\
\text { temperatura deverão ser desligados }\end{array}$ & Sim \\
\hline Colaborador & $\begin{array}{l}\text { Treinado para realizar o monitoramento e a } \\
\text { coleta de dados referentes à temperatura e } \\
\text { umidade relativa do ar }\end{array}$ & Sim \\
\hline Tempo de descanso & Mínimo de 1 hora e máximo de 2 horas & Não \\
\hline
\end{tabular}

Por outro lado, o tempo de descanso dos frangos, compreendido entre a chegada do caminhão e o descarregamento das gaiolas na plataforma de recepção, era irregular e, na maioria das vezes, não atendeu os tempos mínimo e máximo, conforme pode ser 
visualizado na Figura 2. As linhas em vermelho representam os limites de espera mínimo e máximo (uma e duas horas, respectivamente).

Foram avaliados os tempos de descanso em 219 caminhões e constatado que apenas 79 (36,07\% do total) estavam dentro dos limites estabelecidos. Os outros 140 caminhões, equivalente a $63,93 \%$, se encontravam fora dos limites descritos no Programa Steps.

Tempos inadequados de descanso podem ocasionar perdas por mortalidade, segundo Bressam e Beraquet (2002), quanto menor o tempo de descanso maior a taxa de mortalidade devido ao estresse e, segundo Warris et al. (1999), o longo tempo de descanso também ocasiona estresse e mortalidade dos frangos. Apesar de ainda existirem poucos estudos com resultados focados na mortalidade ocorrida na etapa de descanso pré-abate, Ritz, Webster Czarick (2005) afirmam que $40 \%$ das perdas ocorridas nessa etapa estão ligadas ao estresse térmico, reforçando a importância da existência de um sistema de controle térmico eficiente.

Figura 2. Tempo de descanso em cada caminhão.

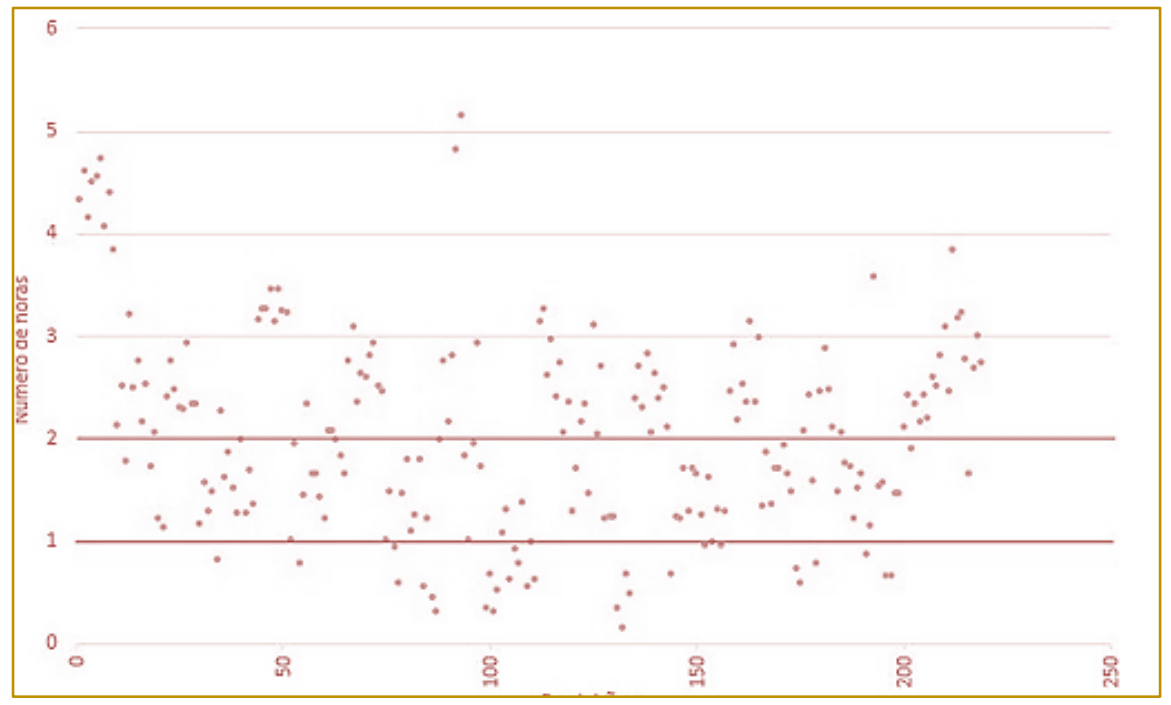

\subsection{BEM-ESTAR NA ETAPA DE DESCARREGAMENTO}

As recomendações do Programa Steps referentes à etapa de descarregamento e o atendimento do frigorífico a tais recomendações estão apresentados no Quadro 2.

Verificou-se que o local de recepção apresentava um desempilhador automático acompanhado de uma esteira móvel, a fim de auxiliar no descarregamento das gaiolas sem causar agitação desnecessária.

Foi verificado que os frangos que apresentavam significativa diferença de tamanho e de peso (frangos caquéticos) e os frangos em estado de sofrimento eram abatidos de maneira emergencial, pois, os colaboradores eram orientados, frequentemente, sobre a importância de tal cuidado para o bem-estar animal. No entanto, os colaboradores não eram devidamente treinados para a realização do abate emergencial. No período de 15 dias ocorreram 23 abates emergenciais e esses foram realizados retirando-se as cabeças e não por meio do destroncamento do pescoço como prevê o Programa.

Os frangos mortos de cada caminhão eram contabilizados e, ao final do abate, o número era anotado em uma planilha de controle de abate diário, conforme previsto no Programa. 
Quadro 2. Atendimento às recomendações do Programa Nacional de Abate Humanitário - Steps Etapa de descarregamento.

\begin{tabular}{|c|c|c|}
\hline $\begin{array}{l}\text { Fatores a serem } \\
\text { considerados }\end{array}$ & Recomendações & $\begin{array}{l}\text { Atende as } \\
\text { recomendações? }\end{array}$ \\
\hline $\begin{array}{l}\text { Ambiente de } \\
\text { recepção }\end{array}$ & $\begin{array}{l}\text { Deve dispor de esteira móvel ou elevador para auxiliar no } \\
\text { descarregamento das gaiolas }\end{array}$ & Sim \\
\hline \multirow{2}{*}{$\begin{array}{c}\text { Abate } \\
\text { emergencial }\end{array}$} & $\begin{array}{l}\text { Os frangos que apresentarem diferença significativa em seu } \\
\text { tamanho e peso e os que estiverem em estado de sofrimento } \\
\text { devem ser abatidos de maneira emergencial }\end{array}$ & Sim \\
\hline & $\begin{array}{l}\text { O abate emergencial deve ser realizado por meio do } \\
\text { destroncamento do pescoço, por um colaborador devidamente } \\
\text { treinado }\end{array}$ & Não \\
\hline $\begin{array}{c}\text { Controle de } \\
\text { frangos mortos }\end{array}$ & Registrar o número de frangos mortos por caminhão & Sim \\
\hline $\begin{array}{l}\text { Descarregamento } \\
\text { das gaiolas }\end{array}$ & Deve ser feito sem causar agitação desnecessária & Não \\
\hline
\end{tabular}

No descarregamento foi observada a ocorrência de forte colisão entre as gaiolas que estavam sendo desempilhadas com as que já estavam na esteira, em direção à linha de pendura. Tal colisão deixa de acontecer apenas durante as pausas diárias de recuperação e almoço quando não há gaiolas na esteira. O espaço compreendido entre o início e o final dessa esteira comporta 51 gaiolas. Multiplicando-se esse número de gaiolas pelo número de pausas diárias (quatro) encontrou-se o número de gaiolas que não sofreram colisão diariamente, que correspondeu a 204 gaiolas.

Considerando-se que, o frigorífico abate, em média, 77.500 frangos/dia/turno (9.687 gaiolas/turno/dia) e levando-se em consideração o número de gaiolas que não sofreram colisão (204) devido às pausas citadas anteriormente, as gaiolas restantes (9.483) equivalem a 75.864 frangos que tiveram suas gaiolas colididas, ou seja, $97,88 \%$ dos frangos abatidos no primeiro turno.

Grandin (2014) afirma que a prática do bemestar nas etapas do manejo pré-abate contribui para maiores qualidade da carne e rendimento de carcaça nas etapas subsequentes. Considerando-se tal afirmação, a não adequação referente ao descarregamento das gaiolas pode proporcionar aos frangos maior nível de estresse, hematomas e fraturas impactando, de forma negativa, na qualidade da carne e no rendimento de carcaça.

O prejuízo ocasionado pela colisão das gaiolas pode ser grande uma vez que entre os pré-requisitos para exportação estão as ausências de manchas na carne e de ossos quebrados. Mesmo para o mercado interno a presença de manchas e de ossos quebrados não é bem vista pelos consumidores, assim tal colisão pode influenciar nas vendas para os mercados interno e externo.

\subsection{BEM-ESTAR NA ETAPA DE PENDURA}

O Quadro 3 apresenta as recomendações descritas no Programa Steps para a etapa de pendura e se tais recomendações estavam sendo atendidas pelo frigorífico.

Seguindo as recomendações para a etapa de pendura, apresentadas no Quadro 3, foi verificado que a linha de pendura conta com um parapeito, possuindo apenas uma pequena variação de altura em um de seus pontos. Luzes azuis são acionadas propiciando um ambiente com uma baixa intensidade de iluminação. Ainda foi verificada a existência de uma luz branca fixada ao fim da linha de pendura direcionada para as gaiolas com objetivo de verificar se todos os frangos foram retirados dessas.

Observou-se o tempo compreendido entre a pendura e a insensibilização e constatou-se que, independente da velocidade média da nórea, esse não foi menor que 12 segundos ou maior que 60 segundos, respeitando o que - Programa prevê. Constatou-se ainda que, em situações emergenciais, os frangos eram removidos da nórea imediatamente.

Durante a etapa de pendura, os colaboradores evitam movimentação desnecessária, no entanto, não mantém as mãos sobre os frangos por 1 ou 2 segundos após a pendura com o objetivo de acalmá-los. Apesar de ser uma recomendação do Programa, é necessário avaliar se tal prática 
poderia comprometer o ritmo de pendura estabelecido pelo frigorífico.

Quadro 3. Atendimento às recomendações do Programa Nacional de Abate Humanitário - Steps Etapa de pendura.

\begin{tabular}{|c|c|c|}
\hline $\begin{array}{l}\text { Fatores a serem } \\
\text { considerados }\end{array}$ & Recomendações & $\begin{array}{l}\text { Atende as } \\
\text { recomendações? }\end{array}$ \\
\hline \multirow{2}{*}{ Linha de pendura } & $\begin{array}{c}\text { Deve ser dotada de um parapeito ao longo de toda a linha até a } \\
\text { entrada da cuba de insensibilização }\end{array}$ & $\operatorname{Sim}$ \\
\hline & $\begin{array}{l}\text { Deve ser disposta de maneira a apresentar o mínimo de curvas e } \\
\text { variações de altura }\end{array}$ & Sim \\
\hline \multirow{2}{*}{$\begin{array}{l}\text { Ambiente de } \\
\text { pendura }\end{array}$} & $\begin{array}{l}\text { O ambiente de pendura deve apresentar baixa intensidade de } \\
\text { iluminação e as portas de acesso devem ser abertas o mínimo } \\
\text { possível }\end{array}$ & Sim \\
\hline & $\begin{array}{c}\text { Ao final da linha de pendura deve haver uma luz direcionada às } \\
\text { gaiolas para averiguar se estão vazias }\end{array}$ & Sim \\
\hline $\begin{array}{l}\text { Tempo } \\
\text { compreendido } \\
\text { entre a pendura e } \\
\text { a insensibilização }\end{array}$ & Não deve ser menor que 12 segundos ou maior que 60 segundos & Sim \\
\hline $\begin{array}{l}\text { Situações } \\
\text { emergenciais } \\
\text { durante a pendura }\end{array}$ & $\begin{array}{l}\text { Caso ocorra queda de energia ou parada de funcionamento é } \\
\text { recomendada a remoção dos frangos dos ganchos até que o } \\
\text { processo normalize }\end{array}$ & Sim \\
\hline \multirow{2}{*}{ Colaboradores } & $\begin{array}{l}\text { Devem evitar a movimentação desnecessária próxima à linha de } \\
\text { pendura }\end{array}$ & Sim \\
\hline & $\begin{array}{l}\text { Recomenda-se que mantenham as mãos sobre o frango após a } \\
\text { pendura por um período de } 1 \text { a } 2 \text { segundos a fim de acalmá-los }\end{array}$ & Não \\
\hline
\end{tabular}

\subsection{BEM-ESTAR NA ETAPA DE} INSENSIBILIZAÇÃO insensibilização pode ser observado no Quadro 4.

O atendimento às recomendações do

Programa Steps para a etapa de

Quadro 4. Atendimento às recomendações do Programa Nacional de Abate Humanitário - Steps Etapa de insensibilização.

\begin{tabular}{|c|c|c|}
\hline \multicolumn{2}{|l|}{$\begin{array}{l}\text { Fatores a serem } \\
\text { considerados }\end{array}$} & $\begin{array}{l}\text { Atende as } \\
\text { recomendações? }\end{array}$ \\
\hline Ganchos & $\begin{array}{l}\text { Devem estar molhados a fim de auxiliar a condução da corrente } \\
\text { elétrica }\end{array}$ & Sim \\
\hline \multirow{2}{*}{$\begin{array}{l}\text { Imersão dos } \\
\text { frangos }\end{array}$} & $\begin{array}{l}\text { Devem ser imersos na cuba de insensibilização até a base de suas } \\
\text { asas }\end{array}$ & $\operatorname{Sim}$ \\
\hline & $\begin{array}{l}\text { A cabeça do frango deve ficar o mais próximo possível do eletrodo } \\
\text { localizado na base da cuba }\end{array}$ & Sim \\
\hline \multirow{2}{*}{$\begin{array}{l}\text { Disposição dos } \\
\quad \text { eletrodos }\end{array}$} & $\begin{array}{l}\text { Deve estender-se por toda a base da cuba para que haja corrente } \\
\text { homogênea }\end{array}$ & $\operatorname{Sim}$ \\
\hline & Não devem estar afastados há mais de $5 \mathrm{~cm}$ da parede da cuba & Sim \\
\hline $\begin{array}{l}\text { Uniformidade do } \\
\text { lote }\end{array}$ & Recomenda-se lotes uniformes & $\operatorname{Sim}$ \\
\hline \multirow{3}{*}{$\begin{array}{l}\text { Parâmetros de } \\
\text { insensibilização }\end{array}$} & Corrente mínima de 0,12 ampères por frango & Não \\
\hline & Frequência variando entre 400 a $1500 \mathrm{~Hz}$ & Sim \\
\hline & $\begin{array}{l}\text { Devem ser dispostos em um visor para facilitar o monitoramento e a } \\
\text { modificação, caso necessária }\end{array}$ & Sim \\
\hline $\begin{array}{l}\text { Monitoramento dos } \\
\text { frangos }\end{array}$ & $\begin{array}{l}\text { Na fase tônica (perda da consciência e enrijecimento do corpo), o } \\
\text { frango deve apresentar pescoço arqueado, asas fechadas, tremor } \\
\text { involuntário, olhos abertos, pernas estendidas e ausência de } \\
\text { respiração rítmica; Após, a fase clônica (contração e contorcimento } \\
\text { das extremidades do corpo) é caracterizada por movimentos } \\
\text { descoordenados das asas; Por fim, ausência de reflexos oculares e } \\
\text { da terceira pálpebra. }\end{array}$ & Não \\
\hline
\end{tabular}


Seguindo o que prevê o Programa para a etapa de insensibilização, os ganchos eram molhados facilitando o fluxo da corrente elétrica. A imersão dos frangos acontecia até a base de suas asas de forma que sua cabeça ficasse o mais próximo do eletrodo. $O$ eletrodo se estendia por toda a base da cuba promovendo uma maior homogeneidade do choque.

Além disso, os frangos caquéticos não eram pendurados a fim de promover maior uniformidade no lote e propiciar a correta regulagem da altura da cuba de insensibilização e dos parâmetros de insensibilização, no entanto, tal uniformidade era comprometida quando havia diferença significativa no tamanho e no peso entre lotes de frangos e também quando os lotes eram mistos (machos e fêmeas).

Como o frigorífico abate lotes de sexos diferentes, a diferença de peso médio entre os lotes, pode favorecer a ocorrência de frangos mal insensibilizados, pois, apenas no início do abate era verificado se os frangos estavam sendo insensibilizados corretamente. Já as alterações nos parâmetros de insensibilização eram feitas apenas se os sangradores responsáveis pelo repasse manual reportassem o bater coordenado de asas, porém, não eram monitorados os reflexos oculares.

Os parâmetros de insensibilização eram dispostos em painel, de fácil visualização, sendo que a frequência estava dentro dos parâmetros estabelecidos no Programa, porém, em apenas uma das coletas a corrente era de no mínimo 0,12 ampères/frango, 0 que compromete a insensibilização (Tabela 1).

A Tabela 1 apresenta as informações referentes à insensibilização. No total, foram avaliados 9.945 frangos, com peso vivo médio de $3,087 \mathrm{~kg}$ (entre 2,690 a 3,408 kg), desse total, 494 frangos foram mal insensibilizados $(4,96 \%)$, o que pode estar associado à falta de ajuste nos parâmetros de insensibilização de um lote para outro e ao uso de parâmetros de insensibilização inadequados.

Tabela 1. Número de frangos mal insensibilizados, horário, sexo, peso e parâmetros de insensibilização utilizados.

\begin{tabular}{|c|c|c|c|c|c|c|c|}
\hline Data & Horário & Sexo & $\begin{array}{l}\text { Número de } \\
\text { frangos } \\
\text { observados }\end{array}$ & $\begin{array}{c}\text { Número de } \\
\text { frangos mal } \\
\text { insensibilizados }\end{array}$ & $\begin{array}{l}\text { Peso } \\
\text { vivo } \\
\text { médio } \\
(\mathrm{Kg})\end{array}$ & $\begin{array}{c}\text { Corrente } \\
\text { (A) }\end{array}$ & $\begin{array}{l}\text { Frequência } \\
\qquad(\mathrm{Hz})\end{array}$ \\
\hline 24/08 & 07:32 & Macho & 663 & 44 & 2,833 & 0,076 & 750 \\
\hline $25 / 08$ & $05: 25$ & Fêmea & 663 & 42 & 3,039 & 0,069 & 750 \\
\hline $26 / 08$ & $10: 15$ & Macho & 663 & 25 & 2,690 & 0,087 & 750 \\
\hline $29 / 08$ & $12: 02$ & Fêmea & 663 & 34 & 2,812 & 0,069 & 750 \\
\hline $30 / 08$ & 08:09 & Macho & 663 & 51 & 3,408 & 0,083 & 750 \\
\hline $31 / 08$ & $12: 00$ & Macho & 663 & 37 & 3,109 & 0,09 & 750 \\
\hline 01/09 & $12: 16$ & Macho & 663 & 20 & 3,197 & 0,12 & 750 \\
\hline 02/09 & 08:08 & Macho & 663 & 17 & 3,200 & 0,10 & 750 \\
\hline 05/09 & 04:30 & Macho & 663 & 23 & 3,048 & 0,078 & 750 \\
\hline 06/09 & $12: 21$ & Fêmea & 663 & 27 & 2,856 & 0,10 & 750 \\
\hline 08/09 & $05: 22$ & Fêmea & 663 & 42 & 3,109 & 0,062 & 750 \\
\hline 09/09 & 11:07 & Fêmea & 663 & 23 & 2,748 & 0,074 & 750 \\
\hline $12 / 09$ & $13: 21$ & Macho & 663 & 38 & 3,209 & 0,089 & 750 \\
\hline $13 / 09$ & $07: 14$ & Macho & 663 & 31 & 3,087 & 0,074 & 750 \\
\hline $14 / 09$ & $04: 15$ & Macho & 663 & 40 & 3,125 & 0,072 & 750 \\
\hline \multicolumn{2}{|c|}{ Total/Média } & & 9.945 & 494 & 3,087 & 0,078 & 750 \\
\hline
\end{tabular}

\subsection{PLANO DE AÇÃO}

\subsubsection{PRIORIZAÇÃO DAS CAUSAS DE NÃO ATENDIMENTO ÀS RECOMENDAÇÕES DO PROGRAMA STEPS}

A Matriz GUT auxiliou na priorização das causas do não atendimento às recomendações do Programa, assim, pontuações foram atribuídas às causas, levando-se em consideração a gravidade, a urgência e a tendência de cada uma delas e, determinados os respectivos graus críticos. A partir da determinação dos graus críticos obteve-se a ordem de priorização apresentada na Tabela 2. Nenhuma das etapas do manejo pré-abate atendeu a todas 
as recomendações do Programa Steps. A causa de maior grau crítico foi o tempo inadequado de descanso, seguido da utilização de parâmetros incorretos na etapa de insensibilização, acúmulo e colisão de gaiolas na etapa de descarregamento, falta de treinamento de colaboradores da pendura, falhas na realização do abate emergencial e, por fim, na etapa de insensibilização, falta de monitoramento do comportamento dos frangos após insensibilizados.

Tabela 2. Ordem de priorização das causas de não atendimento às recomendações do Programa Steps - Matriz GUT.

\begin{tabular}{|l|l|c|c|c|c|c|}
\multicolumn{2}{c}{ Etapa } & \multicolumn{2}{c}{ Causas } & G & T & Grau \\
crítico & $\begin{array}{c}\text { Ordem de } \\
\text { priorização }\end{array}$ \\
\hline Descanso & Tempo inadequado & 4 & 4 & 4 & 64 & 1 \\
\hline Insensibilização & Parâmetros incorretos & 3 & 4 & 4 & 48 & 2 \\
\hline Descarregamento & Acúmulo e colisão de gaiolas & 3 & 5 & 1 & 15 & 3 \\
\hline Pendura & Falta de treinamento de colaboradores & 2 & 2 & 3 & 12 & 4 \\
\hline Descarregamento & Falhas no abate emergencial & 2 & 3 & 1 & 6 & 5 \\
\hline Insensibilização & $\begin{array}{l}\text { Falta de monitoramento do comportamento } \\
\text { dos frangos }\end{array}$ & 1 & 2 & 2 & 4 & 6 \\
\hline
\end{tabular}

G: gravidade; U: urgência; T: tendência; Grau crítico: GxUxT.

A seguir será apresentado o plano de ação proposto para a adequação ao Programa Steps, de acordo com a ordem de priorização apresentada na Tabela 2.

\subsubsection{ADEQUAÇÃO DO TEMPO DE DESCANSO}

Para que seja realizada a adequação do tempo de descanso devem ser considerados: a velocidade média de abate, os tempos médios de descarregamento do caminhão, de transporte e de carregamento dos frangos no aviário (apanha).

A velocidade média de abate utilizada no turno avaliado era de 12.000 frangos/hora. A partir desse valor foi possível calcular o tempo médio de descarregamento de um caminhão que é de, aproximadamente, 20 minutos e 48 segundos, considerando-se que cada caminhão tem capacidade média de 4.160 frangos.

Considerando-se o tempo médio de descarregamento do caminhão (20 minutos e 48 segundos), recomenda-se fila de no mínimo três e no máximo cinco caminhões no galpão de espera, assim, o quarto caminhão terá de esperar mais de uma hora e menos de duas horas.

Para a adequação do tempo, deve-se levar ainda em consideração o horário previsto para o abate, e os tempos de transporte e de carregamento dos frangos no aviário (apanha). Por meio da programação diária de abate é possível estabelecer a sequência de cada caminhão, assim, o programador teria apenas que observar quantos caminhões estão na espera para saber o horário que o caminhão deverá sair do aviário.

\subsubsection{ADEQUAÇÃO DOS PARÂMETROS DE INSENSIBILIZAÇÃO}

Observou-se que mensalmente $4,96 \%$ dos frangos abatidos sofrem insensibilização ineficaz. Para redução desse valor sugere-se que o frigorífico promova curso para os colaboradores da etapa de insensibilização sobre a importância do bem-estar animal e os benefícios que isto traz para a empresa. Também deverão ser abordadas as ações corretivas necessárias para resolução do problema como questões referentes à correta regulagem de altura da cuba e dos parâmetros de insensibilização a cada troca de lote.

Também são necessárias maior rapidez e eficácia na comunicação entre os colaboradores da recepção e da insensibilização para que, no caso de diferença significativa entre lotes, menos frangos sejam insensibilizados com regulagem de altura e parâmetros de insensibilização do lote anterior. Para facilitar a comunicação recomenda-se a aquisição de comunicadores eletrônicos. O controle de dados referentes ao peso médio e horário de troca de lote auxiliará na minimização de frangos mal insensibilizados, promovendo maior bem-estar. 


\subsubsection{DESCARREGAMENTO DAS GAIOLAS NA ESTEIRA DE RECEPÇÃO}

Para evitar o acúmulo e a colisão de gaiolas na esteira de recepção, propõem-se a aquisição de um sensor ótico a ser colocado um metro à frente de onde acontece a colisão, ao lado da esteira. O sensor emitirá um sinal para o desempilhador automático e este, imediatamente deixará de descarregar. O objetivo desse sensor é diminuir o acúmulo de gaiolas na esteira e consequentemente a colisão.

\subsubsection{TREINAMENTO DOS COLABORADORES DA PENDURA}

A recomendação do Programa de colocar a mão sobre o frango com objetivo de acalmá-lo não será proposta. Sugere-se, primeiramente, a realização de estudos a fim de avaliar se os colaboradores serão capazes de executar tal procedimento e de pendurar o número de frangos necessários sem prejudicar o ritmo de pendura estabelecido pelo frigorífico.

\subsubsection{REALIZAÇÃO DO ABATE EMERGENCIAL}

Para a realização adequada do abate emergencial sugere-se o treinamento de dois colaboradores da recepção, para que realizem o abate utilizando a técnica de destroncamento do pescoço.

\subsubsection{MONITORAMENTO DO COMPORTAMENTO DOS FRANGOS APÓS A INSENSIBILIZAÇÃO}

Sugere-se instruir os colaboradores sobre os comportamentos que não devem ser apresentados pelos frangos após a insensibilização. Nesse curso, deverá ser apresentada uma planilha de controle para a análise do número de frangos com sinais de má insensibilização, com um campo para a anotação das causas, o que auxiliará no controle do processo. Sugere-se ainda orientações sobre a correta regulagem de altura da cuba e dos parâmetros de insensibilização a cada troca de lote e ressaltar a importância da comunicação com os colaboradores da recepção, a fim de fazer os devidos ajustes no caso de diferença significativa entre lotes.

\section{CONCLUSÕES}

A utilização da Matriz GUT possibilitou a priorização das causas do não atendimento às recomendações do Programa Steps para as etapas do manejo de pré-abate de frangos em um frigorífico.

Nenhuma das etapas do manejo pré-abate avaliadas atendeu a todas as recomendações do Programa Steps. A causa de maior grau crítico foi o tempo inadequado de descanso, seguido da utilização de parâmetros incorretos de insensibilização, acúmulo e colisão de gaiolas na etapa de descarregamento, falta de treinamento de colaboradores da pendura, falhas na realização do abate emergencial e, na etapa de insensibilização, falta de monitoramento do comportamento dos frangos depois de insensibilizados.

Apesar do não atendimento às recomendações em todas as etapas de manejo pré-abate, a maioria das recomendações do Programa Steps foram atendidas, porém, a importância do bem-estar animal não é conhecida por grande parte dos colaboradores.

Para a adequação do tempo de descanso devem ser considerados o horário previsto para o abate e os tempos de apanha e de transporte, a fim de que a fila seja de no mínimo três e no máximo cinco caminhões no galpão de espera. Para redução do percentual de frangos mal insensibilizados sugere-se a capacitação dos colaboradores sobre a importância do bem-estar animal, comportamentos que não devem ser apresentados pelos frangos após a insensibilização e ações corretivas necessárias para resolução do problema. Também são necessárias maior rapidez e eficácia na comunicação entre colaboradores da recepção e da insensibilização para adequação dos parâmetros de acordo com o lote.

Para evitar o acúmulo e a colisão de gaiolas no descarregamento propõem-se a aquisição de um sensor ótico e, para a realização adequada do abate emergencial sugere-se o treinamento de dois colaboradores. A recomendação do Programa de, na etapa de pendura, colocar a mão sobre o frango com objetivo de acalmá-lo não será proposta. Sugere-se, primeiramente, a realização de estudos a fim de avaliar se os colaboradores serão capazes de executar tal procedimento e 
pendurar os frangos necessários sem prejudicar o ritmo de pendura estabelecido pelo frigorífico.

\section{REFERÊNCIAS}

[1] Abepro - Associação Brasileira de Engenharia de Produção. Áreas e Subáreas da Engenharia de Produção, 2008. Disponível em: <http://www.abepro.org.br/interna.asp?p=399\&m= 424\&ss $=1 \& c=362>$ Acesso em: 13 set. 2016.

[2] Abipecs - Associação Brasileira da Indústria Produtora e Exportadora de Carne Suína. Próximos passos do Programa Nacional de Abate Humanitário. $2010 . \quad$ Disponível em: <http://www.ruralcentro.uol.com.br/noticias/proximo s-passos-do-programa-nacional-de-abatehumanitario-31800> Acesso em: 13 set. 2016.

[3] Bressan, M. C.; Beraquet, N. J. Efeito dos fatores pré e pós abate sobre a qualidade da carne de peito de frango. Ciência e Agrotecnologia, v. 26, n. 5, p. 1049-1059, 2002.

[4] Correa, M. B. B. Probabilidade e Estatística. $2^{\underline{a}}$ ed. Belo Horizonte: PUC Minas Virtual, 2003.

[5] Grandin, T. Animal Welfare and Society Concerns Finding the Missing Link. Meat Science, Savoy, n. 98, p. 461-469. 2014. Disponível em: <https://ac.els-cdn.com/S0309174014001314/1s2.0-S0309174014001314-main.pdf?_tid=spdf6d2da3a9-fef5-4c66-8768

b774bd083bd4\&acdnat $=1519388012 \_456 d c e 661 d$ df55240e8d2d287e4c138c> Acesso em: 13 set. 2016.

[6] Jorge, P. S. Avaliação do bem-estar durante o pré-abate e abate e condição sanitária de diferentes segmentos da produção avícola. 2008. 107f. Tese (Doutorado em Medicina Veterinária) - Faculdade de Ciências Agrárias e Veterinárias, Jaboticabal, 2008. Disponível em: $<$ http://www.fcav.unesp.br/download/pgtrabs/mvp/ d/401.pdf > Acesso em: 13 set. 2016.

[7] Kepner, C. H.; Tregoe, B. O Administrador Racional: a solução de problemas e tomada de decisões. $2^{\underline{a}}$ ed. São Paulo: Atlas, 1981.

[8] Ludtke, C. B. et al. Abate humanitário de aves. Rio de Janeiro: WSPA, 2010. Disponível em: $<$ http://www.agricultura.gov.br/assuntos/boaspraticas-e-bem-estar-animal/arquivos-publicacoesbem-estar-animal/programa-steps-abatehumanitario-de-aves.pdf> Acesso em: 13 set. 2016.

[9] Mitchell, M. A.; Kettlewell, P. J. Physiological stress and welfare of broiler chickens in transit: solutions not problems! Poultry Science, v. 77, n. 12, p.1803-1814. 1998
Para estudos futuros sugere-se ainda quantificar as perdas ocasionadas pelo não atendimento do Programa ao rendimento de carcaça e à qualidade da carne de frangos.

[10] Olivo, R. O mundo do frango: cadeia produtiva da carne de frango. Criciúma: Varela, 2006.

[11] Ritz, C. W.; Webster, A. B.; Czarick, M. Evaluation of hot weather thermal environment and incidence of mortality associated with broiler live haul. Journal of Applied Poultry Research, Savoy, v. 14, p. 594-602. 2005. Disponível em: $<$ https://academic.oup.com/japr/articleabstract/14/3/594/832574> Acesso em: 13 set. 2016

[12] Rodrigues, D. R. et al. Abate humanitário de aves: Revisão. Revista PUBVET - Medicina Veterinária e Zootecnia, Maringá, v.10, n.9, p. 650658,2016

[13] Rui, B. R.; Angrimani, D. S. R.; Silva, M. A. A. Pontos críticos no manejo pré-abate de frango de corte: jejum, captura, carregamento, transporte e tempo de espera no abatedouro. Ciência Rural, Santa Maria, v. 41, n. 7, p. 1290-1296, 2011. Disponível em: $<$ http://www.scielo.br/scielo.php?script=sci_arttext \&pid=S0103-

$84782011000700030 \& \operatorname{lng}=e n \& n r m=i s o>$. Acesso em13 set. 2016.

[14] Sandercock, D. A. et al. Acute heat stressinduced alterations in blood acid-base status and skeletal muscle membrane integrity in broiler chickens at two ages: Implications for meat quality. Poultry Science, v. 80, n. 4, p. 418-425. 2001.

[15] Silva, I. J. O.; Miranda, K. O. S. Impactos do bem-estar na produção de ovos. Thesis, São Paulo, ano 6, n. 11, p. 89-115. 2009. Disponível em: < http://www.cantareira.br/thesis2/ed_11/5_iran.pdf > Acesso em: 23 fev. 2018.

[16] Silveira, A. M. Parâmetros de bem-estar animal e abate humanitário em frangos de corte. 2013. 53f. Monografia (Especialização em Produção, Tecnologia e Higiene de Alimentos de Origem Animal) - Universidade Federal do Rio Grande do Sul, Porto Alegre. 2013. Disponível em: <http://www.lume.ufrgs.br/handle/10183/72698> Acesso em: 13 set. 2016.

[17] Souto, M. S. M. L. Apostila de Engenharia de métodos. Curso de especialização em Engenharia de Produção - UFPB. João Pessoa. $2002 . \quad$ Disponível em: $<$ https://pt.scribd.com/document/125032778/Mariado-Socorro-Souto-Engenharia-de-Metodos> Acesso em: 13 set. 2016

[18] Takashina, N. T.; Flores, M. C. X. Indicadores da Qualidade e do Desempenho: Como estabelecer metas e medir resultados. Rio de Janeiro: Quaitymark. 1996. 
[19] Tavernari, F. C.; Albino, L. F. T.; Araújo, W. A. G. Manejo pré-abate de frangos de corte. Revista Conselho Federal de Medicina Veterinária, Brasília, Ano 18, n. 56, p. 62-68. 2012.

[20] Vieira, F. M. C. Avaliação das perdas e dos fatores bioclimáticos atuantes na condição de espera pré-abate de frangos de corte. 2008. $176 f$. Dissertação (Mestrado em Física do Ambiente Agrícola) - Escola Superior de Agricultura Luiz de
Queiroz, Piracicaba. 2008. Disponível em: $<$ http://www.teses.usp.br/teses/disponiveis/11/1113 1/tde-25072008-121656/pt-br.php> Acesso em: 13 set. 2016.

[21] Warris, P. D. et al. Effects of lairage time on body temperature and glycogen reserves of broiler chickens held in transport modules. Veterinary Record, v. 145, n. 8, p. 218-222. 1999. 


$$
\text { Alutary }
$$




\section{Adriana Ribeiro de Souza}

Graduanda em Engenharia de Produção pela Faculdade Independente do Nordeste (FAINOR). Exerceu atividades em grupo de pesquisa relacionada a Planejamento de Produtos pela Faculdade Independente do Nordeste. Atua como Cronoalistano Grupo Dass ImplementingSportswearBrands.

\section{Afonso José Lemos}

Graduando em Engenharia de Produção Agroindustrial , Universidade Estadual do Paraná Unespar, campus Fecilcam, Campo Mourão -PR.

\section{Aline Okumoto Gomes}

Mestranda em Engenharia de Produção pela Universidade Federal de São Carlos.

\section{Ana Flavia da Fonseca Barroso}

Engenheira Civil pela Universidade Federal de Juiz de Fora (UFJF), Mestre em Arquitetura pela Universidade Federal do Rio de Janeiro (UFRJ) e atualmente é gestora e professora do Curso de Engenharia de Produção da Universidade Salgado de Oliveira - UNIVERSO/JF.

\section{Anderson Clayton Lima Alencar}

Graduando em Engenharia de Produção pela Universidade Federal de Goiás - UFG (2014 presente), onde desenvolveu atividades de monitoria acadêmica na área de algoritmos e programação de computadores. Atuou como coordenador de marketing no Núcleo Goiano dos estudantes de Engenharia de produção, integrando a comissão organizadora de eventos regionais. Realizou curso de nível técnico em Logística pelo Serviço Nacional de Aprendizagem Industrial - SENAI-GO (2014). No âmbito profissional trabalhou no setor administrativo de uma empresa de varejo desempenhando atividades relacionadas a logística.

\section{André Luiz Francisco Ferreira}

Mestre em Educação pela UCP (2006), especialista em Gestão da Educação à Distância e em Métodos Estatísticos Computacionais pela UFJF (2004). Graduado em Administração de Empresas pela Faculdade de Ciências Contábeis e Administrativas Machado Sobrinho (1992). Atualmente é professor titular da Universidade Salgado de Oliveira Juiz de Fora. Atua nos seguintes temas: Engenharia da Qualidade e Estatística Aplicada. Integrante do Banco de Avaliadores do Sistema Nacional de Avaliação da Educação Superior - BASis, para avaliador externo. Credenciado pelo INEP/MEC para os atos autorizativo de Reconhecimento e Renovação de Reconhecimento de Curso. Homologado pela Comissão Técnica de Acompanhamento da Avaliação - CTAA, através da Portaria ํㅡ 604, de 12 de julho de 2018.

\section{Andréa Machado Groff}

Engenheira Agrônoma graduada pela Universidade Federal do Paraná, Mestre em Zootecnia pela Universidade Estadual de Maringá e Doutora em Agronomia pela Universidade Federal do Paraná (Doutorado sanduíche no Institut National de la Recherche Agronomique - INRA França). Professora Associada do Curso de Engenharia de Produção Agroindustrial da Universidade Estadual do Paraná - UNESPAR. Pesquisadora do GPMAgro - Grupo de Pesquisas em Materiais Agroindustriais. 


\section{ANNE BEATRIZ DE CAMARGO GOMES}

Graduanda em Engenharia de Produção pela instituição de ensino Faculdade Independente do Nordeste - FAINOR. Contribuiu para o projeto CREA-Jr. no ano de 2016 e para o Núcleo Baiano de Estudantes de Engenharia de Produção - NUBEEP em 2017.1. Participou também do grupo de pesquisa para iniciação científica na área de engenharia do produto em 2017.

\section{Antônio Oscar Santos Góes}

O autor possui doutorado em Sociologia Econômica e das Organizações, da Universidade Técnica de Lisboa, do Instituto Superior de Economia e Gestão (2012). O professor é mestre em Administração pela Universidade Federal da Bahia (2003), especialista em Gerenciamento de Micro e Pequenas Empresas - Universidade Federal de Lavras/MG (1999) e graduado em Administração pela Universidade Estadual de Santa Cruz (1991). Atualmente é professor assistente da Universidade Estadual de Santa Cruz. É líder do grupo de pesquisa na Universidade Estadual de Santa Cruz com as temáticas: empreendedorismo, estratégias e competitividade. Tem experiência na área de Administração, com ênfase em Administração de Empresas.

\section{Brehme Rezende de Oliveira}

Engenheiro de Produção pela UNIVERSO/JF - Universidade Salgado de Oliveira - Campus Juiz de Fora - MG e Técnico em Edificações pelo Instituto Federal Educação Ciência e Tecnologia Sudeste MG (CTU) Juiz de Fora - MG.

\section{Brena Bezerra Silva}

Doutoranda em Engenharia de Produção pela Universidade Federal de São Carlos. Docente dos cursos de Engenharia de Produção e Engenharia Civil da Universidade de Franca.

\section{Brunno José Fagundes}

Possui graduação em Ciência da Computação pela Universidade de Santa Cruz do Sul (2015). Tem experiência na área de Ciência da Computação. Atualmente é aluno do Programa de Pós-Graduação em Sistemas e Processos Industriais (Mestrado) pela Universidade de Santa Cruz do Sul, onde realiza seu trabalho sobre o Desenvolvimento de Modelos de Conteúdo para Ambientes Virtuais de Aprendizagem (AVA) que considerem os estilos de aprendizagem dos usuários. É bolsista PROSUP-CAPES.

\section{Carulina Marques}

Graduada em Engenharia de Produção pela Universidade Federal de Goiás (2014). Mestrado em andamento na área de Engenharia de Produção, especificamente em Engenharia de Operações e Processos Industriais pela Universidade Federal de Goiás. Dentre as áreas de pesquisa estão a simulação de sistemas, sustentabilidade e tecnologia da informação verde. Atuante no Grupo de estudos em Modelagem e Simulação (GEMS).

\section{Cesar Augusto Della Piazza}

Possui graduação em Ciências Econômicas pela Pontifícia Universidade Católica de Campinas (2005). Obteve mestrado na Universidade Metodista de Piracicaba - UNIMEP (2008) no Programa de Pós-Graduação em Engenharia de Produção (UNIMEP/PPGEP), na área de Gestão Ambiental e produção. No ano de 2009 se formou em Pós-Graduação Lato Sensu em Metodologia e Pesquisa no Ensino Superior pela FAC - Faculdades Anhanguera Educacional. Possui Doutorado (UNIMEP/PPGEP) concluído em 2012, com estudos relacionados a produção e desempenho ambiental por parte das empresas do setor têxtil. Professor Titular da Universidade Paulista (UNIP) campus Jundiaí. É integrante do corpo de 
Avaliadores dos artigos encaminhados para o SIMPEP - Simpósio de Engenharia de Produção da UNESP-Bauru e do ENEGEP - Encontro Nacional de Engenharia de Produção entre outros

\section{Cícero Roberto de Oliveira Moura}

Graduação em Tecnologia Mecatrônica pelo Instituto Federal de Educação, Ciência e Tecnologia do Ceará - IFCE. Especialização em Tecnologias na Educação na Faculdade Christus. Mestrado em Engenharia de Produção pela Universidade Federal da Paraíba UFPB

\section{Claudio Luiz Melo de Souza}

Doutor em Produção Vegetal (UENF, 2001), Mestre (UFRRJ, 1997) e graduado em Ciências Agrícolas (UFRRJ, 1994), pós-graduado em Engenharia de Produção; Matemática Financeira e Estatística. Foi Diretor do Instituto Superior de Tecnologia de Campos por duas gestões de (2003 a 2011). Atualmente de Estatística do Laboratório de Engenharia Agrícola da Universidade Estadual do Norte Fluminense onde leciona ao nível de graduação as disciplinas Estatística Básica e experimental e para o Mestrado e Doutorado em Produção Vegetal, Genética e Melhoramento e Ciência Animal a disciplina Estatística Aplicada I. Desde 2012, leciona para os Curso de Engenharia de Produção, Mecânica e Civil na Universidade Cândido Mendes de Campos dos Goytacazes, Geometria Descritiva e Inovação Tecnológica, desde 2016, Gestão da Inovação Tecnológica para o Curso de Mestrado em Engenharia de Produção da UCAM-Campos, onde sua linha de pesquisa e desde 2018 para p Mestrado Profissional em Pesquisa Operacional e Inteligência Computacional da UCAM-Campos, dentro da pesquisa operacional, visa a amostragem e análise de previsão e demanda de energia de biomassa oriunda de diversas inovações tecnológicas.

\section{Dalton Matsuo Tavares}

Doutor em Engenharia Mecânica, área de concentração de dinâmica das máquinas e sistemas (EESC/USP 2010), mestre em Ciências da Computação (ICMC/USP 2002) e Bacharel em Ciência da Computação (IBILCE/Unesp 1999). Sua formação inclui o desenvolvimento de pesquisas voltadas a área de robótica, em padrões de comunicação industrial e plataformas de controle abertas, voltadas à integração padronizada de dispositivos em ambientes de produção. Além disso, tem experiência na área de Ciência da Computação, com ênfase em Sistemas Operacionais e Segurança de Redes.

\section{Daniel Xavier Sousa}

Graduando em Engenharia de Mecatrônica pelo Instituto Federal de Educação, Ciência e Tecnologia do Ceará

\section{Danielli Cossul}

Estudante de Psicologia da Universidade de Santa Cruz do Sul, RS. Atualmente é bolsista de iniciação científica da Fundação de Amparo e Pesquisa do Estado do Rio Grande do Sul (FAPERGS) pela Universidade de Santa Cruz do Sul, RS.

\section{Dayane Menezes Bessa}

Graduanda em Engenharia de Produção (Universidade de Franca). 


\section{Ed Carlo Rosa Paiva}

Engenheiro Civil (1997); Mestre em Engenharia Civil - Saneamento Ambiental (2008) e Doutor em Engenharia Agrícola - Recursos Hídricos e Ambientais (2011) pela Universidade Federal de Viçosa (UFV). Professor do Curso de Engenharia Civil da Universidade Federal de Goiás Regional Catalão desde de julho de 2009. Atua nas áreas de Saneamento: água, águas residuárias e resíduos sólidos. Também atua na área de patologia de revestimentos, uso de materiais alternativos para construção, uso racional da água, e conforto térmico e eficiência energética.

\section{Elcimara Rabelo de Oliveira}

Mestranda em Gestão Organizacional pela Universidade Federal de Goiás desde 2016; - Pós Graduada em Engenharia da Produção pelo Centro de Ensino Superior de Catalão desde 2009 (384 horas), Título do TCC: A importância da aplicação dos requisitos da NBR ISO 9001 nas organizações educacionais?; - Pós graduada em Matemática Pura e Aplicada pela Universidade Federal de Goiás desde 2007 (448 horas); - Graduada em Matemática pela Universidade Federal de Goiás desde 2003 (2.432 horas de curso e 192 horas de participação em congressos e conferências).

\section{Élcio Barreira da Silva Castro}

Profissional com formação em Engenharia Mecânica (UGF),especialista ferroviário da MRS Logística, lecionando no ensino técnico e universitário, pós-graduação em Análise de Sistemas pelo Instituto ORT, em Sistemas Abertos pela UBM e em Gestão de Negócios pelo IBMEC

\section{Elizabeth Ferreira de Pádua Campos}

Possui graduação em BIBLIOTECONOMIA pela Universidade Federal do Estado do Rio de Janeiro (2012). Tem experiência na área de Ciência da Informação, com ênfase em Ciência da Informação. Especialista em Programa de políticas de igualdade racial nas escolas pela Universidade Federal de Ouro Preto concluído em 2015. Cursando segunda graduação em licenciatura em Historia pelo Instituto Graduarte.

\section{Euclides Fernandes dos Reis}

Possui graduação em Geografia pela Universidade Federal de Goiás (2006) e graduação em Engenharia Elétrica pela Faculdade Politécnica de Uberlândia (2012).

\section{EVERTON COSTA SANTOS}

Bacharel em Engenharia de Produção e Sistemas e Mestre em Modelagem Computacional em Ciência e Tecnologia, ambos pela Universidade Estadual de Santa Cruz - UESC. Atua como docente no curso de Engenharia de Produção na Faculdade Arnaldo Horácio Ferreira FAAHF. Exerceu atividades no grupo de pesquisa em Matemática Aplicada e Computacional na Universidade Estadual de Santa Cruz relacionadas aos seguintes temas: Termodinâmica, Análise de falhas do produto e Tecnologias CAD/CAE.

\section{Fábio Esperança}

Engenheiro Mecânico pela Universidade Católica de Petrópolis-UCP, pós-graduado em Eng ${ }^{\underline{a}}$ Ambiental e Enga ${ }^{a}$ de Manutenção, pela Universidade Federal do Rio de Janeiro-UFRJ, certificado internacional em gerenciamento de projetos, Prince 2 Practitioner. Mais de trinta anos de trabalho, como gestor de contratos/projetos, obras industriais e outros, para grandes empresas nacionais e internacionais. Mestrando em Gestão de Sistemas de Engenharia pela Universidade Católica de Petrópolis-UCP/ PE-RJ. 


\section{Fabricio Freitas da Silva}

Mestre em Engenharia de Produção (2018) e graduado em Engenharia de Produção (2014) pela Universidade Candido Mendes. Atuação em Pesquisa Operacional, Modelagem Multicriterial e Ponderação pelo Método de Lawsh.

\section{Fausto Teodoro Neves}

Mestrando em Gestão Organizacional da Universidade Federal de Goiás Campus Catalão UFG (01/2018). Foi aluno especial no crédito "Ágora virtual e democracia" no mestrado interdisciplinar de Direitos Humanos - UFG (02/2014). Especialista em Ciências Criminais pela Faculdade Pitágoras de Uberlândia/MG (2008-2009). Graduado em Direito pelo Centro de Ensino Superior de Catalão/GO - CESUC (2007). Tem experiência na área de Direito, com ênfase em Direito Penal. Atuante como advogado dativo na comarca de Catalão/GO. Atualmente é Advogado sócio-proprietário-fundador do escritório de advocacia "Teodoro, Marra e Neves advogados", na cidade de Catalão/GO e Docente do curso superior sequencial em "Segurança Pública e Privada" na instituição "Avança Cursos Preparatórios parceira da Faculdade Cambury" pólo de Goiânia-GO, Gerente de Gestão da Procuradoria Geral do Município de Catalão-Goiás(12/2017), Diretor Tesoureiro da OAB-GO Subseção Catalão-GO (2016/2018).

\section{Fernanda Batista Hagge}

Graduanda do curso de Engenharia de Produção pela Universidade Estadual de Santa Cruz. A autora foi aluna de Iniciação Científica, sendo bolsista ICB, desenvolvendo o trabalho intitulado "A inovação no processo produtivo nos negócios: o caso da cerveja artesanal.", o qual foi apresentado no $23^{\circ}$ Seminário de Iniciação Científica da UESC. Atuou como Gerente de Projetos na empresa júnior Optimus Engenharia Júnior (2016-2017). Atualmente, assume a função de Estagiário Superior na empresa AMBEV.

\section{Fernando Cerutti Aguiar}

Mestrando em Engenharia de Produção (UCAM - campos dos Goytacazes- RJ). Especialista em Administração Pública pela Universidade Candido Mendes (2015). Graduado em Administração pelo Fundação Educacional Machado Sobrinho (2005). Exerce o cargo de Diretor Administrativo do Instituto Federal Fluminense - Campus Santo Antônio de Pádua desde 2015.

\section{Fernando José Gómez Paredes}

Possui graduação em Ingeniería Industrial pela Universidad Centroamericana "José Simeón Cañas"(2009) e mestrado em Engenharia de Produção pela Universidade Federal de São Carlos(2016), doutorando em Engenharia de Produção pela Universidade Federal de São Carlos. Atualmente é Professor universitário da Universidad Centroamericana "José Simeón Cañas". Atuando principalmente nos seguintes temas:Lean Manufacturing, Quick Response Manufacturing, lead time

\section{Francisco Costa Machado Neto}

Graduando do 8o período do Curso de Engenharia de Produção do Centro Universitário Integrado. Gerente Administrativo/ Vice Presidente da Promax Empresa Juinor de (20172018). 


\section{Gabriel Andrian Gentilin}

Engenheiro de Produção Agroindustrial graduado pela Universidade Estadual do Paraná, Green Belt pela R\&L Associados e Pós graduando em Gerenciamento de Projetos pelo Grupo Integrado. Analista de PCP no grupo CCRR.

\section{Guilherme Fernando Ribeiro}

Guilherme Fernando Ribeiro possui graduação em Matemática e Engenharia de Produção Agroindustrial pela Universidade Estadual do Paraná (UNESPAR), Campus de Campo Mourão (FECILCAM). É Mestre em Engenharia de Produção pela Universidade Tecnológica Federal do Paraná (UTFPR), Campus de Ponta Grossa. Atuou na Linha de Pesquisa de Gestão do Conhecimento e Inovação e no Grupo de Pesquisa de Desenvolvimento de Produtos e Processos de Manufatura.

\section{Guilherme Ferreira}

Estudante de Ciência da Computação da Universidade de Santa Cruz do Sul, RS.

\section{Guilherme Mendes de Souza}

Graduando em Engenharia de Produção (Universidade de Franca).

\section{Gustavo Henrique Marques}

Possui graduação em Engenharia de Alimentos pela Universidade Estadual de Maringá (2009) e graduação em Administração - Integrado Faculdade (2015). Possui especialização em Produção Industrial pela Universidade Estadual de Maringá (2013) e especialização em Sistema Gestão Integrado e Segurança de Alimentos pelo Instituto Food Design (2016). Cursando o Mestrado Profissional em Inovações Tecnológicas ofertado pela UTFPR - Campo Mourão. Atuação como professor no Centro Universitário Integrado.

\section{Hector Leonardo Mota Moreira}

Graduando em Engenharia de Mecatrônica pelo Instituto Federal de Educação, Ciência e Tecnologia do Ceará

\section{Herbert Carneiro Rangel}

Mestrando em Engenharia de Produção pela Universidade Cândido Mensdes (2018), Engenheiro de Produção formado pela Universidade Salgado de Oliveira (2009). Formação em Tecnólogo em Automação Industrial pelo Centro Federal de Educação Tecnológica (2006). Formação em Técnico em Eletrotécnico pelo Centro Federal de Educação Tecnológica (1995). Formação em Técnico em Química pelo Centro Federal de Educação Tecnológica (1980). Funcionário da empresa Petrobras Petróleo Brasileiro SA desde março de 1984 com cargo de Técnico de Operação Sênior e função de Gerente Setorial de Plataforma atuando na área de produção de petróleo nas plataformas da Bacia de Campos.

\section{Higor Coimbra Lucindo}

Engenheiro de Produção pela Universidade Salgado de Oliveira - UNIVERSO/JF 


\section{Iasmin Alexandrino de Miranda}

Graduada em Gestão da Qualidade pela Universidade Federal do Ceará - UFC. Estudante do curso de Administração pela Estácio do Ceará. Atuo na área de Gestão da Qualidade, como analista da qualidade responsável pelos processos na Guararapes Confecções S/A (Maior indústria de Confecção da América Latina).

\section{Igor Cassiano Rangel}

Graduado em Engenharia de Produção pela Universidade Salgado de Oliveira (2008). Mestre em Engenharia de Produção pela Universidade Cândido Mendes (2018). Atualmente é professor do Instituto Federal Fluminense.

\section{Igor de Prince}

Graduando do 8o período do Curso de Engenharia de Produção do Centro Universitário Integrado. Diretor de Marketing da Promax Empresa Júnior de (2017-2018)

\section{Isadora Costa Vasconcelos Vieira}

Graduanda em Engenharia Mecatrônica pelo Instituto Federal de Ciência, Educação e Tecnologia do Ceará - IFCE. Técnica em Mecânica Industrial pelo Instituto Federal de Ciência, Educação e Tecnologia do Ceará - IFCE (2017)

\section{Jessika Kauanny de Souza Eurico}

Bacharel em Engenharia de Produção pela Universidade Estadual de Santa Cruz, atualmente docente no Senai - Ilhéus nas disciplinas de gestão e projeto. Atuei na Suzano Papel e Celulose durante dois anos no Planejamento/Operação Logística, como primeira experiência na indústria. Além disso fui voluntária na empresa júnior, Optimus Engenharia Junior, durante dois anos e meio. Creio que toda forma de aprendizado é uma via de mão dupla, em que o desenvolvimento é mútuo. Assim, teremos e seremos profissionais melhores, para contribuir para um mundo melhor.

\section{Jessycka Brandão Santana}

Graduanda em Engenharia de Produção Agroindustrial , Universidade Estadual do Paraná Unespar, campus Fecilcam, Campo Mourão -PR.

\section{JOANA MARCELINO GOMES}

Graduada em Engenharia de Produção pela UNISUAM. Experiência na área de processos comerciais e logísticos. Conhecimento em elaboração de campanhas promocionais e estratégias comerciais, ênfase em treinamento de equipe. Atuação no setor de suprimentos, verificando necessidades e ordenando processos de recebimento, armazenamento, separação e entrega. Conhecimento em implantação de projetos, já tendo atuado como líder.

\section{João Lucas Ferreira dos Santos}

Graduando em Engenharia de Produção Agroindustrial , Universidade Estadual do Paraná Unespar, campus Fecilcam, Campo Mourão -PR.

\section{João Luiz Cesarino Ferreira}

Professor Colégio Politécnico PIO XII (atuando na área de eletrônica e segurança do trabalho), Engenheiro de Produção pela UNIVERSO/ JF- MG, Especialista em Engenharia de Segurança do Trabalho pela UNIVERSO/ JF- MG, Especialista em Engenharia Ambiental e 
Sanitária Básica pela UNESA/ JF-MG, Mestrando em Gestão de Sistemas de Engenharia pela Universidade Católica de Petrópolis-UCP/ PE-RJ. Empresário no ramo de prestação de serviços de manutenção de aparelhos eletroeletrônicos e consultor na área de segurança do trabalho e ambiental.

\section{JONATAS DOS SANTOS WELTE}

Graduado em Engenharia de Produção pela UNISUAM. Experiência na Rede Municipal dando aulas de reforço como professor de matemática. Vivência nas rotinas de supervisão de operação, dos operadores de Usina e operadores de subestação; processos do almoxarifado e procedimentos técnicos e químicos da usina Furnas Centrais Elétricas S.A.

\section{José Eduardo Machado Barroso}

Graduado em Medicina Veterinária pela Faculdade de Agronomia e Medicina Veterinária/UnB. Pós graduado em Gestão em Saúde pela UEG. Bacharel em Direito pelo Cesuc. Com experiência na área de clínica e cirurgia veterinária, e saúde pública. É Advogado e Médico Veterinário efetivo da Prefeitura Municipal de Catalão, atualmente é Chefe do Departamento de Vigilância Sanitária da Secretaria Municipal de Saúde de Catalão, GO e Professor do curso de Medicina Veterinária da Faculdade Una de Catalão.

\section{José Waldo Martínez Espinosa}

Possui graduação em Engenharia Química pela Universidade Federal de São Carlos (1988), mestrado em Ciência e Engenharia dos Materiais pela Universidade Federal de São Carlos (1992) e doutorado em Ciência e Engenharia dos Materiais pela Universidade Federal de São Carlos (2000). Atualmente é professor associado da Universidade Federal de Goiás Regional Catalão. Atua na área de Engenharia de Produção e Ciência dos Materiais, com ênfase em materiais nanoestruturados e fotoluminescência. Engenharia Ambiental com ênfase em produção mais limpa e sustentabilidade.

\section{Julio Cezar Negri Ramos}

Graduado em Tecnologia em Design Gráfico pelo Instituto Federal Fluminense (2004). Atualmente é professor do Curso Superior em Design Gráfico e Programador Visual da Reitoria do Instituto Federal Fluminense, além de Mestrando em Engenharia de Produção e professor do curso de Tecnologia em Gestão de Comércio Varejista na Universidade Candido Mendes de Campos. Tem experiência na área de Comunicação, com ênfase em Criação de Marcas, Identidades Visuais, Mídias impressas e Digitais, atuando principalmente nos seguintes temas: design gráfico, projeto gráfico, identidade visual, produção gráfica e diagramação. É sócio-proprietário da agência Contexto Comunicação e Design desde 2010.

\section{Karine Bessa Porto Pinheiro Vasques}

Graduação em Administração pelo Centro Universitário Christus - UniChristus (2004). Mestrado em Administração pela Universidade Estadual do Ceará - UECE(2007). Doutorado em Saúde Coletiva pela Faculdade de Medicina da Universidade Federal do Ceará UFC(2016)

\section{Karine de Jesus Santana}

Mestranda em Engenharia de Produção/ UFG. Pós graduada em Gestão de Negócios com Ênfase em Finanças Corporativa/UEG. Graduada em Administração pela Universidade Estadual de Montes Claros. Atualmente docente nível II no Instituto Tecnológico de Goiás, ministrando as disciplinas de Empreendedorismo, Marketing e Responsabilidade Social. Bolsista do PRONATEC, no curso Técnico em Logística, com foco em Legislação, 
Organização empresarial, Cadeia de Suprimento, Desenvolvimento de Produto, Tecnologia e Qualidade na Gestão de Estoque.

\section{Kêmyle Moreira Silva}

Graduanda em Engenharia de Produção pela Faculdade Independente do Nordeste (FAINOR). Participou em 2017 do projeto de iniciação científica na área de engenharia do produto e estagiou em uma fábrica de produtos de limpeza na cidade de Vitória da Conquista - BA.

\section{Laura Teixiera Hohl}

Graduanda em Engenharia de Produção - Universidade Federal de Goiás-UFG

\section{Liane Mahlmann Kipper}

Professora titular da Universidade de Santa Cruz do Sul e Coordenadora do Mestrado em Sistemas e Processos Industriais de 2013 até 2015. Atua no Programa de Pós-Graduação em Sistemas e Processos Industriais nas áreas de gestão do conhecimento, inovação e criatividade, e em gerenciamento de processos e métodos e técnicas de pesquisa desenvolvendo atividades principalmente nos seguintes temas: melhoria de processos, sistemas enxutos: inovação, criatividade, desenvolvimento de produtos e proteção do conhecimento; e em gestão por processos e tecnologias para otimização e melhoria de processos. Tem também experiência na área de Física, com ênfase Mecânica, Ciências Térmicas, Ótica e Física Experimental. De 1995 até 2009 atou junto a gestão universitária em especial nas áreas de pesquisa e pós-graduação (lato sensu e stricto sensu). Atualmente trabalha junto aos cursos de graduação e extensão da área tecnológica da UNISC, no TECNOUNISC coordenando a implantação do Laboratório Interativo de Criatividade (LIC) e junto ao Mestrado em Sistemas e Processos Industriais nas áreas de métodos e técnicas de pesquisa, gestão de processos e gestão do conhecimento.

\section{Luciana Vieira de Melo}

Mestranda em Engenharia de Produção pela Universidade Federal de Goiás (UFG). Possui graduação em Engenharia de Produção pela Universidade Federal de Goiás (UFG). Experiência profissional como Assistente Administrativo na empresa Mitsubishi Motors no departamento de Desenvolvimento de Manufatura, auxiliando em atividades de elaboração de folhas de processo, desenvolvimento de novos dispositivos e acompanhamento de novos projetos com elaboração de cronogramas e controle de documentos. Possui experiência na área de Engenharia de Produção.

\section{Luis Fernando Quintino}

Publicou 8 livros e mais de 60 artigos em periódicos nacionais e internacionais. Possui mais de 20 anos de experiência Profissional nas áreas de Engenharia Elétrica com Ênfase em Controle e Automação de Processos Industriais, Mecatrônica, TI industria, Gerenciamento de Projetos e Gestão da Produção e Operações. Desenvolveu aplicações e projetos para empresas como Petrobras, Transpetro, General Motors do Brasil, Ford do Brasil, Rockwell Automation, Souza Cruz, SESC, Móveis Itatiaia, Taum Chemie, Sudamax, Biofral, Persico Pizzamiglio, Despurifil, Conferly Cosmética, Hair Shine e outras. Na área acadêmica possui mais de 10 anos de experiência docente em cursos de nível técnico, graduação e pós graduação. Como também mais de 8 anos de experiencia em Gestão Acadêmica e Pedagógica. 


\section{Luiz Lúcio de Aragão Pedroso}

Doutorando (aluno especial) em Engenharia de Produção e Sistemas - CEFET , Mestre em Engenharia de Produção - UCAM-Campos, Especialista em Engenharia Econômica e Administração Industrial - UFRJ, Graduado em Engenharia de Produção - CNEC - Rio das Ostras - RJ, Graduado em Economia - UNISUAM. Profissional da Indústria de Oleo e Gas com mais de 20 anos de experiência trabalhando em diversas empresas multinacionais no Brasil, Estados Unidos e Africa onde ocupou a posição de Controller e Supply Chain Manager, também atua como professor de Curso de Pós Graduação em Gestão Empresarial

\section{Luiza Albuquerque Santos}

Bacharel em engenharia de produção pela Universidade Estadual de Santa Cruz e pósgraduanda em gerenciamento de projetos pelo Senac SP. Amo trabalhar e estudar. Não há nada mais gratificante em liderar projetos e ver os seus resultados! Amo receber emoções e testemunhar felicidades da equipe, e poder deixar o mundo um pouquinho mais bonito e amável com minha contribuição!

\section{Marcela Cabral Mendes Barroso}

Possui graduação em Medicina Veterinária pela Universidade de Brasília (2007) e mestrado em Ciências Veterinárias pela Universidade Federal de Uberlândia (2015). Realizou residencia em Clínica Médica no Hospital Veterinário de Pequenos Animais da Universidade de Brasília (2008). Tem experiência na área de Medicina Veterinária, com ênfase em Clínica Médica de Pequenos Animais. Atualmente é Fiscal Estadual Agropecuária da Agrodefesa, no estado de Goiás.

\section{Marcio do Carmo Boareto}

Mestrando no Programa de Pós-Graduação em Gestão Organizacional (PPGGO), 2018, pela Universidade Federal de Goiás - Regional Catalão. Especialização em Gestão Financeira e Controladoria pela Universidade Federal de Goías (2015). Possui graduação em ADMINISTRAÇÃO pela Universidade Federal de Goiás (2013).Tem experiência na área de Administração, com ênfase em Administração Financeira.

\section{MARCOS DOS SANTOS}

Doutor em Sistemas, Apoio à Decisão e Logística pela Universidade Federal Fluminense; é Mestre em Engenharia de Produção pela COPPE/UFRJ. Professor da Pós-graduação em Sistemas e Computação do Instituto Militar de Engenharia (IME); Professor de Métodos Analíticos de Apoio à Tomada de Decisão do Instituto de Estudos Estratégicos da Universidade Federal Fluminense (INEST-UFF); Membro permanente do Comitê de loT e Smart Cities da ASSESPRO; faz parte da Diretoria da Sociedade Brasileira de Pesquisa Operacional (SOBRAPO). É Oficial Superior da Marinha do Brasil com 25 anos de carreira. Professor de Matemática Avançada do curso de Engenharia da Computação do IME, Professor do curso de Engenharia de Produção da UNISUAM e do SENAI CETIQT. Coordena um grupo de pesquisa de modelagem matemática com centenas de trabalhos científicos publicados em congressos e periódicos nacionais e internacionais.

\section{Marcus Vinicius Castro Witczak}

Possui graduação em Psicologia pela Universidade Federal do Rio Grande do Sul (1998), mestrado em Psicologia Social e Institucional pela Universidade Federal do Rio Grande do Sul (2001) e doutorado em Psicologia na Pontifícia Universidade Católica do Rio Grande do Sul (2009). Atualmente é professor adjunto do Departamento de Psicologia da Universidade de Santa Cruz do Sul, atuando no Serviço de Reabilitação Física - SRFis e Laboratório de Criatividade. Tem experiência na área de Psicologia Social e do Trabalho, com ênfase em 
saúde do trabalhador. Participa de grupos de estudos, nos seguintes temas: gerontologia social; inclusão, trabalho e qualidade de vida; mídia e representações sociais.

\section{Marlon Figueiredo Coura de Oliveira}

Pós-graduado pela PUC Minas de Belo Horizonte em Automação de subestações de transmissão e distribuição; Bacharel em Engenharia de Produção Pela Unipac - Barão de Cocais-MG; Técnico eletroeletrônico pelo Colégio e Faculdade Kennedy - João MonlevadeMG; Atuante como profissional de Alta Tensão em uma multinacional no ramo de mineração.

\section{Matheus Araujo dos Santos}

Graduando em Engenharia de Mecatrônica pelo Instituto Federal de Educação, Ciência e Tecnologia do Ceará

\section{Matheus Felipe Pires}

Graduando do 8ำ período do Curso de Engenharia de Produção do Centro Universitário Integrado.

\section{Milton Erthal Junior}

Engenheiro Agrônomo (UFV - 1995), Mestrado (UENFF - 1999) e Doutorado (UENF - 2004) em Produção Vegetal. Professor do Instituto Federal Fluminense, onde atua nos cursos técnicos em Meio Ambiente, graduação em Engenharia Ambiental e Mestrado Profissional em Sistemas Aplicados a Engenharia e Gestão. Na Universidade Cândido Mendes-Campos, atua no Doutorado em Planejamento Regional e Gestão da Cidade, programa de Mestrado em Pesquisa Operacional e Inteligência Computacional e nos cursos de Engenharia. Atua com Pesquisa Operacional, Auxílio multicritério à Decisão e Gestão Ambiental. Experiência em Entomologia, atuando especificamente em: Bioquímica, Ecologia, Comportamento e Controle biológico de insetos, usando formigas cortadeiras como modelo.

\section{Milton Erthal Júnior}

Possui graduação em Engenharia Agronômica pela Universidade Federal de Viçosa (1995), mestrado (1999) e Doutorado (2004) em Produção Vegetal pela Universidade Estadual do Norte Fluminense Darcy Ribeiro. Atualmente é professor do Instituto Federal de Educação, Ciência e Tecnologia Fluminense, campus Campos-Guarus, onde atua nos cursos técnicos em Meio Ambiente, graduação em Engenharia Ambiental e Mestrado Profissional em Sistemas Aplicados a Engenharia e Gestão. Na Universidade Cândido Mendes-Campos, atua no programa de Doutorado Acadêmico em Planejamento Regional e Gestão da Cidade, programa de Mestrado Profissional em Pesquisa Operacional e Inteligência Computacional e nos cursos de graduação em engenharia. Na Universidade Estadual do Norte Fluminense Darcy Ribeiro atua como professor colaborador. Tem experiência na área de Pesquisa Operacinal, com ênfase na área de Auxílio multicritério à Decisão e Gestão Ambiental. Experiência em Entomologia, atuando especificamente em: Bioquímica , Ecologia, Comportamento e Controle biológico de insetos, usando formigas cortadeiras como modelo.

\section{Moacir Godinho Filho}

Graduação em Engenharia de Produção - Materiais pela Universidade Federal de São Carlos (1998), MBA na Fundação Getúlio Vargas - FGV (2000), mestrado em Engenharia de Produção pela Universidade Federal de São Carlos (2001), doutorado em Engenharia de Produção pela Universidade Federal de São Carlos (2004), pós-doutorado em Quick Response Manufacturing - QRM (Manufatura Responsiva) na Universidade de Wisconsin at Madison - USA (2007) e pós-doutorado em aplicação de System Dynamics e Factory Physics à gestão de sistemas de produção na North Carolina State University - USA (2008). 
Atualmente é professor associado 2 da Universidade Federal de São Carlos, pesquisador nível $1 \mathrm{C}$ do CNPQ e editor adjunto do periódico Gestão \& Produção. Tem experiência na área de Engenharia de Produção, com ênfase em Gerência de Produção, atuando principalmente nos seguintes temas: Gerência da Produção, Planejamento e Controle da Produção (PCP), Estratégia de Manufatura, Quick Response Manufacturing, Manufatura Enxuta, Análise de Sistemas de Manufatura, Logística, Pesquisa Operacional aplicada ao PCP e à logística, Simulação aplicada ao PCP e à Logística, Factory Physics, scheduling, e System Dynamics aplicado à gestão de sistemas de produção. Professor Moacir tem mais de 80 artigos publicados em periódicos com seletiva política editorial (dentre esses destacam-se mais de 40 artigos publicados em journals com alto fator de impacto (JCR).

\section{Naiara Faiad Sebba Calife Garcia}

Possui graduação em Engenharia Elétrica ênfase Eletrônica pela UFU (Universidade Federal de Uberlândia - 2003). Mestrado em Engenharia de Produção pela UFSCar ( Universidade Federal de São Carlos - 2008). Professora Adjunta I do curso de Engenharia de Produção da Universidade Federal de Goiás - Regional Catalão, atuando principalmente nas seguintes áreas: Logística, Armazenagem, Gestão da Cadeia de Suprimentos e Logística hospitalar. Possui experiência na área hospitalar atuando em gestão hospitalar e gestão financeira.

\section{Nélio Domingues Pizzolato}

Possui graduação em Engenharia Industrial Mecânica pela Pontifícia Universidade Católica do Rio de Janeiro (1963), bolsista do governo da Suiça na ETH de Zurique (1966), mestrado em Engenharia de Produção pela Pontifícia Universidade Católica do Rio de Janeiro (1971), doutorado em Business School - University of North Carolina (1977) e pós-doutorado na Université de Montréal (1987). Contratado pela Pontifícia Universidade Católica do Rio de Janeiro como professor assistente em outubro 1969, tornou-se professor associado em 1978 e professor emérito em 2015. A partir de 2014 tornou-se professor da Universidade Católica de Petrópolis-UCP/RJ.

\section{Nelson Dias da Costa Júnior}

Graduado em Engenharia de Produção pela Universidade Federal de Goiás, Pós-Graduado no MBA em Gestão Empresarial pela Universidade Cruzeiro do Sul e Mestrando em Engenharia de Produção pela Universidade Federal de Goiás. Possui experiência como Empreendedor no setor de Serviços Gráficos, além de experiência na área de Planejamento e Controle de Manutenção em Indústria Química.

\section{Omar Ouro-Salim}

Possui graduação em Marketing pela universidade de Lomé (2013). Tem experiência na área de estratégia marketing. Estagio de 3 meses no departamento das operações bancárias locais no banco BSIC em 2014. Formação em WORD e EXCEL na universidade de Lomé (2014). Dois anos de ensino em escola particular nas áreas de matemática e física (20132014). Obteve diploma de língua francesa DALF C2 na aliança francesa de Lomé (2014). Também obteve um certificado em língua inglesa nível avançado no site de myenglishonline (2017). Atualmente Aluno Regular no Mestrado Profissional na área de Gestão Organizacional pela Universidade Federal de Goiás Regional Catalão (2017-2018).

\section{Paulo Renato Pakes}

Doutor em Engenharia de Produção pela Universidade Federal de São Carlos. Docente dos cursos de Engenharia de Produção e Engenharia Civil da Universidade de Franca. 


\section{Pedro Henrique Borges Xavier}

Graduando em Engenharia de Produção UFG (Universidade Federal de Goiás - Regional Catalão). Possui projetos de pesquisa principalmente nas seguintes áreas: Logística, Armazenagem, Gestão da Cadeia de Suprimentos, Planejamento e Controle da Produção e Pesquisa Operacional.

\section{Priscila Pereira Suzart de Carvalho}

Engenheira de Produção formada pela Universidade Estadual de Santa Cruz (2009), especialização em Engenharia de Segurança do Trabalho pela Faculdade de Tecnologia e Ciências (2011), mestra em Engenharia Industrial pela Universidade Federal da Bahia (2013) e doutoranda em Engenharia Industrial pela Universidade Federal da Bahia. Atualmente é professora do Curso de Engenharia de Produção da Universidade Estadual de Santa Cruz (UESC). Desenvolve trabalhos nas áreas de logística, gestão da cadeia de suprimentos, ergonomia, higiene e segurança do trabalho.

\section{Rejane Frozza}

Possui graduação em Informática pela Pontifícia Universidade Católica do Rio Grande do Sul (1993), mestrado em Computação pela Universidade Federal do Rio Grande do Sul (1997) e doutorado em Computação pela Universidade Federal do Rio Grande do Sul (2004). Realização de estágio doutoral sanduíche na Université Joseph Fourier (Grenoble/France) de 2001 a 2002. Atualmente é professora adjunta da Universidade de Santa Cruz do Sul, Santa Cruz do Sul, RS, no Departamento de Computação e no Programa de Pós-Graduação em Sistemas e Processos Industriais - Mestrado. Tem experiência na área de Computação, com ênfase em Inteligência Artificial, atuando principalmente nos seguintes temas: Sistemas Tutores Inteligentes, Agentes Pedagógicos em Sistemas Virtuais de Aprendizagem, Gestão do Conhecimento, Sistemas Multiagentes, Redes Neurais Artificiais, Sistemas Difusos, Sistemas de Raciocínio Baseado em Casos.

\section{Robert Alexandre de Ávila}

Técnico em Automação Industrial pelo SENAI, graduado em Engenharia de Produção pela UNIVERSO/JF e MBA em Gerenciamento de Projetos pela FGV. Atualmente, atua como Analista de Projetos em uma empresa especialista em Programas de Eficiência Energética.

\section{Roberto Fernandes dos Reis Filho}

Graduação em Engenharia Civil. Universidade Federal de Goiás, UFG, Brasil.

\section{RODRIGO LINHARES LAURIA}

Mestre em Gestão e Estratégia em Negócios pela UFRRJ e Engenheiro Mecânico pela UFRJ. Dezesseis anos de experiência profissional bem diversificada, adquirida na área industrial de grandes empresas, atuando na gestão otimizada da produção, manutenção, Organização \& Métodos e projetos sempre tendo como fundamentos os métodos da filosofia lean manufacturing. Nove anos de experiência como professor universitário, já tendo lecionado como professor substituto na UFRJ e hoje professor do curso de engenharia de produção da UNISUAM e da Pós Graduação em Gestão de Projetos da UGB.

\section{Rony Peterson da Rocha}

Doutor e Mestre em Engenharia Química - Modelagem e Otimização de Processos, pelo Programa de Pós-Graduação em Engenharia Química, Universidade Estadual de Maringá (UEM) (2015-2011). Especialista em MBA em Gestão Empresarial e em Gestão Ambiental pela FECILCAM - Faculdade Estadual de Ciências e Letras de Campo Mourão (2012-2007). 
Graduado em Engenheiro de Produção Agroindustrial, pela Universidade Estadual do Paraná - Campus de Campo Mourão (2004). Professor Adjunto do Colegiado de Engenharia de Produção, Universidade Estadual do Paraná - Campus de Campo Mourão, Campo Mourão/PR. Pesquisador do Grupo de Estudos e Pesquisas em Processos e Gestão de Operações (GEPPGO). Coordenador do Curso de Engenharia de Produção Agroindustrial (2016-2017)

\section{Rosana Brito Santos}

Formada em Administração, Especialista em Gestão de Pessoas e Mestre em Gestão de Organizações Aprendentes (UFPB). Decente dos Colegiados de Curso de Administração e Engenharia de Produção da Faculdade Independente do Nordeste. Articuladora de Projetos de Extensão; Membro dos Núcleos Docente Estruturante (NDE's) dos Colegiados de Curso de Administração (presencial) e Curso Superior Tecnológico em Gestão de Pessoas (EAD) e Curso Superior Tecnológico em Logística (EAD).

\section{Rubya Vieira de Mello Campos}

Graduada em Engenharia de Produção Agroindustrial pela Universidade Estadual do Paraná - UNESPAR/Campus de Campo Mourão - FECILCAM (2008). Especialista em Gestão em Agronegócio pelo Centro Universitário de Maringá - CESUMAR (2009). Mestre em Engenharia Urbana - Departamento de Engenharia Civil pela Universidade Estadual de Maringá - UEM (2012). Doutora em Engenharia Química pela Universidade Estadual de Maringá - UEM (2017). Coordenadora do Departamento de Engenharia de Produção da Faculdade Integrado de Campo Mourão. Pesquisadora da área de Engenharia da Sustentabilidade e Engenharia do Produto.

\section{Sandro Ítalo de Oliveira}

Estudante de Engenharia de Produção na escola de engenharia e arquitetura da UNIFANOR WYDEN. Possuo certificação GreenBelt em Lean Six Sigma pelo IBMEC. Atuo na área de Gestão da Qualidade na GUARARAPES CONFECÇÕES S/A (Maior indústria de Confecção da América Latina), onde também atuei na área de Gestão da Produção.

\section{Sara da Costa Fernandes}

Mestre em Gestão Organizacional pela Universidade Federal de Goiás (UFG). Possui graduação em Administração de Empresas pelo Centro de Ensino Superior de Catalão (2008) e graduação em Ciências Contábeis pela Universidade Anhanguera (2015). É especialista em Finanças e Estratégias Empresariais pelo Centro de Ensino Superior de Catalão (2010), e especialista em Controladoria pela Universidade Anhanguera (2017). Possui experiência de gestão no setor bancário, nas áreas de operações e comercial. Atualmente, trabalha na empresa Mitsubishi Motors, atuando como analista na gestão e análise de custos, despesas e orçamentos. Também é tutora do curso a distância de Graduação em Administração Pública na Universidade Federal de Goiás - UFG.

\section{Stella Jacyszyn Bachega}

Possui doutorado e mestrado em Engenharia da Produção na Universidade Federal de São Carlos (UFSCar) e graduação em Administração pela Universidade Federal de Lavras (UFLA). Atualmente é docente em regime 40h dedicação exclusiva na Universidade Federal de Goiás - Regional Catalão. Dentre as áreas de atuação em ensino, pesquisa e extensão, estão: pesquisa operacional, sistemas e tecnologia da informação, gestão de operações, sustentabilidade e administração. Realiza pesquisas que proporcionem abordagens transversais envolvendo duas ou mais das seguintes áreas: administração de setores específicos, engenharia de produção, computação, ambiental, estatística e automação. Ainda, é líder do Grupo de Estudos em Modelagem e Simulação-GEMS. 


\section{Tatiana Kimura Kodama}

Graduada em Engenharia de Produção pela Universidade Federal da Grande Dourados (2012) e Mestre em Engenharia de Produção pela Universidade Federal de São Carlos (2015).

\section{Thainara Danielle Barbosa Marçal}

Graduanda em Engenharia de Produção - Universidade Federal de Goiás-UFG

\section{Vagner Rosalem. Universidade Federal de Goiás.}

Possui graduação em Administração de Empresas pela Faculdade de Economia e Administração São Paulo (1992), mestrado em Administração pela Universidade Federal de Lavras (2007) e doutorado em Administração de Empresas pela Fundação Getúlio Vargas SP (2013). Atualmente é avaliador institucional do Conselho Estadual de Educação do Estado de Goiás, professor pesquisador da Universidade Federal de Goiás.

\section{Vivian Karina Bianchini}

Doutora em Engenharia de Produção pela Universidade Federal de São Carlos. Coordenadora e Docente dos cursos de Engenharia de Produção e Engenharia Civil da Universidade de Franca.

\section{Wagner Costa Botelho}

Profo. Doutor em Engenharia de Produção (UNIP, 2013), Mestre em Engenharia de Produção (UNIP, 2005), graduação em Engenharia Elétrica pela Universidade de Mogi das Cruzes (UMC, 1989). Pós-graduações: Engenharia de Segurança do Trabalho (UNIP, 1996), Complementação Pedagógica em Matemática (FATEMA, 1997), Engenharia de Produção (USJ, 2003), MBA em Gestão Ambiental (UNINOVE, 2009) e Gestão Escolar (FAMOSP, 2017). Atuando a 23 anos na área da educação de nível técnico, graduação e pós-graduação, e 27 anos na de engenharia elétrica, produção e segurança do trabalho.

\section{Wesley Barbosa de Oliveira}

Pós-graduado em Engenharia de Projetos de Sistemas da Informação, Graduado em Sistemas da Informação e Técnico em Eletrônica. Coordenador de Cursos na Faculdade Drummond. Parecerista de cursos técnicos. Coordenador do NEAD Drummond. 
Agência Brasileira do ISBN

ISBN 978-85-7042-014-5

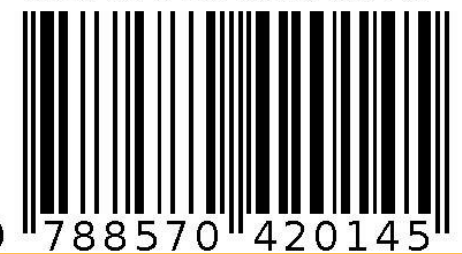

